\title{
Approved Lists of Bacterial Names
}

\author{
edited by \\ V.B.D. SKERMAN, ${ }^{1}$ VICKI McGOWAN, ${ }^{1}$ AND P.H.A. SNEATH ${ }^{2}$ \\ Department of Microbiology, University of Queensland, St. Lucia, Queensland 4067, Australia ${ }^{1}$ and MRC \\ Microbial Systematics Unit, University of Leicester, Leicester LE1 England 7RH, ${ }^{2}$ \\ on behalf of
}

The Ad Hoc Committee of the Judicial Commission of the ICSB

\section{INTRODUCTION}

At the meeting of the Judicial Commission of the ICSB held in Jerusalem on the 29th March, 1973 an Ad Hoc Committee was appointed (Minute 22) to organize a review of the currently valid names of bacteria with the object of retaining only names for those taxa which were adequately described and, if cultivable, for which there was a Type, Neotype or Reference strain available; to compile these names under the title of Approved Lists of Bacterial Names and to publish the lists in the International Journal of Systematic Bacteriology, to become effective on January 1, 1980. This date would then replace May 1, 1753 (International Code of Nomenclature of Bacteria and Viruses. Rule 10) as the new date for determining priorities for names of new taxa.

The members of the Ad Hoc Committee originally appointed to oversee the task were S.P. Lapage, H.P.R. Seeliger and V.B.D. Skerman (Chairman). Following his election as President-Elect of IAMS, H.P.R. Seeliger resigned from the Committee and was replaced by J.G. Holt. P.H.A. Sneath, as Chairman of the Judicial Commission, was coopted to the Committee. This Committee was responsible for the editing of the first draft of the Approved Lists of Bacterial Names published in the IJSB (26, 1976, 563-599).

The Ad Hoc Committee was reconstituted by the Judicial Commission during its meetings at the International Congress of the IAMS in Munich in September, 1978, with V.B.D. Skerman (Chairman), P.H.A. Sneath (newly elected Chairman of the ICSB) and L.G. Wayne (newly elected Chairman of the Judicial Commission) as Committee members. This Committee was assigned wide powers to complete the work on the Lists and arrange publication.
The initial Committee agreed that, as a basis for inquiry, all names which had been included in the eighth edition of Bergey's Manual of Determinative Bacteriology, whether listed as recognised species, synonyms, species incertae sedis, or under other headings should be circulated; that all Subcommittees on Taxonomy of the ICSB should be asked for advice on the retention of taxa for which the Subcommittees were responsible and that specialists be approached for advice on other taxa - only a small list of taxa remained to be considered by the Ad Hoc Committee itself. Advice was also sought on additional names of taxa which had been validly published since the publication of the Manual. Special provision had been made in the Code of Nomenclature for the inclusion of names validly published after the 1st January, 1978 (Rule 24a).

A list of specialists was drawn up and approved by the Ad Hoc Committee. Each specialist was asked to associate two others in reaching a decision on name retention. The Chairman accepted the responsibility for coordination of work associated with the selection of generic names and specific and subspecific epithets and P.H.A. Sneath for the names of higher taxa.

\section{Names of Genera, Species and Subspecies:}

The Lists of names of species and subspecies were circulated by airmail in April, 1976 and a draft list of names recommended for retention published in the IJSB $(26,1976$, 563-599) together with the list of those people associated with that stage of the project. Reference may be made to the draft list for details of the procedures adopted in processing the information.

The object of publishing the draft list was to enable microbiologists, in general, to submit 
opinions to the Ad Hoc Committee. Several were received. Some of these resulted in modification to lists submitted by Subcommittees on Taxonomy and others.

Rule 24a of the Code of Nomenclature provided, inter alia, for the publication with each bacterial name the name(s) of the author(s) who originally proposed it, a reference to an effectively published description of each species and its nomenclatural type whenever possible, and a Type, Neotype or Reference strain by its designation.

To conserve space in publication, it was agreed that for all references to the 8th edition of Bergey's Manual (Buchanan, R.E. and N.E. Gibbons (eds). 1974. Bergey's Manual of Determinative Bacteriology, 8th ed. The Williams and Wilkins Co., Baltimore) be contracted to 'Bergey 8 '.

Although these requirements were formally published in the Code on 1st January, 1976 little action was taken by those responsible for various taxa and in order to assist resolution of the problem, the Chairman and his staff produced a document which listed Collections of Cultures of Microorganisms which held Type, Neotype and Reference strains for those species whose names appeared in the draft list and subsequent amendments. This list, which will be published elsewhere as a publication of the World Data Center for Microorganisms, has been used as a guide to the deletion of numerous names for which no cultures could be located.

The requirements of Rule 24a together with the list of strains, were discussed at a meeting of the ICSB with Subcommittees on Taxonomy at the International Congress for Microbiology in Munich in September, 1978 where the decision was made to list only one designation for each strain and preferably that of the American Type Culture Collection, where available. Because of difficulties associated with locating references to publications in which Type strains, Neotype strains or Reference strains had been designated, it was agreed that references would be given only to those publications concerned with the naming of the taxa and to descriptions of the taxa.

The Judicial Commission also determined that publication should be in the January (1980) issue of the IJSB, thus negating the requirement of Rule 24a that publication take place prior to 1st January, 1980. This action enabled the inclusion in the Approved Lists of names of all new taxa which had been validated by publication in the October, 1979 issue of the IJSB and so has obviated the need to make any further additions to the Approved Lists of Bacterial Names.

Formal notice of these requirements was circulated, by airmail, to all Subcommittees and specialists on 5th February, 1979 requesting return of the information by 31st August, 1979. Meanwhile, the Chairman and his staff proceeded as far as possible with the compilation of the whole of the required information, subsequently making use of such submissions as were ultimately received from others, to verify compilations already made.

Computer printouts, in the final format of assembled information, were distributed by airmail to all participants in July, 1979 for the purpose of verification and for the provision of information which was still missing.

A final decision to retain or delete some names was based on our ability to obtain the relevant information.

\section{Names of Taxa Above the Rank of Genus:}

Compilation of names of higher taxa was undertaken by Sneath and his associates. No draft list was published but a proposal was discussed at some length in an open meeting at the Munich Congress. The format of the list as submitted was modified to conform with the format adopted for the names of the genera and species. References given in this section of the lists are restricted to those relating to the higher taxa. Those to genera will be found in the list of genera and species.

\section{Designation of Strains:}

Strains have been designated by accession numbers of Culture Collections in which they have been deposited. Every effort has been made to ensure that the strains are actually available but no guarantee of this can be given. Names, which have been omitted, may be revived if the location of suitable strains can be ascertained.

The following is a list of addresses of institutions, together with acronyms used to assign accession numbers.

AMRC FAO-WHO International Reference Centre for Animal Myco- 
plasmas, Institute for Medical Microbiology, University of Aarhus, Aarhus, Denmark.

ATCC American Type Culture Collection, Rockville, Maryland 20852, U.S.A.

BKM All-Union Collection of Microorganisms, Institute of Microbiology, USSR Academy of Sciences, Moscow, USSR.

BKMW Culture Collection, Institute of Microbiology, USSR Academy of Sciences, Moscow, USSR.

CBS Centraalbureau voor Schimmelcultures, Baarn, The Netherlands.

CCM Czechoslovak Collection of Microorganisms, J.E. Purkyne University, Brno, Czechoslovakia.

CDC Center for Disease Control, Atlanta, Georgia, U.S.A.

CIP Collection of the Institute Pasteur, Paris, France.

DSM Deutsche Sammlung von Mikroorganismen, Gottingen, Federal Republic of Germany.

IAM Institute of Applied Microbiology, University of Tokyo, Tokyo, Japan.

IFO Institute for Fermentation, Osaka, Japan.

IMRU Institute of Microbiology, Rutgers - The State University, New Brunswick, New Jersey, U.S.A.

IMV Institute of Microbiology and Virology, Academy of Sciences of the Ukrainian SSR.

INA Institute for New Antibiotics, Moscow, USSR.

INMI Institute for Microbiology, USSR Academy of Sciences, Moscow, USSR.

IPV

KCC Kaken Chemical Company Ltd., Tokyo, Japan.

LIA Museum of Cultures, Leningrad Research Institute of Antibiotics, 23 Ogorodnikov Prospect, Leningrad L-20, USSR.

LSU Louisiana State University, Baton Rouge, Louisiana, U.S.A.

LMD Laboratorium voor Microbiologie der Landbouwhogeschool,
Wageningen, The Netherlands.

NCDO National Collection of Dairy Organisms, National Institute for Research in Dairying, University of Reading, England, UK.

NCIB National Collection of Industrial Bacteria, Torry Research Station, Aberdeen, Scotland, UK.

NCMB National Collection of Marine Bacteria, Torry Research Station, Aberdeen, Scotland, UK.

NCPPB National Collection of Plant Pathogenic Bacteria, Plant $\mathrm{Pa}$ thology Laboratory, Harpenden, England, UK.

NCTC National Collection of Type Cultures, Central Public Health Laboratory, Colindale, London, England, UK.

NIAID National Institute of Allergy and Infectious Diseases, Hamilton, Montana, U.S.A.

NIHJ National Institute of Health, Tokyo, Japan.

NRC National Research Council, Ottawa, Canada.

NRL Neisseria Reference Laboratory, US Public Health Service Hospital, Seattle, Washington, U.S.A.

NRRL Northern Utilization Research and Development Division, US Department of Agriculture, Peoria, Illinois, U.S.A.

PDDCC Culture Collection of Plant Diseases Division, New Zealand Department of Scientific and Industrial Research, Auckland, New Zealand.

TC

Thaxter Collection, Farlow Herbarium, Harvard University, Boston, Massachusetts, U.S.A.

UMH

University of Missouri Herbarium, Missouri, U.S.A.

Culture Collection, Department of Microbiology, University of Queensland, Brisbane, Australia.

VKM Institute of Microbiology, Academy of Sciences of the USSR, Moscow, USSR.

VPI Virginia Polytechnic Institute and State University, Blacksburg, Virginia, U.S.A.

WINDSOR Culture Collection, University of Windsor, Windsor, Ontario, Canada. 


\section{Acknowledgements:}

Whilst the task of compilation and preparation of manuscripts for publication has been of necessity concentrated in two areas, the successful completion of the task would not have been possible without the associated efforts of a large number of people whose names are recorded here.

T.V. Aristovskaya, P.K.C. Austwick, E. Baldacci, L. Barksdale, E. Barnes, P. Baumann, J.H. Becking, E.L. Biberstein, I. Bousfield, K. Bovre, W.J. Brinley-Morgan, D. Brenner, T. Brock, E. Brockman, M. Bryant, J.C. Burnham, J. Carr, W. Catlin, E.P. Cato, D. Claus, G. Colman, R.R. Colwell, M.J. Corbel, K.T. Crabtree, T. Cross, G.A. Dubinina, P. Dugan, D.W. Dye, K. Eimhjellen, G. Eldering, W.H. Ewing, S. Faine, S.M. Finegold, E.A. Freundt, W. Frederiksen, A.L. Furniss, E. Garvie, N.E. Gibbons, M. Goodfellow, M. Gordon, B.V. Gronov, H. Hatt, A.C. Hayward, M. Hendrie, S.D. Henriksen, A. Henssen, G.J. Hermann, G. Gobbs, L.V. Holdeman, R. Hugh, D.B. Johnstone, D. Jones, L.V. Kalakoutskii, O. Kandler, K.-A. Karlsson, R.M. Keddie, M. Killian, K. Kitahara, J. Knapp, W. Knapp, M. Kocur, N.R. Krieg, S.P. Lapage, J.M. Larkin, H. Lautrop, H.A. Lechevalier, J. DeLey, R. Locci, S. Maier, N.S. Mair, P.H. Makela, M. Mandel, E. McCoy, H.D. McCurdy, K. McNiel, W.E.C. Moore, N. Nishida, H. Nonomura, R.A. Ormsbee, F. Orskov, I. Orskov, E. van Oye, O.M. Parinkina, N. Pfennig, J.E. Phillips, F. Pichinoty, M. Pittman, T. Pridham, C.I. Randles, J.W.M. LaRiviere, M. Rhodes-Roberts, D.S. Roberts, R. Rohde, B. Rowe, E.B. Rozlycky, E. Runyon, R. Sakazaki, V. Scardovi, D. Schafer, R.J. Sidler, J.M. Shewan, G.C. Simmons, I.J. Slotnick, R.M. Smibert, P.H. Smith, J.T. Staley, M. Starr, Y. Terasaki, Y.T. Tchan, E. Thal, J. Thompson, H. Truper, G. Tunevall, D.C. Turk, M. Veron, N. Walker, S.W. Watson, G. Wauters, L. Wayne, R.E. Weaver, O.B. Weeks, E. Weiss, H.J. Welshimer, S. Williams, G.A. Zavarzin, J.G. Zeikus, K. Zinneman.

Thanks are also due to Miss Annette McLennan who typed the original manuscripts and to Dr. Lindsay Sly, Dr. Horst Doelle and Mrs. Elizabeth Marden for considerable assistance in the search for Culture Collections maintaining strains of taxa in the Approved
Lists and other information and to the numerous other unnamed people who have assisted in various ways in laboratories throughout the world.

The computer programs used in compiling these lists were written and controlled by $\mathrm{Mr}$. Geoffrey Dengate, Systems Programmer, Prentice Computer Centre, University of Queensland. His help and expertise are sincerely acknowledged.

Financial assistance of the following is gratefully acknowledged: Bergey's Manual Trust, Deutsche Gesellschaft für Hygiene und Mikrobiologie, International Association of Microbiological Societies, International Union of Biological Sciences, Society for Applied Bacteriology, Society for General Microbiology, and the United Kingdom Federation of Culture Collections.

\section{SPECIFIC INFORMATION RELATING TO THE APPROVED LISTS OF BACTERIAL NAMES}

The names included in these Lists are those selected by Subcommittees on Taxonomy of the ICSB, specialist advisers and, where the former have not been available or have declined to advise, by the members of the Ad Hoc Committee.

With few exceptions (vide infra) names which have been included in the Lists are those which

were validly published before the $1 \mathrm{st}$ January, 1978 and which have been listed by advisers.

- have been validly published since the 1st January, 1978 by publication in the IJSB or by inclusion in the lists of new names cited in the IJSB (to and including Volume 29, Part 4, 1979) as having been effectively published in other Journals.

Specific attention is drawn to the following

1. Names included in the Approved List of Bacterial Names are the only names which are nomenclaturally valid as at the 1st January, 1980. All other names which have appeared in the literature prior to 1st January, 1980 are nomenclaturally invalid. Names which have been effectively published in Journals other than the IJSB but which have not been cited in the 
lists of new names published in the IJSB, have not been validly published under Rule 27 of the Code of Nomenclature. Such names may be validated by publication in forthcoming issues of the IJSB and will simply constitute names of new taxa.

2. No name appearing in the Approved Lists of Bacterial Names is conserved in the sense defined under Rule $56 \mathrm{~b}$ of the Code of Nomenclature (1976 Revision).

3. Any name previously rejected by the Judicial Commission remains a nomen rejiciendum and can no longer be used to name a bacterium.

4. By majority decision of the Ad Hoc Committee, supported by an overwhelming majority of the members of the ICSB, all strains of bacteria which were submitted as nomenclatural Type strains, Neotype strains, Proposed Neotype strains or Reference strains have been elevated to the status of Type strains. The few objections which were received to the elevation of reference strains to Type status were based on concern that such reference strains may not prove to be the best choice for Type strains. This objection however, applies equally to quite a number of Type strains, particularly monotypes of which there are, and will continue to be, several. It seemed more appropriate that names appearing in the Approved Lists of Bacterial Names, which constitutes a new base for future nomenclature, should have Type status or be omitted.

5. For some names included in the Lists no strains were available. These names were retained to preserve the status of

A. some microorganisms for which habitats are well known, which have distinct morphological characters but which have never been isolated. In most cases only the Type Species has been retained to preserve the status of the genus.

B. a genus which contained well described species for which representative strains were available for all but the Type Species of the genus itself.

Exclusion of the Type Species would have necessitated the exclusion of the genus as a whole under Rule $20 \mathrm{c}$ of the Code of Nomenclature. There were several of these. It is hoped that early action will be taken to request the Judicial Commission to conserve these genera with new Type Species in order that each species within these genera will be represented by a Type strain in a recognised culture collection.

6. The Ad Hoc Committee has repeatedly stressed that its task was nomenclatural and not taxonomic; further that Subcommittees and others were not required to solve taxonomic problems before advising on retention of names. They were requested to omit names of doubtful species as such species could be revived (see 8 below).

Because there are some differences of opinion regarding the generic position of some species it has been necessary to include the same microorganism under two names, each with the same specific epithet and the same nomenclatural type strain. In such instances cross-reference has been made to the alternate name. This applied specifically to the species in the genus Beneckea and the genus Vibrio and to a few instances in the Enterobacteriaceae. For this reason it is necessary here to reaffirm the statement made previously that no name in the Approved Lists of Bacterial Names has been conserved. Names in the Lists may later be conserved, rejected, merged with other names or subjected to any other valid nomenclatural act.

7. The names of some genera, for which there are no available strains for the Type Species, have been omitted from the Lists in order to permit the resolution of a very difficult nomenclatural situation arising from the recent publication of provisional names which have no standing in nomenclature but which have been cited by subsequent authors as though they were valid. Addition of new species, with nomenclatural types, to an invalidly published generic name renders the new names equally invalid. This refers specifically to the methane oxidising bacteria, where the otherwise valid name Methanomonas has been omitted in the hope that by so doing the impasse caused by the illegitimate substitution of the name Methylomonas may be resolved. Specialists in this field are now urged to publish a fully validated list of appropriate species.

8. Reuse and revival of names which do not 
appear in the Approved Lists of Bacterial Names is authorized by Rule 28a. In addition, the Code of Nomenclature (1976 Revision) contains a number of Provisional Rules. At the time of publication of this List these Rules still have only provisional status. It will require a specific act on the part of the Judicial Commission at a formally constituted meeting to raise these Provisional Rules to Rule status. Meanwhile they continue to be inapplicable.

Revival of Names: A name which has not appeared in the Approved Lists of Bacterial Names and which has not been listed as a nomen rejiciendum by the Judicial Commission may be revived (nomen revictum) if it is to be used for the same taxon to which (in the author's opinion) it was originally applied. For citation of such names see Rule 28a and Provisional Rules B2 and B3.

As most names which have not been included in the Approved Lists of Bacterial Names have been omitted because of uncertainty of the validity of the taxa to which they apply, the revival of names should be practised very conservatively.

Reuse of names - Specific and Subspecific epithets: There never has been any rule which forbids the use of the same specific epithet for taxa within different genera.

Many contributors to the Approved Lists of Bacterial Names have voiced considerable concern at the possibility that a specific epithet may be used within the same genus as that in which it was originally used but for the naming of a taxon to which it was not originally applied.

Unless the Judicial Commission takes action to prevent such usage, the Ad Hoc Committee can only urge taxonomists to avoid such reusage as may lead to considerable confusion in future nomenclature.

For the same reason taxonomists are urged not to use as a specific epithet within a genus a name which has been used for an infrasubspecific subdivision of a species within that genus. This applies particularly to several genera of predominantly plant pathogens, where previously cited species have been relegated to the status of pathovars within species listed in the
Approved Lists of Bacterial Names. As such infrasubspecific pathovars may later be elevated to the status of subspecies or species, preemption of the pathovar name as a specific or subspecific epithet of a different taxon would obviously cause confusion.

The International Society for Plant Pathology is publishing, in the Review of Plant Pathology, a list of pathovars of species which appear in the Approved Lists of Bacterial Names. Taxonomists are urged to consult this list before proposing new specific epithets or reusing or reviving old epithets for new species within the relevant genera.

Reuse of generic names: The reuse of a generic name which has not appeared in the Approved Lists of Bacterial Names and which has not been listed as a nomen rejiciendum by the Judicial Commission does not appear to be fraught with the same difficulties as those associated with specific and subspecific epithets. Taxonomists are nevertheless asked to seriously consider the possibility of confusion arising from the use of such names before taking such action.

The correct form of citation for reused names is given in Provisional Rules B1 and B4.

9. Omissions from Approved Lists of Bacterial Names. No names will be added to or removed from the Approved Lists of Bacterial Names. Attention may be drawn to errors in nomenclature or to errors in spelling or citations of references and such communications should be directed to the Executive Secretary, ICSB for transmission to the appropriate body. Please note that the omission of diacritical signs was intentional and dictated by the limitations of the computers used in setting up the type. These omissions do not constitute 'errors' in the above sense.

Every effort has been made to obviate errors by reference of the computer printouts of the final information to the original advisers for correction and also for insertion of some missing information. The final printout prior to production of the bromide copy for printing has been checked by the Chairman but the magnitude of the task allowed only of a search for the more glaring errors of which there were fortunately few. 
Note: No Nomenclatural Type is required for the categories of Division, Class or Subclass.

\section{DIVISION}

Firmacutes Gibbons and Murray 1978

Gibbons, N.E. and R.G.E. Murray. 1978.

International Journal of Systematic Bacteriology 28:1-6.

Gracilicutes Gibbons and Murray 1978

Gibbons, N.E. and R.G.E. Murray. 1978.

International Journal of Systematic Bacteriology 28:1-6.

\section{CLASS}

Actinomycetes Krassilnikov 1949

Krassilnikov, N.A. 1949. Opredelitelv Bakterii i Actinomicetov. Akademii Nauk SSSR Moscow. pp. 328.

\section{Bacteria Haeckel 1894}

Haeckel, E.H. 1894. Systematische Phylogenie der Protisten und Planzen. I.G. Reimer, Berlin. p. 40.

Microtatobiotes Philip 1956

Philip, C.B. 1956. Canadian Journal of Microbiology 2:261-270.

Mollicutes Edward and Freundt 1967

Edward, D.G. ff. and E.A. Freundt. 1967. International Journal of Systematic Bacteriology 17:267-268.

Photobacteria Gibbons and Murray 1978 Gibbons, N.E. and R.G.E. Murray. 1978. International Journal of Systematic Bacteriology 28:1-6.

Schizomycetes Naegeli 1857

Naegeli, C. von. 1857 in Caspari, R. Botanische Zeitung 15:749-776.

Scotobacteria Gibbons and Murray 1978 Gibbons, N.E. and R.G.E. Murray. 1978. International Journal of Systematic Bacteriology 28:1-6.

\section{SUBCLASS}

Anoxyphotobacteriae Gibbons and Murray 1978 Gibbons, N.E. and R.G.E. Murray. 1978. International Journal of Systematic Bacteriology 28:1-6.
ORDER

Actihomycetales Buchanan 1917

Buchanan, R.E. 1917. Journal of Bacteriology 2:155-164. Type genus: Actinomyces Harz 1877

\section{Bacillales Prevot 1953}

Prevot, A.R. 1953 in Hauduroy, P., G. Ehringer, G. Guillot, J. Magrou, A.R. Prevot, Rosset and A. Urbain. Dictionnaire des bacteries pathogenes. 2nd ed. Masson, Paris. pp. 692. Type genus: Bacillus Cohn 1872

Beggiatoales Buchanan 1957

Buchanan, R.E. 1957 in Breed, R.S., E.G.D. Murray and N.R. Smith (eds). Bergey's Manual of Determinative Bacteriology, 7th ed. The Williams and Wilkins Co., Baltimore. pp. 837-853. Type genus: Beggiatoa Trevisan 1842

\section{Caryophanales Peshkoff 1939}

Peshkoff, M.A. 1939. Doklady Akademii Nauk SSSR 25:239-242. Type genus: Caryophanon Peshkoff 1939

Caulobacterales Henrici and Johnson 1935

Henrici, A.T. and D. Johnson. 1935. Journal of Bacteriology 29:3-4. Type genus: Caulobacter Henrici and Johnson 1935

Chlamydiales Storz and Page 1971

Storz, J. and L.A. Page. 1971. International Journal of Systematic Bacteriology 21:332-334. Type genus: Chlamydia Jones, Rake and Stearns 1945

Chlorobiales Gibbons and Murray 1978 Gibbons, N.E. and R.G.E. Murray. 1978. International Journal of Systematic Bacteriology 28:1-6. Type genus: Chlorobium Nadson 1906

\section{Clostridiales Prevot 1953}

Prevot, A.R. 1953 in Hauduroy, P., G. Ehringer, G. Guillot, J. Magrou, A.R. Prevot, Rosset and A. Urbain. Dictionnaire des bacteries pathogenes. 2nd 
ed. Masson, Paris. pp. 692. Type genus: Clostridium Prazmowski 1880

Cytophagales Leadbetter 1974

Leadbetter, E.R. 1974. in Bergey 8. pp. 99-127. Type genus: Cytophaga Winogradsky 1929

\section{Eubacteriales Buchanan 1917}

Buchanan, R.E. 1917. Journal of Bacteriology 2:347-350. Type genus: Eubacterium Prevot 1938

\section{Hyphomicrobiales Douglas 1957}

Douglas, H.C. 1957 in Breed, R.S., E.G.D. Murray and N.R. Smith (eds). Bergey's Manual of Determinative Bacteriology, 7th ed. The Williams and Wilkins Co., Baltimore. pp. 276-280. Type genus: Hyphomicrobium Stutzer and Hartleb 1899

\section{Lysobacterales Christensen and Cook 1978}

Christensen, P. and F.D. Cook. 1978. International Journal of Systematic Bacteriology 28:367-393. Type genus: Lysobacter Christensen and Cook 1978

\section{Micrococcales Prevot 1940}

Prevot, A.R. 1940. Manuel de classification et de determination des bacteries anaerobies. 1st ed. Masson, Paris. pp. 223. Type genus: Micrococcus Cohn 1872

\section{Mycobacteriales Janke 1924}

Janke, A. 1924. Allgemeine technische Mikrobiologie. I. Teil. Die Mikroorganismen. T. Steinkopf, Dresden und Leipzig. pp. 1-342. Type genus: Mycobacterium Lehmann and Neumann 1896

\section{Mycoplasmatales Freundt 1955}

Freundt, E.A. 1955. International Bulletin of Bacteriological Nomenclature and Taxonomy 5:67-78. Type genus: $M y c o-$ plasma Nowak 1929

Myxococcales Tchan, Pochon and Prevot 1948 Tchan, Y.T., J. Pochon and A.R. Prevot. 1948. Annales de l'Institut Pasteur (Paris) 74:394-400. Type genus: Myxococcus Thaxter 1892
Pseudomonadales Orla-Jensen 1921

Orla-Jensen, S. 1921. Journal of Bacteriology 6:263-273. Type genus: Pseudomonas Migula 1894

Rhodospirillales Pfennig and Truper 1971

Pfennig, N. and H.G. Truper. 1971. International Journal of Systematic Bacteriology 21:17-18. Type genus: Rhodospirillum Molisch 1904

Rickettsiales Gieszczkiewicz 1939

Gieszczkiewicz, M. 1939. Bulletin de l'Academie Polonaise des Sciences. Serie des Sciences Biologiques 1:9-27. Type genus: Rickettsia da Rocha-Lima 1916

Spirillales Prevot 1940

Prevot, A.R. 1940. Manuel de classification et de determination des bacteries anaerobies. 1st ed. Masson, Paris. pp. 223. Type genus: Spirillum Ehrenberg 1832

Spirochaetales Buchanan 1917

Buchanan, R.E. 1917. Journal of Bacteriology 2:155-164. Type genus: Spirochaeta Ehrenberg 1835

\section{SUBORDER}

Caulobacterineae Breed, Murray and Hitchens 1944

Breed, R.S., E.G.D. Murray and A.P. Hitchens. 1944. Bacteriological Reviews 8: 255-260. Type genus: Caulobacter Henrici and Johnson 1935

Eubacteriineae Breed, Murray and Hitchens 1944

Breed, R.S., E.G.D. Murray and A.P. Hitchens. 1944. Bacteriological Reviews 8: 255-260. Type genus: Eubacterium Prevot 1938

Pseudomonadineae Breed, Murray and Smith 1957

Breed, R.S., E.G.D. Murray and N.R. Smith (eds). Bergey's Manual of Determinative Bacteriology, 7th ed. The Williams and Wilkins Co., Baltimore. p. 67. Type genus: Pseudomonas Migula 1894 


\section{TRIBE}

Acetobactereae Pribram 1929

Pribram, E. 1929. Journal of Bacteriology 18:361-394. Type genus: Acetobacter Beijerinck 1898

Bacteroideae Castellani and Chalmers 1919 Castellani, A. and A.J. Chalmers. 1919. Manual of tropical medicine, 3rd ed. Williams, Wood and Co., New York. Type genus: Bacteroides Castellani and Chalmers 1919

\section{Brevibacterieae Prevot 1961}

Prevot, A.R. 1961. Traite de systematique bacterienne. Dunod, Paris. Volume 2. pp. 771. Type genus: Brevibacterium Breed 1953

\section{Brucelleae Murray 1948}

Murray, E.G.D. 1948 in Breed, R.S., E.G.D. Murray and A.P. Hitchens (eds). Bergey's Manual of Determinative Bacteriology, 6th ed. The Williams and Wilkins Co., Baltimore. pp. 545-595. Type genus: Brucella Meyer and Shaw 1920

Chromobacterieae Winslow, Broadhurst, Buchanan, Krumwiede, Rogers and Smith 1920

Winslow, C.E.A., J. Broadhurst, R.E. Buchanan, C. Krumwiede Jr., L.A. Rogers and G.H. Smith. Journal of Bacteriology 5:191-229. Type genus: Chromobacterium Bergonzini 1881

\section{Ehrlichieae Philip 1957}

Philip, C.B. 1957 in Breed, R.S., E.G.D. Murray and N.R. Smith (eds). Bergey's Manual of Determinative Bacteriology, 7th ed. The Williams and Wilkins Co., Baltimore. p. 933. Type genus: Ehrlichia Moshkovski 1945

Erwinieae Winslow, Broadhurst, Buchanan,Krumwiede, Rogers and Smith 1920

Winslow, C.E.A., J. Broadhurst, R.E. Buchanan, C. Krumwiede Jr., L.A. Rogers and G.H. Smith. 1920. Journal of Bacteriology 5:191-229. Type genus: Erwinia Winslow, Broadhurst, Buchanan, Krumwiede, Rogers and Smith 1920
Escherichieae Bergey, Breed, Murray and Hitchens 1939

Bergey, D.H., R.S. Breed, E.G.D. Murray and A.P. Hitchens (eds). 1939. Bergey's Manual of Determinative Bacteriology, 5th ed. The Williams and Wilkins Co., Baltimore. p. 388. Type genus: Escherichia Castellani and Chalmers 1919

Eubacterieae Prevot 1961

Prevot, A.R. 1961. Traite de systematique bacterienne. Dunod, Paris. Volume 2. pp. 771. Type genus: Eubacterium Prevot 1938

Haemophileae Castellani and Chalmers 1919 Castellani, A. and A.J. Chalmers. 1919. Manual of tropical medicine, 3rd ed. Williams, Wood and Co., New York. p. 933. Type genus: Haemophilus Winslow, Broadhurst, Buchanan, Krumwiede, Rogers and Smith 1917

Lactobacilleae Winslow, Broadhurst, Buchanan, Krumwiede, Rogers and Smith 1920 Winslow, C.E.A., J. Broadhurst, R.E. Buchanan, C. Krumwiede Jr., L.A. Rogers and G.H. Smith. 1920. Journal of Bacteriology 5:191-229. Type genus: Lactobacillus Beijerinck 1901

\section{Micrococceae Prevot 1961}

Prevot, A.R. 1961. Traite de systematique bacterienne. Dunod, Paris. Volume 2. p. 31. Type genus: Micrococcus Cohn 1872

Pasteurelleae Castellani and Chalmers 1919 Castellani, A. and A.J. Chalmers. 1919. Manual of tropical medicine, 3rd ed. Williams, Wood and Co., New York. p. 943. Type genus: Pasteurella Trevisan 1887

\section{Proteeae Castellani and Chalmers 1919}

Castellani, A. and A.J. Chalmers. 1919. Manual of tropical medicine, 3rd ed. Williams, Wood and Co., New York. p. 932. Type genus: Proteus Hauser 1885

\section{Pseudomonadeae Kluyver and van Niel 1936} Kluyver, A.J. and C.B. van Niel. 1936. Zentralblatt fur Bakteriologie, Parasitenkunde, Infektionskrankheiten und 
Hygiene. Abteilung II. 94:369-403. Type genus: Pseudomonas Migula 1894

\section{Rhizobieae Prevot 1948}

Prevot, A.R. 1948. Manuel de classification et de determination des bacteries anaerobies. 2nd ed. Masson, Paris. pp. 290. Type genus: Rhizobium Frank 1889

\section{Rickettsieae Philip 1957}

Philip, C.B. 1957 in Breed, R.S., E.G.D. Murray and N.R. Smith (eds). Bergey's Manual of Determinative Bacteriology, 7th ed. The Williams and Wilkins Co., Baltimore. Type genus: Rickettsia da Rocha-Lima 1916

\section{Salmonelleae Kalz 1957}

Kalz, G. 1957 in Breed, R.S., E.G.D. Murray and N.R. Smith (eds). Bergey's Manual of Determinative Bacteriology, 7th ed. The Williams and Wilkins Co., Baltimore. pp. 368-384. Type genus: Salmonella Lignieres 1900

Serratieae Bergey, Breed, Murray and Hitchens 1939

Bergey, D.H., R.S. Breed, E.G.D. Murray and A.P. Hitchens (eds). 1939. Bergey's Manual of Determinative Bacteriology, 5th ed. The Williams and Wilkins Co., Baltimore. p. 359. Type genus: Serratia Bizio 1823

\section{Spirilleae Kluyver and van Niel 1936}

Kluyver, A.J. and C.B. van Niel. 1936. Zentralblatt fur Bakteriologie, Parasitenkunde, Infektionskrankheiten und Hygiene. Abteilung II. 94:369-403. Type genus: Spirillum Ehrenberg 1832

\section{Staphylococceae Prevot 1940}

Prevot, A.R. 1940. Manuel de classification et de determination des bacteries anaerobies. 1st ed. Masson, Paris. pp. 223. Type genus: Staphylococcus Rosenbach 1884

\section{Streptococceae Trevisan 1889}

Trevisan, V. 1889. I generi e le specie delle Batteriacee. Zanaboni and Gabuzzi, Milano. p. 29. Type genus: Streptococcus Rosenbach 1884
Thiobacilleae Pribram 1929

Pribram, E. 1929. Journal of Bacteriology 18:361-394. Type genus: Thiobacillus Beijerinck 1904

\section{Wolbachieae Philip 1955}

Philip, C.B. 1955. Bacteriological Reviews 19:271. Type genus: Wolbachia Hertig 1936

\section{FAMILY}

Acholeplasmataceae Edward and Freundt 1970 Edward, D.G. ff. and E.A. Freundt. 1970. Journal of General Microbiology 62:1-2. Type genus: Acholeplasma Edward and Freundt 1970

Achromatiaceae Massart 1901

Massart, J. 1901. Recueil de l'Institut Botanique 'Leo Errara', (Bruxelles) 5:251282. Type genus: Achromatium Schewiakoff 1893

\section{Actinomycetaceae Buchanan 1918}

Buchanan, R.E. 1918. Journal of Bacteriology 3:403-406. Type genus: Actinomyces Harz 1877

\section{Actinoplanaceae Couch 1955}

Couch, J.N. 1955. Journal of Elisha Mitchell Scientific Society 71:269. Type genus: Actinoplanes Couch 1950

\section{Anaplasmataceae Philip 1957}

Philip, C.B. 1957 in Breed, R.S., E.G.D. Murray and N.R. Smith (eds). Bergey's Manual of Determinative Bacteriology, 7th ed. The Williams and Wilkins Co., Baltimore. pp. 980-984. Type genus: Anaplasma Theiler 1910

\section{Archangiaceae Jahn 1924}

Jahn, E. 1924. Beitrage zur botanishcen Protistologie. I. Die Polyangiden. Verlag von Gebruder Borntraeger, Leipzig. p. 66. Type genus: Archangium Jahn 1924

Azotobacteraceae Pribram 1933

Pribram, E. 1933. Klassification der Sćhizomyceten. F. Deuticke, Leipzig. pp. 1-143. Type genus: Azotobacter Beijerinck 1901 


\section{Bacillaceae Fischer 1895}

Fischer, A. 1895. Jahrbuch fur Wissenschaftliche Botanik 27:1-163. Type genus: Bacillus Cohn 1872

\section{Bacteroidaceae Pribram 1933}

Pribram, E. 1933. Klassification der Schizomyceten. F. Deuticke, Leipzig. pp. 1-143. Type genus: Bacteroides Castellani and Chalmers 1919

\section{Bartonellaceae Gieszczykiewicz 1939}

Gieszczykiewicz, M. 1939. Bulletin de l'Academie Polonaise des Sciences. Serie des Sciences Biologiques 1:9-27. Type genus: Bartonella Strong, Tyzzer and Sellards 1915

\section{Beggiatoaceae Migula 1894}

Migula, W. 1894. Arbeiten aus dem Bakteriologischen Institut der Technischen Hochschule zu Karlsruhe 1:235-238. Type genus: Beggiatoa Trevisan 1842

\section{Brevibacteriaceae Breed 1953}

Breed, R.S. 1953. Riassunti delle Communicazioni, VI Congresso Internazionale Microbiologia Roma, 1:10-15. Type genus: Brevibacterium Breed 1953

\section{Brucellaceae Breed, Murray and Smith 1957} Breed, R.S., E.G.D. Murray and N.R. Smith (eds). 1957. Bergey's Manual of Determinative Bacteriology, 7th ed. The Williams and Wilkins Co., Baltimore. p. 394. Type genus: Brucella Meyer and Shaw 1920

Caryophanaceae Peshkoff 1939

Peshkoff, M.A. 1939. Doklady Akademii Nauk SSSR 25:239-242. Type genus: Caryophanon Peshkoff 1939

Caulobacteraceae Henrici and Johnson 1935

Henrici, A.T. and D. Johnson. 1935. Journal of Bacteriology 29:3-4. Type genus: Caulobacter Henrici and Johnson 1935

\section{Chlamydiaceae Rake 1957}

Rake, G. 1957 in Breed, R.S., E.G.D. Murray and N.R. Smith (eds). Bergey's Manual of Determinative Bacteriology, 7th ed. The Williams and Wilkins Co., Baltimore. pp. 957-968. Type genus: Chlamydia Jones, Rake and Stearns 1945

\section{Chlorobiaceae Copeland 1956}

Copeland, H.F. 1956. The classification of lower organisms. Pacific Books, Palo Alto, California. p. 31. Type genus: Chlorobium Nadson 1906

\section{Chromatiaceae Bavendamm 1924}

Bavendamm, W. 1924 in Kalkwitz (ed). Die farblosen und roten Schwefelbakterien des Suss-und Salzwassers. Pflanzenforschung, Berlin-Dahlem. pp. 1-156. Type genus: Chromatium Perty 1852

Clostridiaceae Pribram 1933

Pribram, E. 1933. Klassification der Schizomyceten. F. Deuticke, Leipzig. pp. 1-143. Type genus: Clostridium Prazmowski 1880

Corynebacteriaceae Lehmann and Neumann 1907

Lehmann, K.B. and R. Neumann. 1907. Lehmann's Medizin, Handatlanten $X$. Atlas und Grundriss der Bakteriologie und Lehrbuch der speziellen bakteriologischen Diagnostik. 4. Auflage. J.F. Lehmann, Munchen. p. 500. Type genus: Corynebacterium Lehmann and Neumann 1896

\section{Crenotrichaceae Hansgirg 1888}

Hansgirg, A. 1888. Oesterreichische Botanische Zeitschrift 38:227-230. Type genus: Crenothrix Cohn 1870

Cystobacteraceae McCurdy 1970

McCurdy, H.D. 1970. International Journal of Systematic Bacteriology 20: 283-296. Type genus: Cystobacter Schroeter 1886

\section{Cytophagaceae Stanier 1940}

Stanier, R.Y. 1940. Journal of Bacteriology 40:619-636. Type genus: Cytophaga Winogradsky 1929

\section{Dermatophilaceae Austwick 1958}

Austwick, P.K.C. 1958. Veterinary Reviews and Annotations 4:33-48. Type 
genus: Dermatophilus (Van Saceghem 1915) Gordon 1964

Ehrlichiaceae Moshkovski 1945

Moshkovski, S.D. 1945. Advances in Modern Biology (Moscow) 19:1-44. Type genus: Ehrlichia Moshkovski 1945 see below

\section{Frankiaceae Becking 1970}

Becking, J.H. 1970. International Journal of Systematic Bacteriology 20:201-220. Type genus: Frankia Brunchorst 1886

Gallionellaceae Henrici and Johnson 1935

Henrici, A.T. and D. Johnson. 1935. Journal of Bacteriology 29:3-4. Type genus: Gallionella Ehrenberg 1838

Halobacteriaceae Gibbons 1974

Gibbons, N.E. 1974. in Bergey 8. pp. 269-272. Type genus: Halobacterium Elazari-Volcani 1957

Hyphomicrobiaceae Babudieri 1950

Babudieri, B. 1950. R.C. 1st Supplement, Sanita, Roma 13:580-591. Type genus: Hyphomicrobium Stutzer and Hartleb 1899

Lactobacillaceae Winslow, Broadhurst, Buchanan, Krumwiede, Rogers and Smith 1917

Winslow, C.E.A., J. Broadhurst, R.E. Buchanan, C. Krumwiede Jr., L.A. Rogers and G.H. Smith 1917. Journal of Bacteriology 2:505-566. Type genus: Lactobacillus Beijerinck 1901

Legionellaceae Brenner, Steigerwalt and McDade 1979

Brenner, D.J., A.G. Steigerwalt and J.E. McDade. 1979. International Journal of Systematic Bacteriology 29:436; Effective publication Brenner, D.J., A.G. Steigerwalt and J.E. McDade. 1979. Annals of Internal Medicine 90:656-658. Type genus: Legionella Brenner, Steigerwalt and McDade 1979

$\dagger$ Editor's note: The family name Enterobacteriaceae Rahn 1937 (type genus Escherichia Castellani and Chalmers 1919) has been challenged and is presently sub judice (see S.P. Lapage, Int. J. Syst. Bacteriol. 29:265-266, 1979; Judicial Commission Minute 29, Int. J. Syst. Bacteriol. 29:267-269, 1979).
Leptospiracene Hovind-Houger 1978

Hovind-Houger, K. 1978. International Journal of Systematic Bacteriology 29: 245-251. Type genus: Leptospira Noguchi 1917

Leucotrichaceae Buchanan 1957

Buchanan, R.E. 1957 in Breed, R.S., E.G.D. Murray and N.R. Smith (eds). Bergey's Manual of Determinative Bacteriology, 7th ed. The Williams and Wilkins Co., Baltimore. pp. 850-851. Type genus: Leucothrix Oersted 1884

Lysobacteraceae Christensen and Cook 1978

Christensen, P. and F.D. Cook. 1978. International Journal of Systematic Bacteriology 28:367-393. Type genus: Lysobacter Christensen and Cook 1978

Methanobacteriaceae Barker 1956

Barker, H.A. 1956. Bacterial fermentations. John Wiley, New York. p. 15. Type genus: Methanobacterium Kluyver and van Niel 1936

Micrococcaceae Pribram 1929

Pribram, E. 1929. Journal of Bacteriology 18:361-394. Type genus: Micrococcus Cohn 1872

Micromonosporaceae Krassilnikov 1938

Krassilnikov, N.A. 1938. Ray fungi and related organisms, Actinomycetales. Akademii Nauk SSSR, Moscow. p. 272. Type genus: Micromonospora Orskov 1923

\section{Mycobacteriaceae Chester 1897}

Chester, F.D. 1897. Delaware Agricultural Experiment Station Bulletin 9:38-145. Type genus: Mycobacterium Lehmann and Neumann 1896

Mycoplasmataceae Freundt 1955

Freundt, E.A. 1955. International Bulletin of Bacteriological Nomenclature and Taxonomy 5:67-78. Type genus: Mycoplasma Nowak 1929

Myxococcaceae Jahn 1924

Jahn, E. 1924. Beitrage zur botanischen Protistologie. I. Die Polyangiden. Verlag von Gebruder Borntraeger, Leipzig. p. 
403. Type genus: Myxococcus Thaxter 1892

\section{Neisseriaceae Prevot 1933}

Prevot, A.R. 1933. Annales des Sciences Naturelles Zoologie et Biologie Animale 15:23-260. Type genus: Neisseria Trevisan 1885

Nevskiaceae Henrici and Johnson 1935

Henrici, A.T. and D. Johnson. 1935. Journal of Bacteriology 29:3-4. Type genus: Nevskia Famintzin 1892

Nitrobacteraceae Buchanan 1917

Buchanan, R.E. 1917. Journal of Bacteriology 2:347-350. Type genus: Nitrobacter Winogradsky 1892

Nocardiaceae Castellani and Chalmers 1919 Castellani, A. and A.J. Chalmers. 1919. Manual of tropical medicine, 3rd ed. Williams, Wood and Co., New York. p. 1040. Type genus: Nocardia Trevisan 1889

\section{Oscillospiraceae Peshkoff 1940}

Peshkoff, M.A. 1940. Zhurnal Obshchei Biologii 1:597-617. Type genus: Oscillospira Chatton and Perard 1913

\section{Pasteuriaceae Laurent 1890}

Laurent, E. 1890. Comptes Rendus de l'Academie des Sciences Paris 111:754756. Type genus: Pasteuria Metchnikoff 1888

\section{Peptococcaceae Rogosa 1971}

Rogosa, M. 1971. International Journal of Systematic Bacteriology 21:234-237. Type genus: Peptococcus Kluyver and van Niel 1936

Planococcaceae Krassilnikov 1949

Krassilnikov, N.A. 1949. Opredelitelv Bakterii i Actinomicetov. Akademii Nauk SSSR, Moscow. pp. 328. Type genus: Planococcus Migula 1894

\section{Polyangiaceae Jahn 1924}

Jahn, E. 1924. Beitrage zur botanischen Protistologie. I. Die Polyangiden. Verlag von Gebruder Borntraeger, Leipzig. p. 75. Type genus: Polyangium Link 1809
Propionibacteriaceae Delwiche 1957

Delwiche, E.A. 1957 in Breed, R.S., E.G.D. Murray and N.R. Smith (eds). Bergey's Manual of Determinative Bacteriology, 7th ed. The Williams and Wilkins Co., Baltimore. p. 569. Type genus: Propionibacterium Orla-Jensen 1909

Pseudomonadaceae Winslow, Broadhust, Buchanan, Krumwiede, Rogers and Smith 1917

Winslow, C.E.A., J. Broadhurst, R.E. Buchanan, C. Krumwiede Jr., L.A. Rogers and G.H. Smith. 1917. Journal of Bacteriology 2:505-566. Type genus: Pseudomonas Migula 1894

\section{Rhizobiaceae Conn 1938}

Conn, H.J. 1938. Journal of Bacteriology 36:320-321. Type genus: Rhizobium Frank 1889

Rhodospirillaceae Pfennig and Truper 1971 Pfennig, N. and H.G. Truper. 1971. International Journal of Systematic Bacteriology 21:17-18. Type genus: Rhodospirillum Molisch 1907

Rickettsiaceae Pinkerton 1936

Pinkerton, H. 1936. Parasitology 28:172189. Type genus: Rickettsia da RochaLima 1916

Simonsiellaceae Steed 1962

Steed, P.D.M. 1962. Journal of General Microbiology 29:615-624. Type genus: Simonsiella Schmid 1922

\section{Spirillaceae Migula 1894}

Migula, N. 1894. Arbeiten aus dem Bakteriologischen Institut der Technischen Hochschule zu Karlsruhe 1:235:238. Type genus: Spirillum Ehrenberg 1832

\section{Spirochaetaceae Swellengrebel 1907}

Swellengrebel, N.H. 1907. Annales de l'Institut Pasteur (Paris) 21:562-586. Type genus: Spirochaeta Ehrenberg 1835

Spirosomaceae Larkin and Borrall 1978

Larkin, J.M. and R. Borrall. 1978. International Journal of Systematic Bacteriology 28:595-596. Type genus: Spirosoma Migula 1894 
Streptomycetaceae Waksman and Henrici 1943 Waksman, S.A. and A.T. Henrici. 1943. Journal of Bacteriology 46:337-341. Type genus: Streptomyces Waksman and Henrici 1943

Streptococcaceae Deibel and Seeley 1974

Deibel, R.H. and H.W. Seeley Jr. 1974.

in Bergey 8. pp. 490-517. Type genus:

Streptococcus Rosenbach 1884

Thiocapsacene Bavendamm 1924

Bavendamm, W. 1924. Die farblosen und roten Schwefelbakterien des Suss-und Salzwassers. Pflanzenforschung, BerlinDahlem. pp. 1-156. Type genus: Thiocapsa Winogradsky 1888

Treponemataceae Robinson 1948

Robinson, G.H. 1948 in Breed, R.S.,
E.G.D. Murray and A.P. Hitchens (eds). Bergey's Manual of Determinative Bacteriology, 6th ed. The Williams and Wilkins Co., Baltimore. pp. 1051-1058. Type genus: Treponema Schaudinn 1905

\section{Veillonellaceae Rogosa 1971}

Rogosa, M. 1971. International Journal of Systematic Bacteriology 21:231-233. Type genus: Veillonella Prevot 1933

\section{Vibrionaceae Veron 1965}

Veron, M. 1965. Comptes Rendus de l'Academie des Sciences Paris 261:52435246. Type genus: Vibrio Pacini 1854

Vitreoscillaceae Pringsheim 1949

Pringsheim, E.G. 1949. Bacteriological Reviews 13:47-98. Type genus: Vitreoscilla Pringsheim 1949 
Note: Abbreviations used for genera in the following lists are used for brevity only and are not intended or recommended as contractions in the nomenclatural sense.

Acetobacter Beijerinck 1898

Beijerinck, M. 1898. Zentralblatt fur Bakteriologie, Parasitenkunde, Infektionskrankheiten und Hygiene. Abteilung II. 4:209-216. Type species: $A$. aceti (Pasteur 1864) Beijerinck 1898

Description: Bergey 8.

A. aceti (Pasteur 1864) Beijerinck 1898

Pasteur, L. 1864. Annales scientifiques de l'Ecole normale superieure. Paris 1:113158; Beijerinck, M. 1898. Zentralblatt fur Bakteriologie, Parasitenkunde, Infektionskrankheiten und Hygiene. Abteilung II. 4:209-216. Type strain: NCIB 8621

Description: Bergey 8 .

A. aceti subsp. aceti (Pasteur 1864) De Ley and Frateur 1974

Pasteur, L. 1864. Annales scientifiques de l'Ecole normale superieure. Paris 1:113158; De Ley, J. and J. Frateur. 1974 in Bergey 8. Type strain: NCIB 8621

Description: Bergey 8.

A. aceti subsp. liquefaciens (Asai 1935) De Ley and Frateur 1974

Asai, T. 1935. Journal of the Agricultural Chemical Society of Japan 11:674-708; De Ley, J. and J. Frateur. 1974 in Bergey 8. Type strain: IAM 1834

Description: Bergey 8.

A. aceti subsp. orleanensis (Henneberg 1906) De Ley and Frateur 1974

Henneberg, W. 1906. Deutsche Essigindustrie 10:106-108; De Ley, J. and J. Frateur. 1974 in Bergey 8. Type strain: ATCC 12876

Description: Bergey 8.

A. aceti subsp. xylinum (Brown 1886) De Ley and Frateur 1974

Brown, A.J. 1886. Journal of the Chemical Society (London) 49:432-439; De Ley, J. and J. Frateur. 1974 in Bergey 8. Type strain: ATCC 23767 Description: Bergey 8.

A. pasteurianus (Hansen 1879) Beijerinck 1916 Hansen, E.C. 1879. Compte Rendu des travaux du Laboratoire Carlsberg 1:96100; Beijerinck, M. 1916. Verslagen van de gewone vergadering der wis- en natuurkundige afdeeling. Koninklijke Akademie van wetenschappen te Amsterdam 18:1198-2000. Type strain: LMD
22.1

Description: Bergey 8 .

A. pasteurianus subsp. ascendens (Henneberg 1898) De Ley and Frateur 1974

Henneberg, W. 1898. Deutsche Essigindustrie 2:145-148; De Ley, J. and J. Frateur. 1974 in Bergey 8. Type strain: LMD 51.1

Description: Bergey 8.

A. pasteurianus subsp. estunensis (Carr 1958) De Ley and Frateur 1974

Carr, J.G. 1958. Antonie van Leeuwenhoek Journal of Microbiology and Serology 24:157-160; De Ley, J. and J. Frateur. 1974 in Bergey 8. Type strain: ATCC 23753

Description: Bergey 8.

A. pasteurianus subsp. lovaniensis (Frateur 1950) De Ley and Frateur 1974

Frateur, J. 1950. Cellule 53:287-392; De Ley, J. and J. Frateur. 1974 in Bergey 8. Type strain: ATCC 12875

Description: Bergey 8.

A. pasteurianus subsp. paradoxus (Frateur 1950) De Ley and Frateur 1974

Frateur, J. 1950. Cellule 53: 287-392; De Ley, J. and J. Frateur. 1974 in Bergey 8. Type strain: LMD 53.6

Description: Bergey 8 .

A. pasteurianus subsp. pasteurianus (Hansen 1879) De Ley and Frateur 1974

Hansen, E.C. 1879. Compte Rendu des Travaux du Laboratoire Carlsberg 1:96100; De Ley, J. and J. Frateur. 1974 in Bergey 8. Type strain: LMD 22.1

Description: Bergey 8.

A. peroxydans Visser't Hooft 1925

Visser't Hooft, F: 1925. Dissertation. Technical University, Delft, Meinema. pp. 1-129. Type strain: ATCC 12874

Description: Bergey 8 .

Acetobacterium Balch, Schoberth, Tanner and Wolfe 1977

Balch, W.E., S. Schoberth, R.S. Tanner and R.S. Wolfe. 1977. International Journal of Systematic Bacteriology 27: 355-361. Type species: $A$. woodii Balch, Schoberth, Tanner and Wolfe 1977

Description: Balch, W.E., S. Schoberth, R.S. Tanner and R.S. Wolfe. 1977. Ibid. 
A. woodii Balch, Schoberth, Tanner and Wolfe 1977

Balch, W.E., S. Schoberth, R.S. Tanner and R.S. Wolfe. 1977. International Journal of Systematic Bacteriology 27: 355-361. Type strain: ATCC 29683

Description: Balch, W.E., S. Schoberth, R.S. Tanner and R.S. Wolfe. 1977. Ibid.

Acholeplasma Edward and Freundt 1970

Edward, D.G. ff. and E.A. Freundt. 1970. Journal of General Microbiology 62:1-2. Type species: A. laidlawii (Freundt 1955) Edward and Freundt 1970

Description: Bergey 8.

A. axanthum Tully and Razin 1970

Tully, J.G. and S. Razin. 1970. Journal of Bacteriology 103:751-754. Type strain: ATCC 25176

Description: Tully, J.G. 1979 in Barile, M.F., S. Razin, J.G. Tully and R.F. Whitcomb (eds). The Mycoplasmas. Academic Press, New York, Volume I. pp. 431-449.

A. equifetale Kirchoff 1974

Kirchoff, H. 1974. Zentralblatt fur Veterinarmedizin Reihe B 21:207-210. Type strain: ATCC 29724

Description: Kirchoff, H. 1978. International Journal of Systematic Bacteriology 28:76-81.

A. granularum (Switzer 1964) Edward and Freundt 1970

Switzer, W.P. 1964 in Dunne (ed). Diseases of Swine, 2nd ed. lowa State University Press, Ames. pp. 498-507; Edward, D.G. ff. and E.A. Freundt. 1970. Journal of General Microbiology 62:1-2. Type strain: ATCC 19168

Description: Tully, J.G. 1979 in Barile, M.F., S. Razin, J.G. Tully and R.F. Whitcomb (eds). The Mycoplasmas. Academic Press, New York, Volume I. pp. 431-449.

A. hippikon Kirchoff 1974

Kirchoff, H. 1974. Zentralblatt fur Veterinarmedizin Reihe B 21:207-210. Type strain: ATCC 29725

Description: Kirchoff, H. 1978. International Journal of Systematic Bacteriology 28:76-81.

A. laidlawii (Freundt 1955) Edward and Freundt 1970
Freundt, E.A. 1955. International Bulletin of Bacteriological Nomenclature and Taxonomy 5:67-78; Edward, D.G. ff. and E.A. Freundt. 1970. Journal of General Microbiology 62:1-2. Type strain: ATCC 23206

Description: Tully, J.G. 1979 in Barile, M.F., S. Razin, J.G. Tully and R.F. Whitcomb (eds). The Mycoplasmas. Academic Press, New York, Volume I. pp. 431-449.

A. modicum Leach 1973

Leach, R.H. 1973. Journal of General Microbiology 75:135-153. Type strain: ATCC 29102

Description: Tully, J.G. 1979 in Barile, M.F., S. Razin, J.G. Tully and R.F. Whitcomb (eds). The Mycoplasmas. Academic Press, New York, Volume I. pp. 431-449.

A. oculi Al-Aubaidi, Dardiri, Muscoplatt and McCauley 1973

Al-Aubaidi, J.M., A.H. Dardiri, C.C. Muscoplatt and E.H. McCauley. 1973. Cornell Veterinarian 63:117-129. Type strain: ATCC 27350

Description: Tully, J.G. 1979 in Barile, M.F., S. Razin, J.G. Tully R.F. Whitcomb (eds). The Mycoplasmas. Academic Press, New York, Volume I. pp. 431-449.

\section{Achromatium Schewiakoff 1893}

Schewiakoff, W. 1893. Uber einen neuen bacterienahnlichen Organismus des Susswassers. Habilitations schrift, Universitat Heidelberg C. Winter. pp. 1-36. Type species: $A$. oxaliferum Schewiakoff 1893

Description: Bergey 8.

A. oxaliferum Schewiakoff 1893

Schewiakoff, W. 1893. Uber einen neuen bacterienahnlichen Organismus des Susswassers. Habilitations schrift, Universitat Heidelberg C. Winter. pp. 1-36. Type strain: no culture isolated.

Description: West, G.S. and B.M. Griffiths. 1909. Proceedings of the Royal Society London B, Biological Sciences 81: 398-405. 
98:756-766. Type species: A. fermentans Rogosa 1969

Description: Bergey 8.

\section{A. fermentans Rogosa 1969}

Rogosa, M. 1969. Journal of Bacteriology 98:756-766. Type strain: ATCC 25085

Description: Holdeman, L.V., E.P. Cato and W.E.C. Moore (eds). 1977. Anaerobe Laboratory Manual, 4th ed. Virginia Polytechnic Institute and State University, Blacksburg, Virginia. pp. 1-156.

\section{Acinetobacter Brisou and Prevot 1954} Brisou, J. and A.R. Prevot. 1954. Annales de l'Institut Pasteur (Paris) 86:722-728. Type species: $A$. calcoaceticus (Beijerinck 1911) Baumann, Doudoroff and Stanier 1968

Description: Bergey 8.

A. calcoaceticus (Beijerinck 1911) Baumann, Doudoroff and Stanier 1968

Beijerinck, M.W. 1911. Proceedings of the Royal Academy of Sciences (Amsterdam) 13:1066-1077; Baumann, P., M. Doudoroff and R.Y. Stanier. 1968. Journal of Bacteriology 95:1520-1541. Type strain: ATCC 23055

Description: Henriksen, S.D. 1973. Bacteriological Reviews 37:522-561.

A. Iwoffii (Audureau 1940) Brisou and Prevot 1954

Audureau, A. 1940. Annales de l'Institut Pasteur (Paris) 64:126-166; Brisou, J. and A.R. Prevot. 1954. Annales de l'Institut Pasteur (Paris) 86:722-728. Type strain: ATCC 15309

Description: Henriksen, S.D. 1973. Bacteriological Reviews 37:522-561.

\section{Actinobacillus Brumpt 1910}

Brumpt, E. 1910. Precis de Parasitologie. 1st ed., Masson et Cie, Paris. Type species: A. lignieresii Brumpt 1910

Description: Bergey 8.

A. actinomycetemcomitans (Klinger 1912) Topley and Wilson 1929

Klinger, R. 1912. Zentralblatt fur Bakteriologie, Parasitenkunde, Infektionskrankheiten und Hygiene. Abteilung I. 62:191-200; Topley, W.W.C. and G.S. Wilson. 1929. The principles of bacteriology and immunity. 1st ed. Edward Arnold and Co., London. pp. 1-
587. Type strain: NCTC 9710

Description: King, E.O. and H.W. Tatum. 1962. Journal of Infectious Diseases 111: 85-94.

A. capsulatus Arseculeratne 1962

Arseculeratne, S.N. 1962. Journal of Comparative Pathology and Therapeutics 72:33-39. Type strain: Frederiksen P243

Description: Arseculeratne, S.N. 1962. Ibid.

A. equuli (van Straaten 1918) Haupt 1934

van Straaten, H. 1918. Bacteriologische Bevindingen bij eenigo gevallen van Pyosepticaemie (Lahme) der veulens. Verslag van den Werksaamheden der Rijksseruminrichting voor 1916-1917, Rotterdam. pp. 71-76; Haupt, H. 1934. Archiv fur wissenschaftliche und praktische Tierheilkunde 67:513-524. Type strain: ATCC 19392

Description: Bergey 8 .

A. lignieresii Brumpt 1910

Brumpt, E. 1910. Precis de Parasitologie. 1st ed., Masson et Cie, Paris. p. 849. Type strain: NCTC 4189

Description: Bergey 8.

A. suis van Dorssen and Jaartsveld 1962

van Dorssen, C.A. and F.H.J. Jaartsveld 1962. Tijdschrift voor Diergeneeskunde 87:448-450. Type strain: CCM 5586

Description: Mair, N.S., C.J. Randall, G.W. Thomas, J.F. Harbourne, C.T. McCrea and K.P. Cowl. 1974. Journal of Comparative Pathology 84:113-119.

Actinomadura Lechevalier and Lechevalier 1970 Lechevalier, H.A. and M.P. Lechevalier. 1970 in Prauser, H. (ed). The Actinomycetales. VEB Gustav Fischer Verlag, Jena. pp. 393-405. Type species: A. madurae (Vincent 1894) Lechevalier and Lechevalier 1970

Description: Lechevalier, H.A. and M.P. Lechevalier. 1970. Ibid.

A. africana Preobrazhenskaya and Sveshnikova 1974

Preobrazhenskaya, T.P. and M.A. Sveshnikova. 1974. Mikrobiologiya 43:735-738. Type strain: INA 1839

Description: Preobrazhenskaya, T.P. and M.A. Sveshnikova. 1974. Ibid.

A. aurantiaca Lavrova and Preobrazhenskaya 1975 
Lavrova, N.V. and T.P. Preobrazhenskaya. 1975. Antibiotiki 20:483-488. Type strain: INA 1933

Description: Lavrova, N.V. and T.P. Preobrazhenskaya. 1975. Ibid.

A. carminata Gauze, Sveshnikova, Ukholina, Gavrilina, Filicheva and Gladkikh 1973

Gauze, G.F., M.A. Sveshnikova, R.S. Ukholina, G.V. Gavrilina, V.A. Filicheva and E.G. Gladkikh. 1973. Antibiotiki 18: 675-678. Type strain: INA 4281

Description: Gauze, G.F., M.A. Sveshnikova, R.S. Ukholina, G.V. Gavrilina, V.A. Filicheva and E.G. Gladkikh. 1973. Ibid.

A. citrea Lavrova, Preobrazhenskaya and Sveshnikova 1972

Lavrova, N.V., T.P. Preobrazhenskaya and M.A. Sveshnikova. 1972. Antibiotiki 17:965-970. Type strain: ATCC 27887

Description: Lavrova, N.V., T.P. Preobrazhenskaya and M.A. Sveshnikova. 1972. Ibid.

A. coerulea Preobrazhenskaya, Lavrova, Ukholina and Nechaeva 1975

Preobrazhenskaya, T.P., N.V. Lavrova, R.S. Ukholina and N.P. Nechaeva. 1975. Antibiotiki 20:404-409. Type strain: INA 765

Description: Preobrazhenskaya, T.P., N.V. Lavrova, R.S. Ukholina and N.P. Nechaeva. 1975. Ibid.

A. coeruleofusca Preobrazhenskaya and Sveshnikova 1974

Preobrazhenskaya, T.P. and M.A. Sveshnikova. 1974. Mikrobiologiya 43:735-738.

Type strain: INA 1335

Description: Preobrazhenskaya, T.P. and M.A. Sveshnikova. 1974. Ibid.

A. cremea Preobrazhenskaya, Lavrova, Ukholina and Nechaeva 1975

Preobrazhenskaya, T.P., N.V. Lavrova, R.S. Ukholina and N.P. Nechaeva. 1975. Antibiotiki 20:404-409. Type strain: INA 292

Description: Preobrazhenskaya, T.P., N.V. Lavrova, R.S. Ukholina and N.P. Necheva. 1975. Ibid.

A. fastidiosa Soina, Sokolov and Agre 1975

Soina, V.S., A.A. Sokolov and N.S. Agre. 1975. Mikrobiologiya 44:883-887. Type strain: INMI 104

Description: Soina, V.S., A.A. Sokolov and N.S. Agre. 1975. Ibid.
A. flava Gauze, Maksimova, Ollkhovatova, Sveshnikova, Kochetkova and Ilchenko 1974

Gauze, G.F., T.S. Maksimova, O.L. Ollkhovatova, M.A. Sveshnikova, G.V. Kochetkova and G.B. Ilchenko. 1974. Antibiotiki 9:771-775. Type strain: ATCC 29533

Description: Gauze, G.F., T.S. Maksimova, O.L. Ollkhovatova, M.A. Sveshnikova, G.V. Kochetkova and G.B. Ilchenko. 1974. Ibid.

A. helvata Nonomura and Ohara 1971 Nonomura, H. and Y. Ohara. 1971. Journal of Fermentation Technology 49: 904-912. Type strain: ATCC 27295

Description: Nonomura, $H$. and Y. Ohara. 1971. Ibid.

A. livida Lavrova and Preobrazhenskaya 1975 Lavrova, N.V. and T.P. Preobrazhenskaya. 1975. Antibiotiki 20:483-488. Type strain: INA 1678

Description: Lavrova, N.V. and T.P. Preobrazhenskaya. 1975. Ibid.

A. longispora Preobrazhenskaya and Sveshnikova 1974

Preobrazhenskaya, T.P. and M.A. Sveshnikova. 1974. Mikrobiologiya 43:864-868.

Type strain: INA 10222

Description: Preobrazhenskaya, T.P. and M.A. Sveshnikova. 1974. Ibid.

A. luteofluorescens (Shinobu 1962)

Preobrazhenskaya, Lavrova and Blinov 1975

Shinobu, R. 1962. Memoirs of the Osaka University of the Liberal Arts and Education B Natural Science 11:115-122; Preobrazhenskaya, T.P., N.V. Lavrova and N.O. Blinov. 1975. Mikrobiologiya 44:524-527. Type strain: IFO 13057

Description: Preobrazhenskaya, T.P., N.V. Lavrova and N.O. Blinov. 1975. Ibid.

A. madurae (Vincent 1894) Lechevalier and Lechevalier 1970

Vincent, H. 1894. Annales de l'Institut Pasteur (Paris) 8:129-151; Lechevalier, H.A. and M.P. Lechevalier. 1970 in Prauser, H. (ed). The Actinomycetales. VEB Gustav Fischer Verlag, Jena. pp. 393-405. Type strain: NCTC 5654

Description: Lechevalier, H.A. and M.P. Lechevalier. 1970. Ibid.

A. malachitica Lavrova, Preobrazhenskaya and 
Sveshnikova 1972

Lavrova, N.V., T.P. Preobrazhenskaya and M.A. Sveshnikova. 1972. Antibiotiki 17:965-970. Type strain: ATCC 27888

Description: Lavrova, N.V., T.P. Preobrazhenskaya and M.A. Sveshnikova. 1972. Ibid.

A. pelletieri (Laveran 1906) Lechevalier and Lechevalier 1970

Laveran, A. 1906. Comptes Rendus des Seances de la Societe de Biologie (Paris) 61:340-341; Lechevalier, H.A. and M.P. Lechevalier. 1970 in Prauser, H. (ed). The Actinomycetales. VEB Gustav Fischer Verlag, Jena. pp. 393-405. Type strain: NCTC 4162

Description: Lechevalier, H.A. and M.P. Lechevalier. 1970. Ibid.

A. pusilla Nonomura and Ohara 1971

Nonomura, H. and Y. Ohara. 1971. Journal of Fermentation Technology 49: 904-912. Type strain: ATCC 27296

Description: Nonomura, H. and Y. Ohara. 1971. Ibid.

A. roseola Lavrova and Preobrazhenskaya 1975 Lavrova, N.V. and T.P. Preobrazhenskaya. 1975. Antibiotiki 20:483-488. Type strain: INA 1671

Description: Lavrova, N.V. and T.P. Preobrazhenskaya. 1975. Ibid.

A. roseoviolacea Nonomura and Ohara 1971

Nonomura, H. and Y. Ohara. 1971. Journal of Fermentation Technology 49: 904-912. Type strain: ATCC 27297

Description: Nonomura, H. and Y. Ohara. 1971. Ibid.

A. rubra (Sveshnikova, Maksimova and Kudrina 1969) Meyer and Sveshnikova 1974

Sveshnikova, M.A., T.S. Maksimova and E.S. Kudrina. 1969. Mikrobiologiya 38: 883-893; Meyer, J. and M.A. Sveshnikova. 1974. Zeitschrift fur Allgemeine Mikrobiologie 14:167-170. Type strain: ATCC 27031

Description: Meyer, J. and M.A. Sveshnikova. 1974. Ibid.

A. salmonea Preobrazhenskaya, Lavrova, Ukholina and Nechaeva 1975

Preobrazhenskaya, T.P., N.V. Lavrova, R.S. Ukholina and N.P. Nechaeva. 1975. Antibiotiki 20:404-409. Type strain: INA 2488

Description: Preobrazhenskaya, T.P., N.V.
Lavrova, R.S. Ukholina and N.P. Nechaeva. 1975. Ibid.

A. spadix Nonomura and Ohara 1971

Nonomura, H. and Y. Ohara. 1971.

Journal of Fermentation Technology 49:

904-912. Type strain: ATCC 27298

Description: Nonomura, H. and Y. Ohara. 1971. Ibid.

A. verrucosospora Nonomura and Ohara 1971

Nonomura, H. and Y. Ohara. 1971.

Journal of Fermentation Technology 49:

904-912. Type strain: ATCC 27299

Description: Nonomura, $H$. and Y. Ohara. 1971. Ibid.

A. vinacea Lavrova and Preobrazhenskaya 1975 Lavrova, N.V. and T.P. Preobrazhenskaya. 1975. Antibiotiki 20:483-488. Type strain: INA 1682

Description: Lavrova, N.V. and T.P. Preobrazhenskaya. 1975. Ibid.

Actinomyces Harz 1877

Harz, C.O. 1877-1878. Deutsche Zeitschrift fur Thiermedizin 5:125-140.

Type species: A. bovis Harz 1877

Description: Bergey 8.

A. bovis Harz 1877

Harz, C.O. 1877-1878. Deutsche Zeitschrift fur Thiermedizin 5:125-140. Type strain: ATCC 13683

Description: Bergey 8.

A. humiferus Gledhill and Casida 1969 Gledhill, W.E. and L.E. Casida. 1969. Applied Microbiology 18:114-121. Type strain: ATCC 25174

Description: Gledhill, W.E. and L.E. Casida. 1969. Ibid.

A. israelii (Kruse 1896) Lachner-Sandoval 1898 Kruse, W. 1896 in Flugge, C. Die Mikroorganismen 3rd ed. Vol. 2, Vogel, Leipzig. pp. 48-96; Lachner-Sandoval, V. 1898. Uber Strahlenpilze. Inaugural Dissertation Strassburg. Universitats Buchdruckerei Von Carl Georgi, Bonn. Type strain: ATCC 12102

Description: Bergey 8.

A. naeslundii Thompson and Lovestedt 1951 Thompson, L. and S.A. Lovestedt. 1951. Proceedings of the Staff Meetings of the Mayo Clinic 26:169-175. Type strain: ATCC 12104

Description: Bergey 8.

A. odontolyticus Batty 1958 
Batty, I. 1958. Journal of Pathology and Bacteriology 75:455-459. Type strain: ATCC 17929

Description: Bergey 8.

A. viscosus (Howell, Jordan, Georg and Pine 1965) Georg, Pine and Gerencser 1969

Howell, A., H.V. Jordan, L.K. Georg and L. Pine. 1965. Sabouraudia 4:65-67; Georg, L.K., L. Pine and M.A. Gerencser. 1969. International Journal of Systematic Bacteriology 19:291-293. Type strain: ATCC 15987

Description: Bergey 8.

\section{Actinoplanes Couch 1950}

Couch, J.N. 1950. Journal of the Elisha Mitchell Scientific Society 66:87-92. Type species: A. philippinensis Couch 1950

Description: Bergey 8.

A. armeniacus Kalakoutskii and Kusnetsov 1964 Kalakoutskii, L.V. and V.D. Kusnetsov. 1964. Mikrobiologiya 33:613. Type strain: ATCC 15676

Description: Bergey 8.

A. brasiliensis Thiemann, Beretta, Coronelli and Pagani 1969

Thiemann, J.E., G. Beretta, C. Coronelli and H. Pagani. 1969. Journal of Antibiotics 22:119-125. Type strain: ATCC 25844

Description: Thiemann, J.E., G. Beretta, C. Coronelli and H. Pagani. 1969. Ibid.

A. deccanensis Parenti, Pagani and Beretta 1975

Parenti, F., H. Pagani and G. Beretta. 1975. Journal of Antibiotics 28:247-252. Type strain: ATCC 21983

Description: Parenti, F., H. Pagani and G. Beretta. 1975. Ibid.

A. ferrugineus Palleroni 1978

Palleroni, N.J. 1978. International Journal of Systematic Bacteriology 29:51-55. Type strain: ATCC 29868

Description: Palleroni, N.J. 1978. Ibid.

A. italicus Beretta 1973

Beretta, G. 1973. International Journal of Systematic Bacteriology 23:37-41. Type strain: ATCC 27366

Description: Beretta, G. 1973. Ibid.

A. missouriensis Couch 1963

Couch, J.N. 1963. Journal of the Elisha Mitchell Scientific Society 79:53-70. Type strain: ATCC 14538
Description: Bergey 8.

A. philippinensis Couch 1950

Couch, J.N. 1950. Journal of the Elisha Mitchell Scientific Society 66:87-92. Type strain: ATCC 12427

Description: Bergey 8.

A. rectilineatus Lechevalier and Lechevalier 1975

Lechevalier, M.P. and H.A. Lechevalier. 1975. International Journal of Systematic Bacteriology 25:371-376. Type strain: ATCC 29234

Description: Lechevalier, M.P. and H.A. Lechevalier. 1975. Ibid.

A. utahensis Couch 1963

Couch, J.N. 1963. Journal of the Elisha Mitchell Scientific Society 79:53-70. Type strain: ATCC 14539

Description: Bergey 8.

Actinopolyspora Gochnauer, Leppard, Komaratat, Kates, Novitsky and Kushner 1975

Gochnauer, M.B., G.G. Leppard, P. Komaratat, M. Kates, T. Novitsky and D.J. Kushner. 1975. Canadian Journal of Microbiology 21:1500-1511. Type species: A. halophila Gochnauer, Leppard, Komaratat, Kates, Novitsky and Kushner 1975

Description: Gochnauer, M.B., G.G. Leppard, P. Komaratat, M. Kates, T. Novitsky and D.J. Kushner. 1975. Ibid.

A. halophila Gochnauer, Leppard, Komaratat, Kates, Novitsky and Kushner 1975

Gochnauer, M.B., G.G. Leppard, P. Komaratat, M. Kates, T. Novitsky and D.J. Kushner. 1975. Canadian Journal of Microbiology 21:1500-1511. Type strain: ATCC 27976

Description: Gochnauer, M.B., G.G. Leppard, P. Komaratat, M. Kates, T. Novitsky and D.J. Kushner. 1975. Ibid.

Actinopycnidium Krassilnikov 1962

Krassilnikov, N.A. 1962. Mikrobiologiya 31:250-253 (English Translation 204-207).

Type species: $A$. caeruleum Krassilnikov 1962

Description: Krassilnikov, N.A. 1962. Ibid.

A. caeruleum Krassilnikov 1962

Krassilnikov, N.A. 1962. Mikrobiologiya 31:204-207. Type strain: ATCC 15719 
Description: Krassilnikov, N.A. 1962. Ibid.

Actinosporangium Krassilnikov and Yuan 1961

Krassilnikov, N.A. and C.S. Yuan. 1961. Izvestiya Akademii Nauk SSSR Seriya Biologicheskaya 8:113-116. Type species: A. violaceum Krassilnikov and Yuan 1961 Description: Krassilnikov, N.A. and C.S. Yuan. 1961. Ibid.

A. violaceum Krassilnikov and Yuan 1961 Krassilnikov, N.A. and C.S. Yuan. 1961. Izvestiya Akademii Nauk SSSR Seriya Biologicheskaya 8:113-116. Type strain: ATCC 15813

Description: Krassilnikov, N.A. and C.S. Yuan. 1961. Ibid.

Actinosynnema Hasegawa, Lechevalier and Lechevalier 1978

Hasegawa, T., M.P. Lechevalier and H.A. Lechevalier. 1978. International Journal of Systematic Bacteriology 28:304-310. Type species: $A$. mirum Hasegawa, Lechevalier and Lechevalier 1978

Description: Hasegawa, T., M.P. Lechevalier and H.A. Lechevalier. 1978. Ibid.

A. mirum Hasegawa, Lechevalier and Lechevalier 1978

Hasegawa, T., M.P. Lechevalier and H.A. Lechevalier. 1978. International Journal of Systematic Bacteriology 28:304-310. Type strain: IMRU 3971

Description: Hasegawa, T., M.P. Lechevalier and H.A. Lechevalier. 1978. Ibid.

\section{Aegyptianella Carpano 1929}

Carpano, M. 1929. Bulletin of the Ministry of Agriculture Egypt 86:1-12. Type species: A. pullorum Carpano 1929 Description: Bergey 8.

A. pullorum Carpano 1929

Carpano, M. 1929. Bulletin of the Ministry of Agriculture Egypt 86:1-12. Type strain: no culture isolated.

Description: Bergey 8.

Aerococcus Williams, Hirch and Cowan 1953 Williams, R.E.O., A. Hirch and S.T. Cowan. 1953. Journal of General Microbiology 8:475-480. Type species: $A$. viridans Williams, Hirch and Cowan 1953 Description: Bergey 8.
A. viridans Williams, Hirch and Cowan 1953 Williams, R.E.O., A. Hirch and S.T. Cowan. 1953. Journal of General Microbiology 8:475-480. Type strain: NCTC 8251

Description: Williams, R.E.O., A. Hirch and S.T. Cowan. 1953. Ibid.

Aeromonas Kluyver and van Niel 1936

Kluyver, A.J. and C.B. van Niel. 1936. Zentralblatt fur Bakteriologie, Parasitenkunde, Infektionskrankheiten und Hygiene. Abteilung II. 94:369-403. Type species: A. hydrophila (Chester 1901) Stanier 1943

Description: Bergey 8.

A. hydrophila (Chester 1901) Stanier 1943

Chester, F.D. 1901. A Manual of Determinative Bacteriology. The MacMillan Co., New York. pp. 1-401; Stanier, R.Y. 1943. Journal of Bacteriology 46:213-214. Type strain: ATCC 7966 Description: Bergey 8.

A. hydrophila subsp. anaerogenes Schubert 1964 Schubert, R.H.W. 1964. Zentralblatt fur Bakteriologie, Parasitenkunde, Infektionskrankheiten und Hygiene. Abteilung I. 193:343-352. Type strain: ATCC 15467 Description: Bergey 8.

A. hydrophila subsp. hydrophila (Chester 1901) Stanier 1943

Chester, F.D. 1901. A Manual of Determinative Bacteriology. The MacMillan Co., New York. pp. 1-401; Stanier, R.Y. 1943. Journal of Bacteriology 46: 213-214. Type strain: ATCC 7966

Description: Bergey 8.

A. hydrophila subsp. proteolytica (Merkel, Traganza, Mukherjee, Griffin and Prescott 1964) Schubert 1969

Merkel, J.R., E.D. Traganza, B.B. Mukherjee, T.B. Griffin and J.M. Prescott. 1964. Journal of Bacteriology 87: 1227-1233; Schubert, R.H.W. 1969. Zentralblatt fur Bakteriologie, Parasitenkunde, Infektionskrankheiten und Hygiene. Abteilung I. 211:409-412. Type strain: ATCC 15338

Description: Bergey 8.

A. punctata (Zimmermann 1890) Snieszko 1957 Zimmermann, O.E.R. 1890. 1. Reihe, Elfter Bericht der Naturwissenschaftlichen Gesellschaft Chemnitz, pp. 54-154; Sni- 
eszko, S.F. 1957 in Breed, R.S., E.G.D. Murray and N.R. Smith (eds). Bergey's Manual of Determinative Bacteriology, 7th ed. The Williams and Wilkins Co., Baltimore. pp. 189-193. Type strain: ATCC 15468

Description: Bergey 8.

A. punctata subsp. caviae (Scherago 1936) Schubert 1964

Scherago, M. 1936. Journal of Bacteriology 31:83; Schubert, R.H.W. 1964. Zentralblatt fur Bakteriologie, Parasitenkunde, Infektionskrankheiten und Hygiene. Abteilung I. 193:343-352. Type strain: ATCC 15468

Description: Bergey 8 .

A. punctata subsp. punctata (Zimmermann 1890) Snieszko 1957

Zimmermann, O.E.R. 1890.1 Reihe Elfter Bericht der Naturwissenschaftlichen Gesellschaft Chemnitz, pp. 54-154; Snieszko, S.F. 1957 in Breed, R.S., E.G.D. Murray and N.R. Smith (eds). Bergey's Manual of Determinative Bacteriology, 7th ed. The Williams and Wilkins Co., Baltimore. pp. 189-193. Type strain: ATCC 15468

Description: Bergey 8.

A. salmonicida (Lehmann and Neumann 1896) Griffin, Snieszko and Friddle 1953

Lehmann, K.B. and R. Neumann. 1896. Atlas und Grundriss der Bakteriologie und Lehrbuch der speziellen bakteriologischen Diagnostik. 1st ed. J.F. Lehmann, Munchen; Griffin, P.J., S.F. Snieszko and S.B. Friddle. 1953. Transactions of the American Fisheries Society 82:129-138. Type strain: NCMB 1102

Description: Bergey 8 .

A. salmonicida subsp. achromogenes (Smith 1963) Schubert 1967

Smith, I.W. 1963. Journal of General Microbiology 33:263-274; Schubert, R.H.W. 1967. International Journal of Systematic Bacteriology 17:273-279. Type strain: NCMB 1110

Description: Bergey 8.

A. salmonicida subsp. masoucida Kimura 1969 Kimura, T. 1969. Fish Pathology (Tokyo) 3:45-52. Type strain: ATCC 27013 Description: Bergey 8.

A. salmonicida subsp. salmonicida (Lehmann and Neumann 1896) Griffin, Snieszko and Friddle 1953

Lehmann, K.B. and R. Neumann. 1896. Atlas und Grundriss der Bakteriologie und Lehrbuch der speziellen bakteriologischen Diagnostik. 1st ed. J.F. Lehmann, Munchen; Griffin, P.J., S.F. Snieszko and S.B. Friddle. 1953. Transactions of the American Fisheries Society 82:129-138. Type strain: NCMB 1102

Description: Bergey 8.

Agrobacterium Conn 1942

Conn, H.J. 1942. Journal of Bacteriology 44:353-360. Type species: $A$. tumefaciens (Smith and Townsend 1907) Conn 1942

Description: Bergey 8.

A. radiobacter (Beijerinck and van Delden 1902) Conn 1942

Beijerinck, M.W. and A. van Delden. 1902. Zentralblatt fur Bakteriologie, Parasitenkunde, Infektionskrankheiten und $\mathrm{Hy}$ giene. Abteilung II. 9:3-43; Conn, H.J. 1942. Journal of Bacteriology 44:353-360. Type strain: ATCC 19358

Description: Bergey 8.

A. rhizogenes (Riker, Banfield, Wright, Keitt and Sagen 1930) Conn 1942

Riker, A.J., W.M. Banfield, W.H. Wright, G.W. Keitt and H.E. Sagen. 1930. Journal of Agricultural Research 41:507-540; Conn, H.J. 1942. Journal of Bacteriology 44:353-360. Type strain: ATCC 11325

Description: Burkholder, W.J. 1957 in Breed, R.S., E.G.D. Murray and N.R. Smith (eds). Bergey's Manual of Determinative Bacteriology, 7th ed. The Williams and Wilkins Co., Baltimore. pp. 288-292.

A. rubi (Hildebrand 1940) Starr and Weiss 1943

Hildebrand, E.M. 1940. Journal of Agricultural Research 61:685-696; Starr, M.P. and J.E. Weiss. 1943. Phytopathology 33:314-318. Type strain: ATCC 13335

Description: Burkholder, W.J. 1957.

A. tumefaciens (Smith and Townsend 1907) Conn 1942

Smith, E.F. and C.O. Townsend. 1907. Science (Washington) 25:671-673; Conn, H.J. 1942. Journal of Bacteriology 44: 353-360. Type strain: ATCC 23308 Description: Bergey 8. 
Agromyces Gledhill and Casida 1969 Gledhill, W.E. and L.E. Casida. 1969. Applied Microbiology 18:340-349. Type species: $A$. ramosus Gledhill and Casida 1969

Description: Gledhill, W.E. and L.E. Casida. 1969. Ibid.

A. ramosus Gledhill and Casida 1969 Gledhill, W.E. and L.E. Casida. 1969. Applied Microbiology 18:114-121. Type strain: ATCC 25173

Description: Gledhill, W.E. and L.E. Casida. 1969. Ibid.

Alcaligenes Castellani and Chalmers 1919

Castellani, A. and A.J. Chalmers. 1919. Manual of Tropical Medicine, 3rd ed. Williams, Wood and Co., New York. Type species: $A$. faecalis Castellani and Chalmers 1919

Description: Bergey 8.

A. aestus Baumann, Baumann, Mandel and Allen 1972

Baumann, L., P. Baumann, M. Mandel and R.D. Allen. 1972. Journal of Bacteriology 110:402-429. Type strain: ATCC 27128

Description: Baumann, L., P. Baumann, M. Mandel and R.D. Allen. 1972. Ibid.

A. aquamarinus (ZoBell and Upham 1944) Hendrie, Holding and Shewan 1974

ZoBell, C.E. and H.C. Upham. 1944. Bulletin Scripps Institution of Oceanography University of California (Technical Series) 5:239-292; Hendrie, M.S., A.J. Holding and J.M. Shewan. 1974. International Journal of Systematic Bacteriology 24:534-550. Type strain: ATCC 14400

Description: Zobell, C.E. and H.C. Upham. 1944. Ibid.

A. cupidus Baumann, Baumann, Mandel and Allen 1972

Baumann, L., P. Baumann, M. Mandel and R.D. Allen. 1972. Journal of Bacteriology 110:402-429. Type strain: ATCC 27124

Description: Baumann, L., P. Baumann, M. Mandel and R.D. Allen. 1972. Ibid.

A. eutrophus Davis 1969

Davis, D.H. 1969 in Davis, D.H., M. Doudoroff, R.Y. Stanier and M. Mandel. International Journal of Systematic
Bacteriology 19:375-390. Type strain: ATCC 17697

Description: Davis, D.H. 1969. Ibid.

A. faecalis Castellani and Chalmers 1919

Castellani, A. and A.J. Chalmers. 1919.

Manual of Tropical Medicine, 3rd ed. Williams, Wood and Co., New York. Type strain: ATCC 8750

Description: Castellani, A. and A.J. Chalmers. 1919. Ibid.

A. latus Palleroni and Palleroni 1978

Palleroni, N.J. and A.V. Palleroni. 1978.

International Journal of Systematic Bacteriology 28:416-424. Type strain: ATCC 29712

Description: Palleroni, N.J. and A.V. Palleroni. 1978. Ibid.

A. pacifus Baumann, Baumann, Mandel and Allen 1972

Baumann, L., P. Baumann, M. Mandel and R.D. Allen. 1972. Journal of Bacteriology 110:402-429. Type strain: ATCC 27122

Description: Baumann, L., P. Baumann, M. Mandel and R.D. Allen. 1972. Ibid.

A. paradoxus Davis 1969

Davis, D.H. 1969 in Davis, D.H., M. Doudoroff, R.Y. Stanier and M. Mandel. International Journal of Systematic Bacteriology 19:375-390. Type strain: ATCC 17713

Description: Davis, D.H. 1969. Ibid.

A. ruhlandii (Packer and Vishniac 1955) Aragno and Schlegel 1977

Packer, L. and W. Vishniac. 1955. Journal of Bacteriology 70:216-233; Aragno, M. and H. Schlegel. 1977. International Journal of Systematic Bacteriology 27:279-281. Type strain: ATCC 15749

Description: Aragno, M. and H. Schlegel. 1977. Ibid.

A. venustus Baumann, Baumann, Mandel and Allen 1972

Baumann, L., P. Baumann, M. Mandel and R.D. Allen. 1972. Journal of Bacteriology 110:402-429. Type strain: ATCC 27125

Description: Baumann, L., P. Baumann, M. Mandel and R.D. Allen. 1972. Ibid.

Alteromonas Baumann, Baumann, Mandel and Allen 1972 
Baumann, L., P. Baumann, M. Mandel and R.D. Allen. 1972. Journal of Bacteriology 110:402-429. Type species: A. macleodii Baumann, Baumann, Mandel and Allen 1972.

Description: Baumann, L., P. Baumann, M. Mandel and R.D. Allen. 1972. Ibid.

A. aurantia Gauthier and Breittmayer 1979

Gauthier, M.J. and V.A. Breittmayer. 1979. International Journal of Systematic Bacteriology 29:366-372. Type strain: ATCC 33046

Description: Gauthier, M.J. and V.A. Breittmayer. 1979. Ibid.

A. citrea Gauthier 1977

Gauthier, M.J. 1977. International Journal of Systematic Bacteriology 27:349354. Type strain: ATCC 29719

Description: Gauthier, M.J. 1977. Ibid.

A. communis Baumann, Baumann, Mandel and Allen 1972

Baumann, L., P. Baumann, M. Mandel and R.D. Allen. 1972. Journal of Bacteriology 110:402-429. Type strain: ATCC 27118

Description: Baumann, L., P. Baumann, M. Mandel and R.D. Allen. 1972. Ibid.

A. espejiana Chan, Baumann, Garza and Baumann 1978

Chan, K.Y., L. Baumann, M.M. Garza and P. Baumann. 1978. International Journal of Systematic Bacteriology 28: 217-222. Type strain: ATCC 29659

Description: Chan, K.Y., L. Baumann, M.M. Garza and P. Baumann. 1978. Ibid.

A. haloplanktis (ZoBell and Upham 1944) Reichelt and Baumann 1973

ZoBell, C.E. and H.C. Upham. 1944. Bulletin of the Scripps Institution of Oceanography, University of California 5: 239-292; Reichelt, J.L. and P. Baumann. 1973. International Journal of Systematic Bacteriology 23:438-441. Type strain: ATCC 14393

Description: Reichelt, J.L. and P. Baumann. 1973. Ibid.

A. macleodii Baumann, Baumann, Mandel and Allen 1972

Baumann, L., P. Baumann, M. Mandel and R.D. Allen. 1972. Journal of Bacteriology 110:402-429. Type strain: ATCC 27126

Description: Baumann, L., P. Baumann,
M. Mandel and R.D. Allen. 1972. Ibid.

A. rubra Gauthier 1976

Gauthier, M.J. 1976. International Journal of Systematic Bacteriology 26:459. 466. Type strain: ATCC 29570

Description: Gauthier, M.J. 1976. Ibid.

A. undina Chan, Baumann, Garza and Baumann 1978

Chan, K.Y., L. Baumann, M.M. Garza and P. Baumann. 1978. International Journal of Systematic Bacteriology 28 : 217-222. Type strain: ATCC 29660

Description: Chan, K.Y., L. Baumann, M.M. Garza and L. Baumann. 1978. Ibid.

A. vaga Baumann, Baumann, Mandel and Allen 1972

Baumann, L., P. Baumann, M. Mandel and R.D. Allen. 1972. Journal of Bacteriology 110: 402-429. Type strain: ATCC 27119

Description: Baumann, L., P. Baumann, M. Mandel and R.D. Allen. 1972. Ibid.

\section{Alysiella Langeron 1923}

Langeron, M. 1923. Annales de Parasitologie Humaine et Comparee 1:113-123. Type species: $A$. filiformis (Schmid 1922) Langeron 1923

Description: Bergey 8 .

A. filiformis (Schmid 1922) Langeron 1923

Schmid, G. 1922 in Simons, H. Zentralblatt fur Bakteriologie, Parasitenkunde, Infektionskrankheiten und Hygiene. Abteilung I. 88:501-510; Langeron, M. 1923. Annales de Parasitologie Humaine et Comparee 1:113-123. Type strain: ATCC 15532

Description: Steed, P.D.M. 1962. Journal of General Microbiology 29:615-624.

Amoebobacter Winogradsky 1888

Winogradsky, S. 1888. Beitrage zur Morphologie und Physiologie der Bacterien. Heft I. Zur Morphologie und Physiologie der Schwefelbacterien. Arthur Felix, Leipzig. pp. 1-120. Type species: $A$. roseus Winogradsky 1888

Description: Bergey 8 .

A. pendens (Molisch 1906) Pfennig and Truper 1971

Molisch, H. 1906. Botanische Zeitung. Abteilung I. 64:223-232; Pfennig, N. and 
H.G. Truper. 1971. International Journal of Systematic Bacteriology 21:11-14. Type strain: DSM 236

Description: Bergey 8.

A. roseus Winogradsky 1888

Winogradsky, S. 1888. Beitrage zur Morphologie und Physiologie der Bacterien. Heft I. Zur Morphologie und Physiologie der Schwefelbacterien. Arthur Felix, Leipzig. pp. 1-120. Type strain: DSM 235

Description: Bergey 8.

\section{Amorphosporangium Couch 1963}

Couch, J.N. 1963. Journal of the Elisha Mitchell Scientific Society 79:53-70. Type species: A. auranticolor Couch 1963

Description: Bergey 8.

A. auranticolor Couch 1963

Couch, J.N. 1963. Journal of the Elisha Mitchell Scientific Society 79:53-70. Type strain: ATCC 15330

Description: Bergey 8.

A. globisporum Thiemann 1967

Thiemann, J.E. 1967. Mycopathologia et Mycologia Applicata 33:233-240. Type strain: ATCC 23056

Description: Thiemann, J.E. 1967. Ibid.

Ampullariella Couch 1964

Couch, J.N. 1964. Journal of the Elisha

Mitchell Scientific Society 80:29. Type species: A. regularis (Couch 1963) Couch 1964

Description: Bergey 8.

A. campanulata (Couch 1963) Couch 1964

Couch, J.N. 1963. Journal of the Elisha Mitchell Scientific Society 79:53-70; Couch, J.N. 1964. Journal of the Elisha Mitchell Scientific Society 80:29. Type strain: DSM 43148

Description: Bergey 8.

A. digitata (Couch 1963) Couch 1964

Couch, J.N. 1963. Journal of the Elisha Mitchell Scientific Society 79:53-70; Couch, J.N. 1964. Journal of the Elisha Mitchell Scientific Society 80:29. Type strain: ATCC 15349

Description: Bergey 8.

A. Iobata (Couch 1963) Couch 1964

Couch, J.N. 1963. Journal of the Elisha Mitchell Scientific Society 79:53-70; Couch, J.N. 1964. Journal of the Elisha
Mitchell Scientific Society 80:29. Type strain: ATCC 15350

Description: Bergey 8.

A. regularis (Couch 1963) Couch 1964

Couch, J.N. 1963. Journal of the Elisha

Mitchell Scientific Society 79:53-70;

Couch, J.N. 1964. Journal of the Elisha Mitchell Scientific Society 80:29. Type strain: DSM 43151

Description: Bergey 8.

Anaerobiospirillum Davis, Cleven, Brown and Balish 1976

Davis, C.P., D. Cleven, J. Brown and E. Balish. 1976. International Journal of Systematic Bacteriology 26:498-504. Type species: $A$. succiniciproducens Davis, Cleven, Brown and Balish 1976

Description: Davis, C.P., D. Cleven, J. Brown and E. Balish. 1976. Ibid.

A. succiniciproducens Davis, Cleven, Brown and Balish 1976

Davis, C.P., D. Cleven, J. Brown and E. Balish. 1976. International Journal of Systematic Bacteriology 26:498-504. Type strain: ATCC 29305

Description: Davis, C.P., D. Cleven, J. Brown and E. Balish. 1976. Ibid.

Anaeroplasma Robinson, Allison and Hartman 1975

Robinson, I.M., M.J. Allison and P.A. Hartman. 1975. International Journal of Systematic Bacteriology 25:173-181. Type species: $A$. abactoclasticum Robinson, Allison and Hartman 1975

Description: Robinson, I.M., M.J. Allison and P.A. Hartman. 1975. Ibid.

A. abactoclasticum Robinson, Allison and Hartman 1975

Robinson, I.M., M.J. Allison and P.A. Hartman. 1975. International Journal of Systematic Bacteriology 25:173-181. Type strain: ATCC 27879

Description: Robinson, I.M., M.J. Allison and P.A. Hartman. 1975. Ibid.

A. bactoclasticum (Robinson and Hungate 1973) Robinson and Allison 1975

Robinson, J.P. and R.E. Hungate. 1973. International Journal of Systematic Bacteriology 23:171-181; Robinson, I.M. and M.J. Allison. 1975. International Journal of Systematic Bacteriology 25:182-186. 
Type strain: ATCC 27112

Description: Robinson, I.M. and M.J. Allison. 1975. Ibid.

Anaerovibrio Hungate 1966

Hungate, R.E. 1966. The rumen and its microbes. Academic Press, New York. Type species: A. lipolytica Hungate 1966 Description: Hungate, R.E. 1966. Ibid.

A. lipolytica Hungate 1966

Hungate, R.E. 1966. The rumen and its microbes. Academic Press, New York. Type strain: VPI 7553

Description: Holdeman, L.V., E.P. Cato and W.E.C. Moore (eds). 1977. Anaerobe Laboratory Manual, 4th ed. Virginia Polytechnic Institute and State University, Blacksburg, Virginia. pp. 1-156.

\section{Anaplasma Theiler 1910}

Theiler, A. 1910. Report to the Government, Transvaal, South Africa. Veterinary Bacteriology, Department of Agriculture 1908-9:7-64. Type species: $A$. marginale Theiler 1910

Description: Bergey 8.

A. marginale Theiler 1910

Theiler, A. 1910. Transvaal S. Afr. Rep.

Vet. Bacteriol. Dep. Agr. 1908-9:7-64.

Type strain: no culture isolated.

Description: Bergey 8.

A. ovis Lestoquard 1924

Lestoquard, F. 1924. Bulletin de la

Societe de Pathologie Exotique 17:784-

787. Type strain: no culture isolated.

Description: Bergey 8.

Ancalochloris Gorlenko and Lebedeva 1971

Gorlenko, V.M. and E.V. Lebedeva. 1971. Mikrobiologiya 40:1035-1039. Type species: $A$. perfilievii Gorlenko and Lebedeva 1971

Description: Gorlenko, V.M. and E.V. Lebedeva. 1971. Ibid.

A. perfilievii Gorlenko and Lebedeva 1971

Gorlenko, V.M. and E.V. Lebedeva. 1971.

Mikrobiologiya 40:1035-1039. Type strain: no pure culture.

Description: Gorlenko, V.M. and E.V. Lebedeva. 1971. Ibid.

\section{Ancalomicrobium Staley 1968}

Staley, J.T. 1968. Journal of Bacteriology
95:1921-1942. Type species: $A$. adetum Staley 1968

Description: Bergey 8.

A. adetum Staley 1968

Staley, J.T. 1968. Journal of Bacteriology 95:1921-1942. Type strain: ATCC 23632

Description: Staley, J.T. 1968. Ibid.

Aquaspirillum Hylemon, Wells, Krieg and Jannasch 1973

Hylemon, P.B., J.S. Wells Jr., N.R. Krieg and H.W. Jannasch. 1973. International Journal of Systematic Bacteriology 23: 340-380. Type species: $A$. serpens Hylemon, Wells, Krieg and Jannasch 1973

Description: Bergey 8 .

A. anulus (Williams and Rittenberg 1957) Hylemon, Wells, Krieg and Jannasch 1973

Williams, M.A. and S.C. Rittenberg. 1957. International Bulletin of Bacteriological Nomenclature and Taxonomy 7: 49-110; Hylemon, P.B., J.S. Wells Jr., N.R. Krieg and H.W. Jannasch. 1973. International Journal of Systematic Bacteriology 23:340-380. Type strain: NCIB 9012

Description: Hylemon, P.B., J.S. Wells Jr., N.R. Krieg and H.W. Jannasch. 1973. Ibid.

A. aquaticum Hylemon, Wells, Krieg and Jannasch 1973

Hylemon, P.B., J.S. Wells Jr., N.R. Krieg and H.W. Jannasch. 1973. International Journal of Systematic Bacteriology 23: 340-380. Type strain: ATCC 11330

Description: Hylemon, P.B., J.S. Wells Jr., N.R. Krieg and H.W. Jannasch. 1973. Ibid.

A. autotrophicum Aragno and Schlegel 1978 Aragno, M. and H.G. Schlegel. 1978. International Journal of Systematic Bacteriology 28:112-116. Type strain: DSM 732

Description: Aragno, M. and H.G. Schlegel. 1978. Ibid.

A. bengal Kumar, Banerjee, Bowdre, McElroy and Krieg 1974

Kumar, R., A.K. Banerjee, J.H. Bowdre, L.J. McElroy and N.R. Krieg. 1974. International Journal of Systematic Bacteriology 24:453-458. Type strain: 


\section{ATCC 27641}

Description: Kumar, R., A.K. Banerjee, J.H. Bowdre, L.J. McElroy and N.R. Krieg. 1974. Ibid.

A. delicatum (Leifson 1962) Hylemon, Wells, Krieg and Jannasch 1973

Leifson, E. 1962. International Bulletin of Bacteriological Nomenclature and Taxonomy 12:161-170; Hylemon, P.B., J.S. Wells Jr., N.R. Krieg and H.W. Jannasch. 1973. International Journal of Systematic Bacteriology 23:340-380. Type strain: ATCC 14667

Description: Hylemon, P.B., J.S. Wells Jr., N.R. Krieg and H.W. Jannasch. 1973. Ibid.

A. dispar Hylemon, Wells, Krieg and Jannasch 1973

Hylemon, P.B., J.S. Wells Jr., N.R. Krieg and H.W. Jannasch. 1973. International Journal of Systematic Bacteriology 23: 340-380. Type strain: ATCC 27510

Description: Krieg, N.R. and P.B. Hylemon. 1976. Annual Review of Microbiology 30:303-325.

A. fasciculus Strength, Isani, Linn, Williams, Vandermolen, Laughon and Krieg 1976

Strength, W.J., B. Isani, D.M. Linn, F.D. Williams, G.E. Vandermolen, B.E. Laughon and N.R. Krieg. 1976. International Journal of Systematic Bacteriology 26: 253-267. Type strain: ATCC 27740

Description: Strength, W.J., B. Isani, D.M. Linn, F.D. Williams, G.E. Vandermolen, B.E. Laughon and N.R. Krieg. 1976. Ibid.

A. giesbergeri (Williams and Rittenberg 1957) Hylemon, Wells, Krieg and Jannasch 1973

Williams, M.A. and S.C. Rittenberg. 1957. International Bulletin of Bacteriological Nomenclature and Taxonomy 7: 49-110; Hylemon, P.B., J.S. Wells Jr., N.R. Krieg and H.W. Jannasch. 1973. International Journal of Systematic Bacteriology 23:340-380. Type strain: ATCC 11334

Description: Hylemon, P.B., J.S. Wells Jr., N.R. Krieg and H.W. Jannasch. 1973. Ibid.

A. gracile (Canale-Parola, Rosenthal and Kupfer 1966) Hylemon, Wells, Krieg and Jannasch 1973
Canale-Parola, E., S.L. Rosenthal and D.G. Kupfer. 1966. Antonie van Leeuwenhoek Journal of Microbiology and Serology 32:113-124; Hylemon, P.B., J.S. Wells Jr., N.R. Krieg and H.W. Jannasch. 1973. International Journal of Systematic Bacteriology 23:340-380. Type strain: ATCC 19624

Description: Hylemon, P.B., J.S. Wells Jr., N.R. Krieg and H.W. Jannasch. 1973. Ibid.

A. itersonii (Giesberger 1936) Hylemon, Wells, Krieg and Jannasch 1973

Giesberger, G. 1936. Inaugural Dissertation Utrecht. pp. 1-136; Hylemon, P.B., J.S. Wells Jr., N.R. Krieg and H.W. Jannasch. 1973. International Journal of Systematic Bacteriology 23:340-380. Type strain: ATCC 12639

Description: Hylemon, P.B., J.S. Wells Jr., N.R. Krieg and H.W. Jannasch. 1973. Ibid.

A. itersonii subsp. itersonii (Giesberger 1936) Hylemon, Wells, Krieg and Jannasch 1973

Giesberger, G. 1936. Inaugural Dissertation Utrecht. pp. 1-136; Hylemon, P.B., J.S. Wells Jr., N.R. Krieg and H.W. Jannasch. 1973. International Journal of Systematic Bacteriology 23:340-380. Type strain: ATCC 12639

Description: Hylemon, P.B., J.S. Wells Jr., N.R. Krieg and H.W. Jannasch. 1973. Ibid.

A. itersonii subsp. nipponicum (Terasaki 1973) Terasaki 1979

Terasaki, Y. 1973. Bulletin of the Suzugamine Women's College, Natural Science 17:1-71; Terasaki, Y. 1979. International Journal of Systematic Bacteriology 29:130-144. Type strain: IFO 13615

Description: Terasaki, Y. 1979. Ibid.

A. metamorphum (Terasaki 1961) Hylemon, Wells, Krieg and Jannasch 1973

Terasaki, Y. 1961. Botanical Magazine (Tokyo) 74:220-227; Hylemon, P.B., J.S. Wells Jr., N.R. Krieg and H.W. Jannasch. 1973. International Journal of Systematic Bacteriology 23:340-380. Type strain: ATCC 15280

Description: Hylemon, P.B., J.S. Wells Jr., N.R. Krieg and H.W. Jannasch. 
1973. Ibid.

A. peregrinum (Pretorius 1963) Hylemon, Wells, Krieg and Jannasch 1973

Pretorius, W.A. 1963. Journal of General Microbiology 32:403-408; Hylemon, P.B., J.S. Wells Jr., N.R. Krieg and H.W. Jannasch. 1973. International Journal of Systematic Bacteriology 23:340-380. Type strain: ATCC 15387

Description: Hylemon, P.B., J.S. Wells Jr., N.R. Krieg and H.W. Jannasch. 1973. Ibid.

A. peregrinum subsp. integrum (Terasaki 1973) Terasaki 1979

Terasaki, Y. 1973. Bulletin of the Suzugamine Women's College, Natural Science 17:1-71; Terasaki, Y. 1979. International Journal of Systematic Bacteriology 29:130-144. Type strain: IFO 13617

Description: Terasaki, Y. 1979. Ibid.

A. peregrinum subsp. peregrinum (Pretorius 1963) Hylemon, Wells, Krieg and Jannasch 1973

Pretorius, W.A. 1963. Journal of General Microbiology 32:403-408; Hylemon, P.B., J.S. Wells Jr., N.R. Krieg and H.W. Jannasch. 1973. International Journal of Systematic Bacteriology 23:340-380. Type strain: ATCC 15387

Description: Hylemon, P.B., J.S. Wells Jr., N.R. Krieg and H.W. Jannasch. 1973. Ibid.

A. polymorphum (Williams and Rittenberg 1957) Hylemon, Wells, Krieg and Jannasch 1973

Williams, M.A. and S.C. Rittenberg. 1957. International Bulletin of Bacteriological Nomenclature and Taxonomy 7:49-110; Hylemon, P.B., J.S. Wells Jr., N.R. Krieg and H.W. Jannasch. 1973. International Journal of Systematic Bacteriology 23:340-380. Type strain: ATCC 11332

Description: Hylemon, P.B., J.S. Wells Jr., N.R. Krieg and H.W. Jannasch. 1973. Ibid.

A. psychrophilum (Terasaki 1973) Terasaki 1979

Terasaki, Y. 1973. Bulletin of the Suzugamine Women's College, Natural Science 17:1-71; Terasaki, Y. 1979. International Journal of Systematic Bac- teriology 29:130-144. Type strain: IFO 13611

Description: Terasaki, Y. 1979. Ibid.

A. putridiconchylium (Terasaki 1961) Hylemon, Wells, Krieg and Jannasch 1973

Terasaki, Y. 1961. Botanical Magazine (Tokyo) 74:79.85; Hylemon, P.B., J.S. Wells Jr., N.R. Krieg and H.W. Jannasch. 1973. International Journal of Systematic Bacteriology 23:340-380. Type strain: ATCC 15279

Description: Hylemon, P.B., J.S. Wells Jr., N.R. Krieg and H.W. Jannasch. 1973. Ibid.

A. serpens (Muller 1786) Hylemon, Wells, Krieg and Jannasch 1973

Muller, O.F. 1786. Animalcula Infusoria Fluviatilia et Marina, Quae Detexit. Systematice Descripsit et Ad Vivum Delineari Curavit, pp. 1-367; Hylemon, P.B., J.S. Wells Jr., N.R. Krieg and H.W. Jannasch. 1973. International Journal of Systematic Bacteriology 23:340380. Type strain: ATCC 12638

Description: Hylemon, P.B., J.S. Wells Jr., N.R. Krieg and H.W. Jannasch. 1973. Ibid.

A. sinuosum (Williams and Rittenberg 1957) Hylemon, Wells, Krieg and Jannasch 1973

Williams, M.A. and S.C. Rittenberg. 1957. International Bulletin of Bacteriological Nomenclature and Taxonomy 7:49-110; Hylemon, P.B., J.S. Wells Jr., N.R. Krieg and H.W. Jannasch. 1973. International Journal of Systematic Bacteriology 23:340-380. Type strain: ATCC 9786

Description: Hylemon, P.B., J.S. Wells Jr., N.R. Krieg and H.W. Jannasch. 1973. Ibid.

Arachnia Pine and Georg 1969

Pine, L. and L.K. Georg. 1969. International Journal of Systematic Bacteriology 19:267-272. Type species: $A$. propionica (Buchanan and Pine 1962) Pine and Georg 1969

Description: Bergey 8.

A. propionica (Buchanan and Pine 1962) Pine and Georg 1969

Buchanan, B.B. and L. Pine. 1962. Journal of General Microbiology 28:305- 
323; Pine, L. and L. Georg. 1969. International Journal of Systematic Bacteriology 19:267-272. Type strain: ATCC 14157

Description: Holdeman, L.V., E.P. Cato and W.E.C. Moore (eds). 1977. Anaerobe Laboratory Manual, 4th ed. Virginia Polytechnic Institute and State University, Blacksburg, Virginia. pp. 1-156.

Archangium Jahn 1924

Jahn, E. 1924. Beitrage zur botanischen Protistologie. I. Die Polyangiden. Verlag von Gebruder Borntraeger, Leipzig. Type species: $A$. gephyra Jahn 1924

Description: Bergey 8.

A. gephyra Jahn 1924

Jahn, E. 1924. Beitrage zur botanischen Protistologie. I. Die Polyangiden. Verlag von Gebruder Borntraeger, Leipzig. Type strain: ATCC 25201

Description: Bergey 8.

Arthrobacter Conn and Dimmick 1947

Conn, H.J. and I. Dimmick. 1947. Journal of Bacteriology 54:291-303. Type species: A. globiformis (Conn 1928) Conn and Dimmick 1947

Description: Bergey 8.

A. atrocyaneus Kuhn and Starr 1960

Kuhn, D.A. and M.P. Starr. 1960. Archiv fur Mikrobiologie 36:175-181. Type strain: ATCC 13752

Description: Kuhn, D.A. and M.P. Starr. 1960. Ibid.

A. aurescens Phillips 1953

Phillips, H.C. 1953. Iowa State Journal of Science 27:240-241. Type strain: ATCC 13344

Description: Phillips, H.C. 1953. Ibid.

A. citreus Sacks 1954

Sacks, L.E. 1954. Journal of Bacteriology

67:342-345. Type strain: ATCC 11624

Description: Bergey 8.

A. crystallopoietes Ensign and Rittenberg 1963

Ensign, J.C. and S.C. Rittenberg. 1963.

Archiv fur Mikrobiologie 47:137-153.

Type strain: ATCC 15481

Description: Ensign, J.C. and S.C. Rittenberg. 1963. Ibid.

A. duodecadis Lochhead 1958

Lochhead, A.G. 1958. Archiv fur Mikrobiologie 31:163-170. Type strain: ATCC
13347

Description: Lochhead, A.G. 1958. Ibid.

A. flavescens Lochhead 1958

Lochhead, A.G. 1958. Archiv fur Mikrobiologie 31:163-170. Type strain: ATCC 13348

Description: Lochhead, A.G. 1958. Ibid.

A. globiformis (Conn 1928) Conn and Dimmick 1947

Conn, H.J. 1928. New York State Agricultural Experimental Station Technical Bulletin No. 138:3-26; Conn, H.J. and I. Dimmick. 1947. Journal of Bacteriology 54:291-303. Type strain: ATCC 8010

Description: Bergey 8.

A. histidinolovorans Adams 1954

Adams, E. 1954. Journal of Biological Chemistry 209:829-846. Type strain: ATCC 11442

Description: Keddie, R.M. and G.L. Cure. 1977. Journal of Applied Bacteriology 42: 229-252.

A. mysorens Nand and Rao 1972

Nand, K. and D.V. Rao. 1972. Zentralblatt fur Bakteriologie, Parasitenkunde, Infektionskrankheiten und Hygiene. Abteilung II. 127:324-331. Type strain: NCIB 10583

Description: Nand, K. and D.V. Rao. 1972. Ibid.

A. nicotianae Giovannozzi-Sermanni 1959

Giovannozzi-Sermanni, G. 1959. Il Tabacco (Rome) 63:83-86. Type strain: ATCC 15236

Description: Giovannozzi-Sermanni, G. 1959. Ibid.

A. oxydans Sguros 1954

Sguros, P.L. 1954. Bacteriological Proceedings 1954:21-22. Type strain: ATCC 14358

Description: Sguros, P.L. 1955. Journal of Bacteriology 69:28-37.

A. pascens Lochhead and Burton 1953

Lochhead, A.G. and M.O. Burton. 1953.

Canadian Journal of Botany 31:7-22.

Type strain: ATCC 13346

Description: Lochhead, A.G. and M.O. Burton. 1953. Ibid.

A. picolinophilus Tate and Ensign 1974

Tate, R.L. and J.C. Ensign. 1974.

Canadian Journal of Microbiology 20:691-

694. Type strain: ATCC 27854 
Description: Tate, R.L. and J.C. Ensign. 1974. Ibid.

A. polychromogenes Schippers-Lammertse, Muijsers and Klatser-Oedekerk 1963

Schippers-Lammertse, A.F., A.O. Muijsers and K.B. Klatser-Oedekerk. 1963. Antonie van Leeuwenhoek Journal of Microbiology and Serology 29:1-15. Type strain: ATCC 15216

Description: Schippers-Lammertse, A.F., A.O. Muijsers and K.B. Klatser-Oedekerk. 1963. Ibid.

A. radiotolerans Yoshinaka, Yano and Yamaguchi 1973

Yoshinaka, T., K. Yano and H. Yamaguchi. 1973. Agricultural and Biological Chemistry 37:2269-2275. Type strain: IAM 12072

Description: Yoshinaka, T., K. Yano and H. Yamaguchi. 1973. Ibid.

A. ramosus Jensen 1960

Jensen, V. 1960. Kongelige Veterinaer-og Landbohojskole Arsskrift pp. 123-132.

Type strain: ATCC 13727

Description: Jensen, V. 1960. Ibid.

A. siderocapsulatus Dubinin and Zhdanov 1975 Dubinin, G. and A.V. Zhdanov. 1975. International Journal of Systematic Bacteriology 25:340-350. Type strain: BKM-B N 1122

Description: Dubinin, G. and A.V. Zhdanov. 1975. Ibid.

A. simplex (Jensen 1934) Lochhead 1957

Jensen, H.L. 1934. Proceedings of the Linnean Society of New South Wales 59: 19-61; Lochhead, A.G. 1957 in Breed, R.S., E.G.D. Murray and N.R. Smith (eds). Bergey's Manual of Determinative Bacteriology, 7th ed. The Williams and Wilkins Co., Baltimore. pp. 605-612. Type strain: ATCC 6946

Description: Bergey 8.

A. terregens Lochhead and Burton 1953

Lochhead, A.G. and M.O. Burton. 1953. Canadian Journal of Botany 31:7-22. Type strain: ATCC 13345

Description: Bergey 8.

A. tumescens (Jensen 1934) Conn and Dimmick 1947

Jensen, H.L. 1934. Proceedings of the Linnean Society of New South Wales 59: 19-61; Conn, H.J. and I. Dimmick. 1947. Journal of Bacteriology 54:291-303. Type strain: ATCC 6947

Description: Bergey 8.

A. ureafaciens (Krebs and Eggleston 1939) Clark 1955

Krebs, H.A. and L.V. Eggleston. 1939. Enzymologia 7:310-320; Clark, F.E. 1955. International Bulletin of Bacteriological Nomenclature and Taxonomy 5:111-113. Type strain: ATCC 7562

Description: Bergey 8.

A. variabilis Muller 1961

Muller, G. 1961. Zentralblatt fur Bakteriologie, Parasitenkunde, Infektionskrankheiten und Hygiene. Abteilung II. 114: 520-537. Type strain: ATCC 15753

Description: Muller, G. 1961. Ibid.

A. viscosus Gasdorf, Benedict, Cadmus, Anderson and Jackson 1965

Gasdorf, H.J., R.G. Benedict, M.C. Cadmus, R.F. Anderson and R.W. Jackson. 1965. Journal of Bacteriology 90: 147-150. Type strain: ATCC 19584

Description: Gasdorf, H.J., R.G. Benedict, M.C. Cadmus, R.F. Anderson and R.W. Jackson. 1965. Ibid.

Asticcacaulis Poindexter 1964

Poindexter, J.S. 1964. Bacteriological Reviews 28:231-295. Type species: $A$. excentricus Poindexter 1964

Description: Bergey 8.

A. biprosthecium Pate, Porter and Jordan 1973

Pate, J.L., J.S. Porter and T.L. Jordan. 1973. Antonie van Leeuwenhoek Journal of Microbiology and Serology 39:569-583. Type strain: ATCC 27554

Description: Pate, J.L., J.S. Porter and T.L. Jordan. 1973. Ibid.

A. excentricus Poindexter 1964

Poindexter, J.S. 1964. Bacteriological Reviews 28:231-295. Type strain: ATCC 15261

Description: Poindexter, J.S. 1964. Ibid.

Azomonas Winogradsky 1938

Winogradsky, S. 1938. Annales de l'Institut Pasteur (Paris) 60:351-400. Type species: A. agilis (Beijerinck 1901) Winogradsky 1938

Description: Bergey 8.

A. agilis' (Beijerinck 1901) Winogradsky 1938

Beijerinck, M.W. 1901. Zentralblatt fur Bakteriologie, Parasitenkunde, Infektion- 
skrankheiten und Hygiene. Abteilung II. 7:561-582; Winogradsky, S. 1938. Annales de l'Institut Pasteur (Paris) 60:351-400. Type strain: ATCC 7494

Description: Thompson, J.P. and V.B.D. Skerman. 1979. Azotobacteraceae - the taxonomy and ecology of the aerobic nitrogen-fixing bacteria. Academic Press, London. pp. 290-294.

A. insignis (Derx 1951) Jensen 1955

Derx, H.G. 1951. Proceedings Koninklijke Nederlandse Akademie van Wetenschappen Series C 54:342-350; Jensen, V. 1955. Botanisk Tidsskrift 52:143-157. Type strain: UQM 1966

Description: Thompson, J.P. and V.B.D. Skerman. 1979. Azotobacteraceae - the taxonomy and ecology of the aerobic nitrogen-fixing bacteria. Academic Press, London. pp. 294-297.

Azospirillum Tarrand, Krieg and Dobereiner 1979

Tarrand, J.J., N.R. Krieg and J. Dobereiner. 1979. International Journal of Systematic Bacteriology 29:79-80; Effective publication Tarrand, J.J., N.R. Krieg and J. Dobereiner. 1978. Canadian Journal of Microbiology 24:967-980. Type species: A. lipoferum (Beijerinck 1925) Tarrand, Krieg and Dobereiner 1979

Description: Tarrand, J.J., N.R. Krieg and J. Dobereiner. 1978. Ibid.

A. brasiliense Tarrand, Krieg and Dobereiner 1979

Tarrand, J.J., N.R. Krieg and J. Dobereiner. 1979. International Journal of Systematic Bacteriology 29:79-80; Effective publication Tarrand, J.J., N.R. Krieg and J. Dobereiner. 1978. Canadian Journal of Microbiology 24:967-980. Type strain: ATCC 29145

Description: Tarrand, J.J., N.R. Krieg and J. Dobereiner. 1978. Ibid.

A. lipoferum (Beijerinck 1925) Tarrand, Krieg and Dobereiner 1979

Beijerinck, M.W. 1925. Zentralblatt fur Bakteriologie, Parasitenkunde, Infektionskrankheiten und Hygiene. Abteilung II. 63:353-359; Tarrand, J.J., N.R. Krieg and J. Dobereiner. 1979. International Journal of Systematic Bacteriology 29:79-80; Effective publication Tarrand, J.J., N.R.
Krieg and J. Dobereiner. 1978. Canadian Journal of Microbiology 24:967-980. Type strain: ATCC 29707

Description: Tarrand, J.J., N.R. Krieg and J. Dobereiner. 1978. Ibid.

Azotobacter Beijerinck 1901

Beijerinck, M.W. 1901. Zentralblatt fur Bakteriologie, Parasitenkunde, Infektionskrankheiten und Hygiene. Abteilung II. 7:561-582. Type species: $A$. chroococcum Beijerinck 1901

Description: Bergey 8.

A. beijerinckii Lipman 1904

Lipman, J.G. 1904. Report of the New Jersey Agricultural Experiment Station 25:237-289. Type strain: ATCC 19360

Description: Thompson, J.P. and V.B.D. Skerman. 1979. Azotobacteraceae - the taxonomy and ecology of the aerobic nitrogen-fixing bacteria. Academic Press, London. pp. 277-281.

A. chroococcum Beijerinck 1901

Beijerinck, M.W. 1901. Zentralblatt fur Bakteriologie, Parasitenkunde, Infektionskrankheiten und Hygiene. Abteilung II. 7:561-582. Type strain: ATCC 9043

Description: Thompson, J.P. and V.B.D. Skerman 1979. Azotobacteraceae - the taxonomy and the ecology of the aerobic nitrogen-fixing bacteria. Academic Press, London. pp. 263-266.

A. macrocytogenes Jensen 1955

Jensen, H. 1955. Acta Agriculturae Scandinavica 5:280-294. Type strain: ATCC 12335

Description: Thompson, J.P. and V.B.D. Skerman. 1979. Azotobacteraceae - the taxonomy and ecology of the aerobic nitrogen-fixing bacteria. Academic Press, London. pp. 306-309. (as Azomonotrichon macrocytogenes)

A. nigricans Krassilnikov 1949

Krassilnikov, N.A. 1949. Guide to the bacteria and actinomycetes. Akademiya Nauk SSSR, Moscow. pp. 1-830. Type strain: UQM 1967

Description: Thompson, J.P. and V.B.D. Skerman. 1979. Azotobacteraceae taxonomy and ecology of the aerobic nitrogen-fixing bacteria. Academic Press, London. pp. 267-271.

A. paspali Dobereiner 1966 
Dobereiner, J. 1966. Pesquisas Agropecuar Brasil 1:357-365. Type strain: ATCC 23833

Description: Thompson, J.P. and V.B.D. Skerman. 1979. Azotobacteraceae - taxonomy and ecology of the aerobic nitrogenfixing bacteria. Academic Press, London. pp. 306-309. (as Azorhizophilus paspali)

A. vinelandii Lipman 1903

Lipman, J.G. 1903. Report of the New Jersey Agricultural Experiment Station 24:217-285. Type strain: ATCC 478

Description: Thompson, J.P. and V.B.D. Skerman. 1979. Azotobacteraceae - taxonomy and ecology of the aerobic nitrogenfixing bacteria. Academic Press, London. pp. 283-287.

\section{Bacillus Cohn 1872}

Cohn, F. 1872. Beitrage zur Biologie der Pflanzen 1:127-224. Type species: $B$. subtilis (Ehrenberg 1835) Cohn 1872

Description: Bergey 8.

B. acidocaldarius Darland and Brock 1971

Darland, G. and T.D. Brock. 1971. Journal of General Microbiology 67:9-15.

Type strain: ATCC 27009

Description: Bergey 8.

B. alcalophilus Vedder 1934

Vedder, A. 1934. Antonie van Leeuwenhoek Journal of Microbiology and Serology 1:141-147. Type strain: ATCC 27647

Description: Boyer, E.W., M.B. Ingle and G.D. Mercer. 1973. International Journal of Systematic Bacteriology 23:238-242.

B. alvei Cheshire and Cheyne 1885

Cheshire, F.R. and W.W. Cheyne. 1885. Journal of the Royal Microscopic Society, Series II 5:581-601. Type strain: ATCC 6344

Description: Bergey 8 .

B. anthracis Cohn 1872

Cohn, F. 1872. Beitrage zur Biologie der Pflanzen 1:127-224. Type strain: ATCC 14578

Description: Bergey 8 .

B. badius Batchelor 1919

Batchelor, M.D. 1919. Journal of Bacteriology 4:23-34. Type strain: ATCC 14574 Description: Bergey 8.

B. brevis Migula 1900

Migula, W. 1900. System der Bakterien,
Vol. 2. Gustav Fischer, Jena. Type strain: ATCC 8246

Description: Bergey 8.

B. cereus Frankland and Frankland 1887

Frankland, G.C. and P.F. Frankland. 1887. Royal Society London, Philosophical Transactions, Series B, Biological Sciences 178:257-287. Type strain: ATCC 14579

Description: Bergey 8.

B. circulans Jordan 1890

Jordan, E.O. 1890 in Sedgewick, W.T. in The Report of the Massachusetts Board of Health. pp. 821-844. Type strain: ATCC 4513

Description: Bergey 8.

B. coagulans Hammer 1915

Hammer, B.W. 1915. Iowa Agricultural Experimental Station Research Bulletin 19:119-131. Type strain: ATCC 7050

Description: Bergey 8 .

B. fastidiosus den Dooren de Jong 1929

den Dooren de Jong, L.E. 1929. Zentralblatt fur Bakteriologie, Parasitenkunde, Infektionskrankheiten und Hygiene. Abteilung II. 79:344-353. Type strain: Delft LMD 29-14

Description: Bongaerts, G.P.A. and G.D. Vogels. 1976. Journal of Bacteriology 125: 689-697.

B. firmus Bredemann and Werner 1933

Bredemann, G. and W. Werner. 1933 in Werner, W. Zentralblatt fur Bakteriologie, Parasitenkunde, Infektionskrankheiten und Hygiene. Abteilung II. 87:446-475. Type strain: ATCC 14575

Description: Gordon, R.E., J.L. Hyde and J.A. Moore. 1977. International Journal of Systematic Bacteriology 27:256-262.

B. globisporus Larkin and Stokes 1967 Larkin, J.M. and J.L. Stokes. 1967. Journal of Bacteriology 94:889-895. Type strain: ATCC 23301

Description: Bergey 8.

B. globisporus subsp. globisporus Larkin and Stokes 1967

Larkin, J.M. and J.L. Stokes. 1967. Journal of Bacteriology 94:889-895. Type strain: ATCC 23301

Description: Bergey 8 .

B. globisporus subsp. marinus Ruger and Richter 1979

Ruger, H.-J. and G. Richter. 1979. 
International Journal of Systematic Bacteriology 29:196-203. Type strain: ATCC 29841

Description: Ruger, H.-J. and G. Richter. 1979. Ibid.

B. insolitus Larkin and Stokes 1967

Larkin, J.M. and J.L. Stokes. 1967. Journal of Bacteriology 94:889-895. Type strain: ATCC 23299

Description: Larkin, J.M. and J.L. Stokes. 1967. Ibid.

B. larvae White 1906

White, G.F. 1906. United States Department of Agriculture, Bureau of Entomology, Technical Series No. 14. Type strain: ATCC 9545

Description: Bergey 8.

B. laterosporus Laubach 1916

Laubach, C.A. 1916. Journal of Bacteriology 1:505-512. Type strain: ATCC 64

Description: Bergey 8.

B. lentimorbus Dutky 1940

Dutky, S.R. 1940. Journal of Agricultural

Research 61:57-68. Type strain: ATCC 14707

Description: Bergey 8.

B. lentus Gibson 1935

Gibson, T. 1935. Zentralblatt fur Bakteriologie, Parasitenkunde, Infektionskrankheiten und Hygiene. Abteilung II. 92: 364-380. Type strain: ATCC 10840

Description: Gordon, R.E., J.L. Hyde and J.A. Moore. 1977. International Journal of Systematic Bacteriology 27:256-262.

B. licheniformis (Weigmann 1898) Chester 1901

Weigmann, H. 1898. Zentralblatt fur Bakteriologie, Parasitenkunde, Infektionskrankheiten und Hygiene. Abteilung II. 4:820-834; Chester, F.D. 1901. A Manual of Determinative Bacteriology. The Macmillan Co., New York, pp. 1401. Type strain: ATCC 14580

Description: Bergey 8.

B. macerans Schardinger 1905

Schardinger, F. 1905. Zentralblatt fur Bakteriologie, Parasitenkunde, Infektionskrankheiten und Hygiene. Abteilung II. 14:772-781. Type strain: ATCC 8244

Description: Bergey 8.

B. macquariensis Marshall and Ohye 1966 Marshall, B.J. and D.F. Ohye. 1966. Journal of General Microbiology 44:41-
46. Type strain: ATCC 23464

Description: Marshall, B.J. and D.F. Ohye. 1966. Ibid.

B. megaterium de Bary 1884

de Bary, A. 1884. Vergleichende Morphologie und Biologie der Pilze, Mycetozoen und Bacterien. Wilhelm Engelmann, Leipzig. Type strain: ATCC 14581

Description: Bergey 8.

B. mycoides Flugge 1886

Flugge, C. 1886. Die Mikroorganismen.

F.C.W. Vogel, Leipzig. Type strain: ATCC 6462

Description: Bergey 8.

B. pantothenticus Proom and Knight 1950

Proom, H. and B.C.J.G. Knight. 1950.

Journal of General Microbiology 4:539-

541. Type strain: ATCC 14576

Description: Bergey 8.

B. pasteurii (Miquel 1889) Chester 1898

Miquel, P. 1889. Annales Micrographie 1:

506-519; Chester, F.D. 1898. Delaware

Agricultural Experimental Station Annual

Report 10:47-137. Type strain: ATCC

11859

Description: Bergey 8.

B. polymyxa (Prazmowski 1880) Mace 1889

Prazmowski, A. 1880. Inaugural Disserta-

tion. Hugo Voigt, Leipzig. pp. 1-58;

Mace, E. 1889. Traite Pratique de

Bacteriologie, 1st ed. J.-B. Balliere. Paris.

pp. 1-711. Type strain: ATCC 842

Description: Bergey 8.

B. popilliae Dutky 1940

Dutky, S.R. 1940. Journal of Agricultural

Research 61:57-68. Type strain: ATCC 14706

Description: Bergey 8 .

B. pumilus Meyer and Gottheil 1901

Meyer, A. and O. Gottheil. 1901 in

Gottheil, O. Zentralblatt fur Bakteriologie, Parasitenkunde, Infektionskrankheiten und Hygiene. Abteilung II. 7:680-691. Type strain: ATCC 7061

Description: Bergey 8.

B. sphaericus Meyer and Neide 1904

Meyer, A. and E. Neide. 1904 in Neide,

E. Zentralblatt fur Bakteriologie, Parasi-

tenkunde, Infektionskrankheiten und

Hygiene. Abteilung II. 12:337-352. Type

strain: ATCC 14577

Description: Bergey 8.

B. stearothermophilus Donk 1920 
Donk, P.J. 1920. Journal of Bacteriology 5:373-374. Type strain: ATCC 12980

Description: Bergey 8.

B. subtilis (Ehrenberg 1835) Cohn 1872

Ehrenberg, C.G. 1835. Physikalische Abhandlungen der Koeniglichen Akademie der Wissenschaften zu Berlin aus den Jahren 1833-1835, pp. 145-336; Cohn, F. 1872. Beitrage zur Biologie der Pflanzen 1875 1:127-224. Type strain: ATCC 6051

Description: Bergey 8 .

B. thuringiensis Berliner 1915

Berliner, E. 1915. Zeitschrift fur angewandte Entomologie Berlin 2:29-56. Type strain: ATCC 10792

Description: Bergey 8.

Bacterionema Gilmour, Howell and Bibby 1961 Gilmour, M.N., A. Howell Jr. and B.G. Bibby. 1961. Bacteriological Reviews 25: 131-141. Type species: $B$. matruchotii (Mendel 1919) Gilmour, Howell and Bibby 1961

Description: Bergey 8.

B. matruchotii (Mendel 1919) Gilmour, Howell and Bibby 1961

Mendel, J. 1919. Comptes Rendus des Seances de la Societe de Biologie (Filiales) 82:583-586; Gilmour, M.N., A. Howell Jr. and B.G. Bibby. 1961. Bacteriological Reviews 25:131-141. Type strain: ATCC 14266

Description: Bergey 8.

Bacteroides Castellani and Chalmers 1919

Castellani, A. and A.J. Chalmers. 1919. Manual of tropical medicine. 3rd ed. Williams, Wood and Co., New York. pp. 959-960. Type species: $B$. fragilis (Veillon and Zuber 1898) Castellani and Chalmers 1919

Description: Bergey 8.

B. amylophilus Hamlin and Hungate 1956

Hamlin, L.J. and R.E. Hungate. 1956. Journal of Bacteriology 72:548-554. Type strain: ATCC 29744

Description: Cato, E.P., W.E.C. Moore and M.P. Bryant. 1978. International Journal of Systematic Bacteriology 28: 491-495.

B. asaccharolyticus (Holdeman and Moore 1970) Finegold and Barnes 1977

Holdeman, L.V. and W.E.C. Moore. 1970 in Cato, E.P., C.S. Cummins, L.V. Holdeman, J.L. Johnson, W.E.C. Moore, R.M. Smibert and L.DS. Smith (eds). Outline of clinical methods in anaerobic bacteriology, 2nd revision. Virginia Polytechnic Institute, Anaerobe Laboratory, Blacksburg, Virginia. pp. 33-44; Finegold, S.M. and E:M. Barnes. 1977. International Journal of Systematic Bacteriology 27:388-391. Type strain: ATCC 25260

Description: Finegold, S.M. and E.M. Barnes. 1977. Ibid.

B. bivius Holdeman and Johnson 1977

Holdeman, L.V. and J.L. Johnson. 1977. International Journal of Systematic Bacteriology 27:337-345. Type strain: ATCC 29303

Description: Holdeman, L.V. and J.L. Johnson. 1977. Ibid.

B. capillosus (Tissier 1908) Kelly 1957

Tissier, H. 1908. Annales de l'Institut Pasteur (Paris) 22:189-208; Kelly, C.D. 1957 in Breed, R.S., E.G.D. Murray and N.R. Smith (eds). Bergey's Manual of Determinative Bacteriology, 7th ed. The Williams and Wilkins Co., Baltimore. pp. 424-436. Type strain: ATCC 29799

Description: Holdeman, L.V., E.P. Cato and W.E.C. Moore (eds). 1977. Anaerobe Laboratory Manual, 4th ed. Virginia Polytechnic Institute and State University, Blacksburg, Virginia. pp. 1-156.

B. coagulans Eggerth and Gagnon 1933

Eggerth, A.H. and B.H. Gagnon. 1933. Journal of Bacteriology 25:389-413. Type strain: ATCC 29798

Description: Holdeman, L.V., E.P. Cato and W.E.C. Moore (eds). 1977. Anaerobe Laboratory Manual, 4th ed. Virginia Polytechnic Institute and State University, Blacksburg, Virginia. pp. 1-156.

B. disiens Holdeman and Johnson 1977

Holdeman, L.V. and J.L. Johnson. 1977. International Journal of Systematic Bacteriology 27:337-345. Type strain: ATCC 29426

Description: Holdeman, L.V. and J.L. Johnson. 1977. Ibid.

B. distasonis Eggerth and Gagnon 1933

Eggerth, A.H. and B.H. Gagnon. 1933. Journal of Bacteriology 25:389-413. Type strain: ATCC 8503 
Description: Holdeman, L.V., E.P. Cato and W.E.C. Moore (eds). 1977. Anaerobe Laboratory Manual, 4th ed. Virginia Polytechnic Institute and State University, Blacksburg, Virginia. pp. 1-156.

B. eggerthii Holdeman and Moore 1974

Holdeman, L.V. and W.E.C. Moore. 1974. International Journal of Systematic Bacteriology 24:260-277. Type strain: ATCC 27754

Description: Holdeman, L.V., E.P. Cato and W.E.C. Moore (eds). 1977. Anaerobe Laboratory Manual, 4th ed. Virginia Polytechnic Institute and State University, Blacksburg, Virginia. pp. 1-156.'

B. fragilis (Veillon and Zuber 1898) Castellani and Chalmers 1919

Veillon, A. and A. Zuber. 1898. Archives de Medecine Experimentale et d'Anatomie Pathologique 10:517-545; Castellani, A. and A.J. Chalmers. 1919. Manual of tropical medicine. 3rd ed. Williams, Wood and Co., New York. Type strain: ATCC 25285

Description: Holdeman, L.V., E.P. Cato and W.E.C. Moore (eds). 1977. Anaerobe Laboratory Manual, 4th ed. Virginia Polytechnic Institute and State University, Blacksburg, Virginia. pp. 1-156.

B. furcosus (Veillon and Zuber 1898) Hauduroy, Ehringer, Urbain, Guillot and Magrou 1937

Veillon, A. and A. Zuber. 1898. Archives de Medecine Experimentale et d'Anatomie Pathologique 10:517-545; Hauduroy, P., G. Ehringer, A. Urbain, G. Guillot and J. Magrou. 1937. Dictionnaire des bacteries pathogenes. Masson et $\mathrm{Cie}$, Paris. Type strain: ATCC 25662

Description: Holdeman, L.V., E.P. Cato and W.E.C. Moore (eds). 1977. Anaerobe Laboratory Manual, 4th ed. Virginia Polytechnic Institute and State University, Blacksburg, Virginia. pp. 1-156.

B. hypermegas Harrison and Hansen 1963

Harrison, Jr., A.P. and P.A. Hansen. 1963. Antonie van Leeuwenhoek Journal of Microbiology and Serology 29:22-28.

Type strain: ATCC 25560

Description: Holdeman, L.V., E.P. Cato and W.E.C. Moore (eds). 1977. Anaerobe Laboratory Manual, 4th ed. Virginia Polytechnic Institute and State University,
Blacksburg, Virginia. pp. 1-156.

B. melaninogenicus (Oliver and Wherry 1921) Roy and Kelly 1939

Oliver, W.W. and W.B. Wherry. 1921. Journal of Infectious Diseases 28:341-344; Roy, T.E. and C.D. Kelly. 1939 in Bergey, D.H., R.S. Breed, E.G.D. Murray and A.P. Hitchens (eds). Bergey's Manual of Determinative Bacteriology, 5th ed. The Williams and Wilkins Co., Baltimore. pp. 556-558. Type strain: ATCC 25845

Description: Holdeman, L.V., E.P. Cato and W.E.C. Moore (eds). 1977. Anaerobe Laboratory Manual, 4th ed. Virginia Polytechnic Institute and State University, Blacksburg, Virginia. pp. 1-156.

B. melaninogenicus subsp. intermedius Holdeman and Moore 1970

Holdeman, L.V. and W.E.C. Moore. 1970 in Cato, E.P., C.S. Cummins, L.V. Holdeman, J.L. Johnson, W.E.C. Moore, R.M. Smibert and L.DS. Smith (eds). Outline of clinical methods in anaerobic bacteriology, 2nd revision. Virginia Polytechnic Institute Anaerobe Laboratory, Blacksburg, Virginia. pp. 33-44. Type strain: ATCC 25611

Description: Holdeman, L.V., E.P. Cato and W.E.C. Moore (eds). 1977. Anaerobe Laboratory Manual, 4th ed. Virginia Polytechnic Institute and State University, Blacksburg, Virginia. pp. 1-156.

B. melaninogenicus subsp. melaninogenicus (Oliver and Wherry 1921) Holdeman and Moore 1970

Oliver, W.W. and W.B. Wherry. 1921. Journal of Infectious Diseases 28:341-344; Holdeman, L.V. and W.E.C. Moore. 1970 in Cato, E.P., C.S. Cummins, L.V. Holdeman, J.L. Johnson, W.E.C. Moore, R.M. Smibert and L.DS. Smith (eds). Outline of clinical methods in anaerobic bacteriology, 2nd revision. Virginia Polytechnic Institute Anaerobe Laboratory, Blacksburg, Virginia. pp. 33-44. Type strain: ATCC 25845

Description: Holdeman, L.V., E.P. Cato and W.E.C. Moore (eds). 1977. Anaerobe Laboratory Manual, 4th ed. Virginia Polytechnic Institute and State University, Blacksburg, Virginia. pp. 1-156.

B. microfusus Kaneuchi and Mitsuoka 1978

Kaneuchi, C. and T. Mitsuoka. 1978. 
International Journal of Systematic Bacteriology 28:478-481. Type strain: ATCC 29728

Description: Kaneuchi, C. and T. Mitsuoka. 1978. Ibid.

B. multiacidus Mitsuoka, Terada, Watanabe and Uchida 1974

Mitsuoka, T., A. Terada, K. Watanabe and K. Uchida. 1974. International Journal of Systematic Bacteriology 24:3541. Type strain: ATCC 27723

Description: Holdeman, L.V., E.P. Cato and W.E.C. Moore (eds). 1977. Anaerobe Laboratory Manual, 4th ed. Virginia Polytechnic Institute and State University, Blacksburg, Virginia. pp. 1-156.

B. nodosus (Beveridge 1941) Mraz 1963

Beveridge, W.I.B. 1941. Council of Scientific Industrial Research Australian Bulletin 140:1-56; Mraz, O. 1963 in Mraz, O., J. Tesarcik and R. Varejka (eds). Nomina und Synonyma der pathogenen und saprophytaren Mikroben, isoliert aus den wirtschaftlich oder epidemiologisch bedeutenden Wirbeltieren und Lebensmitteen tierischer Herkunft. VEB Gustav Fischer Verlag, Jena. pp. 53334. Type strain: ATCC 25549

Description: Holdeman, L.V., E.P. Cato and W.E.C. Moore (eds). 1977. Anaerobe Laboratory Manual, 4th ed. Virginia Polytechnic Institute and State University, Blacksburg, Virginia. pp. 1-156.

B. ochraceus Prevot, Joubert, Tardieux and de Cadore 1956

Prevot, A.R., P. Tardieux, L. Joubert and F. de Cadore. 1956. Annales de l'Institut Pasteur (Paris) 91:787-798. Type strain: ATCC 27872

Description: Bergey 8.

B. oralis Loesche, Socransky and Gibbons 1964 Loesche, W.J., S.S. Socransky and R.J. Gibbons. 1964. Journal of Bacteriology 88:1329-1337. Type strain: VPI D27B-24

Description: Holdeman, L.V., E.P. Cato and W.E.C. Moore (eds). 1977. Anaerobe Laboratory Manual, 4th ed. Virginia Polytechnic Institute and State University, Blacksburg, Virginia. pp. 1-156.

B. ovatus Eggerth and Gagnon 1933

Eggerth, A.H. and B.H. Gagnon. 1933. Journal of Bacteriology 25:389-413. Type strain: ATCC 8483
Description: Holdeman, L.V., E.P. Cato and W.E.C. Moore (eds). 1977. Anaerobe Laboratory Manual, 4th ed. Virginia Polytechnic Institute and State University, Blacksburg, Virginia. pp. 1-156.

B. pneumosintes (Olitsky and Gates 1921) Holdeman and Moore 1970

Olitsky, P.K. and F.L. Gates. 1921. Journal of Experimental Medicine 33:713729; Holdeman, L.V. and W.E.C. Moore. 1970 in Cato, E.P., C.S. Cummins, L.V. Holdeman, J.L. Johnson, W.E.C. Moore, R.M. Smibert and L.DS. Smith (eds). Outline of clinical methods in anaerobic bacteriology. 2nd revision. Virginia Polytechnic Institute Anaerobe Laboratory, Blacksburg, Virginia. Type strain: ATCC 33048

Description: Holdeman, L.V., E.P. Cato and W.E.C. Moore (eds), 1977. Anaerobe Laboratory Manual, 4th ed. Virginia Polytechnjc Institute and State University, Blacksburg, Virginia. pp. 1-156.

B. praeacutus (Tissier 1908) Holdeman and Moore 1970

Tissier, H. 1908. Annales de l'Institut Pasteur (Paris) 22:189-208; Holdeman, L.V. and W.E.C. Moore. 1970 in Cato, E.P., C.S. Cummins, L.V. Holdeman, J.L. Johnson, W.E.C. Moore, R.M. Smibert and L.DS. Smith (eds). Outline of clinical methods in anaerobic bacteriology, 2nd revision. Virginia Polytechnic Institute Anaerobe Laboratory, Blacksburg, Virginia. Type strain: ATCC 25539

Description: Holdeman, L.V., E.P. Cato and W.E.C. Moore (eds). 1977. Anaerobe Laboratory Manual, 4th ed. Virginia Polytechnic Institute and State University, Blacksburg, Virginia. pp. 1-156.

B. putredinis (Weinberg, Nativelle and Prevot 1937) Kelly 1957

Weinberg, M., R. Nativelle and A.R. Prevot. 1937. Les Microbes Anaerobies. Masson et Cie, Paris. pp. 1-1186; Kelly, C.D. 1957 in Breed, R.S., E.G.D. Murray and N.R. Smith (eds). Bergey's Manual of Determinative Bacteriology, 7th ed. The Williams and Wilkins Co., Baltimore. pp. 424-436. Type strain: ATCC 29800

Description: Holdeman, L.V., E.P. Cato and W.E.C. Moore (eds). 1977. Anaerobe Laboratory Manual, 4th ed. Virginia 
Polytechnic Institute and State University, Blacksburg, Virginia. pp. 1-156.

B. ruminicola Bryant, Small, Bouma and Chu 1958

Bryant, M.P., N. Small, C. Bouma and H. Chu. 1958. Journal of Bacteriology 76: 15-23. Type strain: ATCC 19189

Description: Holdeman, L.V., E.P. Cato and W.E.C. Moore (eds). 1977. Anaerobe Laboratory Manual, 4th ed. Virginia Polytechnic Institute and State University, Blacksburg, Virginia. pp. 1-156.

B. ruminicola subsp. brevis Bryant, Small, Bouma and Chu 1958

Bryant, M.P., N. Small, C. Bouma and H. Chu. 1958. Journal of Bacteriology 76: 15-23. Type strain: ATCC 19188

Description: Holdeman, L.V., E.P. Cato and W.E.C. Moore (eds). 1977. Anaerobe Laboratory Manual, 4th ed. Virginia Polytechnic Institute and State University, Blacksburg, Virginia. pp. 1-156.

B. ruminicola subsp. ruminicola Bryant, Small, Bouma and Chu 1958

Bryant, M.P., N. Small, C. Bouma and H. Chu. 1958. Journal of Bacteriology 76: 15-23. Type strain: ATCC 19189

Description: Holdeman, L.V., E.P. Cato and W.E.C. Moore (eds). 1977. Anaerobe Laboratory Manual, 4th ed. Virginia Polytechnic Institute and State University, Blacksburg, Virginia. pp. 1-156.

B. splanchnicus Werner, Rintelen and KunstekSantos 1975

Werner, H., G. Rintelen and H. KunstekSantos. 1975. Zentralblatt fur Bakteriologie, Parasitenkunde, Infektionskrankheiten und Hygiene. Abteilung I. 231:133-144. Type strain: ATCC 29572

Description: Holdeman, L.V., E.P. Cato and W.E.C. Moore (eds). 1977. Anaerobe Laboratory Manual, 4th ed. Virginia Polytechnic Institute and State University, Blacksburg, Virginia. pp. 1-156.

B. succinogenes Hungate 1950

Hungate, R.E. 1950. Bacteriological Reviews 14:1-49. Type strain: ATCC 19169

Description: Cato, E.P., W.E.C. Moore and M.P. Bryant. 1978. International Journal of Systematic Bacteriology 28: 491-495.

B. termitidis (Sebald 1962) Holdeman and
Moore 1970

Sebald, M. 1962. Etude sur les bacteries anaerobies gram-negatives asporulees. Theses de L'universite Paris, Imprimerie Barneoud S. A. Laval, France. pp. 1-171; Holdeman, L.V. and W.E.C. Moore. 1970 in Cato, E.P., C.S. Cummins, L.V. Holdeman, J.L. Johnson, W.E.C. Moore, R.M. Smibert and L.DS. Smith (eds). Outline of clinical methods in anaerobic bacteriology, 2nd revision. Virginia Polytechnic Institute Anaerobe Laboratory, Blacksburg, Virginia. Type strain: NCTC 11300

Description: Sebald, M. 1962. Ibid.

B. thetaiotaomicron (Distaso 1912) Castellani and Chalmers 1919

Distaso, A. 1912. Zentralblatt fur Bakteriologie, Parasitenkunde, Infektionskrankheiten und Hygiene. Abteilung I. 62:433468; Castellani, A. and A.J. Chalmers. 1919. Manual of Tropical Medicine, 3rd ed. Williams, Wood and Co., New York. Type strain: ATCC 29148

Description: Holdeman, L.V., E.P. Cato and W.E.C. Moore (eds). 1977. Anaerobe Laboratory Manual, 4th ed. Virginia Polytechnic Institute and State University, Blacksburg, Virginia. pp. 1-156.

B. uniformis Eggerth and Gagnon 1933

Eggerth, A.H. and B.H. Gagnon. 1933. Journal of Bacteriology 25:389-413. Type strain: ATCC 8492

Description: Holdeman, L.V., E.P. Cato and W.E.C. Moore (eds). 1977. Anaerobe Laboratory Manual, 4th ed. Virginia Polytechnic Institute and State University, Blacksburg, Virginia. pp. 1-156.

B. ureolyticus Jackson and Goodman 1978

Jackson, F.L. and Y.E. Goodman. 1978. International Journal of Systematic Bacteriology 28:197-200. Type strain: NCTC 10941

Description: Jackson, F.L. and Y.E. Goodman. 1978. Ibid.

B. vulgatus Eggerth and Gagnon 1933

Eggerth, A.H. and B.H. Gagnon. 1933. Journal of Bacteriology 25:389-413. Type strain: ATCC 8482

Description: Holdeman, L.V., E.P. Cato and W.E.C. Moore (eds). 1977. Anaerobe Laboratory Manual, 4th ed. Virginia Polytechnic Institute and State University, 
Blacksburg, Virginia. pp. 1-156.

Bactoderma Tepper and Korshunova 1973

Tepper, S.Z. and G.F. Korshunova. 1973.

Mikrobiologiya 42:430-434. Type species:

B. alba Tepper and Korshunova 1973

Description: Tepper, S.Z. and G.F. Korshunova. 1973. Ibid.

B. alba Tepper and Korshunova 1973

Tepper, S.Z. and G.F. Korshunova. 1973. Mikrobiologiya 42:430-434. Type strain: no culture available.

Description: Tepper, S.Z. and G.F. Korshunova. 1973. Ibid.

B. rosea (Winogradsky and Winogradsky 1933) Tepper and Korshunova 1973

Winogradsky, S.N. and H. Winogradsky. 1933. Annales de l'Institut Pasteur (Paris) 50:350-434; Tepper, S.Z. and G.F. Korshunova. 1973. Mikrobiologiya 42:430434. Type strain: BKMW 1344

Description: Tepper, S.Z. and G.F. Korshunova. 1973. Ibid.

\section{Bartonella Strong, Tyzzer and Sellards 1915}

Strong, R.P., E.E. Tyzzer and A.W. Sellards. 1915. Journal of the American Medical Association 64:806-808. Type species: B. bacilliformis (Strong, Tyzzer, Brues, Sellards and Gastiaburu 1913) Strong, Tyzzer and Sellards 1915

Description: Bergey 8.

B. bacilliformis (Strong, Tyzzer, Brues, Sellards and Gastiaburu 1913) Strong, Tyzzer and Sellards 1915

Strong, R.P., E.E. Tyzzer, C.T. Brues, A.W. Sellards and J.C. Gastiaburu. 1913. Journal of the American Medical Association 61:1713-1716; Strong, R.P., E.E. Tyzzer and A.W. Sellards. 1915. Journal of the American Medical Association 64: 806-808. Type strain: no culture available. Description: Bergey 8.

\section{Bdellovibrio Stolp and Starr 1963}

Stolp, H.J. and M.P. Starr. 1963. Antonie van Leeuwenhoek Journal of Microbiology and Serology 29:217-248. Type species: $B$. bacteriovorus Stolp and Starr 1963 Description: Bergey 8.

B. bacteriovorus Stolp and Starr 1963

Stolp, H.J. and M.P. Starr. 1963. Antonie van Leeuwenhoek Journal of Microbiology and Serology 29:217-248. Type strain: NCIB 9529

Description: Stolp, H.J. and M.P. Starr. 1963. Ibid.

B. starrii Seidler, Mandel and Baptist 1972

Seidler, R.J., M. Mandel and J.N Baptist. 1972. Journal of Bacteriology 109:209-217. Type strain: ATCC 15145

Description: Seidler, R.J., M. Mandel and J.N. Baptist. 1972. Ibid.

B. stolpii Seidler, Mandel and Baptist 1972

Seidler, R.J., M. Mandel and J.N. Baptist. 1972. Journal of Bacteriology 109:209-217. Type strain: DSM 50722

Description: Seidler, R.J., M. Mandel and J.N. Baptist. 1972. Ibid.

\section{Beggiatoa Trevisan 1842}

Trevisan, V. 1842. Prospetto della Flora Euganea. Coi Tipi Del Seminario, Padova. pp. 1-68. Type species: B. alba (Vaucher 1803) Trevisan 1845

Description: Bergey 8.

B. alba (Vaucher 1803) Trevisan 1845

Vaucher, J.P. 1803. Histoire des conferves d'eau douce, contenant leurs different modes de reproduction, et la description de leurs principales especes. J.J. Paschoud, Geneva. pp. 1-285; Trevisan, V. 1845. Nomenclator Algarum. Impr du seminaire, Padone. pp. 58-59. Type strain: LSU B18LD

Description: Bergey 8 .

\section{Beijerinckia Derx 1950}

Derx, H.G. 1950. Proceedings Koninklijke Nederlandse Akademie van Wetenschappen Series C 53:140-147. Type species: $B$. indica (Starkey and De 1939) Derx 1950 Description: Bergey 8 .

B. derxii Tchan 1957

Tchan, Y.T. 1957. Proceedings of the Linnean Society New South Wales 82: 314-316. Type strain: UQM 1968

Description: Thompson, J.P. and V.B.D. Skerman. 1979. Azotobacteraceae taxonomy and ecology of the aerobic nitrogen-fixing bacteria. Academic Press, London. pp. 347-352.

B. fluminensis Dobereiner and Ruschel 1958 Dóbereiner, J. and A.P. Ruschel. 1958. Revista de Biologia 1:261-272. Type strain: UQM 1685 
Description: Thompson, J.P. and V.B.D. Skerman. 1979. Azotobacteraceae - taxonomy and ecology of the aerobic nitrogenfixing bacteria. Academic Press, London. pp. 337-341.

B. indica (Starkey and De 1939) Derx 1950

Starkey, R.L. and P.K. De. 1939. Soil Science 47:329-343; Derx, H.G. 1950. Proceedings Koninklijke Nederlandse Akademie van Wetenschappen Series C 53: 140-147. Type strain: ATCC 9039

Description: Thompson, J.P. and V.B.D. Skerman. 1979. Azotobacteraceae - taxonomy and ecology of the aerobic nitrogenfixing bacteria. Academic Press, London. pp. 328-332.

B. mobilis Derx 1950

Derx, H.G. 1950. Bogoriensis 1:1-11. Type strain: UQM 1969

Description: Thompson, J.P. and V.B.D. Skerman. 1979. Azotobacteraceae taxonomy and ecology of the aerobic nitrogen-fixing bacteria. Academic Press, London. pp. 333-336.

\section{Beneckea Campbell 1957}

Campbell, L.L. 1957 in Breed, R.S., E.G.D. Murray and N.R. Smith (eds). Bergey's Manual of Determinative Bacteriology, 7th ed. The Williams and Wilkins Co., Baltimore. pp. 328-332. Type species: B. campbellii Baumann, Baumann and Mandel 1971

Description: Campbell, L.L. 1957. Ibid.

B. alginolytica (Miyamoto, Nakamura and Takizawa 1961) Baumann, Baumann and Mandel 1971 (See also Vibrio alginolyticus)

Miyamoto, Y., K. Nakamura and K. Takizawa. 1961. Japanese Journal of Microbiology 5:477-486; Baumann, P., L. Baumann and M. Mandel. 1971. Journal of Bacteriology 107:268-294. Type strain: ATCC 17749

Description: Baumann, P., L. Baumann and M. Mandel. 1971. Ibid.

B. campbellii Baumann, Baumann and Mandel 1971

Baumann, P., L. Baumann and $M$. Mandel. 1971. Journal of Bacteriology 107:268-294. Type strain: ATCC 25920

Description: Baumann, P., L. Baumann and M. Mandel. 1971. Ibid.
B. harveyi (Johnson and Shunk 1936) Reichelt and Baumann 1973 (See also Lucibacterium harveyi)

Johnson, F.H. and I.V. Shunk. 1936. Journal of Bacteriology 31:585-593; Reichelt, J.L. and P. Baumann. 1973. Archiv fur Mikrobiologie 94:283-330. Type strain: ATCC 14126

Description: Reichelt, J.L. and P. Baumann. 1973. Ibid.

B. natriegens (Payne, Eagon and Williams 1961) Baumann, Baumann and Mandel 1971

Payne, W.J., R.G. Eagon and A.K. Williams. 1961. Antonie van Leeuwenhoek Journal of Microbiology and Serology 27:121-128; Baumann, P., L. Baumann and M. Mandel. 1971. Journal of Bacteriology 107:268-294. Type strain: ATCC 14048

Description: Baumann, P., L. Baumann and M. Mandel. 1971. Ibid.

B. nigrapulchrituda Baumann, Baumann, Mandel and Allen 1971

Baumann, P., L. Baumann, M. Mandel and R.D. Allen. 1971. Journal of Bacteriology 108:1380-1383. Type strain: ATCC 27043

Description: Baumann, P., L. Baumann, M. Mandel and R.D. Allen. 1971. Ibid.

B. parahaemolytica (Fujino, Miwatani, Yasuda, Kondo, Takeda, Akita, Kotera, Okada, Nishimura, Shimizu, Tamura and Tamura 1965) Baumann, Baumann and Mandel 1971 (See also Vibrio parahaemolyticus)

Fujino, T., T. Miwatani, J. Yasuda, M. Kondo, Y. Takeda, Y. Akita, K. Kotera, M. Okada, H. Nishimura, Y. Shimizu, T. Tamura and Y. Tamura. 1965. Biken Journal 8:63-71; Baumann, P., L. Baumann and M. Mandel. 1971. Journal of Bacteriology 107:268-294. Type strain: ATCC 17802

Description: Baumann, P., L. Baumann and J.L. Reichelt. 1973. Journal of Bacteriology 113:1144-1155.

B. pelagia Baumann, Baumann and Mandel 1971

Baumann, P., L. Baumann and $M$. Mandel. 1971. Journal of Bacteriology 107:268-294. Type strain: ATCC 25916 Description: Baumann, P., L. Baumann and M. Mandel. 1971. Ibid. 
B. splendida (Beijerinck 1900) Reichelt, Baumann and Baumann 1979

Beijerinck, M.W. 1900. Proceedings of the Academy of Sciences (Amsterdam) 3: 352-365; Reichelt, J.L., P. Baumann and L. Baumann. 1979 in International Journal of Systematic Bacteriology 29:7980; Effective publication Reichelt, J.L., P. Baumann and L. Baumann. 1976. Archives of Microbiology 110:101-120. Type strain: NCMB 1

Description: Reichelt, J.L., P. Baumann and L. Baumann. 1976. Ibid.

B. vulnifica Reichelt, Baumann and Baumann 1979

Reichelt, J.L., P. Baumann and L. Baumann. 1979 in International Journal of Systematic Bacteriology 29:79-80; Effective publication Reichelt, J.L., P. Baumann and L. Baumann. 1976. Archives of Microbiology 110:101-120. Type strain: ATCC 27562

Description: Reichelt, J.P., P. Baumann and L. Baumann. 1976. Ibid.

\section{Bifidobacterium Orla-Jensen 1924}

Orla-Jensen, S. 1924. Lait 4:468-474.

Type species: B. bifidum (Tissier 1900)

Orla-Jensen 1924

Description: Bergey 8.

B. adolescentis Reuter 1963

Reuter, G. 1963. Zentralblatt fur Bakteriologie, Parasitenkunde, Infektionskrankheiten und Hygiene. Abteilung I. 191: 486-507. Type strain: ATCC 15703 biotype a

Description: Reuter, G. 1971. International Journal of Systematic Bacteriology 21: 273-275.

B. angulatum Scardovi and Crociani 1974

Scardovi, V. and F. Crociani. 1974. International Journal of Systematic Bacteriology 24:6-20. Type strain: ATCC 27535

Description: Scardovi, V. and F. Crociani. 1974. Ibid.

B. animalis (Mitsuoka 1969) Scardovi and Trovatelli 1974

Mitsuoka, T. 1969. Zentralblatt fur Bakteriologie, Parasitenkunde, Infektionskrankheiten und Hygiene. Abteilung I. 210:52-64; Scardovi, V. and L.D. Trovatelli. 1974. International Journal of
Systematic Bacteriology 24:21-18. Type strain: ATCC 25527

Description: Scardovi, V. and L.D. Trovatelli. 1974. Ibid.

B. asteroides Scardovi and Trovatelli 1969

Scardovi, V. and L.D. Trovatelli. 1969.

Zentralblatt fur Bakteriologie, Parasiten-

kunde, Infektionskrankheiten und Hygiene. Abteilung II. 123:64-88. Type strain: ATCC 25910

Description: Scardovi, V. and L.D. Trovatelli. 1969. Ibid.

B. bifidum (Tissier 1900) Orla-Jensen 1924

Tissier, H. 1900. Theses, Paris pp. 1-253; Orla-Jensen, S. 1924. Lait 4:468-474. Type strain: Ti(Tissier) Anaerobe Collection, Institut Pasteur Lille

Description: Werner, H. and H.P.R. Seeliger. 1964. Pathologia et Microbiologia 27:212-215.

B. boum Scardovi, Trovatelli, Biavati and Zani 1979

Scardovi, V., L.D. Trovarelli, B. Biavati and G. Zani. 1979. International Journal of Systematic Bacteriology 29:291-311. Type strain: ATCC 27917

Description: Scardovi, V., L.D. Trovatelli, B. Biavati and G. Zani. 1979. Ibid.

B. breve Reuter 1963

Reuter, G. 1963. Zentralblatt fur Bakteriologie, Parasitenkunde, Infektionskrankheiten und Hygiene. Abteilung I. 191:486-507. Type strain: ATCC 15700

Description: Reuter, G. 1971. International Journal of Systematic Bacteriology 21: 273-275.

B. catenulatum Scardovi and Crociani 1974 Scardovi, V. and F. Crociani. 1974. International Journal of Systematic Bacteriology 24:6-20. Type strain: ATCC 27539

Description: Scardovi, V. and F. Crociani. 1974. Ibid.

B. choerinum Scardovi, Trovatelli, Biavati and Zani 1979

Scardovi, V., L.D. Trovatelli, B. Biavati and G. Zani. 1979. International Journal of Systematic Bacteriology 29:291-311. Type strain: ATCC 27686

Description: Scardovi, V., L.D. Trovatelli, B. Biavati and G. Zani. 1979. Ibid.

B. cuniculi Scardovi, Trovatelli, Biavati and 
Zani 1979

Scardovi, V., L.D. Trovatelli, B. Biavati and G. Zani. 1979. International Journal of Systematic Bacteriology 29:291-311. Type strain: ATCC 27916

Description: Scardovi, V., L.D. Trovatelli, B. Biavati and G. Zani. 1979. Ibid.

B. dentium Scardovi and Crociani 1974

Scardovi, V. and F. Crociani. 1974. International Journal of Systematic Bacteriology 24:6-20. Type strain: ATCC 27534

Description: Scardovi, V. and F. Crociani. 1974. Ibid.

B. indicum Scardovi and Trovatelli 1969

Scardovi, V. and L.D. Trovatelli. 1969. Zentralblatt fur Bakteriologie, Parasitenkunde, Infektionskrankheiten und Hygiene. Abteilung II. 123:64-88. Type strain: ATCC 25912

Description: Scardovi, V. and L.D. Trovatelli. 1969. Ibid.

B. infantis Reuter 1963

Reuter, G. 1963. Zentralblatt fur Bakteriologie, Parasitenkunde, Infektionskrankheiten und Hygiene. Abteilung I. 191:486-507. Type strain: ATCC 15697

Description: Reuter, G. 1971. International Journal of Systematic Bacteriology 21: 273-275.

B. longum Reuter 1963

Reuter, G. 1963. Zentralblatt fur Bakteriologie, Parasitenkunde, Infektionskrankheiten und Hygiene. Abteilung I. 191:486-507. Type strain: ATCC 15707

Description: Reuter, G. 1971. International Journal of Systematic Bacteriology 21: 273-275.

B. magnum Scardovi and Zani 1974

Scardovi, V. and G. Zani. 1974. International Journal of Systematic Bacteriology 24:29-34. Type strain: ATCC 27540

Description: Scardovi, V. and G. Zani. 1974. Ibid.

B. pseudocatenulatum Scardovi, Trovatelli, Biavati and Zani 1979

Scardovi, V., L.D. Trovatelli, B. Biavati and G. Zani. 1979. International Journal of Systematic Bacteriology 29:291-311.

Type strain: ATCC 27919
Description: Scardovi, V., L.D. Trovatelli, B. Biavati and G. Zani. 1979. Ibid.

B. pseudolongum Mitsuoka 1969

Mitsuoka, T. 1969. Zentralblatt fur Bakteriologie, Parasitenkunde, Infektionskrankheiten und Hygiene. Abteilung I. 210:52-64. Type strain: ATCC 25526

Description: Mitsuoka, T. 1969. Ibid.

B. pullorum Trovatelli, Crociani, Pedinotti and Scardovi 1974

Trovatelli, L.D., F. Crociani, M. Pedinotti and V. Scardovi. 1974. Archives of Microbiology 98:187-198. Type strain: ATCC 27685

Description: Trovatelli, L.D., F. Crociani, M. Pedinotti and V. Scardovi. 1974. Ibid.

B. suis Matteuzzi, Crociani, Zani and Trovatelli 1971

Matteuzzi, D., F. Crociani, G. Zani and L.D. Trovatelli. 1971. Zeitschrift fur Allgemeine Mikrobiologie 11:387-395.

Type strain: ATCC 27533

Description: Matteuzzi, D., F. Crociani, G. Zani and L.D. Trovatelli. 1971. Ibid.

B. thermophilium Mitsuoka 1969

Mitsuoka, T. 1969. Zentralblatt fur Bakteriologie, Parasitenkunde, Infektionskrankheiten und Hygiene. Abteilung 1 210:52-64. Type strain: ATCC 25525

Description: Mitsuoka, T. 1969. Ibid.

\section{Blastobacter Zavarzin 1961}

Zavarzin, G.A. 1961. Mikrobiologiya 30: 952-975 (English translation 774-791). Type species: B. henricii Zavarzin 1961 Description: Bergey 8.

B. henricii Zavarzin 1961

Zavarzin, G.A. 1961. Mikrobiologiya 30: 952-975 (English translation 774-791). Type strain: no culture isolated. Description: Bergey 8 .

Blastococcus Ahrens and Moll 1970

Ahrens, R. and G. Moll. 1970. Archiv fur Mikrobiologie 70:243-265. Type species: B. aggregatus Ahrens and Moll 1970

Description: Ahrens, R. and G. Moll. 1970. Ibid.

B. aggregatus Ahrens and Moll 1970

Ahrens, R. and G. Moll. 1970. Archiv fur Mikrobiologie 70:243-265. Type strain: ATCC 25902

Description: Ahrens, R. and G. Moll. 
1970. Ibid.

Blattabacterium Hollande and Favre 1931

Hollande, A.C. and R. Favre. 1931. Comptes Rendus des Seances de la Societe de Biologie (Paris) 107:752-754. Type species: B. cuenoti (Mercier 1906) Hollande and Favre 1931

Description: Bergey 8 .

B. cuenoti (Mercier 1906) Hollande and Favre 1931

Mercier, L. 1906. Comptes Rendus des Seances de la Societe de Biologie (Paris) 61:682-684; Hollande, A.C. and R. Favre. 1931. Comptes Rendus des Seances de la Societe de Biologie (Paris) 107:752-754. Type strain: no culture isolated.

Description: Brooks, M.A. 1970. Journal of Invertebrate Pathology 16:249-258.

\section{Bordetella Moreno-Lopez 1952}

Moreno-Lopez, M. 1952. Microbiologia Espanola 5:117-181. Type species: $B$. pertussis (Bergey, Harrison, Breed, Hammer and Huntoon 1923) Moreno-Lopez 1952

Description: Bergey 8.

B. bronchiseptica (Ferry 1912) Morenb-Lopez 1952

Ferry, N.S. 1912. Veterinary Journal 68: 376-391; Moreno-Lopez, M. 1952. Microbiologia Espanola 5:117-181. Type strain: ATCC 19395

Description: Bergey 8.

B. parapertussis (Eldering and Kendrick 1938) Moreno-Lopez 1952

Eldering, G. and P. Kendrick. 1938. Journal of Bacteriology 35:561-572; Moreno-Lopez, M. 1952. Microbiologia Espanola 5:117-181. Type strain: NCTC 5952

Description: Bergey 8 .

B. pertussis (Bergey, Harrison, Breed, Hammer and Huntoon 1923) Moreno-Lopez 1952 Bergey, D.H., F.C. Harrison, R.S. Breed, B.W. Hammer and F.M. Huntoon. 1923. Bergey's Manual of Determinative Bacteriology, 1st ed. The Williams and Wilkins Co., Baltimore. pp. 1-442; Moreno-Lopez, M. 1952. Microbiologia Espanola 5:117181. Type strain: ATCC 9797

Description: Bergey 8.
Borrelia Swellengrebel 1907

Swellengrebel, N.H. 1907. Annales de l'Institut Pasteur (Paris) 21:562-586. Type species: B. anserina (Sakharoff 1891) Bergey, Harrison, Breed, Hammer and Huntoon 1925

Description: Bergey 8.

B. anserina (Sakharoff 1891) Bergey, Harrison, Breed, Hammer and Huntoon 1925

Sakharoff, M.N. 1891. Annales de l'Institut Pasteur (Paris) 5:564-566; Bergey, D.H., F.C. Harrison, R.S. Breed, B.W. Hammer and F.M. Huntoon (eds). 1925. Bergey's Manual of Determinative Bacteriology, 2nd ed. The Williams and Wilkins Co., Baltimore. pp. 1-462. Type strain: no culture available.

Description: Bergey 8.

B. brasiliensis Davis 1952

Davis, G.E. 1952. Journal of Parasitology 38:473-476. Type strain: no culture available.

Description: Bergey 8.

B. caucasica (Kandelaki 1945) Davis 1957

Kandelaki according to Maruashvili, G.M. 1945. Meditsinskaya Parazitologiya i Parazitarnye Bolezni 14:24-27; Davis, G.E. 1957 in Breed, R.S., E.G.D. Murray and N.R. Smith (eds). Bergey's Manual of Determinative Bacteriology, 7th ed. The Williams and Wilkins Co., Baltimore. pp. 892-907. Type strain: no culture available.

Description: Bergey 8.

B. crocidurae (Leger 1917) Davis 1957

Leger, A. 1917. Bulletin de la Societe de Pathologie Exotique 10:280-281; Davis, G.E. 1957 in Breed, R.S., E.G.D. Murray and N.R. Smith (eds). Bergey's Manual of Determinative Bacteriology, 7th ed. The Williams and Wilkins Co., Baltimore. pp. 892-907. Type strain: no culture available.

Description: Bergey 8.

B. dugesii (Mazzotti 1949) Davis 1957

Mazzotti, L. 1949. Revista del Instituto de Salubridad y Enfermedades Tropicales Mexico 10:277-281; Davis, G.E. 1957 in Breed, R.S., E.G.D. Murray and N.R. Smith (eds). Bergey's Manual of Determinative Bacteriology, 7th ed. The Williams and Wilkins Co., Baltimore. pp. 892-907. Type strain: no culture available. 
Description: Bergey 8.

B. duttonii (Novy and Knapp 1906) Bergey, Harrison, Breed, Hammer and Huntoon 1925

Novy, F.G. and R.E. Knapp. 1906. Journal of Infectious Diseases 3:291-393; Bergey, D.H., F.C. Harrison, R.S. Breed, B.W. Hammer and F.M. Huntoon (eds). 1925. Bergey's Manual of Determinative Bacteriology, 2nd ed. The Williams and Wilkins Co., Baltimore. pp. 1-462. Type strain: no culture available.

Description: Bergey 8.

B. graingeri (Heisch 1953) Davis 1957

Heisch, R.B. 1953. Parasitology 43:133135; Davis, G.E. 1957 in Breed, R.S., E.G.D. Murray and N.R. Smith (eds). Bergey's Manual of Determinative Bacteriology, 7th ed. The Williams and Wilkins Co., Baltimore. pp. 892-907. Type strain: no culture available.

Description: Bergey 8.

B. harveyi (Garnham 1947) Davis 1948

Garnham, P.C.C. 1947. East African Medical Journal 24:47-51; Davis, G.E. 1948. Annual Review of Microbiology 2: 305-334. Type strain: no culture available.

Description: Bergey 8.

B. hermsii (Davis 1942) Steinhaus 1946

Davis, G.E. 1942. Publications of the American Association for the Advancement of Science No. 18, pp. 41-47; Steinhaus, E.A. 1946. Insect Microbiology. Comstock Publishing Co., Ithaca, New York. Type strain: no culture available.

Description: Bergey 8.

B. hispanica (de Buen 1926) Steinhaus 1946

de Buen, S. 1926. Annales de Parasitologie Humaine et Comparee 4:185-192; Steinhaus, E.A. 1946. Insect Microbiology. Comstock Publishing Co., Ithaca, New York. Type strain: no culture available.

Description: Bergey 8.

B. latyschewii (Sofiev 1941) Davis 1948

Sofiev, M.S. 1941. Medical Parasitology (Moscow) 10:337-373; Davis, G.E. 1948. Annual Review of Microbiology 2:305334. Type strain: no culture available.

Description: Bergey 8.

B. mazzottii Davis 1956

Davis, G.E. 1956. American Journal of
Hygiene 63:13-17. Type strain: no culture available.

Description: Bergey 8.

B. parkeri (Davis 1942) Steinhaus 1946

Davis, G.E. 1942. Publications of the American Association for the Advancement of Science No. 18, pp. 41-47; Steinhaus, E.A. 1946. Insect Microbiology. Comstock Publishing Co., Ithaca, New York. Type strain: no culture available.

Description: Bergey 8.

B. persica (Dschunkowsky 1913) Steinhaus 1946

Dschunkowsky, E. 1913. Deutsche Medizinische Wochenschrift 39:419-420; Steinhaus, E.A. 1946. Insect Microbiology. Comstock Publishing Co., Ithaca, New York. Type strain: no culture available.

Description: Bergey 8.

B. recurrentis (Lebert 1874) Bergey, Harrison, Breed, Hammer and Huntoon 1925

Lebert, H. 1874 in Ziemssen's Handbuch der Speciellen Pathologie und Therapie, Ed. 2. F.C.W. Vogel, Leipzig. pp. 267304; Bergey, D.H., F.C. Harrison, R.S. Breed, B.W. Hammer and F.M. Huntoon (eds). 1925. Bergey's Manual of Determinative Bacteriology, 2nd ed. The Williams and Wilkins Co., Baltimore. pp. 1-462. Type strain: no culture available.

Description: Bergey 8.

B. theileri (Laveran 1903) Bergey, Harrison, Breed, Hammer and Huntoon 1925

Laveran, A. 1903. Compte Rendu de l'Academie des Sciences (Paris) 136:939941; Bergey, D.H., F.C. Harrison, R.S. Breed, B.W. Hammer and F.M. Huntoon (eds). 1925. Bergey's Manual of Determinative Bacteriology, 2nd ed. The Williams and Wilkins Co., Baltimore. pp. 1-462. Type strain: no culture available.

Description: Bergey 8.

B. tillae Zumpt and Organ 1961

Zumpt, F. and D. Organ. 1961. South African Journal of Laboratory and Clinical Medicine 7:31-35. Type strain: no culture available.

Description: Bergey 8.

B. turicatae (Brumpt 1933) Steinhaus 1946

Brumpt, E. 1933. Comptes Rendus des Seances de la Societe de Biologie (Paris) 
113:1369-1372; Steinhaus, E.A. 1946. Insect Microbiology. Comstock Publishing Co., Ithaca, New York. Type strain: no culture available.

Description: Bergey 8 .

B. venezuelensis (Brumpt 1921) Brumpt 1922

Brumpt, E. 1921 in Lavier, These, Paris. p. 207; Brumpt, E. 1922 in Roger, G.H.,

F. Widal and P.J. Teissier (eds). Nouveau Traite de Medecine. Masson, Paris 4:491531. Type strain: no culture available.

Description: Bergey 8.

\section{Branhamella Catlin 1970}

Catlin, B.W. 1970 International Journal of Systematic Bacteriology 20:155-159. Type species: $B$. catarrhalis (Frosch and Kolle 1896) Catlin 1970

Description: Bergey 8.

B. catarrhalis (Frosch and Kolle 1896) Catlin 1970

Frosch, P. and W. Kolle. 1896 in Flugge, C. (ed). Die Mikroorganismen. F.C.W. Vogel, Leipzig. pp. 154-155; Catlin, B.W. 1970. International Journal of Systematic Bacteriology 20:155-159. Type strain: ATCC 25238

Description: Bergey 8.

\section{Brevibacterium Breed 1953}

Breed, R.S. 1953. Riassunti delle Communicazione VI Congresso Internazionale di Microbiologia, Roma 1:1314. Type species: B. linens (Wolff 1910) Breed 1953

Description: Breed, R.S. 1953. Ibid.

B. acetylicum (Levine and Soppeland 1926) Breed 1957

Levine, M. and L. Soppeland. 1926. Bulletin of the lowa State Agricultural College 77:1-72; Breed, R.S. 1957 in Breed, R.S., E.G.D. Murray and N.R. Smith (eds). Bergey's Manual of Determinative Bacteriology, 7th ed. The Williams and Wilkins Co., Baltimore. pp. 490-503. Type strain: ATCC 953

Description: Keddie, R.M. and G.L. Cure. 1978 in Bousfield, I.J. and A.G. Callely (eds). Special Publications of the Society for General Microbiology I. Coryneform Bacteria. Academic Press, London. pp. 47-84.

B. albidum Komagata and Iizuka 1964
Komagata, K. and H. Iizuka. 1964. Journal of the Agricultural Chemical Society of Japan 38:496-502. Type strain: ATCC 15831

Description: Komagata, K. and H. Iizuka. 1964. Ibid.

B. ammoniagenes (Cooke and Keith 1927) Breed 1953

Cooke, J.V. and H.R. Keith. 1927 Journal of Bacteriology 13:315-319; Breed, R.S. 1953. Riassunti delle Communicazione VI Congresso Internazionale di Microbiologia, Roma 1:13-14. Type strain: ATCC 6871

Description: Keddie, R.M. and G.L. Cure. 1978 in Bousfield, I.J. and A.G. Callely (eds). Special Publications of the Society for General Microbiology I. Coryneform Bacteria. Academic Press, London. pp 47-84.

B. citreum Komagata and Iizuka 1964

Komagata, K. and H. Iizuka. 1964. Journal of the Agricultural Chemical Society of Japan 38:496-502. Type strain: ATCC 15828

Description: Komagata, K. and H. Iizuka. 1964. Ibid.

B. divaricatum Su and Yamada 1960

Su, Y. and K. Yamada. 1960. Bulletin of the Agricultural Chemical Society of Japan 24:69-74. Type strain: ATCC 14020

Description: Abe, S., K. Takayama and S. Kinoshita. 1967. Journal of General and Applied Microbiology 13:279-301.

B. fermentans Chatelain and Second 1966

Chatelain, R. and L. Second. 1966. Annales de l'Institut Pasteur (Paris) 111: 630-644. Type strain: CIP 6611

Description: Chatelain, R. and L. Second. 1966. Ibid.

B. frigoritolerans Delaporte and Sasson 1967

Delaporte, B. and A. Sasson. 1967. Compte Rendu de l'Academie des Sciences. Paris, Series D, 264:2257-2260. Type strain: ATCC 25097

Description: Delaporte, B. and A. Sasson. 1967. Ibid.

B. halotolerans Delaporte and Sasson 1967

Delaporte, B. and A. Sasson. 1967. Compte Rendu de l'Academie des Sciences. Paris, Series D, 264:2257-2260. Type strain: ATCC 25096 
Description: Delaporte, B. and A. Sasson. 1967. Ibid.

B. imperiale (Steinhaus 1941) Breed 1953

Steinhaus, E.A. 1941. Journal of Bacteriology 42:757-790; Breed, R.S. 1953. Riassunti delle Communicazione VI Congresso Internazionale di Microbiologia, Roma 1:13-14. Type strain: ATCC 8365

Description: Steinhaus, E.A. 1941. Ibid.

B. incertum (Steinhaus 1941) Breed 1953

Steinhaus, E.A. 1941. Journal of Bacteriology 42:757-790; Breed, R.S. 1953. Riassunti delle Communicazione VI Congresso Internazionale di Microbiologia, Roma 1:13-14. Type strain: ATCC 8363

Description: Steinhaus, E.A. 1941. Ibid.

B. linens (Wolff 1910) Breed 1953

Wolff, M. 1910. Mitteilungen des KaiserWilhelm-Instituts fur Landwirtschaft in Bromberg 3:69-92; Breed, R.S. 1953. Riassunti delle Communicazione VI Congresso Internazionale di Microbiologia, Roma 1:13-14. Type strain: ATCC 9172

Description: Crombach, W.H.J. 1974. Antonie van Leeuwenhoek Journal of Microbiology and Serology 40:361-376.

B. liquefaciens Okabayashi and Masuo 1960 Okabayashi, T. and E. Masuo. 1960. Chemical and Pharmaceutical Bulletin (Tokyo) 8:1084-1088. Type strain: ATCC 14929

Description: Okabayashi, T., M. Ide, T. Hattori and A. Yoshimoto. 1962. Annual Report of Shionogi Research Laboratory 12:191-197.

B. luteum Komagata and lizuka 1964 Komagata, K. and H. Iizuka. 1964. Journal of the Agricultural Chemical Society of Japan 38:496-502. Type strain: ATCC 15830

Description: Komagata, K. and H. Iizuka. 1964. Ibid.

B. Iyticum Takayama, Udagawa and Abe $\mathbf{1 9 6 0}$

Takayama, K., K. Udagawa and S. Abe. 1960. Journal of the Agricultural Chemical Society of Japan 34:652-656. Type strain: ATCC 15921

Description: Takayama, K., K. Udagawa and S. Abe. 1960. Ibid.

B. oxydans Chatelain and Second 1966

Chatelain, R. and L. Second. 1966.
Annales de l'Institut Pasteur (Paris) 111: 630-644. Type strain: CIP 6612

Description: Chatelain, R. and L. Second. 1966. Ibid.

B. protophormiae Lysenko 1959

Lysenko, O. 1959. Journal of Insect Pathology 1:34-42. Type strain: ATCC 19271

Description: Lysenko, O. 1959. Ibid.

B. pusillum Iizuka and Komagata 1965

Iizuka, H. and K. Komagata. 1965. Journal of General and Applied Microbiology 11:1-14. Type strain: ATCC 19096

Description: Iizuka, H. and K. Komagata. 1965. Ibid.

B. saperdae Lysenko 1959

Lysenko, O. 1959. Journal of Insect Pathology 1:34-42. Type strain: ATCC 19272

Description: Lysenko, O. 1959. Ibid.

B. stationis (ZoBell and Upham 1944) Breed 1953

ZoBell, C.E. and H.C. Upham. 1944. Bulletin Scripps Institution of Oceanography University of California (Technical Series) 5:239-292; Breed, R.S. 1953. Riassunti delle Cmmunicazione Vi Congresso Internazionale di Microbiologia, Roma 1:13-14. Type strain: ATCC 14403

Description: ZoBell, C.E. and H.C. Upham. 1944. Ibid.

B. testaceum Komagata and Iizuka 1964

Komagata, K. and H. Iizuka. 1964. Journal of the Agricultural Chemical Society of Japan 38:496-502. Type strain: ATCC 15829

Description: Komagata, K. and H. lizuka. 1964. Ibid.

B. vitarumen (Bechdel, Honeywell, Dutscher and Knutsen 1928) Breed 1957

Bechdel, S.I., H.E. Honeywell, R.A. Dutscher and M.H. Knutsen. 1928. Journal of Biological Chemistry 80:231238; Breed, R.S. 1957 in Breed, R.S., E.G.D. Murray and N.R. Smith (eds). Bergey's Manual of Determinative Bacteriology, 7th ed. The Williams and Wilkins Co., Baltimore. pp. 490-503. Type strain: ATCC 10234

Description: Breed, R.S. 1957. Ibid.

Brochothrix Sneath and Jones 1976 
Sneath, P.H.A. and D. Jones. 1976. International Journal of Systematic Bacteriology 26:102-104. Type species: $B$. thermosphacta (McLean and Sulzbacher 1953) Sneath and Jones 1976

Description: Sneath, P.H.A. and D. Jones. 1976. Ibid.

B. thermosphacta (McLean and Sulzbacher 1953) Sneath and Jones 1976

McLean, R.A. and W.L. Sulzbacher. 1953. Journal of Bacteriology 65:428-433; Sneath, P.H.A. and D. Jones. 1976. International Journal of Systematic Bacteriology 26:102-104. Type strain: ATCC 11509

Description: Sneath, P.H.A. and D. Jones. 1976. Ibid.

Brucella Meyer and Shaw 1920

Meyer, K.F. and E.B. Shaw. 1920. Journal of Infectious Diseases 27:173-184. Type species: B. melitensis (Hughes 1893) Meyer and Shaw 1920

Description: Bergey 8.

B. abortus (Schmidt 1901) Meyer and Shaw 1920

Schmidt, J. 1901 in Schmidt, J. and F. Weis. Bakterienne. Naturhistorisk Grundlag for det Bakteriologiske Studium, Morten Porsild, Kobenhavn 18991901. pp. 248-296; Meyer, K.F. and E.B. Shaw. 1920. Journal of Infectious Diseases 27:173-184. Type strain: ATCC 23448 Description: Bergey 8.

B. canis Carmichael and Bruner 1968

Carmichael, L.E. and D.W. Bruner. 1968. Cornell Veterinarian 58:579-592. Type strain: ATCC 23365

Description: Bergey 8.

B. melitensis (Hughes 1893) Meyer and Shaw 1920

Hughes, M.L. 1893. Mediterranean Nature 2:325-327; Meyer, K.F. and E.B. Shaw. 1920. Journal of Infectious Diseases 27:173-184. Type strain: ATCC 23456

Description: Bergey 8 .

B. neotomae Stoenner and Lackman 1957

Stoenner, H.G. and D.B. Lackman. 1957. American Journal of Veterinary Research 18:947-951. Type strain: ATCC 23459

Description: Bergey 8.

B. ovis Buddle 1956
Buddle, M.B. 1956. Journal of Hygiene 54:351-364. Type strain: ATCC 25840

Description: Bergey 8.

B. suis Huddleson 1929

Huddleson, I.F. 1929. Michigan State College Agricultural Experimental Station Technical Bulletin 100:1-16. Type strain: ATCC-23444

Description: Bergey 8.

Butyrivibrio Bryant and Small 1956

Bryant, M.P. and N. Small. 1956. Journal of Bacteriology 72:16-21. Type species: $B$. fibrisolvens Bryant and Small 1956

Description: Bergey 8 .

B. crossotus Moore, Johnson and Holdeman 1976

Moore, W.E.C., J.L. Johnson and L.V. Holdeman. 1976. International Journal of Systematic Bacteriology 26:238-252. Type strain: VPI T9-40A

Description: Moore, W.E.C., J.L. Johnson and L.V. Holdeman. 1976. Ibid.

B. fibrisolvens Bryant and Small 1956

Bryant, M.P. and N. Small. 1956. Journal of Bacteriology 72:16-21. Type strain: ATCC 19171

Description: Holdeman, L.V., E.P. Cato and W.E.C. Moore (eds). 1977. Anaerobe Laboratory Manual, 4th ed. Virginia Polytechnic Institute and State University, Blacksburg, Virginia. pp. 1-156.

Calymmatobacterium Aragao and Vianna 1913 Aragao, H. and G. Vianna. 1913. Memorias do Instituto Oswaldo Cruz Rio de Janeiro 5:211-238. Type species: $C$. granulomatis Aragao and Vianna 1913 Description: Bergey 8.

C. granulomatis Aragao and Vianna 1913

Aragao, H. and G. Vianna. 1913. Memorias do Instituto Oswaldo Cruz Rio de Janeiro 5:211-238. Type strain: no strain extant.

Description: Bergey 8.

\section{Campylobacter Sebald and Veron 1963}

Sebald, M. and M. Veron. 1963. Annales de l'Institut Pasteur (Paris) 105:897-910. Type species: $C$. fetus (Smith and Taylor 1919) Sebald and Veron 1963 Description: Bergey 8 . 
C. coli (Doyle 1948) Veron and Chatelain 1973 Doyle, L.P. 1948. American Journal of Veterinary Research 9:50-51; Veron, $\mathbf{M}$. and R. Chatelain. 1973. International Journal of Systematic Bacteriology 23: 122-134. Type strain: CIP 7080

Description: Veron, M. and R. Chatelain. 1973. Ibid.

C. fetus (Smith and Taylor 1919) Sebald and Veron 1963

Smith, T. and M.S. Taylor. 1919. Journal of Experimental Medicine 30:299-311; Sebald, M. and M. veron. 1963. Annales de l'Institut Pasteur (Paris) 105:897-910. Type strain: CIP 5396

Description: Veron, M. and R. Chatelain. 1973. International Journal of Systematic Bacteriology 23:133-134.

C. fetus subsp. fetus (Smith and Taylor 1919) Veron and Chatelain 1973

Smith, T. and M.S. Taylor. 1919. Journal of Experimental Medicine 30:299-311; Veron, M. and R. Chatelain. 1973. International Journal of Systematic Bacteriology 23:122-134. Type strain: CIP 5396

Description: Veron, M. and R. Chatelain. 1973. Ibid.

C. fetus subsp. venerealis (Florent 1959) Veron and Chatelain 1973

Florent, A. 1959. Proceedings 10th International Veterinary Congress Madrid 2:953-957; Veron, M. and R. Chatelain. 1973. International Journal of Systematic Bacteriology 23:122-134. Type strain: ATCC 19483

Description: Veron, M. and R. Chatelain. 1973. Ibid.

C. jejuni (Jones, Orcutt and Little 1931) Veron and Chatelain 1973

Jones, F.S., M. Orcutt and R.B. Little. 1931. Journal of Experimental Medicine 53:853-864; Veron, M. and R. Chatelain. 1973. International Journal of Systematic Bacteriology 23:122-134. Type strain: CIP 702

Description: Veron, M. and R. Chatelain. 1973. Ibid.

C. sputorum (Prevot 1940) Veron and Chatelain 1973

Prevot, A.R. 1940. Annales de l'Institut Pasteur (Paris) 64:117-125; Veron, M. and R. Chatelain. 1973. International
Journal of Systematic Bacteriology 23: 122-134. Type strain: strain Forsyth ER33 (Location not yet determined)

Description: Loesche, W.J., R.J. Gibbons and S.S. Socransky. 1965. Journal of Bacteriology 89:1 109-1116.

C. sputorum subsp. bubulus (Florent 1953) Veron and Chatelain 1973

Florent, A. 1953. Comptes Rendus des Seances de la Societe de Biologie 147: 2066-2069; Veron, M. and R. Chatelain. 1973. International Journal of Systematic Bacteriology 23:122-134. Type strain: CIP 53103

Description: Veron, M. and R. Chatelain. 1973. Ibid.

C. sputorum subsp. sputorum (Prevot 1940) Veron and Chatelain 1973

Prevot, A.R. 1940. Annales de l'Institut Pasteur (Paris) 64:117-125; Veron, $M$. and R. Chatelain. 1973. International Journal of Systematic Bacteriology 23: 122-134. Type strain: strain Forsyth ER33 Description: Loesche, W.J., R.J. Gibbons and S.S. Socransky. 1965. Journal of Bacteriology 89:1109-1116.

\section{Capsularis Prevot 1938}

Prevot, A.R. 1938. Annales de l'Institut Pasteur (Paris) 60:285-307. Type species: C. zoogleiformans (Weinberg, Nativelle and Prevot 1937) Prevot 1938

Description: Prevot, A:R., A. Turpin and P. Kaiser. 1967. Les bacteries anaerobies. Dunod, Paris. p. 272.

C. zoogleiformans (Weinberg, Nativelle and Prevot 1937) Prevot 1938

Weinberg, M., R. Nativelle and A.R. Prevot. 1937. Les microbes anaerobies. Masson et Cie; Prevot, A.R. 1938. Annales de l'Institut Pasteur (Paris) 60: 285-307. Type strain: VPI D28K-1

Description: Prevot, A.R., A. Turpin and P. Kaiser. 1967. Les bacteries anaerobies. Dunod, Paris. p. 272.

Cardiobacterium Slotnick and Dougherty 1964 Slotnick, I.J. and M. Dougherty. 1964. Antonie van Leeuwenhoek Journal of Microbiology and Serology 30:261-272. Type species: $C$. hominis Slotnick and Dougherty 1964

Description: Bergey 8 . 
C. hominis Slotnick and Dougherty 1964

Slotnick, I.J. and M. Dougherty. 1964. Antonie van Leeuwenhoek Journal of Microbiology and Serology 30:261-272. Type strain: ATCC 15826

Description: Bergey 8 .

Caryophanon Peshkoff 1939

Peshkoff, M.A. 1939. Doklady Akademii Nauk SSSR 25:239-242. Type species: $C$. latum Peshkoff 1939

Description: Bergey 8.

C. latum Peshkoff 1939

Peshkoff, M.A. 1939. Doklady Akademii Nauk SSSR 25:239-242. Type strain: NCIB 9533

Description: Bergey 8.

\section{Caseobacter Crombach 1978}

Crombach, W.H.J. 1978. International Journal of Systematic Bacteriology 28: 354-366. Type species: C. polymorphus Crombach 1978

Description: Crombach, W.H.J. 1978. Ibid.

C. polymorphus Crombach 1978

Crombach, W.H.J. 1978. International Journal of Systematic Bacteriology 28: 354-366. Type strain: LMD AC 256

Description: Crombach, W.H.J. 1978. Ibid.

Caulobacter Henrici and Johnson 1935

Henrici, A.T. and D. Johnson. 1935. Journal of Bacteriology 30:61-92. Type species: $C$. vibrioides Henrici and Johnson 1935

Description: Bergey 8 .

C. bacteroides Poindexter 1964

Poindexter, J.S. 1964. Bacteriological Reviews 28:231-295. Type strain: ATCC 15254

Description: Poindexter, J.S. 1964. Ibid.

C. crescentus Poindexter 1964

Poindexter, J.S. 1964. Bacteriological Reviews 28:231-295. Type strain: ATCC 15252

Description: Poindexter, J.S. 1964. Ibid.

C. fusiformis Poindexter 1964

Poindexter, J.S. 1964. Bacteriological Reviews 28:231-295. Type strain: ATCC 15257

Description: Poindexter, J.S. 1964. Ibid.
C. halobacteroides Poindexter 1964

Poindexter, J.S. 1964. Bacteriological Reviews 28:231-295. Type strain: ATCC 15269

Description: Poindexter, J.S. 1964. Ibid.

C. henricii Poindexter 1964

Poindexter, J.S. 1964. Bacteriological Reviews 28:231-295. Type strain: ATCC 15253

Description: Poindexter, J.S. 1964. Ibid.

C. intermedius Poindexter 1964

Poindexter, J.S. 1964. Bacteriological Reviews 28:231-295. Type strain: ATCC 15262

Description: Poindexter, J.S. 1964. Ibid.

C. leidyia Poindexter 1964

Poindexter, J.S. 1964. Bacteriological Reviews 28:231-295. Type strain: ATCC 15260

Description: Poindexter, J.S. 1964. Ibid.

C. maris Poindexter 1964

Poindexter, J.S. 1964. Bacteriological Reviews 28:231-295. Type strain: ATCC 15268

Description: Poindexter, J.S. 1964. Ibid.

C. subvibrioides Poindexter 1964

Poindexter, J.S. 1964. Bacteriological Reviews 28:231-295. Type strain: ATCC 15264

Description: Poindexter, J.S. 1964. Ibid.

C. vibrioides Henrici and Johnson 1935

Henrici, A.T. and D. Johnson. 1935. Journal of Bacteriology 30:61-92. Type strain: Stove CB51 (not extant)

Description: Poindexter, J.S. 1964. Bacteriological Reviews 28:231-295.

Cellulomonas Bergey, Harrison, Breed, Hammer and Huntoon 1923

Bergey, D.H., F.C. Harrison, R.S. Breed, B.W. Hammer and F.M. Huntoon 1923. Bergey's Manual of Determinative Bacteriology, 1st ed. The Williams and Wilkins Co., Baltimore. pp. 1-442. Type species: C. flavigena (Kellerman and McBeth 1912) Bergey, Harrison, Breed, Hammer and Huntoon 1923

Description: Bergey 8 .

C. biazotea (Kellerman, McBeth, Scales and Smith 1913) Bergey, Harrison, Breed, Hammer and Huntoon 1923

Kellerman, K.F., I.G. McBeth, F.M. Scales and N.R. Smith. 1913. 
Zentralblatt fur Bakteriologie, Parasitenkunde, Infektionskrankheiten und Hygiene. Abteilung II. 39:502-522; Bergey, D.H., F.C. Harrison, R.S. Breed, B.W. Hammer and F.M. Huntoon. 1923. Bergey's Manual of Determinative Bacteriology, 1st ed. The Williams and Wilkins Co., Baltimore. pp. 1-442. Type strain: ATCC 486

Description: Bergey, D.H., F.C. Harrison, R.S. Breed, B.W. Hammer and F.M. Huntoon. 1923. Ibid.

C. cellasea (Kellerman, McBeth, Scales and Smith 1913) Bergey, Harrison, Breed, Hammer and Huntoon 1923

Kellerman, K.F., I.G. McBeth, F.M. Scales and N.R. Smith. 1913. Zentralblatt fur Bakteriologie, Parasitenkunde, Infektionskrankheiten und Hygiene. Abteilung II. 39:502-522; Bergey, D.H., F.C. Harrison, R.S. Breed, B.W. Hammer and F.M. Huntoon. 1923. Bergey's Manual of Determinative Bacteriology, 1st ed. The Williams and Wilkins Co., Baltimore. pp. 1-442. Type strain: ATCC 487

Description: Kellerman, K.F., I.G. McBeth, F.M. Scales and N.R. Smith. 1913. Ibid.

C. fimi (McBeth and Scales 1913) Bergey, Harrison, Breed, Hammer and Huntoon 1923

McBeth, I.G. and F.M. Scales. 1913. United States Department of Agriculture Bureau of Plant Industry Bulletin 266:152; Bergey, D.H., F.C. Harrison, R.S. Breed, B.W. Hammer and F.M. Huntoon. 1923. Bergey's Manual of Determinative Bacteriology, 1st ed. The Williams and Wilkins Co., Baltimore. pp. 1-442. Type strain: ATCC 484

Description: McBeth, I.G. and F.M. Scales. 1913. Ibid.

C. flavigena (Kellerman and McBeth 1912) Bergey, Harrison, Breed, Hammer and Huntoon 1923

Kellerman, K.F. and I.G. McBeth. 1912. Zentralblatt fur Bakteriologie, Parasitenkunde, Infektionskrankheiten und Hygiene. Abteilung II. 34:485-494; Bergey, D.H., F.C. Harrison, R.S. Breed, B.W. Hammer and F.M. Huntoon 1923. Bergey's Manual of Determinative Bacter- iology, 1st ed. The Williams and Wilkins Co., Baltimore. pp. 1-442. Type strain: ATCC 482

Description: Bergey 8 .

C. gelida (Kellerman, McBeth, Scales and Smith 1913) Bergey, Harrison, Breed, Hammer and Huntoon 1923

Kellerman, K.F., I.G. McBeth, F.M. Scales and N.R. Smith. 1913. Zentralblatt fur Bakteriologie, Parasitenkunde, Infektionskrankheiten und Hygiene. Abteilung II. 39:502-522; Bergey, D.H., F.C. Harrison, R.S. Breed, B.W. Hammer and F.M. Huntoon. 1923. Bergey's Manual of Determinative Bacteriology, 1st ed. The Williams and Wilkins Co., Baltimore. pp. 1-442. Type strain: ATCC 488

Description: Kellerman, K.F., I.G. McBeth, F.M. Scales and N.R. Smith. 1913. Ibid.

C. uda (Kellerman, McBeth, Scales and Smith 1913) Bergey, Harrison, Breed, Hammer and Huntoon 1923

Kellerman, K.F., I.G. McBeth, F.M. Scales and N.R. Smith. 1913. Zentralblatt fur Bakteriologie, Parasitenkunde, Infektionskrankheiten und Hygiene. Abteilung II. 39:502-522; Bergey, D.H., F.C. Harrison, R.S. Breed, B.W. Hammer and F.M. Huntoon. 1923. Bergey's Manual of Determinative Bacteriology, 1st ed. The Williams and Wilkins Co., Baltimore. pp. 1-442. Type strain: ATCC 491

Description: Kellerman, K.F., I.G. McBeth, F.M. Scales and N.R. Smith. 1913. Ibid.

Chainia Thirumalachar 1955

Thirumalachar, M.J. 1955. Nature (London) 176:934-935. Type species: $C$. antibiotica Thirumalachar 1955

Description: Thirulmalachar, M.J. 1955. Ibid.

C. antibiotica Thirumalachar 1955

Thirumalachar, M.J. 1955. Nature (London) 176:934-935. Type strain: ATCC 15721

Description: Shirling, E.B. and D. Gottlieb. 1972. International Journal of Systematic Bacteriology 22:265-394.

C. flava Thirumalachar and Sukapure 1964

Thirumalachar, M.J. and R.S. Sukapure. 
1964. Hindustan Antibiotics Bulletin 6: 157-166. Type strain: ATCC 19347

Description: Thirulmalachar, M.J. and R.S. Sukapure. 1964. Ibid.

C. fumigata Thirumalachar, Sukapure, Rahalkar and Gopalkrishnan 1966

Thirumalachar, M.J., R.S. Sukapure, P.W. Rahalkar and K.S. Gopalkrishnan. 1966. Hindustan Antibiotics Bulletin 9:1014. Type strain: ATCC 19345

Description: Thirulmalachar, M.J., R.S. Sukapure, P.W. Rahalkar and K.S. Gopalkrishnan. 1966. Ibid.

C. minutisclerotica Thirumalachar, Rahalkar, Deshmukh and Sukapure 1965

Thirumalachar, M.J., P.W. Rahalkar, P.V. Deshmukh and R.S. Sukapure. 1965. Hindustan Antibiotics Bulletin 8:6-9. Type strain: ATCC 17757

Description: Shirling, E.B. and D. Gottlieb. 1972. International Journal of Systematic Bacteriology 22:265-394.

C. nigra Thirumalachar 1955

Thirumalachar, M.J. 1955. Nature (London) 176:934-935. Type strain: ATCC 17756

Description: Shirling, E.B. and D. Gottlieb. 1972. International Journal of Systematic Bacteriology 22:265-394.

C. ochracea Kuznetsov 1962

Kuznetsov, V.D. 1962. Mikrobiologiya 31: 534-539. Type strain: ATCC 15814

Description: Shirling, E.B. and D. Gottlieb. 1972. International Journal of Systematic Bacteriology 22:265-394.

C. olivacea Thirumalachar and Sukapure 1964

Thirumalachar, M.J. and R.S. Sukapure. 1964. Hindustan Antibiotics Bulletin 6: 157-166. Type strain: ATCC 15722

Description: Shirling, E.B. and D. Gottlieb. 1972. International Journal of Systematic Bacteriology 22:265-394.

C. poonensis Thirumalachar 1960

Thirumalachar, M.J. 1960 in Kalakoutskii, L.V. and N.A. Krassilnikov in Rautenshtein, Ya. I. Transactions of the Institute of Microbiology, Academy of Sciences USSR 8:1-344. Type strain: ATCC 15723

Description: Shirling, E.B. and D. Gottlieb. 1972. International Journal of Systematic Bacteriology 22:265-394.

C. purpurogena Thirumalachar and Sukapure
1964

Thirumalachar, M.J. and R.S. Sukapure. 1964. Hindustan Antibiotics Bulletin 6: 157-166. Type strain: ATCC 19348

Description: Shirling, E.B. and D. Gottlieb. 1972. International Journal of Systematic Bacteriology 22:265-394.

C. rosea Thirumalachar 1966

Thirumalachar, M.J. 1966 in Thirumalachar, M.J., R.S. Sukapure, P.W. Rahalkar and K.S. Gopalkrishnan. Hindustan Antibiotics Bulletin 9:10-14. Type strain: ATCC 17755

Description: Shirling, E.B. and D. Gottlieb. 1972. International Journal of Systematic Bacteriology 22:265-394.

C. rubra Thirumalachar 1955

Thirumalachar, M.J. 1955. Nature (London) 176:934-935. Type strain: ATCC 17754

Description: Shirling, E.B. and D. Gottlieb. 1972. International Journal of Systematic Bacteriology 22-265-394.

C. violens Kalakoutskii and Krassilnikov 1960 Kalakoutskii, L.V. and N.A. Krassilnikov. 1960. Transactions of the Institute of Microbiology, Academy of Science USSR 8:45-55. Type strain: ATCC 15898

Description: Shirling, E.B. and D. Gottlieb. 1972. International Journal of Systematic Bacteriology 22:265-394.

Chlamydia Jones, Rake and Stearns 1945

Jones, H., G. Rake and B. Stearns. 1945. Journal of Infectious Diseases 76:55-69. Type species: C. trachomatis (Busacca 1935) Rake 1957

Description: Bergey 8.

C. psittaci (Lillie 1930) Page 1968

Lillie, R.D. 1930. Public Health Report 45:773-778; Page, L.A. 1968. International Journal of Systematic Bacteriology 18 : 51-66. Type strain: ATCC VR 125 Description: Bergey 8.

C. trachomatis (Busacca 1935) Rake 1957

Busacca, A. $1935 . \quad$ Archives d'Ophthalmologie 52:567-572; Rake, G. 1957 in Breed, R.S., E.G.D. Murray and N.R. Smith (eds). Bergey's Manual of Determinative Bacteriology, 7th ed. The Williams and Wilkins Co., Baltimore. pp. 957-968. Type strain: ATCC VR 571 
Description: Bergey 8.

Chlorobium Nadson 1906

Nadson, G.A. 1906. Bulletin du Jardin Botanique, St. Petersbourg 6:190. Type species: C. limicola Nadson 1906

Description: Bergey 8 .

C. chlorovibrioides Gorlenko, Chebotarev and Kachalkin 1974

Gorlenko, V.M., E.N. Chebotarev and V.I. Kachalkin. 1974. Mikrobiologiya 43: 908-914. Type strain: DSM 1377

Description: Gorlenko, V.M., E.N. Chebotarev and V.I. Kachalkin. 1974. Ibid.

C. limicola Nadson 1906

Nadson, G.A. 1906. Bulletin du Jardin Botanique, St. Petersbourg 6:190. Type strain: DSM 245

Description: Bergey 8 .

C. phaeobacteroides Pfennig 1968

Pfennig, N. 1968. Archiv fur Mikrobiologie 63:224-226. Type strain: DSM 266

Description: Bergey 8.

C. phaeovibrioides Pfennig 1968

Pfennig, N. 1968. Archiv fur Mikrobiologie 63:224-226. Type strain: DSM 269

Description: Bergey 8.

C. vibrioforme Pelsh 1936

Pelsh, A.D. 1936. Trudy Solyanoi Laboratorii, Vsesoyuznogo Instituta Metallurgi NISNKT. Izdatelstvo Akademya Nauk SSSR, Moscow eningrad 5:49-126. Type strain: DSM 260 Description: Bergey 8.

Chloroflexus Pierson and Castenholz 1974

Pierson, B.K. and R.W. Castenholz. 1974. Archives of Microbiology 100:5-24. Type species: $C$. aurantiacus Pierson and Castenholz 1974

Description: Pierson, B.K. and R.W. Castenholz. 1974. Ibid.

C. aurantiacus Pierson and Castenholz 1974

Pierson, B.K. and R.W. Castenholz. 1974. Archives of Microbiology 100:5-24. Type strain: ATCC 29366

Description: Pierson, B.K. and R.W. Castenholz. 1974. Ibid.

Chloronema Dubinina and Gorlenko 1975 Dubinina, G.A. and V.M. Gorlenko. 1975. Mikrobiologiya 44:511-517. Type species: C. giganteum Dubinina and Gorlenko
1975

Description: Dubinina, G.A. and V.M. Gorlenko. 1975. Ibid.

C. giganteum Dubinina and Gorlenko 1975

Dubinina, G.A. and V.M. Gorlenko. 1975.

Mikrobiologiya 44:511-517. Type strain: no pure culture.

Description: Dubinina, G.A. and V.M. Gorlenko. 1975. Ibid.

Chondromyces Berkeley and Curtis 1874

Berkeley, M.J. and M.A. Curtis. 1874 in Berkeley, M.J. Grevillea 3:49-64. Type species: $C$. crocatus Berkeley and Curtis 1874

Description: Bergey 8 .

C. apiculatus Thaxter 1897

Thaxter, R. 1897. Botanical Gazette 23: 395-411. Type strain: TC 4481

Description: Bergey 8.

C. catenulatus Thaxter 1904

Thaxter, R. 1904. Botanical Gazette 37:

405-416. Type strain: TC 4517

Description: Bergey 8 .

C. crocatus Berkeley and Curtis 1874

Berkeley, M.J. and M.A. Curtis. 1874 in

Berkeley, M.J. Grevillea 3:49-64. Type strain: TC 601

Description: Bergey 8.

C. lanuginosus Kofler 1913

Kofler, L. 1913. Sitzungsberichte der Akademie der Wissenschaften in Wien. Mathematisch-naturwissenschaftliche

Klasse Abteilung I. 122:845-876. Type strain: TC 4494

Description: Kofler, L. 1913. Ibid.

C. pediculatus Thaxter 1904

Thaxter, R. 1904. Botanical Gazette 37: 405-416. Type strain: TC 4524

Description: Bergey 8 .

Chromatium Perty 1852

Perty, M. 1852. Zur Kenntnis kleinster Lebensformen. Jent and Reinert, Bern IVIII, pp. 1-228. Type species: C. okenii (Ehrenberg 1838) Perty 1852

Description: Bergey 8 .

C. buderi Truper and Jannasch 1968

Truper, H.G. and H.W. Jannasch. 1968.

Archiv fur Mikrobiologie 61:363-372.

Type strain: ATCC 25588

Description: Bergey 8. 
C. gracile Strzeszewski 1913

Strzeszewski, B. 1913. Bulletin de l'Academie des Sciences de Cracovie, Serie B. pp. 309-334. Type strain: DSM 203

Description: Bergey 8.

C. minus Winogradsky 1888

Winogradsky, S. 1888. Beitrage zur Morphologie und Physiologie der Bacterien. Heft I. Zur Morphologie und Physiologie der Schwefelbacterien. Arthur Felix, Leipzig. pp. 1-120. Type strain: DSM 178

Description: Bergey 8.

C. minutissimum Winogradsky 1888

Winogradsky, S. 1888. Beitrage zur Morphologie und Physiologie der Bacterien. Heft 1. Zur Morphologie und Physiologie der Schwefelbacterien. Arthur Felix, Leipzig. pp. 1-120. Type strain: DSM 1376

Description: Bergey 8.

C. okenii (Ehrenberg 1838) Perty 1852

Ehrenberg, C.G. 1838. Die Infusionsthierchen als vollkommene Organismen. L. Voss, Leipzig; Perty, M. 1852. Zur Kenntnis kleinster Lebensformen. Jent and Reinert, Bern I-VIII, pp. 1-228. Type strain: DSM 169

Description: Bergey 8.

C. vinosum (Ehrenberg 1838) Winogradsky 1888

Ehrenberg, C.G. 1838. Die Infusionsthierchen als vollkommene Organismen. L. Voss, Leipzig; Winogradsky, S. 1888. Beitrage zur Morphologie und Physiologie der Bacterien. Heft I. Zur Morphologie und Physiologie der Schwefelbacterien. Arthur Felix, Leipzig. pp. 1120. Type strain: ATCC 17899

Description: Bergey 8.

C. violascens Perty 1852

Perty, M. 1852. Zur Kenntnis kleinster Lebensformen. Jent and Reinert, Bern 1VIII. pp. 1-228. Type strain: ATCC 17096

Description: Bergey 8.

C. warmingii (Cohn 1875) Migula 1900

Cohn, F. 1875. Beitrage zur Biologie der

Pflanzen 1:141-207; Migula, W. 1900. System der Bakterien, Vol. 2. Gustav Fischer, Jena. Type strain: ATCC 14959

Description: Bergey 8.
C. weissei Perty 1852

Perty, M. 1852. Zur Kenntnis kleinster Lebensformen. Jent and Reinert, Bern IVIII. pp. 1-228. Type strain: DSM 171 Description: Bergey 8 .

\section{Chromobacterium Bergonzini 1881}

Bergonzini, C. 1881. Annuar Soc. Nat. Modena, Series 2, 14:149-158. Type species: $C$. violaceum Bergonzini 1881

Description: De Ley, J., P. Segers and M. Gillis. 1978. International Journal of Systematic Bacteriology 28:154-168.

C. violaceum Bergonzini 1881

Bergonzini, C. 1881. Annuar. Soc. Nat. Modena, Series 2, 14:149-158. Type strain: ATCC 12472

Description: De Ley, J., P. Segers and M. Gillis. 1978. International Journal of Systematic Bacteriology 28:154-168.

Citrobacter Werkman and Gillen 1932 Werkman, C.H. and G.F. Gillen. 1932. Journal of Bacteriology 23:167-182. Type species: C. freundii (Braak 1928) Werkmann and Gillen 1932

Description: Bergey 8 .

C. diversus (Burkey 1928) Werkman and Gillen 1932

Burkey, L.A. 1928. Iowa State College Journal of Science 3:57-100; Werkman, C.H. and G.F. Gillen. 1932. Journal of Bacteriology 23:167-182. Type strain: ATCC 27156

Description: Ewing, W.H. and B.R. Davis. 1972. International Journal of Systematic Bacteriology 22:12-18.

C. freundii (Braak 1928) Werkman and Gillen 1932

Braak, H.R. 1928. Onderzoekingen over vergisting van glycerine. Thesis. Meinema W.D. Uitgever- Delft. pp. 1-233; Werkman, C.H. and G.F. Gillen. 1932. Journal of Bacteriology 23:167-182. Type strain: ATCC 8090

Description: Bergey 8 .

C. koseri Frederiksen 1970

Frederiksen, W. 1970. Publication of the Faculty of Sciences University J.E. Purkyne, Brno. 47:89-94. Type strain: ATCC 27028

Description: Frederiksen, W. 1970. Ibid. 
Clostridium Prazmowski 1880

Prazmowski, A. 1880. Inaugural Dissertation Hugo Voigt, Leipzig. pp. 1-58. Type species: C. butyricum Prazmowski 1880 Description: Bergey 8.

C. absonum Nakamura, Shimamura, Hayase and Nishida 1973

Nakamura, S., T. Shimamura, M. Hayase and S. Nishida. 1973. International Journal of Systematic Bacteriology 23: 419-429. Type strain: ATCC 27555

Description: Nakamura, S., T. Shimamura, M. Hayase and S. Nishida. 1973. Ibid.

C. acetobutylicum McCoy, Fred, Peterson and Hastings 1926

McCoy, E., E.B. Fred, W.H. Peterson and E.G. Hastings. 1926. Journal of Infectious Diseases 39:457-483. Type strain: ATCC 824

Description: Holdeman, L.V., E.P. Cato and W.E.C. Moore (eds). 1977. Anaerobe Laboratory Manual, 4th ed. Virginia Polytechnic Institute and State University, Blacksburg, Virginia. pp. 1-156.

C. acidiurici (Liebert 1909) Barker 1938

Liebert, F. 1909. Verslagen van de gewone vergadering der wis- en natuurkundige afdeeling. K. Akademie van wetenschappen te Amsterdam. 17:9901001; Barker, H.A. 1938. Journal of Bacteriology 36:322-323. Type strain: ATCC 7906

Description: Bergey 8.

C. aminovalericum Hardman and Stadtman 1960

Hardman, J.K. and T.C. Stadtman. 1960. Journal of Bacteriology 79:549-552. Type strain: ATCC 13725

Description: Holdeman, L.V., E.P. Cato and W.E.C. Moore (eds). 1977. Anaerobe Laboratory Manual, 4th ed. Virginia Polytechnic Institute and State University, Blacksburg, Virginia. pp. 1-156.

C. aurantibutyricum Hellinger 1944

Hellinger, E. 1944. Commemorative Volume to Dr. Weizmann's 70th Birthday Private print November 1944. pp. 37-46. Type strain: ATCC 17777

Description: Holdeman, L.V., E.P. Cato and W.E.C. Moore (eds). 1977. Anaerobe Laboratory Manual, 4th ed. Virginia Polytechnic Institute and State University,
Blacksburg, Virginia. pp. 1-156.

C. barati (Prevot 1938) Holdeman and Moore 1970

Prevot, A.R. 1938. Annales de l'Institut Pasteur (Paris) 61:72-91; Holdeman, L.V. and W.E.C. Moore. 1970 in Cato, E.P., C.S. Cummins, L.V. Holdeman, J.L. Johnson, W.E.C. Moore, R.M. Smibert and L.DS. Smith (eds). Outline of clinical methods in anaerobic bacteriology, 2nd revision. Virginia Polytechnic Institute Anaerobe Laboratory, Blacksburg, Virginia. pp. 57-66. Type strain: ATCC 27638

Description: Holdeman, L.V., E.P. Cato and W.E.C. Moore (eds). 1977. Anaerobe Laboratory Manual, 4th ed. Virginia Polytechnic Institute and State University, Blacksburg, Virginia. pp. 1-156.

C. barkeri Stadtman, Stadtman, Pastan and Smith 1972

Stadtman, E.R., T.C. Stadtman, I. Pastan and L.DS. Smith. 1972. Journal of Bacteriology 110:758-760. Type strain: ATCC 25849

Description: Holdeman, L.V., E.P. Cato and W.E.C. Moore (eds). 1977. Anaerobe Laboratory Manual, 4th ed. Virginia Polytechnic Institute and State University, Blacksburg, Virginia. pp. 1-156.

C. beijerinckii Donker 1926 Donker, H.J.L. 1926. Dissertations Delft. W.D. Meinema, Delft. Type strain: ATCC 25752

Description: Holdeman, L.V., E.P. Cato and W.E.C. Moore (eds). 1977. Anaerobe Laboratory Manual, 4th ed. Virginia Polytechnic Institute and State University, Blacksburg, Virginia. pp. 1-156.

C. bifermentans (Weinberg and Seguin 1918) Bergey, Harrison, Breed, Hammer and Huntoon 1923

Weinberg, M. and P. Seguin. 1918. La gangrene gazeuse-Bacteriologie, Reproduction experimentale, Sereotherapie. Masson et Cie, Paris, pp. 1-444; Bergey, D.H., F.C. Harrison, R.S. Breed, B.W. Hammer and F.M. Huntoon. 1923. Bergey's Manual of Determinative Bacteriology, 1st ed. The Williams and Wilkins Co., Baltimore. pp. 1-442. Type strain: ATCC 638

Description: Holdeman, L.V., E.P. Cato and W.E.C. Moore (eds). 1977. Anaerobe 
Laboratory Manual, 4th ed. Virginia Polytechnic Institute and State University, Blacksburg, Virginia. pp. 1-156.

C. botulinum (van Ermengem 1896) Bergey, Harrison, Breed, Hammer and Huntoon 1923

van Ermengem, E. 1896. Zentralblatt fur Bakteriologie, Parasitenkunde, Infektionskrankheiten und Hygiene. Abteilung I. 19:442-444; Bergey, D.H., F.C. Harrison, R.S. Breed, B.W. Hammer and F.M. Huntoon. 1923. Bergey's Manual of Determinative Bacteriology, 1st ed. The Williams and Wilkins Co., Baltimore. pp. 1-442. Type strain: ATCC 25763

Description: Holdeman, L.V., E.P. Cato and W.E.C. Moore (eds). 1977. Anaerobe Laboratory Manual, 4th ed. Virginia Polytechnic Institute and State University, Blacksburg, Virginia. pp. 1-156.

C. butyricum Prazmowski 1880

Prazmowski, A. 1880 . Inaugural Dissertation Hugo Voigt, Leipzig, pp. 158. Type strain: ATCC 19398

Description: Holdeman, L.V., E.P. Cato and W.E.C. Moore (eds). 1977. Anaerobe Laboratory Manual, 4th ed. Virginia Polytechnic Institute and State University, Blacksburg, Virginia. pp. 1-156.

C. cadaveris (Klein 1899) McClung and McCoy 1957

Klein, E. 1899. Zentralblatt fur Bakteriologie, Parasitenkunde, Infektionskrankheiten und Hygiene. Abteilung I. 25:278284; McClung, L.S. and E. McCoy. 1957 in Breed, R.S., E.G.D. Murray and N.R. Smith (eds). Bergey's Manual of Determinative Bacteriology, 7th ed. The Williams and Wilkins Co., Baltimore. pp. 634-693. Type strain: ATCC 25783

Description: Holdeman, L.V., E.P. Cato and W.E.C. Moore (eds). 1977. Anaerobe Laboratory Manual, 4th ed. Virginia Polytechnic Institute and State University, Blacksburg, Virginia. pp. 1-156.

C. carnis (Klein 1904) Spray 1939

Klein, E. 1904. Zentralblatt fur Bakteriologie, Parasitenkunde, Infektionskrankheiten und Hygiene. Abteilung I. 35:459-461; Spray, R.S. 1939 in Bergey, D.H., R.S. Breed, E.G.D. Murray and A.P. Hitchens (eds). Bergey's Manual of Determinative Bacteriology, 5th ed. The
Williams and Wilkins Co., Baltimore. pp. 743-790. Type strain: ATCC 25777

Description: Holdeman, L.V., E.P. Cato and W.E.C. Moore (eds). 1977. Anaerobe Laboratory Manual 4th ed. Virginia Polytechnic Institute and State University, Blacksburg, Virginia. pp. 1-156.

C. celatum Hauschild and Holdeman 1974

Hauschild, A.H.W. and L.V. Holdeman. 1974. International Journal of Systematic Bacteriology 24:478-481. Type strain: ATCC 27791

Description: Hauschild, A.H.W. and L.V. Holdeman 1974. Ibid.

C. cellobioparum Hungate 1944

Hungate, R.E. 1944. Journal of Bacteriology 48:499-513. Type strain: ATCC 15832

Description: Holdeman, L.V., E.P. Cato and W.E.C. Moore (eds). 1977. Anaerobe Laboratory Manual, 4th ed. Virginia Polytechnic Institute and State University, Blackburg, Virginia. pp. 1-156.

C. chauvoei (Arloing, Cornevin and Thomas 1887) Scott 1928

Arloing, S., Cornevin and Thomas. 1887. Le charbon symptomatique du boeuf. 2nd ed. Asselin and Houzeau, Paris. pp. 1281; Scott, J.P. 1928. Cornell Veterinarian 18:259-271. Type strain: ATCC 10092

Description: Holdeman, L.V., E.P. Cato and W.E.C. Moore (eds). 1977. Anaerobe Laboratory Manual, 4th ed. Virginia Polytechnic Institute and State University, Blacksburg, Virginia. pp. 1-156.

C. clostridiiforme (Burri and Ankersmit 1906) Kaneuchi, Watanabe, Terada, Benno and Mitsuoka 1976

Burri, R. and P. Ankersmit. 1906 in Ankersmit, P. Zentralblatt fur Bakteriologie, Parasitenkunde, Infektionskrankheiten und Hygiene. Abteilung I. 40:100-118; Kaneuchi, C., K. Watanabe, A. Terada, Y. Benno and T. Mitsuoka. 1976. International Journal of Systematic Bacteriology 26:195-204, 341. Type strain: ATCC 25537

Description: Cato, E.P. and C.W. Salmon. 1976. International Journal of Systematic Bacteriology 26:205-211.

C. coccoides Kaneuchi, Benno and Mitsuoka 1976

Kaneuchi, C., Y. Benno and T. Mitsuoka. 
1976. International Journal of Systematic Bacteriology 26:482-486. Type strain: ATCC 29236

Description: Kaneuchi, C., Y. Benno and T. Mitsuoka. 1976. Ibid.

C. cochlearium (Douglas, Fleming and Colebrook 1919) Bergey, Harrison, Breed, Hammer and Huntoon 1923

Douglas, S.R., A. Fleming and L. Colebrook. 1919. Medical Research Council (Great Britain) Special Report Series 57:1-159; Bergey, D.H., F.C. Harrison, R.S. Breed, B.W. Hammer and F.M. Huntoon. 1923. Bergey's Manual of Determinative Bacteriology, 1st ed. The Williams and Wilkins Co., Baltimore. pp. 1-442. Type strain: ATCC 17787

Description: Holdeman, L.V., E.P. Cato and W.E.C. Moore (eds). 1977. Anaerobe Laboratory Manual, 4th ed. Virginia Polytechnic Institute and State University, Blacksburg, Virginia. pp. 1-156.

C. cocleatum Kaneuchi, Miyazato, Shinjo and Mitsuoka 1979

Kaneuchi, C., T. Miyazato, T. Shinjo and T. Mitsuoka. 1979. International Journal of Systematic Bacteriology 29:1-12. Type strain: ATCC 29902

Description: Kaneuchi, C., T. Miyazato, T. Shinjo and T. Mitsuoka. 1979. Ibid.

C. difficile (Hall and O'Toole 1935) Prevot 1938

Hall, I.C. and E. O'Toole. 1935. American Journal of Diseases of Children 49:390-402; Prevot, A.R. 1938. Annales de l'Institut Pasteur (Paris) 61:72-91. Type strain: ATCC 9689

Description: Holdeman, L.V., E.P. Cato and W.E.C. Moore (eds). 1977. Anaerobe Laboratory Manual, 4th ed. Virginia Polytechnic Institute and State University, Blacksburg, Virginia. pp. 1-156.

C. durum Smith and Cato 1974

Smith, L.DS. and E.P. Cato. 1974. Canadian Journal of Microbiology 20: 1393-1397. Type strain: ATCC 27763

Description: Smith, L.DS. and E.P. Cato. 1974. Ibid.

C. fallax (Weinberg and Seguin 1915) Bergey, Harrison, Breed, Hammer and Huntoon 1923

Weinberg, M. and P. Seguin. 1915. Comptes Rendus des Seances de la
Societe de Biologie, Paris 78:686-689; Bergey, D.H., F.C. Harrison, R.S. Breed, B.W. Hammer and F.M. Huntoon. 1923. Bergey's Manual of Determinative Bacteriology, 1st ed. The Williams and Wilkins Co., Baltimore. pp. 1-442. Type strain: ATCC 19400

Description: Holdeman, L.V., E.P. Cato and W.E.C. Moore (eds). 1977. Anaerobe Laboratory Manual, 4th ed. Virginia Polytechnic Institute and State University, Blacksburg, Virginia. pp. 1-156.

C. felsineum (Carbone and Tombolato 1917) Bergey, Breed, Murray and Hitchens 1939

Carbone, D. and A. Tombolato. 1917. Stazioni Sperimentali Agrarie Italiane 50: 563-575; Bergey, D.H., R.S. Breed, E.G.D. Murray and A.P. Hitchens (eds). 1939. Bergey's Manual of Determinative Bacteriology, 5th ed. The Williams and Wilkins Co., Baltimore. pp. 1-1032. Type strain: ATCC 17788

Description: Holdeman, L.V., E.P. Cato and W.E.C. Moore (eds). 1977. Anaerobe Laboratory Manual, 4th ed. Virginia Polytechnic Institute and State University, Blacksburg, Virginia. pp. 1-156.

C. formicoaceticum Andreesen, Gottschalk and Schlegel 1970

Andreesen, J.R., G. Gottschalk and H.G. Schlegel. 1970. Archiv fur Mikrobiologie 72:154-174. Type strain: ATCC 27076

Description: Andreeson, J.R., G. Gottschalk and H.G. Schlegel. 1970. Ibid.

C. ghoni Prevot 1938

Prevot, A.R. 1938. Annales de l'Institut Pasteur (Paris) 61:72-91. Type strain: ATCC 25757

Description: Holdeman, L.V., E.P. Cato and W.E.C. Moore (eds). 1977. Anaerobe Laboratory Manual, 4th ed. Virginia Polytechnic Institute and State University, Blacksburg, Virginia. pp. 1-156.

C. glycolicum Gaston and Stadtman 1963 Gaston, L.W. and E.R. Stadtman. 1963. Journal of Bacteriology 85:356-362. Type strain: ATCC 14880

Description: Holdeman, L.V., E.P. Cato and W.E.C. Moore (eds). 1977. Anaerobe Laboratory Manual, 4th ed. Virginia Polytechnic Institute and State University, Blacksburg, Virginia. pp. 1-156. 
C. haemolyticum (Hall 1929) Scott, Turner and Vawter 1935

Hall, I.C. 1929. Journal of Infectious Diseases 45:156-162; Scott, J., A.W. Turner and L.R. Vawter. 1935. Twelfth International Veterinary Congress 2:168182. Type strain: ATCC 9650

Description: Holdeman, L.V., E.P. Cato and W.E.C. Moore (eds). 1977. Anaerobe Laboratory Manual, 4th ed. Virginia Polytechnic Institute and State University, Blacksburg, Virginia. pp. 1-156.

C. hastiforme MacLennan 1939

MacLennan, J.D. 1939. Journal of Pathology and Bacteriology 49:535-548. Type strain: VPI 12193

Description: Holdeman, L.V., E.P. Cato and W.E.C. Moore (eds). 1977. Anaerobe Laboratory Manual, 4th ed. Virginia Polytechnic Institute and State University, Blacksburg, Virginia. pp. 1-156.

C. histolyticum (Weinberg and Seguin 1916) Bergey, Harrison, Breed, Hammer and Huntoon 1923

Weinberg, M. and P. Seguin. 1916. Comptes Rendus de l'Academie des Seances Paris 163:449-451; Bergey, D.H., F.C. Harrison, R.S. Breed, B.W. Hammer and F.M. Huntoon. 1923. Bergey's Manual of Determinative Bacteriology, 1st ed. The Williams and Wilkins Co., Baltimore. pp. 1-442. Type strain: ATCC 19401

Description: Holdeman, L.V., E.P. Cato and W.E.C. Moore (eds). 1977. Anaerobe Laboratory Manual, 4th ed. Virginia Polytechnic Institute and State University, Blacksburg, Virginia. pp. 1-156.

C. indolis McClung and McCoy 1957

McClung, L.S. and E. McCoy. 1957 in Breed, R.S., E.G.D. Murray and N.R. Smith (eds). Bergey's Manual of Determinative Bacteriology, 7th ed. The Williams and Wilkins Co., Baltimore. pp. 634-693. Type strain: ATCC 25771

Description: Holdeman, L.V., E.P. Cato and W.E.C. Moore (eds). 1977. Anaerobe Laboratory Manual, 4th ed. Virginia Polytechnic Institute and State University, Blacksburg, Virginia. pp. 1-156.

C. innocuum Smith and King 1962

Smith, L.DS. and E. King. 1962. Journal of Bacteriology 83:938-939. Type strain:

\section{ATCC 14501}

Description: Holdeman, L.V., E.P. Cato and W.E.C. Moore (eds). 1977. Anaerobe Laboratory Manual, 4th ed. Virginia Polytechnic Institute and State University, Blacksburg, Virginia. pp. 1-156.

C. irregularis (Choukevitch 1911) Prevot 1938

Choukevitch, J. 1911. Annales de l'Institut Pasteur (Paris) 25:345-368; Prevot, A.R. 1938. Annales de l'Institut Pasteur (Paris) 61:72-91. Type strain: ATCC 25756

Description: Holdeman, L.V., E.P. Cato and W.E.C. Moore (eds). 1977. Anaerobe Laboratory Manual, 4th ed. Virginia Polytechnic Institute and State University, Blacksburg, Virginia. pp. 1-156.

C. kluyveri Barker and Taha 1942

Barker, H.A. and S.M. Taha. 1942. Journal of Bacteriology 43:347-363. Type strain: NCIB 10680

Description: Bergey 8.

C. Ientoputrescens Hartsell and Rettger 1934 Hartsell, S.E. and L.F. Rettger. 1934. Journal of Bacteriology 27:497-514. Type strain: ATCC 17794

Description: Bergey 8.

C. leptum Moore, Johnson and Holdeman 1976 Moore, W.E.C., J.L. Johnson and L.V. Holdeman. 1976. International Journal of Systematic Bacteriology 26:238-252. Type strain: ATCC 29065

Description: Moore, W.E.C., J.L. Johnson and L.V. Holdeman. 1976. Ibid.

C. limosum Andre 1948

Andre, 1948 in Prevot, A.R. Annales de l'Institut Pasteur (Paris) 74:157-170. Type strain: ATCC 25620

Description: Holdeman, L.V., E.P. Cato and W.E.C. Moore (eds). 1977. Anaerobe Laboratory Manual, 4th ed. Virginia Polytechnic Institute and State University, Blacksburg, Virginia. pp. 1-156.

C. lituseburense (Laplanche and Saissac 1948) McClung and McCoy 1957

Laplanche, J. and R. Saissac. 1948 in Prevot, A.R. Annales de l'Institut Pasteur (Paris) 74:157-170; McClung, L.S. and E. McCoy. 1957 in Breed, R.S., E.G.D. Murray and N.R. Smith (eds). Bergey's Manual of Determinative Bacteriology, 7th ed. The Williams and Wilkins Co., Baltimore. pp. 634-693. Type strain: 


\section{ATCC 25759}

Description: Holdeman, L.V., E.P. Cato and W.E.C. Moore (eds). 1977. Anaerobe Laboratory Manual, 4th ed. Virginia Polytechnic Institute and State University, Blacksburg, Virginia. pp. 1-156.

C. malenominatum (Weinberg, Nativelle and Prevot 1937) Spray 1948

Weinberg, M., R. Nativelle and A.R. Prevot. 1937. Les Microbes Anaerobies. Masson et Cie, Paris. pp. 1-1186; Spray, R.S. 1948 in Breed, R.S., E.G.D. Murray and A.P. Hitchens (eds). Bergey's Manual of Determinative Bacteriology, 6th ed. The Williams and Wilkins Co., Baltimore. pp. 763-827. Type strain: ATCC 25776

Description: Holdeman, L.V., E.P. Cato and W.E.C. Moore (eds). 1977. Anaerobe Laboratory Manual, 4th ed. Virginia Polytechnic Institute and State University, Blacksburg, Virginia. pp. 1-156.

C. mangenotii (Prevot and Zimmes-Chaverou 1947) McClung and McCoy 1957

Prevot, A.R. and Zimmes-Chaverou. 1947. Annales de l'Institut Pasteur (Paris) 73:602-604; McClung, L.S. and E. McCoy. 1957 in Breed, R.S., E.G.D. Murray and N.R. Smith (eds). Bergey's Manual of Determinative Bacteriology. 7th ed. The Williams and Wilkins Co., Baltimore. pp. 634-693. Type strain: ATCC 25761

Description: Holdeman, L.V., E.P. Cato and W.E.C. Moore (eds). 1977. Anaerobe Laboratory Manual, 4th ed. Virginia Polytechnic Institute and State University, Blacksburg, Virginia. pp. 1-156.

C. nexile Holdeman and Moore 1974

Holdeman, L.V. and W.E.C. Moore. 1974. International Journal of Systematic Bacteriology 24:260-277. Type strain: ATCC 27757

Description: Holdeman, L.V. and W.E.C. Moore. 1974. Ibid.

C. novyi (Migula 1894) Bergey, Harrison, Breed, Hammer and Huntoon 1923

Migula, W. 1894. Zeitschrift fur Hygiene 17:209; Bergey, D.H., F.C. Harrison, R.S. Breed, B.W. Hammer and F.M. Huntoon. 1923. Bergey's Manual of Determinative Bacteriology, 1st ed. The Williams and Wilkins Co., Baltimore. pp. 1-442. Type strain: ATCC 17861
Description: Holdeman, L.V., E.P. Cato and W.E.C. Moore (eds). 1977. Anaerobe Laboratory Manual, 4th ed. Virginia Polytechnic Institute and State University, Blacksburg, Virginia. pp. 1-156.

C. oceanicum Smith 1970

Smith, L.DS. 1970. Journal of Bacteriology 103:811-813. Type strain: ATCC 25647

Description: Holdeman, L.V., E.P. Cato and W.E.C. Moore (eds). 1977. Anaerobe Laboratory Manual, 4th ed. Virginia Polytechnic Institute and State University, Blacksburg, Virginia. pp. 1-156.

C. oroticum (Wachsman and Barker 1954) Cato, Moore and Holdeman 1968

Wachsman, J.T. and H.A. Barker. 1954. Journal of Bacteriology 68:400-404; Cato, E., W.E.C. Moore and L.V. Holdeman. 1968. International Journal of Systematic Bacteriology 18:9-13. Type strain: ATCC 13619

Description: Holdeman, L.V., E.P. Cato and W.E.C. Moore (eds). 1977. Anaerobe Laboratory Manual, 4th ed. Virginia Polytechnic Institute and State University, Blacksburg, Virginia. pp. 1-156.

C. paraperfringens Nakamura, Tamai and Nishida 1970

Nakamura, S., K. Tamai and S. Nishida. 1970. Medical Biology 80:137-140. Type strain: ATCC 27639

Description: Nakamura, S., T. Shimamura, M. Hayase and S. Nishida. 1973. Ibid.

C. paraputrificum (Bienstock 1906) Snyder 1936

Bienstock, B. 1906. Annales de l'Institut Pasteur (Paris) 20:407-415; Snyder, M.L. 1936. Journal of Bacteriology 32:401-410. Type strain: ATCC 25780

Description: Holdeman, L.V., E.P. Cato and W.E.C. Moore (eds). 1977. Anaerobe Laboratory Manual, 4th ed. Virginia Polytechnic Institute and State University, Blacksburg, Virginia. pp. 1-156.

C. pasteurianum Winogradsky 1895

Winogradsky, S. 1894-95. Archives of Science and Biology, St. Petersbourg 3: 297-352. Type strain: ATCC 6013

Description: Holdeman, L.V., E.P. Cato and W.E.C. Moore (eds). 1977. Anaerobe Laboratory Manual, 4th ed. Virginia 
Polytechnic Institute and State University, Blacksburg, Virginia. pp. 1-156.

C. perenne (Prevot 1940) McClung and McCoy 1957

Prevot, A.R. 1940. Comptes Rendus des Seances de la Societe de Biologie (Paris) 133:574-577; McClung, L.S. and E. McCoy. 1957 in Breed, R.S., E.G.D. Murray and N.R. Smith (eds). Bergey's Manual of Determinative Bacteriology, 7th ed. The Williams and Wilkins Co., Baltimore. pp. 634-693. Type strain: ATCC 25782

Description: Holdeman, L.V., E.P. Cato and W.E.C. Moore (eds). 1977. Anaerobe Laboratory Manual, 4th ed. Virginia Polytechnic Institute and State University, Blacksburg, Virginia. pp. 1-156.

C. perfringens (Veillon and Zuber 1898) Hauduroy, Ehringer, Urbain, Guillot and Magrou 1937

Veillon, A. and A. Zuber. 1898. Archives de Medicine Experimentale et d'Anatomie Pathologique 10:517-545; Hauduroy, P., G. Ehringer, A. Urbain, G. Guillot and J. Magrou. 1937. Dictionnaire des bacteries pathogenes. Masson et Cie, Paris. pp. 1597. Type strain: ATCC 13124

Description: Holdeman, L.V., E.P. Cato and W.E.C. Moore (eds). 1977. Anaerobe Laboratory Manual, 4th ed. Virginia Polytechnic Institute and State University, Blacksurg, Virginia. pp. 1-156.

C. propionicum Cardon and Barker 1946

Cardon, B.P. and H.A. Barker. 1946. Journal of Bacteriology 52:629-634. Type strain: ATCC 25522

Description: Holdeman, L.V., E.P. Cato and W.E.C. Moore (eds). 1977. Anaerobe Laboratory Manual, 4th ed. Virginia Polytechnic Institute and State University, Blacksburg, Virginia. pp. 1-156.

C. putrefaciens (McBryde 1911) Sturges and Drake 1927

McBryde, C.N. 1911. United States Bureau of Animal Industry 132:1-55; Sturges, W.S. and E.T. Drake. 1927. Journal of Bacteriology 14:175-179. Type strain: ATCC 25786

Description: Holdeman, L.V., E.P. Cato and W.E.C. Moore (eds). 1977. Anaerobe Laboratory Manual, 4th ed. Virginia Polytechnic Institute and State University,
Blacksburg, Virginia. pp. 1-156.

C. putrificum (Trevisan 1889) Reddish and Rettger 1922

Trevisan, V. 1889. I Generi e le Specie delle Battieriacee. Zanaboni and Gabuzzi, Milano; Reddish, G. and L. Rettger. 1922. Abstracts of Bacteriology 6:9. Type strain: ATCC 25784

Description: Holdeman, L.V., E.P. Cato and W.E.C. Moore (eds). 1977. Anaerobe Laboratory Manual, 4th ed. Virginia Polytechnic Institute and State University, Blacksburg, Virginia. pp. 1-156.

C. quercicolum Stankewich, Cosenza and Shigo 1971

Stankewich, J.P., B.J. Cosenza and A.L. Shigo. 1971. Antonie van Leeuwenhoek Journal of Microbiology and Serology 37: 299-302. Type strain: ATCC 25974

Description: Holdeman, L.V., E.P. Cato and W.E.C. Moore (eds). 1977. Anaerobe Laboratory Manual, 4th ed. Virginia Polytechnic Institute and State University, Blacksburg, Virginia. pp. 1-156.

C. ramosum (Veillon and Zuber 1898) Holdeman, Cato and Moore 1971

Veillon, A. and A. Zuber. 1898. Archives de Medecine Experimentale et d'Anatomie Pathologique 10:51-545; Holdeman, L.V., E.P. Cato and W.E.C. Moore. 1971. International Journal of Systematic Bacteriology 21:35-39. Type strain: ATCC 25582

Description: Holdeman, L.V., E.P. Cato and W.E.C. Moore (eds). 1977. Anaerobe Laboratory Manual, 4th ed. Virginia Polytechnic Institute and State University, Blacksburg, Virginia. pp. 1-156.

C. rectum (Heller 1922) Holdeman and Moore 1972

Heller, H.H. 1922. Journal of Bacteriology 7:1-38; Holdeman, L.V. and W.E.C. Moore. 1972. Anaerobe Laboratory Manual Virginia Polytechnic Institute Anaerobe Laboratory, Blacksburg, Virginia. Type strain: ATCC 25751

Description: Holdeman, L.V., E.P. Cato and W.E.C. Moore (eds). 1977. Anaerobe Laboratory Manual, 4th ed. Virginia Polytechnic Institute and State University, Blacksburg, Virginia. pp. 1-156.

C. sardiniensis Prevot 1938

Prevot, A.R. 1938. Annales de l'Institut 
Pasteur (Paris) 61:72-91. Type strain: VPI 2971

Description: Holdeman, L.V., E.P. Cato and W.E.C. Moore (eds). 1977. Anaerobe Laboratory Manual, 4th ed. Virginia Polytechnic Institute and State University, Blacksburg, Virginia. pp. 1-156.

C. sartagoformum Partansky and Henry 1935 Partansky, A.M. and B.S. Henry. 1935. Journal of Bacteriology 30:559-571. Type strain: ATCC 25778

Description: Holdeman, L.V., E.P. Cato and W.E.C. Moore (eds). 1977. Anaerobe Laboratory Manual, 4th ed. Virginia Polytechnic Institute and State University, Blacksburg, Virginia. pp. 1-156.

C. scatologenes (Weinberg and Ginsbourg 1927) Prevot 1948

Weinberg, M. and B. Ginsbourg. 1927. Donnees recentes dur les microbes anaerobies et leur role en pathologie. Masson et Cie, Paris. pp. 1-291; Prevot, A.R. 1948. Manuel de classification et de determination des bacteries anaerobies, 2nd ed. Masson et Cie, Paris. pp. 1-290. Type strain: ATCC 25775

Description: Holdeman, L.V., E.P. Cato and W.E.C. Moore (eds). 1977. Anaerobe Laboratory Manual, 4th ed. Virginia Polytechnic Institute and State University, Blacksburg, Virginia. pp. 1-156.

C. septicum (Mace 1889) Ford 1927

Mace, E. 1889. Traite Pratique de Bacteriologie, 1st ed. J.-B. Balliere and Sons, Paris 1-III. pp. 1-711; Ford, W.W. 1927. Text-book of Bacteriology. Saunders, Philadelphia. pp. 1-1069. Type strain: ATCC 12464

Description: Holdeman, L.V., E.P. Cato and W.E.C. Moore (eds). 1977. Anaerobe Laboratory Manual, 4th ed. Virginia Polytechnic Institute and State University, Blacksburg, Virginia. pp. 1-156.

C. sordellii (Hall and Scott 1927) Prevot 1938 Hall, I.C. and J.P. Scott. 1927. Journal of Infectious Diseases 41:329-335; Prevot, A.R. 1938. Annales de l'Institut Pasteur (Paris) 61:72-91. Type strain: NCIB 10717

Description: Holdeman, L.V., E.P. Cato and W.E.C. Moore (eds). 1977. Anaerobe Laboratory Manual, 4th ed. Virginia Polytechnic Institute and State University,
Blacksburg, Virginia. pp. 1-156.

C. sphenoides (Douglas, Fleming and Colebrook 1919) Bergey, Harrison, Breed, Hammer and Huntoon 1923

Douglas, S.R., A. Fleming and L. Colebrook. 1919. Medical Research Council (Great Britain) Special Report Series 57:1-159; Bergey, D.H., F.C. Harrison, R.S. Breed, B.W. Hammer and F.M. Huntoon. 1923. Bergey's Manual of Determinative Bacteriology, 1st ed. The Williams and Wilkins Co., Baltimore. pp. 1-442. Type strain: ATCC 19403

Description: Holdeman, L.V., E.P. Cato and W.E.C. Moore (eds). 1977. Anaerobe Laboratory Manual, 4th ed. Virginia Polytechnic Institute and State University, Blacksburg, Virginia. pp. 1-156.

C. spiroforme Kaneuchi, Miyazato, Shinjo and Mitsuoka 1979

Kaneuchi, C., T. Miyazato, T. Shinjo and T. Mitsuoka. 1979. International Journal of Systematic Bacteriology 29:1-12. Type strain: ATCC 29900

Description: Kaneuchi, C., T. Miyazato, T. Shinjo and T. Mitsuoka. 1979. Ibid.

C. sporogenes (Metchnikoff 1908) Bergey, Harrison, Breed, Hammer and Huntoon 1923

Metchnikoff, E. 1908. Annales de l'Institut Pasteur (Paris) 22:929-955; Bergey, D.H., F.C. Harrison, R.S. Breed, B.W. Hammer and F.M. Huntoon. 1923. Bergey's Manual of Determinative Bacteriology 1 st ed. The Williams and Wilkins Co., Baltimore. pp. 1-442. Type strain: ATCC 3584

Description: Holdeman, L.V., E.P. Cato and W.E.C. Moore (eds). 1977. Anaerobe Laboratory Manual, 4th ed. Virginia Polytechnic Institute and State University, Blacksburg, Virginia. pp. 1-156.

C. sporosphaeroides Soriano and Soriano 1948

Soriano, S. and A. Soriano. 1948. Revista de la Asocion Argentina de Dietologia 6: 36-41. Type strain: ATCC 25781

Description: Holdeman, L.V., E.P. Cato and W.E.C. Moore (eds). 1977. Anaerobe Laboratory Manual, 4th ed. Virginia Polytechnic Institute and State University, Blacksburg, Virginia. pp. 1-156.

C. sticklandii Stadtman and McClung 1957

Stadtman, T.C. and L.S. McClung. 1957. Journal of Bacteriology 73:218-219. Type 
strain: ATCC 12662

Description: Holdeman, L.V., E.P. Cato and W.E.C. Moore (eds). 1977. Anaerobe Laboratory Manual, 4th ed. Virginia Polytechnic Institute and State University, Blacksburg, Virginia. pp. 1-156.

C. subterminale (Hall and Whitehead 1927) Spray 1948

Hall, I.C. and R.W. Whitehead. 1927. Journal of Infectious Diseases 41:51-69; Spray, R.S. 1948 in Breed, R.S., E.G.D. Murray and A.P. Hitchens (eds). Bergey's Manual of Determinative Bacteriology, 6th ed. The Williams and Wilkins Co., Baltimore. pp. 763-827. Type strain: ATCC 25774

Description: Holdeman, L.V., E.P. Cato and W.E.C. Moore (eds). 1977. Anaerobe Laboratory Manual, 4th ed. Virginia Polytechnic Institute and State University, Blacksburg, Virginia. pp. 1-156.

C. symbiosum (Stevens 1956) Kaneuchi, Watanabe, Terada, Benno and Mitsuoka 1976

Stevens, W.C. 1956. Taxonomic studies on the genus Bacteroides and similar forms. Thesis, Vanderbilt University; Kaneuchi, C., K. Watanabe, A. Terada, Y. Benno and T. Mitsuoka. 1976. International Journal of Systematic Bacteriology 26:195-204. Type strain: ATCC 14940

Description: Kaneuchi, C., K. Watanabe, A. Terada, Y. Benno and T. Mitsuoka. 1976. Ibid.

C. tertium (Henry 1917) Bergey, Harrison, Breed, Hammer and Huntoon 1923

Henry, H. 1917. Journal of Pathology and Bacteriology 21:344-385; Bergey, D.H., F.C. Harrison, R.S. Breed, B.W. Hammer and F.M. Huntoon. 1923. Bergey's Manual of Determinative Bacteriology, 1st ed. The Williams and Wilkins Co., Baltimore. pp. 1-442. Type strain: ATCC 14573

Description: Holdeman, L.V., E.P. Cato and W.E.C. Moore (eds). 1977. Anaerobe Laboratory Manual, 4th ed. Virginia Polytechnic Institute and State University, Blacksburg, Virginia. pp. 1-156.

C. tetani (Flugge 1886) Bergey, Harrison, Breed, Hammer and Huntoon 1923

Flugge, C. 1886. Die Mikroorganismen. F.C.W. Vogel, Leipzig. pp. 1-692; Bergey,
D.H., F.C. Harrison, R.S. Breed, B.W. Hammer and F.M. Huntoon. 1923. Bergey's Manual of Determinative Bacteriology, 1st ed. The Williams and Wilkins Co., Baltimore. pp. 1-442. Type strain: ATCC 19406

Description: Holdeman, L.V., E.P. Cato and W.E.C. Moore (eds). 1977. Anaerobe Laboratory Manual, 4th ed. Virginia Polytechnic Institute and State University, Blacksburg, Virginia. pp. 1-156.

C. thermoaceticum Fontaine, Peterson, McCoy and Johnson 1942

Fontaine, F.E., W.H. Peterson, E. McCoy and M.J. Johnson. 1942. Journal of Bacteriology 43:701-715. Type strain: DSM 521

Description: Fontaine, F.E., W.H. Peterson, E. McCoy and M.J. Johnson. 1942. Ibid.

C. thermocellum Viljoen, Fred and Peterson 1926

Viljoen, J.A., E.B. Fred and W.H. Peterson. 1926. Journal of Agricultural Science Cambridge 16:1-17. Type strain: ATCC 27405

Description: Bergey 8.

C. thermohydrosulfuricum Klaushofer and Parkkinen 1965

Klaushofer, H. and E. Parkkinen. 1965. Zeitschrift fur Zuckerindustrien Boehmen 15:445-449. Type strain: DSM 567

Description: Matteuzzi, D., F. Hollaus and B. Bravati. 1978. International Journal of Systematic Bacteriology 28 528-531.

C. thermosaccharolyticum McClung 1935

McClung, L.S. 1935. Journal of Bacteriology 29:189-203. Type strain: ATCC 7956

Description: Holdeman, L.V., E.P. Cato and W.E.C. Moore (eds). 1977. Anaerobe Laboratory Manual, 4th ed. Virginia Polytechnic Institute and State University, Blacksburg, Virginia. pp. 1-156.

C. tyrobutyricum van Beynum and Pette 1935 van Beynum, J. and J.W. Pette. 1935. Zentralblatt fur Bakteriologie, Parasitenkunde, Infektionskrankheiten und Hygiene. Abteilung II. 93:198-212. Type strain: ATCC 25755

Description: Holdeman, L.V., E.P. Cato and W.E.C. Moore (eds). 1977. Anaerobe 
Laboratory Manual, 4th ed. Virginia Polytechnic Institute and State University, Blacksburg, Virginia. pp. 1-156.

C. villosum Love, Jones and Bailey 1979 Love, D.N., R.F. Jones and M. Bailey. 1979. International Journal of Systematic Bacteriology 29:241-244. Type strain: NCTC 11220

Description: Love, D.N., R.F. Jones and M. Bailey. 1979. Ibid.

Coprococcus Holdeman and Moore 1974 Holdeman, L.V. and W.E.C. Moore. 1974. International Journal of Systematic Bacteriology 24:260-277. Type species: $C$. eutactus Holdeman and Moore 1974

Description: Holdeman, L.V. and W.E.C. Moore. 1974. Ibid.

C. catus Holdeman and Moore 1974 Holdeman, L.V. and W.E.C. Moore. 1974. International Journal of Systematic Bacteriology 24:260-277. Type strain: VPI C6-61

Description: Holdeman, L.V. and W.E.C. Moore. 1974. Ibid.

C. comes Holdeman and Moore 1974

Holdeman, L.V. and W.E.C. Moore. 1974. International Journal of Systematic Bacteriology 24:260-277. Type strain: VPI C1-38

Description: Holdeman, L.V. and W.E.C. Moore. 1974. Ibid.

C. eutactus Holdeman and Moore 1974

Holdeman, L.V. and W.E.C. Moore. 1974. International Journal of Systematic Bacteriology 24:260-277. Type strain: ATCC 27759

Description: Holdeman, L.V. and W.E.C. Moore. 1974. Ibid.

Corynebacterium Lehmann and Neumann 1896 Lehmann, K.B. and R. Neumann. 1896. Atlas und Grundriss der Bakteriologie und Lehrbuch der speciellen bakteriologischen Diagnostik. 1st ed. J.F. Lehmann, Munchen. Type species: $C$. diphtheriae (Kruse 1886) Lehmann and Neumann 1896

Description: Bergey 8.

C. betae Keyworth, Howell and Dowson 1956 Keyworth, W.G., J.T.S. Howell and W.J. Dowson. 1956. Plant Pathology 5:88-90. Type strain: NCPPB 374
Description: Dye, D.W. and W.J. Kemp. 1977. New Zealand Journal of Agricultural Research 20:563-582.

C. beticola Abdou 1969

Abdou, M. A-F. 1969. Phytopathologische Zeitschrift 66:147-167. Type strain: NCPPB 2256

Description: Bergey 8 .

C. bovis Bergey, Harrison, Breed, Hammer and Huntoon 1923

Bergey, D.H., F.C. Harrison, R.S. Breed, B.W. Hammer and F.M. Huntoon. 1923 Bergey's Manual of Determinative Bacteriology, 1st ed. The Williams and Wilkins Co., Baltimore. pp. 1-442. Type strain: ATCC 7715

Description: Bergey 8.

C. callunae (Lee and Good 1963) Yamada and Komagata 1972

Lee, W.H. and R.C. Good. 1963. Official Gazette of the United States Patent Office 789:1349; Yamada, K. and K. Komagata. 1972. Journal of General and Applied Microbiology 18:417-431. Type strain: ATCC 15991

Description: Yamada, K. and K. Komagata. 1972. Journal of General and Applied Microbiology 18:399-416.

C. cystitidis Yanagawa and Honda 1978

Yanagawa, R. and E. Honda. 1978. International Journal of Systematic Bacteriology 28:209-216. Type strain: ATCC 29593

Description: Yanagawa, R. and E. Honda. 1978. Ibid.

C. diphtheriae (Kruse 1886) Lehmann and Neumann 1896

Kruse, W. 1886 in Flugge, C. Die Mikroorganismen. F.C.W. Vogel, Leipzig; Lehmann, K.B. and R. Neumann. 1896. Atlas und Grundriss der Bakteriologie und Lehrbuch der speziellen bakteriologischen Diagnostik. 1st ed. J.F. Lehmann, Munchen. Type strain: ATCC 27010

Description: Barksdale, L. 1970. Bacteriological Reviews 34:414.

C. equi Magnusson 1923

Magnusson, M. 1923. Archiv fur wissenschaftliche u. praktische Tierheilkunde 50: 22-38. Type strain: ATCC 6939

Description: Bergey 8.

C. fascians (Tilford 1936) Dowson 1942 
Tilford, P.E. 1936. Journal of Agricultural Research 53:383-394; Dowson, W.J. 1942. Transactions of the British Mycological Society 25:311-314. Type strain: ATCC 12974

Description: Bergey 8.

C. flaccumfaciens (Hedges 1922) Dowson 1942 Hedges, F. 1922. Science (Washington) 55:433-434; Dowson, W.J. 1942. Transactions of the British Mycological Society 25:311-314. Type strain: NCPPB 1446

Description: Bergey 8.

C. flavescens Barksdale, Laneelle, Pollice, Asselineau, Welby and Norgard 1979

Barksdale, L., M.-A. Leneelle, M.C. Pollice, J. Asselineau, M. Welby and M.V. Norgard. 1979. International Journal of Systematic Bacteriology 29:222233. Type strain: ATCC 10340

Description: Barksdale, L., M.-A. Laneelle, M.C. Pollice, J. Asselineau, M. Welby and M.V. Norgard. 1979. Ibid.

C. glutamicum (Kinoshita, Nakayama and Akita 1958) Abe, Takayama and Kinoshita 1967

Kinoshita, S., S. Nakayama and S. Akita. 1958. Bulletin of the Agricultural Chemical Society of Japan 22:176-185; Abe, S., K. Takayama and S. Kinoshita. 1967. Journal of General and Applied Microbiology 13:279-301. Type strain: ATCC 13032

Description: Yamada, K. and K. Komagata. 1972. Journal of General and Applied Microbiology 18:399-416.

C. hoagii (Morse 1912) Eberson 1918

Morse, M.E. 1912. Journal of Infectious Diseases 11:253-285; Eberson, F. 1918. Journal of Infectious Diseases 23:1-42. Type strain: ATCC 7005

Description: Yamada, K. and K. Komagata. 1972. Journal of General and Applied Microbiology 18:399-416.

C. ilicis Mandel, Guba and Litsky 1961

Mandel, M., E.F. Guba and W. Litsky. 1961. Bacteriological Proceedings 1961:61.

Type strain: ATCC 14264

Description: Dye, D.W. and W.J. Kemp. 1977. New Zealand Journal of Agricultural Research 20:563-582.

C. insidiosum (McCulloch 1925) Jensen 1934 McCulloch, L. 1925. Phytopathology 15: 496-497; Jensen, H.J. 1934. Proceedings of the Linnean Society of New South Wales 59:19-61. Type strain: NCPPB 1109

Description: Bergey 8.

C. kutscheri (Migula 1900) Bergey, Harrison, Breed, Hammer and Huntoon 1925

Migula, W. 1900. System der Bakterien, Vol. 2. Gustav Fischer, Jena; Bergey, D.H., F.C. Harrison, R.S. Breed, B.W. Hammer and F.M. Huntoon (eds). 1925. Bergey's Manual of Determinative Bacteriology, 2nd ed. The Williams and Wilkins Co., Baltimore. pp. 1-462. Type strain: ATCC 15677

Description: Bergey 8.

C. lilium Lee and Good 1963

Lee, W.H. and R.C. Good. 1963. Official Gazette of the United States Patent Office 789:1349. Type strain: ATCC 15990

Description: Yamada, K. and K. Komagata. 1972. Journal of General and Applied Microbiology 18:399-416.

C. michiganense (Smith 1910) Jensen 1934

Smith, E.F. 1910. Science (Washington) 31:794-796; Jensen, H.L. 1934. Proceedings of the Linnean Society of New South Wales 59:19-61. Type strain: NCPPB 2979

Description: Bergey 8.

C. nebraskense (Schuster, Hoff, Mandel and Lazar 1973) emend. Vidaver and Mandel 1974

Schuster, M.L., B. Hoff, M. Mandel and I. Lazar. 1973. 27th Annual Corn and Sorghum Research Conference Proceedings, 1972, 27:176-191; Vidaver, A.K. and M. Mandel. 1974. International Journal of Systematic Bacteriology 24:482-485. Type strain: NCPPB 2581

Description: Vidaver, A.K. and $M$. Mandel. 1974. Ibid.

C. oortii Saaltink and Maas Geesteranus 1969

Saaltink, G.J. and H.P. Maas Geesteranus. 1969. Netherlands Journal of Plant Pathology 75:123-128. Type strain: ATCC 25283

Description: Saaltink, G.J. and H.P. Maas Geesteranus. 1969. Ibid.

C. paurometabolum Steinhaus 1941

Steinhaus, E.A. 1941. Journal of Bacteriology 42:757-790. Type strain: ATCC 8368 
Description: Bergey 8.

C. pilosum Yanagawa and Honda 1978

Yanagawa, R. and E. Honda. 1978. International Journal of Systematic Bacteriology 28:209-216. Type strain: ATCC 29592

Description: Yanagawa, R. and E. Honda. 1978. Ibid.

C. poinsettiae (Starr and Pirone 1942) Burkholder 1948

Starr, M.P. and P.P. Pirone. 1942. Phytopathology 32:1076-1081; Burkholder, W.H. 1948 in Breed, R.S., E.G.D. Murray and A.P. Hitchens (eds). Bergey's Manual of Determinative Bacteriology, 6th ed. The Williams and Wilkins Co., Baltimore. pp. 381-408. Type strain: ATCC 9682

Description: Bergey 8.

C. pseudodiphtheriticum Lehmann and Neumann 1896

Lehmann, K.B. and R. Neumann. 1896. Atlas und Grundriss der Bakteriologie und Lehrbuch der speziellen bakteriologischen Diagnostik. 1st ed. J.F. Lehmann, Munchen. Type strain: ATCC 10700

Description: Bergey 8.

C. pseudotuberculosis (Buchanan 1911) Eberson 1918

Buchanan, R.E. 1911. Veterinary Bacteriology. W.B. Saunders Co., Philadelphia; Eberson, F. 1918. Journal of Infectious Diseases 23:1-42. Type strain: ATCC 19410

Description: Bergey 8.

C. pyogenes (Glage 1903) Eberson 1918

Glage, F. 1903. Zeitschrift fur Fleisch und Milchhygiene 13:166-175; Eberson, F. 1918. Journal of Infectious Diseases 23:142. Type strain: ATCC 19411

Description: Bergey 8.

C. rathayi (Smith 1913) Dowson 1942

Smith, E.F. 1913. Science (Washington) 38:926; Dowson, W.J. 1942. Transactions of the British Mycological Society 25:311314. Type strain: NCPPB 2980

Description: Dye, D.W. and W.J. Kemp. 1977. New Zealand Journal of Agricultural Research 20:563-582.

C. renale (Migula 1900) Ernst 1906 Migula, W. 1900. System der Bakterien, Vol. 2. Gustav Fischer, Jena; Ernst, W.
1906. Zentralblatt fur Bakteriologie, Parasitenkunde, Infektionskrankheiten und Hygiene. Abteilung I. 40:79-91. Type strain: ATCC 19412

Description: Bergey 8.

C. sepedonicum (Spieckermann and Kotthoff 1914) Skaptason and Burkholder 1942

Spieckermann, A. and P. Kotthoff. 1914. Landwirtschaftliche Jahrbucher Berlin 46: 659-732; Skaptason, J.B. and W.H. Burkholder. 1942. Phytopathology 32:439. 441. Type strain: ATCC 33113

Description: Bergey 8.

C. striatum (Chester 1901) Eberson 1918

Chester, F.D. 1901. A manual of determinative bacteriology. The Macmillan Co., New York. pp. 1-401; Eberson, F. 1918. Journal of Infectious Diseases 23:1-42. Type strain: ATCC 6940

Description: Bergey 8.

C. xerosis Lehmann and Neumann 1899

Lehmann, K.B. and R. Neumann. 1899. Lehmann's Medizin, Handatlanten X. Atlas und Grundriss der Bakteriologie und Lehrbuch der speziellen bakteriologischen Diagnostik. 2. Auflage. 2:1-497. Type strain: ATCC 373

Description: Bergey 8.

Cowdria Moshkovski 1947

Moshkovski, S.D. 1947. Science (Washington) 106:62. Type species: $C$. ruminantium (Cowdry 1925) Moshkovski 1947

Description: Bergey 8.

C. ruminantium (Cowdry 1925) Moshkovski 1947

Cowdry, E.V. 1925. Journal of Experimental Medicine 42:231-252; Moshkovski, S.D. 1947. Science (Washington) 106:62. Type strain: no culture isolated. Description: Bergey 8.

Coxiella (Philip 1943) Philip 1948

Philip, C.B. 1943. American Journal of Hygiene 37:301-309; Philip, C.B. 1948. Public Health Report 63:58. Type species: C. burnetii (Derrick 1939) Philip 1948

Description: Bergey 8.

C. burnetii (Derrick 1939) Philip 1948

Derrick, E.H. 1939. Medical Journal of Australia 1:14; Philip, C.B. 1948. Public Health Report 63:58. Type strain: ATCC 
VR 615

Description: Bergey 8.

\section{Crenothrix Cohn 1870}

Cohn, F. 1870. Beitrage zur Biologie der Pflanzen 1:108-131. Type species: $C$. polyspora Cohn 1870

Description: Bergey 8.

C. polyspora Cohn 1870

Cohn, F. 1870. Beitrage zur Biologie der Pflanzen 1:108-131. Type strain: no culture isolated.

Description: Bergey 8.

Cristispira Gross 1910

Gross, J. 1910. Mitteilungen aus der Zoologischen Station zu Neapel 20:41-93.

Type species: C. pectinis Gross 1910

Description: Bergey 8.

C. pectinis Gross 1910

Gross, J. 1910. Mitteilungen aus der Zoologischen Station zu Neapel 20:41-93.

Type strain: no culture isolated.

Description: Bergey 8.

Curtobacterium Yamada and Komagata 1972

Yamada, K. and K. Komagata. 1972. Journal of General and Applied Microbiology 18:417-431. Type species: $C$. citreum (Komagata and lizuka 1964) Yamada and Komagata 1972

Description: Yamada, K. and K. Komagata. 1972. Ibid.

C. albidum (Komagata and Iizuka 1964) Yamada and Komagata 1972

Komagata, K. and H. Iizuka. 1964. Journal of the Agricultural Chemical Society of Japan 38:496-502; Yamada, K. and K. Komagata. 1972. Journal of General and Applied Microbiology 18: 417-431. Type strain: ATCC 15831

Description: Yamada, K. and K. Komagata. 1962. Ibid.

C. citreum (Komagata and Iizuka 1964) Yamada and Komagata 1972

Komagata, K. and H. Iizuka. 1964. Journal of the Agricultural Chemical Society of Japan 38:496-502; Yamada, K. and K. Komagata. 1972. Journal of General and Applied Microbiology 18: 417-431. Type strain: ATCC 15828

Description: Yamada, K. and K. Komagata. 1972. Ibid.
C. luteum (Komagata and Iizuka 1964) Yamada and Komagata 1972

Komagata, K. and H. lizuka. 1964. Journal of the Agricultural Chemical Society of Japan 38:496-502; Yamada, K. and K. Komagata. 1972. Journal of General and Applied Microbiology 18: 417-431. Type strain: IAM 1623

Description: Yamada, K. and K. Komagata. 1972. Ibid.

C. pusillum (Iizuka and Komagata 1965) Yamada and Komagata 1972

Iizuka, H. and K. Komagata. 1965. Journal of General and Applied Microbiology 11:1-14; Yamada, K. and K. Komagata. 1972. Journal of General and Applied Microbiology 18:417-431. Type strain: ATCC 19096

Description: Yamada, K. amd K. Komagata. 1972. Ibid.

C. saperdae (Lysenko 1959) Yamada and Komagata 1972

Lysenko, O. 1959. Journal of Insect Pathology 1:34-42; Yamada, K. and K. Komagata. 1972. Journal of General and Applied Microbiology 18:417-431. Type strain: ATCC 19272

Description: Yamada, K. and K. Komagata. 1972. Ibid.

C. testaceum (Komagata and Iizuka 1964) Yamada and Komagata 1972

Komagata, K. and H. lizuka. 1964. Journal of the Agricultural Chemical Society of Japan 38:496-502; Yamada, K. and K. Komagata. 1972. Journal of General and Applied Microbiology 18: 417-431. Type strain: ATCC 15829

Description: Yamada, K. and K. Komagata. 1972. Ibid.

\section{Cystobacter Schroeter 1886}

Schroeter, J. 1885-1889 in Cohn, F. Kryptogamenflora von Schlesien. Band 3, Heft 3, Pilze J.U. Kern's Verlag, Breslau. pp. 1-814. Type species: $C$. fuscus Schroeter 1886

Description: Bergey 8 .

C. ferrugineus (Krzemieniewska and Krzemieniewski 1927) McCurdy 1970

Krzemieniewska, $\mathrm{H}$. and S. Krzemieniewski. 1927. Acta Societatis Botanicorum Poloniae 5:79-98; McCurdy, H.D. 1970. International Journal of Systematic Bac- 
teriology 20:283-296. Type strain: Windsor M-203

Description: Bergey 8 .

C. fuscus Schroeter 1886

Schroeter, J. 1885-1889 in Cohn, F. Kryptogamenflora von Schlesien. Band 3, Heft 3, Pilze J.U. Kern's Verlag, Breslau. pp. 1-814. Type strain: ATCC 25194

Description: Bergey 8.

C. minus (Krzemieniewska and Krzemieniewski 1926) McCurdy 1970

Krzemieniewska, $H$. and $S$. Krzemieniewski. 1926. Acta Societatis Botanicorum Poloniae 4:1-54; McCurdy, H.D. 1970. International Journal of Systematic Bacteriology 20:283-296. Type strain: Windsor M-307

Description: Bergey 8 .

Cytophaga Winogradsky 1929

Winogradsky, S. 1929. Annales de l'Institut Pasteur (Paris) 43:549-633. Type species: C. hutchinsonii Winogradsky 1929

Description: Bergey 8 .

C. aquatilis Strohl and Tait 1978

Strohl, W.R. and L.R. Tait. 1978. International Journal of Systematic Bacteriology 28:293-303. Type strain: ATCC 29551

Description: Strohl, W.R. and L.R. Tait. 1978. Ibid.

C. fermentans Bachmann 1955

Bachmann, B.J. 1955. Journal of General Microbiology 13:541-551. Type strain: ATCC 19072

Description: Bergey 8.

C. flevensis van der Meulen, Harder and Veldkamp 1974

van der Meulen, H.J., W. Harder and H. Veldkamp. 1974. Antonie van Leeuwenhoek Journal of Microbiology and Serology 40:329-346. Type strain: ATCC 27944

Description: van der Meulen, H.J., W. Harder and H. Veldkamp. 1974. Ibid.

C. hutchinsonii Winogradsky 1929

Winogradsky, S. 1929. Annales de l'Institut Pasteur (Paris) 43:549-633. Type strain: NCIB 9469

Description: Bergey 8 .

C. johnsonae Stanier 1947

Stanier, R.Y. 1947. Journal of Bacteriology 53:297-315. Type strain:
ATCC 17061

Description: Bergey 8 .

C. latercula Lewin 1969

Lewin, R.A. 1969. Journal of General Microbiology 58:189-206. Type strain: ATCC 23177

Description: Lewin, R.A. 1969. Ibid.

C. lytica Lewin 1969

Lewin, R.A. 1969. Journal of General Microbiology 58:189-206. Type .strain: ATCC 23178

Description: Lewin, R.A. 1969. Ibid.

C. salmonicolor Veldkamp 1961

Veldkamp, H. 1961. Journal of General Microbiology 26:331-342. Type strain: ATCC 19041

Description: Veldkamp, H. 1961. Ibid.

Dactylosporangium Thiemann, Pagani and Beretta 1967

Thiemann, J.E., H. Pagani and G. Beretta. 1967. Archiv fur Mikrobiologie 58:42-52. Type species: D. aurantiacum Thiemann, Pagani and Beretta 1967

Description: Bergey 8.

D. aurantiacum Thiemann, Pagani and Beretta 1967

Thiemann, J.E., H. Pagani and G. Beretta. 1967. Archiv fur Mikrobiologie 58:42-52. Type strain: ATCC 23491

Description: Bergey 8 .

D. thailandense Thiemann, Pagani and Beretta 1967

Thiemann, J.E., H. Pagani and G. Beretta. 1967. Archiv fur Mikrobiologie 58:42-52. Type strain: ATCC 23490

Description: Bergey 8.

Dermatophilus (Van Saceghem 1915) Gordon 1964

Van Saceghem, R. 1915. Bulletin de la Societe de Pathologie Exotique 8:354-359; Gordon, M.A. 1964. Journal of Bacteriology 88:509-522. Type species: $D$. congolensis (Van Saceghem 1915) Gordon 1964 Description: Bergey 8.

D. congolensis (Van Saceghem 1915) Gordon 1964

Van Saceghem, R. 1915. Bulletin de la Societe de Pathologie Exotique 8:354-359; Gordon, M.A. 1964. Journal of Bacteriology 88:509-522. Type strain: ATCC 14637 
Description: Bergey 8 .

Derxia Jensen, Petersen, De and Bhattacharya 1960

Jensen, H.L., E.J. Petersen, P.K. De and R. Bhattacharya. 1960. Archiv fur Mikrobiologie 36:182-195. Type species: D. gummosa Jensen, Petersen, De and Bhattacharya 1960

Description: Bergey 8.

D. gummosa Jensen, Petersen, De and Bhattacharya 1960

Jensen, H.L., E.J. Petersen, P.K. De and R. Bhattacharya. 1960. Archiv fur Mikrobiologie 36:182-195. Type strain: ATCC 15994

Description: Thompson, J.P. and V.B.D. Skerman. 1979. Azotobacteraceae - the taxonomy and ecology of the aerobic nitrogen-fixing bacteria. Academic Press, London. pp. 310-313.

Desulfomonas Moore, Johnson and Holdeman 1976

Moore, W.E.C., J.L. Johnson and L.V. Holdeman. 1976. International Journal of Systematic Bacteriology 26:238-252. Type species: D. pigra Moore, Johnson and Holdeman 1976

Description: Moore, W.E.C., J.L. Johnson and L.V. Holdeman. 1976. Ibid.

D. pigra Moore, Johnson and Holdeman 1976

Moore, W.E.C., J.L. Johnson and L.V. Holdeman. 1976. International Journal of Systematic Bacteriology 26:238-252. Type strain: ATCC 29098

Description: Moore, W.E.C., J.L. Johnson and L.V. Holdeman. 1976. Ibid.

Desulfotomaculum Campbell and Postgate 1965 Campbell, L.L. and J.R. Postgate. 1965. Bacteriological Reviews 29:359-363. Type species: $D$. nigrificans (Werkman and Weaver 1927) Campbell and Postgate 1965

Description: Bergey 8.

D. acetoxidans Widdel and Pfennig 1977

Widdel, F. and N. Pfennig. 1977 in International Journal of Systematic Bacteriology 27:306; Effective publication Widdel, F. and N. Pfennig. 1977. Archives of Microbiology 112:119-122. Type strain: DSM 771
Description: Widdel, F. and N. Pfennig. 1977. Ibid.

D. nigrificans (Werkman and Weaver 1927) Campbell and Postgate 1965

Werkman, C.H. and H.J. Weaver. 1927. Iowa State Journal of Science 2:57-67; Campbell, L.L. and J.R. Postgate. 1965. Bacteriological Reviews 29:359-363. Type strain: ATCC 19998

Description: Bergey 8.

D. orientis Campbell and Postgate 1965 Campbell, L.L. and J.R. Postgate. 1965. Bacteriological Reviews 29:359-363. Type strain: ATCC 19365

Description: Bergey 8 .

D. ruminis Campbell and Postgate 1965

Campbell, L.L. and J.R. Postgate. 1965. Bacteriological Reviews 29:359-363. Type strain: ATCC 23193

Description: Bergey 8.

Desulfovibrio Kluyver and van Niel 1936

Kluyver, A.J. and B.C. van Niel. 1936. Zentralblatt fur Bakteriologie, Parasitenkunde, Infektionskrankheiten und Hygiene. Abteilung II. 94:369-403. Type species: $D$. desulfuricans (Beijerinck 1895) Kluyver and van Niel 1936

Description: Bergey 8.

D. africanus Campbell, Kasprzycki and Postgate 1966

Campbell, L.L., M.A. Kasprzycki and J.R. Postgate. 1966. Journal of Bacteriology 92:1122-1127. Type strain: NCIB 8401

Description: Campbell, L.L., M.A. Kasprzycki and J.R. Postgate. 1966. Ibid.

D. desulfuricans (Beijerinck 1895) Kluyver and van Niel 1936

Beijerinck, M.W. 1895. Zentralblatt fur Bakteriologie, Parasitenkunde, Infektionskrankheiten und Hygiene. Abteilung I. 1: 104-114; Kluyver, A.J. and C.B. van Niel. 1936. Zentralblatt fur Bakteriologie, Parasitenkunde, Infektionskrankheiten und $\mathrm{Hy}$ giene. Abteilung II. 94:369-403. Type strain: NCIB 8307

Description: Bergey 8.

D. desulfuricans subsp. aestuarii Postgate and Campbell 1966

Postgate, J.R. and L.L. Campbell. 1966. Bacteriological Reviews 30:732-738. Type strain: NCIB 9335 
Description: Bergey 8.

D. desulfuricans subsp. desulfuricans (Beijerinck 1895) Kluyver and van Niel 1936

Beijerinck, M.W. 1895. Zentralblatt fur Bakteriologie, Parasitenkunde, Infektionskrankheiten und Hygiene. Abteilung I. 1:104-114; Kluyver, A.J. and C.B. van Niel. 1936. Zentralblatt fur Bakteriologie, Parasitenkunde, Infektionskrankheiten und Hygiene. Abteilung II. 94:369-403. Type strain: NCIB 8307

Description: Bergey 8.

D. gigas Le Gall 1963

Le Gall, J. 1963. Journal of Bacteriology 86:1120. Type strain: NCIB 9332

Description: Le Gall, J. 1963. Ibid.

D. salexigens Postgate and Campbell 1966

Postgate, J.R. and L.L. Campbell. 1966. Bacteriological Reviews 30:732-738. Type strain: ATCC 14822

Description: Bergey 8.

D. thermophilus Rozanova and Khudyakova 1974

Rozanova, E.P. and A.I. Khudyakova. 1974. Microbiology 43:908-912. Type strain: VKM V-1128

Description: Rozanova, E.P. and A.I. Khudyakova. 1974. Ibid.

D. vulgaris Postgate and Campbell 1966

Postgate, J.R. and L.L. Campbell. 1966.

Bacteriological Reviews 30:732-738. Type strain: DSM 644

Description: Bergey 8.

D. vulgaris subsp. oxamicus Postgate and Campbell 1966

Postgate, J.R. and L.L. Campbell. 1966. Bacteriological Reviews 30:732-738. Type strain: NCIB 9442

Description: Bergey 8.

D. vulgaris subsp. vulgaris Postgate and Campbell 1966

Postgate, J.R. and L.L. Campbell. 1966. Bacteriological Reviews 30:732-738. Type strain: DSM 644

Description: Bergey 8.

\section{Desulfuromonas Pfennig and Biebl 1977}

Pfennig, N. and H. Biebl. 1977 in International Journal of Systematic Bacteriology 27:306; Effective publication
Pfennig, N. and H. Biebl. 1976. Archives of Microbiology 110:1-10. Type species: D. acetoxidans Pfennig and Biebl 1977

Description: Pfennig, N. and H. Biebl. 1976. Ibid.

D. acetoxidans Pfennig and Biebl 1977

Pfennig, N. and H. Biebl. 1977 in International Journal of Systematic Bacteriology 27:306; Effective publication Pfennig, N. and H. Biebl. 1976. Archives of Microbiology 110:1-10. Type strain: DSM 684

Description: Pfennig, N. and H. Biebl. 1976. Ibid.

\section{Ectothiorhodospira Pelsh 1936}

Pelsh, A.O. 1936. Trudy Solyanoi Laboratorii Vsesoyuznogo Instituta Metallurgii NISNKT. Izdatelstvo Akademya Nauk SSSR, Moscow

eningrad 5: 49-126. Type species: $E$. mobilis Pelsh 1936

Description: Bergey 8.

E. halochloris Imhoff and Truper 1979

Imhoff, J.F, and H.G. Truper. 1979 in International Journal of Systematic Bacteriology 29:79-80; Effective publication Imhoff, J.F. and H.G. Truper. 1977. Archives of Microbiology 114:114-121. Type strain: DSM 1059

Description: Imhoff, J.F. and H.G. Truper. 1977. Ibid.

E. halophila Raymond and Sistrom 1969

Raymond, J.C. and W.R. Sistrom. 1969. Archiv fur Mikrobiologie 69:121-126. Type strain: DSM 244

Description: Bergey 8.

E. mobilis Pelsh 1936

Pelsh, A.D. 1936. Trudy Solyanoi Laboratorii. Vsesoyuznogo Instituta Metallurgii NISNKT. Izdatelstvo Akademya Nauk SSSR, Moscow

eningrad 5:49-126. Type strain: DSM 237

Description: Bergey 8.

E. shaposhnikovii Cherni, Soloveva, Fedorova and Kondrateva 1969

Cherni, N.E., J.V. Soloveva, V.D. Fedorova and E.N. Kondrateva. 1969. Mikrobiologiya 38:479-484. Type strain: DSM 243 
Description: Bergey 8.

Edwardsiella Ewing and McWhorter 1965

Ewing, W.H. and A.C. McWhorter. 1965 in Ewing, W.H., A.C. McWhorter, M.R. Escobar and A.H. Lubin. International Bulletin of Bacteriological Nomenclature and Taxonomy 15:33-38. Type species: $E$. tarda Ewing and McWhorter 1965

Description: Bergey 8.

E. anguillimortifera (Hoshina 1962) Sakazaki and Tamura 1975

Hoshina, T. 1962. Bulletin of the Society of Scientific Fisheries (Japan) 28:162; Sakazaki, R. and K. Tamura. 1975. International Journal of Systematic Bacteriology 25:219-220. Type strain: ATCC 15947

Description: Sakazaki, R. and K. Tamura. 1975. Ibid.

E. tarda Ewing and McWhorter 1965

Ewing, W.H. and A.C. McWhorter. 1965 in Ewing, W.H., A.C. McWhorter, M.R. Escobar and A.H. Lubin. International Bulletin of Bacteriological Nomenclature and Taxonomy 15:33-38. Type strain: ATCC 15947

Description: Ewing, W.H., A.C. McWhorter, M.R. Escobar and A.H. Lubin. 1965. Ibid.

Ehrlichia Moshkovski 1945

Moshkovski, S.D. 1945. Advances in Modern Biology (Moscow) 19:1-44. Type species: E. canis (Donatien and Lestoquard 1935) Moshkovski 1945

Description: Bergey 8.

E. canis (Donatien and Lestoquard 1935) Moshkovski 1945

Donatien, A. and F. Lestoquard. 1935. Bulletin de la Societe de Pathologie Exotique 28:418-419; Moshkovski, S.D. 1945. Advances in Modern Biology (Moscow) 19:1-44. Type strain: no culture isolated.

Description: Bergey 8.

E. phagocytophila (Foggie 1949) Philip 1962

Foggie, A. 1949. Journal of General Microbiology 3:5-6; Philip, C.B. 1962. Report 2nd Meeting FAOIE Expert Panel on Tick-borne Diseases of livestock, Cairo. United Nations, Rome 1962. pp. 41-43. Type strain: no culture isolated. Description: Bergey 8.

Eikenella Jackson and Goodman 1972 Jackson, F.L. and Y.E. Goodman. 1972. International Journal of Systematic Bacteriology 22:73-77. Type species: $E$. corrodens (Eiken 1958) Jackson and Goodman 1972

Description: Jackson, F.L. and Y.E. Goodman. 1972. Ibid.

E. corrodens (Eiken 1958) Jackson and Goodman 1972

Eiken, M. 1958. Acta Pathologica et Microbiologica Scandinavica 43:404-416; Jackson, F.L. and Y.E. Goodman. 1972. International Journal of Systematic Bacteriology 22:73-77. Type strain: ATCC 23834

Description: Bergey 8.

Elytrosporangium Falcao de Morais, Batista and Massa 1966

Falcao de Morais, J.O., A.C. Batista and D.M.G. Massa. 1966. Mycopathologia et Mycologia Applicata 30:161-171. Type species: E. brasiliensis Falcao de Morais, Batista and Massa 1966

Description: Falcao de Morais, J.O., C. Batista and D.M.G. Massa. 1966. Ibid.

E. brasiliensis Falcao de Morais, Batista and Massa 1966

Falcao de Morais, J.O., C. Batista and D.M.G. Massa. 1966. Mycopathologia et Mycologia Applicata 30:161-171. Type strain: ATCC 23727

Description: Falcao de Morais, J.O., C. Batista and D.M.G. Massa. 1966. Ibid.

E. carpinense Falcao de Morais, Oliveira da Silva and Machado 1971

Falcao de Morais, J.O., J. Oliveira da Silva and C. Machado. 1971. Revista Microbiologia Brazil 2:203-206. Type strain: 70-6-2 (Lab. Microbiol. Inst. Biociencias Univer. Federal Pernambucco, Recife, Brazil)

Description: Falcao de Morais, J.O., J. Oliveira da Silva and C. Machado. 1971. Ibid. 
E. spirale Falcao de Morais 1970

Falcao de Morais, J.O. 1970. Revista Microbiologia Brazil 1:79-84. Type strain: ATCC 25664

Description: Falcao de Morais, J.O. 1970. Ibid.

Enterobacter Hormaeche and Edwards 1960 Hormaeche, E. and P.R. Edwards. 1960. International Bulletin of Bacteriological Nomenclature and Taxonomy 10:71-74. Type species: E. cloacae (Jordan 1890) Hormaeche and Edwards 1960 Description: Bergey 8.

E. aerogenes Hormaeche and Edwards 1960 Hormaeche, E. and P.R. Edwards. 1960. International Bulletin of Bacteriological Nomenclature and Taxonomy 10:71-74. Type strain: ATCC 13048

Description: Hormaeche, E. and P.R. Edwards. 1960. Ibid.

E. agglomerans Ewing and Fife 1972

Ewing, W.H. and M.A. Fife. 1972. International Journal of Systematic Bacteriology 22:4-11. Type strain: ATCC 27155

Description: Ewing, W.H. and M.A. Fife. 1972. Ibid.

E. cloacae (Jordon 1890) Hormaeche and Edwards 1960

Jordan, E.O. 1890 in Sedgewick, W.T. Report of the Massachusettes Board of Public Health, pp. 821-844; Hormaeche, E. and P.R. Edwards. 1960. International Bulletin of Bacteriological Nomenclature and Taxonomy 10:71-74. Type strain: ATCC 13047

Description: Hormaeche, E. and P.R. Edwards. 1960. Ibid.

\section{Eperythrozoon Schilling 1928}

Schilling, V. 1928. Klinische Wochenschrift 7:1854-1855. Type species: $E$. coccoides Schilling 1928

Description: Bergey 8.
E. coccoides Schilling 1928

Schilling, V. 1928. Klinische Wochenschrift 7:1854-1855. Type strain: no culture isolated.

Description: Bergey 8 .

E. ovis Neitz, Alexander and du Toit 1934 Neitz, W.O., R.A. Alexander and P.J. du Toit. 1934. Onderstepoort Journal of Veterinary Science 3:263-274. Type strain: no culture isolated.

Description: Bergey 8.

E. parvum Splitter 1950

Splitter, E.J. 1950. Science (Washington) 111:513-514. Type strain: no culture isolated.

Description: Bergey 8.

E. suis Splitter 1950

Splitter, E.J. 1950. Science (Washington) 111:513-514. Type strain: no culture isolated.

Description: Bergey 8.

E. wenyonii Adler and Ellenbogen 1934

Adler, S. and V. Ellenbogen. 1934. Journal of Comparative Pathology 47:220221. Type strain: no culture isolated.

Description: Bergey 8.

Erwinia Winslow, Broadhurst, Buchanan, Krumwiede, Rogers and Smith 1920

Winslow, C.E.A., J. Broadhurst, R.E. Buchanan, C. Krumwiede Jr., L.A. Rogers and G.H. Smith. 1920. Journal of Bacteriology 5:191-229. Type species: $E$. amylovora (Burrill 1882) Winslow, Broadhurst, Buchanan, Krumwiede, Rogers and Smith 1920

Description: Bergey 8.

E. amylovora (Burrill 1882) Winslow, Broadhurst, Buchanan, Krumwiede, Rogers and Smith 1920

Burrill, T.J. 1882. Illinois Industrial University 11th Report pp. 93-157; Winslow, C.E.A., J. Broadhurst, R.E. Buchanan, C. Krumwiede Jr., L.A. Rogers and G.H. Smith. 1920. Journal of Bacteriology 5:191-229. Type strain: ATCC 15580

Description: Bergey 8.

E. ananas Serrano 1928

Serrano, F.B. 1928. Philippine Journal of Science 36:271-305. Type strain: NCPPB 1846

Description: Bergey 8 . 
E. cancerogena Urosevic 1966

Urosevic, B. 1966. Lesnicky casopsis 12: 493-505. Type strain: NCPPB 2176

Description: Urosevic, B. 1966. Ibid.

E. carnegieana Standring 1942 (See also Pectobacterium carnegieana)

Standring, E.T. 1942 in Lightle, P.C., E.T. Standring and J.G. Brown. Phytopathology 32:303-313. Type strain: NCPPB 439

Description: Bergey 8 .

E. carotovora (Jones 1901) Bergey, Harrison, Breed, Hammer and Huntoon 1923 (See also Pectobacterium carotovorum)

Jones, L.R. 1901. Zentralblatt fur Bakteriologie, Parasitenkunde, Infektionskrankheiten und Hygiene. Abteilung II. 7:1221; Bergey, D.H., F.C. Harrison, R.S. Breed, B.W. Hammer and F.M. Huntoon. 1923. Bergey's Manual of Determinative Bacteriology, 1st ed. The Williams and Wilkins Co., Baltimore. pp. 1-442. Type strain: ATCC 15713

Description: Bergey 8.

E. carotovora subsp. atroseptica (van Hall 1902) Dye 1969

van Hall, C.J.J. 1902. Inaugural Dissertation Amsterdam; Dye, D.W. 1969. New Zealand Journal of Science 12:8197. Type strain: NCPPB 549

Description: Bergey 8.

E. carotovora subsp. carotovora (Jones 1901) Bergey, Harrison, Breed, Hammer and Huntoon 1923

Jones, L.R. 1901. Zentralblatt fur Bakteriologie, Parasitenkunde, Infektionskrankheiten und Hygiene. Abteilung II. 7:1221; Bergey, D.H., F.C. Harrison, R.S. Breed, B.W. Hammer and F.M. Huntoon. 1923. Bergey's Manual of Determinative Bacteriology, lst ed. The Williams and Wilkins Co., Baltimore. pp. 1-442. Type strain: ATCC 15713

Description: Bergey 8.

E. chrysanthemi Burkholder, McFadden and Dimock 1953 (See also Pectobacterium chrysanthemi)

Burkholder, W.H., L.A. McFadden and A.V. Dimock. 1953. Phytopathology 43: 522-526. Type strain: ATCC 11663 Description: Bergey 8.

E. cypripedii (Hori 1911) Bergey, Harrison, Breed, Hammer and Huntoon 1923 (See also Pectobacterium cypripedii)

Hori, S. 1911. Zentralblatt fur Bakteriologie, Parasitenkunde, Infektionskrankheiten und Hygiene. Abteilung II. 31:85-92; Bergey, D.H., F.C. Harrison, R.S. Breed, B.W. Hammer and F.M. Huntoon. 1923. Bergey's Manual of Determinative Bacteriology, 1st ed. The Williams and Wilkins Co., Baltimore. pp. 1-442. Type strain: PDDCC 1591

Description: Bergey 8.

E. dissolvens (Rosen 1922) Burkholder 1948

Rosen, H.R. 1922. Phytopathology 12: 497-499; Burkholder, W.H. 1948 in Breed, R.S., E.G.D. Murray and A.P. Hitchens (eds). Bergey's Manual of Determinative Bacteriology, 6th ed. The Williams and Wilkins Co., Baltimore. pp. 463-478. Type strain: ATCC 23373

Description: Dye, D.W. 1969. New Zealand Journal of Science 12:833-839.

E. herbicola (Lohnis 1911) Dye 1964

Lohnis, F. 1911. Landwirtschaftlichbakteriologisches Praktikum. Gebruder Borntraeger, Berlin. pp. 1-156; Dye, D.W. 1964. New Zealand Journal of Science 7: 261-269. Type strain: NCPPB 2971

Description: Bergey 8.

E. mallotivora Goto 1976

Goto, M. 1976. International Journal of Systematic Bacteriology 26:467-473. Type strain: ATCC 29573

Description: Goto, M. 1976. Ibid.

E. milletiae (Kawakami and Yoshida 1920) Magrou 1937

Kawakami, K. and S. Yoshida. 1920. Botanical Magazine Tokyo 34:110-115; Magrou, J. 1937 in Hauduroy, P., G. Ehringer, A. Urbain, G. Guillot and J. Magrou (eds). Dictionnaire des bacteries pathogenes. Masson et Cie, Paris. p. 60. Type strain: NCPPB 2519

Description: Dye, D.W. 1969. New Zealand Journal of Science 12:223-236.

E. nigrifluens Wilson, Starr and Berger 1957 Wilson, E.E., M.P. Starr and J.A. Berger. 1957. Phytopathology 47:669-673. Type strain: ATCC 13028

Description: Wilson, E.E., M.P. Starr and J.A. Berger. 1957. Ibid.

E. nimipressuralis (Carter 1945) Dye 1969

Carter, J.C. 1945. Illinois Natural History Survey Bulletin 23:407-448; Dye, D.W. 
1969. New Zealand Journal of Science 12:833-839. Type strain: ATCC 9912

Description: Dye, D.W. 1969. Ibid.

E. paradisiaca Fernandez-Borrero and LopezDuque 1970

Fernandez-Borrero, $O$. and S. LopezDuque. 1970. Cenicafe 21:3-44. Type strain: NCPPB 2511

Description: Fernandez-Borrero, O. and S. Lopez-Duque. 1970. Ibid.

E. quercina Hildebrand and Schroth 1967

Hildebrand, D.C. and M.N. Schroth. 1967. Phytopathology 57:250-253. Type strain: ATCC 29281

Description: Hildebrand, D.C. and M.N. Schroth. 1967. Ibid.

E. rhapontici (Millard 1924) Burkholder 1948 (See also Pectobacterium rhapontici)

Millard, W.A. 1924. Bulletin of the University of Leeds and the Yorkshire Council for Agricultural Education 134:128; Burkholder, W.H. 1948 in Breed, R.S., E.G.D. Murray and A.P. Hitchens (eds). Bergey's Manual of Determinative Bacteriology, 6th ed. The Williams and Wilkins Co., Baltimore. pp. 463-478. Type strain: ATCC 29283

Description: Bergey 8.

E. rubrifaciens Wilson, Zeitoun and Fredrickson 1967

Wilson, E.E., F.M. Zeitoun and D.L. Fredrickson. 1967. Phytopathology 57: 618-621. Type strain: ATCC 29291

Description: Wilson, E.E., F.M. Zeitoun and D.L. Fredrickson. 1967. Ibid.

E. salicis (Day 1924) Chester 1939

Day, W.R. 1924. Oxford Forestry Memoirs 3:1-30; Chester, F.D. 1939 in Bergey, R.S., E.G.D. Murray and A.P. Hitchens (eds). Bergey's Manual of Determinative Bacteriology, 5th ed. The Williams and Wilkins Co., Baltimore. pp. 404-420. Type strain: ATCC 15712

Description: Bergey 8.

E. stewartii (Smith 1898) Dye 1963

Smith, E.F. 1898. Proceedings of the American Association for the Advancement of Science 47:422-426; Dye, D.W. 1963. New Zealand Journal of Science 6:495-506. Type strain: ATCC 8199

Description: Bergey 8.

E. tracheiphila (Smith 1895) Bergey, Harrison,
Breed, Hammer and Huntoon 1923

Smith, E.F. 1895. Zentralblatt fur Bakteriologie, Parasitenkunde, Infektionskrankheiten und Hygiene. Abteilung II. 1:364-373; Bergey, D.H., F.C. Harrison, R.S. Breed, B.W. Hammer and F.M. Huntoon. 1923. Bergey's Manual of Determinative Bacteriology, 1st ed. The Williams and Wilkins Co., Baltimore. pp. 1-442. Type strain: NCPPB 2452

Description: Bergey 8.

E. uredovora (Pon, Townsend, Wessman, Schmitt and Kingsolver 1954) Dye 1963

Pon, D.S., C.E. Townsend, G.E. Wessman, C.G. Schmitt and C.H. Kingsolver. 1954. Phytopathology 44:707-710; Dye, D.W. 1963. New Zealand Journal of Science 6:146-149. Type strain: ATCC 19321

Description: Bergey 8 .

Erysipelothrix Rosenbach 1909

Rosenbach, F.J. 1909. Zeitschrift fur Hygiene und Infektionskrankheiten Medizinische Mikrobiologie, Immunologie und Virologie 63:343-371. Type species: $E$. rhusiopathiae (Migula 1900) Buchanan 1918

Description: Bergey 8 .

E. rhusiopathiae (Migula 1900) Buchanan 1918 Migula, W. 1900. System der Bakterien, Vol. 2. Gustav Fischer, Jena; Buchanan, R.E. 1918. Journal of Bacteriology 3:2761. Type strain: ATCC 19414

Description: Bergey 8.

Escherichia Castellani and Chalmers 1919

Castellani, A. and A.J. Chalmers. 1919. Manual of tropical medicine, 3rd ed. Williams, Wood and Co., New York. Type species: $E$. coli (Migula 1895) Castellani and Chalmers 1919

Description: Bergey 8.

E. adecarboxylata Leclerc 1962 Leclerc, H. 1962. Annales de l'Institut Pasteur (Paris) 102:726-741. Type strain: ATCC 23216

Description: Leclerc, H. 1962. Ibid.

E. blattae Burgess, McDermott and Whiting 1973

Burgess, N.R.H., S.N. McDermott and J. Whiting. 1973. Journal of Hygiene (Cambridge) 71:I. Type strain: CDC 
9005-74

Description: Burgess, N.R.H., S.N. McDermott and J. Whiting. 1973. Ibid.

E. coli (Migula 1895) Castellani and Chalmers 1919

Migula, W. 1895 in Engler, A. and K. Prantl (eds). Die Naturlichen Pfanzenfamilien, W. Engelmann, Leipzig, Teil I, Abteilung Ia. pp. 20-30; Castellani, A. and A.J. Chalmers. 1919. Manual of tropical medicine. 3rd ed. Williams, Wood and Co., New York. Type strain: ATCC 11775

Description: Bergey 8.

\section{Eubacterium Prevot 1938}

Prevot, A.R. 1938. Annales de l'Institut Pasteur (Paris) 60:285-307. Type species: E. foedans (Klein 1908) Prevot 1938

Description: Bergey 8.

E. aerofaciens (Eggerth 1935) Prevot 1938

Eggerth, A.H. 1935. Journal of Bacteriology 30:277-299; Prevot, A.R. 1938. Annales de l'Institut Pasteur (Paris) 60: 285-307. Type strain: ATCC 25986

Description: Holdeman, L.V., E.P. Cato and W.E.C. Moore (eds). 1977. Anaerobe Laboratory Manual, 4th ed. Virginia Polytechnic Institute and State University, Blacksburg, Virginia. pp. 1-156.

E. alactolyticum (Prevot and Taffanel 1942) Holdeman and Moore 1970

Prevot, A.R. and J. Taffanel. 1942. Annales de l'Institut Pasteur (Paris) 68: 259-262; Holdeman, L.V. and W.E.C. Moore. 1970. in Cato, E.P., C.S. Cummins, L.V. Holdeman, J.L. Johnson, W.E.C. Moore, R.M. Smibert and L.DS. Smith (eds). Outline of clinical methods in anaerobic bacteriology, 2nd revision. Virginia Polytechnic Institute Anaerobe Laboratory, Blacksburg, Virginia. pp. 2330. Type strain: ATCC 23263

Description: Holdeman, L.V., E.P. Cato and W.E.C. Moore (eds). 1977. Anaerobe Laboratory Manual, 4th ed. Virginia Polytechnic Institute and State University, Blacksburg, Virginia. pp. 1-156.

E. biforme (Eggerth 1935) Prevot 1938

Eggerth, A.H. 1935. Journal of Bacteriology 30:277-299; Prevot, A.R. 1938. Annales de l'Institut Pasteur (Paris) 60: 285-307. Type strain: ATCC 27806
Description: Holdeman, L.V. and W.E.C. Moore. 1974. International Journal of Systematic Bacteriology 24:260-277.

E. budayi (Le Blaye and Guggenheim 1914) Holdeman and Moore 1970

Le Blaye, R. and H. Guggenheim. 1914. Manuel pratique de diagnostic bacteriologique et de technique appliquee a la determination des bacteries. Vigot Freres (eds). Paris. pp. 1-444; Holdeman, L.V. and W.E.C. Moore. 1970 in Cato, E.P., C.S. Cummins, L.V. Holdeman, J.L. Johnson, W.E.C. Moore, R.M. Smibert and L.DS. Smith (eds). Outline of clinical methods in anaerobic bacteriology, 2nd revision. Virginia Polytechnic Institute Anaerobe Laboratory, Blacksburg, Virginia. pp. 23-30. Type strain: ATCC 25541

Description: Holdeman, L.V., E.P. Cato and W.E.C. Moore (eds). 1977. Anaerobe Laboratory Manual, 4th ed. Virginia Polytechnic Institute and State University, Blacksburg, Virginia. pp. 1-156.

E. cellulosolvens (Bryant, Small, Bouma and Robinson 1958) Holdeman and Moore 1972

Bryant, M.P., N. Small, C. Bouma and I.M. Robinson. 1958. Journal of Bacteriology 76:529-537; Holdeman, L.V. and W.E.C. Moore. 1972 in Holdeman, L.V. and W.E.C. Moore (eds). Anaerobe Laboratory Manual. Virginia Polytechnic Institute Anaerobe Laboratory, Blacksburg, Virginia. pp. 39-47. Type strain: Bryant B348

Description: Holdeman, L.V., E.P. Cato and W.E.C. Moore (eds). 1977. Anaerobe Laboratory Manual, 4th ed. Virginia Polytechnic Institute and State University, Blacksburg, Virginia. pp. 1-156.

E. combesii (Prevot and Laplanche 1947) Holdeman and Moore 1970

Prevot, A.R. and J. Laplanche. 1947. Annales de l'Institut Pasteur (Paris) 73: 687-688; Holdeman, L.V. and W.E.C. Moore. 1970 in Cato, E.P., C.S. Cummins, L.V. Holdeman, J.L. Johnson, W.E.C. Moore, R.M. Smibert and L.DS. Smith (eds). Outline of clinical methods in anaerobic bacteriology, 2nd revision. Virginia Polytechnic Institute Anaerobe Laboratory, Blacksburg, Virginia. pp. 2330. Type strain: ATCC 25545 
Description: Holdeman, L.V., E.P. Cato and W.E.C. Moore (eds). 1977. Anaerobe Laboratory Manual, 4th ed. Virginia Polytechnic Institute and State University, Blacksburg, Virginia. pp. 1-156.

E. contortum (Prevot 1947) Holdeman, Cato and Moore 1971

Prevot, A.R. 1947. Annales de l'Institut Pasteur (Paris) 73:409-418; Holdeman, L.V., E.P. Cato and W.E.C. Moore. 1971. International Journal of Systematic Bacteriology 21:304-306. Type strain: ATCC 25540

Description: Holdeman, L.V., E.P. Cato and W.E.C. Moore (eds). 1977. Anaerobe Laboratory Manual, 4th ed. Virginia Polytechnic Institute and State University, Blacksburg, Virginia. pp. 1-156.

E. cylindroides (Rocchi 1908) Holdeman and Moore 1970

Rocchi, G. 1908. Bulletino delle Scienze Mediche (Societa di Bologna) 8:457-528; Holdeman, L.V. and W.E.C. Moore. 1970 in Cato, E.P., C.S. Cummins, L.V. Holdeman, J.L. Johnson, W.E.C. Moore, R.M. Smibert and L.DS. Smith (eds). Outline of clinical methods in anaerobic bacteriology, 2nd revision. Virginia Polytechnic Institute Anaerobe Laboratory, Blacksburg, Virginia. pp. 23-30. Type strain: ATCC 27803

Description: Holdeman, L.V., E.P. Cato and W.E.C. Moore (eds). 1977. Anaerobe Laboratory Manual, 4th ed. Virginia Polytechnic Institute and State University, Blacksburg, Virginia. pp. 1-156.

E. dolichum Moore, Johnson and Holdeman 1976

Moore, W.E.C., J.L. Johnson and L.V. Holdeman. 1976. International Journal of Systematic Bacteriology 26:238-252. Type strain: ATCC 29143

Description: Moore, W.E.C., J.L. Johnson and L.V. Holdeman. 1976. Ibid.

E. eligens Holdeman and Moore 1974

Holdeman, L.V. and W.E.C. Moore. 1974. International Journal of Systematic Bacteriology 24:260-277. Type strain: VPI C15-48

Description: Holdeman, L.V. and W.E.C. Moore. 1974. Ibid.

E. fissicatena Taylor 1972

Taylor, M.M. 1972. Journal of General
Microbiology 71:457-463. Type strain: NCIB 10446

Description: Taylor, M.M. 1972. Ibid.

E. formicigenerans Holdeman and Moore 1974

Holdeman, L.V. and W.E.C. Moore. 1974. International Journal of Systematic Bacteriology 24:260-277. Type strain: ATCC 27755

Description: Holdeman, L.V. and W.E.C. Moore. 1974. Ibid.

E. hadrum Moore, Johnson and Holdeman 1976 Moore, W.E.C., J.L. Johnson and L.V. Holdeman. 1976. International Journal of Systematic Bacteriology 26:238-252. Type strain: VPI B2-52

Description: Moore, W.E.C., J.L. Johnson and L.V. Holdeman. 1976. Ibid.

E. hallii Holdeman and Moore 1974

Holdeman, L.V. and W.E.C. Moore. 1974. International Journal of Systematic Bacteriology 24:260-277. Type strain: VPI B4-27

Description: Holdeman, L.V. and W.E.C. Moore. 1974. Ibid.

E. lentum (Eggerth 1935) Prevot 1938 Eggerth, A.H. 1935. Journal of Bacteriology 30:277-299; Prevot, A.R. 1938. Annales de l'Institut Pasteur (Paris) 60: 285-307. Type strain: ATCC 25559

Description: Holdeman, L.V., E.P. Cato and W.E.C. Moore (eds). 1977. Anaerobe Laboratory Manual, 4th ed. Virginia Polytechnic Institute and State University, Blacksburg, Virginia. pp. 1-156.

E. limosum (Eggerth 1935) Prevot 1938 Eggerth, A.H. 1935. Journal of Bacteriology 30:277-299; Prevot, A.R. 1938. Annales de l'Institut Pasteur (Paris) 60:285-307. Type strain: ATCC 8486

Description: Holdeman, L.V., E.P. Cato and W.E.C. Moore (eds). 1977. Anaerobe Laboratory Manual, 4th ed. Virginia Polytechnic Institute and State University, Blacksburg, Virginia. pp. 1-156.

E. moniliforme (Repaci 1910) Holdeman and Moore 1970

Repaci, G. 1910. Comptes Rendus des Seances de la Societe de Biologie (Paris) 68:410-412; Holdeman, L.V. and W.E.C. Moore. 1970 in Cato, E.P., C.S. Cummins, L.V. Holdeman, J.L. Johnson, W.E.C. Moore, R.M. Smibert and L.DS. Smith (eds). Outline of clinical methods 
in anaerobic bacteriology, 2nd revision. Virginia Polytechnic Institute Anaerobe Laboratory, Blacksburg, Virginia. pp. 2330. Type strain: ATCC 25546

Description: Holdeman, L.V., E.P. Cato and W.E.C. Moore (eds). 1977. Anaerobe Laboratory Manual, 4th ed. Virginia Polytechnic Institute and State University, Blacksburg, Virginia. pp. 1-156.

E. multiforme (Distaso 1911) Holdeman and Moore 1970

Distaso, A. 1911. Zentralblatt fur Bakteriologie, Parasitenkunde, Infektionskrankheiten und Hygiene. Abteilung I. 59:97103; Holdeman, L.V. and W.E.C. Moore. 1970. in Cato, E.P., C.S. Cummins, L.V. Holdeman, J.L. Johnson, W.E.C. Moore, R.M. Smibert and L.DS. Smith (eds). Outline of clinical methods in anaerobic bacteriology, 2nd revision. Virginia Polytechnic Institute Anaerobe Laboratory, Blacksburg, Virginia. pp. 23-30. Type strain: ATCC 25552

Description: Holdeman, L.V., E.P. Cato and W.E.C. Moore (eds). 1977. Anaerobe Laboratory Manual, 4th ed. Virginia Polytechnic Institute and State University, Blacksburg, Virginia. pp. 1-156.

E. nitritogenes Prevot 1940

Prevot, A.R. 1940. Comptes Rendus des Seances de la Societe de Biologie (Paris) 134:353-355. Type strain: ATCC 25547

Description: Holdeman, L.V., E.P. Cato and W.E.C. Moore (eds). 1977. Anaerobe Laboratory Manual, 4th ed. Virginia Polytechnic Institute and State University, Blacksburg, Virginia. pp. 1-156.

E. plexicaudatum Wilkins, Fulghum and Wilkins 1974

Wilkins, T.D., R.S. Fulghum and J.H. Wilkins. 1974. International Journal of Systematic Bacteriology 24:408-411. Type strain: VPI 7582

Description: Wilkins, T.D., R.S. Fulghum and J.H. Wilkins. 1974. Ibid.

E. ramulus Moore, Johnson and Holdeman 1976

Moore, W.E.C., J.L. Johnson and L.V. Holdeman. 1976. International Journal of Systematic Bacteriology 26:238-252. Type strain: ATCC 29099

Description: Moore, W.E.C., J.L. Johnson and L.V. Holdeman. 1976. Ibid.
E. rectale (Hauduroy, Ehringer, Urbain, Guillot and Magrou 1937) Prevot 1938

Hauduroy, P., G. Ehringer, A. Urbain, G. Guillot and J. Magrou. 1937. Dictionnaire des bacteries pathogenes. Masson et Cie, Paris; Prevot, A.R. 1938. Annales de l'Institut Pasteur (Paris) 60:285-307. Type strain: VPI 0989

Description: Holdeman, L.V., E.P. Cato and W.E.C. Moore (eds). 1977. Anaerobe Laboratory Manual, 4th ed. Virginia Polytechnic Institute and State University, Blacksburg, Virginia. pp. 1-156.

E. ruminantium Bryant 1959

Bryant, M.P. 1959. Bacteriological Reviews 23:125-153. Type strain: ATCC 17233

Description: Holdeman, L.V., E.P. Cato and W.E.C. Moore (eds). 1977. Anaerobe Laboratory Manual, 4th ed. Virginia Polytechnic Institute and State University, Blacksburg, Virginia. pp. 1-156.

E. saburreum (Prevot 1966) Holdeman and Moore 1970

Prevot, A.R. 1966. Manual for the classification and determination of the anaerobic bacteria. 1st American ed. transl. by V. Fredette, Lea and Febiger, Philadelphia. pp. 1-402; Holdeman, L.V. and W.E.C. Moore. 1970. In Cato, E.P., C.S. Cummins, L.V. Holdeman, J.L. Johnson, W.E.C. Moore, R.M. Smibert and L.DS. Smith (eds). Outline of clinical methods in anaerobic bacteriology, 2nd revision. Virginia Polytechnic Institute Anaerobe Laboratory, Blacksburg, Virginia. pp. 23-30. Type strain: VPI 11763

Description: Holdeman, L.V., E.P. Cato and W.E.C. Moore (eds). 1977. Anaerobe Laboratory Manual, 4th ed. Virginia Polytechnic Institute and State University, Blacksburg, Virginia. pp. 1-156.

E. siraeum Moore, Johnson and Holdeman 1976 Moore, W.E.C., J.L. Johnson and L.V. Holdeman. 1976. International Journal of Systematic Bacteriology 26:238-252. Type strain: ATCC 29066

Description: Moore, W.E.C., J.L. Johnson and L.V. Holdeman. 1976. Ibid.

E. tarantellus Udey, Young and Sallman 1977 Udey, L.R., E. Young and B. Sallman. 1977 in International Journal of Systematic Bacteriology 27:306; Effective 
publication Udey, L.R., E. Young and B. Sallman. 1977. Journal of the Fisheries Research Board of Canada 34:402-409. Type strain: ATCC 29255

Description: Udey, L.R., E. Young and B. Sallman. 1977. Ibid.

E. tenue (Bergey, Harrison, Breed, Hammer and Huntoon 1923) Holdeman and Moore 1970

Bergey, D.H., F.C. Harrison, R.S. Breed, B.W. Hammer and F.M. Huntoon. 1923. Bergey's Manual of Determinative Bacteriology, 1st ed. The Williams and Wilkins Co., Baltimore. pp. 1-442; Holdeman, L.V. and W.E.C. Moore. 1970 in Cato, E.P., C.S. Cummins, L.V. Holdeman, J.L. Johnson, W.E.C. Moore, R.M. Smibert and L.DS. Smith (eds). Outline of clinical methods in anaerobic bacteriology, 2nd revision. Virginia Polytechnic Institute Anaerobe Laboratory, Blacksburg, Virginia. pp. 23-30. Type strain: ATCC 25553

Description: Holdeman, L.V., E.P. Cato and W.E.C. Moore (eds). 1977. Anaerobe Laboratory Manual, 4th ed. Virginia Polytechnic Institute and State University, Blacksburg, Virginia. pp. 1-156.

E. tortuosum (Debono 1912) Prevot 1938

Debono, M. 1912. Zentralblatt fur Bakteriologie, Parasitenkunde, Infektionskrankheiten und Hygiene. Abteilung $I$. 62:229-234; Prevot, A.R. 1938. Annales de l'Institut Pasteur (Paris) 60:285-307. Type strain: ATCC 25548

Description: Holdeman, L.V., E.P. Cato and W.E.C. Moore (eds). 1977. Anaerobe Laboratory Manual, 4th ed. Virginia Polytechnic Institute and State University, Blacksburg, Virginia. pp. 1-156.

E. ventriosum (Tissier 1908) Prevot 1938

Tissier, H. 1908. Annales de l'Institut Pasteur (Paris) 22:189-208; Prevot, A.R. 1938. Annales de l'Institut Pasteur (Paris) 60:285-307. Type strain: ATCC 27560

Description: Holdeman, L.V., E.P. Cato and W.E.C. Moore (eds). 1977. Anaerobe Laboratory Manual, 4th ed. Virginia Polytechnic Institute and State University, Blacksburg, Virginia. pp. 1-156.

Excellospora Agre and Guzeva 1975

Agre, N.S. and L.N. Guzeva. 1975. Mikrobiologiya 44:459-463. Type species:
E. viridilutea Agre and Guzeva 1975

Description: Agre, N.S. and L.N. Guzeva. 1975. Ibid.

E. viridilutea Agre and Guzeva 1975

Agre, N.S. and L.N. Guzeva. 1975. Mikrobiologiya 44:459-463. Type strain: INMI 187

Description: Agre, N.S. and L.N. Guzeva. 1975. Ibid.

Flavobacterium Bergey, Harrison, Breed, Hammer and Huntoon 1923

Bergey, D.H., F.C. Harrison, R.S. Breed, B.W. Hammer and F.M. Huntoon. 1923. Bergey's Manual of Determinative Bacteriology, 1st ed. The Williams and Wilkins Co., Baltimore. pp. 1-442. Type species: $F$. aquatile (Frankland and Frankland 1889) Bergey, Harrison, Breed, Hammer and Huntoon 1923

Description: Bergey 8 .

F. acidificum Steinhaus 1941

Steinhaus, E.A. 1941. Journal of Bacteriology 42:757-790. Type strain: NCIB 9891

Description: Steinhaus, E.A. 1941. Ibid.

F. acidurans Millar 1973

Millar, W.N. 1973. International Journal of Systematic Bacteriology 23:142-150. Type strain: ATCC 27383

Description: Millar, W.N. 1973. Ibid.

F. aquatile (Frankland and Frankland 1889) Bergey, Harrison, Breed, Hammer and Huntoon 1923

Frankland, G.C. and P.F. Frankland. 1889. Zeitschrift fur Hygiene und Infektionskrankheiten Medizinische Mikrobiologie, Immunologie und Virologie 6:373-400; Bergey, D.H., F.C. Harrison, R.S. Breed, B.W. Hammer and F.M. Huntoon. 1923. Bergey's Manual of Determinative Bacteriology, 1st ed. The Williams and Wilkins Co., Baltimore. pp. 1-442. Type strain: ATCC 11947

Description: Weeks, O.B. 1955. Journal of Bacteriology 69:649-658.

F. balustinum Harrison 1929

Harrison, F.C. 1929. Canadian Journal of Research 1:214-239. Type strain: NCTC 11212

Description: Harrison, F.C. 1929. Ibid.

F. capsulatum Leifson 1962

Leifson, E. 1962. International Bulletin of 
Bacteriological Nomenclature and Taxonomy 12:161-170. Type strain: ATCC 14666

Description: Leifson, E. 1962. Ibid.

F. devorans (Zimmermann 1890) Bergey, Harrison, Breed, Hammer and Huntoon 1923

Zimmermann, O.E.R. 1890. 1. Reihe, Elfter Bericht der Naturwissenschaftlichen Gesellschaft Chemnitz, pp. 54-154; Bergey, D.H., F.C. Harrison, R.S. Breed, B.W. Hammer and F.M. Huntoon. 1923. Bergey's Manual of Determinative Bacteriology, 1st ed. The Williams and Wilkins Co., Baltimore. pp. 1-442. Type strain: ATCC 10829

Description: Bergey 8.

F. esteraromaticum (Omelianski 1923) Bergey, Harrison, Breed, Hammer and Huntoon 1930

Omelianski, V.L. 1923. Journal of Bacteriology 8:393-419; Bergey, D.H., F.C. Harrison, R.S. Breed, B.W. Hammer and F.M. Huntoon (eds). 1930. Bergey's Manual of Determinative Bacteriology, 3rd ed. The Williams and Wilkins Co., Baltimore. pp. 1-589. Type strain: ATCC 8091

Description: Bergey, D.H., F.C. Harrison, R.S. Breed, B.W. Hammer and F.M. Huntoon. 1930. Ibid.

F. ferrugineum Sickles and Shaw 1934

Sickles, G.M. and M. Shaw. 1934. Journal of Bacteriology 28:415-431. Type strain: ATCC 13524

Description: Sickles, G.M. and M. Shaw. 1934. Ibid.

F. halmephilium Elazari-Volcani 1940

Elazari-Volcani, B. 1940. Studies on the microflora of the Dead Sea. In Hebrew, English summary. Thesis, Hebrew University Jerusalem. Type strain: ATCC 19717

Description: Elazari-Volcani, B. 1940. Ibid.

F. heparinum Payza and Korn 1956

Payza, A.N. and E.D. Korn. 1956. Journal of Biological Chemistry 223:853858. Type strain: ATCC 13125

Description: Payza, A.N. and E.D. Korn. 1956. Ibid.

F. indoltheticum Campbell and Williams 1951

Campbell, L.L. and O.B. Williams. 1951. Journal of General Microbiology 5:894905. Type strain: ATCC 27950
Description: Campbell, L.L. and O.B. Williams. 1951. Ibid.

F. marinotypicum ZoBell and Upham 1944

ZoBell, C.E. and H.C. Upham. 1944.

Bulletin Scripps Institution of Oceanography University of California (Technical Series) 5:239-292. Type strain: ATCC 19260

Description: Zobell, C.E. and H.C. Upham. 1944. Ibid.

F. meningosepticum King 1959

King, E.O. 1959. American Journal of Clinical Pathology 31:241-247. Type strain: ATCC 13253

Description: King, E.O. 1959. Ibid.

F. oceanosedimentum Carty and Litchfield 1978 Carty, C.E. and C.D. Litchfield. 1978. International Journal of Systematic Bacteriology 28:561-566. Type strain: ATCC 31317

Description: Carty, C.E. and C.D. Litchfield. 1978. Ibid.

F. odoratum Stutzer 1929

Stutzer, M. 1929. Zentralblatt fur Bakteriologie, Parasitenkunde, Infektionskrankheiten und Hygiene. Abteilung I. 102:113. Type strain: ATCC 4651

Description: Stutzer, M. 1929. Ibid.

F. okeanokoites ZoBell and Upham 1944

ZoBell, C.E. and H.C. Upham. 1944. Bulletin Scripps Institution of Oceanography University of California (Technical Series) 5:239-292. Type strain: CCM 320

Description: Zobell, C.E. and H.C. Upham. 1944. Ibid.

F. resinovorum Delaporte and Daste 1956

Delaporte, B. and P. Daste. 1956. Compte Rendu de l'Academie des Sciences (Paris) 242:831-834. Type strain: NCIB 8767

Description: Delaporte, B. and P. Daste. 1956. Ibid.

F. uliginosum ZoBell and Upham 1944

ZoBell, C.E. and H.C. Upham. 1944. Bulletin Scripps Institution of Oceanography University of California (Technical Series) 5:239-292. Type strain: ATCC 14397

Description: Zobell, C.E. and H.C. Upham. 1944. Ibid.

Flectobacillus Larkin, Williams and Taylor 1977 Larkin, J.M., P.M. Williams and R. 
Taylor. 1977. International Journal of Systematic Bacteriology 27:147-156. Type species: $F$. major Larkin, Williams and Taylor 1977

Description: Larkin, J.M., P.M. Williams and R. Taylor. 1977. Ibid.

F. major (Gromov 1963) Larkin, Williams and Taylor 1977

Gromov, B.V. 1963. Doklady Akademii Nauk SSSR 152:733-734; Larkin, J.M., P.M. Williams and R. Taylor. 1977. International Journal of Systematic Bacteriology 27:147-156. Type strain: DSM 103

Description: Larkin, J.M., P.M. Williams and R. Taylor. 1977. Ibid.

F. marinus (Raj 1976) Borrall and Larkin 1978 Raj, H.D. 1976. International Journal of Systematic Bacteriology 26:528-544; Borrall, R. and J.M. Larkin. 1978. International Journal of Systematic Bacteriology 28:341-343. Type strain: ATCC 25205

Description: Raj, H.D. 1976. Ibid.

\section{Flexibacter Soriano 1945}

Soriano, S. 1945. Ciencia e Investigacion (Buenos Aires) 1:92-93. Type species: $F$. flexilis Soriano 1945

Description: Bergey 8.

F. aggregans (Lewin 1969) Leadbetter 1974 Lewin, R.A. 1969. Journal of General Microbiology 58:189-206; Leadbetter, E.R. 1974 Bergey 8. Type strain: ATCC 23162

Description: Lewin, R.A. 1969. Ibid.

F. aurantiacus Lewin 1969

Lewin, R.A. 1969. Journal of General Microbiology 58:189-206. Type strain: ATCC 23107

Description: Lewin, R.A. 1969. Ibid.

F. flexilis Soriano 1945

Soriano, S. 1945. Ciencia e Investigacion (Buenos Aires) 1:92-93. Type strain: ATCC 23079

Description: Soriano, S. 1945. Ibid.

F. litoralis Lewin 1969

Lewin, R.A. 1969. Journal of General Microbiology 58:189-206. Type strain: ATCC 23117

Description: Lewin, R.A. 1969. Ibid.

F. polymorphus Lewin 1974

Lewin, R.A. 1974. Journal of General Microbiology 82:393-403. Type strain:
ATCC 27820

Description: Lewin, R.A. 1974. Ibid.

F. roseolus Lewin 1969

Lewin, R.A. 1969. Journal of General Microbiology 58:189-206. Type strain: ATCC 23088

Description: Lewin, R.A. 1969. Ibid.

F. ruber Lewin 1969

Lewin, R.A. 1969. Journal of General Microbiology 58:189-206. Type strain: ATCC 23103

Description: Lewin, R.A. 1969. Ibid.

F. sancti Lewin 1969

Lewin, R.A. 1969. Journal of General Microbiology 58:189-206. Type strain: ATCC 23092

Description: Lewin, R.A. 1969. Ibid.

F. tractuosus (Lewin 1969) Leadbetter 1974

Lewin, R.A. 1969. Journal of General Microbiology 58:189-206; Leadbetter, E.R. 1974 Bergey 8. Type strain: ATCC 23168

Description: Lewin, R.A. 1969. Ibid.

Flexithrix Lewin 1970

Lewin, R.A. 1970. Canadian Journal of Microbiology 16:511-515. Type species: $F$. dorotheae Lewin 1970

Description: Bergey 8.

F. dorotheae Lewin 1970

Lewin, R.A. 1970. Canadian Journal of Microbiology 16:511-515. Type strain: ATCC 23163

Description: Lewin, R.A. 1970. Ibid.

\section{Francisella Dorofeev 1947}

Dorofeev, K.A. 1947. Symposium Research Works Institute Epidemiology and Microbiology Chita 1:170-180. Type species: F. tularensis (McCoy and Chapin 1912) Dorofeev 1947

Description: Bergey 8.

F. novicida (Larson, Wicht and Jellison 1955) Olsufiev, Emelyanova and Dunaeva 1959

Larson, C.L., W. Wicht and W.L. Jellison. 1955. Public Health Report 70: 253-258; Olsufiev, N.G., O.S. Emelyanova and T.N. Dunaeva. 1959. Journal of Hygiene, Epidemiology, Microbiology and Immunology (Prague) 3:138-149. Type strain: ATCC 15482

Description: Bergey 8.

F. tularensis (McCoy and Chapin 1912) Doro- 
feev 1947

McCoy, G.W. and C.W. Chapin. 1912. Journal of Infectious Diseases 10:61-72; Dorofeev, K.A. 1947. Symposium Research Works Institute Epidemiology and Microbiology Chita 1:170-180. Type strain: ATCC 6223

Description: Bergey 8 .

Frankia Brunchorst 1886

Brunchorst, J. 1886. Botanische Institut Tubingen 2:151-177. Type species: $F$. alni (Woronin 1866) Von Tubeuf 1895

Description: Bergey 8.

F. alni (Woronin 1866) Von Tubeuf 1895

Woronin, M. 1866. Memoires de l'Academie des Sciences St Petersburg 10: 1-10; Von Tubeuf, K. 1895. Pflanzenkrankheiten durch kryptogame Parasiten verursacht. Verlag J Springer, Berlin. pp. 1-599. Type strain: no culture isolated.

Description: Bergey 8.

\section{Fusobacterium Knorr 1922}

Knorr, M. 1922. Zentralblatt fur Bakteriologie, Parasitenkunde, Infektionskrankheiten und Hygiene. Abteilung I. 89:422. Type species: $F$. nucleatum Knorr 1922

Description: Bergey 8 .

F. gonidiaformans (Tunnicliff and Jackson 1925) Moore and Holdeman 1970

Tunnicliff, R. and L. Jackson. 1925. Journal of Infectious Diseases 36:430-438; Moore, W.E.C. and L.V. Holdeman. 1970 in Cato, E.P., C.S. Cummins, L.V. Holdeman, J.L. Johnson, W.E.C. Moore, R.M. Smibert and L.DS. Smith (eds). Outline of clinical methods in anaerobic bacteriology 2nd revision. Virginia Polytechnic Institute Anaerobe Laboratory, Blacksburg, Virginia. Type strain: ATCC 25563

Description: Holdeman, L.V., E.P. Cato and W.E.C. Moore (eds). 1977. Anaerobe Laboratory Manual, 4th ed. Virginia Polytechnic Institute and State University, Blacksburg, Virginia. pp. 1-156.

F. mortiferum (Harris 1901) Moore and Holdeman 1970

Harris, N.M. 1901. Journal of Experimental Medicine 6:519-547; Moore, W.E.C. and L.V. Holdeman 1970 in
Cato, E.P., C.S. Cummins, L.V. Holdeman, J.L. Johnson, W.E.C. Moore, R.M. Smibert and L.DS. Smith (eds). Outline of clinical methods in anaerobic bacteriology 2nd revision. Virginia Polytechnic Institute Anaerobe Laboratory, Blacksburg, Virginia. Type strain: ATCC 25557

Description: Holdeman, L.V., E.P. Cato and W.E.C. Moore (eds). 1977. Anaerobe Laboratory Manual 4th ed. Virginia Polytechnic Institute and State University, Blacksubrg, Virginia. pp. 1-156.

F. naviforme (Jungano 1909) Moore and Holdeman 1970

Jungano, M. 1909. Comptes Rendus des Seances de la Societe de Biologie (Paris) 66:122-124; Moore, W.E.C. and L.V. Holdeman. 1970 in Cato, E.P., C.S. Cummins, L.V. Holdeman, J.L. Johnson, W.E.C. Moore, R.M. Smibert and L.DS. Smith (eds). Outline of clinical in anaerobic bacteriology, 2nd revision. Virginia Polytechnic Institute Anaerobe Laboratory, Blacksburg, Virginia. Type strain: ATCC 25832

Description: Holdeman, L.V., E.P. Cato and W.E.C. Moore (eds). 1977. Anaerobe Laboratory Manual 4th ed. Virginia Polytechnic Institute and State University, Blacksburg, Virginia. pp. 1-156.

F. necrogenes (Weinberg, Nativelle and Prevot 1937) Moore and Holdeman 1970

Weinberg, M., R. Nativelle and A.R. Prevot. 1937. Masson et Cie, Paris. pp. 11186; Moore, W.E.C. and L.V. Holdeman. 1970 in Cato, E.P., C.S. Cummins, L.V. Holdeman, J.L. Johnson, W.E.C. Moore, R.M. Smibert and L.DS. Smith (eds). Outline of clinical methods in anaerobic bacteriology, 2nd revision. Virginia Polytechnic Institute Anaerobe Laboratory, Blacksburg, Virginia. Type strain: ATCC 25556

Description: Holdeman, L.V., E.P. Cato and W.E.C. Moore (eds). 1977. Anaerobe Laboratory Manual 4th ed. Virginia Polytechnic Institute and State University, Blacksburg, Virginia. pp. 1-156.

F. necrophorum (Flugge 1886) Moore and Holdeman 1969

Flugge, C. 1886. Die Mikroorganismen F.C.W. Vogel, Leipzig. pp. 1-692; Moore, 
W.E.C. and L.V. Holdeman. 1969 in Cato, E.P., C.S. Cummins, L.V. Holdeman, J.L. Johnson, W.E.C. Moore, R.M. Smibert and L.DS. Smith (eds). Outline of clinical methods in anaerobic bacteriology, lst revision. Virginia Polytechnic Institute Anaerobe Laboratory, Blacksburg, Virginia. pp. 1-107. Type strain: ATCC 25286

Description: Holdeman, L.V., E.P. Cato and W.E.C. Moore (eds). 1977. Anaerobe Laboratory Manual, 4th ed. Virginia Polytechnic Institute and State University, Blacksburg, Virginia. pp. 1-156.

F. nucleatum Knorr 1922

Knorr, M. 1922. Zentralblatt fur Bakteriologie, Parasitenkunde, Infektionskrankheiten und Hygiene. Abteilung I. 89:422. Type strain: ATCC 25586

Description: Holdeman, L.V., E.P. Cato and W.E.C. Moore (eds). 1977. Anaerobe Laboratory Manual, 4th ed. Virginia Polytechnic Institute and State University, Blacksburg, Virginia. pp. 1-156.

F. perfoetens (Tissier 1905) Moore and Holdeman 1973

Tissier, H. 1905. Annales de l'Institut Pasteur (Paris) 19:109-123; Moore, W.E.C. and L.V. Holdeman. 1973. International Journal of Systematic Bacteriology 23:69-74. Type strain: ATCC 29250

Description: Van Assche, P.F. and A.T. Wilssens. 1977. International Journal of Systematic Bacteriology 27:1-5.

F. plauti Seguin 1928

Seguin, P. 1928. Comptes Rendus des Seances de la Societe de Biologie (Paris) 99:439-442. Type strain: ATCC 29863

Description: Holdeman, L.V., E.P. Cato and W.E.C. Moore (eds). 1977. Anaerobe Laboratory Manual, 4th ed. Virginia Polytechnic Institute and State University, Blacksburg, Virginia. pp. 1-156.

F. prausnitzii (Hauduroy, Ehringer, Urbain, Guillot and Magrou 1937) Moore and Holdeman 1970

Hauduroy, P., G. Ehringer, A. Urbain, G. Guillot, and J. Magrou. 1937. Dictionnaire des bacteries pathogenes. Masson et Cie, Paris. pp. 1-597; Moore, W.E.C. and L.V. Holdeman. 1970 in Cato, E.P., C.S. Cummins, L.V. Holdeman, J.L. Johnson,
W.E.C. Moore, R.M. Smibert and L.DS. Smith (eds). Outline of clinical methods in anaerobic bacteriology, 2nd revision. Virginia Polytechnic Institute Anaerobe Laboratory, Blacksburg, Virginia. Type strain: ATCC 27768

Description: Holdeman, L.V., E.P. Cato and W.E.C. Moore (eds). 1977. Anaerobe Laboratory Manual, 4th ed. Virginia Polytechnic Institute and State University, Blacksburg, Virginia. pp. 1-156.

F. russii (Hauduroy, Ehringer, Urbain, Guillot and Magrou 1937) Moore and Holdeman 1970

Hauduroy, P., G. Ehringer, A. Urbain, G. Guillot, and J. Magrou. 1937. Dictionnaire des bacteries pathogenes. Masson et Cie, Paris. pp. 1-597; Moore, W.E.C. and L.V. Holdeman. 1970 in Cato, E.P., C.S. Cummins, L.V. Holdeman, J.L. Johnson, W.E.C. Moore, R.M. Smibert and L.DS. Smith (eds). Outline of clinical methods in anaerobic bacteriology, 2nd revision. Virginia Polytechnic Institute Anaerobe Laboratory, Blacksburg, Virginia. Type strain: ATCC 25533

Description: Holdeman, L.V., E.P. Cato and W.E.C. Moore (eds). 1977. Anaerobe Laboratory Manual, 4th ed. Virginia Polytechnic Institute and State University, Blacksburg, Virginia. pp. 1-156.

F. varium (Eggerth and Gagnon 1933) Moore and Holdeman 1969

Eggerth, A.H. and B.H. Gagnon. 1933. Journal of Bacteriology 25:389-413; Moore, W.E.C. and L.V. Holdeman. 1969 in Cato, E.P., C.S. Cummins, L.V. Holdeman, J.L. Johnson, W.E.C. Moore, R.M. Smibert and L.DS Smith (eds). Outline of clinical methods in anaerobic bacteriology, 1st revision. Virginia Polytech Institute Anaerobe Laboratory, Blacksburg, Virginia. pp. 1-107. Type strain: ATCC 8501

Description: Holdeman, L.V., E.P. Cato and W.E.C. Moore (eds). 1977 Anaerobe Laboratory Manual, 4th ed. Virginia Polytechnic Institute and State University, Blacksburg, Virginia. pp. 1156.

Gallionella Ehrenberg 1838

Ehrenberg, C.G. 1838. Die Infusionsthier- 
chen als vollkommene Organismen. $L$. Voss, Leipzig. Type species: $G$. ferruginea Ehrenberg 1838

Description: Bergey 8.

G. ferruginea Ehrenberg 1838

Ehrenberg, C.G. 1838. Type strain: no culture isolated.

Description: Bergey 8.

\section{Gemella Berger 1960}

Berger, U. 1960. Zeitschrift fur Hygiene und Infektionskrankheiten Medizinische Mikrobiologie, Immunologie und Virologie 146:253-259. Type species: $G$. haemolysans (Thjotta and Boe 1938) Berger 1960

Description: Bergey 8.

G. haemolysans (Thjotta and Boe 1938) Berger 1960

Thjotta, T. and J. Boe. 1938. Acta Pathologica et Bacteriologica Scandinavica Supplement 37:527-531; Berger, U. 1960. Zeitschrift fur Hygiene und Infektionskrankheiten Medizinische Mikrobiologie, Immunologie und Virologie 146:253-259. Type strain: ATCC 10379 Description: Bergey 8.

\section{Gemmiger Gossling and Moore 1975}

Gossling, J. and W.E.C. Moore. 1975. International Journal of Systematic Bacteriology 25:202-207. Type species: $G$. formicilis Gossling and Moore 1975

Description: Gossling, J. and W.E.C. Moore. 1975. Ibid.

G. formicilis Gossling and Moore 1975 Gossling, J. and W.E.C. Moore. 1975. International Journal of Systematic Bacteriology 25:202-207. Type strain: ATCC 27749

Description: Gossling, J. and W.E.C. Moore. 1975. Ibid.

Geodermatophilus Luedemann 1968

Luedemann, G.M. 1968. Journal of Bacteriology 96:1848-1858. Type species: G. obscurus Luedemann 1968

Description: Bergey 8.

G. obscurus Luedemann 1968

Luedemann, G.M. 1968. Journal of Bacteriology 96:1848-1858. Type strain: ATCC 25078

Description: Luedemann, G.M. 1968. Ibid.
Gluconobacter (Asai 1935) Asai, Iizuka and Komagata 1964

Asai, T. 1935. Journal of the Agricultural Chemical Society of Japan 11:674-708; Asai, T., H. lizuka and K. Komagata. 1964. Journal of General and Applied Microbiology 10:95-126. Type species: $G$. oxydans (Henneberg 1897) De Ley 1961 Description: Bergey 8.

G. oxydans (Henneberg 1897) De Ley 1961

Henneberg, W. 1897. Zentralblatt fur Bakteriologie, Parasitenkunde, Infektionskrankheiten und Hygiene. Abteilung II. 3:223-231; De Ley, J. 1961. Journal of General Microbiology 24:3150. Type strain: ATCC 19357

Description: Bergey 8.

G. oxydans subsp. industrius (Henneberg 1898) De Ley and Frateur 1974

Henneberg, W. 1898. Deutsche Essigindustrie 2:145-148; De Ley, J. and J. Frateur. 1974 in Bergey 8. Type strain: LMD 24.1

Description: Bergey 8.

G. oxydans subsp. melanogenes (Beijerinck 1911) De Ley and Frateur 1974

Beijerinck, M. 1911. Zentralblatt fur Bakteriologie, Parasitenkunde, Infektionskrankheiten und Hygiene. Abteilung II. 29:169-176; De Ley, J. and J. Frateur. 1974 in Bergey 8. Type strain: LMD 29.2 Description: Bergey 8 .

G. oxydans subsp. oxydans (Henneberg 1897) De Ley 1961

Henneberg, W. 1897. Zentralblatt fur Bakteriologie, Parasitenkunde, Infektionskrankheiten und Hygiene. Abteilung II. 3:223-231; De Ley, J. 1961. Journal of General Microbiology 24:3150. Type strain: ATCC 19357

Description: Bergey 8.

G. oxydans subsp. sphaericus Ameyama 1975 Ameyama, M. 1975. International Journal of Systematic Bacteriology 25:365-370. Type strain: IFO 12467

Description: Ameyama, M. 1975. Ibid.

G. oxydans subsp. suboxydans (Kluyver and de Leeuw 1924) De Ley and Frateur 1974 Kluyver, A.J. and F.J.G. de Leeuw. 1924. Tijdschrift voor vergeeijkende geneeskunde, gezondheidsleer en parasitaire en infectieziekten 10:170-281; De Ley, J. and J. Frateur. 1974 in Bergey 8. Type strain: 
LMD 23.2

Description: Bergey 8.

Haemobartonella Tyzzer and Weinman 1939

Tyzzer, E.E. and D. Weinman. 1939. American Journal of Hygiene 30:141-157. Type species: $H$. muris (Mayer 1921) Tyzzer and Weinman 1939

Description: Bergey 8.

H. muris (Mayer 1921) Tyzzer and Weinman 1939

Mayer, M. 1921. Archiv fur Schiffs und Tropenhygiene 25:150-152; Tyzzer, E.E. and D. Weinman. 1939. American Journal of Hygiene 30:141-157. Type strain: no culture isolated.

Description: Bergey 8.

Haemophilus Winslow, Broadhurst, Buchanan, Krumwiede, Rogers and Smith 1917

Winslow, C.E.A., J. Broadhurst, R.E. Buchanan, C. Krumwiede Jr., L.A. Rogers and G.H. Smith. 1917. Journal of Bacteriology 2:505-566. Type species: $H$. influenzae (Lehmann and Neumann 1896) Winslow, Broadhurst, Buchanan, Krumwiede, Rogers and Smith 1917

Description: Bergey 8.

H. aegyptius (Trevisan 1889) Pittman and Davis 1950

Trevisan, V. 1889. I. Generi e le Specie delle Battieriacee. Zanaboni and Gabuzzi, Milano; Pittman, M. and D.J. Davis. 1950. Journal of Bacteriology 59:413-426.

Type strain: ATCC 11116

Description: Pittman, M. and D.J. Davis. 1950. Ibid.

H. aphrophilus Khairat 1940

Khairat, O. 1940. Journal of Pathology and Bacteriology 50:497-505. Type strain: NCTC 5906

Description: Kilian, M. 1976. Journal of General Microbiology 93:9-62.

H. avium Hinz and Kunjara 1977

Hinz, K.H. and C. Kunjara. 1977. International Journal of Systematic Bacteriology 27:324-329. Type strain: ATCC 29546

Description: Hinz, K.H. and C. Kunjara. 1977. Ibid.

H. ducreyi (Neveu-Lemaire 1921) Bergey, Harrison, Breed, Hammer and Huntoon 1923 Neveu-Lemaire, M. 1921. Precis de la parasitologie humaine, 5th ed. J. Lemaire Paris; Bergey, D.H., F.C. Harrison, R.S. Breed, B.W. Hammer and F.M. Huntoon. 1923. Bergey's Manual of Determinative Bacteriology, 1st ed. The Williams and Wilkins Co., Baltimore. p. 271. Type strain: CIP 542

Description: Kilian, M. 1976. Journal of General Microbiology 93:9-62.

H. haemoglobinophilus (Lehmann and Neumann 1907) Murray 1939

Lehmann, K.B. and R. Neumann. 1907. Lehmann's Medizin, Handatlanten. X Atlas und Grundriss der Bakteriologie und Lehrbuch der speziellen bakteriologischen Diagnostik. Vol. 2, 4th ed. p. 270; Murray, R.G.E. 1938 in Bergey, D.H., R.S. Breed, E.G.D. Murray and A.P. Hitchens (eds). Bergey's Manual of Determinative Bacteriology, 5th ed. The Williams and Wilkins Co., Baltimore. p. 309. Type strain: NCTC 1659

Description: Kilian, M. 1976. Journal of General Microbiology 93:9-62.

H. haemolyticus Bergey, Harrison, Breed, Hammer and Huntoon 1923

Bergey, D.H., F.C. Harrison, R.S. Breed, B.W. Hammer and F.M. Huntoon. 1923. Bergey's Manual of Determinative Bacteriology, 1st ed. The Williams and Wilkins Co., Baltimore. p. 271. Type strain: NCTC 10659

Description: Kilian, M. 1976. Journal of General Microbiology 93:9-62.

H. influenzae (Lehmann and Neumann 1896) Winslow, Broadhurst, Buchanan, Krumwiede, Rogers and Smith 1917

Lehmann, K.B. and R. Neumann. 1896. Atlas und Grundriss der Bakteriologie und Lehrbuch der speziellen bakteriologischen Diagnostik. 1st ed. J.F. Lehmann, Munchen; Winslow, C.E.A., J. Broadhurst, R.E. Buchanan, C. Krumwiede Jr., L.A. Rogers and G.H. Smith. 1917. Journal of Bacteriology 2:505-566. Type strain: NCTC 8143

Description: Kilian, M. 1976. Journal of General Microbiology 93:9-63.

H. paragallinarum Biberstein and White 1969 Biberstein, E.L. and D.C. White. 1969. Journal of Medical Microbiology 2:75-78. Type strain: ATCC 29545

Description: Hinz, K.H. and C. Kunjara. 
1977. International Journal of Systematic Bacteriology 27:324-329.

H. parahaemolyticus Pittman 1953

Pittman, M. 1953. Journal of Bacteriology 65:750-751. Type strain: ATCC 10014 Description: Kilian, M. 1976. Journal of General Microbiology 93:9-62.

H. parainfluenzae Rivers 1922

Rivers, T.M. 1922. Johns Hopkins Hospital Bulletin 33:429-431. Type strain: NCTC 7857

Description: Kilian, M. 1976. Journal of General Microbiology 93:9-62.

H. paraphrohaemolyticus Zinnemann, Rogers, Frazer and Devaraj 1971

Zinnemann, K., K.B. Rogers, J. Frazer and S.K. Devaraj. 1971. Journal of Medical Microbiology 4:139-143. Type strain: NCTC 10670

Description: Zinnemann, K., K.B. Rogers, J. Frazer and S.K. Devaraj. 1971. Ibid.

H. paraphrophilus Zinnemann, Rogers, Frazer and Boyce 1968

Zinnemann, K., K.B. Rogers, J. Frazer and J.M.H. Boyce. 1968. Journal of Pathology and Bacteriology 96:413-419. Type strain: NCTC 10557

Description: Kilian, M. 1976. Journal of General Microbiology 93:9-62.

H. parasuis Biberstein and White 1969

Biberstein E.L. and D.C. White. 1969. Journal of Medical Microbiology 2:75-78. Type strain: ATCC 19417

Description: Kilian, M. 1976. Journal of General Microbiology 93:9-62.

H. piscium Sniezko, Griffin and Friddle 1950

Sniezko, S.F., P.J. Griffin and S.B. Friddle. 1950. Journal of Bacteriology 59: 699-710. Type strain: ATCC 10801

Description: Kilian, M. 1976. Journal of General Microbiology 93:9-62.

H. pleuropneumoniae (Matthews and Pattison 1961) Shope 1964

Matthews, P.R.J. and I.H. Pattison. 1961. Journal of Comparative Pathology 71:4452; Shope, R.E. 1964. Journal of Experimental Medicine 119:357-368. Type strain: ATCC 27088

Description: Kilian, M., J. Nicolet and E.L. Biberstein. 1978. International Journal of Systematic Bacteriology 28:2026.

H. segnis Kilian 1977
Kilian, M. 1977 in International Journal of Systematic Bacteriology 27:306; Effective publication Kilian, M. 1976. Journal of General Microbiology 93:9-62. Type strain: NCTC 10977

Description: Kilian, M. and J. Theilade. 1978. International Journal of Systematic Bacterioloy 28:411-415.

H. vaginalis Gardner and Dukes 1955

Gardner, H.L. and C.D. Dukes. 1955. American Journal of Obstetrics and Gynecology 69:962-976. Type strain: ATCC 14018

Description: Bergey 8.

Hafnia Moller 1954

Moller, V. 1954. Acta Pathologica et Microbiologica Scandinavica 35:259-277.

Type species: $H$. alvei Moller 1954

Description: Bergey 8.

H. alvei Moller 1954

Moller, V. 1954. Acta Pathologica et Microbiologica Scandinavica 35:259-277. Type strain: ATCC 13337

Description: Ewing, W.H. and M.A. Fife. 1968. International Journal of Systematic Bacteriology 18:263-271.

Haliscomenobacter van Veen, van der Kooij, Geuze and van der Vlies 1973

van Veen, W.L., D. van der Kooij, E.C.W.A. Geuze and A.W. van der Vlies. 1973. Antonie van Leeuwenhoek Journal of Microbiology and Serology 39:207-216. Type species: $\boldsymbol{H}$. hydrossis van Veen, van der Kooij, Geuze and van der Vlies 1973

Description: van Veen, W.L., D. van der Kooij, E.C.W.A. Geuze and A.W. van der Vlies. 1973. Ibid.

H. hydrossis van Veen, van der Kooij, Geuze and van der Vlies 1973

van Veen, W.L., D. van der Kooij, E.C.W.A. Geuze and A.W. van der Vlies. 1973. Antonie van Leeuwenhoek Journal of Microbiology and Serology 39:207-216.

Type strain: ATCC 27775

Description: van Veen, W.L., D. van der Kooij, E.C.W.A. Geuze and A.W. van der Vlies. 1970. Ibid.

Halobacterium Elazari-Volcani 1957 Elazari-Volcani, B. 1957 in Breed, R.S., E.G.D. Murray and N.R. Smith (eds). 
Bergey's Manual of Determinative Bacteriology, 7th ed. The Williams and Wilkins Co., Baltimore. pp. 207-212. Type species: $H$. salinarium (Harrison and Kennedy 1922) Elazari-Volcani 1957

Description: Bergey 8.

H. cutirubrum (Lochhead 1934) Elazari-Volcani 1957

Lochhead, A.G. 1934. Canadian Journal of Research 10:275-286; Elazari-Volcani, B. 1957 in Breed, R.S., E.G.D. Murray and N.R. Smith (eds). Bergey's Manual of Determinative Bacteriology, 7th ed. The Williams and Wilkins Co., Baltimore. pp. 207-212. Type strain: NRC 34001

Description: Colwell, R.R., C.D. Litchfield, R.H. Vreeland, N.E. Gibbons and L.A. Kiefer. 1979. International Journal of Systematic Bacteriology 29:379-399.

H. halobium (Petter 1931) Elazari-Volcani 1957 Petter, H.F.M. 1931. Proceedings Academy of Science, Amsterdam 34:14171423; Elazari-Volcani, B. 1957 in Breed, R.S., E.G.D. Murray and N.R. Smith (eds). Bergey's Manual of Determinative Bacteriology, 7th ed. The Williams and Wilkins Co., Baltimore. pp. 207-212. Type strain: NCIB 8720

Description: Petter, H.F.M. 1931. Ibid.

H. saccharovorum Tomlinson and Hochstein 1977

Tomlinson, G.A. and L.I. Hochstein. 1977 in International Journal of Systematic Bacteriology 27:306; Effective publication Tomlinson, G.A. and L.I. Hochstein. 1976. Canadian Journal of Microbiology 22:587-591. Type strain: ATCC 29252

Description: Tomlinson, G.A. and L.I. Hochstein. 1976. Ibid.

H. salinarium (Harrison and Kennedy 1922) Elazari-Volcani 1957

Harrison, F.C. and M.E. Kennedy. 1922. Proceedings of the Royal Society of Canada, Section 5, 16:101-152; ElazariVolcani, B. 1957 in Breed, R.S., E.G.D. Murray and N.R. Smith (eds). Bergey's Manual of Determinative Bacteriology, 7th ed. The Williams and Wilkins Co., Baltimore. pp. 207-212. Type strain: NRC 34002

Description: Colwell, R.R., C.D. Litchfield, R.H. Vreeland, N.E. Gibbons and L. A. Kiefer. 1979. International Journal of Systematic Bacteriology 29:379-399.

H. trapanicum (Petter 1931) Elazari-Volcani 1957

Petter, H.F.M. 1931. Proceedings Academy of Science, Amsterdam 34:1417-1423; Elazari-Volcani, B. 1957 in Breed, R.S., E.G.D. Murray and N.R. Smith (eds). Bergey's Manual of Determinative Bacteriology, 7th ed. The Williams and Wilkins Co., Baltimore. pp. 207-212. Type strain: NRC 34021

Description: Petter, H.F.M. 1931. Ibid.

H. vallismortis Gonzalez, Gutierrez and Ramirez 1979

Gonzalez, C., C. Gutierrez and C. Ramirez. 1979 in International Journal of Systematic Bacteriology 29:436; Effective publication Gonzalez, C., C. Gutierrez and C. Ramirez. 1978. Canadian Journal of Microbiology 24:710-715. Type strain: ATCC 29715

Description: Gonzalez, C., C. Gutierrez and C. Ramirez. 1978. Ibid.

H. volcanii Mullakhanbhai and Larson 1975

Mullakhanbhai, M.F. and H. Larson. 1975. Archives of Microbiology 104:207. 214. Type strain: NCMB 2012

Description: Mullakhanbhai, M.F. and H. Larson. 1975. Ibid.

\section{Halococcus Schoop 1935}

Schoop, G. 1935. Deutsche Tierarztliche Wochenschrift 43:817-820. Type species: H. morrhuae (Farlow 1880) Kocur and Hodgkiss 1973

Description: Bergey 8 .

H. morrhuae (Farlow 1880) Kocur and Hodgkiss 1973

Farlow, W.G. 1880. United States Fisheries Commission Report for 1878 pp. 969. 974; Kocur, M. and W. Hodgkiss. 1973. International Journal of Systematic Bacteriology 23:151-156. Type strain: ATCC 17082

Description: Kocur, M. and W. Hodgkiss. 1973. Ibid.

Herpetosiphon Holt and Lewin 1968

Holt, J.G. and R.A. Lewin. 1968. Journal of Bacteriology 95:2407-2408. Type species: $H$. aurantiacus Holt and Lewin 1968 Description: Bergey 8 .

H. aurantiacus Holt and Lewin 1968 
Holt, J.G. and R.A. Lewin. 1968. Journal of Bacteriology 95:2407-2408. Type strain: ATCC 23779

Description: Holt, J.G. and R.A. Lewin. 1968. Ibid.

H. cohaerens Lewin 1970

Lewin, R.A. 1970. Canadian Journal of Microbiology 16:517-520. Type strain: ATCC 23123

Description: Lewin, R.A. 1970. Ibid.

H. geysericola (Copeland 1936) Lewin 1970

Copeland, J.J. 1936. Annals of the New York Academy of Sciences 36:1-232; Lewin, R.A. 1970. Canadian Journal of Microbiology 16:517-520. Type strain: ATCC 23076

Description: Lewin, R.A. 1970. Ibid.

H. nigricans Lewin 1970

Lewin, R.A. 1970. Canadian Journal of Microbiology 16:517-520. Type strain: ATCC 23147

Description: Lewin, R.A. 1970. Ibid.

H. persicus Lewin 1970

Lewin, R.A. 1970. Canadian Journal of Microbiology 16:517-520. Type strain: ATCC 23167

Description: Lewin, R.A. 1970. Ibid.

Hyphomicrobium Stutzer and Hartleb 1899

Stutzer, A. and R. Hartleb. 1899. Mitteilungen des Landwirtschaftlichen Institutes der Kaiserlichen Universitat Breslau 1:75-100. Type species: $H$. vulgare Stutzer and Hartleb 1899

Description: Bergey 8.

H. indicum Johnson and Weisrock 1969

Johnson, R.M. and W.P. Weisrock. 1969.

International Journal of Systematic Bacteriology 19:295-307. Type strain: ATCC 19614

Description: Bergey 8.

H. neptunium Leifson 1964

Leifson, E. 1964. Antonie van Leeuwenhoek Journal of Microbiology and Serology 30:249-256. Type strain: ATCC 15444 Description: Bergey 8.

H. vulgare Stutzer and Hartleb 1899

Stutzer, A. and R. Hartleb. 1899. Mitteilungen des Landwirtschaftlichen Institutes der Kaiserlichen Universitat Breslau 1:75-100. Type strain: NCIB 8698

Description: Bergey 8.
Intrasporangium Kalakoutskii, Kirillova and Krassilnikov 1967

Kalakoutskii, L.V., I.P. Kirillova and N.A. Krassilnikov. 1967. Journal of General Microbiology 48:79-85. Type species: $I$. calvum Kalakoutskii, Kirillova and Krassilnikov 1967

Description: Kalakoutskii, L.V., I.P. Kirillova and N.A. Krassilnikov. 1976. Ibid.

I. calvum Kalakoutskii, Kirillova and Krassilnikov 1967

Kalakoutskii, L.V., I.P. Kirillova and N.A. Krassilnikov. 1967. Journal of General Microbiology 48:79-85. Type strain: ATCC 23552

Description: Kalakoutskii, L.V., I.P. Kirillova and N.A. Krassilnikov. 1967. Ibid.

Janthinobacterium De Ley, Segers and Gillis 1978

De Ley, J., P. Segers and M. Gillis. 1978. International Journal of Systematic Bacteriology 28:154-168. Type species: $J$. lividum (Eisenberg 1891) De Ley, Segers and Gillis 1978

Description: De Ley, J., P. Segers and M. Gillis. 1978. Ibid.

J. lividum De Ley, Segers and Willis 1978

De Ley, J., P. Segers and M. Gillis. 1978. International Journal of Systematic Bacteriology 28:154-168. Type strain; NCTC 9796

Description: De Ley, J., P. segers and M. Gillis. 1978. Ibid.

Kineosporia Pagani and Parenti 1978

Pagani, H. and F. Parenti. 1978. International Journal of Systematic Bacteriology 28:401-406. Type species: $K$. aurantiaca Pagani and Parenti 1978

Description: Pagani, H. and F. Parenti. 1978. Ibid.

K. aurantiaca Pagani and Parenti 1978

Pagani, H. and F. Parenti. 1978. International Journal of Systematic Bacteriology 28:401-406. Type strain: ATCC 29727

Description: Pagani, H. and F. Parenti. 1978. Ibid.

Kingella Henriksen and Bovre 1976 Henriksen, S.D. and K. Bovre. 1976. 
International Journal of Systematic Bacteriology 26:447-450. Type species: $K$. kingae (Henriksen and Bovre 1968) Henriksen and Bovre 1976

Description: Henriksen, S.D. and K. Bovre. 1976. Ibid.

K. denitrificans Snell and Lapage 1976 Snell, J.J.S. and S.P. Lapage. 1976. International Journal of Systematic Bacteriology 26:451-458. Type strain: NCTC 10995

Description: Snell, J.J.S. and S.P. Lapage. 1976. Ibid.

K. indologenes Snell and Lapage 1976

Snell, J.J.S. and S.P. Lapage. 1976. International Journal of Systematic Bacteriology 26:451-458. Type strain: ATCC 25869

Description: Snell, J.J.S. and S.P. Lapage 1976. Ibid.

K. kingae (Henriksen and Bovre 1968) Henriksen and Bovre 1976

Henriksen, S.D. and K. Bovre. 1968. Journal of General Microbiology 51:377385; Henriksen, S.D. and K. Bovre. 1976. International Journal of Systematic Bacteriology 26:447-450. Type strain: ATCC 23330

Description: Henriksen, S.D. and K. Bovre. 1976. Ibid.

Kitasatoa Matsumae and Hata 1968

Matsumae, A.M. and T. Hata. 1968 in Matsumae, A.M., M. Ohtani, H. Takeshima and T. Hata. Journal of Antibiotics (Tokyo) 21:616-625. Type species: $K$. purpurea Matsumae and Hata 1968

Description: Bergey 8.

K. diplospora Matsumae, Ohtani and Hata 1968

Matsumae, A.M., M. Ohtani and T. Hata. 1968 in Matsumae, A.M., M. Ohtani, H. Takeshima and T. Hata. Journal of Antibiotics (Tokyo) 21:616625. Type strain: ATCC 27788

Description: Bergey 8.

K. kauaiensis Matsumae, Ohtani and Hata 1968

Matsumae, A.M., M. Ohtani and T. Hata. 1968 in Matsumae, A.M., M. Ohtani, H. Takeshima and T. Hata. Journal of Antibiotics (Tokyo) 21:616625. Type strain: ATCC 21405
Description: Bergey 8.

K. nagasakiensis Matsumae and Hata 1968

Matsumae, A.M. and T. Hata. 1968 in

Matsumae, A.M., M. Ohtani, H. Takeshi-

ma and T. Hata. Journal of Antibiotics

(Tokyo) 21:616-625. Type strain: ATCC 27789

Description: Bergey 8.

K. purpurea Matsumae and Hata 1968

Matsumae, A.M. and T. Hata. 1968 in Matsumae, A.M., M. Ohtani, H. Takeshi$\mathrm{ma}$ and T. Hata. Journal of Antibiotics (Tokyo) 21:616-625. Type strain: ATCC 27787

Description: Bergey 8.

Klebsiella Trevisan 1885

Trevisan, V. 1885. Atti della Accademia Fisica-Medica-Statistica in Milano (ser 4) 3:92-107. Type species: $K$. pneumoniae (Schroeter 1886) Trevisan 1887

Desrciption: Bergey 8.

K. mobilis Bascomb, Lapage, Willcox and Curtis 1971

Bascomb, S., S.P. Lapage, W.R. Willcox and M.A. Curtis. 1971. Journal of General Microbiology 66:279-295. Type strain: ATCC 13048

Description: Bascomb, S., S.P. Lapage, W.R. Willcox and M.A. Curtis. 1971. Ibid.

K. ozaenae (Abel 1893) Bergey, Harrison, Breed, Hammer and Huntoon 1925

Abel, R. 1893. Zentralblatt fur Bakteriologie, Parasitenkunde, Infektionskrankheiten und Hygiene. Abteilung 1 . 13:161-173; Bergey, D.H., F.C. Harrison, R.S. Breed, B.W. Hammer and F.M. Huntoon (eds). 1925. Bergey's Manual of Determinative Bacteriology, 2nd ed. The Williams and Wilkins Co., Baltimore. pp. 1-462. Type strain: ATCC 11296

Description: Bergey 8.

K. oxytoca (Flugge 1886) Lautrop 1956

Flugge, C. 1886. Die Mikroorganismen. F.C.W. Vogel, Leipzig; Lautrop, H. 1956. Acta Pathologica et Microbiologica Scandinavica 39:375-384. Type strain: ATCC 13182

Description: Lautrop, H. 1956. Ibid.

K. pneumoniae (Schroeter 1886) Trevisan 1887 Schroeter, J. 1885-1889 in Cohn, F. Kryptogamenflora von Schlesien. Band 3, 
Heft 3, Pilze J.U. Kern's Verlag, Breslau. pp. 1-814; Trevisan, V. 1887. Rendiconti dell'Instituto Lombardo di Scienze e Lettere (Ser 2) 20:88-105. Type strain: ATCC 13883

Description: Bergey 8.

K. rhinoscleromatis Trevisan 1887

Trevisan, V. 1887. Rendiconti dell'Instituto Lombardo di Scienze e Lettere (Ser 2) 20:88-105. Type strain: ATCC 13884

Description: Bergey 8.

\section{Kurthia Trevisan 1885}

Trevisan, V. 1885. Atti della Accademia Fisia-Medica-Statistica in Milano (Series 4) 3:92-107. Type species: $K$. zopfii (Kurth 1883) Trevisan 1885

Description: Bergey 8.

K. zopfii (Kurth 1883) Trevisan 1885

Kurth, H. 1883. Berichte der Deutschen botanischen Gesellschaft 1:97-100; Trevisan, V. 1885. Atti della Accademia FisiaMedica-Statistica in Milano (Series 4) 3: 92-107. Type strain: NCIB 9878

Description: Bergey 8.

\section{Lachnospira Bryant and Small 1956}

Bryant, M.P. and N. Small. 1956. Journal of Bacteriology 72:22-26. Type species: L. multiparis Bryant and Small 1956

Description: Bergey 8.

L. multiparis Bryant and Small 1956

Bryant, M.P. and N. Small. 1956. Journal of Bacteriology 72:22-26. Type strain: ATCC 19207

Description: Holdeman, L.V., E.P. Cato and W.E.C. Moore (eds). 1977. Anaerobe Laboratory Manual, 4th ed. Virginia Polytechnic Institute and State University, Blacksburg, Virginia. pp. 1-156.

\section{Lactobacillus Beijerinck 1901}

Beijerinck, M.W. 1901. Archives Neerlandaises des Sciences Exactes et Naturelles (Section 2) 6:212-243. Type species: $L$. delbrueckii (Leichmann 1896) Beijerinck 1901

Description: Bergey 8.

L. acidophilus (Moro 1900) Hansen and Mocquot 1970

Moro, E. 1900. Jahrbuch fur Kinderheil- kunde und physiche Erziehung 52:38-55; Hansen, P.A. and G. Mocquot. 1970. International Journal of Systematic Bacteriology 20:325-327. Type strain: ATCC 4356

Description: Hansen, P.A. and G. Mocquot. 1970. Ibid.

L. brevis (Orla-Jensen 1919) Bergey, Breed, Hammer, Huntoon, Murray and Harrison 1934

Orla-Jensen, S. 1919. The lactic acid bacteria. Host, Copenhagen. pp. 1-196; Bergey, D.H., R.S. Breed, B.W. Hammer, F.M. Huntoon, E.G.D. Murray and F.C. Harrison. 1934. Bergey's Manual of Determinative Bacteriology, 4th ed. The Williams and Wilkins Co., Baltimore. pp. 1-664. Type strain: ATCC 14869

Description: Rogosa, M. and P.A. Hansen. 1971. International Journal of Systematic Bacteriology 21:177-186.

L. buchneri (Henneberg 1903) Bergey, Harrison, Breed, Hammer, and Huntoon 1923

Henneberg, W. 1903. Zeitschrift fur Spiritusindustrie 26:329-332; Bergey, D.H., F.C. Harrison, R.S. Breed, B.W. Hammer, and F.M. Huntoon. 1923. Bergey's Manual of Determinative Bacteriology, 1st ed. The Williams and Wilkins Co., Baltimore. pp. 1-442. Type strain: ATCC 4005

Description: Rogosa, M. and P.A. Hansen. 1971. Ibid.

L. bulgaricus (Orla-Jensen 1919) Rogosa and Hansen 1971

Orla-Jensen, S. 1919. The lactic acid bacteria. Host, Copenhagen. pp. 1-196; Rogosa, M. and P.A. Hansen. 1971. International Journal of Systematic Bacteriology 21:177-186. Type strain: ATCC 11842

Description: Rogosa, M. and P.A. Hansen. 1971. Ibid.

L. casei (Orla-Jensen 1916) Hansen and Lessel 1971

Orla-Jensen, S. 1916. Maelkeri-Bakteriologi. Schonberske Forlag, Copenhagen; Hansen, P.A. and E.F. Lessel. 1971. International Journal of Systematic Bacteriology 21:69-71. Type strain: ATCC 393

Description: Bergey 8 .

L. casei subsp. alactosus Mills and Lessel 1973 
Mills, C.K. and E.F. . Lessel. 1973. International Journal of Systematic Bacteriology 23:67-68. Type strain: ATCC 27216

Description: Mills, C.K. and E.F. Lessel. 1973. Ibid.

L. casei subsp. casei (Orla-Jensen 1916) Hansen and Lessel 1971

Orla-Jensen, S. 1916. MaelkeriBakteriologi. Schonberske Forlag, Copenhagen; Hansen, P.A. and E.F. Lessel. 1971. International Journal of Systematic Bacteriology 21:69-71. Type strain: ATCC 393

Description: Bergey 8.

L. casei subsp. pseudoplantarum Abo-Elnaga and Kandler 1965

Abo-Elnaga, I.G. and O. Kandler. 1965. Zentralblatt fur Bakteriologie, Parasitenkunde, Infektionskrankheiten und Hygiene. Abteilung II. 119:1-36. Type strain: ATCC 25598

Description: Bergey 8.

L. casei subsp. rhamnosus Hansen 1968

Hansen, P.A. 1968. A report by the Taxonomic Subcommittee on Lactobacilli and Closely Related Organisms. American Type Culture Collection, Rockville, Maryland. p. 76. Type strain: ATCC 7469

Description: Bergey 8.

L. casei subsp. tolerans Abo-Elnaga and Kandler 1965

Abo-Elnaga, I.G. and O. Kandler. 1965. Zentralblatt fur Bakteriologie, Parasitenkunde, Infektionskrankheiten und Hygiene. Abteilung II. 119:1-39. Type strain: ATCC 25599

Description: Bergey 8.

L. catenaforme (Eggerth 1935) Moore and Holdeman 1970

Eggerth, A.H. 1935. Journal of Bacteriology 30:277-299; Moore, W.E.C. and L.V. Holdeman. 1970. IN Cato, E.P., C.S. Cummins, L.V. Holdeman, J.L. Johnson, W.E.C. Moore, R.M. Smibert and L.DS. Smith (eds). Outline of clinical methods in anaerobic bacteriology, 2nd revision. Virginia Polytechnic Institute Anaerobe Laboratory, Blacksburg, Virginia pp. 1522. Type strain: ATCC 25536

Description: Holdeman, L.V., E.P. Cato and W.E.C. Moore (eds). 1977. Anaerobe
Laboratory Manual, 4th ed. Virginia Polytechnic Institute and State University, Blacksburg, Virginia. pp. 1-156.

L. cellobiosus Rogosa, Wiseman, Mitchell and Disraely 1953

Rogosa, M., R.F. Wiseman, J.A. Mitchell and M.N. Disraely. 1953. Journal of Bacteriology 65:681-699. Type strain: ATCC 11739

Description: Bergey 8.

L. collinoides Carr and Davies 1972

Carr, J.G. and P.A. Davies. 1972. Journal of Applied Bacteriology 35:463. Type strain: ATCC 27612

Description: Carr, J.G. and P.A. Davies. 1972. Ibid.

L. confusus (Holzapfel and Kandler 1969) Sharpe, Garvie and Tilbury 1972

Holzapfel, W. and O. Kandler. 1969. Zentralblatt fur Bakteriologie, Parasitenkunde, Infektionskrankheiten und Hygiene. Abteilung II. 123:657-666; Sharpe, M.E., E.I. Garvie and R. Tilbury. 1972. Applied Microbiology 23:389-397. Type strain: ATCC 10881

Description: Sharpe, M.E., E.I. Garvie and R. Tilbury. 1972. Ibid.

L. coryniformis Abo-Elnaga and Kandler 1965 Abo-Elnaga, I.G. and O. Kandler. 1965. Zentralblatt fur Bakteriologie, Parasitenkunde, Infektionskrankheiten und Hygiene. Abteilung II. 119:1-36. Type strain: DSM 20001

Description: Bergey 8.

L. coryniformis subsp. coryniformis Abo-Elnaga and Kandler 1965

Abo-Elnaga, I.G. and O. Kandler. 1965. Zentralblatt fur Bakteriologie, Parasitenkunde, Infektionskrankheiten und Hygiene. Abteilung II. 119:1-36. Type strain: DSM 20001

Description: Bergey 8.

L. coryniformis subsp. torquens Abo-Elnaga and Kandler 1965

Abo-Elnaga, I.G. and O. Kandler. 1965. Zentralblatt fur Bakteriologie, Parasitenkunde, Infektionskrankheiten und Hygiene. Abteilung II. 119:1-36. Type strain: ATCC 25600

Description: Bergey 8.

L. crispatus (Brygoo and Aladame 1953) Moore and Holdeman 1970

Brygoo, E.R. and N. Aladame. 1953. 
Annales de l'Institut Pasteur (Paris) 84: 640-641; Moore, W.E.C. and L.V. Holdeman. 1970 in Cato, E.P., C.S. Cummins, L.V. Holdeman, J.L. Johnson, W.E.C. Moore, R.M. Smibert and L.DS. Smith (eds). Outline of clinical methods in anaerobic bacteriology, 2nd revision. Virginia Polytechnic Institute Anaerobe Laboratory, Blacksburg, Virginia. pp. 1521. Type strain: VPI 3199

Description: Holdeman, L.V., E.P. Cato and W.E.C. Moore (eds). 1977. Anaerobe Laboratory Manual, 4th ed. Virginia Polytechnic Institute and State University, Blacksburg, Virginia. pp. 1-156.

L. curvatus (Troili-Petersson 1903) Abo-Elnaga and Kandler 1965

Troili-Petersson, G. 1903. Zentralblatt fur Bakteriologie, Parasitenkunde, Infektionskrankheiten und Hygiene. Abteilung II. 11:120-143; Abo-Elnaga, I.G. and $O$. Kandler. 1965. Zentralblatt fur Bakteriologie, Parasitenkunde, Infektionskrankheiten und Hygiene. Abteilung II. 119:1-36. Type strain: ATCC 25601

Description: Bergey 8.

L. delbrueckii (Leichmann 1896) Beijerinck 1901

Leichmann, G. 1896. Zentralblatt fur Bakteriologie, Parasitenkunde, Infektionskrankheiten und Hygiene. Abteilung II. 2:281-285; Beijerinck, M.W. 1901. Archives Neerlandaises des Sciences Exactes et Naturelles (Section 2) 6:212-243. Type strain: ATCC 9649

Description: Rogosa, M. and P.A. Hansen. 1971. International Journal of Systematic Bacteriology 21:177-186.

L. fermentum Beijerinck 1901

Beijerinck, M.W. 1901. Archives Neerlandaises des Sciences Exactes et Naturelles (Section 2) 6:212-243. Type strain: ATCC 14931

Description: Rogosa, M. and P.A. Hansen. 1971. International Journal of Systematic Bacteriology 21:177-186.

L. fructivorans Charlton, Nelson and Werkman 1934

Charlton, D.B., M.E. Nelson and C.H. Werkman. 1934. Iowa State Journal of Science 9:1-11. Type strain: ATCC 8288

Description: Bergey 8.

L. fructosus Kodama 1956
Kodama, R. 1956. Journal of the Agricultural Chemical Society of Japan 30:705-708. Type strain: ATCC 13162

Description: Kodama, R. 1956. Ibid.

L. helveticus (Orla-Jensen 1919) Bergey, Harrison, Breed, Hammer and Huntoon 1925

Orla-Jensen, S. 1919. The lactic acid bacteria. Host, Copenhagen. pp. 1-196; Bergey, D.H., F.C. Harrison, R.S. Breed, B.W. Hammer and F.M. Huntoon (eds). 1925. Bergey's Manual of Determinative Bacteriology, 2nd ed. The Williams and Wilkins Co., Baltimore. pp. 1-462. Type strain: ATCC 15009

Description: Rogosa, M. and P.A. Hansen. 1971. International Journal of Systematic Bacteriology 21:177-186.

L. heterohiochii Kitahara, Kaneko and Goto 1957

Kitahara, K., T. Kaneko and O. Goto. 1957. Journal of General and Applied Microbiology 3:111-120. Type strain: ATCC 15435

Description: Bergey 8.

L. hilgardii Douglas and Cruess 1936

Douglas, H.C. and W.V. Cruess. 1936. Food Research 1:113-119. Type strain: ATCC 8290

Description: Bergey 8.

L. homohiochii Kitahara, Kaneko and Goto 1957

Kitahara, K., T. Kaneko and O. Goto. 1957. Journal of General and Applied Microbiology 3:111-120. Type strain: ATCC 15434

Description: Bergey 8.

L. jensenii Gasser, Mandel and Rogosa 1970 Gasser, F., M. Mandel and M. Rogosa. 1970. Journal of General Microbiology 62:219-222. Type strain: ATCC 25258 Description: Bergey 8.

L. lactis (Orla-Jensen 1919) Bergey, Breed, Hammer, Huntoon, Murray and Harrison 1934

Orla-Jensen, S. 1919. The lactic acid bacteria. Host, Copenhagen. pp. 1-196; Bergey, D.H., R.S. Breed, B.W. Hammer, F.M. Huntoon, E.G.D. Murray and F.C. Harrison (eds). 1934. Bergey's Manual of Determinative Bacteriology, 4th ed. The Williams and Wilkins Co., Baltimore. pp. 1-664. Type strain: ATCC 12315

Description: Rogosa, M. and P.A. Han- 
sen. 1971. International Journal of Systematic Bacteriology 21:177-186.

L. leichmannii (Henneberg 1903) Bergey, Harrison, Breed, Hammer and Huntoon 1923 Henneberg, W. 1903. Zeitschrift fur Spiritusindustrie 26:329-332; Bergey, D.H., F.C. Harrison, R.S. Breed, B.W. Hammer and F.M. Huntoon. 1923. Bergey's Manual of Determinative Bacteriology, 1st ed. The Williams and Wilkins Co., Baltimore. pp. 1-442. Type strain: ATCC 4797

Description: Rogosa, M. and P.A. Hansen. 1971. International Journal of Systematic Bacteriology 21:177-186.

L. mali Carr and Davies 1970

Carr, J.G. and P.A. Davies. 1970. Journal of Applied Bacteriology 33:768-774. Type strain: ATCC 27053

Description: Carr, J.G. and P.A. Davis. 1970. Ibid.

L. maltaromicus Miller, Morgan and Libbey 1974

Miller III, A., M.E. Morgan and L.M. Libbey. 1974. International Journal of Systematic Bacteriology 24:346-354. Type strain: ATCC 27865

Description: Miller III, A., M.E. Morgan and L.M. Libbey. 1974. Ibid.

L. minutus (Hauduroy, Ehringer, Urbain, Guillot and Magrou 1937) Moore and Holdeman 1972

Hauduroy, P., G. Ehringer, A. Urbain, G. Guillot and J. Magrou. 1937. Dictionnaire des bacteries pathogenes. Masson et Cie, Paris. pp. 1-597; Moore, W.E.C. and L.V. Holdeman. 1972 in Holdeman, L.V. and W.E.C. Moore (eds). Anaerobe Laboratory Manual. Virginia Polytechnic Institute Anaerobe Laboratory, Blacksburg, Virginia. Type strain: VPI 9428

Description: Holdeman, L.V., E.P. Cato, and W.E.C. Moore (eds). 1977. Anaerobe Laboratory Manual, 4th ed. Virginia Polytechnic Institute and State University, Blacksburg, Virginia. pp. 1-156.

L. plantarum (Orla-Jensen 1919) Bergey, Harrison, Breed, Hammer and Huntoon 1923

Orla-Jensen, S. 1919. The lactic acid bacteria. Host, Copenhagen. pp. 1-196; Bergey, D.H., F.C. Harrison, R.S. Breed, B.W. Hammer and F.M. Huntoon. 1923.
Bergey's Manual of Determinative Bacteriology, lst ed. The Williams and Wilkins Co., Baltimore. pp. 1-442. Type strain: ATCC 14917

Description: Bergey 8.

L. rogosae Holdeman and Moore 1974

Holdeman, L.V. and W.E.C. Moore. 1974. International Journal of Systematic Bacteriology 24:260-277. Type strain: VPI C37-38

Description: Holdeman, L.V. and W.E.C'. Moore. 1974. Ibid.

L. ruminis Sharpe, Latham, Garvie, Zirngibl and Kandler 1973

Sharpe, M.E., M.J. Latham, E.I. Garvie, J. Zirngibl and O. Kandler. 1973. Journal of General Microbiology 77:37-49. Type strain: ATCC 27780

Description: Sharpe, M.E., M.J. Latham, E.I. Garvie, J. Zirngibl and O. Kandler. 1973. Ibid.

L. sake Katagiri, Kitahara and Fukami 1934 Katagiri, H., K. Kitahara and K. Fukami. 1934. Bulletin of the Agricultural Chemical Society of Japan 10:156-157. Type strain: ATCC 15521

Description: Katagiri, H., K. Kitahara and K. Fukami. 1934. Ibid

L. salivarius Rogosa, Wiseman, Mitchell and Disraely 1953

Rogosa, M., R.F. Wiseman, J.A. Mitchell and M.N. Disraely. 1953. Journal of Bacteriology 65:681-699. Type strain: ATCC 11741

Description: Bergey 8.

L. salivarius subsp. salicinius Rogosa, Wiseman, Mitchell and Disraely 1953

Rogosa, M., R.F. Wiseman, J.A. Mitchell and M.N. Disraely. 1953. Journal of Bacteriology 65:681-699. Type strain: ATCC 11742

Description: Bergey 8.

L. salivarius subsp. salivarius Rogosa, Wiseman, Mitchell and Disraely 1953

Rogosa, M., R.F. Wiseman, J.A. Mitchell and M.N. Disraely. 1953. Journal of Bacteriology 65:681-699. Type strain: ATCC 11741

Description: Bergey 8.

L. trichodes Fornachon, Douglas and Vaughn 1949

Fornachon, J.C.M., H.C. Douglas and R.H. Vaughn. 1949. Hilgardia 19:129. 
132. Type strain: ATCC 27394

Description: Bergey 8.

L. viridescens Kandler and Abo-Elnaga 1966 Kandler, O. and I.G. Abo-Elnaga. 1966. Zentralblatt fur Bakteriologie, Parasitenkunde, Infektionskrankheiten und Hygiene. Abteilung II. 120:753-754. Type strain: ATCC 12706

Description: Bergey 8.

L. vitulinus Sharpe, Latham, Garvie, Zirngibl and Kandler 1973

Sharpe, M.E., M.J. Latham, E.I. Garvie, J. Zirngibl and O. Kandler. 1973. Journal of General Microbiology 77:37-49. Type strain: ATCC 27783

Description: Sharpe, M.E., M.J. Latham, E.I. Garvie, J. Zirngibl and O. Kandler. 1973. Ibid.

L. xylosus Kitahara 1938

Kitahara, K. 1938. Journal of the Agricultural Chemical Society of Japan 14:1449-1465. Type strain: ATCC 15577

Description: Bergey 8.

\section{Lamprocystis Schroeter 1886}

Schroeter, J. 1885-1889 in Cohn, F. Kryptogamenflora von Schlesien. Band 3, Heft 3, Pilze J.U. Kern's Verlag, Breslau. pp. 1-814. Type species: $L$. roseopersicina (Kutzing 1849) Schroeter 1886

Description: Bergey 8.

L. roseopersicina (Kutzing 1849) Schroeter 1886

Kutzing, F.T. 1849. Species Algarum. Lipsiae, pp. 1-922; Schroeter, J. 18851889 in Cohn, F. Kryptogamenflora von Schlesien. Band 3, Heft 3, Pilze J.U. Kern's Verlag. Breslau, pp. 1-814. Type strain: DSM 229

Description: Bergey 8 .

Lampropedia Schroeter 1886

Schroeter, J. 1885-1889 in Cohn, F. Kryptogamenflora von Schlesien. Band 3, Heft 3, Pilze J.U. Kern's Verlag, Breslau. pp. 1-814. Type species: $L$. hyalina (Ehrenberg 1832) Schroeter 1886

Description: Bergey 8 .

L. hyalina (Ehrenberg 1832) Schroeter 1886

Ehrenberg, C.G. 1832. Abhandlungen der Deutschen Akademie der Wissenschaften zu Berlin 1830:1-88; Schroeter, J. 18851889 in Cohn, F. Kryptogamenflora von
Schlesien. Band 3, Heft 3, Pilze J.U. Kern's Verlag, Breslau. pp. 1-814. Type strain: ATCC 11041

Description: Bergey 8 .

Legionella Brenner, Steigerwalt and McDade 1979

Brenner, D.J., A.G. Steigerwalt and J.E. McDade. 1979. International Journal of Systematic Bacteriology 29:436; Effective publication Brenner, D.J., A.G. Steigerwalt and J.E. McDade. 1979. Annals of Internal Medicine 90:656-658. Type species: L. pneumophila Brenner, Steigerwalt and McDade 1979

Description: Brenner, D.J., A.G. Steigerwalt and J.E. McDade. 1979. Ibid.

L. pneumophila Brenner, Steigerwalt and McDade 1979

Brenner, D.J., A.G. Steigerwalt and J.E. McDade. 1979. International Journal of Systematic Bacteriology 29:436; Effective pbulication Brenner, D.J., A.G. Steigerwalt and J.E. McDade. 1979. Annals of Internal Medicine 90:656-658. Type strain: ATCC 33152

Description: Brenner, D.J., A.G. Steigerwalt and J.E. McDade. 1979. Ibid.

Leptospira Noguchi 1917

Noguchi, H. 1917. Journal of Experimental Medicine 25:755-763. Type species: $L$. interrogans (Stimson 1907) Wenyon 1926 Description: Bergey 8.

L. biflexa (Wolbach and Binger 1914) Noguchi 1918

Wolbach, S.B. and C.A.L. Binger. 1914. Journal of Medical Research 30:23-26; Noguchi, H. 1918. Journal of Experimental Medicine 27:575-592. Type strain: ATCC 23582

Description: Bergey 8 .

L. interrogans (Stimson 1907) Wenyon 1926

Stimson, A.M. 1907. Public Health Report 22:541; Wenyon, C.M. 1926 in Wenyon, C.M. Protozoology, Vol. 2. Williams, Wood and Co., New York. pp. 1233-1288. Type strain: ATCC 23581

Description: Bergey 8.

Leptothrix Kutzing 1843

Kutzing, F.T. 1843. Phycologia Generalis. Leipzig. Type species: L. ochracea (Roth 
1797) Kutzing 1843

Description: Bergey 8.

L. cholodnii Mulder and van Veen 1963

Mulder, E.G. and W.L. van Veen. 1963.

Antonie van Leeuwenhoek Journal of

Microbiology and Serology 29:121-153.

Type strain: LVMW 99

Description: Mulder, E.G. and W.L. van Veen. 1963. Ibid.

L. lopholea Dorff 1934

Dorff, P. 1934. Pflanzenforschung, Jena.

16:1-62. Type strain: LVMW 124

Description: Mulder, E.G. and W.L. van

Veen. 1963. Antonie van Leeuwenhoek Journal of Microbiology and Serology 29: 121-153.

L. ochracea (Roth 1797) Kutzing 1843

Roth, A.W. 1797. Catalecta botanica quibus plantae novae et minus cognitae describuntur atque illustrantur. Lipsiae in Bibliopolio I.G. Mulleriano, Fasc. 1; Kutzing, F.T. 1843. Phycologia Generalis. Leipzig. Type strain: no culture available. Description: Bergey 8.

\section{Leptotrichia Trevisan 1879}

Trevisan, V. 1879. R C Institut Lombardo (Seriale 2) 12:133-151. Type species: L. buccalis (Robin 1853) Trevisan 1879

Description: Bergey 8 .

L. buccalis (Robin 1853) Trevisan 1879

Robin, C. 1853. J.-B. Bailliere, Paris. pp. 1-702; Trevisan, V. 1879. R C Institut Lombardo (Seriale 2) 12:133-151. Type strain: ATCC 14201

Description: Holdeman, L.V., E.P. Cato and W.E.C. Moore (eds). 1977. Anaerobe Laboratory Manual, 4th ed. Virginia Polytechnic Institute and State University, Blacksburg, Virginia. pp. 1-156.

\section{Leuconostoc van Tieghem 1878}

van Tiegham, P. 1878. Annales des Sciences Naturelles Botanique 7:180-203. Type species: L. mesenteroides (Tsenkovskii 1878) van Tiegham 1878

Description: Bergey 8.

L. cremoris (Kundsen and Sorenson 1929) Garvie 1960

Kundsen, S. and A. Sorenson. 1929. Zentralblatt fur Bakteriologie, Parasitenkunde, Infektionskrankheiten und
Hygiene. Abteilung II. 79:75-85; Garvie, E.I. 1960. Journal of Dairy Research 27: 283-292. Type strain: NCDO 543

Description: Garvie, E.I. 1979. International Journal of Systematic Bacteriology 29:149-151.

L. dextranicum (Beijerinck 1912) Hucker and Pederson 1930

Beijerinck, M.W. 1912. Folia Mikrobiologiya (Delft) 1:4-100; Hucker, G.J. and C.S. Pederson. 1930. Technical Bulletin New York State Agricultural Experiment Station 167:3-80. Type strain: NCDO 529 Description: Garvie, E.I. 1979. International Journal of Systematic Bacteriology 29:149-151.

L. lactis Garvie 1960

Garvie, E.I. 1960. Journal of Dairy Research 27:283-292. Type strain: NCDO 533

Description: Garvie, E.I. 1960. Ibid.

L. mesenteroides (Tsenkovskii 1878) van Tieghem 1878

Tsenkovskii, L. 1878. Proceedings of the Society of Natural Sciences of the Imperial University of Kharkov 12:137167; van Tieghem, P. 1878. Annales des Sciences Naturelles Botanique 7:180-203. Type strain: ATCC 8293

Description: Garvie, E.I. 1979. International Journal of Systematic Bacteriology 29:149-151.

L. oenos Garvie 1967

Garvie, E.I. 1967. Journal of General Microbiology 48:431-438. Type strain: NCDO 1674

Description: Garvie, E.I. 1967. Ibid.

L. paramesenteroides Garvie 1967

Garvie, E.I. 1967. Journal of General Microbiology 48:439-447. Type strain: NCDO 803

Description: Garvie, E.I. 1967. Ibid.

Leucothrix Oersted 1844

Oersted, A.S. 1844. De Regionibus marinis. Elementa Topographiae Historiconaturalis Freti Oeresund. Inaugural Dissertation. J.C. Scharling, Copenhagen. Type species: $L$. mucor Oersted 1844 Description: Bergey 8.

L. mucor Oersted 1844

Oersted, A.S. 1844. De Regionibus Marinis. Elementa Topographiae Histori- 
conaturalis Freti Oeresund. Inaugural Dissertation. J.C. Scharling, Copenhagen. Type strain: ATCC 25107

Description: Bergey 8.

Levinea Young, Kenton, Hobbs and Moody 1971

Young, V.M., D.M. Kenton, B.J. Hobbs and M.R. Moody. 1971. International Journal of Systematic Bacteriology 21:5863. Type species: L. amalonatica Young, Kenton, Hobbs and Moody 1971

Description: Young, V.M., D.M. Kenton, B.J. Hobbs and M.R. Moody. 1971. Ibid.

L. amalonatica Young, Kenton, Hobbs and Moody 1971

Young, V.M., D.M. Kenton, B.J. Hobbs and M.R. Moody. 1971. International Journal of Systematic Bacteriology 21:5863. Type strain: ATCC 25405

Description: Young, V.M., D.M. Kenton, B.J. Hobbs and M.R. Moody. 1971. Ibid.

L. malonatica Young, Kenton, Hobbs and Moody 1971

Young, V.M., D.M. Kenton, B.J. Hobbs and M.R. Moody. 1971. International Journal of Systematic Bacteriology 21:5863. Type strain: ATCC 25408

Description: Young, V.M., D.M. Kenton, B.J. Hobbs and M.R. Moody. 1971. Ibid.

Listeria Pirie 1940

Pirie, J.H.H. 1940. Science (Washington) 91:383. Type species: L. monocytogenes (Murray, Webb and Swann 1926) Pirie 1940

Description: Bergey 8.

L. denitrificans Prevot 1961

Prevot, A.R. 1961. Traite de Systematique Bacterienne, Vol. 2, Dunod, Paris. pp. 1-771. Type strain: ATCC 14870

Description: Bergey 8.

L. grayi Errebo Larsen and Seeliger 1966

Errebo Larsen, H. and H.P.R. Seeliger. 1966. Proceedings of the Third International Symposium on Listeriosis July 1316, Bilthoven. p. 35 . Type strain: ATCC 19120

Description: Bergey 8.

L. monocytogenes (Murray, Webb and Swann 1926) Pirie 1940

Murray, E.G.D., A.A. Webb and M.B.R.
Swann. 1926. Journal of Pathology and Bacteriology 29:407-439; Pirie, J.H.H. 1940. Science (Washington) 91:383. Type strain: ATCC 15313

Description: Bergey 8.

L. murrayi Welshimer and Meredith 1971

Welshimer, H.J. and A. Meredith. 1971. International Journal of Systematic Bacteriology 21:3-7. Type strain: ATCC 25401

Description: Bergey 8.

Lucibacterium Hendrie, Hodgkiss and Shewan 1970

Hendrie, M.S., W. Hodgkiss and J.M. Shewan. 1970. Journal of General Microbiology 64:151-169. Type species: $L$. harveyi (Johnson and Shunk 1936) Hendrie, Hodgkiss and Shewan 1970 Description: Bergey 8.

L. harveyi (Johnson and Shunk 1936) Hendrie, Hodgkiss and Shewan 1970 (See also Beneckea harveyi)

Johnson, F.H. and I.V. Shunk. 1936. Journal of Bacteriology 31:585-592; Hendrie, M.S., W. Hodgkiss and J.M. Shewan. 1970. Journal of General Microbiology 64:151-169. Type strain: ATCC 14126

Description: Johnson, F.H. and I.V. Shunk. 1936. Ibid.

\section{Lysobacter Christensen and Cook 1978}

Christensen, P. and F.D. Cook. 1978. International Journal of Systematic Bacteriology 28:367-393. Type species: $L$. enzymogenes Christensen and Cook 1978

Description: Christensen, P. and F.D. Cook. 1978. Ibid.

L. antibioticus Christensen and Cook 1978 Christensen, P. and F.D. Cook. 1978. International Journal of Systematic Bacteriology 28:367-393. Type strain: ATCC 29479

Description: Christensen, P. and F.D. Cook. 1978. Ibid.

L. brunescens Christensen and Cook 1978 Christensen, P. and F.D. Cook. 1978. International Journal of Systematic Bacteriology 28:367-393. Type strain: ATCC 29482

Description: Christensen, P. and F.D. Cook. 1978. Ibid. 
L. enzymogenes Christensen and Cook 1978 Christensen, P. and F.D. Cook. 1978. International Journal of Systematic Bacteriology 28:367-393. Type strain: ATCC 29487

Description: Christensen, P. and F.D. Cook. 1978. Ibid.

L. gummosus Christensen and Cook 1978 Christensen, P. and F.D. Cook. 1978. International Journal of Systematic Bacteriology 28:367-393. Type strain: ATCC 29489

Description: Christensen, P. and F.D. Cook. 1978. Ibid.

Macromonas Utermohl and Koppe 1924 Utermohl, H. and F. Koppe. 1924 in Koppe, F. Archiv fur Hydrobiologie 14: 619-672. Type species: $M$. mobilis (Lauterborn 1915) Utermohl and Koppe 1924 Description: Bergey 8.

M. mobilis (Lauterborn 1915) Utermohl and Koppe 1924

Lauterborn, R. 1915. Verhandlungen des Naturhistorisch- Medizinischen Vereins zu Heidelberg 13:395-481. Type strain: no culture available.

Description: Bergey 8.

\section{Megasphaera Rogosa 1971}

Rogosa, M. 1971. International Journal of Systematic Bacteriology 21:187-189. Type species: $M$. elsdenii (Gutierrez, Davis, Lindahl and Warwick 1959) Rogosa 1971 Description: Bergey 8.

M. elsdenii (Gutierrez, Davis, Lindahl and Warwick 1959) Rogosa 1971

Gutierrez, J., R.E. Davis, I.L. Lindahl and E.J. Warwick. 1959. Applied Microbiology 7:16-22; Rogosa, M. 1971. International Journal of Systematic Bacteriology 21:187-189. Type strain: ATCC 25940

Description: Holdeman, L.V., E.P. Cato and W.E.C. Moore (eds). 1977. Anaerobe Laboratory Manual, 4th ed. Virginia Polytechnic Institute and State University, Blacksburg, Virginia. pp. 1-156.

\section{Melittangium Jahn 1924}

Jahn, E. 1924. Beitrage zur botanischen Protistologie. I. Die Polyangiden. Verlag von Gebruder Borntraeger, Leipzig. Type species: $M$. boletus Jahn 1924

Description: Bergey 8.

M. alboraceum (Peterson 1959) McCurdy 1971

Peterson, J.E. 1959. Mycologia 51:163-

172; McCurdy, H.D. 1971. International Journal of Systematic Bacteriology 21:5054. Type strain: UMH Slides Peterson 72

Description: Peterson, J.E. 1959. Ibid.

M. boletus Jahn 1924

Jahn, E. 1924. Beitrage zur botanischen Protistologie. I. Die Polyangiden. Verlag von Gebruder Borntraeger, Leipzig. Type strain: not

Description: Jahn, E. 1924. Ibid.

M. lichenicola (Thaxter 1892) McCurdy 1971

Thaxter, R. 1892. Botanical Gazette 17: 389-406; McCurdy, H.D. 1971. International Journal of Systematic Bacteriology 21:50-54. Type strain: ATCC 25944

Description: McCurdy, H.D. 1971. Ibid.

Meniscus Irgens 1977

Irgens, R.L. 1977. International Journal of Systematic Bacteriology 27:38-43. Type species: $M$. glaucopis Irgens 1977

Description: Irgens, R.L. 1977. Ibid.

M. glaucopis Irgens 1977

Irgens, R.L. 1977. International Journal of Systematic Bacteriology 27:38-43. Type strain: ATCC 29398

Description: Irgens, R.L. 1977. Ibid.

Methanobacterium Kluyver and van Niel 1936 Kluyver, A.J. and C.B. van Niel. 1936. Zentralblatt fur Bakteriologie, Parasitenkunde, Infektionskrankheiten und Hygiene. Abteilung II. 94:369-403. Type species: $M$. formicicum Schnellen 1947 Description: Bergey 8.

M. arbophilicum Zeikus and Henning 1975 Zeikus, J.G. and D.L. Henning. 1975. Antonie van Leeuwenhoek Journal of Microbiology and Serology 41:543-552. Type strain: DSM 1125

Description: Zeikus, J.G. and D.L. Henning. 1975. Ibid.

M. formicicum Schnellen 1947

Schnellen, C.G.T.P. 1947. Onderzoekingen over de methaangisting. Thesis, Delft. pp. 1-137. Type strain: DSM 863

Description: Mylorie, R.L. and R.E. Hungate. 1954. Canadian Journal of Microbiology 1:55-64. 
M. mobile Paynter and Hungate 1968

Paynter, M.J.B. and R.E. Hungate. 1968. Journal of Bacteriology 95:1943-1951. Type strain: DSM 1539

Description: Paynter, M.J.B. and R.E. Hungate. 1968. Ibid.

M. ruminantium Smith and Hungate 1958

Smith, P.H. and R.E. Hungate. 1958. Journal of Bacteriology 75:713-718. Type strain: DSM 1093

Description: Bergey 8.

M. thermoautotrophicum Zeikus and Wolfe 1972

Zeikus, J.G. and R.S. Wolfe. 1972. Journal of Bacteriology 109:707-713. Type strain: ATCC 29096

Description: Zeikus, J.G. and R.S. Wolfe. 1972. Ibid.

Methanococcus Kluyver and van Niel 1936 emend. Barker 1936

Kluyver, A.J. and C.B. van Niel. 1936. Zentralblatt fur Bakteriologie, Parasitenkunde, Infektionskrankheiten und Hygiene. Abteilung II. 94:369-403; Barker, H.A. 1936. Archiv fur Mikrobiologie 7: 420-438. Type species: M. mazei Barker 1936

Description: Bergey 8.

M. mazei Barker 1936

Barker, H.A. 1936. Archiv fur Mikrobiologie 7:420-438. Type strain: not

Description: Bergey 8.

M. vannielii Stadtman and Barker 1951

Stadtman, T.C. and H.A. Barker. 1951. Journal of Bacteriology 62:269-280. Type strain: DSM 1224

Description: Stadtman, T.C. and H.A. Barker. 1951. Ibid.

Methanosarcina Kluyver and van Niel 1936 emend. Barker 1956

Kluyver, A.J. and C.B. van Niel. 1936. Zentralblatt fur Bakteriologie, Parasitenkunde, Infektionskrankheiten und Hygiene. Abteilung II. 94:369-403; Barker, H.A. 1956. Bacterial fermentations. John Wiley and Sons, New York. pp. 195. Type species: $M$. methanica (Smit 1930) Kluyver and van Niel 1936

Description: Bergey 8.

M. barkeri Schnellen 1947

Schnellen, C.G.T.P. 1947. Onderzoekingen over de methaangisting. Thesis, Delft. pp. 1-137. Type strain: DSM 800

Description: Mah, R.A., M.R. Smith and L. Baresi. 1978. Applied and Environmental Microbiology 35:1174-1184.

M. methanica (Smit 1930) Kluyver and van Niel 1936

Smit, J. 1930. Die Garungssarcinen. Eine Monographie. Pflanzenforschung Heft 14, pp. 1-59; Kluyver, A.J. and C.B. van Niel. 1936. Zentralblatt fur Bakteriologie, Parasitenkunde, Infektionskrankheiten und Hygiene. Abteilung II. 94:369-403. Type strain: not

Description: Bergey 8.

Methanospirillum Ferry, Smith and Wolfe 1974 Ferry, J.G., P.H. Smith and R.S. Wolfe. 1974. International Journal of Systematic Bacteriology 24:465-469. Type species: $M$. hungatii Ferry, Smith and Wolfe 1974

Description: Ferry, J.G., P.H. Smith and R.S. Wolfe. 1974. Ibid.

M. hungatii Ferry, Smith and Wolfe 1974

Ferry, T.G., P.H. Smith and R.S. Wolfe. 1974. International Journal of Systematic Bacteriology 24:465-469. Type strain: ATCC 27890

Description: Ferry, J.G., P.H. Smith and R.S. Wolfe. 1974. Ibid.

Methylobacillus Yordy and Weaver 1977

Yordy, J.R. and T.L. Weaver. 1977. International Journal of Systematic Bacteriology 27:247-255. Type species: $M$. glycogenes Yordy and Weaver 1977

Description: Yordy, J.R. and T.L. Weaver. 1977. Ibid.

M. glycogenes Yordy and Weaver 1977 Yordy, J.R. and T.L. Weaver. 1977. International Journal of Systematic Bacteriology 27:247-255. Type strain: ATCC 29475

Description: Yordy, J.R. and T.L. Weaver. 1977. Ibid.

Methylobacterium Patt, Cole and Hanson 1976 Patt, T.E., G.C. Cole and R.S. Hanson. 1976. International Journal of Systematic Bacteriology 26:226-229. Type species: $M$. organophilum Patt, Cole and Hanson 1976

Description: Patt, T.E., G.C. Cole and 
R.S. Hanson. 1976. Ibid.

M. organophilum Patt, Cole and Hanson 1976 Patt, T.E., G.C. Cole and R.S. Hanson. 1976. International Journal of Systematic Bacteriology 26:226-229. Type strain: ATCC 27886

Description: Patt, T.E., G.C. Cole and R.S. Hanson. 1976. Ibid.

Methylococcus Foster and Davis 1966

Foster, J.W. and R.H. Davis. 1966. Journal of Bacteriology 91:1924-1931. Type species: $M$. capsulatus Foster and Davis 1966

Description: Foster, J.W. and R.H. Davis. 1966. Ibid.

M. capsulatus Foster and Davis 1966

Foster, J.W. and R.H. Davis. 1966. Journal of Bacteriology 91:1924-1931. Type strain: ATCC 19069

Description: Foster, J.W. and R.H. Davis. 1966. Ibid.

M. thermophilus Malashenko, Romanovskaya, Bogachenko and Stved 1975

Malashenko, Y.R., V.A. Romanovskaya, V.N. Bogachenko and A.D. Stved. 1975. Mikrobiologiya 44:855-862 (English translation 773-779). Type strain: IMV-2Yu

Description: Malashenko, Y.R., V.A. Romanovskaya, V.N. Bogachenko and A.D. Stved. 1975. Ibid.

Microbacterium Orla-Jensen 1919

Orla-Jensen, S. 1919. The lactic acid bacteria. Host, Copenhagen. pp. 1-196. Type species: $M$. lacticum Orla-Jensen 1919

Description: Robinson, K. 1966. Journal of Applied Bacteriology 29:607-615.

M. lacticum Orla-Jensen 1919

Orla-Jensen, S. 1919. The lactic acid bacteria. Host, Copenhagen. pp. 1-196. Type strain: ATCC 8180

Description: Robinson, K. 1966. Journal of Applied Bacteriology 29:607-615.

Microbispora Nonomura and Ohara 1957

Nonomura, H. and Y. Ohara. 1957. Journal of Fermentation Technology 35: 307-311. Type species: $M$. rosea Nonomura and Ohara 1957

Description: Bergey 8.

M. aerata (Gerber and Lechevalier 1964) Cross
1974

Gerber, N.N. and M.P. Lechevalier. 1964. Biochemistry 3:598-602; Cross, $T$. 1964. Bergey 8. Type strain: ATCC 15448

Description: Bergey 8.

M. amethystogenes Nonomura and Ohara 1960 Nonomura, H. and Y. Ohara. 1960. Journal of Fermentation Technology 38: 401-409. Type strain: DSM 43164

Description: Bergey 8.

M. bispora (Henssen 1957) Lechevalier 1965

Henssen, A. 1957. Archiv fur Mikrobiologie 26:373-414; Lechevalier, H.A. 1965. International Bulletin of Bacteriological Nomenclature and Taxonomy 15:139-142. Type strain: ATCC 19993

Description: Bergey 8.

M. chromogenes Nonomura and Ohara 1960

Nonomura, H. and Y. Ohara. 1960. Journal of Fermentation Technology 38: 401-409. Type strain: DSM 43165

Description: Bergey 8.

M. diastatica Nonomura and Ohara 1960

Nonomura, H. and Y. Ohara. 1960. Journal of Fermentation Technology 38: 401-409. Type strain: KCC A-0023

Description: Bergey 8.

M. echinospora Nonomura and Ohara 1971

Nonomura, H. and Y. Ohara. 1971. Journal of Fermentation Technology 49: 887-894. Type strain: ATCC 27300

Description: Nonomura, H. and Y. Ohara. 1971. Ibid.

M. parva Nonomura and Ohara 1960

Nonomura, H. and Y. Ohara. 1960. Journal of Fermentation Technology 38: 401-409. Type strain: KCC A-0024

Description: Bergey 8.

M. rosea Nonomura and Ohara 1957

Nonomura, H. and Y. Ohara. 1957. Journal of Fermentation Technology 35: 307-311. Type strain: ATCC 12950

Description: Bergey 8.

M. thermodiastatica Nonomura and Ohara 1969

Nonomura, H. and Y. Ohara. 1969. Journal of Fermentation Technology 47: 701-709. Type strain: ATCC 27098

Description: Nonomura, H. and Y. Ohara. 1969. Ibid.

M. thermorosea Nonomura and Ohara 1969 
Nonomura, H. and Y. Ohara. 1969. Journal of Fermentation Technology 47: 701-709. Type strain: ATCC 27099

Description: Nonomura, $\mathrm{H}$. and Y. Ohara. 1969. Ibid.

\section{Micrococcus Cohn 1872}

Cohn, F. 1872. Beitrage zur Biologie der Pflanzen 1:127-224. Type species: $M$. luteus (Schroeter 1872) Cohn 1872

Description: Bergey 8.

M. agilis Ali-Cohen 1889

Ali-Cohen, C.H. 1889. Zentralblatt fur Bakteriologie, Parasitenkunde, Infektionskrankheiten und Hygiene. Abteilung I. 6: 33-36. Type strain: ATCC 966

Description: Kocur, M. and K.H. Schleifer. 1975. International Journal of Systematic Bacteriology 25:294-297.

M. halobius Onishi and Kamekura 1972

Onishi, H. and M. Kamekura. 1972. International Journal of Systematic Bacteriology 22:233-236. Type strain: ATCC 21727

Description: Onishi, H. and M. Kamekura. 1972. Ibid.

M. kristinae Kloos, Tornabene and Schleifer 1974

Kloos, W.E., T.G. Tornabene and K.H. Schleifer. 1974. International Journal of Systematic Bacteriology 24:79-101. Type strain: ATCC 27570

Description: Kloos, W.E., T.G. Tornabene and K.H. Schleifer. 1974. Ibid.

M. luteus (Schroeter 1872) Cohn 1872

Schroeter, J. 1872 in Cohn, F. 1875.

Beitrage zur Biologie der Pflanzen, J.U. Kern's Verlag, Breslau. pp. 109-126; Cohn, F. 1872. Beitrage zur Biologie der Pflanzen 1:127-224. Type strain: ATCC 4698

Description: Kocur, M., Z. Pacova and T. Martinec. 1972. International Journal of Systematic Bacteriology 22:218-223.

M. lylae Kloos, Tornabene and Schleifer 1974 Kloos, W.E., T.G. Tornabene and K. Schleifer. 1974. International Journal of Systematic Bacteriology 24:79-101. Type strain: ATCC 17566

Description: Kloos, W.E., T.G. Tornabene and K. Schleifer. 1974. Ibid.

M. nishinomiyaensis Oda 1935

Oda, M. 1935. Journal of Fermentation and Technology 13:1202-1228. Type strain: ATCC 29093

Description: Kocur, M., K.H. Schleifer and W.E. Kloos. 1975. International Journal of Systematic Bacteriology 25: 290-293.

M. roseus Flugge 1886

Flugge, C. 1886. Die Mikroorganismen. F.C.W. Vogel, Leipzig. Type strain: ATCC 186

Description: Kocur, M. and Z. Pacova. 1970. International Journal of Systematic Bacteriology 20:233-240.

M. sedentarius ZoBell and Upham 1944

ZoBell, C.E. and H.C. Upham. 1944.

Bulletin Scripps Institution of Oceanography University of California (Technical Series) 5:239-292. Type strain: ATCC 14392

Description: Kloos, W.E., T.G. Tornabene and K.H. Schleifer. 1974. International Journal of Systematic Bacteriology 24:79101.

M. varians Migula 1900

Migula, W. 1900. System der Bakterien.

Vol. 2. Gustav Fischer, Jena. Type strain: ATCC 15306

Description: Kocur, M. and T. Martinec. 1972. International Journal of Systematic Bacteriology 22:228-232.

\section{Microcyclus Orskov 1928}

Orskov, J. 1928. Zentralblatt fur Bakteriologie, Parasitenkunde, Infektionskrankheiten und Hygiene. Abteilung I. 107: 180-184. Type species: $M$. aquaticus Orskov 1928

Description: Larkin, J.M., P.M. Williams and R. Taylor. 1977. International Journal of Systematic Bacteriology27:147156.

M. aquaticus Orskov 1928

Orskov, J. 1928. Zentralblatt fur Bakteriologie, Parasitenkunde, Infektionskrankheiten und Hygiene. Abteilung I. 107:180-184. Type strain: ATCC 25396

Description: Larkin, J.M., P.M. Williams and R. Taylor. 1977. International Journal of Systematic Bacteriology 27: 147-156.

Microellobosporia Cross, Lechevalier and Lechevalier 1963 
Cross, T., M.P. Lechevalier and H.A. Lechevalier. 1963. Journal of General Microbiology 31:421-429. Type species: $M$. cinerea Cross, Lechevalier and Lechevalier 1963

Description: Bergey 8.

M. cinerea Cross, Lechevalier and Lechevalier 1963

Cross, T., M.P. Lechevalier and H.A. Lechevalier. 1963. Journal of General Microbiology 31:421-429. Type strain: ATCC 15840

Description: Cross, T., M.P. Lechevalier and H.A. Lechevalier. 1963. Ibid.

M. flavea Cross, Lechevalier and Lechevalier 1963

Cross, T., M.P. Lechevalier and H.A. Lechevalier. 1963. Journal of General Microbiology 31:421-429. Type strain: ATCC 15332

Description: Cross, T., M.P. Lechevalier and H.A. Lechevalier. 1963. Ibid.

M. grisea (Konev, Tsyganov, Minbayev and Morozov 1967) Pridham 1970

Konev, I.E., V.A. Tsyganov, P. Minbayev and V.M. Morozov. 1967. Mikrobiologiya 36:308-317; Pridham, T.G. 1970. Bulletin of the United States Department of Agriculture 1424:1-55. Type strain: ATCC 19618

Description: Bergey 8.

M. violacea (Tsyganov, Zhukova and Timofeeva 1964) Pridham 1974

Tsyganov, V.A., R.A. Zhukova and K.A. Timofeeva. 1964. Mikrobiologiya 33:863869; Pridham, T.G. 1974. Bergey 8. Type strain: DSM 43167

Description: Bergey 8.

\section{Micromonospora Orskov 1923}

Orskov, J. 1923. Investigations into the morphology of the ray fungi. Levin and Munksgaard, Copenhagen, Denmark. Type species: $M$. chalcea (Foulerton 1905) Orskov 1923

Description: Bergey 8.

M. aurantiaca Sveshnikova, Maksimova and Kudrina 1969

Sveshnikova, M.A., T.S. Maksimova and E.S. Kudrina. 1969. Mikrobiologiya 38: 754-763. Type strain: ATCC 27029

Description: Sveshnikova, M.A., T.S. Maksimova and E.S. Kudrina. 1969. Ibid.
M. brunnea Sveshnikova, Maksimova and Kudrina 1969

Sveshnikova, M.A., T.S. Maksimova and E.S. Kudrina. 1969. Mikrobiologiya 38: 754-763. Type strain: ATCC 27334

Description: Sveshnikova, M.A., T.S. Maksimova and E.S. Kudrina. 1969. Ibid.

M. carbonacea Luedemann and Brodsky 1965 Luedemann, G.M. and B.C. Brodsky. 1965. Antimicrobial Agents and Chemotherapy 1964:47-52. Type strain: ATCC 27114

Description: Bergey 8.

M. carbonacea subsp. aurantiaca Luedemann and Brodsky 1965

Luedemann, G.M. and B.C. Brodsky. 1965. Antimicrobial Agents and Chemotherapy 1964:47-52. Type strain: ATCC 27115

Description: Bergey 8.

M. carbonacea subsp. carbonacea Luedemann and Brodsky 1965

Luedemann, G.M. and B.C. Brodsky. 1965. Antimicrobial Agents and Chemotherapy 1964:47-52. Type strain: ATCC 27114

Description: Bergey 8.

M. chalcea (Foulerton 1905) Orskov 1923

Foulerton, A.G.R. 1905. Lancet 1:1199. 1200; Orskov, J. 1923. Investigations into the morphology of the ray fungi. Levin and Munksgaard, Copenhagen, Denmark. Type strain: ATCC 12452

Description: Bergey 8.

M. coerulea Jensen 1932

Jensen, H.L. 1932. Proceedings of the Linnean Society of New South Wales 57: 173-180. Type strain: ATCC 27008 Description: Bergey 8.

M. echinospora Luedemann and Brodsky 1964 Luedemann, G.M. and B.C. Brodsky. 1964. Antimicrobial Agents and Chemotherapy 1963:116-124. Type strain: ATCC 15837

Description: Bergey 8 .

M. echinospora subsp. echinospora Luedemann and Brodsky 1964

Luedemann, G.M. and B.C. Brodsky. 1964. Antimicrobial Agents and Chemotherapy 1963:116-124. Type strain: ATCC 15837

Description: Bergey 8.

M. echinospora subsp. ferruginea Luedemann 
and Brodsky 1964

Luedemann, G.M. and B.C. Brodsky. 1964. Antimicrobial Agents and Chemotherapy 1963:116-124. Type strain: ATCC 15836

Description: Bergey 8 .

M. echinospora subsp. pallida Luedemann and Brodsky 1964

Luedemann, G.M. and B.C. Brodsky. 1964. Antimicrobial Agents and Chemotherapy 1963:116-124. Type strain: ATCC 15838

Description: Bergey 8.

M. gallica (Erikson 1935) Waksman 1961

Erickson, D. 1935. Medical Research Council (Great Britain) Special Report series 203:5-61; Waksman, S.A. 1961. The Actinomycetes. Vol. 2. Classification, identification and descriptions of genera and species. The Williams and Wilkins Co., Baltimore. pp. 1-363. Type strain: NCTC 4582

Description: Bergey 8 .

M. halophytica Weinstein, Luedemann, Oden and Wagman 1968

Weinstein, M.J., G.M. Luedemann, E.M. Oden and G.H. Wagman. 1968. Antimicrobial Agents and Chemotherapy 1967: 435-441. Type strain: ATCC 27596

Description: Bergey 8.

M. halophytica subsp. halophytica Weinstein, Luedemann, Oden and Wagman 1968

Weinstein, M.J., G.M. Luedemann, E.M. Oden and G.H. Wagman. 1968. Antimicrobial Agents and Chemotherapy 1967: 435-441. Type strain: ATCC 27596

Description: Bergey 8.

M. halophytica subsp. nigra Weinstein, Luedemann, Oden and Wagman 1968

Weinstein, M.J., G.M. Luedemann, E.M. Oden and G.H. Wagman. 1968. Antimicrobial Agents and Chemotherapy 1967:435-441. Type strain: ATCC 33088

Description: Bergey 8.

M. inositola Kawamoto, Okachi, Kato, Yamamoto, Takahahashi, Takasawa and Nara 1974

Kawamoto, I., R. Okachi, H. Kato, S. Yamamoto, I. Takahashi, S. Takasawa and T. Nara. 1974. Journal of Antibiotics 27:493-501. Type strain: ATCC 21773 Description: Bergey 8.

M. purpurea Luedemann and Brodsky 1964
Luedemann, G.M. and B.C. Brodsky. 1964. Antimicrobial Agents and Chemotherapy 1963:116-124. Type strain: ATCC 15835

Description: Bergey 8 .

M. purpureochromogenes (Waksman and Curtis 1916) Luedemann 1971

Waksman, S.A. and R.E. Curtis. 1916. Soil Science 1:99-134; Luedemann, G.M. 1971. International Journal of Systematic Bacteriology 21:240-247. Type strain: ATCC 27007

Description: Bergey 8.

M. rhodorangea Wagman, Testa, Marquez and Weinstein 1974

Wagman, G.H., R.T. Testa, J.A. Marquez and M.J. Weinstein. 1974. Antimicrobial Agents and Chemotherapy 6:144-149. Type strain: ATCC 27932

Description: Wagman, G.H., R.T. Testa, J.A. Marquez and M.J. Weinstein. 1974. Ibid.

Micropolyspora Lechevalier, Solotorovsky and McDurmont 1961

Lechevalier, H.A., M. Solotorovsky and C.I. McDurmont. 1961. Journal of General Microbiology 26:11-18. Type species: $M$. brevicatena Lechevalier, Solotorovsky and McDurmont 1961

Description: Bergey 8.

M. angiospora Zhukova, Tsyganov and Morozov 1968

Zhukova, R.A., V.A. Tsyganov and V.M. Morozov. 1968. Mikrobiologiya 37:724728. Type strain: LIA $3479-30$

Description: Zhukova, R.A., V.A. Tsyganov and V.M. Morozov. 1968. Ibid.

M. brevicatena Lechevalier, Solotorovsky and McDurmont 1961

Lechevalier, H.A., M. Solotorovsky and C.I. McDurmont. 1961. Journal of General Microbiology 26:11-18. Type strain: ATCC 15333

Description: Bergey 8 .

M. faeni Cross, Maciver and Lacey 1968

Cross, T., A.M. Maciver and J. Lacey. 1968. Journal of General Microbiology 50:351-359. Type strain: ATCC 15347

Description: Bergey 8.

M. internatus Agre, Guzeva and Dorokhova 1974

Agre, N.S., L.N. Guzeva and L.A. 
Dorokhova. 1974. Mikrobiologiya 43:577583. Type strain: INMI 632

Description: Agre, N.S., L.N. Guzeva and L.A. Dorokhova. 1974. Ibid.

M. rectivirgula (Krassilnikov and Agre 1964) Prauser and Momirova 1970

Krassilnikov, N.A. and N.S. Agre. 1964. Hindustan Antibiotics Bulletin 6:97-107; Prauser, H. and S. Momirova. 1970. Zeitschrift fur Allgemeine Mikrobiologie 10:219-222. Type strain: INMI 683

Description: Bergey 8.

Microscilla Pringsheim 1951

Pringsheim, E.G. 1951. Journal of General Microbiology 5:124-149. Type species: M. marina Pringsheim 1951

Description: Pringsheim, E.G. 1951. Ibid.

M. marina (Pringsheim 1951) Lewin 1969

Pringsheim, E.G. 1951. Journal of General Microbiology 5:124-149; Lewin, R.A. 1969. Journal of General Microbiology 58:189-206. Type strain: ATCC 23134

Description: Lewin, R.A. 1969. Ibid.

Microtetraspora Thiemann, Pagani and Beretta 1968

Thiemann, J.E., H. Pagani and G. Beretta. 1968. Journal of General Microbiology 50:295-303. Type species: $M$. glauca Thiemann, Pagani and Beretta 1968

Description: Thiemann, J.E., H. Pagani and G. Beretta. 1968. Ibid.

M. fusca Thiemann, Pagani and Beretta 1968

Thiemann, J.E., H. Pagani and G. Beretta. 1968. Journal of General Microbiology 50:295-303. Type strain: ATCC 23058

Description: Thiemann, J.E., H. Pagani and G. Beretta. 1968. Ibid.

M. glauca Thiemann, Pagani and Beretta 1968 Thiemann, J.E., H. Pagani and G. Beretta. 1968. Journal of General Microbiology 50:295-303. Type strain: ATCC 23057

Description: Thiemann, J.E., H. Pagani and G. Beretta. 1968. Ibid.

M. niveoalba Nonomura and Ohara 1971

Nonomura, H. and Y. Ohara. 1971. Journal of Fermentation Technology 49: 887-894. Type strain: ATCC 27301
Description: Thiemann, J.E., H. Pagani and G. Beretta. 1968. Journal of General Microbiology 50:295-303.

M. viridis Nonomura and Ohara 1971

Nonomura, H. and Y. Ohara. 1971. Journal of Fermentation Technology 49: 887-894. Type strain: ATCC 27103

Description: Thiemann, J.E., H. Pagani and G. Beretta. 1968. Journal of General Microbiology 50:295-303.

Moraxella Lwoff 1939

Lwoff, A. 1939. Annales de l'Institut Pasteur (Paris) 62:168-176. Type species: M. lacunata (Eyre 1900) Lwoff 1939

Description: Bergey 8.

M. anatipestifer (Hendrickson and Hilbert 1932) Bruner and Fabricant 1954

Hendrickson, J.M. and K.F. Hilbert. 1932. Cornell Veterinarian 22:239-252; Bruner, D.W. and J. Fabricant. 1954. Cornell Veterinarian 44:461-464. Type strain: ATCC 11845

Description: Henriksen, S.D. 1973. Bacteriological Reviews 37:522-561.

M. atlantae Bovre, Fuglesang, Hagen, Jantzen and Froholm 1976

Bovre, K., J.E. Fuglesang, N. Hagen, E. Jantzen and L.O. Froholm. 1976. International Journal of Systematic Bacteriology 26:511-521. Type strain: ATCC 29525

Description: Bovre, K., J.E. Fuglesang, N. Hagen, E. Jantzen and L.O. Froholm. 1976. Ibid.

M. bovis (Hauduroy, Ehringer, Urbain, Guillot and Magrou 1937) Murray 1948

Hauduroy, P., G. Ehringer, A. Urbain, G. Guillot and J. Magrou. 1937. Dictionnaire des Bacteries Pathogenes. Masson et Cie, Paris. p. 247; Murray, E.G.D. 1948 in Breed, R.S., E.G.D. Murray and A.P. Hitchens (eds). Bergey's Manual of Determinative Bacteriology, 6th ed. The Williams and Wilkins Co., Baltimore. pp. 590-592. Type strain: ATCC 10900

Description: Henriksen, S.D. 1973. Bacteriological Reviews 37:522-561.

M. catarrhalis (Frosch and Kolle 1896) Henriksen and Bovre 1968

Frosch, P. and W. Kolle. 1896 in Flugge, C. Die Mikroorganismen. 3rd ed. Verlag von Vogel, Leipzig. Part 2. p. 154; Henriksen, S.D. and K. Bovre. 1968. 
Journal of General Microbiology 51:387392. Type strain: ATCC 25238

Description: Catlin, B.W. 1970. International Journal of Systematic Bacteriology 20:155-159.

M. caviae (Pelczar 1953) Henriksen and Bovre 1968

Pelczar, M.J. 1953. Journal of Bacteriology 65:744; Henriksen, S.D. and K. Bovre. 1968. Journal of General Microbiology 51:387-392. Type strain: ATCC 14659

Description: Berger, U. 1963. Ergebnisse der Mikrobiologie, Immunitatsforschung und experimentellen Therapie 36:97-167.

M. equi Hughes and Pugh 1970

Hughes, D.E. and G.W. Pugh. 1970. American Journal of Veterinary Research 31:457-462. Type strain: ATCC 25576

Description: Hughes, D.E. and G.W. Pugh. 1970. Ibid.

M. lacunata (Eyre 1900) Lwoff 1939

Eyre, J.W. 1900. Journal of Pathology and Bacteriology 6:1-13; Lwoff, A. 1939. Annales de l'Institut Pasteur (Paris) 62: 168-176. Type strain: ATCC 17967

Description: Henriksen, S.D. 1973. Bacteriological Reviews 37:522-561.

M. nonliquefaciens (Scarlett 1916) Lwoff 1939

Scarlett, M. 1916. Annales d'Oculistique (Paris) 153:100-111; Lwoff, A. 1939. Annales de l'Institut Pasteur (Paris) 62: 168-176. Type strain: ATCC 19975

Description: Henriksen, S.D. 1973. Bacteriological Reviews 37:522-561.

M. osloensis Bovre and Henriksen 1967

Bovre, K. and S.D. Henriksen. 1967. International Journal of Systematic Bacteriology 17:127-135. Type strain: ATCC 19976

Description: Henriksen, S.D. 1973. Bacteriological Reviews 37:522-561.

M. ovis (Lindqvist 1960) Henriksen and Bovre 1968

Lindqvist, K. 1960. Journal of Infectious Diseases 106:162-165; Henriksen, S.D. and K. Bovre. 1968. Journal of General Microbiology 51:387-392. Type strain: ATCC 33078

Description: Berger, U. 1963. Ergebnisse der Mikrobiologie, Immunitatsforschung und experimentellen Therapie 36:97-167.

M. phenylpyruvica Bovre and Henriksen 1967

Bovre, K. and S.D. Henriksen. 1967.
International Journal of Systematic Bacteriology 17:343-360. Type strain: ATCC 23333

Description: Henriksen, S.D. 1973. Bacteriological Reviews 37:522-561.

M. saccharolytica Flamm 1956

Flamm, H. 1956. Zentralblatt fur Bakteriologie, Parasitenkunde, Infektionskrankheiten und Hygiene. Abteilung I. 166: 498-502. Type strain: ATCC 19245

Desçription: Flamm, H. 1956. Ibid.

M. urethralis Lautrop, Bovre and Frederiksen 1970

Lautrop, H., K. Bovre and W. Frederiksen. 1970. Acta Pathologica et Microbiologica Scandinavica, Section B, 78:255-256. Type strain: ATCC 17960

Description: Lautrop, H., K. Bovre and W. Frederiksen. 1970. Ibid.

\section{Morganella Fulton 1943}

Fulton, MacD. 1943. Journal of Bacteriology 46:79-81. Type species: $M$. morganii (Winslow, Kligler and Rothberg 1919) Brenner, Farmer, Fanning, Steigerwalt, Klykken, Wathen, Hickman and Ewing 1978

Description: Fulton, MacD. 1943. Ibid.

M. morganii (Winslow, Kligler and Rothberg 1919) Brenner, Farmer, Fanning, Steigerwalt, Klykken, Wathen, Hickman and Ewing 1978

Winslow, C.E.A., I.J. Kligler and W. Rothberg. 1919. Journal of Bacteriology 4:429-503; Brenner, D.J., J.J. Farmer III, G.R. Fanning, A.G. Steigerwalt, P. Klykken, H.G. Wathen, F.W. Hickman and W.H. Ewing. 1978. International Journal of Systematic Bacteriology 28: 269-282. Type strain: ATCC 25830

Description: Brenner, D.J., J.J. Farmer III, G.R. Fanning, A.G. Steigerwalt, P. Klykken, H.G. Wathen, F.W. Hickman and W.H. Ewing. 1978. Ibid.

Mycobacterium Lehmann and Neumann 1896 Lehmann, K.B. and R. Neumann. 1896. Atlas und Grundriss der Bacteriologie und Lehrbuch der speziellen bacteriologischen Diagnostik. 1st ed. J.F. Lehmann, Munchen. Type species: $M$. tuberculosis (Zopf 1883) Lehmann and Neumann 1896 Description: Bergey 8. 
M. africanum Castets, Rist and Boisvert 1969 Castets, M., N. Rist and H. Boisvert. 1969. Medecin D'Afrique Noire 16:321322. Type strain: ATCC 25420

Description: Bergey 8.

M. asiaticum Weiszfeiler, Karasseva and Karczag 1971

Weiszfeiler, J., G.V. Karasseva and E. Karczag. 1971. Acta Microbiologica Academiae Scientiarum Hungaricae 18:247252. Type strain: ATCC 25276

Description: Weiszfeiler, J., G.V. Karasseva and E. Karczag. 1971. Ibid.

M. aurum Tsukamura 1966

Tsukamura, M. 1966. Journal of General Microbiology 45:253-273. Type strain: ATCC 23366

Description: Tsukamura, M. 1966. Ibid.

M. avium Chester 1901

Chester, F.D. 1901. A manual of determinative bacteriology. The Macmillan Co., New York. Type strain: ATCC 25291

Description: Meissner, G., K.H. Schroder, G.E. Amadio, W. Anz, S. Chaparas, H.W.B. Engel, P.A. Jenkins, W. Kappler, H.H. Kleeberg, E. Kubala, M. Kubin, D. Lauterbach, A. Lind, M. Magnusson, Zd. Mikova, S.R. Pattyn, W.B. Schaefer, J.L. Stanford, M. Tsukamura, L.G. Wayne, I. Willers and E. Wolinsky. 1974. Journal of General Microbiology 83:207-235.

M. bovis Karlson and Lessel 1970

Karlson, A.G. and E.F. Lessel. 1970. International Journal of Systematic Bacteriology 20:273-282. Type strain: ATCC 19210

Description: Karlson, A.G. and E.F. Lessel. 1970. Ibid.

M. chelonei Bergey, Harrison, Breed, Hammer and Huntoon 1923

Bergey, D.H., F.C. Harrison, R.S. Breed, B.W. Hammer and F.M. Huntoon. 1923. Bergey's Manual of Determinative Bacteriology, 1st ed. The Williams and Wilkins Co., Baltimore. Type strain: NCTC 946

Description: Kubica, G.P., I. Baess, R.E. Gordon, P.A. Jenkins, J.B.G. Kwapinski, C. McDurmont, S.R. Pattyn, H. Saito, V. Silcox, J.L. Stanford, K. Takeya and M. Tsukamura. 1972. Journal of General Microbiology 73:55-70.

M. chelonei subsp. abscessus (Moore and
Frerichs 1953) Kubica, Baess, Gordon, Jenkins, Kwapinski, McDurmont, Pattyn, Saito, Silcox, Stanford, Takeya and Tsukamura 1972

Moore, M. and J.B. Frerichs. 1953. Journal of Investigative Dermatology 20: 133-169; Kubica, G.P., I. Baess, R.E. Gordon, P.A. Jenkins, J.B.G. Kwapinski, C. McDurmont, S.R. Pattyn, H. Saito, V. Silcox, J.L. Stanford, K. Takeya and M. Tsukamura. 1972. Journal of General. Microbiology 73:55-70. Type strain: ATCC 19977

Description: Kubica, G.P., I. Baess, R.E. Gordon, P.A. Jenkins, J.B.G. Kwapinski, G. McDurmont, S.R. Pattyn, H. Saito, V. Silcox, J.L. Stanford, K. Takeya and M. Tsukamura. 1972. Ibid.

M. chelonei subsp. chelonei (Bergey, Harrison, Breed, Hammer and Huntoon 1923) Kubica, Baess, Gordon, Jenkins, Kwapinski, McDurmont, Pattyn, Saito, Silcox, Stanford, Takeya and Tsukamura 1972

Bergey, D.H., F.C. Harrison, R.S. Breed, B.W. Hammer and F.M. Huntoon. 1923. Bergey's Manual of Determinative Bacteriology, 1st ed. The Williams and Wilkins Co., Baltimore; Kubica, G.P., I. Baess, R.E. Gordon, P.A. Jenkins, J.B.G. Kwapinski, C. McDurmont, S.R. Pattyn, H. Saito, V. Silcox, J.H. Stanford, K. Takeya and M. Tsukamura. 1972. Journal of General Microbiology 73:55-70. Type strain: NCTC 946

Description: Kubica, G.P., I. Baess, R.E. Gordon, P.A. Jenkins, J.B.G. Kwapinski, C. McDurmont, S.R. Pattyn, H. Saito, V. Silcox, J.L. Stanford, K. Takeya and M. Tsukamura. 1972. Ibid.

M. chitae Tsukamura 1967

Tsukamura, M. 1967. Japanese Journal of Microbiology 11:43-47. Type strain: ATCC 19627

Description: Tsukamura, M. 1967. Ibid.

M. duvalii Stanford and Gunthorpe 1971

Stanford, J.L. and W.J. Gunthorpe. 1971. British Journal of Experimental Pathology 52:627-637. Type strain: NCTC 358

Description: Stanford, J.L. and W.J. Gunthorpe. 1971. Ibid.

M. farcinogenes Chamoiseau 1973 Chamoiseau, G. 1973. Annales de Microbiologie de l'Institut Pasteur (Paris) 124: 
215-222. Type strain: NCTC 10955

Description: Chamoiseau, G. 1973. Ibid.

M. flavescens Bojalil, Cerbon and Trujillo 1962

Bojalil, L.F., J. Cerbon and A. Trujillo.

1962. Journal of General Microbiology

28:333-346. Type strain: ATCC 14474

Description: Kubica, G.P., I. Baess, R.E. Gordon, P.A. Jenkins, J.B.G. Kwapinski, C. McDurmont, S.R. Pattyn, H. Saito, V. Silcox, J.L. Stanford, K. Takeya and M. Tsukamura. 1972. Journal of General Microbiology 73:55-70.

M. fortuitum da Costa Cruz 1938

da Costa Cruz, J.C. 1938. Acta Medica (Rio de Janeiro) 1:297-301. Type strain: ATCC 6841

Description: Kubica, G.P., I. Baess, R.E. Gordon, P.A. Jenkins, J.B.G. Kwapinski, C. McDurmont, S.P. Pattyn, H. saito, V. Silcox, J.L. Stanford, K. Takeya and M. Tsukamura. 1972. Journal of General Microbiology 73:55-70.

M. gadium Casal and Calero 1974

Casal, M. and J.R. Calero. 1974. Tubercle 55:299-308. Type strain: ATCC 27726

Description: Casel, M. and J.R. Calero. 1974. Ibid.

M. gastri Wayne 1966

Wayne, L.G. 1966. American Review of Respiratory Diseases 93:919-928. Type strain: ATCC 15754

Description: Wayne, L.G. 1966. Ibid.

M. gilvum Stanford and Gunthorpe 1971

Stanford, J.L. and W.J. Gunthorpe. 1971.

British Journal of Experimental Pathology 52:627-637. Type strain: NCTC 10742

Description: Stanford, J.L. and W.J. Gunthorpe. 1971. Ibid.

M. gordonae Bojalil, Cerbon and Trujillo 1962 Bojalil, L.F., J. Cerbon and A. Trujillo. 1962. Journal of General Microbiology 28:333-346. Type strain: ATCC 14470

Description: Wayne, L.G., T.M. Dietz, C. Gernez-Rieux, P.A. Jenkins, W. Kappler, G.P. Kubica, J.B.G. Kwapinski, G. Meissner, S.R. Pattyn, E.H. Runyon, K.H. Schroder, V.A. Silcox, A. Tacquet, M. Tsukamura and E. Wolinsky. 1971. Journal of General Microbiology 66:255271.

M. haemophilum Sompolinsky, Lagziel, Naveh and Yankilevitz 1978
Sompolinsky, D., A. Lagziel, D. Naveh and L. Yankilevitz. 1978. International Journal of Systematic Bacteriology 28:6775. Type strain: ATCC 29548

Description: Sompolinsky, D., A. Lagziel, D. Naveh and T. Yankilevitz. 1978. Ibid.

M. intracellulare (Cuttino and McCabe 1949) Runyon 1965

Cuttino, J.T. and A.M. McCabe. 1949. American Journal of Clinical Pathology 25:1-34; Runyon, E.H. 1965. Advances in Tuberculosis Research 14:235-287. Type strain: ATCC 13950

Description: Meissner, G., K.H. Schroder, G.E. Amadio, W. Anz, S. Chaparas, H.W.B. Engel, P.A. Jenkins, W. Kappler, H.H. Kleeberg, E. Kubala, M. Kubin, D. Lauterbach, A. Lind, M. Magnusson, $Z$ d. Mikova, S.R. Pattyn, W.B. Schaefer, J.L. Stanford, M. Tsukamura, L.G. Wayne, I. Willers and E. Wolinsky. 1974. Journal of General Microbiology 83:207-235.

M. kansasii Hauduroy 1955

Hauduroy, P. 1955. Derniers aspects du monde des mycobacteries. Masson et Cie, Paris. Type strain: ATCC 12478

Description: Bergey 8.

M. komossense Kazda and Muller 1979

Kazda, J. and K. Muller. 1979. International Journal of Systematic Bacteriology 29:361-365. Type strain: ATCC 33013

Description: Kazda, J. and K. Muller. 1979. Ibid.

M. leprae (Hansen 1880) Lehmann and Neumann 1896

Hansen, G.A. 1880. Virchows Archiv fur pathologische Anatomie und Physiologie und fur klinische Medizin 79:32-42; Lehmann, K.B. and R. Neumann. 1896. Atlas und Grundriss der Bakteriologie und Lehrbuch der speziellen bakteriologischen Diagnostik. 1st ed. J.F. Lehmann, Munchen. Type strain: Has not been cultivated.

Description: Bergey 8.

M. lepraemurium Marchoux and Sorel 1912 Marchoux, E. and F. Sorel. 1912. Annales de l'Institut Pasteur (Paris) 26: 675-700. Type strain: Difficult to cultivate.

Description: Saito, H., K. Yamaoka and K. Kiyotani. 1976. International Journal of Systematic Bacteriology 26:111-115. 
M. malmoense Schroder and Juhlin 1977

Schroder, K.H. and I. Juhlin. 1977. International Journal of Systematic Bacteriology 27:241-246. Type strain: ATCC 29571

Description: Schroder, K.H. and I. Juhlin. 1977. Ibid.

M. marinum Aronson 1926

Aronson, J.D. 1926. Journal of Infectious Diseases 39:314-320. Type strain: ATCC 927

Description: Bergey 8.

M. microti Reed 1957

Reed, G.B. 1957 in Breed, R.S., E.G.D. Murray and N.R. Smith (eds). Bergey's Manual of Determinative Bacteriology, 7th ed. The Williams and Wilkins Co., Baltimore. p. 703. Type strain: NCTC 8710

Description: Bergey 8.

M. nonchromogenicum Tsukamura 1965

Tsukamura, M. 1965. Medical Biology

71:110-113. Type strain: ATCC 19530

Description: Meissner, G., K.H. Schroder, G.E. Amadio, W. Anz, S. Chaparas, H.W.B. Engel, P.A. Jenkins, W. Kappler, H.H. Kleeberg, E. Kubala, M. Kubin, D. Lauterbach, A. Lind, M. Magnusson, Zd. Mikova, S.R. Pattyn, W.B. Schaefer, J.L. Stanford, M. Tsukamura, L.G. Wayne, I. Willers and E. Wolinsky. 1974. Journal of General Microbiology 83:207-235.

M. neoaurum Tsukamura 1972

Tsukamura, M. 1972. Medical Biology 85:229-233. Type strain: ATCC 25795

Description: Tsukamura, M. 1972. Ibid.

M. parafortuitum Tsukamura 1966

Tsukamura, M. 1966. Journal of General Microbiology 42:7-12. Type strain: ATCC 19686

Description: Saito, H., R.E. Gordon, I. Juhlin, W. Kappler, J.B.G. Kwapinski, C. McDurmont, S.R. Pattyn, E.H. Runyon, J.L. Stanford, I. Tarnok, H. Tasaka, M. Tsukamura and J. Weiszfeiler. 1977. International Journal of Systematic Bacteriology 27:75-85.

M. paratuberculosis Bergey, Harrison, Breed, Hammer and Huntoon 1923

Bergey, D.H., F.C. Harrison, R.S. Breed, B.W. Hammer and F.M. Huntoon. 1923. Bergey's Manual of Determinative Bacteriology, 1st ed. The Williams and
Wilkins Co., Baltimore. p. 374. Type strain: ATCC 19698

Description: Thorel, M.F. and L. Valette. 1976. Annales Recherches Veterinaire 7: 207-213.

M. phlei Lehmann and Neumann 1899

Lehmann, K.B. and R. Neumann. 1899. Lehmann's Medizin, Handatlanten X. Atlas und Grundriss der Bakteriologie und Lehrbuch der speziellen bakteriologischen Diagnostik. 2 Auflage. Type strain: ATCC 11758

Description: Kubica, G.P., I. Baess, R.E. Gordon, P.A. Jenkins, J.B.G. Kwapinski, C. McDurmont, S.R. Pattyn, H. Saito, V. Silcox, J.L. Stanford, K. Takeya and M. Tsukamura. 1972. Journal of General Microbiology 73:55-70.

M. scrofulaceum Prissick and Masson 1956

Prissick, F.H. and A.M. Masson. 1956. Canadian Medical Association Journal 75: 798-803. Type strain: ATCC 19981

Description: Wayne, L.G., T.M. Dietz, C. Gernez-Rieux, P.A. Jenkins, W. Kappler, G.P. Kubica, J.B.G. Kwapinski, G. Meissner, S.R. Pattyn, E.H. Runyon, K.H. Schroder, V.A. Silcox, A. Tacquet, M. Tsukamura and E. Wolinsky. 1971. Journal of General Microbiology 66:255271.

M. senegalense (Chamoiseau 1973) Chamoiseau 1979

Chamoiseau, G. 1973. Annales de Microbiologie de l'Institut Pasteur (Paris) 124: 215-222; Chamoiseau, G. 1979. International Journal of Systematic Bacteriology 29:407-410. Type strain: NCTC 10956 Description: Chamoiseau, G. 1973. Ibid.

M. simiae Karassova, Weiszfeiler and Krasznay 1965

Karassova, V., J. Weiszfeiler and E. Krasznay. 1965. Acta Microbiologica Academiae Scientiarum Hungaricae 12: 275-282. Type strain: ATCC 25275 Description: Bergey 8.

M. smegmatis (Trevisan 1889) Lehmann and Neumann 1899

Trevisan, V. 1889. I Generi e le Specie delle Bacteriacee. Zanaboni and Gabuzzi, Milano; Lehmann, K.B. and R. Neumann. 1899. Lehmann's Medizin Handatlanten X. Atlas und Grundriss der Bakteriologie und Lehrbuch der speziellen 
bakteriologischen Diagnostik. 2 Auflage. Type strain: ATCC 19420

Description: Kubica, G.P., I. Baess, R.E. Gordon, P.A. Jenkins, J.B.G. Kwapinski, C. McDurmont, S.R. Pattyn, H. Saito, V. Silcox, J.L. Stanford, K. Takeya and M. Tsukamura. 1972. Journal of General Microbiology 73:55-70.

M. szulgai Marks, Jenkins and Tsukamura 1972

Marks, J., P.A. Jenkins and M. Tsukamura. 1972. Tubercle 53:210-214. Type strain: NCTC 10831

Description: Marks, J., P.A. Jenkins and M. Tsukamura. 1972. Ibid.

M. terrae Wayne 1966

Wayne, L.G. 1966. American Review of Respiratory Diseases 93:919-928. Type strain: ATCC 15755

Description: Meissner, G., K.H. Schroder, G.E. Amadio, W. Anz, S. Chaparas, H.W.B. Engel, P.A. Jenkins, W. Kappler, H.H. Kleeberg, E. Kubala, M. Kubin, D. Lauterbach, A. Lind, M. Magnusson, Zd. Mikova, S.R. Pattyn, W.B. Schaefer, J.L. Stanford, M. Tsukamura, L.G. Wayne, I. Willers and E. Wolinsky. 1974. Journal of General Microbiology 83:207-235.

M. thermoresistibile Tsukamura 1966

Tsukamura, M. 1966. Journal of General Microbiology 45:253-273. Type strain: ATCC 19527

Description: Tsukamura, M. 1966. Ibid.

M. triviale Kubica 1970

Kubica, G.P. 1970 in Kubica, G.P., V.A. Silcox, J.O. Kilburn, R.W. Smithwick, R.E. Beam, W.D. Jones, Jr. and K.D. Stottmeier. International Journal of Systematic Bacteriology 20:161-174. Type strain: ATCC 23292

Description: Kubica, G.P. 1970. Ibid.

M. tuberculosis (Zopf 1883) Lehmann and Neumann 1896

Zopf, W. 1883. Die Spaltpilze, Edward Trewendt, Breslau. pp. 1-100; Lehmann, K.B. and R. Neumann. 1896. Atlas und Grundriss der Bakteriologie und Lehrbuch der speziellen bakteriologischen Diagnostik. 1st ed. J.F. Lehmann, Munchen. Type strain: ATCC 27294

Description: Bergey 8.

M. ulcerans MacCallum, Tolhurst and Buckle 1950
MacCallum, P., J.C. Tolhurst and G. Buckle. 1950 in Fenner, F. Medical Journal of Australia 2:813-818. Type strain: ATCC 19423

Description: Boisvert, H. 1977. Bulletin de la Societe de Pathologie Exotique 70:125131.

M. vaccae Bonicke and Juhasz 1964

Bonicke, R. and S.E. Juhasz. 1964. Zentralblatt fur Bakteriologie, Parasitenkunde, Infektionskrankheiten und Hygiene. Abteilung I. 192:133-135. Type strain: ATCC 15483

Description: Saito, H., R.E. Gordon, I. Juhlin, W. Kappler, J.B.G. Kwapinski, C. McDurmont, S.R. Pattyn, E.H. Runyon, J.L. Stanford, I. Tarnok, H. Tasaka, M. Tsukamura and J. Weiszfeiler. 1977. International Journal of Systematic Bacteriology 27:75-85.

M. xenopi Schwabacher 1959

Schwabacher, H. 1959. Journal of Hygiene 57:57-67. Type strain: NCTC 10042

Description: Meissner, G., K.H. Schroder, G.E. Amadio, W. Anz, S. Chaparas, H.W.B. Engel, P.A. Jenkins, W. Kappler, H.H. Kleeberg, E. Kubala, M. Kubin, D. Lauterbach, A. Lind, M. Magnusson, Zd. Mikova, S.R. Pattyn, W.B. Schaefer, J.L. Stanford, M. Tsukamura, L.G. Wayne, I. Willers and E. Wolinsky. 1974. Journal of General Microbiology 83:207-235.

Mycoplana Gray and Thornton 1928

Gray, P.H.H. and H.G. Thornton. 1928. Zentralblatt fur Bakteriologie, Parasitenkunde, Infektionskrankheiten und Hygiene. Abteilung II. 73:74-96. Type species: $M$. dimorpha Gray and Thornton 1928

Description: Gray, P.H.H. and H.G. Thornton. 1928. Ibid.

M. bullata Gray and Thornton 1928

Gray, P.H.H. and H.G. Thornton. 1928. Zentralblatt fur Bakteriologie, Parasitenkunde, Infektionskrankheiten und Hygiene. Abteilung II. 73:74-96. Type strain: ATCC 4278

Description: Gray, P.H.H. and H.G. Thornton. 1928. Ibid.

M. dimorpha Gray and Thornton 1928 Gray, P.H.H. and H.G. Thornton. 1928. Zentralblatt fur Bakteriologie, Parasiten- 
kunde, Infektionskrankheiten und Hygiene. Abteilung II. 73:74-96. Type strain: ATCC 4279

Description: Gray, P.H.H. and H.G. Thornton. 1928. Ibid.

Mycoplasma Nowak 1929

Nowak, J. 1929. Annales de l'Institut Pasteur (Paris) 43:1330-1352. Type species: $M$. mycoides (Borrel, DujardinBeaumetz, Jeantet and Jouan 1910) Freundt 1955

Description: Bergey 8.

M. agalactiae (Wroblewski 1931) Freundt 1955 Wroblewski, W. 1931. Annales de l'Institut Pasteur (Paris) 47:94-115; Freundt, E.A. 1955. International Bulletin of Bacteriological Nomenclature and Taxonomy 5:67-78. Type strain: NCTC 10123

Description: Cottew, G.S. 1979 in Barile, M.F., S. Razin, J.G. Tully and R.F. Whitcomb (eds). The Mycoplasmas. Academic Press, New York, Volume II. pp. 103-132.

M. alkalescens Leach 1973

Leach, R.H. 1973. Journal of General Microbiology 75:135-153. Type strain: ATCC 29103

Description: Leach, R.H. 1973. Ibid.

M. alvi Gourlay, Wyld and Leach 1977

Gourlay, R.N., S.G. Wyld and R.H. Leach. 1977. International Journal of Systematic Bacteriology 27:86-96. Type strain: ATCC 29626

Description: Gourlay, R.N., S.G. Wyld and R.H. Leach. 1977. Ibid.

M. anatis Roberts 1964

Roberts, D.H. 1964. Veterinary Record 76:470-473. Type strain: ATCC 25524

Description: Bergey 8.

M. arginini Barile, Del Giudice, Carski, Gibbs and Morris 1968

Barile, M.F., R.A. Del Giudice, T.R. Carski, C.J. Gibbs and J.A. Morris. 1968. Proceedings of the Society for Experimental Biology and Medicine 129:489-494. Type strain: ATCC 23838

Description: Gourlay, R.N. and C.J. Howard. 1979 in Barile, M.F., S. Razin, J.G. Tully and R.F. Whitcomb (eds). The Mycoplasmas. Academic Press, New York, Volume II. pp. 49-102.
M. arthritidis (Sabin 1941) Freundt 1955

Sabin, A.B. 1941. Bacteriological Reviews 5:1-66; Freundt, E.A. 1955. International Bulletin of Bacteriological Nomenclature and Taxonomy 5:67-78. Type strain: ATCC 19611

Description: Cassell, G.H. and A. Hill. 1979 in Barile, M.F., S. Razin, J.G. Tully and R.F. Whitcomb (eds). The Mycoplasmas. Academic Press, New York, Volume II. pp. 235-273.

M. bovigenitalium Freundt 1955

Freundt, E.A. 1955. International Bulletin of Bacteriological Nomenclature and Taxonomy 5:67-78. Type strain: ATCC 19852

Description: Gourlay, R.N. and C.J. Howard. 1979 in Barile, M.F., S. Razin, J.G. Tully and R.F. Whitcomb (eds). The Mycoplasmas. Academic Press, New York, Volume II. pp. 49-102.

M. bovirhinis Leach 1967

Leach, R.H. 1967. Annals of the New York Academy of Sciences 143:305-316. Type strain: ATCC 27748

Description: Gourlay, R.N. and C.J. Howard. 1979 in Barile, M.F., S. Razin, J.G. Tully and R.F. Whitcomb (eds). The Mycoplasmas. Academic Press, New York, Volume II. pp. 49-102.

M. bovis (Hale, Helmboldt, Plastridge and Stula 1962) Askaa and Erno 1976

Hale, H.H., C.F. Helmboldt, W.N. Plastridge and E.F. Stula. 1962. Cornell Veterinarian 52:582-591; Askàa, G. and H. Erno. 1976. International Journal of Systematic Bacteriology 26:323-325. Type strain: ATCC 25523

Description: Askaa, G. and H. Erno. 1976. Ibid.

M. bovoculi Langford and Leach 1973

Langford, E.V. and R.H. Leach. 1973. Canadian Journal of Microbiology 19: 1435-1444. Type strain: ATCC 29104

Description: Langford, E.V. and R.H. Leach. 1973. Ibid.

M. buccale Freundt, Taylor-Robinson, Purcell, Chanock and Black 1974

Freundt, E.A., D. Taylor-Robinson, R.H. Purcell, R.M. Chanock and F.T. Black. 1974. International Journal of Systematic Bacteriology 24:252-255. Type strain: ATCC 23636 
Description: Freundt, E.A., D. TaylorRobinson, R.H. Purcell, R.M. Chanock and F.T. Black. 1974. Ibid.

M. canadense Langford, Ruhnke and Onoviran 1976

Langford, E.V., H.L. Ruhnke and O. Onoviran. 1976. International Journal of Systematic Bacteriology 26:212-219. Type strain: ATCC 29418

Description: Langford, E.V., H.L. Ruhnke and O. Onoviran. 1976. Ibid.

M. canis Edward 1955

Edward, D.G. ff. 1955. International Bulletin of Bacteriological Nomenclature and Taxonomy 5:85-93. Type strain: ATCC 19525

Description: Rosendal, S. 1979 in Barile, M.F., S. Razin, J.G. Tully and R.F. Whitcamb (eds). The Mycoplasmas. Academic Press, New York, Volume II. pp. 217-234.

M. capricolum Tully, Barile, Edward, Theodore and Erno 1974

Tully, J.G., M.F. Barile, D.G. ff. Edward, T.S. Theodore and H. Erno. 1974. Journal of General Microbiology 85:102120. Type strain: ATCC 27343

Description: Tully, J.G., M.F. Barile, D.G. ff. Edward, T.S. Theodore and H. Erno. 1974. Ibid.

M. caviae Hill 1971

Hill, A. 1971. Journal of General Microbiology 65:109-113. Type strain: ATCC 27108

Description: Cassel, G.H. and A. Hill. 1979 in Barile, M.F., S. Razin, J.G. Tully and R.F. Whitcomb (eds). The Mycoplasmas. Academic Press, New York, Volume II. pp. 235-273.

M. citelli Rose, Tully and Langford 1978 Rose, D.L., J.G. Tully and E.V. Langford. 1978. International Journal of Systematic Bacteriology 28:567-572. Type strain: ATCC 29760

Description: Rose, D.L., J.G. Tully and E.V. Langford. 1978. Ibid.

M. columbinum Shimizu, Erno and Nagatomo 1978

Shimizu, T., H. Erno and H. Nagatomo. 1978. International Journal of Systematic Bacteriology 28:538-546. Type strain: ATCC 29257

Description: Shimizu, T., H. Erno and H.
Nagatomo. 1978. Ibid.

M. columborale Shimizu, Erno and Nagatomo 1978

Shimizu, T., H. Erno and H. Nagatomo. 1978. International Journal of Systematic Bacteriology 28:538-546. Type strain: ATCC 29258

Description: Shimizu, T., H. Erno and H. Nagatomo. 1978. Ibid.

M. conjunctivae Barile, Del Giudice and Tully 1972

Barile, M.F., R.A. Del Giudice and J.G. Tully. 1972. Infection and Immunity 5:7076. Type strain: ATCC 25834

Description: Barile, M.F., R.A. Del Giudice and J.G. Tully. 1972. Ibid.

M. cynos Rosendal 1973

Rosendal, S. 1973. International Journal of Systematic Bacteriology 23:49-54. Type strain: ATCC 27544

Description: Rosendal, S. 1973. Ibid.

M. dispar Gourlay and Leach 1970

Gourlay, R.N. and R.H. Leach. 1970. Journal of Medical Microbiology 3:111123. Type strain: ATCC 27140

Description: Gourlay, R.N. and C.J. Howard. 1979 in Barile, M.F., S. Razin, J.G. Tully and R.F. Whitcomb (eds). The Mycoplasmas. Academic Press, New York, Volume II. pp. 49-102.

M. edwardii Tully, Barile, Del Giudice, Carski, Armstrong and Razin 1970

Tully, J.G., M.F. Barile, R.A. Del Giudice, T.R. Carski, D. Armstrong and S. Razin. 1970. Journal of Bacteriology 101:346-349. Type strain: ATCC 23462

Description: Rosendal, S. 1979 in Barile, M.F., S. Razin, J.G. Tully and R.F. Whitcomb (eds). The Mycoplasmas. Academic Press, New York, Volume II. pp. 217-234.

M. equigenitalium Kirchhoff 1978

Kirchhoff, H. 1978. International Journal of Systematic Bacteriology 28:496-502. Type strain: ATCC 29869

Description: Kirchhoff, H. 1978. Ibid.

M. equirhinis Allam and Lemcke 1975

Allam, N.M. and R.M. Lemcke. 1975. Journal of Hygiene Cambridge 74:385408. Type strain: ATCC 29420

Description: Allam, N.M. and R.M. Lemcke. 1975. Ibid.

M. faucium Freundt, Taylor-Robinson, Purcell, 
Chanock and Black 1974

Freundt, E.A., D. Taylor-Robinson, R.H. Purcell, R.M. Chanock and F.T. Black 1974. International Journal of Systematic Bacteriology 24:252-255. Type strain: ATCC 25293

Description: Freundt, E.A., D. TaylorRobinson, R.H. Purcell, R.M. Chanock and F.T. Black. 1974. Ibid.

M. feliminutum Heyward, Sabry and Dowdle 1969

Heyward, J.T., M.Z. Sabry and W.R. Dowdle. 1969. American Journal of Veterinary Research 30:615-622. Type strain: ATCC 25749

Description: Rosendal, S. 1979 in Barile, M.F., S. Razin, J.G. Tully and R.F. Whitcomb (eds). The Mycoplasmas. Academic Press, New York, Volume II. pp. 217-234.

M. felis Cole, Golightly and Ward 1967

Cole, B.C., L. Golightly and J.R. Ward. 1967. Journal of Bacteriology 94:14511458. Type strain: ATCC 23391

Description: Bergey 8 .

M. fermentans Edward 1955

Edward, D.G. ff. 1955. International Bulletin of Bacteriological Nomenclature and Taxonomy 5:85-93. Type strain: ATCC 19989

Description: Bergey 8 .

M. flocculare Meyling and Friss 1972 Meyling, A. and N.F. Friis. 1972. Acta Veterinaria Scandinavica 13:287-289. Type strain: ATCC 27399

Description: Rose, D.L. J.G. Tully and R.G. Wittler. 1979. International Journal of Systematic Bacteriology 29:83-91.

M. gallinarum Freundt 1955

Freundt, E.A. 1955. International Bulletin of Bacteriological Nomenclature and Taxonomy 5:67-78. Type strain: ATCC 19708

Description: Bergey 8.

M. gallisepticum Edward and Kanarek 1960 Edward, D.G. ff. and A.D. Kanarek. 1960. Annals of the New York Academy of Sciences 79:696-702. Type strain: ATCC 19610

Description: Bergey 8 .

M. gateae Cole, Golightly and Ward 1967

Cole, B.C., L. Golightly and J.R. Ward. 1967. Journal of Bacteriology 94:1451-
1458. Type strain: ATCC 23392

Description: Bergey 8 .

M. hominis (Freundt 1953) Edward 1955

Freundt, E.A. 1953. Acta Pathologica et

Microbiologica Scandinavica 32:468-480;

Edward, D.G. ff. 1955. International

Bulletin of Bacteriological Nomenclature and Taxonomy 5:85-93. Type strain: ATCC 23114

Description: Bergey 8.

M. hyopneumoniae Mare and Switzer 1965

Mare, C.J. and W.P. Switzer. 1965.

Veterinary Medicine 60:841-846. Type strain: ATCC 25934

Description: Rose, D.L., J.G. Tully and R.G. Wittler. 1979. International Journal of Systematic Bacteriology 29:83-91.

M. hyorhinis Switzer 1955

Switzer, W.P. 1955. American Journal of Veterinary Research 16:540-544. Type strain: ATCC 17981

Description: Whittlestone, P. 1979 in Barile, M.F., S. Razin, J.G. Tully and R.F. Whitcomb (eds). The Mycoplasmas. Academic Press, New York, Volume II. pp. 133-176.

M. hyosynoviae Ross and Karmon 1970

Ross, R.F. and J.A. Karmon. 1970. Journal of Bacteriology 103:707-713. Type strain: ATCC 25591

Description: Whittlestone, P. 1979 in Barile, M.F., S. Razin, J.G. Tully and R.F. Whitcomb (eds). The Mycoplasmas. Academic Press, New York, Volume II. pp. 133-176.

M. iners Edward and Kanarek 1960

Edward, D.G. ff. and A.D. Kanarek. 1960. Annals of the New York Academy of Sciences 79:696-702. Type strain: ATCC 19705

Description: Bergey 8.

M. lipophilum Del Giudice, Purcell, Carski and Chanock 1974

Del Giudice, R.A., R.H. Purcell, T.R. Carski and R.M. Chanock 1974. International Journal of Systematic Bacteriology 24:147-153. Type strain: ATCC 27104

Description: Del Giudice, R.A., R.H. Purcell, T.R. Carski and R.M. Chanock. 1974. Ibid.

M. maculosum Edward 1955

Edward, D.G. ff. 1955. International Bulletin of Bacteriological Nomenclature 
and Taxonomy 5:85-93. Type strain: ATCC 19327

Description: Rosendal, S. 1979 in Barile, M.F., S. Razin, J.G. Tully and R.F. Whitcomb (eds). The Mycoplasmas. Academic Press, New York, Volume II. pp. 217-234.

M. meleagridis Yamamoto, Bigland and Ortmayer 1965

Yamamoto, R., C.H. Bigland and H.B. Ortmayer. 1965. Journal of Bacteriology 90:47-49. Type strain: ATCC 25294

Description: Bergey 8.

M. moatsii Madden, Moats, London, Matthew and Sever 1974

Madden, D.L., K.E. Moats, W.T. London, E.B. Matthew and J.L. Sever. 1974. International Journal of Systematic Bacteriology 24:459-464. Type strain: ATCC 27625

Description: Madden, D.L., K.E. Moats, W.T. London, E.B. Matthew and J.L. Sever. 1974. Ibid.

M. molare Rosendal 1974

Rosendal, S. 1974. International Journal of Systematic Bacteriology 24:125-130. Type strain: ATCC 27746

Description: Rosendal, S. 1974. Ibid.

M. mycoides (Borrel, Dujardin-Beaumetz, Jeantet and Jouan 1910) Freundt 1955

Borrel, A., E. Dujardin-Beaumetz, Jeantet and Jouan. 1910. Annales de l'Institut Pasteur (Paris) 24:168-179; Freundt, E.A. 1955. International Bulletin of Bacteriological Nomenclature and Taxonomy 5: 67-78. Type strain: NCTC 10114

Description: Gourlay, R.N. and C.J. Howard. 1979 in Barile, M.F., S. Razin, J.G. Tully and R.F. Whitcomb (eds). The Mycoplasmas. Academic Press, New York, Volume II. pp. 103-132.

M. mycoides subsp. capri (Edward 1953) Freundt 1955

Edward, D.G. ff. 1953. Veterinary Record 65:873-874; Freundt, E.A. 1955. International Bulletin of Bacteriological Nomenclature and Taxonomy 5:67-78. Type strain: NCTC 10137

Description: Cottew, G.S. 1979 in Barile, M.F., S. Razin, J.G. Tully and R.F. Whitcomb (eds). The Mycoplasmas. Academic Press, New York, Volume II. pp. 103-132.
M. mycoides subsp. mycoides (Borrel, DujardinBeaumetz, Jeantet and Jouan 1910) Freundt 1955

Borrel, A., E. Dujardin-Beaumetz, Jeantet and Jouan. 1910. Annales de l'Institut Pasteur (Paris) 24:168-179; Freundt, E.A. 1955. International Bulletin of Bacteriological Nomenclature and Taxonomy 5: 67-78. Type strain: NCTC 10114

Description: Gourlay, R.N. and C.J. Howard. 1979 in Barile, M.F., S. Razin, J.G. Tully and R.F. Whitcomb (eds). The Mycoplasmas. Academic Press, New York, Volume II. pp. 103-132.

M. neurolyticum (Sabin 1941) Freundt 1955

Sabin, A.B. 1941. Bacteriological Reviews 5:1-66; Freundt, E.A. 1955. International Bulletin of Bacteriological Nomenclature and Taxonomy 5:67-78. Type strain: ATCC 19988

Description: Cassell, G.H. and A. Hill. 1979 in Barile, M.F., S. Razin, J.G. Tully and R.F. Whitcomb (eds). The Mycoplasmas. Academic Press, New York, Volume II. pp. 235-273.

M. opalescens Rosendal 1975

Rosendal, S. 1975. Acta Pathologica et Microbiologica Scandinavica Section B 83:463-470. Type strain: ATCC 27921

Description: Rosendal, S. 1975. Ibid.

M. orale Taylor-Robinson, Canchola, Fox and Chanock 1964

Taylor-Robinson, D., J. Canchola, H. Fox and R.M. Chanock. 1964. American Journal of Hygiene 80:135-148. Type strain: ATCC 23714

Description: Bergey 8.

M. ovipneumoniae Carmichael, St. George, Sullivan and Horsfall 1972

Carmichael, L.E., T.D. St. George, N.D. Sullivan and N. Horsfall. 1972. Cornell Veterinarian 62:654-679. Type strain: ATCC 29419

Description: Cottew, G.S. 1979 in Barile, M.F., S. Razin, J.G. Tully and R.F. Whitcomb (eds). The Mycoplasmas. Academic Press, New York, Volume II. pp. 103-132.

M. pneumoniae Somerson, Taylor-Robinson and Chanock 1963

Somerson, N.L., D. Taylor-Robinson and R.M. Chanock. 1963. American Journal of Hygiene 77:122-128. Type strain: 
ATCC 15531

Description: Bergey 8.

M. primatum Del Giudice, Carski, Barile, Lemcke and Tully 1971

Del Giudice, R.A., T.R. Carski, M.F. Barile, R.M. Lemcke and J. Tully. 1971. Journal of Bacteriology 108:439-445. Type strain: ATCC 25948

Description: Del Giudice, R.A., T.R. Carski, M.F. Barile, R.M. Lemcke and J.G. Tully. 1971. Ibid.

M. pulmonis (Sabin 1941) Freundt 1955

Sabin, A.B. 1941. Bacteriological Reviews 5:1-66; Freundt, E.A. 1955. International Bulletin of Bacteriological Nomenclature and Taxonomy 5:67-78. Type strain: ATCC 19612

Description: Cassell, G.H. and A. Hill. 1979 in Barile, M.F., S. Razin, J.G. Tully and R.F. Whitcomb (eds). The Mycoplasmas. Academic Press, New York, Volume II. pp. 235-273.

M. putrefaciens Tully, Barile, Edward, Theodore and Erno 1974

Tully, J.G., M.F. Barile, D.G. ff. Edward, T.S. Theodore and H. Erno. 1974. Journal of General Microbiology 85:102120. Type strain: ATCC 15718

Description: Tully, J.G., M.F. Barile, D.G. ff. Edward, T.S. Theodore and H. Erno. 1974. Ibid.

M. salivarium Edward 1955

Edward, D.G. ff. 1955. International Bulletin of Bacteriological Nomenclature and Taxonomy 5:85-93. Type strain: ATCC 23064

Description: Bergey 8.

M. spumans Edward 1955

Edward, D.G. ff. 1955. International Bulletin of Bacteriological Nomenclature and Taxonomy 5:85-93. Type strain: ATCC 19526

Description: Rosendal, S. 1979 in Barile, M.F., S. Razin, J.G. Tully and R.F. Whitcomb (eds). The Mycoplasmas. Academic Press, New York, Volume II. pp. 217-234.

M. sualvi Gourlay, Wyld and Leach 1978

Gourlay, R.N., S.G. Wyld and R.H. Leach. 1978. International Journal of Systematic Bacteriology 28:289-292. Type strain: NCTC 10170

Description: Gourlay, R.N., S.G. Wyld and R.H. Leach. 1978. Ibid.

M. subdolum Lemcke and Kirchhoff 1979

Lemcke, R.M. and H. Kirchhoff. 1979.

International Journal of Systematic Bacteriology 29:42-50. Type strain: ATCC 29870

Description: Lemcke, R.M. and H. Kirchhoff. 1979. Ibid.

M. synoviae Olson, Kerr and Campbell 1964

Olson, N.O., K.M. Kerr and A. Camp-

bell. 1964. Avian Diseases 8:209-214.

Type strain: ATCC 25204

Description: Bergey 8.

M. verecundum Gourlay, Leach and Howard 1974

Gourlay, R.N., R.H. Leach and C.J. Howard. 1974. Journal of General Microbiology 81:475-484. Type strain: ATCC 27862

Description: Gourlay, R.N., R.H. Leach and C.J. Howard. 1974. Ibid.

Myxococcus Thaxter 1892

Thaxter, R. 1892. Botanical Gazette 17: 389-406. Type species: $M$. fulvus (Cohn 1875) Jahn 1911

Description: Bergey 8.

M. coralloides Thaxter 1892

Thaxter, R. 1892. Botanical Gazette 17: 389-406. Type strain: ATCC 25202

Description: Bergey 8.

M. disciformis Thaxter 1904

Thaxter, R. 1904. Botanical Gazette 37: 405-416. Type strain: ATCC 33172

Description: Thaxter, R. 1904. Ibid.

M. fulvus (Cohn 1875) Jahn 1911

Cohn, F. 1875. Beitrage zur Biologie der

Pflanzen 1:141-207; Jahn, E. 1911. Kryptogamenflora der Mark Brandenburg 5:187-206. Type strain: ATCC 25199

Description: Bergey 8.

M. macrosporus (Krzemieniewska and Krzemieniewski 1926) Zahler and McCurdy 1974

Krzemieniewska, H. and S. Krzemieniewski. 1926. Acta Societatis Botanicorum Poloniae 4:1-54; Zahler, S.A. and H.D. McCurdy. 1974. Bergey 8. Type strain: Windsor M271

Description: Bergey 8.

M. stipitatus Thaxter 1897

Thaxter, R. 1897. Botanical Gazette 23: 395-411. Type strain: Windsor M78 
Description: Bergey 8.

M. virescens Thaxter 1892

Thaxter, R. 1892. Botanical Gazette 17:

389-406. Type strain: ATCC 25203

Description: Bergey 8.

M. xanthus Beebe 1941

Beebe, J.M. 1941. Journal of Bacteriology

42:193-223. Type strain: ATCC 25232

Description: Bergey 8.

Nannocystis Reichenbach 1970

Reichenbach, H. 1970. Archiv fur Mikrobiologie 70:119-138. Type species: N. exedens Reichenbach 1970

Description: Bergey 8.

N. exedens Reichenbach 1970

Reichenbach, H. 1970. Archiv fur Mikrobiologie 70:119-138. Type strain: DSM 71

Description: Reichenbach, H. 1970. Ibid.

\section{Neisseria Trevisan 1885}

Trevisan, V. 1885. Atti della Accademia Fisica-Medica-Statistica in Milano (Ser 4) 3:92-107. Type species: $N$. gonorrhoeae (Zopf 1885) Trevisan 1885

Description: Bergey 8.

N. animalis Berger 1960

Berger, U. 1960. Zentralblatt fur Bakteriologie, Parasitenkunde, Infektionskrankheiten und Hygiene. Abteilung II. 147: 158-161. Type strain: NCTC 10212

Description: Berger, U. 1960. Ibid.

N. canis Berger 1962

Berger, U. 1962. Zentralblatt fur Bakteriologie, Parasitenkunde, Infektionskrankheiten und Hygiene. Abteilung II. 148:445-457. Type strain: ATCC 14678

Description: Berger, U. 1962. Ibid.

N. caviae Pelczar 1953

Pelczar, M.J. 1953. Journal of Bacteriology 65:744. Type strain: ATCC 14659

Description: Branham, S.E. 1957 in Breed, R.S., E.G.D. Murray and N.R. Smith (eds). Bergey's Manual of Determinative Bacteriology, 7th ed. The Williams and Wilkins Co., Baltimore. pp. 480-485.

N. cinerea (von Lingelsheim 1906) Murray 1939

von Lingelsheim, W. 1906. Klinisches Jahrbuch 15:373-489; Murray, E.G.D. 1939 in Bergey, D.H., R.S. Breed, E.G.D. Murray and A.P. Hitchens (eds). Bergey's Manual of Determinative Bacteriology, 5th ed. The Williams and Wilkins Co., Baltimore. pp. 278-288. Type strain: ATCC 14685

Description: Murray, E.G.D. 1939. Ibid.

N. cuniculi Berger 1962

Berger, U. 1962. Zentralblatt fur Bakteriologie, Parasitenkunde, Infektionskrankheiten und Hygiene. Abteilung II. 148:445-457. Type strain: ATCC 14688

Description: Berger, U. 1962. Ibid.

N. denitrificans Berger 1962

Berger, U. 1962. Zentralblatt fur Bakteriologie, Parasitenkunde, Infektionskrankheiten und Hygiene. Abteilung II. 148: 445-457. Type strain: ATCC 14686

Description: Berger, U. 1962. Ibid.

N. elongata Bovre and Holten 1970

Bovre, K. and E. Holten. 1970. Journal of General Microbiology 60:67-75. Type strain: ATCC 25295

Description: Bovre, K. and E. Holten. 1970. Ibid.

N. elongata subsp. elongata Bovre and Holten 1970

Bovre, K. and E. Holten. 1970. Journal of General Microbiology 60:67-75. Type strain: ATCC 25295

Description: Bovre, K. and E. Holten. 1970. Ibid.

N. elongata subsp. glycolytica Henriksen and Holten 1976

Henriksen, S.D. and E. Holten. 1976. International Journal of Systematic Bacteriology 26:478-481. Type strain: ATCC 29315

Description: Henriksen, S.D. and E. Holten. 1976. Ibid.

N. flava Bergey, Harrison, Breed, Hammer and Huntoon 1923

Bergey, D.H., F.C. Harrison, R.S. Breed, B.W. Hammer and F.M. Huntoon. 1923. Bergey's Manual of Determinative Bacteriology, 1st ed. The Williams and Wilkins Co., Baltimore. pp. 1-442. Type strain: NRL 30,008

Description: Branham, S.E. 1957 in Breed, R.S., E.G.D. Murray and N.R. Smith (eds). Bergey's Manual of Determinative Bacteriology, 7 th ed. The Williams and Wilkins Co., Baltimore. pp. 480-485.

N. flavescens Branham 1930

Branham, S.E. 1930. United States Public Health Services Public Health Report 45: 
845-849. Type strain: ATCC 13120

Description: Bergey 8.

N. gonorrhoeae (Zopf 1885) Trevisan 1885

Zopf, W. 1885. Die Spaltpilze, 3rd ed.

Edward Trewendt, Breslau. pp. 1-127;

Trevisan, V. 1885. Atti della Accademia

Fisica-Medica-Statistica in Milano (Ser 4)

3:92-107. Type strain: ATCC 19424

Description: Bergey 8.

N. lactamica Hollis, Wiggins and Weaver 1969 Hollis, D.G., G.L. Wiggins and R.E. Weaver. 1969. Applied Microbiology 17: 71-77. Type strain: ATCC 23970

Description: Hollis, D.G., G.L. Wiggins and R.E. Weaver. 1969. Ibid.

N. meningitidis (Albrecht and Ghon 1901) Murray 1929

Albrecht, H. and A. Ghon. 1901. Wiener klinische Wochenschrift 14:984-996; Murray, E.G.D. 1929. Medical Research Council (Great Britain) Special Report Series 124:7-142. Type strain: ATCC 13077

Description: Bergey 8.

N. mucosa Veron, Tult and Second 1959

Veron, M., P. Thibault and L. Second. 1959. Annales de l'Institut Pasteur (Paris) 97:497-510. Type strain: ATCC 19696 Description: Bergey 8.

N. ovis Lindqvist 1960

Lindqvist, K. 1960. Journal of Infectious Diseases 106:162-165. Type strain: ATCC 33078

Description: Lindqvist, K. 1960. Ibid.

N. perflava Bergey, Harrison, Breed, Hammer and Huntoon 1923

Bergey, D.H., F.C. Harrison, R.S. Breed, B.W. Hammer and F.M. Huntoon. 1923. Bergey's Manual of Determinative Bacteriology, 1st ed. The Williams and Wilkins Co., Baltimore. pp. 1-442. Type strain: ATCC 10555

Description: Branham, S.E. 1957 in Breed, R.S., E.G.D. Murray and N.R. Smith (eds). Bergey's Manual of Determinative Bacteriology, 7th ed. The Williams and Wilkins Co., Baltimore. pp. 480-485.

N. sicea (von Lingelsheim 1908) Bergey, Harrison, Breed, Hammer and Huntoon 1923

von Lingelsheim, W. 1908. Zentralblatt fur Bakteriologie, Parasitenkunde, Infektionskrankheiten und Hygiene. Abteilung
I. 59:457-476; Bergey, D.H., F.C. Harrison, R.S. Breed, B.W. Hammer and F.M. Huntoon. 1923. Bergey's Manual of Determinative Bacteriology, 1st ed. The Williams and Wilkins Co., Baltimore. pp. 1-442. Type strain: NRL 30,016

Description: Bergey 8.

N. subflava (Flugge 1886) Trevisan 1889

Flugge, 1886. Die Mikroorganismen.

F.C.W. Vogel, Leipzig; Trevisan, V. 1889.

I. Generi e le Specie delle Bactieriacee. Zanaboni and Gabuzzi, Milano. Type strain: NRL 30,017

Description: Bergey 8.

Neorickettsia Philip, Hadlow and Hughes 1953

Philip, C.B., W.J. Hadlow and L.E. Hughes. 1953. Riassunti della Communicazione VI Congresso Internazionale di Microbiologia, Roma 2:256257. Type species: $N$. helminthoeca Philip, Hadlow and Hughes 1953

Description: Bergey 8 .

N. helminthoeca Philip, Hadlow and Hughes 1953

Philip, C.B., W.J. Hadlow and L.E. Hughes. 1953. Riassunti della Communicazione VI Congresso Internazionale di Microbiologia, Roma 2:256-257. Type strain: no culture isolated.

Description: Bergey 8 .

Nevskia Famintzin 1892

Famintzin, A. 1892. Bulletin of the Academy of Science St. Petersbourg New Series 2 34:481-486. Type species: $N$. ramosa Famintzin 1892

Description: Bergey 8.

N. ramosa Famintzin 1892

Famintzin, A. 1892. Bulletin of the Academy of Science St. Petersbourg New Series 2 34:481-486. Type strain: no culture isolated.

Description: Bergey 8.

Nitrobacter Winogradsky 1892

Winogradsky, S. 1892. Arkhiv Biologicheskikh Nauk (St. Petersbourg) 1:87137. Type species: N. winogradskyi Winslow, Broadhurst, Buchanan, Krumwiede, Rogers and Smith 1917

Description: Bergey 8.

N. winogradskyi Winslow, Broadhurst, Buchan- 
an, Krumwiede, Rogers and Smith 1917

Winslow, C.E.A., J. Broadhurst, R.E. Buchanan, C. Krumwiede Jr., L.A. Rogers and G.H. Smith. 1917. Journal of Bacteriology 2:505-566. Type strain: ATCC 25391

Description: Watson, S.W. 1971. International Journal of Systematic Bacteriology 21:254-270.

Nitrococcus Watson and Waterbury 1971

Watson, S.W. and J.B. Waterbury. 1971. Archiv fur Mikrobiologie 77:203-230. Type species: $N$. mobilis Watson and Waterbury 1971

Description: Bergey 8.

N. mobilis Watson and Waterbury 1971

Watson, S.W. and J.B. Waterbury. 1971.

Archiv fur Mikrobiologie 77:203-230.

Type strain: ATCC 25380

Description: Watson, S.W. and J.B. Waterbury. 1971. Ibid.

Nitrosococcus Winogradsky 1892

Winogradsky, S. 1892. Arkhiv Biologicheskikh Nauk (St. Petersbourg) 1:87137. Type species: $N$. nitrosus (Migula 1900) Buchanan 1925

Description: Bergey 8.

N. nitrosus (Migula 1900) Buchanan 1925 Migula, W. 1900. System der Bakterien, Vol. 2. Gustav Fischer, Jena; Buchanan, R.E. 1925. General Systemic Bacteriology. The Williams and Wilkins Co., Baltimore. Type strain: no culture isolated.

Description: Bergey 8.

N. oceanus (Watson 1965) Watson 1971

Watson, S.W. 1965. Limnology and Oceanography 10:274-289; Watson, S.W. 1971. International Journal of Systematic Bacteriology 21:254-270. Type strain: ATCC 19707

Description: Watson, S.W. 1971. Ibid.

Nitrosolobus Watson, Graham, Remsen and Valois 1971

Watson, S.W., L.B. Graham, C.C. Remsen and F.W. Valois. 1971. Archiv fur Mikrobiologie 76:83-203. Type species: N. multiformis Watson, Graham, Remsen and Valois 1971

Description: Bergey 8.
N. multiformis Watson, Graham, Remsen and Valois 1971

Watson, S.W., L.B. Graham, C.C. Remsen and F.W. Valois. 1971. Archiv fur Mikrobiologie 76:83-203. Type strain: ATCC 25196

Description: Watson, S.W. 1971. International Journal of Systematic Bacteriology 21:254-270.

Nitrosomonas Winogradsky 1892

Winogradsky, S. 1892. Arkhiv Biologicheskikh Nauk (St. Petersbourg) 1:87137. Type species: $N$. europaea Winogradsky 1892

Description: Bergey 8.

N. europaea Winogradsky 1892

Winogradsky, S. 1892. Arkhiv Biologicheskikh Nauk (St. Petersbourg) 1: 87-137. Type strain: ATCC 25978

Description: Watson, S.W. 1971. International Journal of Systematic Bacteriology 21:254-270.

Nitrosospira Winogradsky and Winogradsky 1933

Winogradsky, S. and H. Winogradsky. 1933. Annales de l'Institut Pasteur (Paris) 50:350-434. Type species: $N$. briensis Winogradsky and Winogradsky 1933 Description: Bergey 8.

N. briensis Winogradsky and Winogradsky 1933 Winogradsky, S. and H. Winogradsky. 1933. Annales de l'Institut Pasteur (Paris) 50:350-434. Type strain: no culture available.

Description: Watson, S.W. 1971. International Journal of Systematic Bacteriology 21:254-270.

Nitrospina Watson and Waterbury 1971

Watson, S.W. and J.B. Waterbury. 1971.

Archiv fur Mikrobiologie 77:203-230.

Type species: $N$. gracilis Watson and Waterbury 1971

Description: Bergey 8.

N. gracilis Watson and Waterbury 1971

Watson, S.W. and J.B. Waterbury. 1971.

Archiv fur Mikrobiologie 77:203-230.

Type strain: no culture available.

Description: Watson, S.W. and J.B. Waterbury. 1971. Ibid. 
Nocardia Trevisan 1889

Trevisan, V. 1889. I Generi e le Specie delle Battieriacee. Zanaboni and Gabuzzi, Milano. Type species: $N$. asteroides (Eppinger 1891) Blanchard 1896

Description: Bergey 8.

N. amarae Lechevalier and Lechevalier 1974 Lechevalier, M.P. and H.A. Lechevalier. 1974. International Journal of Systematic Bacteriology 24:278-288. Type strain: ATCC 27808

Description: Lechevalier, M.P. and H.A. Lechevalier. 1974. Ibid.

N. asteroides (Eppinger 1891) Blanchard 1896 Eppinger, H. 1891. Beitrage zur pathologischen Anatomie 9:287-328; Blanchard, R. 1896 in Bouchard, C. Traite de Pathologie Generale, Vol. 2, G. Masson, Paris. pp. 1-932. Type strain: ATCC 19247

Description: Gordon, R.E. and J.M. Mihm. 1957. Journal of Bacteriology 73: 15-27.

N. autotrophica (Takamiya and Tubaki 1956) Hirsch 1961

Takamiya, A. and K. Tubaki. 1956. Archiv fur Mikrobiologie 25:58-64; Hirsch, P. 1961. Archiv fur Mikrobiologie 39:360-373. Type strain: ATCC 19727

Description: Shirling, E.B. and D. Gottlieb. 1968. International Journal of Systematic Bacteriology 18:69-189.

N. brasiliensis (Lindenberg 1909) Pinoy 1913 Lindenberg, A. 1909. Archives de Parasitologie 13:265-282; Pinoy, E. 1913. Bulletin de l'Institut Pasteur 11:929-938. Type strain: ATCC 19296

Description: Gordon, R.E. and J.M. Mihm. 1959. Journal of General Microbiology 20:129-135.

N. calcarea Metcalf and Brown 1957

Metcalf, G. and M. Brown. 1957. Journal of General Microbiology 17:567-572. Type strain: ATCC 19369

Description: Metcalf, G. and M. Brown. 1957. Ibid.

N. carnea (Rossi Doria 1891) Castellani and Chalmers 1913

Rossi Doria, T. 1891. Annali dell' Istituto d'Igiene Sperimentale, Universita Roma 1: 399-438; Castellani, A. and A.J. Chalmers. 1913. Manual of Tropical Medicine, 2nd ed. Bailliere, Tindall and Cox,
London. Type strain: ATCC 6847

Description: Gordon, R.E., S.K. Mishra and D.A. Barnett. 1978. Journal of General Microbiology 109:69-78.

N. cellulans Metcalf and Brown 1957

Metcalf, G. and M. Brown. 1957. Journal of General Microbiology 17:567-572. Type strain: ATCC 12830

Description: Metcalf, G. and M. Brown. 1957. Ibid.

N. coeliaca (Gray and Thornton 1928) Waksman and Henrici 1948

Gray, P.H.H. and H.G. Thornton. 1928. Zentralblatt fur Bakteriologie, Parasitenkunde, Infektionskrankheiten und Hygiene. Abteilung II. 73:74-96; Waksman, S.A. and A.T. Henrici. 1948 in Breed, R.S., E.G.D. Murray and A.P. Hitchens (eds). Bergey's Manual of Determinative Bacteriology, 6th ed. The Williams and Wilkins Co., Baltimore. pp. 892-928. Type strain: ATCC 17041

Description: Gordon, R.E., D.A. Barnett, J.E. Handerhan and C. Hor-Nay Pang. 1974. * International Journal of Systematic Bacteriology 24:54-63.

N. corynebacterioides Serrano, Tablante, Serrano, San Blas and Imaeda 1972

Serrano, J.A., R.V. Tablante, A.A. Serrano, G.C. San Blas and T. Imaeda. 1972. Journal of General Microbiology 70:339-349. Type strain: ATCC 14898

Description: Serrano, J.A., R.V. Tablante, A.A. Serrano, G.C. San Blas and T. Imaeda. 1972. Ibid.

N. farcinica Trevisan 1889

Trevisan, V. 1889. I. Generi e le Specie delle Battieriacee. Zanaboni and Gabuzzi, Milano. Type strain: ATCC 3318

Description: Trevisan, V. 1889. Ibid.

N. globerula (Gray 1928) Waksman and Henrici 1948

Gray, P.H.H. 1928. Proceedings of the Royal Society Series B 102:263-280; Waksman, S.A. and A.T. Henrici. 1948 in Breed, R.S., E.G.D. Murray and A.P. Hitchens (eds). Bergey's Manual of Determinative Bacteriology, 6th ed. The Williams and Wilkins Co., Baltimore. pp. 892-928. Type strain: ATCC 19370

Description: Bergey 8.

N. hydrocarbonoxydans Nolof and Hirsch 1962

Nolof, G. and P. Hirsch. 1962. Archiv fur 
Mikrobiologie 44:266-277. Type strain: ATCC 15104

Description: Nolof, G. and P. Hirsch. 1962. Ibid.

N. mediterranei (Margalith and Beretta 1960)

Thiemann, Zucco and Pelizza 1969

Margalith, P. and G. Beretta. 1960. Mycopathologia et Mycologia Applicata 12:189-195; Thiemann, J.E., G. Zucco and G. Pelizza. 1969. Archiv fur Mikrobiologie 67:147-155. Type strain: ATCC 13685

Description: Thiemann, J.E., G. Zucco and G. Pelizza. 1969. Ibid.

N. orientalis (Pittenger and Brigham 1956) Pridham and Lyons 1969

Pittenger, R.C. and R.B. Brigham. 1956. Antibiotics and Chemotherapy 6:642-647; Pridham, T.G. and A.J. Lyons. 1969. Developments in Industrial Microbiology 10:183-221. Type strain: ATCC 19795

Description: Shirling, E.B. and D. Gottlieb. 1968. International Journal of Systematic Bacteriology 18:69-189.

N. otitidis-caviarum Snijders 1924

Snijders, E.P. $1924 . \quad$ Geneeskundig Tijdschrift voor Nederlandsch-Indie 64:8587. Type strain: ATCC 14629

Description: Bergey 8.

N. petroleophila Hirsch and Engel 1956

Hirsch, P. and H. Engel. 1956. Berichte der Deutschen Botanischen Gesellschaft 69:441-454. Type strain: ATCC 15777

Description: Hirsch, P. and H. Engel. 1956. Ibid.

N. restricta (Turfitt 1944) McClung 1974

Turfitt, G.E. 1944. Journal of Bacteriology 47:487-493; McClung, N.M. 1974 Bergey 8. Type strain: DSM 43199

Description: Bergey 8 .

N. saturnea Hirsch 1960

Hirsch, P. 1960. Archiv fur Mikrobiologie 35:391-414. Type strain: ATCC 15809

Description: Hirsch, P. 1960. Ibid.

N. transvalensis Pijper and Pullinger 1927

Pijper, A. and B.D. Pullinger. 1927. Journal of Tropical Medicine and Hygiene 30:153-156. Type strain: ATCC 6865 Description: Gordon, R.E., S.K. Mishra and D.A. Barnett. 1978. Journal of General Microbiology 109:69-78.

N. vaccinii Demaree and Smith 1952

Demaree, J.B. and N.R. Smith. 1952.
Phytopathology 42:249-252. Type strain: ATCC 11092

Description: Demaree, J.B. and N.R. Smith. 1952. Ibid.

Nocardioides Prauser 1976

Prauser, H. 1976. International Journal of Systematic Bacteriology 26:58-65. Type species: $N$. albus Prauser 1976

Description: Prauser, H. 1976. Ibid.

N. albus Prauser 1976

Prauser, H. 1976. International Journal of Systematic Bacteriology 26:58-65. Type strain: ATCC 27980

Description: Prauser, H. 1976. Ibid.

Nocardiopsis Meyer 1976

Meyer, J. 1976. International Journal of Systematic Bacteriology 26:487-493. Type species: N. dassonvillei Meyer 1976

Description: Meyer, J. 1976. Ibid.

N. dassonvillei Meyer 1976

Meyer, J. 1976. International Journal of Systematic Bacteriology 26:487-493. Type strain: ATCC 23218

Description: Meyer, J. 1976. Ibid.

Obesumbacterium Shimwell 1963

Shimwell, J.L. 1963. Brewers Journal 99: 759-760. Type species: $O$. proteus Shimwell 1963

Description: Shimwell, J.L. 1963. Ibid.

O. proteus Shimwell 1963

Shimwell, J.L. 1963. Brewers Journal 99: 759-760. Type strain: NCIB 8771

Description: Shimwell, J.L. 1963. Ibid.

Oceanospirillum Hylemon, Wells, Krieg and Jannasch 1973

Hylemon, P.B., J.S. Wells Jr., N.R. Krieg and H.W. Jannasch. 1973. International Journal of Systematic Bacteriology 23: 340-380. Type species: $O$. linum (Williams and Rittenberg 1957) Hylemon, Wells, Krieg and Jannasch 1973

Description: Hylemon, P.B., J.S. Wells Jr., N.R. Krieg and H.W. Jannasch. 1973. Ibid.

O. beijerinckii (Williams and Rittenberg 1957) Hylemon, Wells, Krieg and Jannasch 1973

Williams, M.A. and S.C. Rittenberg. 1957. International Bulletin of Bacterio- 
logical Nomenclature and Taxonomy 7: 49-110; Hylemon, P.B., J.S. Wells Jr., N.R. Krieg and H.W. Jannasch. 1973. International Journal of Systematic Bacteriology 23:340-380. Type strain: ATCC 12754

Description: Hylemon, P.B., J.S. Wells Jr., N.R. Krieg and H.W. Jannasch. 1973. Ibid.

O. hiroshimense (Terasaki 1973) Terasaki 1979

Terasaki, Y. 1973. Bulletin of the Suzugamine Women's College, Natural Science 17:1-71; Terasaki, Y. 1979. International Journal of Systematic Bacteriology 29:130-144. Type strain: IFO 13616

Description: Terasaki, Y. 1979. Ibid.

O. japonicum (Watanabe 1959) Hylemon, Wells, Krieg and Jannasch 1973

Watanabe, N. 1959. Botanical Magazine (Tokyo) 72:77-86; Hylemon, P.B., J.S. Wells Jr., N.R. Krieg and H.W. Jannasch. 1973. International Journal of Systematic Bacteriology 23:340-380. Type strain: ATCC 19191

Description: Hylemon, P.B., J.S. Wells Jr., N.R. Krieg and H.W. Jannasch. 1973. Ibid.

O. linum (Williams and Rittenberg 1957) Hylemon, Wells, Krieg and Jannasch 1973

Williams, M.A. and S.C. Rittenberg. 1957. International Bulletin of Bacteriological Nomenclature and Taxonomy 7: 49-110; Hylemon, P.B., J.S. Wells Jr., N.R. Krieg and H.W. Jannasch. 1973. International Journal of Systematic Bacteriology 23:340-380. Type strain: ATCC 11336

Description: Hylemon, P.B., J.S. Wells Jr., N.R. Krieg and H.W. Jannasch. 1973. Ibid.

O. maris Hylemon, Wells, Krieg and Jannasch 1973

Hylemon, P.B., J.S. Wells Jr., N.R. Krieg and H.W. Jannasch. 1973. International Journal of Systematic Bacteriology 23: 340-380. Type strain: ATCC 27509

Description: Hylemon, P.B., J.S. Wells Jr., N.R. Krieg and H.W. Jannasch. 1973. Ibid.

O. minutulum (Watanabe 1959) Hylemon, Wells, Krieg and Jannasch 1973
Watanabe, N. 1959. Botanical Magazine (Tokyo) 72:77-86; Hylemon, P.B., J.S. Wells Jr., N.R. Krieg and H.W. Jannasch. 1973. International Journal of Systematic Bacteriology 23:340-380. Type strain: ATCC 19193

Description: Hylemon, P.B., J.S. Wells Jr., N.R. Krieg and H.W. Jannasch. 1973. Ibid.

O. multiglobuliferum (Terasaki 1973) Terasaki 1979

Terasaki, Y. 1973. Bulletin of the Suzugamine Women's College, Natural Science 17:1-71; Terasaki, Y. 1979. International Journal of Systematic Bacteriology 29:130-144. Type strain: IFO 13614

Description: Terasaki, Y. 1979. Ibid.

O. pelagicum (Terasaki 1973) Terasaki 1979

Terasaki, Y. 1973. Bulletin of the Suzugamine Women's College, Natural Science 17:1-71; Terasaki, Y. 1979. International Journal of Systematic Bacteriology 29:130-144. Type strain: IFO 13612

Description: Terasaki, Y. 1979. Ibid.

O. pusillum (Terasaki 1973) Terasaki 1979

Terasaki, Y. 1973. Bulletin of the Suzugamine Women's College, Natural Science 17:1-71; Terasaki, Y. 1979. International Journal of Systematic Bacteriology 29:130-144. Type strain: IFO 13613

Description: Terasaki, Y. 1979. Ibid.

Oerskovia Prauser, Lechevalier and Lechevalier 1970

Prauser, H., M.P. Lechevalier and H.A. Lechevalier. 1970. Applied Microbiology 19:534. Type species: O. turbata (Erikson 1954) Prauser, Lechevalier and Lechevalier 1970

Description: Prauser, H., M.P. Lechevalier and H.A. Lechevalier. 1970. Ibid.

O. turbata (Erikson 1954) Prauser, Lechevalier and Lechevalier 1970

Erikson, D. 1954. Journal of General Microbiology 11:198-208; Prauser, H., M.P. Lechevalier and H.A. Lechevalier. 1970. Applied Microbiology 19:534. Type strain: ATCC 25835

Description: Prauser, H., M.P. Lechevalier and H.A. Lechevalier. 1970. Ibid. 
O. xanthineolytica Lechevalier 1972

Lechevalier, M.P. 1972. International Journal of Systematic Bacteriology 22: 260-264. Type strain: ATCC 27402

Description: Lechevalier, M.P. 1972. Ibid.

Oscillospira Chatton and Perard 1913

Chatton, E. and C. Perard. 1913. Comptes Rendus des Seances de la Societe de Biologie (Paris) 74:1159-1162. Type species: $O$. guilliermondi Chatton and Perard 1913

Description: Bergey 8.

O. guilliermondi Chatton and Perard 1913

Chatton, E. and C. Perard. 1913. Comptes Rendus des Seances de la Societe de Biologie (Paris) 74:1159-1162. Type strain: no culture isolated.

Description: Bergey 8.

\section{Paracoccus Davis 1969}

Davis, D.H. 1969 in Davis, D.H., M. Doudoroff, R.Y. Stanier and M. Mandel. International Journal of Systematic Bacteriology 19:375-390. Type species: $P$. denitrificans (Beijerinck and Minkman 1910) Davis 1969

Description: Bergey 8.

P. denitrificans (Beijerinck and Minkman 1910) Davis 1969

Beijerinck, M.W. and D.C.J. Minkman. 1910. Zentralblatt fur Bakteriologie, Parasitenkunde, Infektionskrankheiten und $\mathrm{Hy}-$ giene. Abteilung II. 25:30-63; Davis, D.H. 1969 in Davis, D.H., M. Doudoroff, R.Y. Stanier and $M$. Mandel. International Journal of Systematic Bacteriology 19: 375-390. Type strain: ATCC 17741

Description: Davis, D.H. 1969. Ibid.

P. halodenitrificans (Robinson and Gibbons 1952) Davis 1969

Robinson, J. and N.E. Gibbons. 1952. Canadian Journal of Botany 30:147-154; Davis, D.H. 1969 in Davis, D.H., M. Doudoroff, R.Y. Stanier and M. Mandel. International Journal of Systematic Bacteriology 19:375-390. Type strain: ATCC 13511

Description: Bergey 8.

\section{Pasteurella Trevisan 1887}

Trevisan, V. 1887. Reale Istituto Lombardo Rendiconti (Ser 2) 20:88-105. Type species: P. multocida (Lehmann and Neumann 1899) Rosenbusch and Merchant 1939

Description: Bergey 8.

P. aerogenes McAllister and Carter 1974

McAllister, H.A. and G.R. Carter. 1974.

American Journal of Veterinary Research 35:917-922. Type strain: ATCC 27883

Description: McAllister, H.A. and G.R. Carter. 1974. Ibid.

P. gallicida (Burrill 1883) Buchanan 1925

Burrill, T.J. 1883. The American Naturalist 17:319-320; Buchanan, R.E. 1925.

General systematic bacteriology. The Williams and Wilkins Co., Baltimore. pp. 412-415. Type strain: NCTC 10322

Description: Buchanan, R.E. 1925. Ibid.

P. gallinarum Hall, Heddleston, Legenhausen and Hughes 1955

Hall, W.J., K.L. Heddleston, D.H. Legenhausen and R.W. Hughes. 1955. American Journal of Veterinary Research 16:598-604. Type strain: ATCC 13361

Description: Mraz, O., P. Jelen and J. Bohacek. 1977. Acta Veterinaria Brno 46: 135-147.

P. haemolytica Newsome and Cross 1932

Newsome, I.E. and F. Cross. 1932. Journal of the American Veterinary Medical Association 80:711-719. Type strain: NCTC 9380

Description: Bergey 8.

P. multocida (Lehmann and Neumann 1899) Rosenbusch and Merchant 1939

Lehmann, K.B. and R. Neumann. 1899. Lehmann's Medizin, Handatlanten Band $\mathrm{X}$. Atlas und Grundriss der Bakteriologie und Lehrbuch der speziellen bakteriologischen Diagnostik. 2 Auflage, Munchen. p. 196; Rosenbusch, C.T. and I.A. Merchant. 1939. Journal of Bacteriology 37:69-89. Type strain: NCTC 10322 Description: Bergey 8.

P. pneumotropica Jawetz 1950 Jawetz, E. 1950. Journal of Infectious Diseases 86:172-183. Type strain: NCTC 8141

Description: Bergey 8.

P. ureae Jones 1962

Jones, D.M. 1962. Journal of Pathology and Bacteriology 83:143-151. Type strain: ATCC 25976

Description: Jones, D.M. 1962. Ibid. 
Pasteuria Metchnikoff 1888

Metchnikoff, E. 1888. Annales de l'Institut Pasteur (Paris) 2:165-170. Type species: $P$. ramosa Metchnikoff 1888

Description: Bergey 8.

P. ramosa Metchnikoff 1888

Metchnikoff, E. 1888. Annales de l'Institut Pasteur (Paris) 2:165-170. Type strain: ATCC 27377

Description: Staley, J.T. 1973. Canadian Journal of Microbiology 19:609-614.

Pectinatus Lee, Mabee and Jangaard 1978 Lee, S.Y., M.S. Mabee and N.O. Jangaard. 1978. International Journal of Systematic Bacteriology 28:582-594. Type species: $P$. cerevisiiphilus Lee, Mabee and Jangaard 1978

Description: Lee, S.Y., M.S. Mabee and N.O. Jangaard. 1978. Ibid.

P. cerevisiiphilus Lee, Mabee and Jangaard 1978

Lee, S.Y., M.S. Mabee and N.O. Jangaard. 1978. International Journal of Systematic Bacteriology 28:582-594. Type strain: ATCC 29359

Description: Lee, S.Y., M.S. Mabee and N.O. Jangaard. 1978. Ibid.

Pectobacterium Waldee 1945

Waldee, E.L. 1945. Iowa State Journal of Science 19:435-484. Type species: $P$. carotovorum (Jones 1901) Waldee 1945

Description: Waldee, E.L. 1945. Ibid.

P. carnegieana (Standring 1942) Brenner, Steigerwalt, Miklos and Fanning 1973 (See also Erwinia carnegieana)

Standring, E.T. 1942 in Lightle, P.C., E.T. Standring and J.G. Brown. Phytopathology 32:303-313; Brenner, D.J., A.G. Steigerwalt, G.V. Miklos and G.R. Fanning. 1973. International Journal of Systematic Bacteriology 23:205-216. Type strain: NCPPB 439

Description: Bergey 8.

P. carotovorum (Jones 1901) Waldee 1945 (See also Erwinia carotovora)

Jones, L.R. 1901. Zentralblatt fur Bakteriologie,

Parasitenkunde, Infektionskrankheiten und Hygiene. Abteilung II. 7:12-21; Waldee, E.L. 1945. Iowa State Journal of Science 19:435-484.
Type strain: ATCC 15713

Description: Bergey 8.

P. chrysanthemi (Burkholder, McFadden and Dimock 1953) Brenner, Steigerwalt, Miklos and Fanning 1973 (See also Erwinia chrysanthemi)

Burkholder, W.H., L.A. McFadden and A.V. Dimock. 1953. Phytopathology 43: 522-526; Brenner, D.J., A.G. Steigerwalt, G.V. Miklos and G.R. Fanning. 1973. International Journal of Systematic Bacteriology 23:205-216. Type strain: ATCC 11663

Description: Bergey 8.

P. cypripedii (Hori 1911) Brenner, Steigerwalt, Miklos and Fanning 1973 (See also Erwinia cypripedii)

Hori, S. 1911. Zentralblatt fur Bakteriologie, Parasitenkunde, Infektionskrankheiten und Hygiene. Abteilung II. 31:85-92; Brenner, D.J., A.G. Steigerwalt, G.V. Miklos and G.R. Fanning. 1973. International Journal of Systematic Bacteriology 23:205-216. Type strain: PDDCC 1591

Description: Bergey 8.

P. rhapontici (Millard 1924) Patel and Kulkarni 1951 (See also Erwinia rhapontici)

Millard, W.A. 1924. Bulletin of the Univeristy of Leeds and the Yorkshire Counsil for Agricultural Education 134:128; Patel, M.K. and Y.S. Kulkarni. 1951. Indian Phytopathology 4:74-84. Type strain: ATCC 29283

Description: Bergey 8.

Pediococcus Balcke 1884

Balcke, J. 1884. Wochenschrift fur Brauerei 1:257 Type species: $P$. damnosus Claussen 1903

Description: Bergey 8.

P. acidilactici Lindner 1887

Lindner, P. 1887. Wochenschrift fur Brauerei 4:437-440. Type strain: NCDO 1859

Description: Garvie, E.I. 1974. International Journal of Systematic Bacteriology 24:301-306.

P. damnosus Claussen 1903

Claussen, N.H. 1903. Compte Rendu des Travaux du Laboratoire de Carlsberg 6: 64-83. Type strain: NCDO 1832

Description: Garvie, E.I. 1974. Interna- 
tional Journal of Systematic Bacteriology 24:301-306.

P. dextrinicus (Coster and White 1964) Back 1978

Coster, E. and H.R. White. 1964. Journal of General Microbiology 37:15-31; Back, W. 1978. International Journal of Systematic Bacteriology 28:523-527. Type strain: DSM 20335

Description: Back, W. 1978. Ibid.

P. halophilus Mees 1934

Mees, R.H. 1934. Thesis. Technical University Delft, Holland. pp. 1-110. Type strain: NCDO 1635

Description: Gunther, H.L. and H.R. White. 1961. Journal of General Microbiology 26:185-197.

P. parvulus Gunther and White 1961

Gunther, H.L. and H.R. White. 1961. Journal of General Microbiology 26:185197. Type strain: NCDO 1634

Description: Gunther, H.L., E. Coster and H.R. White. 1962. International Bulletin of Bacteriological Nomenclature and Taxonomy 12:189-190.

P. pentosaceus Mees 1934

Mees, R.H. 1934. Thesis. Technical University, Delft, Holland. pp. 1-110. Type strain: NCDO 990

Description: Garvie, E.I. 1974. International Journal of Systematic Bacteriology 24:301-306.

Pedomicrobium Aristovskaya 1961

Aristovakaya, T.V. 1961. Doklady Akademii Nauk SSSR 136:954-957. Type species: $P$. ferrugineum Aristovskaya 1961 Description: Bergey 8.

P. ferrugineum Aristovskaya 1961

Aristovskaya, T.V. 1961. Doklady Akademii Nauk SSSR 136:954-957. Type strain: IFAM S-1290

Description: Bergey 8.

P. manganicum Aristovskaya 1961

Aristovskaya, T.V. 1961. Doklady Akademii Nauk SSSR 136:954-957. Type strain: IFAM E-1129

Description: Bergey 8.

\section{Pelodictyon Lauterborn 1913}

Lauterborn, R. 1913. Allgemeine Botanische Zeitschrift 19:97-100. Type species: P. clathratiforme (Szafer 1911) Lauter- born 1913

Description: Bergey 8.

P. clathratiforme (Szafer 1911) Lauterborn 1913

Szafer, W. 1911. Bulletin de l'Academie des Sciences de Cracovie, Serie B. pp. 160-167; Lauterborn, R. 1913. Allgemeine Botanische Zeitschrift 19:97-100. Type strain: no pure culture.

Description: Bergey 8.

P. luteolum (Schmidle 1901) Pfennig and Truper 1971

Schmidle, W. 1901. Beihefte zum Botanischen Zentralblatt 10:179-180; Pfennig, N. and H.G. Truper. 1971. International Journal of Systematic Bacteriology 21:11-14. Type strain: DSM 273 Description: Bergey 8.

P. phaeum Gorlenko 1972

Gorlenko, V.M. 1972. Mikrobiologiya 41: 370-372. Type strain: DSM 728

Description: Gorlenko, V.M. 1972. Ibid.

Peptococcus Kluyver and van Niel 1936

Kluyver, A.J. and C.B. van Niel. 1936. Zentralblatt fur Bakteriologie, Parasitenkunde, Infektionskrankheiten und Hygiene. Abteilung II. 94:369-403. Type species: $P$. niger (Hall 1930) Kluyver and van Niel 1936

Description: Bergey 8.

P. asaccharolyticus (Distaso 1912) Douglas 1957

Distaso, A. 1912. Zentralblatt fur Bakteriologie, Parasitenkunde, Infektionskrankheiten und Hygiene. Abteilung I. 62:433-468; Douglas, H.C. 1957 in Breed, R.S., E.G.D. Murray and N.R. Smith (eds). Bergey's Manual of Determinative Bacteriology, 7th ed. The Williams and Wilkins Co., Baltimore. pp. 474-480. Type strain: ATCC 14963

Description: Holdeman, L.V., E.P. Cato and W.E.C. Moore (eds). 1977. Anaerobe Laboratory Manual, 4th ed. Virginia Polytechnic Institute and State University, Blacksburg, Virginia. pp. 1-156.

P. glycinophilus (Cardon and Barker 1946) Douglas 1957

Cardon, B.P. and H.A. Barker. 1946. Journal of Bacteriology 52:629-634; Douglas, H.C. 1957 in Breed, R.S., E.G.D. Murray and N.R. Smith (eds). 
Bergey's Manual of Determinative Bacteriology, 7th ed. The Williams and Wilkins Co., Baltimore. pp. 474-480. Type strain: ATCC 23195

Description: Douglas, H.C. 1957. Ibid.

P. indolicus (Christiansen 1934) Sorensen 1975

Christiansen, M. 1934. Acta Pathologica et Microbiologica Scandinavica, Supplement 18:42-63; Sorensen, G. 1975. Acta Veterinaria Scandinavica 16:218-225. Type strain: ATCC 29427

Description: Sorensen, G. 1973. Acta Veterinaria Scandinavica 14:301-326.

P. magnus (Prevot 1933) Holdeman and Moore 1972

Prevot, A.R. 1933. Annales Societe Nature 15:23-260; Holdeman, L.V. and W.E.C. Moore (eds). 1972. Anaerobe Laboratory Manual. Virginia Polytechnic Institute Anaerobe Laboratory, Blacksburg, Virginia. Type strain: ATCC 15794

Description: Holdeman, L.V., E.P. Cato and W.E.C. Moore (eds). 1977. Anaerobe Laboratory Manual, 4th ed. Virginia Polytechnic Institute and State University, Blacksburg, Virginia. pp. 1-156.

P. niger (Hall 1930) Kluyver and van Niel 1936

Hall, I.C. 1930. Journal of Bacteriology 20:407-415; Kluyver, A.J. and C.B. van Niel. 1936. Zentralblatt fur Bakteriologie, Parasitenkunde, Infektionskrankheiten und Hygiene. Abteilung II. 94:369-403. Type strain: ATCC 27731

Description: Wilkins, T.D., W.E.C. Moore, S.E.H. West and L.V. Holdeman. 1975. International Journal of Systematic Bacteriology 25:47-49.

P. prevotii (Foubert and Douglas 1948) Douglas 1957

Foubert Jr., E.L. and H.C. Douglas. 1948. Journal of Bacteriology 56:25-34; Douglas, H.C. 1957 in Breed, R.S., E.G.D. Murray and N.R. Smith (eds). Bergey's Manual of Determinative Bacteriology, 7th ed. The Williams and Wilkins Co., Baltimore. pp. 474-480. Type strain: ATCC 9321

Description: Holdeman, L.V., E.P. Cato and W.E.C. Moore (eds). 1977. Anaerobe Laboratory Manual, 4th ed. Virginia Polytechnic Institute and State University,
Blacksburg, Virginia. pp. 1-156.

P. saccharolyticus (Foubert and Douglas 1948) Douglas 1957

Foubert Jr., E.L. and H.C. Douglas. 1948. Journal of Bacteriology 56:25-34; Douglas, H.C. 1957 in Breed, R.S., E.G.D. Murray and N.R. Smith (eds). Bergey's Manual of Determinative Bacteriology, 7th ed. The Williams and Wilkins Co., Baltimore. pp. 474-480. Type strain: ATCC 14953

Description: Holdeman, L.V., E.P. Cato and W.E.C. Moore (eds). 1977. Anaerobe Laboratory Manual, 4th ed. Virginia Polytechnic Institute and State University, Blacksburg, Virginia. pp. 1-156.

Peptostreptococcus Kluyver and van Niel 1936 Kluyver, A.J. and C.B. van Niel. 1936. Zentralblatt fur Bakteriologie, Parasitenkunde, Infektionskrankheiten und Hygiene. Abteilung II. 94:369-403. Type species: P. anaerobius (Natvig 1905) Kluyver and van Niel 1936

Description: Bergey 8 .

P. anaerobius (Natvig 1905) Kluyver and van Niel 1936

Natvig, H. 1905. Archiv fur Gynakologie (Berlin) 76:701-858; Kluyver, A.J. and C.B. van Niel. 1936. Zentralblatt fur Bakteriologie, Parasitenkunde, Infektionskrankheiten und Hygiene. Abteilung II. 94:369-403. Type strain: ATCC 27337

Description: Holdeman, L.V., E.P. Cato and W.E.C. Moore (eds). 1977. Anaerobe Laboratory Manual, 4th ed. Virginia Polytechnic Institute and State University, Blacksburg, Virginia. pp. 1-156.

P. micros (Prevot 1933) Smith 1957

Prevot, A.R. 1933. Annales des Sciences Naturelles 15:23-260; Smith, L.DS. 1957 in Breed, R.S., E.G.D. Murray and N.R. Smith (eds). Bergey's Manual of Determinative Bacteriology, 7th ed. The Williams and Wilkins Co., Baltimore. pp. 533-541. Type strain: VPI 5464

Description: Holdeman, L.V., E.P. Cato and W.E.C. Moore (eds). 1977. Anaerobe Laboratory Manual, 4th ed. Virginia Polytechnic Institute and State University, Blacksburg, Virginia. pp. 1-156.

P. parvulus (Weinberg, Nativelle and Prevot 1937) Smith 1957 
Weinberg, M., R. Nativelle and A.R. Prevot. 1937. Les Microbes Anaerobies. Masson et Cie, Paris. pp. 1-1186; Smith, L.DS. 1957 in Breed, R.S., E.G.D. Murray and N.R. Smith (eds). Bergey's Manual of Determinative Bacteriology, 7th ed. The Williams and Wilkins Co., Baltimore. pp. 533-541. Type strain: VPI 0546

Description: Holdeman, L.V., E.P. Cato and W.E.C. Moore (eds). 1977. Anaerobe Laboratory Manual, 4th ed. Virginia Polytechnic Institute and State University, Blacksburg, Virginia. pp. 1-156.

P. productus (Prevot 1941) Smith 1957

Prevot, A.R. 1941. Comptes Rendus des Seances de la Societe de Biologie (Paris) 135:105-107; Smith, L.DS. 1957 in Breed, R.S., E.G.D. Murray and N.R. Smith (eds). Bergey's Manual of Determinative Bacteriology, 7th ed. The Williams and Wilkins Co., Baltimore. pp. 533-541. Type strain: ATCC 27340

Description: Holdeman, L.V., E.P. Cato and W.E.C. Moore (eds). 1977. Anaerobe Laboratory Manual, 4th ed. Virginia Polytechnic Institute and State University, Blacksburg, Virginia. pp. 1-156.

\section{Photobacterium Beijerinck 1889}

Beijerinck, M.W. 1889. Archives Neerlandaises des Science Exactes et Naturelles 23:401-415. Type species: $P$. phosphoreum (Cohn 1878) Ford 1927

Description: Bergey 8.

P. angustum Reichelt, Baumann and Baumann 1979

Reichelt, J.L., P. Baumann and L. Baumann. 1979 in International Journal of Systematic Bacteriology 29:79-80; Effective publication Reichelt, J.L., P. Baumann and L. Baumann. 1976. Archives of Microbiology 110:101-120. Type strain: ATCC 25915

Description: Baumann, P., L. Baumann and M. Mandel. 1971. Journal of Bacteriology 107:268-294.

P. fischeri (Beijerinck 1889) Reichelt and Baumann 1973 (See also Vibrio fischeri) Beijerinck, M.W. 1889. Archives Neerlandaises des Science Exactes et Naturelles 23:401-415; Reichelt, J.L. and P. Baumann. 1973. Archiv fur Mikrobiologie 94:
283-330. Type strain: ATCC 7744

Description: Reichelt, J.L. and P. Baumann. 1973. Ibid.

P. leiognathi Boisvert, Chatelain and Bassot 1967

Boisvert, H., R. Chatelain and J.-M.

Bassot. 1967. Annales de l'Institut Pasteur (Paris) 112:520-524. Type strain: ATCC 25521

Description: Reichelt, J.L. and P. Baumann. 1975. International Journal of Systematic Bacteriology 25:208-209.

P. phosphoreum (Cohn 1878) Beijerinck 1889

Cohn, F. 1878. Letter to J. Penn which describes Micrococcus phosphoreum. Versameling van stucken betreffende het geneeskundig staats toerzich, 126-130; Beijerinck, M.W. 1889. Archives Neerlandaises des Science Exactes et Naturelles 23:401-415. Type strain: ATCC 11040

Description: Reichelt, J.L. and P. Baumann. 1973. Archiv fur Mikrobiologie 94: 283-330.

\section{Pilimelia Kane 1966}

Kane, W.D. 1966. Journal of the Elisha Mitchell Scientific Society 82:220-230.

Type species: P. terevasa Kane 1966

Description: Bergey 8.

P. anulata Kane 1966

Kane, W.D. 1966. Journal of the Elisha Mitchell Scientific Society 82:220-230.

Type strain: ATCC 25604

Description: Bergey 8.

P. terevasa Kane 1966

Kane, W.D. 1966. Journal of the Elisha Mitchell Scientific Society 82:220-230. Type strain: ATCC 25603

Description: Bergey 8.

Planctomyces Gimesi 1924

Gimesi, N. 1924. Budapest, Kiadja a Magyar Ciszterci. Rend, pp. 1-8. Type species: $P$. bekefii Gimesi 1924

Description: Bergey 8 .

P. bekefii Gimesi 1924

Gimesi, N. 1924. Budapest, Kiadja a Magyar Ciszterci. Rend, pp. 1-8. Type strain: no culture isolated.

Description: Bergey 8.

Planobispora Thiemann and Beretta 1968

Thiemann, J.E. and G. Beretta. 1968. 
Archiv fur Mikrobiologie 62:157-166. Type species: $P$. longispora Thiemann and Beretta 1968

Description: Bergey 8.

P. longispora Thiemann and Beretta 1968

Thiemann, J.E. and G. Beretta. 1968. Archiv fur Mikrobiologie 62:157-166.

Type strain: ATCC 23867

Description: Bergey 8.

P. rosea Thiemann 1970

Thiemann, J.E. 1970 in Prauser, H. (ed). The Actinomycetales. The Jena International Symposium on Taxonomy, Sept. 1968. VEB Gustav Fischer Verlag Jena. pp. 245-257. Type strain: ATCC 23866

Description: Bergey 8.

\section{Planococcus Migula 1894}

Migula, W. 1894. Arbeiten aus dem Bakteriologischen Institut der Technischen Hochschule zu Karlsruhe 1:235-238. Type species: $P$. citreus Migula 1894

Description: Bergey 8.

P. citreus Migula 1894

Migula, W. 1894. Arbeiten aus dem Bakteriologischen Institut der Technischen Hochschule zu Karlsruhe 1:235-238. Type strain: ATCC 14404

Description: Kocur, M., Z. Pacova, W. Hodgkiss and T. Martinec. 1970. International Journal of Systematic Bacteriology 20:241-248.

P. halophilus Novitsky and Kushner 1976

Novitsky, T.J. and D.J. Kushner. 1976. International Journal of Systematic Bacteriology 26:53-57. Type strain: ATCC 27964

Description: Novitsky, T.J. and D.J. Kushner. 1976. Ibid.

Planomonospora Thiemann, Pagani and Beretta 1967

Thiemann, J.E., H. Pagani and G. Beretta. 1967. Giornale di Microbiologia 15:27-38. Type species: $P$. parontospora Thiemann, Pagani and Beretta 1967 Description: Bergey 8.

P. parontospora Thiemann, Pagani and Beretta 1967

Thiemann, J.E., H. Pagani and G. Beretta. 1967. Giornale di Microbiologia 15:27-38. Type strain: ATCC 23863
Description: Bergey 8 .

P. parontospora subsp. antibiotica Thiemann, Coronelli, Pagani, Beretta, Tamoni and Arioli 1968

Thiemann, J.E., C. Coronelli, H. Pagani, G. Beretta, G. Tamoni and V. Arioli. 1968. Journal of Antibiotics (Tokyo) Series A 21:525-531. Type strain: ATCC 23864

Description: Bergey 8.

P. parontospora subsp. parontospora Thiemann, Pagani and Beretta 1967

Thiemann, J.E., H. Pagani and G. Beretta. 1967. Giornale di Microbiologia 15:27-38. Type strain: ATCC 23863

Description: Bergey 8.

P. venezuelensis Thiemann 1970

Thiemann, J.E. 1970 in Prauser, H. (ed). The Actinomycetales. The Jena International Symposium on Taxonomy, Sept. 1968. VEB Gustav Fischer Verlag Jena. pp. 245-257. Type strain: ATCC 23865

Description: Thiemann, J.E. 1970. Ibid.

Pleisomonas Habs and Schubert 1962

Habs, H. and R.H.W. Schubert. 1962.

Zentralblatt fur Bakteriologie,

Parasitenkunde, Infektionskrankheiten und Hygiene. Abteilung I. 186:316-327. Type species: P. shigelloides (Bader 1954) Habs and Schubert 1962

Description: Bergey 8.

P. shigelloides (Bader 1954) Habs and Schubert 1962

Bader, R.E. 1954. Zentralblatt fur Bakteriologie, Parasitenkunde, Infektionskrankheiten und Hygiene. Abteilung $I$. 140:450-456; Habs, H. and R.H.W. Schubert. 1962. Zentralblatt fur Bakteriologie, Parasitenkunde, Infektionskrankheiten und Hygiene. Abteilung I. 186: 316-327. Type strain: ATCC 14029

Description: Bergey 8 .

Polyangium Link 1809

Link, H.F. 1809. Gesellschaft fur Natur (Berlin) 3:3-42. Type species: $P$. vitellinum Link 1809

Description: Bergey 8.

P. fumosum Krzemieniewska and Krzemieniewski 1930

Krzemieniewska; H. and S. Krzemieniewski. 1930. Acta Societatis Botanicorum 
Poloniae 7:250-273. Type strain: Windsor M257

Description: Bergey 8.

P. minor (Peterson 1959) McCurdy 1970

Peterson, J.E. 1959. Mycologia 51:1-8; McCurdy, H.D. 1970. International Journal of Systematic Bacteriology 20:283296. Type strain: UMH Peterson 44

Description: Peterson, J.E. 1959. Ibid.

P. rugiseptum (Peterson 1959) McCurdy 1970 Peterson, J.E. 1959. Mycologia 51:1-8; McCurdy, H.D. 1970. International Journal of Systematic Bacteriology 20: 283-296. Type strain: UMH Peterson 51 Description: Peterson, J.E. 1959. Ibid.

P. vitellinum Link 1809

Link, H.F. 1809. Gesellschaft fur Natur (Berlin) 3:3-42. Type strain: TC 4564

Description: Bergey 8.

Promicromonospora Krassilnikov, Kalakoutskii and Kirillova 1961

Krassilnikov, N.A., L.V. Kalakoutskii and N.F. Kirillova. 1961. Bulletin of the Academy of Sciences USSR (Series Biology) 1:107-112. Type species: $P$. citrea Krassilnikov, Kalakoutskii and Kirillova 1961

Description: Krassilnikov, N.A., L.V. Kalakoutskii and N.F. Kirillova. 1961. Ibid.

P. citrea Krassilnikov, Kalakoutskii and Kirillova 1961

Krassilnikov, N.A., L.V. Kalakoutskii and N.F. Kirillova. 1961. Bulletin of the Academy of Sciences USSR (Series Biology) 1:107-112. Type strain: ATCC 15908

Description: Krassilnikov, N.A., L.V. Kalakoutskii and N.F. Kirillova. 1961. Ibid.

\section{Propionibacterium Orla-Jensen 1909}

Orla-Jensen, S. 1909. Zentralblatt fur Bakteriologie, Parasitenkunde, Infektionskrankheiten und Hygiene. Abteilung II. 22:305-346. Type species: $P$. freudenreichii van Niel 1928

Description: Bergey 8.

P. acidi-propionici Orla-Jensen 1909

Orla-Jensen, S. 1909. Zentralblatt fur Bakteriologie

Parasitenkunde Infektionskrankheiten und Hygiene. Ab- teilung II. 22:305-346. Type strain: ATCC 25562

Description: Holdeman, L.V., E.P. Cato and W.E.C. Moore (eds). 1977. Anaerobe Laboratory Manual, 4th ed. Virginia Polytechnic Institute and State University, Blacksburg, Virginia. pp. 1-156.

P. acnes (Gilchrist 1900) Douglas and Gunter 1946

Gilchrist, T.C. 1900. Johns Hopkins Hospital Report 9:409-430; Douglas, H.D. and S.E. Gunter. 1946. Journal of Bacteriology 52:15-23. Type strain: ATCC 6919

Description: Holdeman, L.V., E.P. Cato and W.E.C. Moore (eds). 1977. Anaerobe Laboratory Manual, 4th ed. Virginia Polytechnic Institute and State University, Blacksburg, Virginia. pp. 1-156.

P. avidum (Eggerth 1935) Moore and Holdeman 1969

Eggerth, A.H. 1935. Journal of Bacteriology 30:277-299; Moore, W.E.C. and L.V. Holdeman. 1969 in Cato, E.P., C.S. Cummins, L.V. Holdeman, J.L. Johnson, W.E.C. Moore, R.M. Smibert and L.DS. Smith (eds). Outline of clinical methods in anaerobic bacteriology. Virginia Polytechnic Institute Anaerobe Laboratory, Blacksburg, Virginia. Type strain: ATCC 25577

Description: Holdeman, L.V., E.P. Cato and W.E.C. Moore (eds). 1977. Anaerobe Laboratory Manual, 4th ed. Virginia Polytechnic Institute and State University, Blacksburg, Virginia. pp. 1-156.

P. freudenreichii van Niel 1928

van Niel, C.B. 1928. The propionic acid bacteria. Uitgeverszaak and Boissevain and Co., Haarlem, Holland. pp. 1-187. Type strain: ATCC 6207

Description: Holdeman, L.V., E.P. Cato and W.E.C. Moore (eds). 1977. Anaerobe Laboratory Manual, 4th ed. Virginia Polytechnic Institute and State University, Blacksburg, Virginia. pp. 1-156.

P. freudenreichii subsp. freudenreichii (van Niel 1928) Moore and Holdeman 1970 van Niel, C.B. 1928. The propionic acid bacteria. Uitgeverszaak and Boissevain and Co., Haarlem, Holland. pp. 1-187; Moore, W.E.C. and L.V. Holdeman. 1970 in Cato, E.P., C.S. Cummins, L.V. 
Holdeman, J.L. Johnson, W.E.C. Moore, R.M. Smibert and L.DS. Smith (eds). Outline of clinical methods in anaerobic bacteriology, 2nd revision. Virginia Polytechnic Institute Anaerobe Laboratory, Blacksburg, Virginia. pp. 15-21. Type strain: ATCC 6207

Description: Holdeman, L.V., E.P. Cato and W.E.C. Moore (eds). 1977. Anaerobe Laboratory Manual, 4th ed. Virginia Polytechnic Institute and State University, Blacksburg, Virginia. pp. 1-156.

P. freudenreichii subsp. shermanii (van Niel 1928) Holdeman and Moore 1970

van Niel, C.B. 1928. The propionic acid bacteria. N.V. Uitgeverszaak and J.W. Boissevain and Co., Haarlem, Holland. pp. 1-187; Moore, W.E.C. and L.V. Holdeman. 1970 in Cato, E.P., C.S. Cummins, L.V. Holdeman, J.L. Johnson, W.E.C. Moore, R.M. Smibert and L.DS. Smith (eds). Outline of clinical methods in anaerobic bacteriology, 2nd revision. Virginia Polytechnic Institute Anaerobe Laboratory, Blacksburg, Virginia. pp. 1521. Type strain: ATCC 9614

Description: Holdeman, L.V., E.P. Cato and W.E.C. Moore (eds). 1977. Anaerobe Laboratory Manual, 4th ed. Virginia Polytechnic Institute and State University, Blacksburg, Virginia. pp. 1-156.

P. granulosum (Prevot 1938) Moore and Holdeman 1970

Prevot, A.R. 1938. Annales de l'Institut Pasteur (Paris) 60:285-307; Moore, W.E.C. and L.V. Holdeman. 1970 in Cato, E.P., C.S. Cummins, L.V. Holdeman, J.L. Johnson, W.E.C. Moore, R.M. Smibert and L.DS. Smith (eds). Outline of clinical methods in anaerobic bacteriology, 2nd revision. Virginia Polytechnic Institute Anaerobe Laboratory, Blacksburg, Virginia. pp. 15-21. Type strain: ATCC 25564

Description: Holdeman, L.V., E.P. Cato and W.E.C. Moore (eds). 1977. Anaerobe Laboratory Manual, 4th ed. Virginia Polytechnic Institute and State University, Blacksburg, Virginia. pp. 1-156.

P. jensenii van Niel 1928

van Niel, C.B. 1928. The propionic acid bacteria. Uitgeverszaak and Boissevain and Co., Haarlem, Holland. pp. 1-187.
Type strain: ATCC 4868

Description: Holdeman, L.V., E.P. Cato and W.E.C. Moore (eds). 1977. Anaerobe Laboratory Manual, 4th ed. Virginia Polytechnic Institute and State University, Blacksburg, Virginia. pp. 1-156.

P. lymphophilum (Torrey 1916) Johnson and Cummins 1972

Torrey, J.C. 1916. Journal of Medical Research 34:65-80; Johnson, J.L. and C.S. Cummins. 1972. Journal of Bacteriology 109:1047-1066. Type strain: ATCC 27520

Description: Holdeman, L.V., E.P. Cato and W.E.C. Moore (eds). 1977. Anaerobe Laboratory Manual, 4th ed. Virginia Polytechnic Institute and State University, Blacksburg, Virginia. pp. 1-156.

P. thoenii van Niel 1928

van Niel, C.B. 1928. The propionic acid bacteria. Uitgeverszaak and Boissevain and Co., Haarlem, Holland. pp. 1-187. Type strain: ATCC 4874

Description: Holdeman, L.V., E.P. Cato and W.E.C. Moore (eds). 1977. Anaerobe Laboratory Manual, 4th ed. Virginia Polytechnic Institute and State University, Blacksburg, Virginia. pp. 1-156.

Prosthecochloris Gorlenko 1970

Gorlenko, V.M. 1970. Zeitschrift fur Allgemeine Mikrobiologie 10:147-149. Type species: P. aestuarii Gorlenko 1970 Description: Bergey 8.

P. aestuarii Gorlenko 1970 Gorlenko, V.M. 1970. Zeitschrift fur Allgemeine Mikrobiologie 10:147-149. Type strain: DSM 271 Description: Bergey 8.

\section{Prosthecomicrobium Staley 1968}

Staley, J.T. 1968. Journal of Bacteriology 95:1921-1942. Type species: $P$. pneumaticum Staley 1968

Description: Bergey 8 .

P. enhydrum Staley 1968

Staley, J.T. 1968. Journal of Bacteriology 95:1921-1942. Type strain: ATCC 23634

Description: Staley, J.T. 1968. Ibid.

P. pneumaticum Staley 1968

Staley, J.T. 1968. Journal of Bacteriology 95:1921-1942. Type strain: ATCC 23633

Description: Staley, J.T. 1968. Ibid. 
Proteus Hauser 1885

Hauser, G. 1885. Uber Faulnisbakterien und deren Beziehungen zur Septicamie. Ein Beitrag zur Morphologie der Spaltpilze. Vogel, Leipzig. Type species: $P$. vulgaris Hauser 1885

Description: Bergey 8.

P. inconstans (Orstein 1920) Shaw and Clarke 1955

Orstein, M. 1920. Zeitschrift fur Hygiene 91:152-178; Shaw, C. and P.H. Clarke. 1955. Journal of General Microbiology 13:155-161. Type strain: ATCC 9886

Description: Shaw, C. and P.H. Clarke. 1955. Ibid.

P. mirabilis Hauser 1885

Hauser, G. 1885. Uber Faulnisbakterien und deren Beziehungen zur Septicamie. Ein Beitrag zur Morphologie der Spaltpilze. Vogel, Leipzig. p. 34. Type strain: ATCC 29906

Description: Rustigian, R. and C.A. Stuart. 1943. Proceedings of the Society for Experimental Biology and Medicine 53:241-243.

P. morganii (Winslow, Kligler and Rothberg 1919) Yale 1939 (See also Morganella morganii)

Winslow, C.E.A., I.J. Kligler and W. Rothberg. 1919. Journal of Bacteriology 4:429-503; Yale, M.W. 1939 in Bergey, D.H., R.S. Breed, E.G.D. Murray and A.P. Hitchens (eds). Bergey's Manual of Determinative Bacteriology, 5th ed. The Williams and Wilkins Co., Baltimore. pp. 430-436. Type strain: ATCC 25830

Description: Rustigian, R. and C.A. Stuart. 1943. Proceedings of the Society for Experimental Biology and Medicine 53:241-243.

P. myxofaciens Cosenza and Podgwaite 1966 Cosenza, B.J. and J.D. Podgwaite. 1966. Antonie van Leeuwenhoek Journal of Microbiology and Serology 32:187-191. Type strain: ATCC 19692

Description: Cosenza, B.J. and J.D. Podgwaite. 1966. Ibid.

P. rettgeri (Hadley, Elkins and Caldwell 1918) Rustigian and Stuart 1943 (See also Providencia rettgeri)

Hadley, P., M.W. Elkins and D.W. Caldwell. 1918. Bulletin of the Rhode
Island Agricultural Experimental Station 174:1-216; Rustigian, R. and C.A. Stuart. 1943. Proceedings of the Society for Experimental Biology and Medicine 53: 241-243. Type strain: ATCC 29944

Description: Rustigian, $R$. and C.A. Stuart. 1943. Ibid.

P. vulgaris Hauser 1885

Hauser, G. 1885. Uber Faulnisbakterien und deren Beziehungen zue Septicamie. Ein Beitrag zur Morphologie der Spaltpilze. Vogel. Leipzig. p. 12. Type strain: ATCC 13315

Description: Rustigian, R. and C.A. Stuart. 1943. Proceedings of the Society for Experimental Biology and Medicine 53:241-243.

\section{Providencia Ewing 1962}

Ewing, W.H. 1962. International Bulletin of Bacteriological Nomenclature and Taxonomy 12:93-102. Type species: $P$. alcalifaciens (de Salles Gomes 1944) Ewing 1962

Description: Ewing, W.H. 1962. Ibid.

P. alcalifaciens (de Salles Gomes 1944) Ewing 1962

de Salles Gomes, L. 1944. Revista do Instituto Adolfo Lutz 14:182-195; Ewing, W.H. 1962. International Bulletin of Bacteriological Nomenclature and Taxonomy 12:93-102. Type strain: ATCC 9886

Description: Ewing, W.H. 1962. Ibid.

P. rettgeri (Hadley, Elkins and Caldwell 1918) Brenner, Farmer, Fanning, Steigerwalt, Klykken, Wathen, Hickman and Ewing 1978 (See also Proteus rettgeri)

Hadley, P., M.W. Elkins and D.W. Caldwell. 1918. Bulletin of the Rhode Island Agricultural Experimental Station 174:1-216; Brenner, D.J., J.J. Farmer III, G.R. Fanning, A.G. Steigerwalt, P. Klykken, H.G. Wathen, F.W. Hickman and W.H. Ewing. 1978. International Journal of Systematic Bacteriology 28: 269-282. Type strain: ATCC 29944

Description: Rustigan, $R$. and C.A. Stuart. 1943. Proceedings of the Society for Experimental Biology and Medicine 53:241-243.

P. stuartii (Buttiaux, Osteux, Fresnoy and Moriamez 1954) Ewing 1962

Buttiaux, R., R. Osteux, R. Fresnoy and 
J. Moriamez. 1954. Annales de l'Institut Pasteur (Paris) 87:375-386; Ewing, W.H. 1962. International Bulletin of Bacteriological Nomenclature and Taxonomy 12: 93-102. Type strain: ATCC 29914

Description: Ewing, W.H. 1962. Ibid.

Pseudomonas Migula 1894

Migula, W. 1894. Arbeiten aus dem Bakteriologischen Institut der Technischen Hochschule zu Karlsruhe 1:235-238. Type species: $P$. aeruginosa (Schroeter 1872) Migula 1900

Description: Bergey 8.

P. acidovorans den Dooren de Jong 1926 den Dooren de Jong, L.E. 1926. Bijdrage tot de kennis van het Mineralisatieproces. Thesis. Technische Hoogeschool, Delft. pp. 1-199. Type strain: ATCC 15668 Description: Bergey 8.

P. aeruginosa (Schroeter 1872) Migula 1900 Schroeter, J. 1872 in Cohn, F. 1875. Beitrage zur Biologie der Pflanzen, J.U. Kern's Verlag, Breslau. pp. 109-126; Migula, W. 1900. System der Bakterien, Vol. 2. Gustav Fischer, Jena. Type strain: ATCC 10145

Description: Bergey 8.

P. agarici Young 1970

Young, J.M. 1970. New Zealand Journal of Agricultural Research 13:977-990. Type strain: ATCC 25941

Description: Young, J.M. 1970. Ibid.

P. alcaligenes Monias 1928

Monias, B.L. 1928. Journal of Infectious Diseases 43:330-334. Type strain: ATCC 14909

Description: Bergey 8.

P. aminovorans den Dooren de Jong 1926 den Dooren de Jong, L.E. 1926. Bijdrage tot de kennis van het mineralisatieproces. Thesis. Technische Hoogeschool, Delft. pp. 1-199. Type strain: ATCC 23314

Description: den Dooren de Jong, L.E. 1926. Ibid.

P. amygdali Psallidas and Panagopoulos 1975

Psallidas, P.G. and C.G. Panagopoulos.

1975. Annales de l'Institut Phytopathologique Benaki N.S. 11:94-108. Type strain: NCPPB 2607

Description: Psallidas, P.G. and C.G. Panagopoulos. 1975. Ibid.

P. andropogonis (Smith 1911) Stapp 1928
Smith, E.F. 1911. Carnegie Institute, Washington 2:1-368; Stapp, C. 1928 in Sorauer, Handbuch der Pflanzenkrankheiten, 5th ed. Paul Parey, Berlin. pp. 758. Type strain: ATCC 23061 Description: Goto, M. and M.P. Starr. 1971. Annals of the Phytopathological Society of Japan 37:233-241.

P. anguilliseptica Wakabayashi and Egusa 1972 Wakabayashi, H. and S. Egusa. 1972. Bulletin of the Japanese Society of Scientific Fisheries 38:577-587. Type strain: NCMB 1949

Description: Wakabayashi, $H$. and $S$. Egusa. 1972. Ibid.

P. asplenii (Ark and Tompkins 1946) Savulescu 1947

Ark, P.A. and C.M. Tompkins. 1946. Phytopathology 36:758-761; Savulescu, T. 1947. Analele Academiei Romane Series III Tom 22, Memoire 4:1-26. Type strain: ATCC 23835

Description: Ark, P.A. and C.M. Tompkins. 1946. Ibid.

P. aurantiaca Nakhimovskaya 1948

Nakhimovskaya, M.I. 1948. Mikrobiologiya 17:58-65. Type strain: NCIB 10068

Description: Nakhimovskaya, M.I. 1948. Ibid.

P. aureofaciens Kluyver 1956

Kluyver, A.J. 1956. Journal of Bacteriology 72:406-411. Type strain: ATCC 13985

Description: Bergey 8.

P. avenae Manns 1909

Manns, T.F. 1909. Bulletin of the Ohio Agriculture Experiment Station 210:91167. Type strain: NCPPB 1011

Description: Schaad, N.W., C.I. Kado and D.R. Sumner. 1975. International Journal of Systematic Bacteriology 25:133-137.

P. azotoformans Iizuka and Komagata 1963 Iizuka, H. and K. Komagata. 1963. Journal of the Agricultural Chemical Society of Japan 37:137-141. Type strain: IAM 1603

Description: lizuka, H. and K. Komagata. 1963. Ibid.

P. beijerinckii Hof 1935

Hof, T. 1935. Recueil des Travaux Botaniques Neerlandais 32:151-173. Type strain: ATCC 19372

Description: Haynes, W.C. 1957 in Breed, R.S., E.G.D. Murray and N.R. Smith 
(eds). Bergey's Manual of Determinative Bacteriology, 7th ed. The Williams and Wilkins Co., Baltimore. pp. 89-183.

P. betle (Ragunathan 1928) Savulescu 1947

Ragunathan, C. 1928. Annals of the Royal Botanical Garden of Peradeniya, Ceylon 11:51-61; Savulescu, T. 1947. Analele Academiei Romane Series III Tom 22, Memoire 4:1-26. Type strain: ATCC 19861

Description: Ragunathan, C. 1928. Ibid.

P. boreopolis Gray and Thornton 1928 Gray, P.H.H. and H.G. Thornton. 1928. Zentralblatt fur Bakteriologie, Parasitenkunde, Infektionskrankheiten und Hygiene. Abteilung II. 73:74-96. Type strain: NCIB 9401

Description: Haynes, W.C. 1957 in Breed, R.S., E.G.D. Murray and N.R. Smith (eds). Bergey's Manual of Determinative Bacteriology, 7th ed. The Williams and Wilkins Co., Baltimore. p. 101.

P. caricapapayae Robbs 1956 Robbs, C.F. 1956. Revista da Sociedade Brasileira de Agronomia 12:73-76. Type strain: NCPPB 1873

Description: Robbs, C.F. 1956. Ibid.

P. caryophylli (Burkholder 1942) Starr and Burkholder 1942

Burkholder, W.H. 1942. Phytopathology 32:141-149; Starr, M.P. and W.H. Burkholder. 1942. Phytopathology 32:598604. Type strain: ATCC 25418

Description: Burkholder, W.J. 1942. Ibid.

P. cattleyae (Pavarino 1911) Savulescu 1947

Pavarino, G.L. 1911. Atti della Reale Accademia dei Lincei 20:233-237; Savulescu, T. 1947. Analele Academiei Romane Series III Tom 22, Memoire 4:1-26. Type strain: NCPPB 961

Description: Ark, P.A. and H.E. Thomas. 1946. Phytopathology 36:695-698.

P. chlororaphis (Guignard and Sauvageau 1894) Bergey, Harrison, Breed, Hammer and Huntoon 1930

Guignard, L. and C. Sauvageau. 1894. Comptes Rendus des Seances de la Societe de Biologie, Paris, Series 10, 1: 841-843; Bergey, D.H., F.C. Harrison, R.S. Breed, B.W. Hammer and F.M. Huntoon (eds). 1930. Bergey's Manual of Determinative Bacteriology, 3rd ed. The Williams and Wilkins Co., Baltimore. pp.
1-589. Type strain: ATCC 9446

Description: Bergey 8.

P. cichorii (Swingle 1925) Stapp 1928

Swingle, D.B. 1925. Phytopathology 15:

730; Stapp, C. 1928. In Sorauer,

Handbuch der Pflanzenkrankheiten, 5th

ed. Paul Parey, Berlin. pp. 758. Type strain: ATCC 10857

Description: Bergey 8.

P. cissicola (Takimoto 1939) Burkholder 1948

Takimoto, S. 1939. Annals of the

Phytopathological Society, Japan 9:41-43;

Burkholder, W.H. 1948 in Breed, R.S.,

E.G.D. Murray and A.P. Hitchens (eds).

Bergey's Manual of Determinative Bacter-

iology, 6th ed. The Williams and Wilkins

Co., Baltimore. pp. 82-150. Type strain:

NCPPB 2982

Description: Goto, M. and T. Makino. 1977. Annals of the Phytopathological Society, Japan 43:40-45.

P. citronellolis Seubert 1960

Seubert, W. 1960. Journal of Bacteriology 79:426-434. Type strain: ATCC 13674

Description: Seubert, W. 1960. Ibid.

P. cocovenenans van Damme, Johannes, Cox and Berends 1960

van Damme, P.A., A.G. Johannes, H.C.

Cox and W. Berends. 1960. Recueil des

Travaux Chimiques des Pays-Bas 79:255-

267. Type strain: NCIB 9450

Description: van Damme, P.A., A.G. Johannes, H.C. Cox and W. Berends. 1960. Ibid.

P. delafieldii Davis 1970

Davis, D.H. 1970 in Davis, D.H., R.Y. Stanier, M. Doudoroff and M. Mandel. Archiv fur Mikrobiologie 70:1-13. Type strain: ATCC 17505

Description: Bergey 8 .

P. diminuta Leifson and Hugh 1954

Leifson, E. and R. Hugh. 1954. Journal of General Microbiology 10:68-70. Type strain: ATCC 11568

Description: Leifson, E. and R. Hugh. 1954. Ibid.

P. doudoroffii Baumann, Baumann, Mandel and Allen 1972

Baumann, L., P. Baumann, M. Mandel and R.D. Allen. 1972. Journal of Bacteriology 110:402-429. Type strain: ATCC 27123

Description. Baumann, L., P. Baumann, 
M. Mandel and R.D. Allen. 1972. Ibid.

P. echinoides Heumann 1962

Heumann, W. 1962. Biologisches Zentralblatt 81:341-354. Type strain: ATCC 14820

Description: Heumann, W. 1962. Ibid.

P. elongata Humm 1946

Humm, H.J. 1946. Bulletin of Duke University Marine Station 3:45-75. Type strain: ATCC 10144

Description: Humm, H.J. 1946. Ibid.

P. facilis (Schatz and Bovell 1952) Davis 1969

Schatz, A. and C.R. Bovell. 1952. Journal of Bacteriology 63:87-98; Davis, D.H. 1969 in Davis, D.H., R.Y. Stanier, M. Doudoroff and $\mathbf{M}$. Mandel. International Journal of Systematic Bacteriology 19: 375-390. Type strain: ATCC 11228

Description: Bergey 8.

P. flava (Niklewski 1910) Davis 1969 Niklewski, B. 1910. Jahrbuch fur Wissenschaftliche Botanik 48:113-142; Davis, D.H. 1969 in Davis, D.H., R.Y. Stanier, M. Doudoroff and $M$. Mandel. International Journal of Systematic Bacteriology 19:375-390. Type strain: DSM 619

Description: Bergey 8.

P. flectens Johnson 1956

Johnson, J.C. 1956. Queensland Journal of Agricultural Science 13:127-158. Type strain: ATCC 12775

Description: Johnson, J.C. 1956. Ibid.

P. fluorescens Migula 1895

Migula, W. 1895 in Engler, A. and K. Prantl (eds). Die Naturlichen Pfanzenfamilien, W. Engelmann, Leipzig, Teil I, Abteilung Ia. pp. 20-30. Type strain: ATCC 13525

Description: Bergey 8.

P. fragi (Eichholz 1902) Gruber 1905

Eichholz, W. 1902. Zentralblatt fur Bakteriologie, Parasitenkunde, Infektionskrankheiten und Hygiene. Abteilung II. 9:425-428; Gruber, T. 1905. Zentralblatt fur Bakteriologie, Parasitenkunde, Infektionskrankheiten und Hygiene. Abteilung II. 14:122-123. Type strain: ATCC 4973

Description: Haynes, W.C. 1957 in Breed, R.S., E.G.D. Murray and N.R. Smith (eds). Bergey's Manual of Determinative Bacteriology, 7th ed. The Williams and
Wilkins Co., Baltimore. p. 110.

P. fulva Iizuka and Komagata 1963

Iizuka, H. and K. Komagata. 1963. Journal of the Agricultural Chemical Society of Japan 37:137-141. Type strain: IAM 1529

Description: lizuka, H. and K. Komagata. 1963. Ibid.

P. gelidicola Kadota 1951

Kadota, H. 1951. Memoirs of the College of Science, Kyoto University 59:54-67. Type strain: IAM 1127

Description: Kadota, H. 1951. Ibid.

P. geniculata (Wright 1895) Chester 1901

Wright, J.H. 1895. Memoirs of the National Academy of Science 7:422-484; Chester, F.D. 1901. A manual of determinative bacteriology. The Macmillan Co., New York. pp. 1-401. Type strain: ATCC 19374

Description: Haynes, W.C. 1957 in Breed, R.S., E.G.D. Murray and N.R. Smith (eds). Bergey's Manual of Determinative Bacteriology, 7th ed. The Williams and Wilkins Co., Baltimore. p. 105.

P. gladioli Severini 1913

Severini, G. 1913. Annali di Botanica (Roma) 11:413-424. Type strain: NCPPB 1891

Description: Hildebrand, D.C., N.J. Palleroni and M. Doudoroff. 1973. International Journal of Systematic Bacteriology 23:433-437.

P. glathei Zolg and Ottow 1975

Zolg, W. and J.C.G. Ottow. 1975. Zeitschrift fur Allgemeine Mikrobiologie 15:287-299. Type strain: ATCC 29195

Description: Zolg, W. and J.C.G. Ottow. 1975. Ibid.

P. glumae Kurita and Tabei 1967

Kurita, T. and H. Tabei. 1967. Annals of the Phytopathological Society, Japan 33: 111. Type strain: NCPPB 2981

Description: Kurita, T. and $H$. Tabei. 1967. Ibid.

P. hibiscicola Moniz 1963

Moniz, L. 1963. Current Science 32:177.

Type strain: ATCC 19867

Description: Moniz, L. 1963. Ibid.

P. huttiensis Leifson 1962

Leifson, E. 1962. International Bulletin of Bacteriological Nomenclature and Taxonomy 12:161-170. Type strain: ATCC 
14670

Description: Leifson, E. 1962. Ibid.

P. indigofera (Voges 1893) Migula 1900

Voges, O. 1893. Zentralblatt fur Bakteriologie,

Parasitenkunde, Infektionskrankheiten und Hygiene. Abteilung I. 14:301-314; Migula, W. 1900. System der Bakterien, Vol. 2. Gustav Fischer, Jena. Type strain: ATCC 19706

Description: Elazari-Volcani, B. 1939. Archiv fur Mikrobiologie 10:343-358.

P. iners lizuka and Komagata 1964

Iizuka, H. and K. Komagata. 1964. Journal of General and Applied Microbiology 10:223-231. Type strain: IAM 1419 Description: lizuka, H. and K. Komagata. 1964. Ibid.

P. lanceolata Leifson 1962

Leifson, E. 1962. International Bulletin of Bacteriological Nomenclature and Taxonomy 12:161-170. Type strain: ATCC 14669

Description: Leifson, E. 1962. Ibid.

P. lemoignei Delafield, Doudoroff, Palleroni, Lusty and Contopoulou 1965

Delafield, F.P., M. Doudoroff, N.J. Palleroni, C.J. Lusty and C.R. Contopoulou. 1965. Journal of Bacteriology 90:1455-1466. Type strain: ATCC 17989

Description: Delafield, F.P., M. Doudoroff, N.J. Palleroni, C.L. Lusty and C.R. Contopoulou. 1965. Ibid.

P. mallei (Zopf 1885) Redfearn, Palleroni and Stanier 1966

Zopf, W, 1885. Die Spaltpilze, 3rd ed. Edward Trewendt, Breslau. pp. 1-127; Redfearn, M.S., N.J. Palleroni and R.Y. Stanier. 1966. Journal of General Microbiology 43:293-313. Type strain: ATCC 23344

Description: Bergey 8.

P. marginalis (Brown 1918) Stevens 1925

Brown, N.A. 1918. Journal of Agricultural Research 13:367-388; Stevens, F.L. 1925. Plant Disease Fungi. MacMillan Co., New York. pp. 469. Type strain: ATCC 10844

Description: Burkholder, W.J. 1957 in Breed, R.S., E.G.D. Murray and N.R. Smith (eds). Bergey's Manual of Determinative Bacteriology, 7th ed. The Williams and Wilkins Co., Baltimore. p. 135.

P. marina (Cobet, Wirsen and Jones 1970) Baumann, Baumann, Mandel and Allen 1972

Cobet, A.B., C. Wirsen and G.E. Jones. 1970. Journal of General Microbiology 62:159-169; Baumann, L., P. Baumann, M. Mandel and R.D. Allen. 1972. Journal of Bacteriology 110:402-429. Type strain: ATCC 25374

Description: Baumann, L., P. Baumann, M. Mandel and R.D. Allen. 1972. Ibid.

P. mendocina Palleroni 1970

Palleroni, N.J. 1970 in Palleroni, N.J., M. Doudoroff, R.Y. Stanier, R.E. Solanes and M. Mandel. Journal of General Microbiology 60:215-231. Type strain: ATCC 25411

Description: Bergey 8.

P. mephitica Claydon and Hammer 1939 Claydon, T.J. and B.W. Hammer. 1939. Journal of Bacteriology 37:252-258. Type strain: NCIB 9672

Description: Haynes, W.C. 1957 in Breed, R.S., E.G.D. Murray and N.R. Smith (eds). Bergey's Manual of Determinative Bacteriology, 7th ed. The Williams and Wilkins Co., Baltimore. p. 111.

P. mesophilica Austin and Goodfellow 1979

Austin, B. and M. Goodfellow. 1979. International Journal of Systematic Bacteriology 29:373-378. Type strain: ATCC 29983

Description: Austin, B. and M. Goodfellow. 1979. Ibid.

P. mucidolens Levine and Anderson 1932 Levine, M. and D.Q. Anderson. 1932. Journal of Bacteriology 23:337-347. Type strain: ATCC 4685

Description: Levine, M. and D.Q. Anderson. 1932. Ibid.

P. nautica Baumann, Baumann, Mandel and Allen 1972

Baumann, L., P. Baumann, M. Mandel and R.D. Allen. 1972. Journal of Bacteriology 110:402-429. Type strain: ATCC 27132

Description: Baumann, L., P. Baumann, M. Mandel and R.D. Allen. 1972. Ibid.

P. nitroreducens Iizuka and Komagata 1964 lizuka, H. and K. Komagata. 1964. Journal of General and Applied Microbiology 10:207-221. Type strain: IAM 1439 
Description: lizuka, H. and K. Komagata. 1964. Ibid.

P. oleovorans Lee and Chandler 1941

Lee, M. and A.C. Chandler. 1941. Journal of Bacteriology 41:373-386. Type strain: ATCC 8062

Description: Lee, M. and A.C. Chandler. 1941. Ibid.

P. palleronii Davis 1970

Davis, D.H. 1970 in Davis, D.H., R.Y.

Stanier, M. Doudoroff and M. Mandel. Archiv fur Mikrobiologie 70:1-13. Type strain: ATCC 17724

Description: Davis, D.H., R.Y. Stanier, M. Doudoroff and M. Mandel. 1970. Ibid.

P. paucimobilis Holmes, Owen, Evans, Malnick and Willcox 1977

Holmes, B., R.J.. Owen, A. Evans, H. Malnick and W.R. Willcox. 1977. International Journal of Systematic Bacteriology 27:133-146. Type strain: ATCC 29837

Description: Holmes, B., R.J. Owen, A. Evans, H. Malnick and W.R. Willcox. 1977. Ibid.

P. pertucinogena Kawai and Yabuuchi 1975

Kawai, Y. and E. Yabuuchi. 1975. International Journal of Systematic Bacteriology 25:317-323. Type strain: ATCC 190

Description: Kawai, Y. and E. Yabuuchi. 1975. Ibid.

P. phenazinium Bell and Turner 1973

Bell, S.C. and J.M. Turner. 1973. Biochemical Society Transactions 1:751753. Type strain: NCIB 11027

Description: Bell, S.C. and J.M. Turner. 1973. Ibid.

P. pickettii Ralston, Palleroni and Doudoroff 1973

Ralston, E., N.J. Palleroni and M. Doudoroff. 1973. International Journal of Systematic Bacteriology 23:15-19. Type strain: ATCC 27511

Description: Ralston, E., N.J. Palleroni and M. Doudoroff. 1973. Ibid.

P. pictorum Gray and Thornton 1928

Gray, P.H.H. and H.G. Thornton. 1928. Zentralblatt fur Bakteriologie, Parasitenkunde, Infektionskrankheiten und Hygiene. Abteilung II. 73:74-96. Type strain: ATCC 23328
Description: Gray, P.H.H. and H.G. Thornton. 1928. Ibid.

P. pseudoalcaligenes Stanier 1966

Stanier, R.Y. 1966 in Stanier, R.Y., N.J.

Palleroni and M. Doudoroff. Journal of General Microbiology 43:159-271. Type strain: ATCC 17440

Description: Bergey 8.

P. pseudoalcaligenes subsp. citrulli Schaad, Sowell, Goth, Colwell and Webb 1978

Schaad, N.W., G. Sowell, R.W. Goth; R.R. Colwell and R.E. Webb. 1978. International Journal of Systematic Bacteriology 28:117-125. Type strain: ATCC 29625

Description: Schaad, N.W., G. Sowell, R.W. Goth, R.R. Colwell and R.E. Webb. 1978. Ibid.

P. pseudoalcaligenes subsp. pseudoalcaligenes Stanier 1966

Stanier, R.Y. 1966 in Stanier, R.Y., N.J. Palleroni and M. Doudoroff. Journal of General Microbiology 43:159-271. Type strain: ATCC 17440

Description: Bergey 8.

P. pseudoflava Auling, Reh, Lee and Schlegel 1978

Auling, G., M. Reh, C.M. Lee and H.G. Schlegel. 1978. International Journal of Systematic Bacteriology 28:82-95. Type strain: DSM 1034

Description: Auling, G., M. Reh, C.M. Lee and H.G. Schlegel. 1978. Ibid.

P. pseudomallei (Whitmore 1913) Haynes 1957

Whitmore, A. 1913. Journal of Hygiene 13:1-34; Haynes, W.C. 1957 in Breed, R.S., E.G.D. Murray and N.R. Smith (eds). Bergey's Manual of Determinative Bacteriology, 7th ed. The Williams and Wilkins Co., Baltimore. pp. 89-152. Type strain: ATCC 23343

Description: Brindle, C.S. and S.T. Cowan. 1951. Journal of Pathology and Bacteriology 63:571-575.

P. putida (Trevisan 1889) Migula 1895

Trevisan, V. 1889. I Generi e le Specie delle Battieriacee. Zanaboni and Gabuzzi, Milano; Migula, W. 1895 in Engler, A. and K. Prantl (eds). Die Naturlichen Pflanzenfamilien, W. Engelmann, Leipzig, Teil I, Abteilung Ia. pp. 1-44. Type strain: ATCC 12633

Description: Bergey 8 . 
P. pyrrocinia Imanaka, Kousaka, Tamura and Arima 1965

Imanaka, H., M. Kousaka, G. Tamura and K. Arima. 1965. Journal of Antibiotics (Tokyo) Series A 18:205-206. Type strain: ATCC 15958

Description: Imanaka, H., M. Kousaka, G. Tamura and K. Arima. 1965. Ibid.

P. radiora Ito and Iizuka 1971

Ito, H. and H. Iizuka. 1971. Agricultural and Biological Chemistry 35:1566-1571. Type strain: ATCC 27329

Description: Ito, H. and H. Iizuka. 1971. Ibid.

P. resinovorans Delaporte, Raymond and Daste 1961

Delaporte, B., M. Raymond and P. Daste. 1961. Comptes Rendus des Seances de l'Academie des Sciences Paris 252:1073. 1075. Type strain: ATCC 14235

Description: Delaporte, B., M. Raymond and P. Daste. 1961. Ibid.

P. rhodos Heumann 1962

Heumann, W. 1962. Biologisches Zentralblatt 81:341-354. Type strain: ATCC 14821

Description: Heumann, W. 1962. Ibid.

P. rubrilineans (Lee, Purdy, Barnum and Martin 1925) Stapp 1928

Lee, H.A., H.A. Purdy, C.C. Barnum and J.P. Martin. 1925. Bulletin, Experiment Station of the Hawaiian Sugar Planters' Association pp. 64-74; Stapp, C. 1928 in Sorauer, Handbuch der Pflanzenkrankheiten, 5th ed. Paul Parey, Berlin. pp. 758. Type strain: ATCC 19307

Description: Hayward, A.C. 1962. Mauritius Sugar Industry Research Institute Occasional Paper No. 13:13-27.

P. rubrisubalbicans (Christopher and Edgerton 1930) Krassilnikov 1949

Christopher, W.N. and C.W. Edgerton. 1930. Journal of Agricultural Research 41:259-267; Krassilnikov, N.A. 1949. Moskva - Leningrad, Izdatel'stvo Akademii Nauk SSSR. pp.1-830. Type strain: ATCC 19308

Description: Hayward, A.C. 1962. Mauritius Sugar Industry Research Institute Occasional Paper No. 13:pp. 27.

P. saccharophila Doudoroff 1940

Doudoroff, M. 1940. Enzymologia 9:5972. Type strain: ATCC 15946
Description: Bergey 8.

P. solanacearum (Smith 1896) Smith 1914

Smith, E.F. 1896. Bulletin, Division of Vegetable Physiology and Pathology, United States Department of Agriculture 12:1-28; Smith, E.F. 1914. Carnegie Institute, Washington 3:1-309. Type strain: ATCC 11696

Description: Bergey 8.

P. spinosa Leifson 1962

Leifson, E. 1962. International Bulletin of Bacteriological Nomenclature and Taxonomy 12:89-92. Type strain: ATCC 14606 Description: Leifson, E. 1962. Ibid.

P. straminae Iizuka and Komagata 1963 lizuka, H. and K. Komagata. 1963. Journal of the Agricultural Chemical Society of Japan 37:137-141. Type strain: IAM 1598

Description: lizuka, H. and K. Komagata. 1963. Ibid.

P. stutzeri (Lehmann and Neumann 1896) Sijderius 1946

Lehmann, K.B. and R. Neumann. 1896. Atlas und Grundriss der Bakteriologie und Lehrbuch der speziellen bakteriologischen Diagnostik. 1st ed. J.F. Lehmann, Munchen; Sijderius, R. 1946. Heterotrophe Bacterien, die thiosulfaat oxydeeren. Thesis, University Amsterdam, pp. 1-146. Type strain: ATCC 17588

Description: Bergey 8 .

P. synxantha (Ehrenberg 1840) Holland 1920

Ehrenberg, C.G. 1840. Bericht Bekannt Verhandlungen der Koniglisch-Preussichen Akademie der Wissenschaftlichen, Berlin 1840:197-219; Holland, D.F. 1920 in Winslow, C.E.A., J. Broadhurst, R.E. Buchanan, C. Krumwiede Jr., L.A. Rogers and G.H. Smith. Journal of Bacteriology 5:191-229. Type strain: ATCC 9890

Description: Haynes, W.C. 1957 in Breed, R.S., E.G.D. Murray and N.R. Smith (eds). Bergey's Manual of Determinative Bacteriology, 7th ed. The Williams and Wilkins Co., Baltimore. p. 104.

P. syringae van Hall 1902

van Hall, C.J.J. 1902. Inaugural Dissertation. Amsterdam. pp. 198. Type strain: ATCC 19310

Description: Bergey 8.

P. taetrolens Haynes 1957 
Haynes, W.C. 1957 in Breed, R.S., E.G.D. Murray and N.R. Smith (eds). Bergey's Manual of Determinative Bacteriology, 7th ed. The Williams and Wilkins Co., Baltimore. pp. 89-152. Type strain: ATCC 4683

Description: Haynes, W.C. 1957. Ibid.

P. testosteroni Marcus and Talalay 1956 Marcus, P.I. and P. Talalay. 1956. Journal of Biological Chemistry 218:661.

Type strain: ATCC 11996

Description: Bergey 8.

P. tolaasii Paine 1919

Paine, S.G. 1919. Annals of Applied Biology 5:206-219. Type strain: NCPPB 2192

Description: Burkholder, W.H. 1957 in Breed, R.S., E.G.D. Murray and N.R. Smith (eds). Bergey's Manual of Determinative Bacteriology, 7th ed. The Williams and Wilkins Co., Baltimore. p. 136.

P. vesicularis (Busing, Doll and Freytag 1953) Galarneault and Leifson 1964

Busing, K.H., W. Doll and K. Freytag. 1953. Archiv fur Mikrobiologie 19:52-86; Galarneault, T.P. and E. Leifson. 1964. International Bulletin of Bacteriological Nomenclature and Taxonomy 14:165-168.

Type strain: ATCC 11426

Description: Bergey 8.

P. viridiflava (Burkholder 1930) Dowson 1939

Burkholder, W.H. 1930. Memoirs, Cornell University Agricultural Experiment Station 127:1-88; Dowson, W.J. 1939. Zentralblatt fur Bakteriologie, Parasitenkunde, Infektionskrankheiten und Hygiene. Abteilung II. 100:177-193. Type strain: ATCC 13223

Description: Billing, E. 1970. Journal of Applied Bacteriology 33:492-500.

P. woodsii (Smith 1911) Stevens 1925

Smith, E.F. 1911. Carnegie Institute, Washington 2:1-368; Stevens, F.L. 1925. Plant disease fungi. MacMillan. New York. Type strain: ATCC 19311

Description: Burkholder, W.H. and C.E.F. Guterman. 1935. Phytopathology 25:114120.

Pseudonocardia Henssen 1957

Henssen, A. 1957. Archiv fur Mikrobiologie 26:373-414. Type species: $P$. thermophila Henssen 1957
Description: Bergey 8 .

P. spinosa Schafer 1971

Schafer, D. 1971 in Henssen, A. and D.

Schafer. International Journal of Systematic Bacteriology 21:29-34. Type strain: ATCC 25924

Description: Bergey 8 .

P. thermophila Henssen 1957

Henssen, A. 1957. Archiv fur Mikrobiologie 26:373-414. Type strain: ATCC 19285 Description: Bergey 8.

Rhizobium Frank 1889

Frank, B. 1889. Berichte der Deutschen Botanischen Gesellschaft 7:332-346. Type species: $R$. leguminosarum (Frank 1879) Frank 1889

Description: Bergey 8.

R. japonicum (Kirchner 1896) Buchanan 1926

Kirchner, O. 1896. Beitrage zur Biologie der Pflanzen 7:213-224; Buchanan, R.E. 1926. Proceedings of the Iowa Academy of Science 33:81-90. Type strain: ATCC 10324

Description: Bergey 8 .

R. leguminosarum (Frank 1879) Frank 1889

Frank, B. 1879. Bericht der Deutschen Botanischen Gesellschaft 37:394-399; Frank, B. 1889. Berichte der Deutschen Botanischen Gesellschaft 7:332-346. Type strain: ATCC 10004

Description: Bergey 8.

R. lupini (Schroeter 1886) Eckhardt, Baldwin and Fred 1931

Schroeter, J. 1885-1889 in Cohn, F. Kryptogamenflora von Schlesien. Band 3, Heft 3, Pilze J.U. Kern's Verlag, Breslau. pp. 1-814; Eckhardt, M.M., I.R. Baldwin and E.B. Fred. 1931. Journal of Bacteriology 21:273-285. Type strain: ATCC 10319

Description: Bergey 8.

R. meliloti Dangeard 1926

Dangeard, P.A. 1926. Botaniste (Paris)

16:1-275. Type strain: ATCC 9930

Description: Bergey 8 .

R. phaseoli Dangeard 1926

Dangeard, P.A. 1926. Botaniste (Paris)

16:1-275. Type strain: ATCC 14482

Description: Bergey 8.

R. trifolii Dangeard 1926

Dangeard, P.A. 1926. Botaniste (Paris) 16:1-275. Type strain: ATCC 14480 
Description: Bergey 8.

\section{Rhodococcus Zopf 1891}

Zopf, W. 1891. Berichte der Deutschen Botanischen Gesellschaft 9:22-28. Type species: $R$. rhodochrous (Zopf 1891) Tsukamura 1974

Description: Goodfellow, $\mathbf{M}$. and $\mathbf{G}$. Alderson. 1977. Journal of General Microbiology 100:99-122.

R. bronchialis (Tsukamura 1971) Tsukamura 1974

Tsukamura, M. 1971. Journal of General Microbiology 68:15-26; Tsukamura, $M$. 1974. Japanese Journal of Microbiology 18:37-44. Type strain: ATCC 25592

Description: Goodfellow, $\mathbf{M}$. and $\mathbf{G}$. Alderson. 1977. Journal of General Microbiology 100:99-122.

R. coprophilus Rowbotham and Cross 1979

Rowbotham, T.J. and T. Cross. 1979. International Journal of Systematic Bacteriology 29:79-80; Effective publication Rowbotham, T.J. and T. Cross. 1977. Journal of General Microbiology 100:123138. Type strain: ATCC 29080

Description: Rowbotham, T.J. and T. Cross. 1977. Ibid.

R. corallinus (Bergey, Harrison, Breed, Hammer and Huntoon 1923) Goodfellow and Alderson 1979

Bergey, D.H., F.C. Harrison, R.S. Breed, B.W. Hammer and F.M. Huntoon. 1923. Bergey's Manual of Determinative Bacteriology, 1st ed. The Williams and Wilkins Co., Baltimore. pp. 1-442; Goodfellow, M. and G. Alderson. 1979. International Journal of Systematic Bacteriology 29:79-80; Effective publication Goodfellow, M. and G. Alderson. 1977. Journal of General Microbiology 100:99122. Type strain: ATCC 25593

Description: Goodfellow, $\mathbf{M}$. and G. Alderson. 1977. Ibid.

R. equi (Magnusson 1923) Goodfellow and Alderson 1979

Magnusson, H. 1923. Archiv fur Wissenschaftliche und Praktische Tierheilkunde 50:22-38; Goodfellow, M. and G. Alderson. 1979. International Journal of Systematic Bacteriology 29:79-80; Effective publication Goodfellow, M. and G. Alderson. 1977. Journal of General
Microbiology 100:99-122. Type strain: ATCC 25729

Description: Goodfellow, M. and G. Alderson. 1977. Ibid.

R. erythropolis (Gray and Thornton 1928) Goodfellow and Alderson 1979

Gray, P.H.H. and H.G. Thornton. 1928. Zentralblatt fur Bakteriologie, Parasitenkunde, Infektionskrankheiten und Hygiene. Abteilung II. 73:74-96; Goodfellow, M. and G. Alderson. 1979. International Journal of Systematic Bacteriology 29:79. 80; Effective publication Goodfellow, $\mathbf{M}$. and G. Alderson. 1977. Journal of General Microbiology 100:99-122. Type strain: ATCC 4277

Description: Goodfellow, M. and G. Alderson. 1977. Ibid.

R. rhodnii Goodfellow and Alderson 1979 Goodfellow, M. and G. Alderson. 1979. International Journal of Systematic Bacteriology 29:79-80; Effective publication Goodfellow, M. and G. Alderson. 1977. Journal of General Microbiology 100:99122. Type strain: KCC A-0203

Description: Goodfellow, $M$. and $G$. Alderson. 1977. Ibid.

R. rhodochrous (Zopf 1891) Tsukamura 1974 Zopf, W. 1891. Berichte der Deutschen Botanischen Gesellschaft 9:22-28; Tsukamura, M. 1974. Japanese Journal of Microbiology 18:37-44. Type strain: ATCC 13808

Description: Goodfellow, M. and G. Alderson. 1977. Journal of General Microbiology 100:99-122.

R. ruber (Kruse 1896) Goodfellow and Alderson 1979

Kruse, W. 1896 in Flugge, C. Die Mikroorganismen. Vol. 2, pp. 48-66; Goodfellow, M. and G. Alderson. 1979. International Journal of Systematic Bacteriology 29:79-80; Effective publication Goodfellow, M. and G. Alderson. 1977. Journal of General Microbiology 100:99122. Type strain: KCC A-0205

Description: Goodfellow, $M$. and $G$. Alderson. 1977. Ibid.

R. rubropertinctus (Hefferan 1904) Goodfellow and Alderson 1979

Hefferan, M. 1904. Zentralblatt fur Bakteriologie, Parasitenkunde, Infektionskrankheiten und Hygiene. Abteilung II. 
11:397-404; Goodfellow, $M$. and G. Alderson. 1979. International Journal of Systematic Bacteriology 29:79-80; Effective publication Goodfellow, M. and G. Alderson. 1977. Journal of General Microbiology 100:99-122. Type strain: ATCC 14352

Description: Goodfellow, $M$. and G. Alderson. 1977. Ibid.

R. terrae (Tsukamura 1971) Tsukamura 1974

Tsukamura, M. 1971. Journal of General Microbiology 68:15-26; Tsukamura, M. 1974. Japanese Journal of Microbiology 18:37-44. Type strain: ATCC 25594

Description: Goodfellow, $M$. and G. Alderson. 1977. Journal of General Microbiology 100:99-122.

\section{Rhodocyclus Pfennig 1978}

Pfennig N. 1978. International Journal of Systematic Bacteriology 28:283-288. Type species: $R$. purpureus Pfennig 1978

Description: Pfennig, N. 1978. Ibid.

R. purpureus Pfennig 1978

Pfennig, N. 1978. International Journal of Systematic Bacteriology 28:283-288. Type strain: DSM 168

Description: Pfennig, N. 1978. Ibid.

Rhodomicrobium Duchow and Douglas 1949

Duchow, E. and H.C. Douglas. 1949. Journal of Bacteriology 58:409-416. Type species: $R$. vannielii Duchow and Douglas 1949

Description: Bergey 8.

R. vannielii Duchow and Douglas 1949

Duchow, E. and H.C. Douglas. 1949. Journal of Bacteriology 58:409-416. Type strain: ATCC 17100

Description: Bergey 8.

Rhodopseudomonas Kluyver and van Niel 1937 Kluyver, A.J. and C.B. van Niel. 1937. Archiv fur Mikrobiologie 8:99-124. Type species: R. palustris (Molisch 1907) van Niel 1944

Description: Bergey 8.

R. acidophila Pfennig 1969

Pfennig, N. 1969. Journal of Bacteriology 99:597-602. Type strain: ATCC 25092

Description: Bergey 8.

R. capsulata (Molisch 1907) van Niel 1944 Molisch, H. 1907. Die Purpurbakterien nach neuen Untersuchungen. G. Fischer, Jena I-VII, pp. 1-95; van Niel, C.B. 1944. Bacteriological Reviews 8:1-118. Type strain: ATCC 11166

Description: Weaver, P.F., J.D. Wall and H. Gest. 1975. Archives of Microbiology 105:207-216.

R. gelatinosa (Molisch 1907) van Niel 1944

Molisch, H. 1907. Die Purpurbakterien nach neuen Untersuchungen. G. Fischer, Jena I-VII, pp. 1-95; van Niel, C.B. 1944. Bacteriological Reviews 8:1-118. Type strain: ATCC 17011

Description: Bergey 8.

R. globiformis Pfennig 1974

Pfennig, N. 1974. Archives of Microbiology 100:197-206. Type strain: DSM 161

Description: Pfennig, N. 1974. Ibid.

R. palustris (Molisch 1907) van Niel 1944

Molisch, H. 1907. Die Purpurbakterien nach neuen Untersuchungen. G. Fischer, Jena I-VII, pp. 1-95; van Niel, C.B. 1944. Bacteriological Reviews 8:1-118. Type strain: ATCC 17001

Description: Bergey 8 .

R. sphaeroides van Niel 1944

van Niel, C.B. 1944. Bacteriological Reviews 8:1-118. Type strain: ATCC 17023

Description: Bergey 8 .

R. sulfidophila Hansen and Veldkamp 1973

Hansen, T.A. and H. Veldkamp. 1973. Archiv fur Mikrobiologie 92:45-58. Type strain: DSM 1374

Description: Hansen, T.A. and H. Veldkamp. 1973. Ibid.

R. sulfoviridis Keppen and Gorlenko 1975

Keppen, O.I. and V.M. Gorlenko. 1975.

Mikrobiologiya 44:258-264. Type strain: DSM 729

Description: Keppen, O.I. and V.M. Gorlenko. 1975. Ibid.

R. viridis Drews and Giesbrecht 1966

Drews, G. and P. Giesbrecht. 1966. Archiv fur Mikrobiologie 53:255-262. Type strain: ATCC 19567

Description: Bergey 8 .

Rhodospirillum Molisch 1907

Molisch, H. 1907. Die Purpurbakterien nach neuen Untersuchungen. G. Fischer, Jena I-VII, pp. 1-95. Type species: $R$. 
rubrum (Esmarch 1887) Molisch 1907

Description: Bergey 8.

R. fulvum van Niel 1944

van Niel, C.B. 1944. Bacteriological Reviews 8:1-118. Type strain: ATCC 157980

Description: Bergey 8.

R. molischianum Giesberger 1947

Giesberger, G. 1947. Antonie van Leeuwenhoek Journal of Microbiology and Serology 13:135-148. Type strain: ATCC 14031

Description: Bergey 8.

R. photometricum Molisch 1907

Molisch, H. 1907. Die Purpurbakterien nach neuen Untersuchungen. G. Fischer, Jena I-VII, pp. 1-95. Type strain: DSM 122

Description: Bergey 8 .

R. rubrum (Esmarch 1887) Molisch 1907

Esmarch, E. 1887. Zentralblatt fur Bakteriologie, Parasitenkunde, Infektionskrankheiten und Hygiene. Abteilung I. 1: 225-230; Molisch, H. 1907. Die Purpurbakterien nach neuen Untersuchungen. $G$. Fisher, Jena I-VII, pp. 1-95. Type strain: ATCC 11170

Description: Bergey 8.

R. tenue Pfennig 1969

Pfennig, N. 1969. Journal of Bacteriology 99:619-920. Type strain: ATCC 25093

Description: Bergey 8.

Rickettsia da Rocha-Lima 1916

da Rocha-Lima, H. 1916. Berliner Klinische Wochenschrift 53:567-569. Type species: $R$. prowazekii da Rocha-Lima 1916

Description: Bergey 8 .

R. akari Huebner, Jellison and Pomerantz 1946 Huebner, R.J., W.L. Jellison and C. Pomerantz. 1946. Public Health Report 61:1677-1682. Type strain: ATCC VR 148

Description: Bergey 8.

R. australis Philip 1950

Philip, C.B. 1950 in Pullen, R.L. Communicable Diseases. Lea and Febiger Co., Philadelphia. pp. 781-788. Type strain: NIAID Phillips 32

Description: Bergey 8.

R. canada McKiel, Bell and Lackmann 1967 McKiel, J.A., E.J. Bell and D.B.
Lackmann. 1967. Canadian Journal of Microbiology 13:503-510. Type strain: ATCC VR 610

Description: Bergey 8.

R. conorii Brumpt 1932

Brumpt, E. 1932. Comptes Rendus des Seances de la Societe de Biologie Filiales 110:1199-1202. Type strain: NIAID Malish 7

Description: Bergey 8.

R. parkeri Lackman, Bell, Stoenner and Pickens 1965

Lackman, D.B., E.J. Bell, H.G. Stoenner and E.G. Pickens. 1965. Health Laboratory Science 2:135-141. Type strain: NIAID maculatum 20

Description: Bergey 8.

R. prowazekii da Rocha-Lima 1916

da Rocha-Lima, H. 1916. Berliner Klinische Wochenschrift 53:567-569. Type strain: ATCC VR 142

Description: Bergey 8.

R. rickettsii (Wolbach 1919) Brumpt 1922

Wolbach, S. 1919. Journal of Medical Research 41:1-197; Brumpt, E. 1922. Precis de Parasitologie. 3rd ed. Masson et Cie, Paris. Type strain: ATCC VR 149

Description: Bergey 8.

R. sennetsu Misao and Kobayashi 1956

Misao, R. and Y. Kobayashi. 1956. Journal of the Japanese Association for Infectious Diseases 30:453-465. Type strain: ATCC VR 367

Description: Bergey 8.

R. sibirica Zdrodovskii 1948

Zdrodovskii, P.F. 1948. Academy of Medical Science Moscow. Type strain: ATCC VR 151

Description: Bergey 8.

R. tsutsugamushi (Hayashi 1920) Ogata 1931 Hayashi, N. 1920. Journal of Parasitology 7:53-68; Ogata, N. 1931. Zentralblatt fur Bakteriologie, Parasitenkunde, Infektionskrankheiten und Hygiene. Abteilung I. 122:249-253. Type strain: ATCC VR 150 Description: Bergey 8.

R. typhi (Wolbach and Todd 1920) Philip 1943 Wolbach, S.B. and J.L. Todd. 1920. Annales de l'Institut Pasteur (Paris) 34: 153-158; Philip, C.B. 1943. American Journal of Hygiene 37:301-309. Type strain: ATCC VR 144 Description: Bergey 8. 
Rickettsiella Philip 1956

Philip, C.B. 1956. Canadian Journal of Microbiology 2:261-270. Type species: $R$. popilliae (Dutky and Gooden 1952) Philip 1956

Description: Bergey 8.

R. popilliae (Dutky and Gooden 1952) Philip 1956

Dutky, S.R. and E.L. Gooden. 1952. Journal of Bacteriology 63:743-750; Philip, C.B. 1956. Canadian Journal of Microbiology 2:261-270. Type strain: no culture isolated.

Description: Bergey 8.

R. stethorae Hall and Badgley 1957

Hall, I.M. and M.E. Badgley. 1957. Journal of Bacteriology 74:452-455. Type strain: no culture isolated.

Description: Bergey 8 .

Rochalimaea (Macchiavello 1947) Krieg 1961

Macchiavello, A. 1947. Prima Reunione Interamericana del Tifo, Mexico. pp. 405426; Krieg, A. 1961. Grundlagen der Insekten-pathologie. Dr. Dietrich Steinkofpp. Verlag, Darmstadt. Type species: $R$. quintana (Schmincke 1917) Krieg 1961

Description: Bergey 8.

R. quintana (Schmincke 1917) Krieg 1961

Schmincke, A. 1917. Munchener Medizinische Wochenschrift 64:961; Krieg, A. 1961. Grundlagen der Insektenpathologie. Dr. Dietrich Steinkopff. Verlag, Darmstadt. Type strain: ATCC VR 358

Description: Bergey 8.

\section{Rothia Georg and Brown 1967}

Georg, L.K. and J.M. Brown. 1967. International Journal of Systematic Bacteriology 17:79-88. Type species: $R$. dentocariosa (Onishi 1949) Georg and Brown 1967

Description: Bergey 8.

R. dentocariosa (Onishi 1949) Georg and Brown 1967

Onishi, M. 1949. Journal of Dental Research 6:273-282; Georg, L.K. and J.M. Brown. 1967. International Journal of Systematic Bacteriology 17:79-88. Type strain: ATCC 17931
Description: Bergey 8 .

Ruminococcus Sijpesteijn 1948

Sijpesteijn, A.K. 1948. Cellulosedecomposing bacteria from the rumen of cattle. Thesis. University of Leiden, The Netherlands. p. 152. Type species: $R$. flavefaciens Sijpesteijn 1948

Description: Bergey 8.

R. albus Hungate 1957

Hungate, R.E. 1957. Canadian Journal of Microbiology 3:289-311. Type strain: ATCC 27210

Description: Holdeman, L.V., E.P. Cato and W.E.C. Moore (eds). 1977. Anaerobe Laboratory Manual, 4th ed. Virginia Polytechnic Institute and State University, Blacksburg, Virginia. pp. 1-156.

R. bromii Moore, Cato and Holdeman 1972

Moore, W.E.C., E.P. Cato and L.V. Holdeman. 1972. International Journal of Systematic Bacteriology 22:78-80. Type strain: ATCC 27255

Description: Holdeman, L.V., E.P. Cato and W.E.C. Moore (eds). 1977. Anaerobe Laboratory Manual, 4th ed. Virginia Polytechnic Institute and State University, Blacksburg, Virginia. pp. 1-156.

R. callidus Holdeman and Moore 1974

Holdeman, L.V. and W.E.C. Moore. 1974. International Journal of Systematic Bacteriology 24:260-277. Type strain: VPI 57-31

Description: Holdeman, L.V. and W.E.C. Moore. 1974. Ibid.

R. flavefaciens Sijpesteijn 1948

Sijpesteijn, A.K. 1948. Cellulose-decomposing bacteria from the rumen of cattle. Thesis, University of Leiden, The Netherlands. Type strain: ATCC 19208

Description: Holdeman, L.V., E.P. Cato and W.E.C. Moore (eds). 1977. Anaerobe Laboratory Manual, 4th ed. Virginia Polytechnic Institute and State University, Blacksburg, Virginia. pp. 1-156.

R. gnavus Moore, Johnson and Holdeman 1976 Moore, W.E.C., J.L. Johnson and L.V. Holdeman. 1976. International Journal of Systematic Bacteriology 26:238-252. Type strain: ATCC 29149

Description: Moore, W.E.C., J.L. Johnson and L.V. Holdeman. 1976. Ibid.

R. lactaris Moore, Johnson and Holdeman 1976 
Moore, W.E.C., J.L. Johnson and L.V. Holdeman. 1976. International Journal of Systematic Bacteriology 26:238-252. Type strain: ATCC 29176

Description: Moore, W.E.C., J.L. Johnson and L.V. Holdeman. 1976. Ibid.

R. obeum Moore, Johnson and Holdeman 1976 Moore, W.E.C., J.L. Johnson and L.V. Holdeman. 1976. International Journal of Systematic Bacteriology 26:238-252. Type strain: ATCC 29174

Description: Moore, W.E.C., J.L. Johnson and L.V. Holdeman. 1976. Ibid.

R. torques Holdeman and Moore 1974

Holdeman, L.V. and W.E.C. Moore. 1974. International Journal of Systematic Bacteriology 24:260-277. Type strain: ATCC 27756

Description: Holdeman, L.V. and W.E.C. Moore. 1976. Ibid.

\section{Runella Larkin and Williams 1978}

Larkin, J.M. and P.M. Williams. 1978. International Journal of Systematic Bacteriology 28:32-36. Type species: $R$. slithyformis Larkin and Williams 1978

Description: Larkin, J.M and P.M. Williams. 1978. Ibid.

R. slithyformis Larkin and Williams 1978 Larkin, J.M. and P.M. Williams. 1978. International Journal of Systematic Bacteriology 28:32-36. Type strain: ATCC 29530

Description: Larkin, J.M. and P.M. Williams. 1978. Ibid.

Saccharomonospora Nonomura and Ohara 1971 Nonomura, H. and Y. Ohara. 1971. Journal of Fermentation Technology 49: 895-903. Type species: $S$. viridis (Schuurmans, Olson and San Clemente 1956) Nonomura and Ohara 1971

Description: Nonomura, H. and Y. Ohara. 1971. Ibid.

S. viridis (Schuurmans, Olson and San Clemente 1956) Nonomura and Ohara 1971 Schuurmans, D.M., B.H. Olson and C.L. San Clemente. 1956. Applied Microbiology 4:61-66; Nonomura, $H$. and $Y$. Ohara. 1971. Journal of Fermentation Technology 49:895-903. Type strain: ATCC 15386

Description: Nonomura, H. and Y. Ohara. 1971. Ibid.
Saccharopolyspora Lacey and Goodfellow 1975

Lacey, J. and M. Goodfellow. 1975. Journal of General Microbiology 88:7678. Type species: $S$. hirsuta Lacey and Goodfellow 1975

Description: Lacey, J. and M. Goodfellow. 1975. Ibid.

S. hirsuta Lacey and Goodfellow 1975

Lacey, J. and M. Goodfellow. 1975. Journal of General Microbiology 88:7678. Type strain: ATCC 27875

Description: Lacey, J. and M. Goodfellow. 1975. Ibid.

\section{Salmonella Lignieres 1900}

Lignieres, J. 1900. Bulletin of the Society for Central Medical Veterinarians ns 18: 389-431. Type species: $S$. cholerae-suis (Smith 1894) Weldin 1927

Description: Bergey 8.

S. arizonae (Borman 1957) Kauffman 1964 Borman, E.K. 1957 in Breed, R.S., E.G.D. Murray and N.R. Smith (eds). Bergey's Manual of Determinative Bacteriology, 7th ed. The Williams and Wilkins Co., Baltimore. pp. 346-348; Kauffman, F. 1964 in van Oye, E. The world problem of slamonellosis. Junk Publications, The Hague. Type strain: ATCC 13314

Description: Kauffman, F. 1964. Ibid.

S. cholerae-suis (Smith 1894) Weldin 1927

Smith, T. 1894. Bulletin of the United States Bureau of Animal Industry 6:6-40; Weldin, J.C. 1927. Iowa State Journal of Science 1:121-197. Type strain: ATCC 13312

Description: Bergey 8.

S. enteritidis (Gaertner 1888) Castellani and Chalmers 1919

Gaertner, E. 1888. Korrespondenzblatt des Allgemeinen arztilchen Vereins von Thuringen 17:573-600; Castellani, A. and A.J. Chalmers. 1919. Manual of tropical medicine, 3rd ed. Williams, Wood and Co., New York. p. 939. Type strain: ATCC 13076

Description: Bergey 8.

S. typhi (Schroeter 1886) Warren and Scott 1930

Schroeter, J. 1885-1889 in Cohn, F. Kryptogamenflora von Schlesien. Band 3, 
Heft 3, Pilze. J.U. Kern's Verlag, Breslau. pp. 1-814; Warren S.H. and W.M. Scott. 1930. Journal of Hygiene 29:415-417. Type strain: ATCC 19430 Description: Bergey 8.

S. typhimurium (Loeffler 1892) Castellani and Chalmers 1919

Loeffler, F. 1892. Zentralblatt fur Bakteriologie, Parasitenkunde, Infektionskrankheiten und Hygiene. Abteilung I. 11:129141; Castellani, A. and A.J. Chalmers. 1919. Manual of tropical medicine, 3rd ed. Williams, Wood and Co., New York. p. 939. Type strain: ATCC 13311

Description: Bergey 8.

\section{Saprospira Gross 1911}

Gross, J. 1911. Mitteilungen aus der Zoologischen Station zu Neapel 20:188203. Type species: $S$. grandis Gross 1911 Description: Bergey 8.

S. grandis Gross 1911

Gross, J. 1911. Mitteilungen aus der Zoologischen Station zu Neapel 20:188203. Type strain: ATCC 23119

Description: Bergey 8.

\section{Sarcina Goodsir 1842}

Goodsir, J. 1842. Edinburgh Medical Surgery Journal 57:430-443. Type species: S. ventriculi Goodsir 1842

Description: Bergey 8.

S. maxima Lindner 1888

Lindner, P. 1888. Inaugural Dissertation, Friedrich-Wilhems Universitat, pp. 1-59. Type strain: DSM 316

Description: Bergey 8.

S. ventriculi Goodsir 1842

Goodsir, J. 1842. Edinburgh Medical Surgery Journal 57:430-443. Type strain: ATCC 19633

Description: Holdeman, L.V., E.P. Cato and W.E.C. Moore (eds). 1977. Anaerobe Laboratory Manual, 4th ed. Virginia Polytechnic Institute and State University, Blacksburg, Virginia. pp. 1-156.

\section{Selenomonas von Prowazek 1913}

von Prowazek, S. 1913. Zentralblatt fur Bakteriologie Parasitenkunde, Infektionskrankheiten und Hygiene. Abteilung I. 70:32-36. Type species: $S$. sputigena (Flugge 1886) Boskamp 1922
Description: Bergey 8.

S. ruminantium (Certes 1889) Wenyon 1926 Certes, A. 1889. Bulletin de la Societe Zoologie Francaise 14:70-73; Wenyon, C.M. 1926. Protozoology, Vol. 1. Bailliere, Tindall and Cox, London. pp. 1778. Type strain: ATCC 12561

Description: Holdeman, L.V., E.P. Cato and W.E.C. Moore (eds). 1977. Anaerobe Laboratory Manual, 4th ed. Virginia Polytechnic Institute and State University, Blacksburg, Virginia. pp. 1-156.

S. ruminantium subsp. lactilytica Bryant 1956 Bryant, M.P. 1956. Journal of Bacteriology 72:162-167. Type strain: ATCC 19205 Description: Bergey 8.

S. ruminantium subsp. ruminantium Bryant 1974

Bryant, M.P. 1974 in Bergey 8. Type strain: ATCC 12561

Description: Bergey 8 .

S. sputigena (Flugge 1886) Boskamp 1922

Flugge, C. 1886. Die Mikroorganismen. F.C.W. Vogel, Leipzig; Boskamp, E. 1922. Zentralblatt fur Bakteriologie Parasitenkunde, Infektionskrankheiten und $\mathrm{Hy}$ giene. Abteilung I. 88:58-73. Type strain: VPI 10068

Description: Holdeman, L.V., E.P. Cato and W.E.C. Moore (eds). 1977. Anaerobe Laboratory Manual, 4th ed. Virginia Polytechnic Institute and State University, Blacksburg, Virginia. pp. 1-156.

Seliberia Aristovskaya and Parinkina 1963 Aristovskaya, T.V. and O.M. Parinkina. 1963. Bulletin of the Academy of Sciences USSR (Series Biology) 218:4956. Type species: $S$. stellata Aristovskaya and Parinkina 1963

Description: Bergey 8.

S. stellata Aristovskaya and Parinkina 1963 Aristovskaya, T.V. and O.M. Parinkina. 1963. Bulletin of the Academy of Sciences USSR (Series Biology) 218:49. 56. Type strain: INMI N-9

Description: Bergey 8.

\section{Serpens Hespell 1977}

Hespell, R.B. 1977. International Journal of Systematic Bacteriology 27:371-381. Type species: S. flexibilis Hespell 1977 Description: Hespell, R.B. 1977. Ibid. 
S. flexibilis Hespell 1977

Hespell, R.B. 1977. International Journal of Systematic Bacteriology 27:371-381. Type strain: ATCC 29606

Description: Hespell, R.B. 1977. Ibid.

\section{Serratia Bizio 1823}

Bizio, B. 1823. Biblioteca Italiana o sia Giornale di Letteratura, Scienz e Arti (Anno VIII) 30:275-295. Type species: $S$. marcescens Bizio 1823

Description: Bergey 8.

S. fonticola Gavini, Ferragut, Izard, Trinel, Leclerc, Lefebvre and Mossel 1979

Gavin, F., C. Ferragut, D. Izard, P.A. Trinel, H. Leclerc, B. Lefebvre and D.A.A. Mossel. 1979. International Journal of Systematic Bacteriology 29:92101. Type strain: ATCC 29844

Description: Gavini, F., C. Ferragut, D. Izard, P.A. Trinel, H. Leclerc, B. Lefebvre and D.A.A. Mossel. 1979. Ibid.

S. liquefaciens (Grimes and Hennerty 1961) Bascomb, Lapage, Willcox and Curtis 1971

Grimes, M. and P.J. Hennerty. 1961. Scientific Proceedings of the Royal Society Dublin 20:89-97; Bascomb, S., S.P. Lapage, W.R. Willcox and M.A. Curtis. 1971. Journal of General Microbiology 66:279-295. Type strain: ATCC 27592

Description: Bascomb, S., S.P. Lapage, W.R. Willcox and M.A. Curtis. 1971. Ibid.

S. marcescens Bizio 1823

Bizio, B. 1923. Biblioteca Italianna o sia Giornale di Letteratura, Scienze e Arti (Anno VIII) 30:275-295. Type strain: ATCC 13880

Description: Grimont, P.A.D., F. Grimont, H.L.C. Dulong de Rosnay and P.H.A. Sneath. 1977. Journal of General Microbiology 98:39-66.

S. marinorubra ZoBell and Upham 1944

ZoBell, C.E. and H.C. Upham. 1944. Bulletin Scripps Institution of Oceanography University of California (Technical Series) 5:239-292. Type strain: ATCC 27593

Description: Grimont, P.A.D., F. Grimont, H.L.C. Dulong de Rosnay and P.H.A. Sneath. 1977. Journal of General
Microbiology 98:39-66.

S. odorifera Grimont, Grimont, Richard, Davis, Steigerwalt and Brenner 1978

Grimont, P.A.D., F. Grimont, C. Richard, B.R. Davis, A.G. Steigerwalt and D.J. Brenner. 1978. International Journal of Systematic Bacteriology 28:453-463. Type strain: CDC 1979-77

Description: Grimont, P.A.D., F. Grimont, C. Richard, B.R. Davis, A.G. Steigerwalt and D.J. Brenner. 1978. Ibid.

S. plymuthica (Dyar 1895) Bergey, Harrison, Breed, Hammer and Huntoon 1923

Dyar, H.G. 1895. Annals of the New York Academy of Sciences 8:322-380; Bergey, D.H., F.C. Harrison, R.S. Breed, B.W. Hammer and F.M. Huntoon. 1923. Bergey's Manual Determinative Bacteriology, 1st ed. The Williams and Wilkins Co., Baltimore. pp. 1-442. Type strain: ATCC 183

Description: Grimont, P.A.D., F. Grimont, H.L.C. Dulong de Rosnay and P.H.A. Sneath. 1977. Journal of General Microbiology 98:39-66.

S. proteamaculans (Paine and Stansfield 1919) Grimont, Grimont and Starr 1978

Paine, S.G. and H. Stansfield. 1919. Annals of Applied Biology 6:27-39; Grimont, P.A.D., F. Grimont and M.P. Starr. 1978. International Journal of Systematic Bacteriology 28:503-510. Type strain: ATCC 19323

Description: Grimont, P.A.D., F. Grimont and M.P. Starr. 1978. Ibid.

S. rubidaea (Stapp 1940) Ewing, Davis, Fife and Lessel 1973

Stapp, C. 1940. Zentralblatt fur Bakteriologie, Parasitenkunde, Infektionskrankheiten und Hygiene. Abteilung II. 102:251-266; Ewing, W.H., B.R. Davis, M.A. Fife and E.F. Lessel. 1973. International Journal of Systematic Bacteriology 23:217-225. Type strain: ATCC 27593

Description: Ewing, W.H., B.R. Davis, M.A. Fife and E.F. Lessel. 1973. Ibid.

Shigella Castellani and Chalmers 1919

Castellani, A. and A.J. Chalmers. 1919. Manual of tropical medicine, 3rd ed. Williams, Wood and Co., New York. Type species: $S$. dysenteriae (Shiga 1898) 
Castellani and Chalmers 1919

Description: Bergey 8.

S. boydii Ewing 1949

Ewing, W.H. 1949. Journal of Bacteriology 57:633-638. Type strain: ATCC 8700

Description: Ewing, W.H. 1949. Ibid.

S. dysenteriae (Shiga 1898) Castellani and Chalmers 1919

Shiga, K. 1898. Zentralblatt fur Bakteriologie, Parasitenkunde, Infektionskrankheiten und Hygiene. Abteilung I. 24:817-828; Castellani, A. and A.J. Chalmers. 1919. Manual of tropical medicine, 3rd ed. Williams, Wood and Co., New York. p. 935. Type strain: ATCC 13313

Description: Bergey 8.

S. flexneri Castellani and Chalmers 1919 Castellani, A. and A.J. Chalmers. 1919. Manual of tropical medicine, 3rd ed. Williams, Wood and Co., New York. p. 937. Type strain: ATCC 29903

Description: Bergey 8.

S. sonnei (Levine 1920) Weldin 1927

Levine, M. 1920. Journal of Infectious Diseases 27:31-39; Weldin, J.C. 1927. Iowa State Journal of Science 1:121-197. Type strain: ATCC 29930

Description: Bergey 8.

\section{Simonsiella Schmid 1922}

Schmid, G. 1922 in Simons, H. Zentralblatt fur Bakteriologie, Parasitenkunde, Infektions- krankheiten und Hygiene. Abteilung I. 88:501-510. Type species: $S$. muelleri Schmid 1922

Description: Bergey 8.

S. crassa Schmid 1922

Schmid, G. 1922 in Simons, H. Zentralblatt fur Bakteriologie, Parasitenkunde, Infektionskrankheiten und Hygiene. Abteilung I. 88:501-510. Type strain: ATCC 15533

Description: Bergey 8.

S. muelleri Schmid 1922

Schmid, G. 1922 in Simons, H. Zentralblatt fur Bakteriologie, Parasitenkunde, Infektionskrankheiten und Hygiene. Abteilung I. 88:501-510. Type strain: ATCC 29453

Description: Kuhn, D.A. and D.A. Gregory. 1978. Current Microbiology 1:11-14.

S. steedae Kuhn and Gregory 1979
Kuhn, D.A. and D.A. Gregory. 1979 in International Journal of Systematic Bacteriology 29:79-80; Effective publication Kuhn, D.A. and D.A. Gregory. 1978. Current Microbiology 1:11-14. Type strain: ATCC 27409

Description: Kuhn, D.A. and D.A. Gregory. 1978. Ibid.

\section{Sphaerotilus Kutzing 1833}

Kutzing, F.T. 1833. Linnaea 8:335-387.

Type species: $S$. natans Kutzing 1833

Description: Bergey 8.

S. natans Kutzing 1833

Kutzing, F.T. 1833. Linnaea 8:335-387. Type strain: ATCC 13338

Description: Stokes, J.L. 1954. Journal of Bacteriology 67:278-291.

Spirillospora Couch 1963

Couch, N.J. 1963. Journal of the Elisha Mitchell Scientific Society 79:53-70. Type species: S. albida Couch 1963

Description: Bergey 8 .

S. albida Couch 1963

Couch, J.N. 1963. Journal of the Elisha Mitchell Scientific Society 79:53-70. Type strain: ATCC 15331

Description: Bergey 8.

Spirillum Ehrenberg 1832

Ehrenberg, C.G. 1832. Abhandlungen der Koniglichen Akademie der Wissenschaften zu Berlin 1830, pp. 1-88. Type species: $S$. volutans Ehrenberg 1832

Description: Bergey 8 .

S. volutans Ehrenberg 1832

Ehrenberg, C.G. 1832. Abhandlungen der Koniglichen Akademie der Wissenschaften zu Berlin 1830, pp. 1-88. Type strain: ATCC 19554

Description: Hylemon, P.B., J.S. Wells Jr., J.H. Bowdre, T.O. MacAdoo and N.R. Krieg. 1973. International Journal of Systematic Bacteriology 23:20-27.

\section{Spirochaeta Ehrenberg 1835}

Ehrenberg, C.G. 1835. Abhandlungen der Preussischen Akademie der Wissenschaften (Berlin) aus den Jahre 1833-1835, pp. 143-336. Type species: $S$. plicatilis Ehrenberg 1835

Description: Bergey 8. 
S. halophila Greenberg and Canale-Parola 1977 Greenberg, E.P. and E. Canale-Parola. 1977 in International Journal of Systematic Bacteriology 27:306; Effective publication Greenberg, E.P. and E. Canale-Parola. 1976. Archives of Microbiology 110:185-194. Type strain: ATCC 29478

Description: Greenberg, E.P. and E. Canale-Parola. 1976. Ibid.

S. plicatilis Ehrenberg 1835

Ehrenberg, C.G. 1835. Abhandlungen der Preussischen Akademie der Wissenschaften (Berlin) aus den Jahre 1833-1835, pp. 143-336. Type strain: no culture available.

Description: Bergey 8.

S. stenostrepta Zuelzer 1912

Zuelzer, M. 1912. Archiv fur Protistenkunde 24:1-59. Type strain: ATCC 25083 Description: Bergey 8.

Spiroplasma Saglio, Lhospital, Lafleche, Dupont, Bove, Tully and Freundt 1973

Saglio, P., M. Lhospital, D. Lafleche, G. Dupont, J.M. Bove, J.G. Tully and E.A. Freundt. 1973. International Journal of Systematic Bacteriology 23:191-204. Type species: $S$. citri Saglio, Lhospital, Lafleche, Dupont, Bove, Tully and Freundt 1973

Description: Bergey 8.

S. citri Saglio, Lhospital, Lafleche, Dupont, Bove, Tully and Freundt 1973

Saglio, P., M. Lhospital, D. Lafleche, G. Dupont, J.M. Bove, J.G. Tully and E.A. Freundt. 1973. International Journal of Systematic Bacteriology 23:191-204. Type strain: ATCC 27556

Description: Saglio, P., M. Lhospital, D. Lafleche, G. Dupont, J.M. Bove, J.G. Tully and E.A. Freundt. 1973. Ibid.

\section{Spirosoma Migula 1894}

Migula, W. 1894. Arbeiten aus dem Bakteriologischen Institut der Technischen Hochschule zu Karlsruhe 1:235-238. Type species: $S$. linguale Migula 1894

Description: Larkin, J.M., P.M. Williams and R. Taylor. 1977. International Journal of Systematic Bacteriology 27: 147-156.

S. linguale Migula 1894

Migula, W. 1894. Arbeiten aus dem
Bakteriologischen Institut der Technischen Hochschule zu Karlsruhe 1:235-238. Type strain: DSM 74

Description: Larkin, J.M., P.M. Williams and R. Taylor. 1977. International Journal of Systematic Bacteriology 27: 147-156.

Sporichthya Lechevalier, Lechevalier and Holbert 1968

Lechevalier, M.P., H.A. Lechevalier and P.E. Holbert. 1968. Annales de l'Institut Pasteur (Paris) 114:277-285. Type species: $S$. polymorpha Lechevalier, Lechevalier and Holbert 1968

Description: Bergey 8.

S. polymorpha Lechevalier, Lechevalier and Holbert 1968

Lechevalier, H.A., M.P. Lechevalier and P.E. Holbert. 1968. Annales de l'Institut Pasteur (Paris) 114:277-285. Type strain: ATCC 23823

Description: Lechevalier, M.P., H.A. Lechevalier and P.E. Holbert. 1968. Ibid.

\section{Sporocytophaga Stanier 1940}

Stanier, R.Y. 1940. Journal of Bacteriolo-

gy 40:619-636. Type species: $S$. myxococcoides (Krzemieniewska 1933)

Stanier 1940

Description: Bergey 8.

S. myxococcoides (Krzemieniewska 1933) Stanier 1940

Krzemieniewska, H. 1933. Archiv fur Mikrobiologie 4:394-408; Stanier, R.Y. 1940. Journal of Bacteriology 40:619-636. Type strain: ATCC 10010 Description: Bergey 8.

\section{Sporolactobacillus Kitahara and Suzuki 1963} Kitahara, K. and J. Suzuki. 1963. Journal of General and Applied Microbiology 9: 59-71. Type species: $S$. inulinus (Kitahara and Suzuki 1963) Kitahara and Lai 1967 Description: Bergey 8.

S. inulinus (Kitahara and Suzuki 1963) Kitahara and Lai 1967

Kitahara, K. and J. Suzuki. 1963. Journal of General and Applied Microbiology 9: 59-71; Kitahara, K. and C.L. Lai. 1967. Journal of General and Applied Microbiology 13:197-203. Type strain: ATCC 15538 
Description: Holdeman, L.V., E.P. Cato and W.E.C. Moore (eds). 1977. Anaerobe Laboratory Manual, 4th ed. Virginia Polytechnic Institute and State University, Blacksburg, Virginia. pp. 1-156.

Sporosarcina Kluyver and van Niel 1936 Kluyver, A.J. and C.B. van Niel. 1936. Zentralblatt fur Bakteriologie, Parasitenkunde, Infektionskrankheiten und Hygiene. Abteilung II. 94:369-403. Type species: S. ureae (Beijerinck 1901) Kluyver and van Niel 1936

Description: Bergey 8.

S. ureae (Beijerinck 1901) Kluyver and van Niel 1936

Beijerinck, M.W. 1901. Zentralblatt fur Bakteriologie, Parasitenkunde, Infektionskrankheiten und Hygiene. Abteilung II. 7:33-61; Kluyver, A.J. and C.B. van Niel. 1936. Zentralblatt fur Bakteriologie, Parasitenkunde, Infektionskrankheiten und $\mathrm{Hy}$ giene. Abteilung II. 94:369-403. Type strain: ATCC 6473

Description: Bergey 8.

\section{Staphylococcus Rosenbach 1884}

Rosenbach, F.J. 1884. Microorganismen bei den Wund-Infections-Krankheiten des Menschen. J.F. Bergmann, Wiesbaden. pp. 1-122. Type species: $S$. aureus Rosenbach 1884

Description: Bergey 8 .

S. aureus Rosenbach 1884

Rosenbach, F.J. 1884. Microorganismen bei den Wund-Infections-Krankheiten des Menschen. J.F. Bergmann, Wiesbaden. pp. 1-122. Type strain: ATCC 12600

Description: Bergey 8.

S. capitis Kloos and Schleifer 1975

Kloos, W.E. and K.H. Schleifer. 1975. International Journal of Systematic Bacteriology 25:62-79. Type strain: ATCC 27840

Description: Kloos, W.E. and K.H. Schleifer. 1975. Ibid.

S. cohnii Schleifer and Kloos 1975

Schleifer, K.H. and W.E. Kloos. 1975. International Journal of Systematic Bacteriology 25:50-61. Type strain: ATCC 29974

Description: Schleifer, K.H. and W.E. Kloos. 1975. Ibid.
S. epidermidis (Winslow and Winslow 1908) Evans 1916

Winslow, C.E.A. and A.R. Winslow. 1908. The systematic relationships of the Coccaceae. John Wiley, New York; Evans, A.C. 1916. Journal of Infectious Diseases 18:437-476. Type strain: ATCC 14990

Description: Bergey 8.

S. haemolyticus Schleifer and Kloos 1975

Schleifer, K.H. and W.E. Kloos. 1975.

International Journal of Systematic Bacteriology 25:50-61. Type strain: ATCC 29970

Description: Schleifer, K.H. and W.E. Kloos. 1975. Ibid.

S. hominis Kloos and Schleifer 1975

Kloos, W.E. and K.H. Schleifer. 1975. International Journal of Systematic Bacteriology 25:62-79. Type strain: ATCC 27844

Description: Kloos, W.E. and K.H. Schleifer. 1975. Ibid.

S. hyicus (Sompolinski 1953) Devriese, Hajek, Oeding, Meyer and Schleifer 1978

Sompolinski, D. 1953. Schweizerishces Archiv fur Tierheilkunde 95:302-339; Devriese, L.A., V. Hajek, P. Oeding, S.A. Meyer and K.H. Schleifer. 1978. International Journal of Systematic Bacteriology 28:482-490. Type strain: ATCC 11249

Description: Devriese, L.A., V. Hajek, P. Oeding, S.A. Meyer and K.H. Schleifer. 1978. Ibid.

S. hyicus subsp. chromogenes Devriese, Hajek, Oeding, Meyer and Schleifer 1978

Devriese, L.A., V. Hajek, P. Oeding, S.A. Meyer and K.H. Schleifer. 1978. International Journal of Systematic Bacteriology 28:482-490. Type strain: NCTC 10530

Description: Devriese, L.A., V. Hajek, P. Oeding, S.A. Meyer and K.H. Schleifer. 1978. Ibid.

S. hyicus subsp. hyicus (Sompolinski 1953) Devriese, Hajek, Oeding, Meyer and Schleifer 1978

Sompolinski, D. 1953. Schweizerisches Archiv fur Tierheilkunde 95:302-339; Devriese, L.A., V. Hajek, P. Oeding, S.A. Meyer and K.H. Schleifer. 1978. International Journal of Systematic Bacteriology 28:482-490. Type strain: ATCC 11249 
Description: Devriese, L.A., V. Hajek, P. Oeding, S.A. Meyer and K.H. Schleifer. 1978. Ibid.

S. intermedius Hajek 1976

Hajek, V. 1976. International Journal of Systematic Bacteriology 26:401-408. Type strain: ATCC 29663

Description: Hajek, V. 1976. Ibid.

S. saprophyticus (Fairbrother 1940) Shaw, Stitt and Cowan 1951

Fairbrother, R.W. 1940. Journal of Pathology and Bacteriology 50:83-88; Shaw, C., J.M. Stitt and S.T. Cowan. 1951. Journal of General Microbiology 5: 1010-1023. Type strain: ATCC 15305

Description: Bergey 8.

S. sciuri Kloos, Schleifer and Smith 1976

Kloos, W.E., K.H. Schleifer and R.F. Smith. 1976. International Journal of Systematic Bacteriology 26:22-37. Type strain: ATCC 29062

Description: Kloos, W.E., K.H. Schleifer and R.F. Smith. 1976. Ibid.

S. sciuri subsp. lentus Kloos, Schleifer and Smith 1976

Kloos, W.E., K.H. Schleifer and R.F. Smith. 1976. International Journal of Systematic Bacteriology 26:22-37. Type strain: ATCC 29070

Description: Kloos, W.E., K.H. Schleifer and R.F. Smith. 1976. Ibid.

S. sciuri subsp. sciuri Kloos, Schleifer and Smith 1976

Kloos, W.E., K.H. Schleifer and R.F. Smith. 1976. International Journal of Systematic Bacteriology 26:22-37. Type strain: ATCC 29062

Description: Kloos, W.E., K.H. Schleifer and R.F. Smith. 1976. Ibid.

S. simulans Kloos and Schleifer 1975

Kloos, W.E. and K.H. Schleifer. 1975.

International Journal of Systematic

Bacteriology 25:62-79. Type strain: ATCC 27848

Description: Kloos, W.E. and K.H. Schleifer. 1975. Ibid.

S. warneri Kloos and Schleifer 1975

Kloos, W.E. and K.H. Schleifer. 1975. International Journal of Systematic Bacteriology 25:62-79. Type strain: ATCC 27836

Description: Kloos, W.E. and K.H. Schleifer. 1975. Ibid.
S. xylosus Schleifer and Kloos 1975

Schleifer, K.H. and W.E. Kloos. 1975. International Journal of Systematic Bacteriology 25:50-61. Type strain: ATCC 29971

Description: Schleifer, K.H. and W.E. Kloos. 1975. Ibid.

Stibiobacter Lyalikova 1974

Lyalikova, N.N. 1974. Mikrobiologiya 43:

799-805. Type species: $S$. senarmontii

Lyalikova 1974

Description: Lyalikova, N.N. 1974. Ibid.

S. senarmontii Lyalikova 1974

Lyalikova, N.N. 1974. Mikrobiologiya 43:

799-805. Type strain: VKM MV-1130

Description: Lyalikova, N.N. 1974. Ibid.

Stigmatella Berkeley and Curtis 1875

Berkeley, M.J. and Curtis. 1875 in

Berkeley, M.J. Grevillea 3:97-112. Type

species: $S$. aurantiaca Berkeley and Curtis 1875

Description: Bergey 8 .

S. aurantiaca Berkeley and Curtis 1875

Berkeley, M.J. and Curtis. 1875 in

Berkeley, M.J. Grevillea 3:97-112. Type strain: ATCC 25190

Description: Reichenbach, $H$. and $M$. Dworkin. 1969. Journal of General Microbiology 58:3-14.

S. erecta (Schroeter 1886) McCurdy 1971

Schroeter, J. 1885-1889 in Cohn, F. Kryptogamenflora von Schlesien. Band 3, Heft 3, Pilze J.U. Kern's Verlag, Breslau. pp. 1-814; McCurdy, H.D. 1971. International Journal of Systematic Bacteriology 21:40-49. Type strain: ATCC 25191

Description: McCurdy, H.D. 1971. Ibid.

Streptobacillus Levaditi, Nicolau and Poincloux 1925

Levaditi, C., S. Nicolau and P. Pioncloux. 1925. Compte Rendu Hebdomadaire des Seances de l'Academie des Sciences (Paris) 180:1188-1190. Type species: $S$. moniliformis Levaditi, Nicolau and Poincloux 1925

Description: Bergey 8.

S. moniliformis Levaditi, Nicolau and Poincloux 1925

Levaditi, C., S. Nicolau and P. Poincloux. 1925. Compte Rendu Hebdomadaire des 
Seances de l'Academie des Sciences (Paris) 180:1188-1190. Type strain: ATCC 14647

Description: Bergey 8.

\section{Streptococcus Rosenbach 1884}

Rosenbach, F.J. 1884. Microorganismen bei den Wund-Infections- Krankheiten des Menschen. K.F. Bergmann, Wiesbaden, pp. 1-122. Type species: $S$. pyogenes Rosenbach 1884

Description: Bergey 8 .

S. acidominimus Ayers and Mudge 1922 Ayers, S.H. and C.S. Mudge. 1922. Journal of Infectious Diseases 31:40-50. Type strain: NCDO 2025

Description: Bergey 8.

S. agalactiae Lehmann and Neumann 1896 Lehmann, K.B. and R. Neumann. 1896. Atlas und Grundriss der Bakteriologie und Lehrbuch der speziellen bakteriologischen Diagnostik. 1st ed. J.F. Lehmann, Munchen. Type strain: NCTC 8181

Description: Bergey 8.

S. anginosus (Andrewes and Horder 1906) Smith and Sherman 1938

Andrewes, F.W. and T.J. Horder. 1906. Lancet 2:708-713; Smith, F.R. and J.M. Sherman. 1939. Journal of Infectious Diseases 62:189. Type strain: NCTC 10713

\section{Description: Bergey 8.}

S. bovis Orla-Jensen 1919

Orla-Jensen, S. 1919. The lactic acid bacteria. Host, Copenhagen. pp. 1-196. Type strain: NCDO 597

Description: Garvie, E.I. and A.J. Bramley. 1979. Journal of Applied Bacteriology 46:557-566.

S. constellatus (Prevot 1924) Holdeman and Moore 1974

Prevot, A.R. 1924. Comptes Rendus des Seances de la Societe de Biologie (Paris) 91:426-428; Holdeman, L.V. and W.E.C. Moore. 1974. International Journal of Systematic Bacteriology 24:260-277. Type strain: ATCC 27823

Description: Holdeman, L.V. and W.E.C. Moore. 1974. Ibid.

S. cremoris Orla-Jensen 1919

Orla-Jensen, S. 1919. The lactic acid bacteria. Host, Copenhagen. pp. 1-196. Type strain: NCDO 607
Description: Whitehead, H.R., C.A.E. Briggs, E.I. Garvie and L.G.M. Newland. 1956. Journal of Dairy Research 23:315318.

S. cricetus Coykendall 1977

Coykendall, A.L. 1977. International Journal of Systematic Bacteriology 27:2630. Type strain: ATCC 19642

Description: Coykendall, A.L. 1977. Ibid.

S. equi Sand and Jensen 1888

Sand, G. and C.O. Jensen. 1888.

Deutsche Zeitschrift fur Tiermedizin und Vergleichende Pathologie 13:437-464.

Type strain: NCTC 9682

Description: Bergey 8.

S. equinus Andrewes and Horder 1906

Andrewes, F.W. and T.J. Horder. 1906.

Lancet 2:708-713. Type strain: ATCC 9812

Description: Fuller, R. and L.G.M. Newland. 1963. Journal of General Microbiology 31:431-434.

S. faecalis Andrewes and Horder 1906 Andrewes, F.W. and T.J. Horder. 1906. Lancet 2:708-713. Type strain: NCTC 775

Description: Shattock, P.Y.F. and A.T.R. Mattick. 1943. Journal of Hygiene Cambridge 43:173-188.

S. faecium Orla-Jensen 1919

Orla-Jensen, S. 1919. The lactic acid bacteria. Host, Copenhagen. pp. 1-196. Type strain: NCTC 7171

Description: Bergey 8.

S. hansenii Holdeman and Moore 1974

Holdeman, L.V. and W.E.C. Moore. 1974. International Journal of Systematic Bacteriology 24:260-277. Type strain: ATCC 27752

Description: Holdeman, L.V. and W.E.C. Moore. 1974. Ibid.

S. iniae Pier and Madin 1976

Pier, G.B. and S.H. Madin. International Journal of Systematic Bacteriology 26: 545-553. Type strain: ATCC 29178

Description: Pier, G.B. and S.H. Madin. 1976. Ibid.

S. intermedius Prevot 1925

Prevot, A.R. 1925. Annales de l'Institut Pasteur (Paris) 39:417-447. Type strain: ATCC 27335

Description: Holdeman, L.V., E.P. Cato and W.E.C. Moore (eds). 1977. Anaerobe 
Laboratory Manual, 4th ed. Virginia Polytechnic Institute and State University, Blacksburg, Virginia. pp. 1-156.

S. lactis (Lister 1873) Lohnis 1909

Lister, J. 1873. Quarterly Journal of Microbiological Science 13:380-408; Lohnis, F. 1909. Zentralblatt fur Bakteriologie, Parasitenkunde, Infektionskrankheiten und Hygiene. Abteilung II. 22: 553-555. Type strain: NCDO 604

Description: Shattock, P.Y.F. and A.T.R. Mattick. 1943. Journal of Hygiene Cambridge 43:173-188.

S. mitis Andrewes and Horder 1906

Andrewes, F.W. and T.J. Horder. 1906. Lancet 2:708-713. Type strain: NCTC 3165

Description: Bergey 8.

S. morbillorum (Prevot 1933) Holdeman and Moore 1974

Prevot, A.R. 1933. Annales des sciences naturelles 15:23-260; Holdeman, L.V. and W.E.C. Moore. 1974. International Journal of Systematic Bacteriology 24:260277. Type strain: ATCC 27824

Description: Holdeman, L.V. and W.E.C. Moore. 1974. Ibid.

S. mutans Clarke 1924

Clarke, J.K. 1924. British Journal of Experimental Pathology 5:141-147. Type strain: ATCC 25175

Description: Coykendall, A.L. 1977. International Journal of Systematic Bacteriology 27:26-30.

S. pleomorphus Barnes, Impey, Stevens and Peel 1979

Barnes, E.M., C.S. Impey, B.J.H. Stevens and J.L. Peel. 1977. International Journal of Systematic Bacteriology 29:79-80; Effective publication Barnes, E.M., C.S. Impey, B.J.H. Stevens and J.L. Peel. 1977. Journal of General Microbiology 102:45-53. Type strain: NCTC 11087

Description: Barnes, E.M., C.S. Impey, B.J.H. Stevens and J.L. Peel. 1977. Ibid.

S. pneumoniae (Klein 1884) Chester 1901

Klein, E. 1884. Practitioner 32:321-352; Chester, F.D. 1901. A manual of determinative bacteriology. The MacMillan Co., New York. pp. 1-401. Type strain: NCTC 7465

Description: Bergey 8.

S. pyogenes Rosenbach 1884
Rosenbach, F.J. 1884. Microorganismen bei den Wund-Infections- Krankheiten des Menschen. J.F. Bergmann, Wiesbaden pp. 1-122. Type strain: ATCC 12344

Description: Bergey 8.

S. raffinolactis Orla-Jensen and Hansen 1932 Orla-Jensen, A.D. and P.A. Hansen. 1932. Zentralblatt fur Bakteriologie, Parasitenkunde, Infektionskrankheiten und Hygiene. Abteilung II. 86:6-29. Type strain: NCDO 617

Description: Garvie, E.I. 1979. International Journal of Systematic Bacteriology 29:152.

S. rattus Coykendall 1977

Coykendall, A.L. 1977. International Journal of Systematic Bacteriology 27:2630. Type strain: ATCC 19645

Description: Coykendall, A.L. 1977. Ibid.

S. salivarius Andrewes and Horder 1906

Andrewes, F.W. and T.J. Horder. 1906.

Lancet 2:708-713. Type strain: ATCC 7073

Description: Bergey 8 .

S. sanguis White and Niven 1946

White, J.C. and C.F. Niven Jr. 1946. Journal of Bacteriology 51:717-722. Type strain: ATCC 10556

Description: Bergey 8 .

S. thermophilus Orla-Jensen 1919

Orla-Jensen, S. 1919. The lactic acid bacteria. Host, Copenhagen. pp. 1-196. Type strain: NCDO 573

Description: Bergey 8.

S. uberis Diernhofer 1932

Diernhofer, K. 1932. Milchwirtschaftliche Forschungen 13:368-374. Type strain: NCTC 3858

Description: Garvie, E.I. and A.J. Bramley. 1979. Journal of Applied Bacteriology 46:295-304.

Streptomyces Waksman and Henrici 1943

Waksman, S.A. and A.T. Henrici. 1943. Journal of Bacteriology 46:337-341. Type species: S. albus (Rossi Doria 1891) Waksman and Henrici 1943

Description: Bergey 8 .

S. aburaviensis Nishimura, Kimura, Tawara, Sasaki, Nakajima, Shimaoka, Okamoto, Shimohara and Isono 1957

Nishimura, H., T. Kimura, K. Tawara, K. Sasaki, K. Nakajima, N. Shimaoka, S. 
Okamoto, M. Shimohara and J. Isono. 1957. Journal of Antibiotics (Tokyo) Series A 10:205-212. Type strain: ATCC 23869

Description: Shirling, E.B. and D. Gottlieb. 1968. International Journal of Systematic Bacteriology 18:279-392.

S. achromogenes Okami and Umezawa 1953 Okami, Y. and H. Umezawa. 1953 in Umezawa, H., T. Takeuchi, Y. Okami and T. Tazaki. Japanese Journal of Medical Science and Biology 6:261-268. Type strain: ATCC 12767

Description: Shirling, E.B. and D. Gottlieb. 1968. International Journal of Systematic Bacteriology 18:69-189.

S. achromogenes subsp. achromogenes Okami and Umezawa 1953

Okami, Y. and H. Umezawa. 1953 in Umezawa, H., T. Takeuchi, Y. Okami and T. Tazaki. Japanese Journal of Medical Science and Biology 6:261-268.

Type strain: ATCC 12767

Description: Shirling, E.B. and D. Gottlieb. 1968. International Journal of Systematic Bacteriology 18:69-189.

S. achromogenes subsp. rubradiris Bhuyan, Owen and Dietz 1965

Bhuyan, B.K., S.P. Owen and A. Dietz. 1965. Antimicrobial Agents and Chemotherapy 1964:91-96. Type strain: CBS 566.70

Description: Bhuyan, B.K., S.P. Owen and A. Dietz. 1965. Ibid.

S. acrimycini (Preobrazhenskaya, Blinov and Ryabova 1957) Pridham, Hesseltine and Benedict 1958

Preobrazhenskaya, T.P., N.O. Blinov and I.D. Ryabova. 1957 in Gauze, G.F., T.P. Preobrazhenskaya, E.S. Kudrina, N.O. Blinov, I.D. Ryabova and M.A. Sveshnikova. Problems of classification of actinomycetes-antagonists. Government Publishing House of Medical Literature, Medgiz, Moscow. 1-398; Pridham, T.G., C.W. Hesseltine and R.G. Benedict. 1958. Applied Microbiology 6:52-79. Type strain: ATCC 19885

Description: Shirling, E.B. and D. Gottlieb. 1968. International Journal of Systematic Bacteriology 18:69-189.

S. afghaniensis Shimo, Shiga, Tomosugi and Kamoi 1959
Shimo, M., T. Shiga, T. Tomosugi and I. Kamoi. 1959. Journal of Antibiotics (Tokyo) Series A 12:1-6. Type strain: ATCC 23871

Description: Shirling, E.B. and D. Gottlieb. 1968. International Journal of Systematic Bacteriology 18:279-392.

S. alanosinicus Thiemann and Beretta 1966

Thiemann, J.E. and G. Beretta. 1966. Journal of Antibiotics (Tokyo) Series A 19:155-160. Type strain: ATCC 15710

Description: Shirling, E.B. and D. Gottlieb. 1972. International Journal of Systematic Bacteriology 22:265-394.

S. albaduncus Tsukiura, Okanishi, Ohmor, Koshiyama, Miyaki, Kitazima and Kawaguchi 1964

Tsukiura, H., M. Okanishi, T. Ohmor, H. Koshiyama, T. Miyaki, H. Kitazima and H. Kawaguchi. 1964. Journal of Antibiotics (Tokyo) Series A 17:39-47. Type strain: ATCC 14698

Description: Shirling, E.B. and D. Gottlieb. 1972. International Journal of Systematic Bacteriology 22:265-394.

S. albidoflavus (Rossi Doria 1891) Waksman and Henrici 1948

Rossi Doria, T. 1891. Annali dell' Istituto d'Igiene Sperimentale della Rendiconti Universita di Roma 1:399-438; Waksman, S.A. and A.T. Henrici. 1948 in Breed, R.S., E.G.D. Murray and A.P. Hitchens (eds). Bergey's Manual of Determinative Bacteriology, 6th ed. The Williams and Wilkins Co., Baltimore. pp. 929-980. Type strain: ATCC 25422

Description: Shirling, E.B. and D. Gottlieb. 1969. International Journal of Systematic Bacteriology 19:391-512.

S. albofaciens Thirumalachar and Bhatt 1960 Thirumalachar, M.J. and V.V. Bhatt. 1960. Hindustan Antibiotics Bulletin 3:6163. Type strain: ATCC 25184

Description: Shirling, E.B. and D. Gottlieb. 1968. International Journal of Systematic Bacteriology 18:279-392.

S. alboflavus (Waksman and Curtis 1916) Waksman and Henrici 1948

Waksman, S.A. and R.E. Curtis. 1916. Soil Science 1:99-134; Waksman, S.A. and A.T. Henrici. 1948 in Breed, R.S., E.G.D. Murray and A.P. Hitchens (eds). Bergey's Manual of Determinative Bacter- 
iology, 6th ed. The Williams and Wilkins Co., Baltimore. pp. 929-980. Type strain: ATCC 12626

Description: Shirling, E.B. and D. Gottlieb. 1968. International Journal of Systematic Bacteriology 18:279-392.

S. albogriseolus Benedict, Shotwell, Pridham, Lindenfelser and Haynes 1954

Benedict, R.G., O.L. Shotwell, T.G. Pridham, L.A. Lindenfelser and W.C. Haynes. 1954. Antibiotics and Chemotherapy 4:653-656. Type strain: NRRL B1305

Description: Shirling, E.B. and D. Gottlieb. 1968. International Journal of Systematic Bacteriology 18:279-392.

S. albolongus Tsukiura, Okanishi, Koshiyama, Ohmori, Miyaki and Kawaguchi 1964

Tsukiura, H., M. Okanishi, H. Koshiyama, T. Ohmori, T. Miyaki and $\mathrm{H}$. Kawaguchi. 1964. Journal of Antibiotics (Tokyo) Series A 17:223-229. Type strain: ATCC 27414

Description: Shirling, E.B. and D. Gottlieb. 1972. International Journal of Systematic Bacteriology 22:265-394.

S. alboniger Porter, Hewitt, Hesseltine, Krupka, Lowery, Wallace, Bohonos and Williams 1952

Porter, J.N., R.I. Hewitt, C.W. Hesseltine, G. Krupka, J.A. Lowery, W.S. Wallace, N. Bohonos and J.H. Williams. 1952. Antibiotics and Chemotherapy 2: 409-4 10. Type strain: ATCC 12461

Description: Shirling, E.B. and D. Gottlieb. 1968. International Journal of Systematic Bacteriology 18:69-189.

S. albospinus Wang, Hamada, Okami and Umezawa 1966

Wang, E.L., M. Hamada, Y. Okami and H. Umezawa. 1966. Journal of Antibiotics (Tokyo) Series A 19:216-221. Type strain: ATCC 29808

Description: Wang, E.L., M. Hamada, Y. Okami and H. Umezawa. 1966. Ibid.

S. albosporeus (Krainsky 1914) Waksman and Henrici 1948

Krainsky, A. 1914. Zentralblatt fur Bakteriologie, Parasitenkunde, Infektionskrankheiten und Hygiene. Abteilung II. 41:649-688; Waksman, S.A. and A.T. Henrici. 1948 in Breed, R.S., E.G.D. Murray and A.P. Hitchens (eds). Bergey's
Manual of Determinative Bacteriology, 6th ed. The Williams and Wilkins Co., Baltimore. pp. 929-980. Type strain: ATCC 15394

Description: Pridham, T.G., A.J. Lyons Jr. and H.L. Seckinger. 1965. International Bulletin of Bacteriological Nomenclature and Taxonomy 15:191-237.

S. albosporeus subsp. albosporeus (Krainsky 1914) Waksman and Henrici 1948

Krainsky, A. 1914. Zentralblatt fur Bakteriologie, Parasitenkunde, Infektionskrankheiten und Hygiene. Abteilung II. 41:649-688; Waksman, S.A. and A.T. Henrici. 1948 in Breed, R.S., E.G.D. Murray and A.P. Hitchens (eds). Bergey's Manual of Determinative Bacteriology, 6th ed. The Williams and Wilkins Co., Baltimore. pp. 929-980. Type strain: ATCC 15394

Description: Pridham, T.G., A.J. Lyons Jr. and H.L. Seckinger. 1965. International Bulletin of Bacteriological Nomenclature and Taxonomy 15:191-237.

S. albosporeus subsp. labilomyceticus Okami, Suzuki and Umezawa 1963

Okami, Y., M. Suzuki and H. Umezawa. 1963. Journal of Antibiotics (Tokyo) Series A 16:152-154. Type strain: NIHJ 425

Description: Okami, Y., M. Suzuki and H. Umezawa. 1963. Ibid.

S. albovinaceus (Kudrina 1957) Pridham, Hesseltine and Benedict 1958

Kudrina, E.S. 1957 in Gauze, G.F., T.P. Preobrazhenskaya, E.S. Kudrina, N.O. Blinov, I.D. Ryabova and M.A. Sveshnikova. Problems in the classification of actinomycetes-antagonists. State Publishing House of Medical Literature, Medgiz, Moscow, USSR; Pridham, T.G., C.W. Hesseltine and R.G. Benedict. 1958. Applied Microbiology 6:52-79. Type strain: ATCC 15823

Description: Shirling, E.B. and D. Gottlieb. 1968. International Journal of Systematic Bacteriology 18:69-189.

S. alboviridis (Duche 1934) Pridham, Hesseltine and Benedict 1958

Duche, J. 1934. Encyclopedie Mycologique 6:1-375; Pridham, T.G., C.W. Hesseltine and R.G. Benedict. 1958. Applied Microbiology 6:52-79. Type 
strain: ATCC 25425

Description: Shirling, E.B. and D. Gottlieb. 1969. International Journal of Systematic Bacteriology 19:391-512.

S. albulus Routien 1969

Routien, J.B. 1969 in Pridham, T.G. and A.J. Lyons, Jr. Developments in Industrial Microbiology 10:183-221. Type strain: ATCC 12757

Description: Shirling, E.B. and D. Gottlieb. 1972. International Journal of Systematic Bacteriology 22:265-394.

S. albus (Rossi Doria 1891) Waksman and Henrici 1943

Rossi Doria, T. 1891. Annali dell' Istituto d'Igiene Sperimentale della Rendiconti Universita di Roma 1:399-438; Waksman, S.A. and A.T. Henrici. 1943. Journal of Bacteriology 46:337-341. Type strain: ATCC 3004

Description: Shirling, E.B. and D. Gottlieb. 1969. International Journal of Systematic Bacteriology 19:391-512.

S. albus subsp. albus (Rossi Doria 1891) Waksman and Henrici 1943

Rossi Doria, T. 1891. Annali dell' Istituto d'Igiene Sperimentale della Rendiconti Universita di Roma 1:399-438; Waksman, S.A. and A.T. Henrici. 1943. Journal of Bacteriology 46:337-341. Type strain: ATCC 3004

Description: Shirling, E.B. and D. Gottlieb. 1969. International Journal of Systematic Bacteriology 19:391-512.

S. albus subsp. pathocidicus Nagatsu, Anzai and Suzuki 1962

Nagatsu, J., K. Anzai and S. Suzuki. 1962. Journal of Antibiotics (Tokyo) Series A 15:103-106. Type strain: ATCC 14510

Description: Bergey 8.

S. almquistii (Duche 1934) Pridham, Hesseltine and Benedict 1958

Duche, J. 1934. Encyclopedie Mycologique 6:1-375; Pridham, T.G., C.W. Hesseltine and R.G. Benedict. 1958. Applied Microbiology 6:52-79. Type strain: ATCC 618

Description: Shirling, E.B. and D. Gottlieb. 1969. International Journal of Systematic Bacteriology 19:391-512.

S. althioticus Yamaguchi, Nakayama, Takeda, Tawara, Maeda, Takeuchi and Umezawa
1957

Yamaguchi, H., Y. Nakayama, K. Takeda, K. Tawara, K. Maeda, T. Takeuchi and H. Umezawa. 1957. Journal of Antibiotics (Tokyo) Series A 10:195200. Type strain: ATCC 19724

Description: Shirling, E.B. and D. Gottlieb. 1968. International Journal of Systematic Bacteriology 18:69-189.

S. amakusaensis Nagatsu, Anzai, Ohkuma and Suzuki 1963

Nagatsu, J., K. Anzai, K. Ohkuma and S. Suzuki. 1963. Journal of Antibiotics (Tokyo) Series A 16:207-210. Type strain: ATCC 23876

Description: Shirling, E.B. and D. Gottlieb. 1968. International Journal of Systematic Bacteriology 18:279-392.

S. ambofaciens Pinnert-Sindico 1954

Pinnert-Sindico, S. 1954. Annales de l'Institut Pasteur (Paris) 87:702-707. Type strain: ATCC 23877

Description: Shirling, E.B. and D. Gottlieb. 1968. International Journal of Systematic Bacteriology 18:279-392.

S. aminophilus Foster 1961

Foster, W.J. 1961 in Oswald, E.J., R.J. Reedy and W.A. Randall. 1956 in Hutter, R. 1961. Archiv fur Mikrobiologie 38: 367-383. Type strain: ATCC 14961

Description: Shirling, E.B. and D. Gottlieb. 1968. International Journal of Systematic Bacteriology 18:279-392.

S. anandii Batra and Bajaj 1965

Batra, S.K. and B.S. Bajaj. 1965. Indian Journal of Experimental Biology 3:240242. Type strain: ATCC 19388

Description: Shirling, E.B. and D. Gottlieb. 1972. International Journal of Systematic Bacteriology 22:265-394.

S. anthocyanicus (Krassilnikov, Sorokina, Alferova and Bezzubenkova 1965) Pridham 1970

Krassilnikov, N.A., E.J. Sorokina, V.A. Alferova and A.P. Bezzubenkova. 1965 in Krassilnikov, N.A. (ed). Biology of selected groups of Actinomycetes (in Russian). Institute of Microbiology, Academy of Science, Publishing Firm 'Nauka', Moscow, USSR. pp. 74-123; Pridham, T.G. 1970. Bulletin of the United States Department of Agriculture 1424:1-55. 
Type strain: ATCC 19821

Description: Bergey 8.

S. antibioticus (Waksman and Woodruff 1941)

Waksman and Henrici 1948

Waksman, S.A. and H.B. Woodruff. 1941. Journal of Bacteriology 42:231-249; Waksman, S.A. and A.T. Henrici. 1948 in Breed, R.S., E.G.D. Murray and A.P. Hitchens (eds). Bergey's Manual of Determinative Bacteriology, 6th ed. The Williams and Wilkins Co., Baltimore. pp. 929-980. Type strain: ATCC 8663

Description: Shirling, E.B. and D. Gottlieb. 1968. International Journal of Systematic Bacteriology 18:279-392.

S. antimycoticus Waksman 1957

Waksman, S.A. 1957 in Breed, R.S., E.G.D. Murray and N.R. Smith (eds). Bergey's Manual of Determinative Bacteriology, 7th ed. The Williams and Wilkins Co., Baltimore. pp. 744-825. Type strain: NRRL 2421

Description: Shirling, E.B. and D. Gottlieb. 1968. International Journal of Systematic Bacteriology 18:279-392.

S. anulatus (Beijerinck 1912) Waksman 1957

Beijerinck, M.W. 1912. Folia Mikrobiologiya (Delft) 1:4-100; Waksman, S.A. 1957 in Breed, R.S., E.G.D. Murray and N.R. Smith (eds). Bergey's Manual of Determinative Bacteriology, 7th ed. The Williams and Wilkins Co., Baltimore. Type strain: CBS 100.18

Description: Shirling, E.B. and D. Gottlieb. 1972. International Journal of Systematic Bacteriology 22:265-394.

S. arabicus Shibata, Nakazawa, Miyake, Inoue and Okabori 1957

Shibata, M., K. Nakazawa, A. Miyake, M. Inoue and A. Okabori. 1957. Annual Report of the Takeda Research Laboratory 16:32-37. Type strain: ATCC 23881

Description: Shirling, E.B. and D. Gottlieb. 1968. International Journal of Systematic Bacteriology 18:279-392.

S. arenae Pridham, Hesseltine and Benedict 1958

Pridham, T.G., C.W. Hesseltine and R.G. Benedict. 1958. Applied Microbiology 6: 52-79. Type strain: NRRL 2377

Description: Shirling, E.B. and D. Gottlieb. 1969. International Journal of Systematic Bacteriology 19:391-512.
S. argenteolus Tresner, Davies and Backus 1961 Tresner, H.D., M.C. Davies and E.J. Backus. 1961. Journal of Bacteriology 81: 70-80. Type strain: ATCC 11009

Description: Shirling, E.B. and D. Gottlieb. 1968. International Journal of Systematic Bacteriology 18:279-392.

S. atratus Shibata, Higashide, Yamamoto and Nakazawa 1962

Shibata, M., E. Higashide, H. Yamamoto and K. Nakazawa. 1962. Agricultural and Biological Chemistry 26:228-233. Type strain: IFO 3897

Description: Shibata, M., E. Higashide, H. Yamamoto and K. Nakazawa. 1962. Ibid.

S. atroolivaceus (Preobrazhenskaya, Blinov and Ryabova 1957) Pridham, Hesseltine and Benedict 1958

Preobrazhenskaya, T.P., N.O. Blinov and I.D. Ryabova. 1957 in Gauze, G.F., T.P. Preobrazhenskova, E.S. Kudrina, N.O. Blinov, I.D. Ryabova and M.A. Sveshnikova. Problems in the classification of actinomycetes-antagonists. Government Publishing House of Medical Literature, Medgiz, Moscow. pp. 1-398; Pridham, T.G., C.W. Hesseltine and R.G. Benedict. 1958. Applied Microbiology 6:52-79. Type strain: ATCC 19725

Description: Shirling, E.B. and D. Gottlieb. 1968. International Journal of Systematic Bacteriology 18:69-189.

S. aurantiacus (Rossi Doria 1891) Waksman 1953

Rossi Doria, T. 1891. Annali dell' Istituto d'Igiene Sperimentale della Rendiconti Universita di Roma 1:399-438; Waksman, S.A. 1953 in Waksman, S.A. and H.A. Lechevalier. Guide to the classification and identification of the actinomycetes and their antibiotics. The Williams and Wilkins Co., Baltimore. pp. 1-246. Type strain: ATCC 19822

Description: Shirling, E.B. and D. Gottlieb. 1969. International Journal of Systematic Bacteriology 19:391-512.

S. aurantiogriseus (Preobrazhenskaya 1957) Pridham, Hesseltine and Benedict 1958 Preobrazhenskaya, T.P. 1957 in Gauze, G.F., T.P. Preobrazhenskaya, E.S. Kudrina, N.O. Blinov, I.D. Ryabova and M.A. Sveshnikova. Problems of classification of 
actinomycetes-antagonists. Government Publishing House of Medical Literature, Medgiz, Moscow. pp. 1-398; Pridham, T.G., C.W. Hesseltine and R.G. Benedict. 1958. Applied Microbiology 6:52-79. Type strain: ATCC 19887

Description: Shirling, E.B. and D. Gottlieb. 1968. International Journal of Systematic Bacteriology 18:279-392.

S. aureocirculatus (Krassilnikov and Yuan 1965) Pridham 1970

Krassilnikov, N.A. and T. Yuan. 1965 in Krassilnikov, N.A. (ed). Biology of individual groups of Actinomycetes (in Russian). pp. 28-57; Pridham, T.G. 1970. Bulletin of the United States Department of Agriculture 1424:1-55. Type strain: ATCC 19823

Description: Shirling, E.B. and D. Gottlieb. 1969. International Journal of Systematic Bacteriology 19:391-512.

S. aureofaciens Duggar 1948

Duggar, B. 1948. Annals of the New York Academy of Science 51:177-181.

Type strain: NRRL 2209

Description: Shirling, E.B. and D. Gottlieb. 1968. International Journal of Systematic Bacteriology 18:279-392.

S. aureoverticillatus (Krassilnikov and Yuan 1960) Pridham 1970

Krassilnikov, N.A. and C.-S. Yuan. 1960. Mikrobiologiya 29:482-489 (English Translation 354-358); Pridham, T.G. 1970. Bulletin of the United States Department of Agriculture 1424:1-55. Type strain: ATCC 15854

Description: Shirling, E.B. and D. Gottlieb. 1968. International Journal of Systematic Bacteriology 18:69-189.

S. avellaneus Baldacci and Grein 1966

Baldacci, E. and A. Grein. 1966. Giornale di Microbiologia 14:185-198. Type strain: ATCC 23730

Description: Shirling, E.B. and D. Gottlieb. 1972. International Journal of Systematic Bacteriology 22:265-394.

S. avidinii Stapley, Mata, Miller, Demny and Woodruff 1964

Stapley, E.O., J.M. Mata, I.M. Miller, T.C. Demny and H.B. Woodruff. 1964. Antimicrobial Agents and Chemotherapy 1963:20-27. Type strain: NRRL 3077

Description: Shirling, E.B. and D.
Gottlieb. 1972. International Journal of Systematic Bacteriology 22:265-394.

S. azureus Kelly, Kutscher and Tuoti 1959

Kelly, J., A.H. Kutscher and F. Tuoti. 1959. Oral Surgery, Oral Medicine and Oral Pathology 12:1334-1339. Type strain: ATCC 14921

Description: Shirling, E.B. and D. Gottlieb. 1968. International Journal of Systematic Bacteriology 18:69-189.

S. baarnensis Pridham, Hesseltine and Benedict 1958

Pridham, T.G., C.W. Hesseltine and R.G. Benedict. 1958. Applied Microbiology 6: 52-79. Type strain: CBS 306.55

Description: Shirling, E.B. and D. Gottlieb. 1968. International Journal of Systematic Bacteriology 18:279-392.

S. bacillaris (Krassilnikov 1958) Pridham 1970 Krassilnikov, N.A. 1958. Folia Biologica (Praha) 4:257-265; Pridham, T.G. 1970. Bulletin of the United States Department of Agriculture 1424:1-55. Type strain: ATCC 15855

Description: Shirling, E.B. and D. Gottlieb. 1972. International Journal of Systematic Bacteriology 22:265-394.

S. badius (Kudrina 1957) Pridham, Hesseltine and Benedict 1958

Kudrina, E.S. 1957 in Gauze, G.F., T.P. Preobrazhenskaya, E.S. Kudrina, N.O. Blinov, I.D. Ryabova and M.A. Sveshnikova. Problems of classification of actinomycetes-antagonists. Government Publishing House of Medical Literature, Medgiz, Moscow. pp. 1-398; Pridham, T.G., C.W. Hesseltine and R.G. Benedict. 1958. Applied Microbiology 6:52-79. Type strain: ATCC 19888

Description: Shirling, E.B. and D. Gottlieb. 1968. International Journal of Systematic Bacteriology 18:69-189.

S. bambergiensis Wallhausser, Nesemann, Prave and Steigler 1966

Wallhausser, K., G. Nesemann, P. Prave and A. Steigler. 1966. Antimicrobial Agents and Chemotherapy 1965:734-736. Type strain: ATCC 13879

Description: Shirling, E.B. and D. Gottlieb. 1972. International Journal of Systematic Bacteriology 22:265-394.

S. bellus Margalith and Beretta 1960 Margalith, P. and G. Beretta. 1960. 
Mycopathologia et Mycologia Applicata 12:189-195. Type strain: ATCC 14925

Description: Shirling, E.B. and D. Gottlieb. 1968. International Journal of Systematic Bacteriology 18:279-392.

S. bikiniensis Johnstone and Waksman 1947 Johnstone, D.B. and S.A. Waksman. 1947. Proceedings of the Society for Experimental Biology and Medicine 65: 294-295. Type strain: ATCC 11062

Description: Shirling, E.B. and D. Gottlieb. 1968. International Journal of Systematic Bacteriology 18:279-392.

S. bluensis Mason, Dietz and Hanka 1963 Mason, D.J., A. Dietz and L.J. Hanka. 1963. Antimicrobial Agents and Chemotherapy 1962:607-613. Type strain: NRRL 2876

Description: Shirling, E.B. and D. Gottlieb. 1972. International Journal of Systematic Bacteriology 22:265-394.

S. bobili (Waksman and Curtis 1916) Waksman and Henrici 1948

Waksman, S.A. and R.E. Curtis. 1916. Soil Science 1:99-134; Waksman, S.A. and A.T. Henrici. 1948 in Breed, R.S., E.G.D. Murray and A.P. Hitchens (eds). Bergey's Manual of Determinative Bacteriology, 6th ed. The Williams and Wilkins Co., Baltimore. pp. 929-980. Type strain: ATCC 3310

Description: Shirling, E.B. and D. Gottlieb. 1968. International Journal of Systematic Bacteriology 18:279-392.

S. bottropensis Waksman 1961

Waksman, S.A. 1961. The Actinomycetes. Vol. 2. Classification, identification and descriptions of genera and species. The Williams and Wilkins Co., Baltimore. pp. 1-363. Type strain: ATCC 25435

Description: Shirling, E.B. and D. Gottlieb. 1969. International Journal of Systematic Bacteriology 19:391-512.

S. cacaoi (Waksman 1932) Waksman and Henrici 1948

Waksman, S.A. 1932 in Bunting, R.H. Annảs of Applied Biology 19:515-517; Waksman, S.A. and A.T. Henrici. 1948 in Breed, R.S., E.G.D. Murray and A.P. Hitchens (eds). Bergey's Manual of Determinative Bacteriology, 6th ed. The Williams and Wilkins Co., Baltimore. pp. 929-980. Type strain: ATCC 3082
Description: Shirling, E.B. and D. Gottlieb. 1968. International Journal of Systematic Bacteriology 18:69-189.

S. cacaoi subsp. asoensis Isono, Nagatsu, Kawashima and Suzuki 1965

Isono, K., J. Nagatsu, Y. Kawashima and S. Suzuki. 1965. Agricultural and Biological Chemistry 29:848-854. Type strain: IFO 13813

Description: Isono, K., J. Nagatsu, Y. Kawashima and S. Suzuki. 1965. Ibid.

S. cacaoi subsp. cacaoi (Waksman 1932) Waksman and Henrici 1948

Waksman, S.A. 1932 in Bunting, R.H. Annals of Applied Biology 19:515-517; Waksman, S.A. and A.T. Henrici. 1948 in Breed, R.S., E.G.D. Murray and A.P. Hitchens (eds). Bergey's Manual of Determinative Bacteriology, 6th ed. The Williams and Wilkins Co., Baltimore. pp. 929-980. Type strain: ATCC 3082

Description: Shirling, E.B. and D. Gottlieb. 1968. International Journal of Systematic Bacteriology 18:69-189.

S. caelestis De Boer, Dietz, Wilkins, Lewis and Savage 1955

De Boer, C., A. Dietz, J.R. Wilkins, C.N. Lewis and G.M. Savage. 1955. Antibiotics Annual 1954:831-841. Type strain: NRRL 2418

Description: Shirling, E.B. and D. Gottlieb. 1968. International Journal of Systematic Bacteriology 18:69-189.

S. caeruleus (Baldacci 1944) Pridham, Hesseltine and Benedict 1958

Baldacci, E. 1944. Atti dell'Istituto Botanico della Universita Laboratorio Crittogamico di Pavia Series 5, 3:139-193; Pridham, T.G., C.W. Hesseltine and R.G. Benedict. 1958. Applied Microbiology 6: 52-79. Type strain: ATCC 27421

Description: Shirling, E.B. and D. Gottlieb. 1972. International Journal of Systematic Bacteriology 22:265-394.

S. californicus (Waksman and Curtis 1916) Waksman and Henrici 1948

Waksman, S.A. and R.E. Curtis. 1916. Soil Science 1:99-134; Waksman, S.A. and A.T. Henrici. 1948 in Breed, R.S., E.G.D. Murray and A.P. Hitchens (eds). Bergey's Manual of Determinative Bacteriology, 6th ed. The Williams and Wilkins Co., Baltimore. pp. 929-980. Type strain: 
ATCC 3312

Description: Shirling, E.B. and D. Gottlieb. 1968. International Journal of Systematic Bacteriology 18:69-189.

S. calvus Backus, Tresner and Campbell 1957 Backus, E.J., H.D. Tresner and T.H. Campbell. 1957. Antibiotics and Chemotherapy 7:532-541. Type strain: ATCC 13382

Description: Shirling, E.B. and D. Gottlieb. 1968. International Journal of Systematic Bacteriology 18:279-392.

S. canarius Vavra and Dietz 1965

Vavra, J. and A. Dietz. 1965. Antimicrobial Agents and Chemotherapy 1964:7579. Type strain: NRRL 2976

Description: Shirling, E.B. and D. Gottlieb. 1972. International Journal of Systematic Bacteriology 22:265-394.

S. canescens Waksman 1957

Waksman, S.A. 1957 in Breed, R.S., E.G.D. Murray and N.R. Smith (eds). Bergey's Manual of Determinative Bacteriology, 7th ed. The Williams and Wilkins Co., Baltimore. Type strain: ATCC 19736 Description: Shirling, E.B. and D. Gottlieb. 1968. International Journal of Systematic Bacteriology 18:69-189.

S. canus Heinemann, Kaplan, Muir and Hooper 1953

Heinemann, B., M.A. Kaplan, R.D. Muir and I.R. Hooper. 1953. Antibiotics and Chemotherapy 3:1239-1242. Type strain: ATCC 12237

Description: Shirling, E.B. and D. Gottlieb. 1968. International Journal of Systematic Bacteriology 18:69-189.

S. capoamus Goncalves de Lima, Albert and Goncalves de Lima 1964

Goncalves de Lima, V.O., C.A. Albert and $O$. Goncalves de Lima. 1964. Anais da Academia Brazileira de Ciencias 36: 317-322. Type strain: ATCC 19006

Description: Shirling, E.B. and D. Gottlieb. 1972. International Journal of Systematic Bacteriology 22:265-394.

S. catenulae Davisson and Finlay 1961

Davisson, J.W. and A.C. Finlay. 1961 in Waksman, S.A. The Actinomycetes. Vol. 2. Classification, identification and descriptions of genera and species. The Williams and Wilkins Co., Baltimore. pp. 1-363. Type strain: ATCC 12476
Description: Shirling, E.B. and D. Gottlieb. 1968. International Journal of Systematic Bacteriology 18:279-392.

S. cavourensis Skarbek and Brady 1978

Skarbek, J.D. and L.R. Brady. 1978. International Journal of Systematic Bacteriology 28:45-53. Type strain: ATCC 14889

Description: Skarbek, J.D. and L.R. Brady. 1978. Ibid.

S. cavourensis subsp. cavourensis Skarbek and Brady 1978

Skarbek, J.D. and L.R. Brady. 1978. International Journal of Systematic Bacteriology 28:45-53. Type strain: ATCC 14889

Description: Skarbek, J.D. and L.R. Brady. 1978. Ibid.

S. cavourensis subsp. washingtonensis Skarbek and Brady 1978

Skarbek, J.D. and L.R. Brady. 1978. International Journal of Systematic Bacteriology 28:45-53. Type strain: ATCC 27732

Description: Skarbek, J.D. and L.R. Brady. 1978. Ibid.

S. cellostaticus Hamada 1958

Hamada, S. 1958. Tohoku Journal of Experimental Medicine 67:173-179. Type strain: ATCC 23894

Description: Shirling, E.B. and D. Gottlieb. 1968. International Journal of Systematic Bacteriology 18:279-392.

S. celluloflavus Nishimura, Kimura and Kuroya 1953

Nishimura, H., T. Kimura and $M$. Kuroya. 1953. Journal of Antibiotics (Tokyo) Series A 6:57-65. Type strain: IFO 13780

Description: Bergey 8 .

S. cellulosae (Krainsky 1914) Waksman and Henrici 1948

Krainsky, A. 1914. Zentralblatt fur Bakteriologie, Parasitenkunde, Infektionskrankheiten und Hygiene. Abteilung II. 41:649-688; Waksman, S.A. and A.T. Henrici. 1948 in Breed, R.S., E.G.D. Murray and A.P. Hitchens (eds). Bergey's Manual of Determinative Bacteriology, 6th ed. The Williams and Wilkins Co., Baltimore. pp. 929-980. Type strain: CBS 122.18

Description: Shirling, E.B. and D. 
Gottlieb. 1969. International Journal of Systematic Bacteriology 19:391-512.

S. champavatii Uma and Narasimha Rao 1959 Uma, B.N. and P.L. Narasimha Rao. 1959. Indian Institute of Sciences Golden Jubilee Research Vol. 1909-1959. Bangalore, India. pp. 130-141. Type strain: NRRL B-5682

Description: Bergey 8.

S. chartreusis Leach, Calhoun, Johnson, Teeters and Jackson 1953

Leach, B.E., K.M. Calhoun, L.E. Johnson, C.M. Teeters and W.G. Jackson. 1953. Journal of the American Chemical Society 75:4011-4012. Type strain: NRRL 2287

Description: Shirling, E.B. and D. Gottlieb. 1968. International Journal of Systematic Bacteriology 18:69-189.

S. chattanoogensis Burns and Holtman 1959

Burns, J. and D.F. Holtman. 1959. Antibiotics and Chemotherapy 9:398-405. Type strain: ATCC 13358

Description: Shirling, E.B. and D. Gottlieb. 1968. International Journal of Systematic Bacteriology 18:69-189.

S. chibaensis Suzuki, Nakamura, Okuma and Tomiyama 1958

Suzuki, S., G. Nakamura, K. Okuma and Y. Tomiyama. 1958. Journal of Antibiotics (Tokyo) Series A 11:81-83. Type strain: ATCC 23895

Description: Shirling, E.B. and D. Gottlieb. 1968. International Journal of Systematic Bacteriology 18:279-392.

S. chrestomyceticus Canevazzi and Scotti 1959 Canevazzi, G. and T. Scotti. 1959. Giornale di Microbiologia 7:242-250. Type strain: ATCC 14947

Description: Shirling, E.B. and D. Gottlieb. 1972. International Journal of Systematic Bacteriology 22:265-394.

S. chromofuscus (Preobrazhenskaya, Blinov and Ryabova 1957) Pridham, Hesseltine and Benedict 1958

Preobrazhenskaya, E.S., N.O. Blinov and I.D. Ryabova. 1957 in Gauze, G.F., T.P. Preobrazhenskaya, E.S. Kudrina, N.O. Blinov, I.D. Ryabova and M.A. Sveshnikova. Problems of classification of actinomycetes-antagonists. Government Publishing House of Medical Literature, Medgiz, Moscow. pp. 1-398; Pridham, T.G., C.W.
Hesseltine and R.G. Benedict. 1958. Applied Microbiology 6:52-79. Type strain: ATCC 23896

Description: Shirling, E.B. and D. Gottlieb. 1968. International Journal of Systematic Bacteriology 18:69-189.

S. chryseus (Krassilnikov, Korenyako and Nikitina 1965) Pridham 1970

Krassilnikov, N.A., A.I. Korenyako and N.I. Nikitina. 1965 in Krassilnikov, N.A. (ed). Biology of selected groups of actinomycetes (in Russian). Institute of Microbiology, Academy of Science, Publishing Firm 'Nauka', Moscow, USSR. pp. 1-372; Pridham, T.G. 1970. Bulletin of the United States Department of Agriculture 1424:1-55. Type strain: ATCC 19829

Description: Shirling, E.B. and D. Gottlieb. 1972. International Journal of Systematic Bacteriology 22:265-394.

S. chrysomallus Lindenbein 1952

Lindenbein, W. 1952. Archiv fur Mikrobiologie 17:361-383. Type strain: ATCC 11523

Description: Shirling, E.B. and D. Gottlieb. 1968. International Journal of Systematic Bacteriology 18:69-189.

S. chrysomallus subsp. chrysomallus Lindenbein 1952

Lindenbein, W. 1952. Archiv fur Mikrobiologie 17:361-383. Type strain: ATCC 11523

Description: Shirling, E.B. and D. Gottlieb. 1968. International Journal of Systematic Bacteriology 18:69-189.

S. chrysomallus subsp. fumigatus Frommer 1959

Frommer, W. 1959. Archiv fur Mikrobiologie 32:187-206. Type strain: NRRL B2289

Description: Hutter, R. 1963. Giornale di Microbiologia 11:191-246.

S. cinereoruber Corbaz, Ettlinger, Keller-Schierlein and Zahner 1957

Corbaz, R., L. Ettlinger, W. KellerSchierlein and H. Zahner. 1957. Archiv fur Mikrobiologie 25:325-332. Type strain: ATCC 19740

Description: Shirling, E.B. and D. Gottlieb. 1968. International Journal of Systematic Bacteriology 18:69-189.

S. cinereoruber subsp. cinereoruber Corbaz, 
Ettlinger, Keller-Schierlein and Zahner 1957

Corbaz, R., L. Ettlinger, W. KellerSchierlein and H. Zahner. 1957. Archiv fur Mikrobiologie 25:325-332. Type strain: ATCC 19740

Description: Shirling, E.B. and D. Gottlieb. 1968. International Journal of Systematic Bacteriology 18:69-189.

S. cinereoruber subsp. fructofermentans Corbaz, Ettlinger, Keller-Schierlein and Zahner 1957

Corbaz, R., L. Ettlinger, W. KellerSchierlein and H. Zahner. 1957. Archiv fur Mikrobiologie 25:325-332. Type strain: NRRL 2588

Description: Ettlinger, L., R. Corbaz and R. Hutter. 1958. Archiv fur Mikrobiologie 31:326-358.

S. cinerochromogenes Miyairi, Takashima, Shimizu and Sakai 1966

Miyairi, N., M. Takashima, K. Shimizu and H. Sakai. 1966. Journal of Antibiotics (Tokyo) Series A 19:56-62. Type strain: IFO 13922

Description: Miyairi, N., M. Takashima, K. Shimizu and H. Sakai. 1966. Ibid.

S. cinnabarinus (Ryabova and Preobrazhenskaya 1957) Pridham, Hesseltine and Benedict 1958

Ryabova, I.D. and T.P. Preobrazhenskaya. 1957 in Gauze, G.F., T.P. Preobrazhenskaya, E.S. Kudrina, N.O. Blinov, I.D. Ryabova and M.A. Sveshnikova. Problems of classification of actinomycetes-antagonists. Government Publishing House of Medical Literature, Medgiz, Moscow. pp. 1-398; Pridham, T.G., C.W. Hesseltine and R.G. Benedict. 1958. Applied Microbiology 6:52-79. Type strain: ATCC 23617

Description: Shirling, E.B. and D. Gottlieb. 1969. International Journal of Systematic Bacteriology 19:391-512.

S. cinnamonensis Okami 1952

Okami, Y. 1952 in Maeda, K., Y. Okami, H. Kosaka, O. Taya and H. Umezawa. Journal of Antibiotics (Tokyo) 5:572-573.

Type strain: ATCC 12308

Description: Ettlinger, L., R. Corbaz and R. Hutter. 1958. Archiv fur Mikrobiologie 31:326-358.

S. cirratus Koshiyama, Okanishi, Ohmori, Mi- yaki, Tsukiura, Matsuzaki and Kawaguchi 1963

Koshiyama, H., M. Okanishi, T. Ohmori, T. Miyaki, H. Tsukiura, M. Matsuzaki and H. Kawaguchi. 1963. Journal of Antibiotics (Tokyo) Series A 16:59-66. Type strain: ATCC 14699

Description: Shirling, E.B. and D. Gottlieb. 1972. International Journal of Systematic Bacteriology 22:265-394.

S. citreofluorescens (Korenyako, Krassilnikov, Nikitina and Sokolova 1960) Pridham 1970

Korenyako, A.I., N.A. Krasillnilov, N.I. Nikitina and A.I. Sokolova. 1960 in Rautenshtein, Ya. I. Transactions of the Institute of Microbiology, Academy of Science USSR 8:1-344; Pridham, T.G. 1970. Bulletin of the United States Department of Agriculture 1424:1-55. Type strain: ATCC 15858

Description: Shirling, E.B. and D. Gottlieb. 1968. International Journal of Systematic Bacteriology 18:279-392.

S. clavifer (Millard and Burr 1926) Waksman 1953

Millard, W.A. and S. Burr. 1926. Annals of Applied Biology 13:580-644; Waksman, S.A. 1953 in Waksman, S.A. and H.A. Lechevalier. Guide to the classification and identification of the actinomycetes and their antibiotics. The Williams and Wilkins Co., Baltimore. pp. 1-246. Type strain: CBS 101.27

Description: Bergey 8.

S. clavuligerus Higgens and Kastner 1971

Higgens, C.E. and R.E. Kastner. 1971. International Journal of Systematic Bacteriology 21:326-331. Type strain: NRRL 3585

Description: Higgens, C.E. and R.E. Kastner. 1971. Ibid.

S. coelescens (Krassilnikov, Sorokina, Alferova and Bezzubenkova 1965) Pridham 1970

Krassilnikov, N.A., E.J. Sorokina, V.A. Alferova and A.P. Bezzubenkova. 1965 in Krassilnikov, N.A. (ed). Biology of selected groups of actinomycetes (in Russian). Institute of Microbiology, Academy of Science, Publishing Firm 'Nauka', Moscow, USSR. pp. 1-372; Pridham, T.G. 1970. Bulletin of the United States Department of Agriculture 1424:1-55. 
Type strain: ATCC 19830

Description: Shirling, E.B. and D. Gottlieb. 1972. International Journal of Systematic Bacteriology 22:265-394.

S. coelicolor (Muller 1908) Waksman and Henrici 1948

Muller, R. 1908. Zentralblatt fur Bakteriologie, Parasitenkunde, Infektionskrankheiten und Hygiene. Abteilung I. 46:195222; Waksman, S.A. and A.T. Henrici. 1948 in Breed, R.S., E.G.D. Murray and A.P. Hitchens (eds). Bergey's Manual of Determinative Bacteriology, 6th ed. The Williams and Wilkins Co., Baltimore. pp. 929-980. Type strain: CBS 210.27

Description: Shirling, E.B. and D. Gottlieb. 1968. International Journal of Systematic Bacteriology 18:279-392.

S. coeruleofuscus (Preobrazhenskaya 1957) Pridham, Hesseltine and Benedict 1958

Preobrazhenskaya, T.P. 1957 in Gauze, G.F., T.P. Preobrazhenskaya, E.S. Kudrina, N.O. Blinov, I.D. Ryabova and M.A. Sveshnikova. Problems of classification of actinomycetes-antagonists. Government Publishing House of Medical Literature, Medgiz, Moscow. pp. 1-398; Pridham, T.G., C.W. Hesseltine and R.G. Benedict. 1958. Applied Microbiology 6:52-79. Type strain: ATCC 23618

Description: Shirling, E.B. and D. Gottlieb. 1968. International Journal of Systematic Bacteriology 18:69-189.

S. coeruleorubidus (Preobrazhenskaya 1957) Pridham, Hesseltine and Benedict 1958

Preobrazhenskaya, T.P. 1957 in Gauze, G.F., T.P. Preobrazhenskaya, E.S. Kudrina, N.O. Blinov, I.D. Ryabova and M.A. Sveshnikova. Problems of classification of actinomycetes-antagonists. Government Publishing House of Medical Literature, Medgiz, Moscow. pp. 1-398; Pridham, T.G., C.W. Hesseltine and R.G. Benedict. 1958. Applied Microbiology 6:52-79. Type strain: ATCC 13740

Description: Shirling, E.B. and D. Gottlieb. 1968. International Journal of Systematic Bacteriology 18:279-392.

S. coerulescens (Preobrazhenskaya 1957) Pridham, Hesseltine and Benedict 1958

Preobrazhenskaya, T.P. 1957 in Gauze, G.F., T.P. Preobrazhenskaya, E.S. Kudrina, N.O. Blinov, I.D. Ryabova and M.A.
Sveshnikova. Problems of classification of actinomycetes-antagonists. Government Publishing House of Medical Literature, Medgiz, Moscow. pp. 1-398; Pridham, T.G., C.W. Hesseltine and R.G. Benedict. 1958. Applied Microbiology 6:52-79. Type strain: ATCC 19896

Description: Shirling, E.B. and D. Gottlieb. 1968. International Journal of Systematic Bacteriology 18:69-189.

S. collinus Lindenbein 1952

Lindenbein, W. 1952. Archiv fur Mikrobiologie 17:361-383. Type strain: ATCC 19743

Description: Shirling, E.B. and D. Gottlieb. 1968. International Journal of Systematic Bacteriology 18:69-189.

S. colombiensis Pridham, Hesseltine and Benedict 1958

Pridham, T.G., C.W. Hesseltine and R.G. Benedict. 1958. Applied Microbiology 6: 52-79. Type strain: ATCC 27425

Description: Shirling, E.B. and D. Gottlieb. 1972. International Journal of Systematic Bacteriology 22:265-394.

S. corchorusii Ahmad and Bhuiyan 1958

Ahmad, K. and J.A.M. Bhuiyan. 1958.

Pakistan Journal of Biological and Agricultural Sciences 1:137-143. Type strain: ATCC 25444

Description: Shirling, E.B. and D. Gottlieb. 1969. International Journal of Systematic Bacteriology 19:391-512.

S. cremeus (Kudrina 1957) Pridham, Hesseltine and Benedict 1958

Kudrina, E.S. 1957 in Gauze, G.F., T.P. Preobrazhenskaya, E.S. Kudrina, N.O. Blinov, I.D. Ryabova and M.A. Sveshnikova. Problems in the classification of actinomycetes-antagonists. State Publishing House of Medical Literature, Medgiz, Moscow. USSR; Pridham, T.G., C.W. Hesseltine and R.G. Benedict. 1958. Applied Microbiology 6:52-79. Type strain: ATCC 19897

Description: Shirling, E.B. and D. Gottlieb. 1968. International Journal of Systematic Bacteriology 18:69-189.

S. crystallinus Tresner, Davies and Backus 1961

Tresner, H.D., M.C. Davies and E.J. Backus. 1961. Journal of Bacteriology 81: 70-80. Type strain: NRRL B-3629

Description: Bergey 8 . 
S. curacoi Cataldi 1963

Cataldi, M. 1963 in Trejo, W. and R.E. Bennett. Journal of Bacteriology 85:676690. Type strain: ATCC 13385

Description: Shirling, E.B. and D. Gottlieb. 1968. International Journal of Systematic Bacteriology 18:69-189.

S. cuspidosporus Higashide, Hasegawa, Shibata, Mizuno and Akaike 1966

Higashide, E., T. Hasegawa, M. Shibata, K. Mizuno and H. Akaike. 1966. Annual Report of the Takeda Research Laboratory 25:1-14. Type strain: IFO 12378

Description: Higashide, E., T. Hasegawa, M. Shibata, K. Mizuno and H. Akaike. 1966. Ibid.

S. cyaneofuscatus (Kudrina 1957) Pridham, Hesseltine and Benedict 1958

Kudrina, E.S. 1957 in Gauze, G.F., T.P. Preobrazhenskaya, E.S. Kudrina, N.O. Blinov, I.D. Ryabova and M.A. Sveshnikova. Problems of classification of actinomycetes-antagonists.

Government

Publishing House of Medical Literature, Medgiz, Moscow. pp. 1-398; Pridham, T.G., C.W. Hesseltine and R.G. Benedict. 1958. Applied Microbiology 6:52-79. Type strain: ATCC 23619

Description: Shirling, E.B. and D. Gottlieb. 1968. International Journal of Systematic Bacteriology 18:69-189.

S. cyaneus (Krassilnikov 1941) Waksman 1953

Krassilnikov, N.A. 1941. Guide to the bacteria and Actinomycetes (in Russian). Institute of Microbiology, Academy of Science, Publishing Firm 'Nauka', Moscow, USSR. pp. 1-830; Waksman, S.A. 1953 in Waksman, S.A. and H.A. Lechevalier. Guide to the classification and identification of the Actinomycetes and their antibiotics. The Williams and Wilkins Co., Baltimore. pp. 1-245. Type strain: ATCC 14923

Description: Shirling, E.B. and D. Gottlieb. 1972. International Journal of Systematic Bacteriology 22:265-394.

S. cyanoalbus (Krassilnikov and Agre 1960) Pridham 1970

Krassilnikov, N.A. and N.S. Agre. 1960 in Rautenshtein, Ya. I. Transactions of the Institute of Microbiology, Academy of Science USSR 8:1-344; Pridham, T.G. 1970. Bulletin of the United States
Department of Agriculture 1424:1-55. Type strain: ATCC 15859

Description: Shirling, E.B. and D. Gottlieb. 1968. International Journal of Systematic Bacteriology 18:279-392.

S. daghestanicus (Sveshnikova 1957) Pridham, Hesseltine and Benedict 1958

Sveshnikova, M.A. 1957 in Gauze, G.F., T.P. Preobrazhenskaya, E.S. Kudrina, N.O. Blinov, I.D. Ryabova and M.A. Sveshnikova. Problems of classification of actinomycetes-antagonists. Government Publishing House of Medical Literature, Medgiz, Moscow. pp. 1-398; Pridham, T.G., C.W. Hesseltine and R.G. Benedict. 1958. Applied Microbiology 6:52-79. Type strain: ATCC 23620

Description: Shirling, E.B. and D. Gottlieb. 1968. International Journal of Systematic Bacteriology 18:69-189.

S. diastaticus (Krainsky 1914) Waksman and Henrici 1948

Krainsky, A. 1914. Zentralblatt fur Bakteriologie, Parasitenkunde, Infektionskrankheiten und Hygiene. Abteilung II. 41:649-688; Waksman, S.A. and A.T. Henrici. 1948 in Breed, R.S., E.G.D. Murray and A.P. Hitchens (eds). Bergey's Manual of Determinative Bacteriology, 6th ed. The Williams and Wilkins Co., Baltimore. pp. 929-980. Type strain: ATCC 3315

Description: Shirling, E.B. and D. Gottlieb. 1972. International Journal of Systematic Bacteriology 22:265-394.

S. diastaticus subsp. ardesiacus (Baldacci, Grein and Spalla 1955) Pridham, Hesseltine and Benedict 1958

Baldacci, E., A. Grein and C. Spalla. 1955. Giornale di Microbiologia 1:127143; Pridham, T.G., C.W. Hesseltine and R.G. Benedict. 1958. Applied Microbiology 6:52-79. Type strain: CBS 100.56

Description: Hutter, R. 1964. Zentralblatt fur Bakteriologie, Parasitenkunde, Infektionskrankheiten und Hygiene. Abteilung II. 117:603-661.

S. diastaticus subsp. diastaticus (Krainsky 1914) Waksman and Henrici 1948

Krainsky, A. 1914. Zentralblatt fur Bakteriologie, Parasitenkunde, Infektionskrankheiten und Hygiene. Abteilung II. 41:649-688; Waksman, S.A. and A.T. 
Henrici, 1948 in Breed, R.S., E.G.D. Murray and A.P. Hitchens (eds). Bergey's Manual of Determinative Bacteriology, 6th ed. The Williams and Wilkins Co., Baltimore. pp. 929-980. Type strain: ATCC 3315

Description: Shirling, E.B. and D. Gottlieb. 1972. International Journal of Systematic Bacteriology 22:265-394.

S. diastatochromogenes (Krainsky 1914) Waksman and Henrici 1948

Krainsky, A. 1914. Zentralblatt fur Bakteriologie, Parasitenkunde, Infektionskrankheiten und Hygiene. Abteilung II. 41:649-688; Waksman, S.A. and A.T. Henrici. 1948 in Breed, R.S., E.G.D. Murray and A.P. Hitchens (eds). Bergey's Manual of Determinative Bacteriology, 6th ed. The Williams and Wilkins Co., Baltimore. pp. 929-980. Type strain: ATCC 12309

Description: Shirling, E.B. and D. Gottlieb. 1972. International Journal of Systematic Bacteriology 22:265-394.

S. djakartensis Huber, Wallhausser, Fries, Steigler and Weidenmuller 1962

Huber, G., K.H. Wallhausser, L. Fries, A. Steigler and H.-L. Weidenmuller. 1962. Arzneimittel Forschung 12:11911195. Type strain: DSM 40743

Description: Bergey 8

S. durhamensis Gordon and Lapa 1966

Gordon, M.A. and E.W. Lapa. 1966. Applied Microbiology 14:754-760. Type strain: ATCC 23194

Description: Shirling, E.B. and D. Gottlieb. 1972. International Journal of Systematic Bacteriology 22:265-394.

S. echinatus Corbaz, Ettlinger, Gaumann, Keller-Schierlein, Kradolfer, Neipp, Prelog, Reusser and Zahner 1957

Corbaz, R., L. Ettlinger, E. Gaumann, W. Keller-Schierlein, F. Kradolfer, L. Neipp, V. Prelog, P. Reusser and $\mathrm{H}$. Zahner. 1957. Helvetica Chimica Acta 40:199-204. Type strain: ATCC 19748

Description: Shirling, E.B. and D. Gottlieb. 1968. International Journal of Systematic Bacteriology 18:69-189.

S. ederensis Wallhausser, Nesemann, Prave and Steigler 1966

Wallhausser, K.H., G. Nesemann, P. Prave and A. Steigler. 1966. Antimicrobi- al Agents and Chemotherapy 1965:734736. Type strain: ATCC 15304

Description: Bergey 8.

S. endus Anderson and Gottlieb 1952

Anderson, H.W. and D. Gottlieb. 1952.

Economic Botany 6:294-308. Type strain:

NRRL 2339

Description: Shirling, E.B. and D. Gottlieb. 1968. International Journal of Systematic Bacteriology 18:279-392.

S. erumpens Calot and Cercos 1963

Calot, L. and A.P. Cercos. 1963. Annales de l'Institut Pasteur (Paris) 105:159-161.

Type strain: ATCC 23266

Description: Bergey 8.

S. erythraeus (Waksman 1923) Waksman and Henrici 1948

Waksman, S.A. 1923 in Bergey, D.H., F.C. Harrison, R.S. Breed, B.W. Hammer and F.M. Huntoon. Bergey's Manual of Determinative Bacteriology, 1st ed. The Williams and Wilkins Co., Baltimore. pp. 339-371; Waksman, S.A. and A.T. Henrici. 1948 in Breed, R.S., E.G.D. Murray and A.P. Hitchens (eds). Bergey's Manual of Determinative Bacteriology, 6th ed. The Williams and Wilkins Co., Baltimore. pp. 929-980. Type strain: ATCC 11635

Description: Shirling, E.B. and D. Gottlieb. 1972. International Journal of Systematic Bacteriology 22:265-394.

S. erythrogriseus Falcao de Morais and Dalia Maia 1959

Falcao de Morais, J.O. and M.H. Dalia Maia. 1959. Revista do Instituto de Antibioticos, Universidade do Recife 2:6367. Type strain: CBS 485.74

Description: Shirling, E.B. and D. Gottlieb. 1972. International Journal of Systematic Bacteriology 22:265-394.

S. eurythermus Corbaz, Ettlinger, Gaumann, Keller-Schierlein, Kradolfer, Neipp, Pre$\log$, Reusser and Zahner 1957

Corbaz, R., L. Ettlinger, E. Gaumann, W. Keller-Schierlein, F. Kradolfer, L. Neipp, V. Prelog, P. Reusser and $\mathrm{H}$. Zahner. 1957. Helvetica Chimica Acta 40:199-203. Type strain: ATCC 14975

Description: Shirling, E.B. and D. Gottlieb. 1968. International Journal of Systematic Bacteriology 18:69-189.

S. exfoliatus (Waksman and Curtis 1916) 
Waksman and Henrici 1948

Waksman, S.A. and R.E. Curtis. 1916. Soil Science 1:99-134; Waksman, S.A. and A.T. Henrici. 1948 in Breed, R.S., E.G.D. Murray and A.P. Hitchens (eds). Bergey's Manual of Determinative Bacteriology, 6th ed. The Williams and Wilkins Co., Baltimore. pp. 929-980. Type strain: ATCC 12627

Description: Shirling, E.B. and D. Gottlieb. 1968. International Journal of Systematic Bacteriology 18:69-189.

S. felleus Lindenbein 1952

Lindenbein, W. 1952. Archiv fur Mikrobiologie 17:361-383. Type strain: ATCC 19752

Description: Shirling, E.B. and D. Gottlieb. 1968. International Journal of Systematic Bacteriology 18:69-189.

S. filamentosus Okami and Umezawa 1953 Okami, Y. and H. Umezawa. 1953 in Okami, Y., T. Okuda, T. Takeuchi, K. Nitta and $H$. Umezawa. Journal of Antibiotics (Tokyo) Series A 6:153-157. Type strain: ATCC 19753

Description: Shirling, E.B. and D. Gottlieb. 1968. International Journal of Systematic Bacteriology 18:69-189.

S. filipinensis Ammann, Gottlieb, Brock, Carter and Whitfield 1955

Ammann, A., D. Gottlieb, T.D. Brock, H.E. Carter and G.B. Whitfield. 1955. Phytopathology 45:559-563. Type strain: NRRL 2437

Description: Shirling, E.B. and D. Gottlieb. 1968. International Journal of Systematic Bacteriology 18:279-392.

S. fimbriatus (Millard and Burr 1926) Waksman and Lechevalier 1953

Millard, W.A. and S. Burr. 1926. Annals of Applied Biology 13:580-644; Waksman, S.A. and H.A. Lechevalier. 1953. Guide to the classification and identification of the actinomycetes and their antibiotics. The Williams and Wilkins Co., Baltimore. pp. 1-246. Type strain: ATCC 15051 Description: Bergey 8 .

S. fimicarius (Duche 1934) Waksman and Henrici 1948

Duche, J. 1934. Encyclopedie Mycologique 6:1-375; Waksman, S.A. and A.T. Henrici. 1948 in Breed, R.S., E.G.D. Murray and A.P. Hitchens (eds). Bergey's
Manual of Determinative Bacteriology, 6th ed. The Williams and Wilkins Co., Baltimore. pp. 929-980. Type strain: CBS 420.34

Description: Shirling, E.B. and D. Gottlieb. 1969. International Journal of Systematic Bacteriology 19:391-512.

S. finlayi (Szabo, Martin, Buti and Partai 1963) Pridham 1970

Szabo, I., M. Marton, I. Buti and G. Partai. 1963. Acta Microbiologica Academiae Scientiarum Hungaricae 10:207214; Pridham, T.G. 1970. Bulletin of the United States Department of Agriculture 1424:1-55. Type strain: ATCC 23340

Description: Shirling, E.B. and D. Gottlieb. 1968. International Journal of Systematic Bacteriology 18:279-392.

S. flaveolus (Waksman 1923) Waksman and Henrici 1948

Waksman, S.A. 1923 in Bergey, D.H., F.C. Harrison, R.S. Breed, B.W. Hammer and F.M. Huntoon. Bergey's Manual of Determinative Bacteriology, 1st ed. The Williams and Wilkins Co., Baltimore. pp. 339-371; Waksman, S.A. and A.T. Henrici. 1948 in Breed, R.S., E.G.D. Murray and A.P. Hitchens (eds). Bergey's Manual of Determinative Bacteriology, 6th ed. The Williams and Wilkins Co., Baltimore. pp. 929-980. Type strain: ATCC 3319

Description: Shirling, E.B. and D. Gottlieb. 1968. International Journal of Systematic Bacteriology 18:69-189.

S. flavidovirens (Kudrina 1957) Pridham, Hesseltine and Benedict 1958

Kudrina, E.S. 1957 in Gauze, G.F., T.P. Preobrazhenskaya, E.S. Kudrina, N.O. Blinov, I.D. Ryabova and M.A. Sveshnikova. Problems of classification of actinomycetes-antagonists. Government Publishing House of Medical Literature, Medgiz, Moscow. pp. 1-398; Pridham, T.G., C.W. Hesseltine and R.G. Benedict. 1958. Applied Microbiology 6:52-79. Type strain: ATCC 19900

Description: Shirling, E.B. and D. Gottlieb. 1969. International Journal of Systematic Bacteriology 19:391-512.

S. flavogriseus (Duche 1934) Waksman and Lechevalier 1953

Duche, J. 1934. Encyclopedie Mycolo- 
gique 6:1-375; Waksman, S.A. and H.A. Lechevalier. 1953. Guide to the classification and identification of the actinomycetes and their antibiotics. The Williams and Wilkins Co., Baltimore. pp. 1-246. Type strain: CBS 101.34

Description: Shirling, E.B. and D. Gottlieb. 1969. International Journal of Systematic Bacteriology 19:391-512.

S. flavotricini (Preobrazhenskaya and Sveshnikova 1957) Pridham, Hesseltine and Benedict 1958

Preobrazhenskaya, T.P. and M.A. Sveshnikova. 1957 in Gauze, G.F., T.P. Preobrazhenskaya, E.S. Kudrina, N.O. Blinov, I.D. Ryabova and M.A. Sveshnikova. Problems of classification of actinomycetes-antagonists. Government Publishing House of Medical Literature, Medgiz, Moscow. pp. 1-398; Pridham, T.G., C.W. Hesseltine and R.G. Benedict. 1958. Applied Microbiology 6:52-79. Type strain: ATCC 23621

Description: Shirling, E.B. and D. Gottlieb. 1968. International Journal of Systematic Bacteriology 18:69-189.

S. flavovirens (Waksman 1923) Waksman and Henrici 1948

Waksman, S.A. 1923 in Bergey, D.H., F.C. Harrison, R.S. Breed, B.W. Hammer and F.M. Huntoon. Bergey's Manual of Determinative Bacteriology, 1st ed. The Williams and Wilkins Co., Baltimore. pp. 339-371; Waksman, S.A. and A.T. Henrici. 1948 in Breed, R.S., E.G.D. Murray and A.P. Hitchens (eds). Bergey's Manual of Determinative Bacteriology, 6th ed. The Williams and Wilkins Co., Baltimore. pp. 929-980. Type strain: ATCC 3320

Description: Shirling, E.B. and D. Gottlieb. 1968. International Journal of Systematic Bacteriology 18:69-189.

S. flocculus (Duche 1934) Waksman and Henrici 1948

Duche, J. 1934. Encyclopedie Mycologique 6:1-375; Waksman, S.A. and A.T. Henrici. 1948 in Breed, R.S., E.G.D. Murray and A.P. Hitchens (eds). Bergey's Manual of Determinative Bacteriology, 6th ed. The Williams and Wilkins Co., Baltimore. pp. 929-980. Type strain: ATCC 25453
Description: Shirling, E.B. and D. Gottlieb. 1969. International Journal of Systematic Bacteriology 19:391-512.

S. floridae Bartz, Ehrlich, Mold, Penner and Smith 1951

Bartz, Q., J. Ehrlich, J.D. Mold, M.A. Penner and R.M. Smith. 1951. American Review of Tuberculosis 63:4-6. Type strain: NRRL 2423

Description: Ettlinger, L., R. Corbaz and R. Hutter. 1958. Archiv fur Mikrobiologie 31:326-358.

S. fluorescens (Krassilnikov 1958) Pridham 1970

Krassilnikov, N.A. 1958. Folia Biologica (Praha) 4:257-265; Pridham, T.G. 1970. Bulletin of the United States Department of Agriculture 1424:1-55. Type strain: ATCC 15860

Description: Shirling, E.B. and D. Gottlieb. 1968. International Journal of Systematic Bacteriology 18:279-392.

S. fradiae (Waksman and Curtis 1916) Waksman and Henrici 1948

Waksman, S.A. and R.E. Curtis. 1916. Soil Science 1:99-134; Waksman, S.A. and A.T. Henrici. 1948 in Breed, R.S., E.G.D. Murray and A.P. Hitchens (eds). Bergey's Manual of Determinative Bacteriology, 6th ed. The Williams and Wilkins Co., Baltimore. pp. 929-980. Type strain: ATCC 10745

Description: Shirling, E.B. and D. Gottlieb. 1968. International Journal of Systematic Bacteriology 18:69-189.

S. fragilis Anderson, Ehrlich, Sun and Burkholder 1956

Anderson, L.E., J. Ehrlich, S.H. Sun and P.R. Burkholder. 1956. Antibiotics and Chemotherapy 6:100-115. Type strain: NRRL 2424

Description: Shirling, E.B. and D. Gottlieb. 1968. International Journal of Systematic Bacteriology 18:279-392.

S. fulvissimus (Jensen 1930) Waksman and Henrici 1948

Jensen, H.L. 1930. Proceedings of the Linnean Society of New South Wales 55: 231-249; Waksman, S.A. and A.T. Henrici. 1948 in Breed, R.S., E.G.D. Murray and A.P. Hitchens (eds). Bergey's Manual of Determinative Bacteriology, 6th ed. The Williams and Wilkins Co., 
Baltimore. pp. 929-980. Type strain: NRRL B-1453

Description: Shirling, E.B. and D. Gottlieb. 1972. International Journal of Systematic Bacteriology 22:265-394.

S. fumanus (Sveshnikova 1957) Pridham, Hesseltine and Benedict 1958

Sveshnikova, M.A. 1957 in Gauze, G.F., T.P. Preobrazhenskaya, E.S. Kudrina, N.O. Blinov, I.D. Ryabova and M.A. Sveshnikova. Problems of classification of actinomycetes-antagonists. Government Publishing House of Medical Literature, Medgiz, Moscow. pp. 1-398; Pridham, T.G., C.W. Hesseltine and R.G. Benedict. 1958. Applied Microbiology 6:52-79. Type strain: ATCC 19904

Description: Shirling, E.B. and D. Gottlieb. 1969. International Journal of . Systematic Bacteriology 19:391-512.

S. galbus Frommer 1959

Frommer, W. 1959. Archiv fur Mikrobiologie 32:187-206. Type strain: ATCC 23910

Description: Shirling, E.B. and D. Gottlieb. 1968. International Journal of Systematic Bacteriology 18:279-392.

S. galilaeus Ettlinger, Corbaz and Hutter 1958 Ettlinger, L., R. Corbaz and R. Hutter. 1958. Archiv fur Mikrobiologie 31:326358. Type strain: NRRL 2722

Description: Shirling, E.B. and D. Gottlieb. 1972. International Journal of Systematic Bacteriology 22:265-394.

S. gancidicus Suzuki 1957

Suzuki, M. 1957. Journal Chiba Medical Society 33:535-542. Type strain: NRRL B-1872

Description: Bergey 8.

S. gardneri (Waksman 1942) Waksman 1961

Waksman, S.A. 1942 in Waksman, S.A., E.S. Horning, M. Welsch and H.B. Woodruff. Soil Science 54:281-296; Waksman, S.A. 1961. The Actinomycetes. Vol. 2. Classification, identification and descriptions of genera and species. The Williams and Wilkins Co., Baltimore. pp. 1-363. Type strain: ATCC 9604

Description: Shirling, E.B. and D. Gottlieb. 1968. International Journal of Systematic Bacteriology 18:279-392.

S. gelaticus (Waksman 1923) Waksman and Henrici 1948
Waksman, S.A. 1923 in Bergey, D.H., F.C. Harrison, R.S. Breed, B.W. Hammer and F.M. Huntoon. Bergey's Manual of Determinative Bacteriology, 1st ed. The Williams and Wilkins Co., Baltimore. pp. 339-371; Waksman, S.A. and A.T. Henrici. 1948 in Breed, R.S., E.G.D. Murray and A.P. Hitchens (eds). Bergey's Manual of Determinative Bacteriology, 6th ed. The Williams and Wilkins Co., Baltimore. pp. 929-980. Type strain: ATCC 3323

Description: Shirling, E.B. and D. Gottlieb. 1968. International Journal of Systematic Bacteriology 18:279-392.

S. geysiriensis Wallhausser, Nesemann, Prave and Steigler 1966

Wallhausser, K.H., G. Nesemann, P. Prave and A. Steigler. 1966. Antimicrobial Agents and Chemotherapy 1965:734736. Type strain: ATCC 15303

Description: Bergey 8.

S. ghanaensis Wallhausser, Nesemann, Prave and Steigler 1966

Wallhausser, K.H., G. Nesemann, P. Prave and A. Steigler. 1966. Antimicrobial Agents and Chemotherapy 1965:734736. Type strain: ATCC 14672

Description: Bergey 8.

S. gibsonii (Erikson 1935) Waksman and Henrici 1948

Erikson, D. 1935. Medical Research Council (Great Britain) Special Report Series 203:5-61; Waksman, S.A. and A.T. Henrici. 1948 in Breed, R.S., E.G.D. Murray and A.P. Hitchens (eds). Bergey's Manual of Determinative Bacteriology, 6th ed. The Williams and Wilkins Co., Baltimore. pp. 929-980. Type strain: ATCC 6852

Description: Bergey 8 .

S. glaucescens (Preobrazhenskaya 1957) Pridham, Hesseltine and Benedict 1958

Preobrazhenskaya, T.P. 1957 in Gauze, G.F., T.P. Preobrazhenskaya, E.S. Kudrina, N.O. Blinov, I.D. Ryabova and M.A. Sveshnikova. Problems of classification of actinomycetes-antagonists. Government Publishing House of Medical Literature, Medgiz, Moscow. pp. 1-398; Pridham, T.G., C.W. Hesseltine and R.G. Benedict. 1958. Applied Microbiology 6: 52-79. Type strain: ATCC 23622 
Description: Shirling, E.B. and D. Gottlieb. 1968. International Journal of Systematic Bacteriology 18:69-189.

S. globisporus (Krassilnikov 1941) Waksman 1953

Krassilnikov, N.A. 1941. Guide to the Bacteria and Actinomycetes (in Russian). Akademiya Nauk SSSR, Moscow. pp. 1830; Waksman, S.A. 1953 in Waksman, S.A. and H.A. Lechevalier. Guide to the classification and identification of the Actinomycetes and their antibiotics. The Williams and Wilkins Co., Baltimore. pp. 1-246. Type strain: ATCC 15864

Description: Shirling, E.B. and D. Gottlieb. 1968. International Journal of Systematic Bacteriology 18:279-392.

S. globisporus subsp. caucasicus (Kudrina 1957) Pridham, Hesseltine and Benedict 1958 Kudrina, E.S. 1957 in Gauze, G.F., T.P. Preobrazhenskaya, E.S. Kudrina, N.O. Blinov, I.D. Ryabova and M.A. Sveshnikova. Problems of classification of actinomycetes-antagonists. Government Publishing House of Medical Literature, Medgiz, Moscow. pp. 1-398; Pridham, T.G., C.W. Hesseltine and R.G. Benedict. 1958. Applied Microbiology 6:52-79. Type strain: ATCC 19907

Description: Bergey 8.

S. globisporus subsp. flavofuscus (Kudrina 1957) Pridham, Hesseltine and Benedict 1958

Kudrina, E.S. 1957 in Gauze, G.F., T.P. Preobrazhenskaya, E.S. Kudrina, N.O. Blinov, I.D. Ryabova and M.A. Sveshnikova. Problems of classification of actinomycetes-antagonists. Government Publishing House of Medical Literature, Medgiz, Moscow. pp. 1-398; Pridham, T.G., C.W. Hesseltine and R.G. Benedict. 1958. Applied Microbiology 6:52-79. Type strain: ATCC 19908

Description: Bergey 8.

S. globisporus subsp. globisporus (Krassilnikov 1941) Waksman 1953

Krassilnikov, N.A. 1941. Guide to the Bacteria and Actinomycetes (in Russian). Akademiya Nauk SSSR, Moscow. pp. 1830; Waksman, S.A. 1953 in Waksman, S.A. and H.A. Lechevalier. Guide to the classification and identification of the Actinomycetes and their antibiotics. The
Williams and Wilkins Co., Baltimore. pp. 1-246. Type strain: ATCC 15864

Description: Shirling, E.B. and D. Gottlieb. 1968. International Journal of Systematic Bacteriology 18:279-392.

S. globosus (Krassilnikov 1941) Waksman 1953

Krassilnikov, N.A. 1941. Guide to the

Bacteria and Actinomycetes (in Russian). Akademiya Nauk SSSR, Moscow. pp. 1830; Waksman, S.A. 1953 in Waksman, S.A. and H.A. Lechevalier. Type strain: NRRL B-2292

Description: Bergey 8.

S. glomeroaurantiacus (Krassilnikov and Yuan 1965) Pridham 1970

Krassilnikov, N.A. and T. Yuan. 1965 in Krassilnikov, N.A. (ed). Biology of individual groups of Actinomycetes (in Russian). pp. 28-57; Pridham, T.G. 1970. Bulletin of the United States Department of Agriculture 1424:1-55. Type strain: ATCC 15866

Description: Shirling, E.B. and D. Gottlieb. 1972. International Journal of Systematic Bacteriology 22:265-394.

S. gobitricini (Preobrazhenskaya and Sveshnikova 1957) Pridham, Hesseltine and Benedict 1958

Preobrazhenskaya, T.P. and M.A. Sveshnikova. 1957 in Gauze, G.F., T.P. Preobrazhenskaya, E.S. Kudrina, N.O. Blinov, I.D. Ryabova and M.A. Sveshnikova. Problems of classification of actinomycetes-antagonists. Government Publishing House of Medical Literature, Medgiz, Moscow. pp. 1-398; Pridham, T.G., C.W. Hesseltine and R.G. Benedict. 1958. Applied Microbiology 6:52-79. Type strain: CBS 123.60

Description: Bergey 8.

S. goshikiensis Niida 1966

Niida, T. 1966 in Shirling, E.B. and D. Gottlieb. International Journal of Systematic Bacteriology 16:313-340. Type strain: ATCC 23914

Description: Shirling, E.B. and D. Gottlieb. 1968. International Journal of Systematic Bacteriology 18:279-392.

S. gougerotii (Duche 1934) Waksman and Henrici 1948

Duche, J. 1934. Encyclopedie Mycologique 6:1-375; Waksman, S.A. and A.T. Henrici. 1948 in Breed, R.S., E.G.D. 
Murray and A.P. Hitchens (eds). Bergey's Manual of Determinative Bacteriology, 6th ed. The Williams and Wilkins Co., Baltimore. pp. 929-980. Type strain: CBS 422.34

Description: Shirling, E.B. and D. Gottlieb. 1969. International Journal of Systematic Bacteriology 19:391-512.

S. graminofaciens Charney, Fisher, Curran, Machlowitz and Tytell 1953

Charney, J., W.P. Fisher, C. Curran, R.A. Machlowitz and A.A. Tytell. 1953. Antibiotics and Chemotherapy 3:12831286. Type strain: ATCC 12705

Description: Shirling, E.B. and D. Gottlieb. 1972. International Journal of Systematic Bacteriology 22:265-394.

S. griseinus Waksman 1959

Waksman, S.A. 1959. Proceedings of the National Academy of Science, U.S.A. 45: 1043-1047. Type strain: ATCC 23915

Description: Shirling, E.B. and D. Gottlieb. 1968. International Journal of Systematic Bacteriology 18:279-392.

S. griseoaurantiacus (Krassilnikov and Yuan 1965) Pridham 1970

Krassilnikov, N.A. and T. Yuan. 1965. in Krassilnikov, N.A. (ed). Biology of individual groups of Actinomycetes (in Russian). pp. 28-57; Pridham, T.G. 1970. Bulletin of the United States Department of Agriculture 1424:1-55. Type strain: ATCC 19840

Description: Shirling, E.B. and D. Gottlieb. 1972. International Journal of Systematic Bacteriology 22:265-394.

S. griseobrunneus Waksman 1961

Waksman, S.A. 1961. The Actinomycetes. Vol. 2. Classification, identification and descriptions of genera and species. The Williams and Wilkins Co., Baltimore. pp. 1-363. Type strain: ATCC 19762

Description: Shirling, E.B. and D. Gottlieb. 1968. International Journal of Systematic Bacteriology 18:69-189.

S. griseochromogenes Fukunaga 1955

Fukunaga, K. 1955 in Fukunaga, K., T. Misato, I. Ishii and M. Asakawa. Bulletin of the Agricultural Chemical Society of Japan 19:181-188. Type strain: ATCC 14511

Description: Shirling, E.B. and D. Gottlieb. 1972. International Journal of
Systematic Bacteriology 22:265-394.

S. griseoflavus (Krainsky 1914) Waksman and Henrici 1948

Krainsky, A. 1914. Zentralblatt fur Bakteriologie, Parasitenkunde, Infektionskrankheiten und Hygiene. Abteilung II. 41:649-688; Waksman, S.A. and A.T. Henrici. 1948 in Breed, R.S., E.G.D. Murray and A.P. Hitchens (eds). Bergey's Manual of Determinative Bacteriology, 6th ed. The Williams and Wilkins Co., Baltimore. pp. 929-980. Type strain: ATCC 25456

Description: Shirling, E.B. and D. Gottlieb. 1969. International Journal of Systematic Bacteriology 19:391-512.

S. griseofuscus Sakamoto, Kondo, Yumoto and Arishima 1962

Sakamoto, J.M., S.-i. Kondo, H. Yumoto and M. Arishima. 1962. Journal of Antibiotics (Tokyo) Series A 15:98-102. Type strain: ATCC 23916

Description: Shirling, E.B. and D. Gottlieb. 1968. International Journal of Systematic Bacteriology 18:279-392.

S. griseoincarnatus (Preobrazhenskaya, Ryabova and Blinov 1957) Pridham, Hesseltine and Benedict 1958

Preobrazhenskaya, T.P., I.D. Ryabova and N.O. Blinov. 1957 in Gauze, G.F., T.P. Preobrazhenskaya, E.S. Kudrina, N.O. Blinov, I.D. Ryabova and M.A. Sveshnikova. Problems of classification of actinomycetes-antagonists. Government Publishing House of Medical Literature, Medgiz, Moscow. pp. 1-398; Pridham, T.G., C.W. Hesseltine and R.G. Benedict. 1958. Applied Microbiology 6:52-79. Type strain: ATCC 23623

Description: Shirling, E.B. and D. Gottlieb. 1968. International Journal of Systematic Bacteriology 18:279-392.

S. griseoloalbus (Kudrina 1957) Pridham, Hesseltine and Benedict 1958

Kudrina, E.S. 1957 in Gauze, G.F., T.P. Preobrazhenskaya, E.S. Kudrina, N.O. Blinov, I.D. Ryabova and M.A. Sveshnikova. Problems of classification of actinomycetes-antagonists. Government Publishing House of Medical Literature, Medgiz, Moscow. pp. 1-398; Pridham, T.G., C.W. Hesseltine and R.G. Benedict. 1958. Applied Microbiology 6:52-79. Type 
strain: ATCC 23624

Description: Shirling, E.B. and D. Gottlieb. 1969. International Journal of Systematic Bacteriology 19:391-512.

S. griseolus (Waksman 1923) Waksman and Henrici 1948

Waksman, S.A. 1923 in Bergey, D.H., F.C. Harrison, R.S. Breed, B.W. Hammer and F.M. Huntoon. Bergey's Manual of Determinative Bacteriology, 1st ed. The Williams and Wilkins Co., Baltimore. pp. 339-371; Waksman, S.A. and A.T. Henrici. 1948 in Breed, R.S., E.G.D. Murray and A.P. Hitchens (eds). Bergey's Manual of Determinative Bacteriology, 6th ed. The Williams and Wilkins Co., Baltimore. pp. 929-980. Type strain: ATCC 3325

Description: Shirling, E.B. and D. Gottlieb. 1968. International Journal of Systematic Bacteriology 18:69-189.

S. griseoluteus Umezawa, Hayano, Maeda, Ogata and Okami 1950

Umezawa, H., S. Hayano, K. Maeda, Y. Ogata and Y. Okami. 1950. Japanese Medical Journal 3:111-117. Type strain: ATCC 12768

Description: Shirling, E.B. and D. Gottlieb. 1972. International Journal of Systematic Bacteriology 22:265-394.

S. griseomycini (Preobrazhenskaya, Blinov and Ryabova 1957) Pridham, Hesseltine and Benedict 1958

Preobrazhenskaya, T.P., N.O. Blinov and I.D. Ryabova. 1957 in Gauze, G.F., T.P. Preobrazhenskaya, E.S. Kudrina, N.O. Blinov, I.D. Ryabova and M.A. Sveshnikova. Problems of classification of antinomycetes-antagonists. Government Publishing House of Medical Literature, Medgiz, Moscow. pp. 1-398; Pridham, T.G., C.W. Hesseltine and R.G. Benedict. 1958. Applied Microbiology 6:52-79. Type strain: ATCC 23625

Description: Shirling, E.B. and D. Gottlieb. 1968. International Journal of Systematic Bacteriology 18:69-189.

S. griseoplanus Backus, Tresner and Campbell 1957

Backus, E.J., H.D. Tresner and T.H. Campbell. 1957. Antibiotics and Chemotherapy 7:532-541. Type strain: ATCC 19766
Description: Shirling, E.B. and D. Gottlieb. 1968. International Journal of Systematic Bacteriology 18:69-189.

S. griseorubens (Preobrazhenskaya, Blinov and Ryabova 1957) Pridham, Hesseltine and Benedict 1958

Preobrazhenskaya, T.P., N.O. Blinov and I.D. Ryabova. 1957 in Gauze, G.F., T.P. Preobrazhenskaya, E.S. Kudrina, N.O. Blinov, I.D. Ryabova and M.A. Sveshnikova. Problems of classification of actinomycetes-antagonists. Government Publishing House of Medical Literature, Medgiz, Moscow. pp. 1-398; Pridham, T.G., C.W. Hesseltine and R.G. Benedict. 1958. Applied Microbiology 6:52-79. Type strain: ATCC 19909

Description: Shirling, E.B. and D. Gottlieb. 1968. International Journal of Systematic Bacteriology 18:69-189.

S. griseoruber Yamaguchi and Saburi 1955

Yamaguchi, T. and Y. Saburi. 1955. Journal of General and Applied Microbiology 1:201-235. Type strain: ATCC 23919

Description: Shirling, E.B. and D. Gottlieb. 1968. International Journal of Systematic Bacteriology 18:279-392.

S. griseorubiginosus (Ryabova and Preobrazhenskaya 1957) Pridham, Hesseltine and Benedict 1958

Ryabova, I.D. and T.P. Preobrazhenskaya. 1957 in Gauze, G.F., T.P. Preobrazhenskaya, E.S. Kudrina, N.O. Blinov, I.D. Ryabova and M.A. Sveshnikova. Problems of classification of actinomycetes-antagonists. Government Publishing House of Medical Literature, Medgiz, Moscow. pp. 1-398; Pridham, T.G., C.W. Hesseltine and R.G. Benedict. 1958. Applied Microbiology 6:52-79. Type strain: ATCC 23627

Description: Shirling, E.B. and D. Gottlieb. 1969. International Journal of Systematic Bacteriology 19:391-512.

S. griseosporeus Niida and Ogasawara 1960

Niida, T. and M. Ogasawara. 1960. Scientific Reports of Meiji Seika Kaisha 3:23-26. Type strain: ATCC 27435

Description: Shirling, E.B. and D. Gottlieb. 1972. International Journal of Systematic Bacteriology 22:265-394.

S. griseostramineus (Preobrazhenskaya, Kudri- 
na, Blinov and Ryabova 1957) Pridham, Hesseltine and Benedict 1958

Preobrazhenskaya, T.P., E.S. Kudrina, N.O. Blinov and I.D. Ryabova. 1957 in Gauze, G.F., T.P. Preobrazhenskaya, E.S. Kudrina, N.O. Blinov, I.D. Ryabova and M.A. Sveshnikova. Problems of classification of actinomycetes-antagonists. Government Publishing House of Medical Literature, Medgiz, Moscow. pp. 1-398; Pridham, T.G., C.W. Hesseltine and R.G. Benedict. 1958. Applied Microbiology 6: 52-79. Type strain: ATCC 23628

Description: Shirling, E.B. and D. Gottlieb. 1968. International Journal of Systematic Bacteriology 18:69-189.

S. griseoviridis Anderson, Ehrlich, Sun and Burkholder 1956

Anderson, L.E., J. Ehrlich, S.H. Sun and P.R. Burkholder. 1956. Antibiotics and Chemotherapy 6:100-115. Type strain: NRRL 2427

Description: Shirling, E.B. and D. Gottlieb. 1968. International Journal of Systematic Bacteriology 18:279-392.

S. griseus (Krainsky 1914) Waksman and Henrici 1948

Krainsky, A. 1914. Zentralblatt fur Bakteriologie, Parasitenkunde, Infektionskrankheiten und Hygiene. Abteilung II. 41:649-688; Waksman, S.A. and A.T. Henrici. 1948 in Breed, R.S., E.G.D. Murray and A.P. Hitchens (eds). Bergey's Manual of Determinative Bacteriology, 6th ed. The Williams and Wilkins Co., Baltimore. pp. 929-980. Type strain: ATCC 23345

Description: Shirling, E.B. and D. Gottlieb. 1968. International Journal of Systematic Bacteriology 18:279-392.

S. griseus subsp. alpha (Ciferri 1927) Pridham 1970

Ciferri, R. 1927. Zentralblatt fur Bakteriologie, Parasitenkunde, Infektionskrankheiten und Hygiene. Abteilung II. 71:8093; Pridham, T.G. 1970. Bulletin of the United States Department of Agriculture 1424:1-55. Type strain: CBS 219.25

Description: Bergey 8

S. griseus subsp. cretosus Pridham 1970

Pridham, T.G. 1970. Bulletin of the United States Department of Agriculture 1424:1-55. Type strain: CBS 137.21
Description: Bergey 8.

S. griseus subsp. griseus (Krainsky 1914) Waksman and Henrici 1948

Krainsky, A. 1914. Zentralblatt fur Bakteriologie, Parasitenkunde, Infektionskrankheiten und Hygiene. Abteilung II. 41:649-688; Waksman, S.A. and A.T. Henrici. 1948 in Breed, R.S., E.G.D. Murray and A.P. Hitchens (eds). Bergey's Manual of Determinative Bacteriology, 6th ed. The Williams and Wilkins Co., Baltimore. pp. 929-980. Type strain: ATCC 23345

Description: Shirling, E.B. and D. Gottlieb. 1968. International Journal of Systematic Bacteriology18:279-392.

S. griseus subsp. solvifaciens Pridham 1970

Pridham, T.G. 1970. Bulletin of the United States Department of Agriculture 1424:1-55. Type strain: NRRL B-1561

Description: Bergey 8.

S. halstedii (Waksman and Curtis 1916) Waksman and Henrici 1948

Waksman, S.A. and R.E. Curtis. 1916. Soil Science 1:99-134; Waksman, S.A. and A.T. Henrici. 1948 in Breed, R.S., E.G.D. Murray and A.P. Hitchens (eds). Bergey's Manual of Determinative Bacteriology, 6th ed. The Williams and Wilkins Co., Baltimore. pp. 929-980. Type strain: ATCC 10897

Description: Shirling, E.B. and D. Gottlieb. 1968. International Journal of Systematic Bacteriology 18:69-189.

S. hawaiiensis Cron, Whitehead, Hooper, Heinemann and Lein 1956

Cron, M.J., D.F. Whitehead, I.R. Hooper, B. Heinemann and J. Lein. 1956. Antibiotics and Chemotherapy 6:63-67. Type strain: ATCC 12236

Description: Shirling, E.B. and D. Gottlieb. 1968. International Journal of Systematic Bacteriology 18:69-189.

S. helvaticus (Krassilnikov, Korenyako and Nikitina 1965) Pridham 1970

Krassilnikov, N.A., A.I. Korenyako and N.I. Nikitina. 1965 in Krassilnikov N.A. Biology of selected groups of actinomycetes (in Russian). Institute of Microbiology, Academy of Science, Publishing Firm 'Nauka', Moscow, USSR. pp. 1-372; Pridham, T.G. 1970. Bulletin of the United States Department of Agriculture 
1424:1-55. Type strain: ATCC 19841

Description: Shirling, E.B. and D. Gottlieb. 1972. International Journal of Systematic Bacteriology 22:265-394.

S. herbaricolor Kawato and Shinobu 1959

Kawato, N. and R. Shinobu. 1959. Memoirs of the Osaka University of the Liberal Arts and Education B. Natural Science 8:114-119. Type strain: ATCC 23922

Description: Shirling, E.B. and D. Gottlieb. 1968. International Journal of Systematic Bacteriology 18:279-392.

S. hirsutus Ettlinger, Corbaz and Hutter 1958

Ettlinger, L., R. Corbaz and R. Hutter. 1958. Archiv fur Mikrobiologie 31:326358. Type strain: ATCC 19773

Description: Shirling, E.B. and D. Gottlieb. 1968. International Journal of Systematic Bacteriology 18:69-189.

S. humidus Nakazawa and Shibata 1956 Nakazawa, K. and M. Shibata. 1956 in Imamura, A., M. Hori, K. Nakazawa, M. Shibata, S. Tatsuoka and A. Miyake. Proceedings of the Japanese Academy of Science 32:648-653. Type strain: ATCC 12760

Description: Shirling, E.B. and D. Gottlieb. 1968. International Journal of Systematic Bacteriology 18:279-392.

S. hydrogenans Lindner, Junk, Nesemann and Schmidt-Thome 1958

Lindner, F., R. Junk, G. Nesemann and J. Schmidt-Thome. 1958. Hoppe-Seyler's Zeitschrift fur Physiologische Chemie 313: 117-123. Type strain: ATCC 19631

Description: Shirling, E.B. and D. Gottlieb. 1972. International Journal of Systematic Bacteriology 22:265-394.

S. hygroscopicus (Jensen 1931) Waksman and Henrici 1948

Jensen, H.L. 1931. Proceedings of the Linnean Society of New South Wales 56: 345-370; Waksman, S.A. and A.T. Henrici. 1948 in Breed, R.S., E.G.D. Murray and A.P. Hitchens (eds). Bergey's Manual of Determinative Bacteriology, 6th ed. The Williams and Wilkins Co., Baltimore. pp. 929-980. Type strain: ATCC 27438

Description: Shirling, E.B. and D. Gottlieb. 1972. International Journal of Systematic Bacteriology 22:265-394.
S. hygroscopicus subsp. angustmyceticus Yuntsen, Ohkuma, Ishii and Yonehara 1956

Yuntsen, H., K. Ohkuma, Y. Ishii and H. Yonehara. 1956. Journal of Antibiotics (Tokyo) Series A 9:195-201. Type strain: ATCC 15484

Description: Bergey 8.

S. hygroscopicus subsp. decoyicus Vavra, Dietz, Churchill, Siminoff and Koepsell 1959

Vavra, J.J., A. Dietz, B.W. Churchill, P. Siminoff and H.J. Koepsell. 1959. Antibiotics and Chemotherapy 9:427-431. Type strain: NRRL 2666

Description: Bergey 8.

S. hygroscopicus subsp. glebosus Ohmori, Okanishi and Kawaguchi 1962

Ohmori, T., M. Okanishi and $\mathrm{H}$. Kawaguchi. 1962. Journal of Antibiotics (Tokyo) Series A 15:21-27. Type strain: ATCC 14607

Description: Ohmori, T., M. Okanishi and H. Kawaguchi. 1962. Ibid.

S. hygroscopicus subsp. hygroscopicus (Jensen 1931) Waksman and Henrici 1948

Jensen, H.L. 1931. Proceedings of the Linnean Society of New South Wales 56: 345-370; Waksman, S.A. and A.T. Henrici. 1948 in Breed, R.S., E.G.D. Murray and A.P. Hitchens (eds). Bergey's Manual of Determinative Bacteriology, 6th ed. The Williams and Wilkins Co., Baltimore. pp. 929-980. Type strain: ATCC 27438

Description: Shirling, E.B. and D. Gottlieb. 1972. International Journal of Systematic Bacteriology 22:265-394.

S. hygroscopicus subsp. ossamyceticus Schmitz, Jubinski, Hooper, Crook, Price and Lein 1965

Schmitz, H., S.D. Jubinski, I.R. Hooper, K.E. Crook Jr., K.E. Price and J. Lein. 1965. Journal of Antibiotics (Tokyo) Series A 18:82-88. Type strain: ATCC 15420

Description: Schmitz, H., S.D. Jubinski, I.R. Hooper, K.E. Crook Jr., K.E. Price and J. Lein. 1965. Ibid.

S. iakyrus deQuerioz and Albert 1962

deQuerioz, V.M. and C.A. Albert. 1962.

Revista do Instituto de Antibioticos, Universidade do Recife 4:33-46. Type strain: ATCC 15375 
Description: Shirling, E.B. and D. Gottlieb. 1972. International Journal of Systematic Bacteriology 22:265-394.

S. indigoferus Shinobu and Kawato 1960 Shinobu, R. and M. Kawato. 1960. Memoirs of the Osaka University of the Liberal Arts and Education B Natural Science 9:49-53. Type strain: ATCC 23924

Description: Shirling, E.B. and D. Gottlieb. 1968. International Journal of Systematic Bacteriology 18:279-392.

S. intermedius (Kruger 1904) Waksman 1953 Kruger, F. 1904. Arbeiten aus der Biologischen Abteilung fur Land- und Forstwirtschaft am Kaiserlichen Gesundheitsamte Band IV, Heft 3, Verlagsbuchhandlung Paul Parey, Verlagsbuchhandlung Julius Springer, Berlin. pp. 275-318; Waksman, S.A. 1953 in Waksman, S.A. and H.A. Lechevalier. Guide to the classification and identification of the Actinomycetes and their antibiotics. The Williams and Wilkins Co., Baltimore. pp. 1-246. Type strain: ATCC 3329

Description: Shirling, E.B. and D. Gottlieb. 1969. International Journal of Systematic Bacteriology 19:391-512.

S. inusitatus Hasegawa, Yamano and Masahiko 1978

Hasegawa, T., T. Yamano and Y. Masahiko. 1978. International Journal of Systematic Bacteriology 28:407-410. Type strain: IFO 13601

Description: Hasegawa, T., T. Yamano and Y. Masahiko. 1978. Ibid.

S. ipomoeae (Person and Martin 1940) Waksman and Henrici 1948

Person, L.H. and W.J. Martin. 1940. Phytopathology 30:913-926; Waksman, S.A. and A.T. Henrici. 1948 in Breed, R.S., E.G.D. Murray and A.P. Hitchens (eds). Bergey's Manual of Determinative Bacteriology, 6th ed. The Williams and Wilkins Co., Baltimore. pp. 929-980. Type strain: ATCC 25462

Description: Shirling, E.B. and D. Gottlieb. 1969. International Journal of Systematic Bacteriology 19:391-512.

S. janthinus (Artamonova and Krassilnikov 1960) Pridham 1970

Artamonova, O.I. and N.A. Krassilnikov.
1960 in Rautenshtein, Ya. I. Transactions of the Institute of Microbiology, Academy of Sciences USSR 8:1-344; Pridham, T.G. 1970. Bulletin of the United States Department of Agriculture 1424:1-55. Type strain: ATCC 15870

Description: Shirling, E.B. and D. Gottlieb. 1968. International Journal of Systematic Bacteriology 18:279-392.

S. kanamyceticus Okami and Umezawa 1957 Okami, Y. and H. Umezawa 1957 in Umezawa, H., M. Ueda, K. Maeda, K. Yagashita, S. Kondo, Y. Okami, R. Utahara, Y. Osato, K. Nitta and T. Takeuchi. Journal of Antibiotics (Tokyo) Series A 10:181-188. Type strain: ATCC 12853

Description: Shirling, E.B. and D. Gottlieb. 1972. International Journal of Systematic Bacteriology 22:265-394.

S. katrae Gupta and Chopra 1963

Gupta, K.C. and I.C. Chopra. 1963. Indian Journal of Microbiology 3:1-4. Type strain: ATCC 27.440

Description: Shirling, E.B. and D. Gottlieb. 1972. International Journal of Systematic Bacteriology 22:265-394.

S. kurssanovii (Preobrazhenskaya, Kudrina, Ryabova and Blinov 1957) Pridham, Hesseltine and Benedict 1958

Preobrazhenskaya, T.P., E.S. Kudrina, I.D. Ryabova and N.O. Blinov. 1957 in Gauze, G.F., T.P. Preobrazhenskaya, E.S. Kudrina, N.O. Blinov, I.D. Ryabova and M.A. Sveshnikova. Problems of classification of actinomycetes-antagonists. Government Publishing House of Medical Literature, Medgiz, Moscow. pp. 1-398; Pridham, T.G., C.W. Hesseltine and R.G. Benedict. 1958. Applied Microbiology 6: 52-79. Type strain: ATCC 15824

Description: Shirling, E.B. and D. Gottlieb. 1968. International Journal of Systematic Bacteriology 18:69-189.

S. lanatus Frommer 1959

Frommer, W. 1959. Archiv fur Mikrobiologie 32:187-206. Type strain: ATCC 19775

Description: Shirling, E.B. and D. Gottlieb. 1968. International Journal of Systematic Bacteriology 18:69-189.

S. lateritius (Sveshnikova 1957) Pridham, Hesseltine and Benedict 1958 
Sveshnikova, M.A. 1957 in Gauze, G.F., T.P. Preobrazhenskaya, E.S. Kudrina, N.O. Blinov, I.D. Ryabova and M.A. Sveshnikova. Problems of classification of actinomycetes-antagonists. Government Publishing House of Medical Literature, Medgiz, Moscow. pp. 1-398; Pridham, T.G., C.W. Hesseltine and R.G. Benedict. 1958. Applied Microbiology 6:52-79. Type strain: ATCC 19913

Description: Shirling, E.B. and D. Gottlieb. 1968. International Journal of Systematic Bacteriology 18:69-189.

S. laurentii Trejo, Dean, Pluscec, Meyers and Brown 1979

Trejo, W.H., L.D. Dean, J. Pluscec, E. Meyers and W.E. Brown. 1979. International Journal of Systematic Bacteriology 29:79-80; Effective publication Trejo, W.H., L.D. Dean, J. Pluscec, E. Meyers and W.E. Brown. 1977. Journal of Antibiotics 30:639-643. Type strain: ATCC 31255

Description: Trejo, W.H., L.D. Dean, J. Pluscec, E. Meyers and W.E. Brown. 1977. Ibid.

S. lavendofoliae (Kuchaeva, Krassilnikov, Taptykova and Gesheva 1961) Pridham 1970 Kuchaeva, A.G., N.A. Krassilnikov, S.D. Taptykova and R.L. Gesheva. 1961. Izvestiya $\mathrm{Na}$ Mikrobiologicheskiya Institut, Bulgarian Academy of sciences, Class of Biological sciences, Sofia 13:103-124; Pridham, T.G. 1970. Bulletin of the United States Department of Agriculture 1424:1-55. Type strain: ATCC 15872

Description: Shirling, E.B. and D. Gottlieb. 1968. International Journal of Systematic Bacteriology 18:279-392.

S. lavendulae (Waksman and Curtis 1916) Waksman and Henrici 1948

Waksman, S.A. and R.E. Curtis. 1916. Soil Science 1:99-134; Waksman, S.A. and A.T. Henrici. 1948 in Breed, R.S., E.G.D. Murray and A.P. Hitchens (eds). Bergey's Manual of Determinative Bacteriology, 6th ed. The Williams and Wilkins Co., Baltimore. pp. 929-980. Type strain: ATCC 8664

Description: Shirling, E.B. and D. Gottlieb. 1968. International Journal of Systematic Bacteriology 18:69-189.

S. lavendulae subsp. grasserius (Kuchaeva,
Krassilnikov, Taptykova and Gesheva 1961) Pridham 1970

Kuchaeva, A.G., N.A. Krassilnikov, S.D. Taptykova and R.L. Gesheva. 1961. Izvestiya $\mathrm{Na}$ Mikrobiologicheskiya Institut, Bulgarian Academy of Sciences, Class of Biological Sciences, Sofia 13:103-124; Pridham, T.G. 1970. Bulletin of the United States Department of Agriculture 1424:1-55. Type strain: ATCC 15875 Description: Bergey 8.

S. lavendulae subsp. lavendulae (Waksman and Curtis 1916) Waksman and Henrici 1948 Waksman, S.A. and R.E. Curtis. 1916. Soil Science 1:99-134; Waksman, S.A. and A.T. Henrici. 1948 in Breed, R.S., E.G.D. Murray and A.P. Hitchens (eds). Bergey's Manual of Determinative Bacteriology, 6th ed. The Williams and Wilkins Co., Baltimore. pp. 929-980. Type strain: ATCC 8664

Description: Shirling, E.B. and D. Gottlieb. 1968. International Journal of Systematic Bacteriology 18:69-189.

S. lavendulocolor (Kuchaeva, Krassilnikov, Taptykova and Gesheva 1961) Pridham 1970 Kuchaeva, A.G., N.A. Krassilnikov, S.D. Taptykova and R.L. Gesheva. 1961. Izvestiya $\mathrm{Na}$ Mikrobiologicheskiya Institut, Bulgarian Academy of sciences, Class of Biological sciences, Sofia 13:103-124; Pridham, T.G. 1970. Bulletin of the United States Department of Agriculture 1424:1-55. Type strain: ATCC 15871 Description: Bergey 8.

S. libani Baldacci and Grein 1966

Baldacci, E. and A. Grein. 1966. Giornale di Microbiologia 14:185-198. Type strain: CBS 753.72

Description: Shirling, E.B. and D. Gottlieb. 1972. International Journal of Systematic Bacteriology 22:265-394.

S. libani subsp. libani Baldacci and Grein 1966 Baldacci, E. and A. Grein. 1966. Giornale di Microbiologia 14:185-198. Type strain: CBS 753.72

Description: Shirling, E.B. and D. Gottlieb. 1972. International Journal of Systematic Bacteriology 22:265-394.

S. libani subsp. rufus Baldacci and Grein 1966 Baldacci, E. and A. Grein. 1966. Giornale di Microbiologia 14:185-198. Type strain: ATCC 23731 
Description: Bergey 8.

S. limosus Lindenbein 1952

Lindenbein, W. 1952. Archiv fur Mikrobiologie 17:361-383. Type strain: ATCC 19778

Description: Shirling, E.B. and D. Gottlieb. 1968. International Journal of Systematic Bacteriology 18:69-189.

S. lincolnensis Mason, Dietz and DeBoer 1963 Mason, D.J., A. Dietz and C. DeBoer. 1963. Antimicrobial Agents and Chemotherapy 1962:554-559. Type strain: NRRL 2936

Description: Shirling, E.B. and D. Gottlieb. 1969. International Journal of Systematic Bacteriology 19:391-512.

S. lipmanii (Waksman and Curtis 1916) Waksman and Henrici 1948

Waksman, S.A. and R.E. Curtis. 1916. Soil Science 1:99-134; Waksman, S.A. and A.T. Henrici. 1948 in Breed, R.S., E.G.D. Murray and A.P. Hitchens (eds). Bergey's Manual of Determinative Bacteriology, 6th ed. The Williams and Wilkins Co., Baltimore. pp. 929-980. Type strain: ATCC 3331

Description: Shirling, E.B. and D. Gottlieb. 1968. International Journal of Systematic Bacteriology 18:69-189.

S. litmocidini (Ryabova and Preobrazhenskaya 1957) Pridham, Hesseltine and Benedict 1958

Ryabova, I.D. and T.P. Preobrazhenskaya. 1957 in Gauze, G.F., T.P. Preobrazhenskaya, E.S. Kudrina, N.O. Blinov, I.D. Ryabova and M.A. Sveshnikova. Problems of classification of actinomycetes-antagonists. Government Publishing House of Medical Literature, Medgiz, Moscow. pp. 1-398; Pridham, T.G., C.W. Hesseltine and R.G. Benedict. 1958. Applied Microbiology 6:52-79. Type strain: ATCC 19914

Description: Shirling, E.B. and D. Gottlieb. 1968. International Journal of Systematic Bacteriology 18:69-189.

S. lomondensis Johnson and Dietz 1969

Johnson, L.E. and A. Dietz. 1969. Applied Microbiology 17:755-759. Type strain: NRRL 3252

Description: Johnson, L.E. and A. Dietz. 1969. Ibid.

S. longisporoflavus Waksman 1953
Waksman, S.A. 1953 in Waksman, S.A. and H.A. Lechevalier. Guide to the classification and identification of the Actinomycetes and their antibiotics. The Williams and Wilkins Co., Baltimore. pp. 1-246. Type strain: ATCC 19915

Description: Shirling, E.B. and D. Gottlieb. 1968. International Journal of Systematic Bacteriology 18:279-392.

S. longispororuber Waksman 1953

Waksman, S.A. 1953 in Waksman, S.A. and H.A. Lechevalier. Guide to the classification and identification of the Actinomycetes and their antibiotics. The Williams and Wilkins Co., Baltimore. pp. 1-246. Type strain: ATCC 27443

Description: Shirling, E.B. and D. Gottlieb. 1972. International Journal of Systematic Bacteriology 22:265-394.

S. longisporus (Krassilnikov 1941) Waksman 1953

Krassilnikov, N.A. 1941. Guide to the bacteria and Actinomycetes (in Russian). Akademiya Nauk SSSR, Moscow. pp. 1830; Waksman, S.A. 1953 in Waksman, S.A. and H.A. Lechevalier. Guide to the classification and identification of the Actinomycetes and their antibiotics. The Williams and Wilkins Co., Baltimore. pp. 1-246. Type strain: ATCC 23931

Description: Shirling, E.B. and D. Gottlieb. 1968. International Journal of Systematic Bacteriology 18:279-392.

S. lucensis Arcamone, Bertazzoli, Canevazzi, diMarco, Ghione and Grein 1957

Arcamone, F., C. Bertazzoli, G. Canevazzi, A. diMarco, M. Ghione and A. Grein. 1957. Giornale di Microbiologia 4:119. 128. Type strain: ATCC 17804

Description: Shirling, E.B. and D. Gottlieb. 1969. International Journal of Systematic Bacteriology 19:391-512.

S. luridus (Krassilnikov, Korenyako, Meksina, Valedinskaya and Veselov 1957) Waksman 1961

Krassilnikov, N.A., A.I. Korenyako, M.M. Meksina, L.K. Valedinskaya and N.M. Veselov. 1957. Mikrobiologiya 26:558-564; Waksman, S.A. 1961. The Actinomycetes. Vol. 2. Classification, identification and descriptions of genera and species. The Williams and Wilkins Co., Baltimore. pp. 1-363. Type strain: ATCC 19782 
Description: Shirling, E.B. and D. Gottlieb. 1968. International Journal of Systematic Bacteriology 18:69-189.

S. Iusitanus Villax 1963

Villax, I. 1963. Antimicrobial Agents and Chemotherapy 1962:661-668. Type strain: NCIB 9585

Description: Shirling, E.B. and D. Gottlieb. 1972. International Journal of Systematic Bacteriology 22:265-394.

S. luteogriseus Schmitz, Deak, Crook and Hooper 1964

Schmitz, H., S.B. Deak, K.E. Crook Jr. and I.R. Hooper. 1964. Antimicrobial Agents and Chemotherapy 1963:89-94. Type strain: ATCC 15072

Description: Shirling, E.B. and D. Gottlieb. 1972. International Journal of Systematic Bacteriology 22:265-394.

S. Iydicus De Boer, Dietz, Silver and Savage 1956

De Boer, C., A. Dietz, W.S. Silver and G.M. Savage. 1956. Antibiotics Annual 1955-1956:886-892. Type strain: NRRL 2433

Description: Shirling, E.B. and D. Gottlieb. 1969. International Journal of Systematic Bacteriology 19:391-512.

S. massasporeus Shinobu and Kawato 1959

Shinobu, R. and M. Kawato. 1959.

Botanical Magazine (Tokyo) 72:283-288.

Type strain: ATCC 19785

Description: Shirling, E.B. and D. Gottlieb. 1968. International Journal of Systematic Bacteriology 18:69-189.

S. matensis Margalith, Beretta and Timbal 1959

Margalith, P., G. Beretta and M.T. Timbal. 1959. Antiobiotics and Chemotherapy 9:71-75. Type strain: ATCC 23935

Description: Shirling, E.B. and D. Gottlieb. 1968. International Journal of Systematic Bacteriology 18:279-392.

S. mauvecolor Okami and Umezawa 1960

Okami, Y. and H. Umezawa. 1960 in Murase, M., T. Hikiji, K. Nitta, Y. Okami, T. Takeuchi and H. Umezawa. Journal of Antibiotics (Tokyo) Series A 14:113-118. Type strain: ATCC 29835

Description: Murase, M., T. Hikiji, K. Nitta, Y. Okami, T. Takeuchi and H. Umezawa. 1960. Ibid.

S. mediolani Arcamone, Camerino, Cotta,
Franceschi, Grein, Penco and Spalla 1969 Arcamone, F., B. Camerino, E. Cotta, G. Franceschi, A. Grein, S. Penco and C. Spalla. 1969. Experientia 24:241-242. Type strain: NCIB 10969

Description: Bianchi, M.L., A. Grein, P. Julita, M.P. Marnati and C. Spalla. 1970. Zeitschrift fur Allgemeine Mikrobiologie 10:237-244.

S. melanogenes Sugawara and Onuma 1957

Sugawara, A. and M. Onuma. 1957. Journal of Antibiotics (Tokyo) Series A 10:138-142. Type strain: ATCC 23937

Description: Shirling, E.B. and D. Gottlieb. 1968. International Journal of Systematic Bacteriology 18:279-392.

S. melanosporofaciens Arcamone, Bertazzoli, Ghione and Scotti 1959

Arcamone, F., C. Bertazzoli, M. Ghione and T. Scotti. 1959. Giornale di Microbiologia 7:207-216. Type strain: ATCC 25473

Description: Shirling, E.B. and D. Gottlieb. 1969. International Journal of Systematic Bacteriology 19:391-512.

S. michiganensis Corbaz, Ettlinger, KellerSchierlein and Zahner 1957

Corbaz, R., L. Ettlinger, W. KellerSchierlein and H. Zahner. 1957. Archiv fur Mikrobiologie 26:192-208. Type strain: ATCC 14970

Description: Shirling, E.B. and D. Gottlieb. 1968. International Journal of Systematic Bacteriology 18:69-189.

S. microflavus (Krainsky 1914) Waksman and Henrici 1948

Krainsky, A. 1914. Zentralblatt fur Bakteriologie, Parasitenkunde, Infektionskrankheiten und Hygiene. Abteilung II. 41:649-688; Waksman, S.A. and A.T. Henrici. 1948 in Breed, R.S., E.G.D. Murray and A.P. Hitchens (eds). Bergey's Manual of Determinative Bacteriology, 6th ed. The Williams and Wilkins Co., Baltimore. pp. 929-980. Type strain: CBS 124.18

Description: Shirling, E.B. and D. Gottlieb. 1969. International Journal of Systematic Bacteriology 19:391-512.

S. minutiscleroticus (Thirumalachar 1965) Pridham 1970

Thirumalachar, M.J. 1965 in Thirumalachar, M.J., P.W. Rahalkar, P.V. Desh- 
mukh and R.S. Sukapure. Hindustan Antibiotics Bulletin 8:6-9; Pridham, T.G. 1970. Bulletin of the United States Department of Agriculture 1424:1-55. Type strain: ATCC 17757

Description: Shirling, E.B. and D. Gottlieb. 1972. International Journal of Systematic Bacteriology 22:265-394.

S. mirabilis Ruschmann 1952

Ruschmann, G. 1952. Pharmazie 7:542550. Type strain: ATCC 27447

Description: Shirling, E.B. and D. Gottlieb. 1972. International Journal of Systematic Bacteriology 22:265-394.

S. misakiensis Nakamura 1961

Nakamura, G. 1961. Journal of Antibiotics (Tokyo) Series A 14:86-89. Type strain: ATCC 23938

Description: Shirling, E.B. and D. Gottlieb. 1968. International Journal of Systematic Bacteriology 18:279-392.

S. misionensis Cercos, Eilberg, Goyena, Souto, Vautier and Widuezynski 1962

Cercos, A.P., B.L. Eilberg, J.G. Goyena, J. Souto, E.E. Vautier and I. Widuezynski. 1962. Revista de Investigaciones Agricolas 16:5-27. Type strain: ATCC 14991

Description: Shirling, E.B. and D. Gottlieb. 1969. International Journal of Systematic Bacteriology 19:391-512.

S. murinus Frommer 1959

Frommer, W. 1959. Archiv fur Mikrobiologie 32:187-206. Type strain: ATCC 19788

Description: Shirling, E.B. and D. Gottlieb. 1968. International Journal of Systematic Bacteriology 18:69-189.

S. mutabilis (Preobrazhenskaya and Ryabova 1957) Pridham, Hesseltine and Benedict 1958

Preobrazhenskaya, T.P. and I.D. Ryabova. 1957 in Gauze, G.F., T.P. Preobrazhenskaya, E.S. Kudrina, N.O. Blinov, I.D. Ryabova and M.A. Sveshnikova. Problems of classification of actinomycetes-antagonists. Government Publishing House of Medical Literature, Medgiz, Moscow. pp. 1-398; Pridham, T.G., C.W. Hesseltine and R.G. Benedict. 1958. Applied Microbiology 6:52-79. Type strain: ATCC 19919

Description: Shirling, E.B. and D.
Gottlieb. 1968. International Journal of Systematic Bacteriology 18:69-189.

S. naganishii Yamaguchi and Saburi 1955

Yamaguchi, H. and Y. Saburi. 1955. Journal of General and Applied Microbiology 1:201-135. Type strain: ATCC 23939

Description: Shirling, E.B. and D. Gottlieb. 1968. International Journal of Systematic Bacteriology 18:279-392.

S. narbonensis Corbaz, Ettlinger, Gaumann, Keller-Schierlein, Kradolfer, Kyburz, Neipp, Prelog, Reusser and Zahner 1955

Corbaz, R., L. Ettiinger, E. Gaumann, W. Keller-Schierlein, F. Kradolfer, E. Kyburz, L. Neipp, V. Prelog, R. Reusser and H. Zahner. 1955. Helvetica Chimica Acta 38:935-942. Type strain: ATCC 19790

Description: Shirling, E.B. and D. Gottlieb. 1968. International Journal of Systematic Bacteriology 18:69-189.

S. nashvillensis McVeigh and Reyes 1961

McVeigh, I. and C.R. Reyes. 1961. Antibiotics and Chemotherapy 11:312319. Type strain: ATCC 25476

Description: Shirling, E.B. and D. Gottlieb. 1969. International Journal of Systematic Bacteriology 19:391-512.

S. neyagawaensis Yamamoto, Nakazawa, Horii and Miyake 1960

Yamamoto, H., K. Nakazawa, S. Horii and A. Miyake. 1960. Journal of the Agricultural Chemical Society of Japan 34:268-272. Type strain: ATCC 27449

Description: Shirling, E.B. and D. Gottlieb. 1972. International Journal of Systematic Bacteriology 22:265-394.

S. nigrescens (Sveshnikova 1957) Pridham, Hesseltine and Benedict 1958

Sveshnikova, M.H. 1957 in Gauze, G.F. T.P. Preobrazhenskaya, E.S. Kudrina, N.O. Blinov, I.D. Ryabova and M.A. Sveshnikova. Problems in the classification of actinomycetes-antagonists. State Publishing House of Medical Literature, Medgiz, Moscow, USSR; Pridham, T.G., C.W. Hesseltine and R.G. Benedict. 1958. Applied Microbiology 6:52-79. Type strain: ATCC 23941 .

Description: Shirling, E.B. and D. Gottlieb. 1968. International Journal of Systematic Bacteriology 18:279-392. 
S. nigrifaciens Waksman 1961

Waksman, S.A. 1961. The Actinomycetes. Vol. 2. Classification, identification and descriptions of genera and species. The Williams and Wilkins Co., Baltimore. pp. 1-363. Type strain: ATCC 19791

Description: Shirling, E.B. and D. Gottlieb. 1968. International Journal of Systematic Bacteriology 18:69-189.

S. nitrosporeus Okami 1952

Okami, Y. 1952. Classification of the antagonistic ray fungi of Japan of the family Streptomycetaceae (in Japanese). Doctoral Dissertation, Hokkaido University. Type strain: ATCC 12769

Description: Shirling, E.B. and D. Gottlieb. 1968. International Journal of Systematic Bacteriology 18:69-189.

S. niveoruber Ettlinger, Corbaz and Hutter 1958

Ettlinger, L., R. Corbaz and R. Hutter. 1958. Archiv fur Mikrobiologie 31:326358. Type strain: ATCC 14971

Description: Ettlinger, L., R. Corbaz and R. Hutter. 1958. Ibid.

S. niveus Smith, Dietz, Sokolski and Savage 1956

Smith, C.G., A. Dietz, W.T. Sokolski and G.M. Savage. 1956. Antibiotics and Chemotherapy 6:135-142. Type strain: NRRL 2466

Description: Hutter, R. 1963. Giornale di Microbiologia 11:191-246.

S. noboritoensis Isono, Yamashita, Tomiyama, Suzuki and Sakai 1957

Isoni, K., S. Yamashita, Y. Tomiyama, S. Suzuki and H. Sakai. 1957. Journal of Antibiotics (Tokyo) Series A 10:21-30. Type strain: ATCC 25477

Description: Shirling, E.B. and D. Gottlieb. 1969. International Journal of Systematic Bacteriology 19:391-512.

S. nodosus Trejo 1961

Trejo, W. 1961 in Waksman, S.A. The Actinomycetes. Vol. 2. Classification, identification and descriptions of genera and species. The Williams and Wilkins Co., Baltimore. pp. 1-363. Type strain: ATCC 14899

Description: Shirling, E.B. and D. Gottlieb. 1968. International Journal of Systematic Bacteriology 18:279-392.

S. nogalater Bhuyan and Dietz 1966
Bhuyan, B.K. and A. Dietz. 1966. Antimicrobial Agents and Chemotherapy 1965:836-844. Type strain: NRRL 3035 Description: Bhuyan, B.K. and A. Dietz. 1966. Ibid.

S. nojiriensis Ishida, Kumagai, Niida, Hamamoto and Shomura 1967

Ishida, N., K. Kumagai, T. Niida, K. Hamamoto and T. Shomura. 1967. Journal of Antibiotics (Tokyo) Series A 20:62-65. Type strain: ATCC 29781

Description: Ishida, N., K. Kumagai, T. Niida, K. Hamamoto and T. Shomura. 1967. Ibid.

S. noursei Brown, Hazen and Mason 1953

Brown, R., E.L. Hazen and A. Mason. 1953. Science 117:609-610. Type strain: ATCC 11455

Description: Ettlinger, L., R. Corbaz and R. Hutter. 1958. Archiv fur Mikrobiologie 31:326-358.

S. novaecaesareae Waksman and Henrici 1948

Waksman, S.A. and A.T. Henrici. 1948

in Breed, R.S., E.G.D. Murray and A.P.

Hitchens (eds). Bergey's Manual of Determinative Bacteriology, 6th ed. The Williams and Wilkins Co., Baltimore. pp. 929-980. Type strain: ATCC 27452

Description: Shirling, E.B. and D. Gottlieb. 1972. International Journal of Systematic Bacteriology 22:265-394.

S. ochraceiscleroticus Pridham 1970

Pridham, T.G. 1970. Bulletin of the United States Department of Agriculture 1424:1-55. Type strain: ATCC 15814

Description: Shirling, E.B. and D. Gottlieb. 1972. International Journal of Systematic Bacteriology 22:265-394.

S. odorifer (Rullmann 1895) Waksman 1953

Rullmann, W. 1895. Inaugural Dissertation. Akademische Buchdruckerei von $F$. Strauv, Munchen, pp. 1-47; Waksman, S.A. 1953 in Waksman, S.A. and H.A. Lechevalier. Guide to the classification and identification of the Actinomycetes and their antibiotics. The Williams and Wilkins Co., Baltimore. pp. 1-246. Type strain: ATCC 6246

Description: Shirling, E.B. and D. Gottlieb. 1972. International Journal of Systematic Bacteriology 22:265-394.

S. olivaceiscleroticus Pridham 1970

Pridham, T.G. 1970. Bulletin of the 
United States Department of Agriculture 1424:1-55. Type strain: ATCC 15722

Description: Shirling, E.B. and D. Gottlieb. 1972. International Journal of Systematic Bacteriology 22:265-394.

S. olivaceoviridis (Preobrazhenskaya and Ryabova 1957) Pridham, Hesseltine and Benedict 1958

Preobrazhenskaya, T.P. and I.D. Ryabova. 1957 in Gauze, G.F., T.P. Preobrazhenskaya, E.S. Kudrina, N.O. Blinov, I.D. Ryabova and M.A. Sveshnikova. Problems of classification of actinomycetesantagonists. Government Publishing House of Medical Literature, Medgiz, Moscow. pp. 1-398; Pridham, T.G., C.W. Hesseltine and R.G. Benedict. 1958. Applied Microbiology 6:52-79. Type strain: ATCC 23630

Description: Shirling, E.B. and D. Gottlieb. 1969. International Journal of Systematic Bacteriology 19:391-512.

S. olivaceus (Waksman 1923) Waksman and Henrici 1948

Waksman, S.A. 1923 in Bergey, D.H., F.C. Harrison, R.S. Breed, B.W. Hammer and F.M. Huntoon. Bergey's Manual of Determinative Bacteriology, 1st ed. The Williams and Wilkins Co., Baltimore. pp. 339-371; Waksman, S.A. and A.T. Henrici. 1948 in Breed, R.S., E.G.D. Murray and A.P. Hitchens (eds). Bergey's Manual of Determinative Bacteriology, 6th ed. The Williams and Wilkins Co., Baltimore. pp. 929-980. Type strain: ATCC 3335

Description: Shirling, E.B. and D. Gottlieb. 1968. International Journal of Systematic Bacteriology 18:68-189.

S. olivochromogenes (Waksman 1923) Waksman and Henrici 1948

Waksman, S.A. 1923 in Bergey, D.H., F.C. Harrison, R.S. Breed, B.W. Hammer and F.M. Huntoon. Bergey's Manual of Determinative Bacteriology, 1st ed. The Williams and Wilkins Co., Baltimore. pp. 339-371; Waksman, S.A. and A.T. Henrici. 1948 in Breed, R.S., E.G.D. Murray and A.P. Hitchens (eds). Bergey's Manual of Determinative Bacteriology, 6th ed. The Williams and Wilkins Co., Baltimore. pp. 929-980. Type strain: ATCC 3336
Description: Shirling, E.B. and D. Gottlieb. 1969. International Journal of Systematic Bacteriology 19:391-512.

S. olivoviridis (Kuchaeva, Krassilnikov, Skryabin and Taptykova 1960) Pridham 1970

Kuchaeva, A.G., N.A. Krassilnikov, G.K. Skryabin and S.D. Taptykova. 1960 in Rautenshtein, Ya. I. Transactions of the Institute of Microbiology, Academy of Sciences USSR 8:1-344; Pridham, T.G. 1970. Bulletin of the United States Department of Agriculture 1424:1-55. Type strain: ATCC 15882

Description: Shirling, E.B. and D. Gottlieb. 1968. International Journal of Systematic Bacteriology 18:279-392.

S. omiyaensis Umezawa and Okami 1950

Umezawa, H. and Y. Okami. 1950 in Umezawa, H., T. Tazaki, Y. Okami and S. Fukuyama. Journal of Antibiotics (Tokyo) 3:292-296. Type strain: ATCC 27454

Description: Shirling, E.B. and D. Gottlieb. 1972. International Journal of Systematic Bacteriology 22:265-394.

S. pactum Bhuyan, Dietz and Smith 1962 Bhuyan, B.K., A. Dietz and C.G. Smith. 1962. Antimicrobial Agents and Chemotherapy 1961:184-190. Type strain: NRRL 2939

Description: Bhuyan, B.K., A. Dietz and C.G. Smith. 1962. Ibid.

S. parvullus Waksman and Gregory 1954

Waksman, S.A. and F.J. Gregory. 1954. Antibiotics and Chemotherapy 4:10501056. Type strain: ATCC 12434

Description: Shirling, E.B. and D. Gottlieb. 1968. International Journal of Systematic Bacteriology 18:69-189.

S. parvus (Krainsky 1914) Waksman and Henrici 1948

Krainsky, A. 1914. Zentralblatt fur Bakteriologie, Parasitenkunde, Infektionskrankheiten und Hygiene. Abteilung II. 41:649-688; Waksman, S.A. and A.T. Henrici. 1948 in Breed, R.S., E.G.D. Murray and A.P. Hitchens (eds). Bergey's Manual of Determinative Bacteriology, 6th ed. The Williams and Wilkins Co., Baltimore. pp. 929-980. Type strain: NRRL B-1455

Description: Shirling, E.B. and D. Gottlieb. 1972. International Journal of 
Systematic Bacteriology 22:265-394.

S. peucetius Grein, Spalla, Di Marco and Canevazzi 1963

Grein, A., C. Spalla, A. Di Marco and G. Canevazzi. 1963. Giornale de Microbiologia 11:109-118. Type strain: ATCC 29050 Description: Bergey 8.

S. phaeochromogenes (Conn 1917) Waksman 1957

Conn, H.J. 1917. Bulletin of the New York State Agricultural Experiment Station 60:3-25; Waksman, S.A. 1957 in Breed, R.S., E.G.D. Murray and N.R. Smith (eds). Bergey's Manual of Determinative Bacteriology, 7th ed. The Williams and Wilkins Co., Baltimore. p. 778. Type strain: ATCC 3338

Description: Ettlinger, L., R. Corbaz and R. Hutter. 1958. Archiv fur Mikrobiologie 32:326-358.

S. phaeofaciens Maeda, Okami, Taya and Umezawa 1952

Maeda, K., Y. Okami, O. Taya and H. Umezawa. 1952. Japanese Medical Journal 5:237-338. Type strain: ATCC 15034

Description: Shirling, E.B. and D. Gottlieb. 1972. International Journal of Systematic Bacteriology 22:265-394.

S. phaeopurpureus Shinobu 1957

Shinobu, R. 1957. Memoirs of the Osaka University of the Liberal Arts and Education B Natural Science 6:63-73. Type strain: ATCC 23946

Description: Shirling, E.B. and D. Gottlieb. 1968. International Journal of Systematic Bacteriology 18:279-392.

S. phaeoviridis Shinobu 1957

Shinobu, R. 1957. Memoirs of the Osaka University of the Liberal Arts and Education B Natural Science 6:63-73. Type strain: ATCC 23947

Description: Shirling, E.B. and D. Gottlieb. 1968. International Journal of Systematic Bacteriology 18:279-392.

S. pilosus Ettlinger, Corbaz and Hutter 1958

Ettlinger, L., R. Corbaz and R. Hutter. 1958. Archiv fur Mikrobiologie 31:326358. Type strain: ATCC 19797

Description: Shirling, E.B. and D. Gottlieb. 1968. International Journal of Systematic Bacteriology 18:69-189.

S. platensis Tresner and Backus 1956

Tresner, H.D. and E.J. Backus. 1956.
Applied Microbiology 4:243-250. Type strain: NRRL 2364

Description: Shirling, E.B. and D. Gottlieb. 1968. International Journal of Systematic Bacteriology 18:279-392.

S. plicatus Pridham, Hesseltine and Benedict 1958

Pridham, T.G., C.W. Hesseltine and R.G. Benedict. 1958. Applied Microbiology 6: 52-79. Type strain: NRRL 2428

Description: Shirling, E.B. and D. Gottlieb. 1969. International Journal of Systematic Bacteriology 19:391-512.

S. pluricolorescens Okami and Umezawa 1961 Okami, Y. and H. Umezawa. 1961 in Waksman, S.A. The Actinomycetes. Vol. 2. Classification, identification and descriptions of genera and species. The Williams and Wilkins Co., Baltimore. pp. 259-260. Type strain: ATCC 19798

Description: Shirling, E.B. and D. Gottlieb. 1968. International Journal of Systematic Bacteriology 18:69-189.

S. polychromogenes Hageman, Penasse and Teillon 1964

Hageman, G., L. Penasse and J. Teillon. 1964 in Hutter, R. Zentralblatt fur Bakteriologie, Parasitenkunde, Infektionskrankheiten und Hygiene. Abteilung II. 117:603- 661. Type strain: ATCC 12595 Description: Shirling, E.B. and D. Gottlieb. 1969. International Journal of Systematic Bacteriology 19:391-512.

S. poonensis (Thirumalachar 1960) Pridham 1970

Thirumalachar, M.J. 1960 in Kalakoutskii, L.V. and N.A. Krassilnikov in Rautenshtein, Ya. I. Transactions of the Institute of Microbiology, Academy of Sciences USSR 8:1-344; Pridham, T.G. 1970. Bulletin of the United States Department of Agriculture 1424:1-55. Type strain: ATCC 15723

Description: Shirling, E.B. and D. Gottlieb. 1972. International Journal of Systematic Bacteriology 22:265-394.

S. praecox (Millard and Burr 1926) Waksman 1953

Millard, W.A. and S. Burr. 1926. Annals of Applied Biology 13:580-644; Waksman, S.A. 1953 in Waksman, S.A. and H.A. Lechevalier. Guide to the classification and identification of the Actinomycetes 
and their antibiotics. The Williams and Wilkins Co., Baltimore. pp. 1-246. Type strain: ATCC 3374

Description: Shirling, E.B. and D. Gottlieb. 1969. International Journal of Systematic Bacteriology 19:391-512.

S. prasinopilosus Ettlinger, Corbaz and Hutter 1958

Ettlinger, L., R. Corbaz and R. Hutter. 1958. Archiv fur Mikrobiologie 31:326358. Type strain: ATCC 19799

Description: Shirling, E.B. and D. Gottlieb. 1968. International Journal of Systematic Bacteriology 18:69-189.

S. prasinosporus Tresner, Hayes and Backus 1966

Tresner, H., J.A. Hayes and E.J. Backus. 1966. International Journal of Systematic Bacteriology 16:161-169. Type strain: ATCC 17918

Description: Tresner, H., J.A. Hayes and E.J. Backus. 1966. Ibid.

S. prasinus Ettlinger, Corbaz and Hutter 1958

Ettlinger, L., R. Corbaz and R. Hutter. 1958. Archiv fur Mikrobiologie 31:326358. Type strain: ATCC 19800

Description: Ettlinger, L., R. Corbaz and R. Hutter. 1958. Ibid.

S. prunicolor (Ryabova and Preobrazhenskaya 1957) Pridham, Hesseltine and Benedict 1958

Ryabova, I.D. and T.P. Preobrazhenskaya. 1957 in Gauze, G.F., T.P. Preobrazhenskaya, E.S. Kudrina, N.O. Blinov, I.D. Ryabova and M.A. Sveshnikova. Problems of classification of actinomycetes-antagonists. Government Publishing House of Medical Literature, Medgiz, Moscow. pp. 1-398; Pridham, T.G., C.W. Hesseltine and R.G. Benedict. 1958. Applied Microbiology 6:52-79. Type strain: ATCC 25487

Description: Shirling, E.B. anD D. Gottlieb. 1969. International Journal of Systematic Bacteriology 19:391-512.

S. psammoticus Virgilio and Hengeller 1960

Virgilio, A. and C. Hengeller. 1960.

Farmaco, Edizione Scientifica 15:164-174.

Type strain: CBS 175.61

Description: Shirling, E.B. and D. Gottlieb. 1969. International Journal of Systematic Bacteriology 19:391-512.

S. pseudogriseolus Okami and Umezawa 1955
Okami, Y. and H. Umezawa. 1955 in Okami, Y., R. Utahara, H. Oyagi, S. Makamura, H. Umezawa, K. Yanagisawa and Y. Tsunematsu. Journal of Antibiotics (Tokyo) Series A 8:126-131. Type strain: ATCC 12770

Description: Hutter, R. 1967. Systematik der Streptomyceten unter besonderer Berucksichtigung der von ihnen gebildeten Antibiotica. Bibl. Microbiol. Fasc. 6,5. Karger AG, Basel, Switzerland. pp. 262288.

S. pseudovenezuelae (Kuchaeva, Krassilnikov, Taptykova and Gesheva 1961) Pridham 1970

Kuchaeva, A.G., N.A. Krassilnikov, S.D. Taptykova and R.L. Gesheva. 1961. Izvestiya $\mathrm{Na}$ Mikrobiologicheskiya Institut, Bulgarian Academy of Sciences, Class of Biological Sciences, Sofia 13:103-124; Pridham, T.G. 1970. Bulletin of the United States Department of Agriculture 1424:1-55. Type strain: ATCC 23951

Description: Shirling, E.B. and D. Gottlieb. 1968. International Journal of Systematic Bacteriology 18:279-392.

S. pulveraceus Shibata, Higashide, Kanzaki, Yamamoto and Nakazawa 1961

Shibata, M., E. Higashide, T. Kanzaki, H. Yamamoto and K. Nakazawa. 1961. Agricultural and Biological Chemistry 25: 171-175. Type strain: ATCC 13875

Description: Shibata, M., E. Higashide, T. Kanzaki, H. Yamamoto and K. Nakazawa. 1961. Ibid.

S. puniceus Patelski 1951

Patelski, R.A. 1951 in Routien, J.B. and A. Hofmann. Antibiotics and Chemotherapy 1:387-389. Type strain: ATCC 19801 Description: Hutter, R. 1963. Giornale di Microbiologia 11:191-246.

S. purpeofuscus Yamaguichi and Saburi 1955 Yamaguichi, T. and Y. Saburi. 1955. Journal of General and Applied Microbiology 1:201-235. Type strain: ATCC 23952

Description: Shirling, E.B. and D. Gottlieb. 1968. International Journal of Systematic Bacteriology 18:279-392.

S. purpurascens Lindenbein 1952

Lindenbein, W. 1952. Archiv fur Mikrobiologie 17:361-383. Type strain: ATCC 25489 
Description: Shirling, E.B. and D. Gottlieb. 1969. International Journal of Systematic Bacteriology 19:391-512.

S. purpurogeneiscleroticus Pridham 1970

Pridham, T.G. 1970. Bulletin of the United States Department of Agriculture 1424:1-55. Type strain: ATCC 19348

Description: Shirling, E.B. and D. Gottlieb. 1972. International Journal of Systematic Bacteriology 22:265-394.

S. racemochromogenes Sugai 1956

Sugai, T. 1956. Journal of Antibiotics (Tokyo) Series B 9:170-179. Type strain: ATCC 23954

Description: Shirling, E.B. and D. Gottlieb. 1968. International Journal of Systematic Bacteriology 18:279-392.

S. rameus Shibata 1959

Shibata, M. 1959. Journal of Antibiotics (Tokyo) Series B 12:398-400. Type strain: ATCC 21273

Description: Shibata, M. 1959. Ibid.

S. ramulosus Ettlinger, Gaumann, Hutter, Keller-Schierlein, Kradolfer, Neipp, Prelog and Zahner 1958

Ettlinger, L., E. Gaumann, R. Hutter, W. Keller-Schierlein, F. Kradolfer, L. Neipp, V. Prelog and H. Zahner. 1958. Helvetica Chimica Acta 41:216-219. Type strain: ATCC 19802

Description: Ettlinger, L., E. Gaumann, R. Hutter, W. Keller-Schierlein, F. Kradolfer, L. Neipp, V. Prelog and H. Zahner. 1958. Ibid.

S. rangoon (Erikson 1935) Pridham, Hesseltine and Benedict 1958

Erikson, D. 1935. Medical Research Council (Great Britain) Special Report Series 203:5-61; Pridham, T.G., C.W. Hesseltine and R.G. Benedict. 1958. Applied Microbiology 6:52-79. Type strain: ATCC 6860

Description: Shirling, E.B. and D. Gottlieb. 1969. International Journal of Systematic Bacteriology 19:391-512.

S. recifensis (Goncalves de Lima, Machado, Araujo, Falcao de Morais and Biermann 1955) Falcao de Morais, Goncalves de Lima and Dalia Maia 1957

Goncalves de Lima, O., M.P. Machado, L. de A. Araujo, J.O. Falcao de Morais and H. Biermann. 1955. Anais da Sociedade de Biologia de Pernambuco 13:
21-36; Falcao de Morais, J.O., O. Goncalves de Lima and M.H. Dalia Maia. 1957. Anais da Sociedade de Biologia de Pernambuco 15:239-253. Type strain: ATCC 19803

Description: Shirling, E.B. and D. Gottlieb. 1968. International Journal of Systematic Bacteriology 18:69-189.

S. regensis Gupta, Sobti and Chopra 1963

Gupta, K.C., R.R. Sobti and I.C. Chopra. 1963. Hindustan Antibiotics Bulletin 6:12-

16. Type strain: ATCC 27461

Description: Shirling, E.B. and D. Gottlieb. 1972. International Journal of Systematic Bacteriology 22:265-394.

S. resistomycificus Lindenbein 1952

Lindenbein, W. 1952. Archiv fur Mikrobiologie 17:361-383. Type strain: NRRL 2290

Description: Shirling, E.B. and D. Gottlieb. 1968. International Journal of Systematic Bacteriology 18:69-189.

S. rimosus Sobin, Finlay and Kane 1953

Sobin, B.A., A.C. Finlay and J.H. Kane. 1953 in Waksman, S.A. and H.A. Lechevalier. Guide to the classification and identification of the Actinomycetes and their antibiotics. The Williams and Wilkins Co., Baltimore. pp. 1-246. Type strain: NRRL 2234

Description: Shirling, E.B. and D. Gottlieb. 1968. International Journal of Systematic Bacteriology 18:279-392.

S. rimosus subsp. paromomycinus Coffey, Anderson, Fisher, Galbraith, Hillegas, Kohberger, Thompson, Weston and Ehrlich 1959

Coffey, G.L., L.E. Anderson, M.W. Fisher, M.M. Galbraith, A.B. Hillegas, D.L. Kohberger, P.E. Thompson, K.S. Weston and J. Ehrlich. 1959. Antibiotics and Chemotherapy 9:730-738. Type strain: NRRL 2455

Description: Bergey 8.

S. rimosus subsp. rimosus Sobin, Finlay and Kane 1953

Sobin, B.A., A.C. Finlay and J.H. Kane. 1953 in Waksman, S.A. and H.A. Lechevalier. Guide to the classification and identification of the Actinomycetes and their antibiotics. The Williams and Wilkins Co., Baltimore. pp. 1-246. Type strain: NRRL 2234 
Description: Shirling, E.B. and D. Gottlieb. 1968. International Journal of Systematic Bacteriology 18:279-392.

S. rishiriensis Kawaguchi, Tsukiura, Okanishi, Miyaki, Ohmori, Fujisawa and Koshiyama 1965

Kawaguchi, H., H. Tsukiura, M. Okanishi, T. Miyaki, T. Ohmori, K. Fujisawa and H. Koshiyama. 1965. Journal of Antibiotics (Tokyo) Series A 18:1-10. Type strain: ATCC 14812

Description: Shirling, E.B. and D. Gottlieb. 1972. International Journal of Systematic Bacteriology 22:265-394.

S. rochei Berger, Jampolsky and Goldberg 1953 Berger, J., L.M. Jampolsky and M.W. Goldberg. 1953 in Waksman, S.A. and H.A. Lechevalier. Guide to the classification and identification of the Actinomycetes and their antibiotics. The Williams and Wilkins Co., Baltimore. pp. 1-246. Type strain: ATCC 10739

Description: Shirling, E.B. and D. Gottlieb. 1968. International Journal of Systematic Bacteriology 18:279-392.

S. roseiscleroticus Pridham 1970

Pridham, T.G. 1970. Bulletin of the United States Department of Agriculture 1424:1-55. Type strain: ATCC 17755

Description: Shirling, E.B. and D. Gottlieb. 1972. International Journal of Systematic Bacteriology 22:265-394.

S. roseodiastaticus (Duche 1934) Waksman 1953

Duche, J. 1934. Encyclopedie Mycologique 6:1-375; Waksman, S.A. 1953 in Waksman, S.A. and H.A. Lechevalier. Guide to the classification and identification of the actinomycetes and their antibiotics. The Williams and Wilkins Co., Baltimore. pp. 1-246. Type strain: CBS 102.34

Description: Ettlinger, L., R. Corbaz and R. Hutter. 1958. Archiv fur Mikrobiologie 31:326-358.

S. roseoflavus Arai 1951

Arai, T. 1951. Journal of Antibiotics (Tokyo) Series A 4:215-221. Type strain: NRRL B-2789

Description: Shirling, E.B. and D. Gottlieb. 1972. International Journal of Systematic Bacteriology 22:265-394.

S. roseofulvus (Preobrazhenskaya 1957) Prid- ham, Hesseltine and Benedict 1958

Preobrazhenskaya, T.P. 1957 in Gauze, G.F., T.P. Preobrazhenskaya, E.S. Kudrina, N.O. Blinov, I.D. Ryabova and M.A. Sveshnikova. Problems of classification of actinomycetes-antagonists. Government Publishing House of Medical Literature Medgiz, Moscow. pp. 1-398; Pridham, T.G., C.W. Hesseltine and R.G. Benedict. 1958. Applied Microbiology 6:52-79. Type strain: ATCC 19921

Description: Shirling, E.B. and D. Gottlieb. 1968. International Journal of Systematic Bacteriology 18:69-189.

S. roseolilacinus (Preobrazhenskaya and Sveshnikova 1957) Pridham, Hesseltine and Benedict 1958

Preobrazhenskaya, T.P. and M.A. Sveshnikova. 1957 in Gauze, G.F., T.P. Preobrazhenskaya, E.S. Kudrina, N.O. Blinov, I.D. Ryabova and M.A. Sveshnikova. Problems of classification of actinomycetes-antagonists. Government Publishing House of Medical Literature, Medgiz, Moscow. pp. 1-398; Pridham, T.G., C.W. Hesseltine and R.G. Benedict. 1958. Applied Microbiology 6:52-79. Type strain: ATCC 19922

Description: Shirling, E.B. and D. Gottlieb. 1968. International Journal of Systematic Bacteriology 18:69-189.

S. roseolus (Preobrazhenskaya and Sveshnikova 1957) Pridham, Hesseltine and Benedict 1958

Preobrazhenskaya, T.P. and M.A. Sveshnikova. 1957 in Gauze, G.F., T.P. Preobrazhenskaya, E.S. Kudrina, N.O. Blinov, I.D. Ryabova and M.A. Sveshnikova. Problems of classification of actinomycetes-antagonists. Government Publishing House of Medical Literature, Medgiz, Moscow. pp. 1-398; Pridham, T.G., C.W. Hesseltine and R.G. Benedict. 1968. Applied Microbiology 6:52-79. Type strain: ATCC 23210

Description: Shirling, E.B. and D. Gottlieb. 1968. International Journal of Systematic Bacteriology 18:69-189.

S. roseosporus Falcao de Morais and Dalia Maia 1961

Falcao de Morais, J.O. and M.H. Dalia Maia. 1961. Revista do Instituto de Antibioticos, Universidade do Recife 3:33- 
60. Type strain: ATCC 23958

Description: Shirling, E.B. and D. Gottlieb. 1968. International Journal of Systematic Bacteriology 18:279-392.

S. roseoviolaceus (Sveshnikova 1957) Pridham, Hesseltine and Benedict 1958

Sveshnikova, M.A. 1957 in Gauze, G.F., T.P. Preobrazhenskaya, E.S. Kudrina, N.O. Blinov, I.D. Ryabova and M.A. Sveshnikova. Problems of classification of actinomycetes-antagonists. Government Publishing House of Medical Literature, Medgiz, Moscow. pp. 1-398; Pridham, T.G., C.W. Hesseltine and R.G. Benedict. 1958. Applied Microbiology 6:52-79. Type strain: ATCC 25493

Description: Shirling, E.B. and D. Gottlieb. 1969. International Journal of Systematic Bacteriology 19:391-512.

S. roseoviridis (Preobrazhenskaya 1957) Pridham, Hesseltine and Benedict 1958

Preobrazhenskaya, T.P. 1957 in Gauze, G.F., T.P. Preobrazhenskaya, E.S. Kudrina, N.O. Blinov, I.D. Ryabova and M.A. Sveshnikova. Problems of classification of actinomycetes-antagonists. Government Publishing House of Medical Literature, Medgiz, Moscow. pp. 1-398; Pridham, T.G., C.W. Hesseltine and R.G. Benedict. 1958. Applied Microbiology 6:52-79. Type strain: ATCC 23959

Description: Shirling, E.B. and D. Gottlieb. 1968. International Journal of Systematic Bacteriology 18:279-392.

S. rubiginosohelvolus (Kudrina 1957) Pridham, Hesseltine and Benedict 1958

Kudrina, E.S. 1957 in Gauze, G.F., T.P. Preobrazhenskaya, E.S. Kudrina, N.O. Blinov, I.D. Ryabova and M.A. Sveshnikova. Problems of classification of actinomycetes-antagonists. Government Publishing House of Medical Literature, Medgiz, Moscow. pp. 1-398; Pridham, T.G., C.W. Hesseltine and R.G. Benedict. 1958. Applied Microbiology 6:52-79. Type strain: ATCC 19926

Description: Shirling, E.B. and D. Gottlieb. 1968.

S. rubiginosus (Preobrazhenskaya, Blinov and Ryabova 1957) Pridham, Hesseltine and Benedict 1958

Preobrazhenskaya, T.P., N.O. Blinov and I.D. Ryabova. 1957 in Gauze, G.F., T.P.
Preobrazhenskaya, E.S. Kudrina, N.O. Blinov, I.D. Ryabova and M.A. Sveshnikova. Problems of classification of actinomycetes-antagonists. Government Publishing House of Medical Literature, Medgiz, Moscow. pp. 1-398; Pridham, T.G., C.W. Hesseltine and R.G. Benedict. 1958. Applied Microbiology 6:52-79. Type strain: ATCC 19927

Description: Shirling, E.B. and D. Gottlieb. 1968. International Journal of Systematic Bacteriology 18:279-392.

S. rutgersensis (Waksman and Curtis 1916) Waksman and Henrici 1948

Waksman, S.A. and R.E. Curtis. 1916. Soil Science 1:99-134; Waksman, S.A. and A.T. Henrici. 1948 in Breed, R.S., E.G.D. Murray and A.P. Hitchens (eds). Bergey's Manual of Determinative Bacteriology, 6th ed. The Williams and Wilkins Co., Baltimore. pp. 929-980. Type strain: ATCC 3350

Description: Shirling, E.B. and D. Gottlieb. 1968. International Journal of Systematic Bacteriology 18:69-189.

S. rutgersensis subsp. castelarense Cercos 1954 Cercos, A.P. 1954. Revista de Investigaciones Agricolas 8:263-283. Type strain: ATCC 15191

Description: Bergey 8.

S. rutgersensis subsp. rutgersensis (Waksman and Curtis 1916) Waksman and Henrici 1948

Waksman, S.A. and R.E. Curtis. 1916. Soil Science 1:99-134; Waksman, S.A. and A.T. Henrici. 1948 in Breed, R.S., E.G.D. Murray and A.P. Hitchens (eds). Bergey's Manual of Determinative Bacteriology, 6th ed. The Williams and Wilkins Co., Baltimore. pp. 929-980. Type strain: ATCC 3350

Description: Shirling, E.B. and D. Gottlieb. 1968. International Journal of Systematic Bacteriology 18:69-189.

S. sampsonii (Millard and Burr 1926) Waksman 1953

Millard, W.A. and S. Burr. 1926. Annals of Applied Biology 13:580-644; Waksman, S.A. 1953 in Waksman, S.A. and H.A. Lechevalier. Guide to the classification and identification of the actinomycetes and their antibiotics. The Williams and Wilkins Co., Baltimore. pp. 1-246. Type 
strain: ATCC 25495

Description: Shirling, E.B. and D. Gottlieb. 1969. International Journal- of Systematic Bacteriology 19:391-512.

S. sclerotialus Pridham 1970

Pridham, T.G. 1970. Bulletin of the United States Department of Agriculture 1424:1-55. Type strain: ATCC 15721

Description: Shirling, E.B. and D. Gottlieb. 1972. International Journal of Systematic Bacteriology 22:265-394.

S. setonii (Millard and Burr 1926) Waksman 1953

Millard, W.A. and S. Burr. 1926. Annals of Applied Biology 13:580-644; Waksman, S.A. 1953 in Waksman, S.A. and H.A. Lechevalier. Guide to the classification and identification of the actinomycetes and their antibiotics. The Williams and Wilkins Co., Baltimore. pp. 1-246. Type strain: ATCC 25497

Description: Shirling, E.B. and D. Gottlieb. 1972. International Journal of Systematic Bacteriology 22:265-394.

S. showdoensis Nishimura, Mayama, Komatsu, Kato, Shimaoka and Tanaka 1964

Nishimura, H., M. Mayama, Y. Komatsu, H. Kato, N. Shimaoka and Y. Tanaka. 1964. Journal of Antibiotics (Tokyo) Series A 17:148-155. Type strain: ATCC 15105

Description: Shirling, E.B. and D. Gottlieb. 1972. International Journal of Systematic Bacteriology 22:265-394.

S. sindenensis Nakazawa and Fujii 1957

Nakazawa, K. and S. Fujii. 1957. Annual Report Takeda Research Labcratory 16: 109-110. Type strain: ATCC 23963

Description: Shirling, E.B. and D. Gottlieb. 1968. International Journal of Systematic Bacteriology 18:279-392.

S. sioyaensis Nishimura, Okamoto, Mayama, Ohtsuka, Nakajima, Tawara, Shimohira and Shimaoka 1961

Nishimura, H., S. Okamoto, M. Mayama, H. Ohtsuka, K. Nakajima, K. Tawara, M. Shimohira and N. Shimaoka. 1961. Journal of Antibiotics (Tokyo) Series A 14:255-263. Type strain: ATCC 13989

Description: Shirling, E.B. and D. Gottlieb. 1968. International Journal of Systematic Bacteriology 18:69-189.

S. somaliensis (Brumpt 1906) Waksman and
Henrici 1948

Brumpt, E. 1906. Archives de Parasitologie 10:489-527; Waksman, S.A. and A.T. Henrici. 1948 in Breed, R.S., E.G.D. Murray and A.P. Hitchens (eds). Bergey's Manual of Determinative Bacteriology, 6th ed. The Williams and Wilkins Co., Baltimore. pp. 929-980. Type strain: ATCC 33201

Description: Waksman, S.A. and A.T. Henrici. 1948. Ibid.

S. sparsogenes Owen, Dietz and Camiener 1963 Owen, S.P., A. Dietz and G.W. Camiener. 1963. Antimicrobial Agents and Chemotherapy 1962:772-779. Type strain: NRRL 2940

Description: Shirling, E.B. and D. Gottlieb. 1969. International Journal of Systematic Bacteriology 19:391-512.

S. spectabilis Mason, Dietz and Smith 1961

Mason, D.J., A. Dietz and R.M. Smith. 1961. Antibiotics and Chemotherapy 11: 118-122. Type strain: NRRL 2494

Description: Shirling, E.B. and D. Gottlieb. 1972. International Journal of Systematic Bacteriology 22:265-394.

S. spheroides Wallick, Harris, Reagan, Ruger and Woodruff 1956

Wallick, H., D.A. Harris, M.A. Reagan, M. Ruger and H.B. Woodruff. 1956. Antibiotics Annual 1955-56:909-917. Type strain: NRRL 2449

Description: Shirling, E.B. and D. Gottlieb. 1968. International Journal of Systematic Bacteriology 18:279-392.

S. spiroverticillatus Shinobu 1958

Shinobu, R. 1958. Botanical Magazine (Tokyo) 71:87-93. Type strain: ATCC 19811

Description: Shirling, E.B. and D. Gottlieb. 1968. International Journal of Systematic Bacteriology 18:69-189.

S. subrutilus Arai, Kuroda, Yamagishi and Katoh 1964

Arai, T., S. Kuroda, S. Yamagishi and Y. Katoh. 1964. Journal of Antibiotics (Tokyo) Series A 17:23-28. Type strain: ATCC 27467

Description: Shirling, E.B. and D. Gottlieb. 1972. International Journal of Systematic Bacteriology 22:265-394.

S. sulphureus (Gasperini 1894) Waksman 1953 Gasperini, G. 1894. Processi verbali della 
Societa Toscana di Scienze naturali di Pisa 9:64-89; Waksman, S.A. 1953 in Waksman, S.A. and H.A. Lechevalier. Guide to the classification and identification of the actinomycetes and their antibiotics. The Williams and Wilkins Co., Baltimore. pp. 1-246. Type strain: ATCC 27468

Description: Shirling, E.B. and D. Gottlieb. 1972. International Journal of Systematic Bacteriology 22:265-394.

S. tanashiensis Hata, Ohki and Higuchi 1952 Hata, T., N. Ohki and T. Higuchi. 1952. Journal of Antibiotics (Tokyo) Series A 5:529-534. Type strain: ATCC 23967

Description: Shirling, E.B. and D. Gottlieb. 1968. International Journal of Systematic Bacteriology 18:279-392.

S. tendae Ettlinger, Corbaz and Hutter 1958 Ettlinger, L., R. Corbaz and R. Hutter. 1958. Archiv fur Mikrobiologie 31:326358. Type strain: ATCC 19812

Description: Ettlinger, L., R. Corbaz and R. Hutter. 1958. Ibid.

S. termitum Duche, Heim and Laboureur 1951 Duche, J., R. Heim and P. Laboureur. 1951 in Heim, R. Bulletin de la Societe Mycologique France 67:359-364. Type strain: ATCC 25499

Description: Shirling, E.B. and D. Gottlieb. 1969. International Journal of Systematic Bacteriology 19:391-512.

S. thermodiastaticus (Bergey, Harrison, Breed, Hammer and Huntoon 1923) Waksman 1953

Bergey, D.H., F.C. Harrison, R.S. Breed, B.W. Hammer and F.M. Huntoon. 1923. Bergey's Manual of Determinative Bacteriology, 1st ed. The Williams and Wilkins Co., Baltimore. pp. 1-442; Waksman, S.A. 1953 in Waksman, S.A. and H.A. Lechevalier. Guide to the classification and identification of the actinomycetes and their antibiotics. The Williams and Wilkins Co., Baltimore. pp. 1-246. Type strain: ATCC 27472

Description: Shirling, E.B. and D. Gottlieb. 1972. International Journal of Systematic Bacteriology 22:265-394.

S. thermonitrificans Desai and Dhala 1967

Desai, A.J. and S.A. Dhala. 1967. Antonie van Leeuwenhoek Journal of Microbiology and Serology 33:137-144.
Type strain: ATCC 23385

Description: Shirling, E.B. and D. Gottlieb. 1972. International Journal of Systematic Bacteriology 22:265-394.

S. thermoviolaceus Henssen 1957

Henssen, A. 1957. Archiv fur Mikrobiologie 26:373-414. Type strain: ATCC 19283 Description: Shirling, E.B. and D. Gottlieb. 1972. International Journal of Systematic Bacteriology 22:265-394.

S. thermoviolaceus subsp. apingens Henssen 1957

Henssen, A. 1957. Archiv fur Mikrobiologie 26:373-414. Type strain: ATCC 19994 Description: Bergey 8.

S. thermoviolaceus subsp. thermoviolaceus Henssen 1957

Henssen, A. 1957. Archiv fur Mikrobiologie 26:373-414. Type strain: ATCC 19283 Description: Shirling, E.B. and D. Gottlieb. 1972. International Journal of Systematic Bacteriology 22:265-394.

S. thermovulgaris Henssen 1957

Henssen, A. 1957. Archiv fur Mikrobiologie 26:373-414. Type strain: ATCC 19284 Description: Shirling, E.B. and D. Gottlieb. 1969. International Journal of Systematic Bacteriology 19:391-512.

S. torulosus Lyons and Pridham 1971

Lyons, A.J. and T.G. Pridham. 1971. Applied Microbiology 22:190-193. Type strain: NRRL B-3889

Description: Lyons, A.J. and T.G. Pridham. 1971. Ibid.

S. toxytricini (Preobrazhenskaya and Sveshnikova 1957) Pridham, Hesseltine and Benedict 1958

Preobrazhenskaya, T.P. and M.A. Sveshnikova. 1957 in Gauze, G.F., T.P. Preobrazhenskaya, E.S. Kudrina, N.O. Blinov, I.D. Ryabova and M.A. Sveshnikova. Problems of classification of actinomycetes-antagonists. Government Publishing House of Medical Literature, Medgiz, Moscow. pp. 1-398; Pridham, T.G., C.W. Hesseltine and R.G. Benedict. 1958. Applied Microbiology 6:52-79. Type strain: ATCC 19813

Description: Shirling, E.B. and D. Gottlieb. 1968. International Journal of Systematic Bacteriology 18:69-189.

S. tricolor (Wollenweber 1920) Waksman 1961 Wollenweber, H.W. 1920. Arbeiten des 
Forschungsinstitutes fur Kartoffelbau, Verlagsbuchandlung Paul Parey, Berlin, No. 2, pp. 1-102; Waksman, S.A. 1961. The Actinomycetes. Vol. 2. Classification, identification and descriptions of genera and species. The Williams and Wilkins Co., Baltimore. pp. 1-363. Type strain: CBS 103.21

Description: Bergey 8.

S. tubercidicus Nakamura 1961

Nakamura, G. 1961. Journal of Antibiotics (Tokyo) Series A 14:90-93. Type strain: ATCC 25502

Description: Shirling, E.B. and D. Gottlieb. 1969. International Journal of Systematic Bacteriology 19:391-512.

S. tuirus Albert and Malaquias de Querioz 1963

Albert, C.A. and V.M. Malaquias de Querioz. 1963. Revista do Instituto de Antibioticos, Universidade do Recife 5:43-

51. Type strain: ATCC 19007

Description: Shirling, E.B. and D. Gottlieb. 1972. International Journal of Systematic Bacteriology 22:265-394.

S. umbrinus (Sveshnikova 1957) Pridham, Hesseltine and Benedict 1958

Sveshnikova, M.A. 1957 in Gauze, G.F., T.P. Preobrazhenskaya, E.S. Kudrina, N.O. Blinov, I.D. Ryabova and M.A. Sveshnikova. Problems of classification of actinomycetes-antagonists. Government Publishing House of Medical Literature, Medgiz, Moscow. pp. 1-398; Pridham, T.G., C.W. Hesseltine and R.G. Benedict. 1958. Applied Microbiology 6:52-79. Type strain: ATCC 19929

Description: Shirling, E.B. and D. Gottlieb. 1969. International Journal of Systematic Bacteriology 19:391-512.

S. variabilis (Preobrazhenskaya, Ryabova and Blinov 1957) Pridham, Hesseltine and Benedict 1958

Preobrazhenskaya, T.P., I.D. Ryabova and N.O. Blinov. 1957 in Gauze, G.F., T.P. Preobrazhenskaya, E.S. Kudrina, N.O. Blinov, I.D. Ryabova and M.A. Sveshnikova. Problems of classification of actinomycetes-antagonists. Government Publishing House of Medical Literature, Medgiz, Moscow. pp. 1-398; Pridham, T.G., C.W. Hesseltine and R.G. Benedict. 1958. Applied Microbiology 6:52-79. Type strain: ATCC 19930

Description: Shirling, E.B. and D. Gottlieb. 1968. International Journal of Systematic Bacteriology 18:69-189.

S. varsoviensis Kurylowicz and Woznicka 1967 Kurylowicz, W. and W. Woznicka. 1967. Medycyna Doswiadczalna i Mikrobiologia 19:1-9. Type strain: ATCC 25505

Description: Shirling, E.B. and D. Gottlieb. 1969. International Journal of Systematic Bacteriology 19:391-512.

S. vastus Szabo and Marton 1958

Szabo, I. and M. Marton. 1958. Agrokemia es Talajtan 7:243-262. Type strain: ATCC 25506

Description: Shirling, E.B. and D. Gottlieb. 1969. International Journal of Systematic Bacteriology 19:391-512.

S. venezuelae Ehrlich, Gottlieb, Burkholder, Anderson and Pridham 1948

Ehrlich, J., D. Gottlieb, P.R. Burkholder, L.E. Anderson and T.G. Pridham. 1948. Journal of Bacteriology 56:467-477. Type strain: NRRL 2277

Description: Shirling, E.B. and D. Gottlieb. 1969. International Journal of Systematic Bacteriology 19:391-512.

S. vinaceus Jones 1952

Jones, K.L. 1952. Papers from the Michigan Academy of Science, Arts and Letters 37:47-48. Type strain: NRRL 2382

Description: Shirling, E.B. and D. Gottlieb. 1972. International Journal of Systematic Bacteriology 22:265-394.

S. vinaceusdrappus Pridham, Hesseltine and Benedict 1958

Pridham, T.G., C.W. Hesseltine and R.G. Benedict. 1958. Applied Microbiology 6: 52-79. Type strain: NRRL 2363

Description: Shirling, E.B. and D. Gottlieb. 1969.' International Journal of Systematic Bacteriology 19:391-512.

S. violaceochromogenes (Ryabova and Preobrazhenskaya 1957) Pridham 1970

Ryabova, I.D. and T.P. Preobrazhenskaya. 1957 in Gauze, G.F., T.P. Preobrazhenskaya, E.S. Kudrina, N.O. Blinov, I.D. Ryabova and M.A. Sveshnikova. Problems of classification of actinomycetes-antagonists. Government Publishing House of Medical Literature, Medgiz, Moscow. pp. 1-398; Pridham, T.G. 1970. Bulletin of 
the United States Department of Agriculture 1424:1-55. Type strain: ATCC 19932

Description: Shirling, E.B. and D. Gottlieb. 1969. International Journal of Systematic Bacteriology 19:391-512.

S. violaceolatus (Krassilnikov, Sorokina, Alferova and Bezzubenkova 1965) Pridham 1970

Krassilnikov, N.A., E.J. Sorokina, V.A. Alferova and A.P. Bezzubenkova. 1965 in Krassilnikov, N.A. (ed). Biology of selected groups of actinomycetes (in Russian). Institute of Microbiology, Academy of Science, Publishing Firm 'Nauka', Moscow, USSR. pp. 1-372; Pridham, T.G. 1970. Bulletin of the United States Department of Agriculture 1424:1-55. Type strain: ATCC 19847

Description: Shirling, E.B. and D. Gottlieb. 1969. International Journal of Systematic Bacteriology 19:391-512.

S. violaceoniger (Waksman and Curtis 1916) Pridham, Hesseltine and Benedict 1958 Waksman, S.A. and R.E. Curtis. 1916. Soil Science 1:99-134; Pridham, T.G., C.W. Hesseltine and R.G. Benedict. 1958. Applied Microbiology 6:52-79. Type strain: NRRL B-1476

Description: Shirling, E.B. and D. Gottlieb. 1972. International Journal of Systematic Bacteriology 22:265-394.

S. violaceorectus (Ryabova and Preobrazhenskaya 1957) Pridham, Hesseltine and Benedict 1958

Ryabova, I.D. and T.P. Preobrazhenskaya. 1957 in Gauze, G.F., T.P. Preobrazhenskaya, E.S. Kudrina, N.O. Blinov, I.D. Ryabova and M.A. Sveshnikova. Problems of classification of actinomycetes-antagonists. Government Publishing House of Medical Literature, Medgiz, Moscow. pp. 1-398; Pridham, T.G., C.W. Hesseltine and R.G. Benedict. 1958. Applied Microbiology 6:52-79. Type strain: ATCC 25514

Description: Shirling, E.B. and D. Gottlieb. 1969. International Journal of Systematic Bacteriology 19:391-512.

S. violaceoruber (Waksman and Curtis 1916) Pridham 1970

Waksman, S.A. and R.E. Cutris. 1916. Soil Science 1:99-134; Pridham, T.G.
1970. Bulletin of the United States Department of agriculture 1424:1-55. Type strain: ATCC 14980

Description: Shirling, E.B. and D. Gottlieb. 1968. International Journal of Systematic Bacteriology 18:69-189.

S. violaceus (Rossi Doria 1891) Waksman 1953

Rossi Doria, T. 1891. Annali dell' Istituto d'Igiene Sperimentale della Rendiconti Universita di Roma 1:399-438; Waksman, S.A. 1953 in Waksman, S.A. and H.A. Lechevalier. Guide to the classification and identification of the actinomycetes and their antibiotics. The Williams and Wilkins Co., Baltimore. pp. 1-246. Type strain: ATCC 15888

Description: Shirling, E.B. and D. Gottlieb. 1969. International Journal of Systematic Bacteriology 19:391-512.

S. violarus (Artamonova and Krassilnikov 1960) Pridham 1970

Artamonova, O.I. and N.A. Krassilnikov. 1960 in Rautenshtein, Ya. I. Transactions of the Institute of Microbiology, Academy of Science USSR 8:1-344; Pridham, T.G. 1970. Bulletin of the United States Department of Agriculture 1424:1-55. Type strain: ATCC 15891

Description: Shirling, E.B. and D. Gottlieb. 1969. International Journal of Systematic Bacteriology 19:391-512.

S. violascens (Preobrazhenskaya and Sveshnikova 1957) Pridham, Hesseltine and Benedict 1958

Preobrazhenskaya, T.P. and M.A. Sveshnikova. 1957 in Gauze, G.F., T.P. Preobrazhenskaya, E.S. Kudrina, N.O. Blinov, I.D. Ryabova and M.A. Sveshnikova. Problems of classification of actinomycetes-antagonists. Government Publishing House of Medical Literature, Medgiz, Moscow. pp. 1-398; Pridham, T.G., C.W. Hesseltine and R.G. Benedict. 1958. Applied Microbiology 6:52-79. Type strain: ATCC 23968

Description: Shirling, E.B. and D. Gottlieb. 1968. International Journal of Systematic Bacteriology 18:279-392.

S. violatus (Artamonova and Krassilnikov 1960) Pridham 1970

Artamonova, O.I. and N.A. Krassilnikov. 1960 in Rautenshtein, Ya. I. Transactions of the Institute of Microbiology, Academy 
of Science USSR 8:1-344; Pridham, T.G. 1970. Bulletin of the United States Department of Agriculture 1424:1-55. Type strain: ATCC 15892

Description: Shirling, E.B. and D. Gottlieb. 1972. International Journal of Systematic Bacteriology 22:265-394.

S. virginiae Grundy, Whitman, Rdzok, Rdzok, Hanes and Sylvester 1952

Grundy, W.E., A.L. Whitman, E.G. Rdzok, E.J. Rdzok, M.E. Hanes and J.C. Sylvester. 1952. Antibiotics and Chemotherapy 2:399-408. Type strain: ATCC 19817

Description: Shirling, E.B. and D. Gottlieb. 1968. International Journal of Systematic Bacteriology 18:69-189.

S. viridiviolaceus (Ryabova and Preobrazhenskaya 1957) Pridham, Hesseltine and Benedict 1958

Ryabova, I.D. and T.P. Preobrazhenskaya. 1957 in Gauze, G.F., T.P. Preobrazhenskaya, E.S. Kudrina, N.O. Blinov, I.D. Ryabova and M.A. Sveshnikova. Problems of classification of actinomycetes-antagonists. Government Publishing House of Medical Literature, Medgiz, Moscow. pp. 1-398; Pridham, T.G., C.W. Hesseltine and R.G. Benedict. 1958. Applied Microbiology 6:52-79. Type strain: ATCC 27478

Description: Shirling, E.B. and D. Gottlieb. 1972. International Journal of Systematic Bacteriology 22:265-394.

S. viridochromogenes (Krainsky 1914) Waksman and Henrici 1948

Krainsky, A. 1914. Zentralblatt fur Bakteriologie, Parasitenkunde, Infektionskrankheiten und Hygiene. Abteilung II. 41:649-688; Waksman, S.A. and A.T. Henrici. 1948 in Breed, R.S., E.G.D. Murray and A.P. Hitchens (eds). Bergey's Manual of Determinative Bacteriology, 6th ed. The Williams and Wilkins Co., Baltimore. pp. 929-980. Type strain: ATCC 14920

Description: Shirling, E.B. and D. Gottlieb. 1972. International Journal of Systematic Bacteriology 22:265-394.

S. viridodiastaticus (Baldacci, Grein and Spalla 1955) Pridham, Hesseltine and Benedict 1958

Baldacci, E., A. Grein and C. Spalla.
1955. Giornale di Microbiologia 1:127143; Pridham, T.G., C.W. Hesseltine and R.G. Benedict. 1958. Applied Microbiology 6:52-79. Type strain: ATCC 25518

Description: Shirling, E.B. and D. Gottlieb. 1969. International Journal of Systematic Bacteriology 19:391-512.

S. viridosporus Pridham, Hesseltine and Benedict 1958

Pridham, T.G., C.W. Hesseltine and R.G. Benedict. 1958. Applied Microbiology 6: 52-79. Type strain: NRRL 2414

Description: Shirling, E.B. and D. Gottlieb. 1972. International Journal of Systematic Bacteriology 22:265-394.

S. werraensis Wallhausser, Huber, Nesemann, Prave and Zepf 1964

Wallhausser, K.H., G. Huber, G. Nesemann, P. Prave and K. Zepf. 1964. Arzneimittel Forschung 14:356-360. Type strain: ATCC 14424

Description: Shirling, E.B. and D. Gottlieb. 1972. International Journal of Systematic Bacteriology 22:265-394.

S. willmorei (Erikson 1935) Waksman and Henrici 1948

Erikson, D. 1935. Medical Research Council (Great Britain) Special Report Series 203:5-61; Waksman, S.A. and A.T. Henrici. 1948 in Breed, R.S., E.G.D. Murray and A.P. Hitchens (eds). Bergey's Manual of Determinative Bacteriology, 6th ed. The Williams and Wilkins Co., Baltimore. pp. 929-980. Type strain: ATCC 6867

Description: Shirling, E.B. and D. Gottlieb. 1972. International Journal of Systematic Bacteriology 22:265-394.

S. xanthochromogenes Arishima, Sakamoto and Sato 1956

Arishima, M., J.M. Sakamoto and T. Sato. 1956. Journal of the Agricultural Chemical Society of Japan 30:469-471. Type strain: ATCC 19818

Description: Shirling, E.B. and D. Gottlieb. 1968. International Journal of Systematic Bacteriology 18:69-189.

S. xanthocidicus Asahi, Nagatsu and Suzuki 1966

Asahi, K., J. Nagatsu and S. Suzuki. 1966. Journal of Antibiotics (Tokyo) Series A 19:195-199. Type strain: ATCC 27480 
Description: Shirling, E.B. and D. Gottlieb. 1972. International Journal of Systematic Bacteriology 22:265-394.

S. xantholiticus (Konev and Tsyganov 1962) Pridham 1970

Konev, I.E. and V.A. Tsyganov. 1962. Mikrobiologiya 31:1023-1028; Pridham, T.G. 1970. Bulletin of the United States Department of Agriculture 1424:1-55. Type strain: ATCC 27481

Description: Shirling, E.B. and D. Gottlieb. 1972. International Journal of Systematic Bacteriology 22:265-394.

S. xanthophaeus Lindenbein 1952

Lindenbein, W. 1952. Archiv fur Mikrobiologie 17:361-383. Type strain: ATCC 19819

Description: Shirling, E.B. and D. Gottlieb. 1968. International Journal of Systematic Bacteriology 18:69-189.

S. yokosukanensis Nakamura 1961

Nakamura, G. 1961. Journal of Antibiotics (Tokyo) Series A 14:94-97. Type strain: ATCC 25520

Description: Shirling, E.B. and D. Gottlieb. 1969. International Journal of Systematic Bacteriology 19:391-512.

S. zaomyceticus Hinuma 1954

Hinuma, Y. 1954. Journal of Antibiotics (Tokyo) Series A 7:134-136. Type strain: ATCC 27482

Description: Shirling, E.B. and D. Gottlieb. 1972. International Journal of Systematic Bacteriology 22:265-394.

\section{Streptosporangium Couch 1955}

Couch, J.N. 1955. Journal of the Elisha Mitchell Scientific Society 71:148-155. Type species: $S$. roseum Couch 1955 Description: Bergey 8.

S. albidum Furumai, Ogawa and Okuda 1968 Furumai, T., H. Ogawa and T. Okuda. 1968. Journal of Antibiotics (Tokyo) 21: 179-181. Type strain: ATCC 25243

Description: Bergey 8.

S. album Nonomura and Ohara 1960

Nonomura, H. and Y. Ohara. 1960. Journal of Fermentation Technology 38: 405-409. Type strain: DSM 43023

Description: Bergey 8.

S. amethystogenes Nonomura and Ohara 1960 Nonomura, H. and Y. Ohara. 1960. Journal of Fermentation Technology 38:
405-409. Type strain: KCC A-2006

Description: Bergey 8.

S. corrugatum Williams and Sharples 1976

Williams, S.T. and G.P. Sharples. 1976. International Journal of Systematic Bacteriology 26:45-52. Type strain: ATCC 29331

Description: Williams, S.T. and G.P. Sharples. 1976. Ibid.

S. indianesis Gupta 1965

Gupta, K.C. 1965. Journal of Antibiotics (Tokyo) Series A 18:125-127. Type strain: KCC A-0053

Description: Gupta, K.C. 1965. Ibid.

S. Iongisporum Schafer 1969

Schafer, D. 1969. Archiv fur Mikrobiologie 66:365-373. Type strain: ATCC 25212 Description: Bergey 8.

S. nondiastaticum Nonomura and Ohara 1969 Nonomura, H. and Y. Ohara. 1969. Journal of Fermentation Technology 47: 701-709. Type strain: ATCC 27101

Description: Bergey 8.

S. pseudovulgare Nonomura and Ohara 1969

Nonomura, H. and Y. Ohara. 1969.

Journal of Fermentation Technology 47:

701-709. Type strain: ATCC 27100

Description: Bergey 8.

S. roseum Couch 1955

Couch, J.N. 1955. Journal of the Elisha Mitchell Scientific Society 71:148-155. Type strain: ATCC 12428

Description: Bergey 8.

S. violaceochromogenes Kawamoto, Takasawa, Okachi, Kohakura, Takahashi and Nara 1975

Kawamoto, I., S. Takasawa, R. Okachi, M. Kohakura, I. Takahashi and T. Nara. 1975. Journal of Antibiotics (Tokyo) 28: 358-365. Type strain: ATCC 21807

Description: Kawamoto, I., S. Takasawa, R. Okachi, M. Kohakura, I. Takahashi and T. Nara. 1975. Ibid.

S. viridialbum Nonomura and Ohara 1960

Nonomura, H. and Y. Ohara. 1960. Journal of Fermentation Technology 38: 405-409. Type strain: KCC A-027

Description: Bergey 8.

S. viridogriseum Okuda, Furumai, Watanabe, Okugawa and Kimura 1966

Okuda, T., T. Furumai, E. Watanabe, Y. Okugawa and S. Kimura. 1966. Journal of Antibiotics (Tokyo) 19:121-127. Type 
strain: ATCC 25242

Description: Bergey 8.

S. viridogriseum subsp. kofuense Nonomura and Ohara 1969

Nonomura, H. and Y. Ohara. 1969. Journal of Fermentation Technology 47: 701-709. Type strain: ATCC 27102

Description: Bergey 8.

S. viridogriseum subsp. viridogriseum Okuda, Furumai, Watanabe, Okugawa and Kimura 1966

Okuda, T., T. Furumai, E. Watanabe, Y. Okugawa and S. Kimura. 1966. Journal of Antibiotics (Tokyo) 19:121-127. Type strain: ATCC 25242

Description: Bergey 8.

S. vulgare Nonomura and Ohara 1960

Nonomura, H. and Y. Ohara. 1960. Journal of Fermentation Technology 38: 405-409. Type strain: KCC A-0028

Description: Bergey 8.

Streptoverticillium Baldacci 1958

Baldacci, E. 1958. Giornale di Microbiologia 6:10-27. Type species: $S$. baldaccii Farina and Locci 1966

Description: Bergey 8.

S. abikoense (Umezawa, Tazaki and Fukuyama 1951) Locci, Baldacci and Petrolini Baldan 1969

Umezawa, H., T. Tazaki and S. Fukuyama. 1951. Japarese Medical Journal 4: 331-346; Locci, R., E. Baldacci and B. Petrolini Baldan. 1969. Giornale di Microbiologia 17:1-60. Type strain: ATCC 12766

Description: Locci, R., E. Baldacci and B. Petrolini Baldan. 1969. Ibid.

S. albireticuli (Nakazawa 1955) Locci, Baldacci and Petrolini Baldan 1969

Nakazawa, K. 1955. Journal of the Agricultural Chemical Society of Japan 29:647-649; Locci, R., E. Baldacci and B. Petrolini Baldan. 1969. Giornale di Microbiologia 17:1-60. Type strain: ATCC 19721

Description: Shirling, E.B. and D. Gottlieb. 1968. International Journal of Systematic Bacteriology 18:69-189.

S. album Locci, Baldacci and Petrolini Baldan 1969

Locci, R., E. Baldacci and B. Petrolini Baldan. 1969. Giornale di Microbiologia
17:1-60. Type strain: NRRL 2401

Description: Locci, R., E. Baldacci and B. Petrolini Baldan. 1969. Ibid.

S. ardum (De Boer, Dietz, Lummis and Savage 1961) Locci, Baldacci and Petrolini Baldan 1969

De Boer, C., A. Dietz, N.E. Lummis and G.M. Savage. 1961. Antimicrobial Agents Annual pp. 17-22; Locci, R., E. Baldacci and B. Petrolini Baldan. 1969. Giornale di Microbiologia 17:1-60. Type strain: NRRL 2817

Description: Locci, R., E. Baldacci and B. Petrolini Baldan. 1969. Ibid.

S. aureoversales Locci, Baldacci and Petrolini Baldan 1969

Locci, R., E. Baldacci and B. Petrolini Baldan. 1969. Giornale di Microbiologia 17:1-60. Type strain: ATCC 15853

Description: Shirling, E.B. and D. Gottlieb. 1969. International Journal of Systematic Bacteriology 19:391-512.

S. baldaccii Farina and Locci 1966

Farina, G. and R. Locci. 1966. Giornale di Microbiologia 14:33-52. Type strain: ATCC 23654

Description: Farina, G. and R. Locci. 1966. Ibid.

S. biverticillatum (Preobrazhenskaya 1957) Farina and Locci 1966

Preobrazhenskaya, T.P. 1957 in Gauze, G.F., T.P. Preobrazhenskaya, E.S. Kudrina, N.O. Blinov, I.D. Ryabova and M.A. Sveshnikova. Problems in the classification of actinomycetes-antagonists. Publishing House of Medical Literature, Medgiz, Moscow. pp. 1-398; Farina, G. and R. Locci. 1966. Giornale di Microbiologia 14:33-52. Type strain: ATCC 23615

Description: Shirling, E.B. and D. Gottlieb. 1968. International Journal of Systematic Bacteriology 18:279-392.

S. blastmyceticum (Watanabe, Tanaka, Fukuhara, Miyairi, Yonehara and Umezawa 1957) Locci, Baldacci and Petrolini Baldan 1969

Watanabe, K., T. Tanaka, K. Fukuhara, N. Miyairi, $H$. Yonehara and $H$. Umezawa. 1957. Journal of Antibiotics (Tokyo) Series A 10:39-45; Locci, R., E. Baldacci and B. Petrolini Baldan. 1969. Giornale di Microbiologia 17:1-60. Type strain: ATCC 19731 
Description: Shirling, E.B. and D. Gottlieb. 1968. International Journal of Systematic Bacteriology 18:69-189.

S. cinnamoneum (Benedict, Dvonch, Shotwell, Pridham and Lindenfelser 1952) Baldacci, Farina and Locci 1966

Benedict, R.G., W. Dvonch, O.L. Shotwell, T.G. Pridham and L.A. Lindenfelser. 1952. Antibiotics and Chemotherapy 2:591-594; Baldacci, E., G. Farina and R. Locci. 1966. Giornale di Microbiologia 14:153-171. Type strain: NRRL B-1285

Description: Shirling, E.B. and D. Gottlieb. 1968. International Journal of Systematic Bacteriology 18:279-392.

S. cinnamoneum subsp. albosporum Thirumalachar 1968

Thirumalachar, M.J. 1968 in Rahalkar, P.W. and M.J. Thirumalachar. Hindustan Antibiotics Bulletin 11:90-96. Type strain: ATCC 25186

Description: Locci, R., E. Baldacci and B. Petrolini Baldan. 1969. Giornale di Microbiologia 17:1-60.

S. cinnamoneum subsp. cinnamoneum Baldacci and Locci 1974

Baldacci, E. and R. Locci. 1974. Bergey

8. Type strain: NRRL B-1285

Description: Shirling, E.B. and D. Gottlieb. 1968. International Journal of Systematic Bacteriology 18:279-392.

S. cinnamoneum subsp. lanosum Thirumalachar 1968

Thirumalachar, M.J. 1968 in Rahalkar, P.W. and M.J. Thirumalachar. Hindustan Antibiotics Bulletin 11:90-96. Type strain: ATCC 25187

Description: Locci, R., E. Baldacci and B. Petrolini Baldan. 1969. Giornale di Microbiologia 17:1-60.

S. cinnamoneum subsp. sparsum Thirumalachar 1968

Thirumalachar, M.J. 1968 in Rahalkar, P.W. and M.J. Thirumalachar. Hindustan Antibiotics Bulletin 11:90-96. Type strain: ATCC 25185

Description: Locci, R., E. Baldacci and B. Petrolini Baldan. 1969. Giornale di Microbiologie 17:1-60.

S. distallicum Locci, Baldacci and Petrolini Baldan 1969

Locci, R., E. Baldacci and B. Petrolini Baldan. 1969. Giornale di Microbiologia
17:1-60. Type strain: NRRL 2886

Description: Locci, R., E. Baldacci and B. Petrolini Baldan. 1969. Ibid.

S. ehimense (Shibata, Honjo, Tokui and Nakazawa 1954) Locci, Baldacci and Petrolini Baldan 1969

Shibata, M., M. Honjo, Y. Tokui and N. Nakazawa. 1954. Journal of Antibiotics (Tokyo) Series B 7:168; Locci, R., E. Baldacci and B. Petrolini Baldan. 1969. Giornale di Microbiologia 17:1-60. Type strain: ATCC 23903

Description: Locci, R., E. Baldacci and B. Petrolini Baldan. 1969. Ibid.

S. eurocidicum (Okami, Utahara, Nakamura and Umezawa 1954) Locci, Baldacci and Petrolini Baldan 1969

Okami, Y., R. Utahara, S. Nakamura and H. Umezawa. 1954. Journal of Antibiotics (Tokyo) Series A 7:98-103; Locci, R., E. Baldacci and B. Petrolini Baldan. 1969. Giornale di Microbiologia 17:1-60. Type strain: ATCC 27428

Description: Shirling, E.B. and D. Gottlieb. 1972. International Journal of Systematic Bacteriology 22:265-394.

S. fervens (De Boer, Dietz, Evans and Michaels 1960) Locci, Baldacci and Petrolini Baldan 1969

De Boer, C., A. Dietz, J.S. Evans and R.M. Michaels. 1960. Antibiotics Annual pp. 220-226; Locci, R., E. Baldacci and B. Petrolini Baldan. 1969. Giornale di Microbiologia 17:1-60. Type strain: NRRL 2755

Description: Shirling, E.B. and D. Gottlieb. 1972. International Journal of Systematic Bacteriology 22:265-394.

S. fervens subsp. fervens Baldacci and Locci 1974

Baldacci, E. and R. Locci. 1974. Bergey 8. Type strain: NRRL 2755

Description: Shirling, E.B. and D. Gottlieb. 1972. International Journal of Systematic Bacteriology 22:265-394.

S. fervens subsp. melrosporus Mason, Lummis and Dietz 1965

Mason, D.J., W.L. Lummis and A. Dietz. 1965. Antimicrobial Agents and Chemotherapy 1964:110-113. Type strain: NRRL 3117

Description: Locci, R., E. Baldacci and B. Petrolini Baldan. 1969. Giornale di 
Microbiologia 17:1-60.

S. flavopersicum (Oliver, Goldstein, Bower, Holper and Otto 1961) Locci, Baldacci and Petrolini Baldan 1969

Oliver, T.J., A. Goldstein, R.R. Bower, J.C. Holper and R.H. Otto. 1961. Antimicrobial Agents and Chemotherapy 1960:495-502; Locci, R., E. Baldacci and B. Petrolini Baldan. 1969. Giornale di Microbiologia 17:1-60. Type strain: NRRL 2820

Description: Locci, R., E. Baldacci and B. Petrolini Baldan. 1969. Ibid.

S. griseocarneum (Benedict, Stodola, Shotwell, Borud and Lindenfelser 1950) Baldacci, Farina and Locci 1966

Benedict, R.G., F.H. Stodola, O.L. Shotwell, A.M. Borud and L.A. Lindenfelser. 1950. Science (Washington) 112: 77-78; Baldacci, E., G. Farina and R. Locci. 1966. Giornale di Microbiologia 14:153-171. Type strain: NRRL B-1068 Description: Shirling, E.B. and D. Gottlieb. 1968. International Journal of Systematic Bacteriology 18:69-189.

S. griseoverticillatum (Shinobu and Shimada 1962) Locci, Baldacci and Petrolini Baldan 1969

Shinobu, R. and Y. Shimada. 1962. Botanical Magazine (Tokyo) 75:170-175; Locci, R., E. Baldacci and B. Petrolini Baldan. 1969. Giornale di Microbiologia 17:1-60. Type strain: ATCC 27436

Description: Shirling, E.B. and D. Gottlieb. 1972. International Journal of Systematic Bacteriology 22:265-394.

S. hachijoense (Hosoya, Komatsu, Soeda and Sonoda 1952) Locci, Baldacci and Petrolini Baldan 1969

Hosoya, S., N. Komatsu, M. Soeda and Y. Sonoda. 1952. Japanese Journal of Experimental Medicine 22:505-509; Locci, R., E. Baldacci and B. Petrolini Baldan. 1969. Giornale di Microbiologia 17:1-60. Type strain: ATCC 19769

Description: Locci, R., E. Baldacci and B. Petrolini Baldan. 1969. Ibid.

S. hiroshimense (Shinobu 1955) Farina and Locci 1966

Shinobu, R. 1955. Seibutsugakkaishi 6:4346; Farina, G. and R. Locci. 1966. Giornale di Microbiologia 14:33-52. Type strain: ATCC 19772
Description: Shirling, E.B. and D. Gottlieb. 1968. International Journal of Systematic Bacteriology 18:69-189.

S. kashmirense (Gupta and Chopra 1963) Locci, Baldacci and Petrolini Baldan 1969 Gupta, K.C. and I.C. Chopra. 1963. Hindustan Antibiotics Bulletin 5:110-112; Locci, R., E. Baldacci and B. Petrolini Baldan. 1969. Giornale di Microbiologia 17:1-60. Type strain: ATCC 27439

Description: Shirling, E.B. and D. Gottlieb. 1972. International Journal of Systematic Bacteriology 22:265-394.

S. kentuckense (Barr and Carman 1956) Baldacci, Farina and Locci 1966

Barr, F.S. and P.E. Carman. 1956. Antibiotics and Chemotherapy 6:286-289; Baldacci, E., G. Farina and R. Locci. 1966. Giornale di Microbiologia 14:153171. Type strain: ATCC 12691

Description: Shirling, E.B. and D. Gottlieb. 1968. International Journal of Systematic Bacteriology 18:279-392.

S. kishiwadense (Shinobu and Kayamura 1964) Locci, Baldacci and Petrolini Baldan 1969 Shinobu, R. and Y. Kayamura. 1964. Botanical Magazine (Tokyo) 77:176-180; Locci, R., E. Baldacci and B. Petrolini Baldan. 1969. Giornale di Microbiologia 17:1-60. Type strain: ATCC 25464

Description: Locci, R., E. Baldacci and B. Petrolini Baldan. 1969. Ibid.

S. ladakanum Hanka, Evans, Mason and Dietz 1966

Hanka, L.J., J.S. Evans, D.J. Mason and A. Dietz. 1967. Antimicrobial Agents and Chemotherapy 1966:619-624. Type strain: NRRL 3191

Description: Shirling, E.B. and D. Gottlieb. 1972. International Journal of Systematic Bacteriology 22:265-394.

S. lavenduligriseum Locci, Baldacci and Petrolini Baldan 1969

Locci, R., E. Baldacci and B. Petrolini Baldan. 1969. Giornale di Microbiologia 17:1-60. Type strain: ATCC 13306

Description: Locci, R., E. Baldacci and B. Petrolini Baldan. 1969. Ibid.

S. lilacinum (Nakazawa, Tanabe, Shibata, Miyake and Takewaka 1956) Locci, Baldacci and Petrolini Baldan 1969

Nakazawa, K., K. Tanabe, M. Shibata, A. Miyake and T. Takewaka. 1956. 
Journal of Antibiotics (Tokyo) Series B 9: 81; Locci, R., E. Baldacci and B. Petrolini Baldan. 1969. Giornale di Microbiologia 17:1-60. Type strain: ATCC 23930

Description: Locci, R., E. Baldacci and B. Petrolini Baldan. 1969. Ibid.

S. luteoverticillatum (Shinobu 1956) Locci, Baldacci and Petrolini Baldan 1969

Shinobu, R. 1956. Memoirs of the Osaka University of the Liberal Arts and Education B 5:84-93; Locci, R., E. Baldacci and B. Petrolini Baldan. 1969. Giornale di Microbiologia 17:1-60. Type strain: ATCC 23933

Description: Locci, R., E. Baldacci and B. Petrolini Baldan. 1969. Ibid.

S. mashuense (Sawazaki, Suzuki, Nakamura, Kawasaki, Yamashita, Isono, Anzai, Serizawa and Sekiyama 1955) Locci, Baldacci and Petrolini Baldan 1969

Sawazaki, T., S. Suzuki, G. Nakamura, M. Kawasaki, S. Yamashita, K. Isono, K. Anzai, Y. Serizawa and Y. Sekiyama. 1955. Journal of Antibiotics (Tokyo) Series A 8:44-47; Locci, R., E. Baldacci and B. Petrolini Baldan. 1969. Giornale di Microbiologia 17:1-60. Type strain: ATCC 23934

Description: Locci, R., E. Baldacci and B. Petrolini Baldan. 1969. Ibid.

S. mobaraense (Nagatsu and Suzuki 1963) Locci, Baldacci and Petrolini Baldan 1969 Nagatsu, J. and S. Suzuki. 1963 in Tamura, S., N. Takahashi, S. Miyamoto, R. Mori, S. Suzuki and J. Nagatsu. 1963. Agricultural and Biological Chemistry 27: 576-582; Locci, R., E. Baldacci and B. Petrolini Baldan. 1969. Giornale di Microbiologia 17:1-60. Type strain: ATCC 29032

Description: Locci, R., E. Baldacci and B. Petrolini Baldan. 1969. Ibid.

S. netropsis (Finlay, Hochstein, Sobin and Murphy 1951) Baldacci, Farina and Locci 1966

Finlay, A.C., F.A. Hochstein, B.A. Sobin and F.X. Murphy. 1951. Journal of the American Chemical Society 73:341-343; Baldacci, E., G. Farina and R. Locci. 1966. Giornale di Microbiologia 14:153171. Type strain: NRRL 2268

Description: Shirling, E.B. and D.
Gottlieb. 1968. International Journal of Systematic Bacteriology 18:279-392.

S. olivoreticulum (Arai, Nakada and Suzuki 1957) Baldacci, Farina and Locci 1966 Arai, M., T. Nakada and M. Suzuki. 1957. Antibiotics and Chemotherapy 7: 435-442; Baldacci, E., G. Farina and R. Locci. 1966. Giornale di Microbiologia 14:153-171. Type strain: ATCC 23943

Description: Shirling, E.B. and D. Gottlieb. 1968. International Journal of Systematic Bacteriology 18:279-392.

S. olivoverticillatum (Shinobu 1956) Baldacci, Farina and Locci 1966

Shinobu, R. 1956. Memoirs of the Osaka University of the Liberal Arts and Education B 5:84-93; Baldacci, E., G. Farina and R. Locci. 1966. Giornale di Microbiologia 14:153-171. Type strain: NRRL B-1994

Description: Baldacci, E., G. Farina and R. Locci. 1966. Ibid.

S. orinoci Cassinelli, Grein, Orezzi, Pennella and Sanfilippo 1967

Cassinelli, G., A. Grein, P. Orezzi, P. Pennella and A. Sanfilippo. 1967. Archiv fur Mikrobiologie 55:358-368. Type strain: ATCC 23202

Description: Shirling, E.B. and D. Gottlieb. 1972. International Journal of Systematic Bacteriology 22:265-394.

S. parvisporogenum Locci, Baldacci and Petrolini Baldan 1969

Locci, R., E. Baldacci and B. Petrolini Baldan. 1969. Giornale di Microbiologia 17:1-60. Type strain: ATCC 12568

Description: Shirling, E.B. and D. Gottlieb. 1972. International Journal of Systematic Bacteriology 22:265-394.

S. rectiverticillatum (Krassilnikov and Yuan 1965) Locci, Baldacci and Petrolini Baldan 1969

Krassilnikov, N.A. and T. Yuan. 1965 in Krassilnikov, N.A. (ed). Biology of individual groups of Actinomycetes (in Russian). Institute of Microbiology, Academy of Science, Publishing Firm 'Nauka', Moscow, USSR. pp. 28-57; Locci, R., E. Baldacci and B. Petrolini Baldan. 1969. Giornale di Microbiologia 17:1-60. Type strain: ATCC 19845

Description: Shirling, E.B. and D. Gottlieb. 1969. International Journal of 
Systematic Bacteriology 19:391-512.

S. roseoverticillatum (Shinobu 1956) Farina and Locci 1966

Shinobu, R. 1956. Memoirs of the Osaka University of the Liberal Arts and Education B 5:84-93; Farina, G. and R. Locci. 1966. Giornale di Microbiologia 14:33-52. Type strain: ATCC 19807

Description: Shirling, E.B. and D. Gottlieb. 1968. International Journal of Systematic Bacteriology 18:69-189.

S. salmonis (Baldacci, Farina and Locci 1966) Locci, Baldacci and Petrolini Baldan 1969 Baldacci, E., G. Farina and R. Locci. 1966. Giornale di Microbiologia 14:153171; Locci, R., E. Baldacci and B. Petrolini Baldan. 1969. Giornale di Microbiologia 17:1-60. Type strain: NRRL B-1472

Description: Locci, R., E. Baldacci and B. Petrolini Baldan. 1969. Ibid.

S. septatum Locci, Baldacci and Petrolini Baldan 1969

Locci, R., E. Baldacci and B. Petrolini Baldan. 1969. Gionale di Microbiologia 17:1-60. Type strain: NRRL 2974

Description: Shirling, E.B. and D. Gottlieb. 1972. International Journal of Systematic Bacteriology 22:265-394.

S. thioluteum (Okami 1952) Baldacci, Farina and Locci 1966

Okami, Y. 1952. Doctoral Dissertation, Hokkaido University; Baldacci, E., G. Farina and R. Locci. 1966. Giornale di Microbiologia 14:153-171. Type strain: CBS 642.72

Description: Shirling, E.B. and D. Gottlieb. 1972. International Journal of Systematic Bacteriology 22:265-394.

Succinimonas Bryant, Small, Bouma and Chu 1958

Bryant, M.P., N. Small, C. Bouma and H. Chu. 1958. Journal of Bacteriology 76: 15-23. Type species: $S$. amylolytica Bryant, Small, Bouma and Chu 1958 Description: Bergey 8.

S. amylolytica Bryant, Small, Bouma and Chu 1958

Bryant, M.P., N. Small, C. Bouma and H. Chu. 1958. Journal of Bacteriology 76: 15-23. Type strain: ATCC 19206

Description: Holdeman, L.V., E.P. Cato and W.E.C. Moore (eds). 1977. Anaerobe Laboratory Manual, 4th ed. Virginia Polytechnic Institute and State University, Blacksburg, Virginia. pp. 1-156.

Succinivibrio Bryant and Small 1956

Bryant, M.P. and N. Small. 1956. Journal of Bacteriology 72:22-26. Type species: $S$. dextrinosolvens Bryant and Small 1956

Description: Bergey 8.

S. dextrinosolvens Bryant and Small 1956

Bryant, M.P. and N. Small. 1956. Journal of Bacteriology 72:22-26. Type strain: ATCC 19716

Description: Holdeman, L.V., E.P. Cato and W.E.C. Moore (eds). 1977. Anaerobe Laboratory Manual, 4th ed. Virginia Polytechnic Institute and State University, Blacksburg, Virginia. pp. 1-156.

Sulfolobus Brock, Brock, Belly and Weiss 1972 Brock, T.D., K.M. Brock, R.T. Belly and R.L. Weiss. 1972. Archiv fur Mikrobiologie 84:54-68. Type species: $S$. acidocaldarius Brock, Brock, Belly and Weiss 1972

Description: Brock, T.D., K.M. Brock, R.T. Belly and R.L. Weiss. 1972. Ibid.

S. acidocaldarius Brock, Brock, Belly and Weiss 1972

Brock, T.D., K.M. Brock, R.T. Belly and R.L. Weiss. 1972. Archiv fur Mikrobiologie 84:54-68. Type strain: DSM 639

Description: Brock, T.D., K.M. Brock, R.T. Belly and R.L. Weiss. 1972. Ibid.

Symbiotes Philip 1956

Philip, C.B. 1956. Canadian Journal of Microbiology 2:261-270. Type species: $S$. lectularius (Arkwright, Atkin and Bacot 1921) Philip 1956

Description: Bergey 8.

S. lectularius (Arkwright, Atkin and Bacot 1921) Philip 1956

Arkwright, J.A., E.E. Atkin and A. Bacot. 1921. Parasitology 13:27-36; Philip, C.B. 1956. Canadian Journal of Microbiology 2:261-270. Type strain: no culture isolated.

Description: Bergey 8.

Thermoactinomyces Tsiklinsky 1899 
Tsiklinsky, P. 1899. Annales de l'Institut Pasteur (Paris) 13:500-505. Type species: T. vulgaris Tsiklinsky 1899

Description: Bergey 8.

T. candidus Kurup, Barboriak, Fink and Lechevalier 1975

Kurup, V.P., J.J. Barboriak, J.N. Fink and M.P. Lechevalier. 1975. International Journal of Systematic Bacteriology 25: 150-154. Type strain: ATCC 27868

Description: Kurup, V.P., J.J. Barboriak, J.N. Fink and M.P. Lechevalier. 1975. Ibid.

T. dichotomica (Krassilnikov and Agre 1964) Cross and Goodfellow 1973

Krassilnikov, N.A. and N.S. Agre. 1964. Mikrobiologiya 33:935-943; Cross, T. and M. Goodfellow. 1973 in Sykes, G. and F.A. Skinner (eds). Actinomycetales, characteristics and practical importance. Academic Press, London. pp. 11-112. Type strain: strain 114 (Department Soil Biology, Moscow University)

Description: Krassilnikov, N.A. and N.S. Agre. 1964. Ibid.

T. peptonophilus Nonomura and Ohara 1971

Nonomura, H. and Y. Ohara. 1971. Journal of Fermentation Technology 49: 895-903. Type strain: ATCC 27302

Description: Nonomura, H. and Y. Ohara. 1971. Ibid.

T. sacchari Lacey 1971

Lacey, J. 1971. Journal of General Microbiology 66:327-338. Type strain: ATCC 27375

Description: Lacey, J. 1971. Ibid.

T. vulgaris Tsiklinsky 1899

Tsiklinsky, P. 1899. Annales de l'Institut Pasteur (Paris) 13:500-505. Type strain: KCC A-0162

Description: Bergey 8 .

Thermomicrobium Jackson, Ramaley and Meinschein 1973

Jackson, T.J., R.F. Ramaley and W.G. Meinschein. 1973. International Journal of Systematic Bacteriology 23:28-36. Type species: $T$. roseum Jackson, Ramaley and Meinschein 1973

Description: Jackson, T.J., R.F. Ramaley and W.G. Meinschein. 1973. Ibid.

T. fosteri Phillips and Perry 1976

Phillips Jr., W.E. and J.J. Perry. 1976.
International Journal of Systematic Bacteriology 26:220-225. Type strain: ATCC 29033

Description: Phillips Jr., W.E. and J.J. Perry. 1976. Ibid.

T. roseum Jackson, Ramaley and Meinschein 1973

Jackson, T.J., R.F. Ramaley and W.G. Meinschein. 1973. International Journal of Systematic Bacteriology 23:28-36. Type strain: ATCC 27502

Description: Jackson, T.J., R.F. Ramaley and W.G. Meinschein. 1973. Ibid.

Thermomonospora Henssen 1957

Henssen, A. 1957. Archiv fur Mikrobiologie 26:373-414. Type species: $T$. curvata Henssen 1957

Description: Bergey 8.

T. alba (Locci, Baldacci and Petrolini Baldan 1967) Cross and Goodfellow 1973

Locci, R., E. Baldacci and B. Petrolini Baldan. 1967. Giornale di Microbiologia 15:79-91; Cross, T. and M. Goodfellow. 1973 in Sykes, G. and F.A. Skinner. Actinomycetales, characteristics and practical importance. Academic Press. London. pp. 11-112. Type strain: IPV 1900

Description: Cross, T. and M. Goodfellow. 1973. Ibid.

T. curvata Henssen 1957

Henssen, A. 1957. Archiv fur Mikrobiologie 26:373-414. Type strain: ATCC 19995 Description: Bergey 8.

T. mesophila Nonomura and Ohara 1971 Nonomura, H. and Y. Ohara. 1971. Journal of Fermentation Technology 49: 895-903. Type strain: ATCC 27303

Description: Nonomura, H. and Y. Ohara. -1971. Ibid.

T. mesouviformis Nonomura and Ohara 1974

Nonomura, H. and Y. Ohara. 1974. Journal of Fermentation Technology 52: 10-13. Type strain: ATCC 27644

Description: Nonomura, $H$. and Y. Ohara. 1974. Ibid.

Thermoplasma Darland, Brock, Samsonoff and Conti 1970

Darland, G., T.D. Brock, W. Samsonoff and S.F. Conti. 1970. Science (Washington) 170:1416-1418. Type species: $T$. 
acidophilum Darland, Brock, Samsonoff and Conti 1970

Description: Bergey 8.

T. acidophilum Darland, Brock, Samsonoff and Conti 1970

Darland, G., T.D. Brock, W. Samsonoff and S.F. Conti. 1970. Science (Washington) 170:1416-1418. Type strain: AMRC$\mathrm{C} 165$

Description: Brock, T.D. 1978. Thermophilic microorganisms and life at high temperatures. Springer-Verlag, New York. pp. 92-116.

Thermus Brock and Freeze 1969

Brock, T.D. and H. Freeze. 1969. Journal of Bacteriology 98:289-297. Type species: T. aquaticus Brock and Freeze 1969

Description: Brock, T.D. and H. Freeze. 1969. Ibid.

T. aquaticus Brock and Freeze 1969

Brock, T.D. and H. Freeze. 1969. Journal of Bacteriology 98:289-297. Type strain: ATCC 25104

Description: Brock, T.D. and H. Freeze. 1969. Ibid.

Thiobacillus Beijerinck 1904

Beijerinck, M.W. 1904. Archives Neerlandaises des Sciences Exactes et Naturelles (Section 2) 9:131-157. Type species: $T$. thioparus Beijerinck 1904

Description: Bergey 8.

T. concretivorus Parker 1945

Parker, C.D. 1945. Australian Journal of Experimental Biology and Medical Science 23:81-90. Type strain: NCIB 8345

Description: Parker, C.D. 1945. Ibid.

T. ferrooxidans Temple and Colmer 1951

Temple, K.L. and A.R. Colmer. 1951. Journal of Bacteriology 62:605-611. Type strain: ATCC 23270

Description: Temple, K.L. and A.R. Colmer. 1951. Ibid.

T. intermedius London 1963

London, J.P. 1963. Archiv fur Mikrobiologie 46:329-337. Type strain: ATCC 15466

Description: London, J.P. 1963. Ibid.

T. neapolitanus Parker 1957

Parker, C.D. 1957 in Breed, R.S., E.G.D. Murray and N.R. Smith (eds). Bergey's Manual of Determinative Bacteriology, 7th ed. The Williams and Wilkins Co., Baltimore. pp. 83-88. Type strain: NCIB 8539

Description: Bergey 8.

T. novellus Starkey 1934

Starkey, R.L. 1934. Journal of Bacteriology 28:365-386. Type strain: ATCC 8093

Description: Bergey 8.

T. perometabolis London and Rittenberg 1967

London, J.P. and S.C. Rittenberg. 1967.

Archiv fur Mikrobiologie 59:218-225.

Type strain: ATCC 23370

Description: London, J.P. and S.C. Rittenberg. 1967. Ibid.

T. thiooxidans Waksman and Joffe 1922

Waksman, S.A. and J.S. Joffe. 1922. Journal of Bacteriology 7:239-256. Type strain: ATCC 19377

Description: Bergey 8.

T. thioparus Beijerinck 1904

Beijerinck, M.W. 1904. Archives Neerlandaises des Sciences Exactes et Naturelles (Section 2) 9:131-157. Type strain: ATCC 8158

Description: Bergey 8.

Thiocapsa Winogradsky 1888

Winogradsky, S. 1888. Beitrage zur Morphologie und Physiologie der Bacterien. Heft I. Zur Morphologie und Physiologie der Schwefelbacterien. Arthur Felix, Leipzig. pp. 1-120. Type species: $T$. roseopersicina Winogradsky 1888

Description: Bergey 8.

T. pfennigii Eimhjellen 1970

Eimhjellen, K.E. 1970. Archiv fur Mikrobiologie 73:193-194. Type strain: DSM 1375

Description: Bergey 8.

T. roseopersicina Winogradsky 1888

Winogradsky, S. 1888. Beitrage zur Morphologie und Physiologie der Bacterien. Heft I. Zur Morphologie und Physiologie der Schwefelbacterien. Arthur Felix, Leipzig. pp. 1-120. Type strain: DSM 217

Description: Bergey 8.

Thiocystis Winogradsky 1888

Winogradsky, S. 1888. Beitrage zur Morphologie und Physiologie der Bacterien. Heft I. Zur Morphologie und 
Physiologie der Schwefelbacterien. Arthur Felix, Leipzig. pp. 1-120. Type species: $T$. violacea Winogradsky 1888

Description: Bergey 8 .

T. gelatinosa (Winogradsky 1888) Pfennig and Truper 1971

Winogradsky, S. 1888. Beitrage zur Morphologie und Physiologie der Bacterien. Heft I. Zur Morphologie und Physiologie der Schwefelbacterien. Arthur Felix, Leipzig. pp. 1-120; Pfennig, N. and H.G. Truper. 1971. International Journal of Systematic Bacteriology 21:11-14. Type strain: DSM 215

Description: Bergey 8.

T. violacea Winogradsky 1888

Winogradsky, S. 1888. Beitrage zur Morphologie und Physiologie der Bacterien. Heft I. Zur Morphologie und Physiologie der Schwefelbacterien. Arthur Felix, Leipzig. pp. 1-120. Type strain: DSM 207

Description: Bergey 8.

Thiodictyon Winogradsky 1888

Winogradsky, S. 1888. Beitrage zur Morphologie und Physiologie der Bacterien. Heft I. Zur Morphologie und Physiologie der Schwefelbacterien. Arthur Felix, Leipzig. pp. 1-120. Type species: $T$. elegans Winogradsky 1888

Description: Bergey 8.

T. bacillosum (Winogradsky 1888) Pfennig and Truper 1971

Winogradsky, S. 1888. Beitrage zur Morphologie und Physiologie der Bacterien. Heft I. Zur Morphologie und Physiologie der Schwefelbacterien. Arthur Felix, Leipzig. pp. 1-120; Pfennig, N. and H.G. Truper. 1971. International Journal of Systematic Bacteriology 21:11-14. Type strain: DSM 234

Description: Bergey 8.

T. elegans Winogradsky 1888

Winogradsky, S. 1888. Beitrage zur Morphologie und Physiologie der Bacterien. Heft I. Zur Morphologie und Physiologie der Schwefelbacterien. Arthur Felix, Leipzig. pp. 1-120. Type strain: DSM 232

Description: Bergey 8.

Thiomicrospira Kuenen and Veldkamp 1972
Kuenen, J.G. and H. Veldkamp. 1972. Antonie van Leeuwenhoek Journal of Microbiology and Serology 38:241-256. Type species: $T$. pelophila Kuenen and Veldkamp 1972

Description: Kuenen, J.G. and H. Veldkamp. 1972. Ibid.

T. denitrificans Timmer-ten Hoor 1975

Timmer-ten Hoor, A. 1975. Netherlands Journal of Sea Research 9:343-351. Type strain: DSM 1251

Description: Timmer-ten Hoor, A. 1975. Ibid.

T. pelophila Kuenen and Veldkamp 1972

Kuenen, J.G. and H. Veldkamp. 1972.

Antonie van Leeuwenhoek Journal of Microbiology and Serology 38:241-256.

Type strain: ATCC 27801

Description: Kuenen, J.G. and H. Veldkamp. 1972. Ibid.

Thiopedia Winogradsky 1888

Winogradsky, S. 1888. Beitrage zur Morphologie und Physiologie der Bacterien. Heft I. Zur Morphologie und Physiologie der Schwefelbacterien. Arthur Felix, Leipzig. pp. 1-120. Type species: $T$. rosea Winogradsky 1888

Description: Bergey 8.

T. rosea Winogradsky 1888

Winogradsky, S. 1888. Beitrage zur Morphologie und Physiologie der Bacterien. Heft I. Zur Morphologie und Physiologie der Schwefelbacterien. Arthur Felix, Leipzig. pp. 1-120. Type strain: no pure culture.

Description: Bergey 8.

Thioploca Lauterborn 1907

Lauterborn, R. 1907. Berichte der Deutschen Botanischen Gesellschaft 25:238242. Type species: $T$. schmidlei Lauterborn 1907

Description: Bergey 8.

T. schmidlei Lauterborn 1907

Lauterborn, R. 1907. Berichte der Deutschen Botanischen Gesellschaft 25:238242. Type strain: no culture isolated.

Description: Lauterborn, R. 1907. Ibid.

Thiospira Visloukh 1914

Visloukh, S.M. 1914. Zhurnal Mikrobiologii 1:42-51. Type species: $T$. winogradskyi 
(Omelianski 1905) Visloukh 1914

Description: Bergey 8.

T. winogradskyi (Omelianski 1905) Visloukh 1914

Omelianski, W. 1905. Zentralblatt fur Bakteriologie, Parasitenkunde, Infektionskrankheiten und Hygiene. Abteilung II. 14:769-772; Visloukh, S.M. 1914. Zhurnal Mikrobiologii 1:42-51. Type strain: no culture available.

Description: Bergey 8.

Thiospirillum Winogradsky 1888

Winogradsky, S. 1888. Beitrage zur Morphologie und Physiologie der Bacterien. Heft I. Zur Morphologie und Physiologie der Schwefelbacterien. Arthur Felix, Leipzig. pp. 1-120. Type species: $T$. jenense (Ehrenberg 1838) Migula 1900 Description: Bergey 8.

T. jenense (Ehrenberg 1838) Migula 1900

Ehrenberg, C.G. 1838. Die Infusionsthierchen als vollkommene Organismen. L. Voss, Leipzig; Migula, W. 1900. System der Bakterien, Vol. 2. Gustav Fischer, Jena. Type strain: DSM 216

Description: Bergey 8.

Thiothrix Winogradsky 1888

Winogradsky, S. 1888. Beitrage zur Morphologie und Physiologie der Bacterien. Heft 1. Zur Morphologie und Physiologie der Schwefelbacterien. Arthur Felix, Leipzig. pp. 1-120. Type species: $T$. nivea (Rabenhorst 1865) Winogradsky 1888

Description: Bergey 8.

T. nivea (Rabenhorst 1865) Winogradsky 1888 Rabenhorst, L. 1865. Flora Europaea Algarum aquae dulcis et submarinae. E. Kummer, Leipzig, Section II. pp. 1-319; Winogradsky, S. 1888. Beitrage zur Morphologie und Physiologie der Bacterien. Heft 1. Zur Morphologie und Physiologie der Schwefelbacterien. Arthur Felix, Leipzig. pp. 1-120. Type strain: no culture isolated.

Description: Bland, J.A. and J.T. Staley. 1978. Archives of Microbiology 117:7987.

Thiovulum Hinze 1913

Hinze, G. 1913. Berichte der Deutschen
Botanischen Gesellschaft 31:189-202. Type species: $T$. majus Hinze 1913

Description: Bergey 8.

T. majus Hinze 1913

Hinze, G. 1913. Berichte der Deutschen Botanischen Gesellschaft 31:189-202. Type strain: no culture isolated.

Description: de Boer, W.E., J.W.M. La Riviere and A.L. Houwink. 1961. Antonie van Leeuwenhoek Journal of Microbiology and Serology 27:447-456.

Toxothrix Molisch 1925

Molisch, H. 1925. Zentralblatt fur Bakteriologie, Parasitenkunde, Infektionskrankheiten und Hygiene. Abteilung II. 65:130-139. Type species: $T$. trichogenes (Cholodny 1924) Beger 1953

Description: Bergey 8.

T. trichogenes (Cholodny 1924) Beger 1953

Cholodny, N. 1924. Zentralblatt fur Bakteriologie, Parasitenkunde, Infektionskrankheiten und Hygiene. Abteilung II. 61:292-298; Beger, H. 1953 in Beger, H. and Bringmann. Zentralblatt fur Bakteriologie, Parasitenkunde, Infektionskrankheiten und Hygiene. Abteilung II. 107:318-334. Type strain: no culture isolated.

Description: Krul, J.M., P. Hirsch and J.T. Staley. 1970. Antonie van Leeuwenhoek Journal of Microbiology and Serology 36:409-420.

Treponema Schaudinn 1905

Schaudinn, F. 1905. Deutsche Medizinische Wochenschrift 31:1728. Type species: $T$. pallidum (Schaudinn and Hoffmann 1905) Schaudinn 1905

Description: Bergey 8.

T. hyodysenteriae Harris, Glock, Christensen and Kinyon 1972

Harris, D.L., R.D. Glock, C.R. Christensen and J.M. Kinyon. 1972. Veterinary Medicine - Small Animal Clinician 67:6164. Type strain: ATCC 27164

Description: Kinyon, J.M. and D.L. Harris. 1979. International Journal of Systematic Bacteriology 29:102-109.

T. innocens Kinyon and Harris 1979

Kinyon, J.M. and D.L. Harris. 1979. International Journal of Systematic Bacteriology 29:102-109. Type strain: ATCC 
29796

Description: Kinyon, J.M. and D.L. Harris. 1979. Ibid.

T. minutum Dobell 1912

Dobell, C.C. 1912. Archiv fur Protistenkunde 26:117-240. Type strain: CIPP 5162

Description: Bergey 8.

T. pallidum (Schaudinn and Hoffmann 1905) Schaudinn 1905

Schaudinn, F. and E. Hoffmann. 1905. Arbeiten aus dem Kaiserlichen Gesundheitsamte (Berlin) 22:528-534; Schaudinn, F. 1905. Deutsche Medizinische Wochenschrift 31:1728. Type strain: no culture available.

Description: Bergey 8.

T. paraluis-cuniculi (Jacobsthal 1920) Smibert 1974

Jacobsthal, E. 1920. Dermatologische Wochenschrift 71:569-571; Smibert, R.M. 1974. Bergey 8. Type strain: no culture available.

Description: Bergey 8.

T. pertenue (Castellani 1905) Castellani and Chalmers 1910

Castellani, A. 1905. Journal of the Ceylon Branch of the British Medical Association 2:54; Castellani, A. and A.J. Chalmers. 1910. Manual of Tropical Medicine, 1st ed. Bailliere, Tindall and Cox, London. Type strain: no culture available.

Description: Bergey 8.

Ureaplasma Shepard, Lunceford, Ford, Purcell, Taylor-Robinson, Razin and Black 1974

Shepard, M.C., C.D. Lunceford, D.K. Ford, R.H. Purcell, D. Taylor-Robinson, S. Razin and F.T. Black. 1974. International Journal of Systematic Bacteriology 24:160-171. Type species: $U$. urealyticum Shepard, Lunceford, Ford, Purcell, Taylor-Robinson, Razin and Black 1974

Description: Shepard, M.C., C.D. Lunceford, D.K. Ford, R.H. Purcell, D. Taylor-Robinson, S. Razin and F.T. Black. 1974. Ibid.

U. urealyticum Shepard, Lunceford, Ford, Purcell, Taylor-Robinson, Razin and Black 1974

Shepard, M.C., C.D. Lunceford, D.K. Ford, R.H. Purcell, D. Taylor-Robinson,
S. Razin and F.T. Black. 1974. International Journal of Systematic Bacteriology 24:160-171. Type strain: ATCC 27618 Description: Shepard, M.C., C.D. Lunceford, D.K. Ford, R.H. Purcell, D. TaylorRobinson, S. Razin and F.T. Black. 1974. Ibid.

Veillonella Prevot 1933

Prevot, A.R. 1933. Annales Societe Nature 15:23-260. Type species: $V$. parvula (Veillon and Zuber 1898) Prevot 1933

Description: Bergey 8.

V. alcalescens Prevot 1933

Prevot, A.R. 1933. Annales Societe Nature 15:23-260. Type strain: ATCC 17745

Description: Bergey 8.

V. alcalescens subsp. alcalescens Prevot 1933 Prevot, A.R. 1933. Annales Societe Nature 15:23-260. Type strain: ATCC 17745

Description: Bergey 8.

V. alcalescens subsp. criceti Rogosa 1965 Rogosa, M. 1965. Journal of Bacteriology 90:704-709. Type strain: ATCC 17747 Description: Bergey 8.

V. alcalescens subsp. dispar Rogosa 1965 Rogosa, M. 1965. Journal of Bacteriology 90:704-709; Type strain: ATCC 17748 Description: Bergey 8.

V. alcalescens subsp. ratti Rogosa 1965 Rosgosa, M. 1965. Journal of Bacteriology 90:704-709. Type strain: ATCC 17746

Description: Bergey 8.

V. parvula (Veillon and Zuber 1898) Prevot 1933

Veillon, A. and A. Zuber. 1898. Archives de Medicine Experimentale et d'Anatomie Pathologique 10:517-545; Prevot, A.R. 1933. Annales Societe Naturelles 15:23260. Type strain: ATCC 10790

Description: Holdeman, L.V., E.P. Cato and W.E.C. Moore (eds). 1977. Anaerobe Laboratory Manual, 4th ed. Virginia Polytechnic Institute and State University, Blacksburg, Virginia. pp. 1-156.

V. parvula subsp. atypica Rogosa 1965 Rogosa, M. 1965. Journal of Bacteriology 90:704-709; Type strain: ATCC 17744 Description: Bergey 8. 
V. parvula subsp. parvula Rogosa 1965

Rogosa, M. 1965. Journal of Bacteriology 90:704-709. Type strain: ATCC 10790 -

Description: Holdeman, L.V., E.P. Cato and W.E.C. Moore (eds). 1977. Anaerobe Laboratory Manual, 4th ed. Virginia Polytechnic Institute and State University, Blacksburg, Virginia. pp. 1-156.

V. parvula subsp. rodentium Rogosa 1965

Rogosa, M. 1965. Journal of Bacteriology 90:704-709; Type strain: ATCC 17743

Description: Bergey 8.

Vibrio Pacini 1854

Pacini, F. 1854. Gazette Medicale de Italiana Toscano Firenze 6:405-412. Type species: V. cholerae Pacini 1854

Description: Bergey 8.

V. albensis Lehmann and Neumann 1896

Lehmann, K.B. and R. Neumann. 1896. Atlas und Grundriss der Bakteriologie und Lehrbuch der speziellen bakteriologischen Diagnostik. 1st ed. J.F. Lehmann, Munchen. Type strain: ATCC 14547

Description: Hendrie, M.S., W. Hodgkiss and J.M. Shewan. 1970. Journal of General Microbiology 64:151-169.

V. alginolyticus (Miyamoto, Nakamura and Takizawa 1961) Sakazaki 1968 (See also Beneckea alginolytica)

Miyamoto, Y., K. Nakamura and K. Takizawa. 1961. Japanese Journal of Microbiology 5:477-486; Sakazaki, R. 1968. Japanese Journal of Medical Science and Biology 21:359-362 Type strain: ATCC 17749

Description: Sakazaki, R. 1968. Ibid.

V. anguillarum Bergeman 1909

Bergeman, A.M. 1909. Berichte der Bayerischen Biologischen Versuchs-Station 2:10-54. Type strain: ATCC 19264

Description: Hastein, T. and J.E. Smith. 1977. Journal of Fish Biology 11:69-75.

V. cholerae Pacini 1854

Pacini, F. 1854. Gazette Medicale de Italiana Toscano Firenze 6:405-412. Type strain: ATCC 14035

Description: Hugh, R. 1965. International Bulletin of Bacteriological Nomenclature and Taxonomy 15:13-24.

V. costicola Smith 1938

Smith, F.B. 1938. Proceedings of the Royal Society Queensland 49:29-52. Type strain: NCMB 701

Description: Bergey 8.

V. fischeri (Beijerinck 1889) Lehmann and Neumann 1896 (See also Photobacterium fischeri)

Beijerinck, M.W. 1889. Archives neerlandaises des Sciences Exactes et Naturelles 23:401-427; Lehmann, K.B. and R. Neumann. 1896. Atlas und Grundriss der Bakteriologie und Lehrbuch der speziellen bakteriologischen Diagnostik. 1st ed. J.F. Lehmann, Munchen. Type strain: ATCC 7744

Description: Hendrie, M.S., W. Hodgkiss and J.M. Shewan. 1971. International Journal of Systematic Bacteriology 21: 217-221.

V. metschnikovii Gamaleia 1888

Gamaleia, M.N. 1888. Annales de l'Institut Pasteur (Paris) 2:482-488. Type strain: NCTC 8443

Description: Lee, J.V., T.J. Donovan and A.L. Furniss. 1978. International Journal of Systematic Bacteriology 28:99-111.

V. parahaemolyticus Sakazaki, Iwanami and Fukumi 1963 (See also Beneckea parahaemolytica)

Sakazaki, R., S. Iwanami and H. Fukumi. 1963. Japanese Journal of Medical Science and Biology 16:161-188. Type strain: ATCC 17802

Description: Fujino, T., R. Sakazaki and K. Tamura. 1974. International Journal of Systematic Bacteriology 24:447-449.

V. succinogenes Wolin, Wolin and Jacobs 1961 Wolin, M.J., E.A. Wolin and N.J. Jacobs. 1961. Journal of Bacteriology 81:911-917. Type strain: ATCC 29543

Description: Holdeman, L.V., E.P. Cato and W.E.C. Moore (eds). 1977. Anaerobe Laboratory Manual, 4th ed. Virginia Polytechnic Institute and State University, Blacksburg, Virginia. pp. 1-156.

Vitreoscilla Pringsheim 1949

Pringsheim, E.G. 1949. Bacteriological Reviews 13:47-98. Type species: $V$. beggiatoides Pringsheim 1949

Description: Bergey 8.

V. beggiatoides Pringsheim 1949

Pringsheim, E.G. 1949. Bacteriological Reviews 13:47-98. Type strain: no culture available. 
Description: Bergey 8 .

V. stercoraria Pringsheim 1951

Pringsheim, E.G. 1951. Journal of

General Microbiology 5:124-149. Type strain: ATCC 15218

Description: Bergey 8.

\section{Wolbachia Hertig 1936}

Hertig, M. 1936. Parasitology 28:453-486.

Type species: W. pipientis Hertig 1936

Description: Bergey 8.

W. melophagi (Noller 1917) Philip 1956

Noller, W. 1917. Archiv fur Schiffs und

Tropenhygiene 21:53-94; Philip, C.B. 1956. Canadian Journal of Microbiology 2:261-270. Type strain: no culture isolated.

Description: Bergey 8.

W. persica Suitor and Weiss 1961

Suitor Jr., E.C. and E. Weiss. 1961. Journal of Infectious Diseases 108:95-106.

Type strain: ATCC VR 331

Description: Bergey 8.

W. pipientis Hertig 1936

Hertig, M. 1936. Parasitology 28:453-486.

Type strain: no culture isolated.

Description: Bergey 8 .

Xanthobacter Wiegel, Wilke, Baumgarten, Opitz and Schlegel 1978

Wiegel, J., D. Wilke, J. Baumgarten, R. Opitz and H.G. Schlegel. 1978. International Journal of Systematic Bacteriology 28:573-581. Type species: $X$. autotrophicus (Baumgarten, Reh and Schlegel 1974) Wiegel, Wilke, Baumgarten, Opitz and Schlegel 1978

Description: Wiegel, J., D. Wilke, J. Baumgarten, R. Opitz and H.G. Schlegel. 1978. Ibid.

X. autotrophicus (Baumgarten, Reh and Schlegel 1974) Wiegel, Wilke, Baumgarten, Opitz and Schlegel 1978

Baumgarten, J., M. Reh and H.G. Schlegel. 1974. Archives of Microbiology 100:207-217. Wiegel, J., D. Wilke, J. Baumgarten, R. Opitz and H.G. Schlegel. 1978. International Journal of Systematic Bacteriology 28:573-581. Type strain: DSM 432

Description: Wiegel, J., D. Wilkie, J. Baumgarten, R. Opitz and H.G. Schlegel. 1978. Ibid.
X. flavus Malik and Claus 1979

Malik, K.A. and D. Claus. 1979. International Journal of Systematic Bacteriology 29:283-287. Type strain: DSM 338

Description: Malik, K.A. and D. Claus. 1979. Ibid.

Xanthomonas Dowson 1939

Dowson, W.J. 1939. Zentralblatt fur Bakteriologie, Parasitenkunde, Infektionskrankheiten und Hygiene. Abteilung II. 100:177-193. Type species: $X$. campestris (Pammel 1895) Dowson 1939

Description: Bergey 8.

X. albilineans (Ashby 1929) Dowson 1943

Ashby, S.F. 1929. Tropical Agriculture, Trinidad 6:135-138; Dowson, W.J. 1943. Transactions of the British Mycological Society 26:4-14. Type strain: NCPPB 2969

Description: Bergey 8 .

X. ampelina Panagopoulos 1969

Panagopoulos, C.G. 1969. Annales de l'Institut Phytopathologique Benaki NS 9: 59-81. Type strain: NCPPB 2217

Description: Panagopoulos, C.G. 1969. Ibid.

X. axonopodis Starr and Garces 1950

Starr, M.P. and C. Garces. 1950. Revista

Facultad Nacional de Agronomia (Medellin) Colombia 11:73-83. Type strain: ATCC 19312

Description: Starr, M.P. and C. Garces. 1950. Ibid.

X. campestris (Pammel 1895) Dowson 1939

Pammel, L.H. 1895. Bulletin of the Iowa

State College Agricultural Experiment Station 27:130-134; Dowson, W.J. 1939. Zentralblatt fur Bakteriologie, Parasitenkunde und Infektionskrankheiten. Abteilung II. 100:177-193. Type strain: NCPPB 528

Description: Bergey 8 .

X. fragariae Kennedy and King 1962

Kennedy, B.W. and T.H. King. 1962. Phytopathology 52:873-875. Type strain: NCPPB 1469

Description: Kennedy, B.W. and T.H. King. 1962. Ibid.

Xenorhabdus Thomas and Poinar 1979

Thomas, G.M. and G.O. Poinar Jr. 1979. 
International Journal of Systematic Bacteriology 29:352-360. Type species: $X$. nematophilus (Poinar and Thomas 1965) Thomas and Poinar 1979

Description: Thomas, G.M. and G.O. Poinar Jr. 1979. Ibid.

X. luminescens Thomas and Poinar 1979

Thomas, G.M. and G.O. Poinar Jr. 1979. International Journal of Systematic Bacteriology 29:352-360. Type strain: ATCC 29999

Description: Thomas, G.M. and G.O. Poinar Jr. 1979. Ibid.

X. nematophilus (Poinar and Thomas 1965) Thomas and Poinar 1979

Poinar Jr., G.O. and G.M. Thomas. 1965. International Bulletin of Bacteriological Nomenclature and Taxonomy 15:249-252; Thomas, G.M. and G.O. Poinar Jr. 1979. International Journal of Systematic Bacteriology 29:352-360. Type strain: ATCC 19061

Description: Thomas, G.M. and G.O. Poinar Jr. 1979. Ibid.

Yersinia van Loghem 1944

van Loghem, J.J. 1944. Antonie van Leeuwenhoek Journal of Microbiology and Serology 10:15-16. Type species: $Y$. pestis (Lehmann and Neumann 1896) van Loghem 1944

Description: Bergey 8.

Y. enterocolitica (Schleifstein and Coleman 1939) Frederiksen 1964

Schleifstein, J.I. and M.B. Coleman. 1939. New York State Journal of Medicine 39:1749-1753; Frederiksen, W. 1964. Proceedings of the XIV Scandinavian Congress of Pathology and Microbiology, Oslo 1964. Norwegian Universities Press, Oslo. pp. 103-104. Type strain: ATCC 9610

Description: Bottone, E.J. 1977. CRC Critical Review in Microbiology 5:211.

Y. pestis (Lehmann and Neumann 1896) van Loghem 1944

Lehmann, K.B. and R. Neumann. 1896. Atlas und Grundriss der Bakteriologie und Lehrbuch der speziellen bacteriologischen Diagnostik. 1st ed. J.F. Lehmann, Munchen. p. 194; van Loghem, J.J. 1944. Antonie van Leeuwenhoek Journal of Microbiology and Serology 10:
15-16. Type strain: ATCC 19428

Description: Bergey 8.

Y. philomiragia Jensen, Owen and Jellison 1969 Jensen, W.I., C.R. Owen and W.L. Jellison. 1969. Journal of Bacteriology 100:1237-1241. Type strain: ATCC 25015 Description: Jensen, W.I., C.R. Owen and W.L. Jellison. 1969. Ibid.

Y. pseudotuberculosis (Pfeiffer 1889) Smith and Thal 1965

Pfeiffer, A. 1889. Uber die bacillare Pseudotuberkulose bei Nagethieren. Verlag von George Thieme, Leipzig. pp. 1-42; Smith, J.E. and E. Thal. 1965. Acta Pathologica and Microbiologica Scandinavica 64:213-223. Type strain: ATCC 29833

Description: Bergey 8.

Y. ruckeri Ewing, Ross, Brenner and Fanning 1978

Ewing, W.H., A.J. Ross, D.J. Brenner and G.R. Fanning. 1978. International Journal of Systematic Bacteriology 28:3744. Type strain: ATCC 29473

Description: Ewing, W.H., A.J. Ross, D.J. Brenner and G.R. Fanning. 1978. Ibid.

Zoogloea Itzigsohn 1868

Itzigsohn, H. 1868. Sitzungs-Berichte der Gesellschaft naturforschender Freunde zu Berlin, 19 November 1867, pp. 30-31. Type species: Z. ramigera Itzigsohn 1868 Description: Bergey 8.

Z. ramigera Itzigsohn 1868

Itzigsohn, H. 1868. Sitzungs-Berichte der Gesellschaft naturforschender Freunde zu Berlin, 19 November 1867, pp. 30-31. Type strain: ATCC 19544

Description: Unz, R.F. 1971. International Journal of Systematic Bacteriology 21:9199.

Zymomonas Kluyver and van Niel 1936

Kluyver, A.J. and C.B. van Niel. 1936. Zentralblatt fur Bakteriologie, Parasitenkunde, Infektionskrankheiten und Hygiene. Abteilung II. 94:369-403. Type species: Z. mobilis (Lindner 1928) Kluyver and van Niel 1936

Description: Bergey 8.

Z. mobilis (Lindner 1928) Kluyver and van Niel 1936

Lindner, P. 1928. Bericht des Westpreus- 
sischen Botanisch-Zoologischen Vereins, 50. pp. 253-255; Kluyver, A.J. and C.B. van Niel. 1936. Zentralblatt fur Bakteriologie, Parasitenkunde, Infektionskrankheiten und Hygiene. Abteilung II. 94: 369-403. Type strain: ATCC 10988

Description: De Ley, J. and J. Swings. 1976. International Journal of Systematic Bacteriology 26:146-157.

Z. mobilis subsp. mobilis (Lindner 1928) De Ley and Swings 1976

Lindner, P. 1928. Bericht des Westpreussischen Botanisch- Zoologischen Vereins, 50. pp. 253-255; De Ley, J. and
J. Swings. 1976. International Journal of Systematic Bacteriology 26:146-157. Type strain: ATCC 10988

Description: De Ley, J. and J. Swings. 1976. Ibid.

Z. mobilis subsp. pomaceae (Millis 1956) De Ley and Swings 1976

Millis, N.F. 1956. Journal of General Microbiology 15:521-528; De Ley, J. and J. Swings. 1976. International Journal of Systematic Bacteriology 26:146-157. Type strain: ATCC 29192

Description: De Ley, J. and J. Swings. 1976. Ibid.

\section{Reprints}

Clothbound copies of the Approved Lists are available for $\$ 10.00$ each from ASM Publication Sales, 1913 I St., N.W., Washington, DC 20006. 